\title{
Flawed strategies to reducing labor exploitations
}

\author{
Citation for published version (APA):
}

Kawakami, M. T. (2017). Flawed strategies to reducing labor exploitations: Reassessing the role of private actors in the global supply chain. [Doctoral Thesis, Maastricht University]. Datawyse / Universitaire Pers Maastricht. https://doi.org/10.26481/dis.20170517mk

Document status and date:

Published: 01/01/2017

DOI:

10.26481/dis.20170517mk

Document Version:

Publisher's PDF, also known as Version of record

\section{Please check the document version of this publication:}

- A submitted manuscript is the version of the article upon submission and before peer-review. There can be important differences between the submitted version and the official published version of record.

People interested in the research are advised to contact the author for the final version of the publication, or visit the DOI to the publisher's website.

- The final author version and the galley proof are versions of the publication after peer review.

- The final published version features the final layout of the paper including the volume, issue and page numbers.

Link to publication

\footnotetext{
General rights rights.

- You may freely distribute the URL identifying the publication in the public portal. please follow below link for the End User Agreement:

www.umlib.nl/taverne-license

Take down policy

If you believe that this document breaches copyright please contact us at:

repository@maastrichtuniversity.nl

providing details and we will investigate your claim.
}

Copyright and moral rights for the publications made accessible in the public portal are retained by the authors and/or other copyright owners and it is a condition of accessing publications that users recognise and abide by the legal requirements associated with these

- Users may download and print one copy of any publication from the public portal for the purpose of private study or research.

- You may not further distribute the material or use it for any profit-making activity or commercial gain

If the publication is distributed under the terms of Article $25 \mathrm{fa}$ of the Dutch Copyright Act, indicated by the "Taverne" license above, 


\section{Flawed Strategies to Reducing Labor Exploitations}

Reassessing the Role of Private Actors in the Global Supply Chain

Mark T. Kawakami 
ISBN 9789461597045

Production, print: Datawyse | Universitaire Pers Maastricht

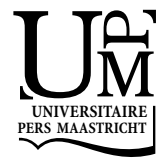

(C) 2017 by Mark Toshiaki Kawakami

All rights reserved. No part of this publication may be reproduced, stored in a retrieval system, or transmitted, in any form or by any means, electronic, mechanical, photocopying, recording, or otherwise, without the prior consent in writing from the author. 


\title{
Flawed Strategies to Reducing Labor Exploitations:
}

\author{
Reassessing the Role of Private Actors in the \\ Global Supply Chain
}

\author{
DISSERTATION \\ to obtain the degree of Doctor \\ at Maastricht University, \\ on the authority of the Rector Magnificus, \\ Prof. dr. Rianne M. Letschert \\ in accordance with the decision of the Board of Deans, \\ to be defended in public \\ on Wednesday 17 May 2017, at 12:00 hours
}

by

Mark Toshiaki Kawakami 


\section{Supervisor:}

Prof. dr. J.M. Smits

\section{Co-Supervisor:}

Dr. G.W.L. Low, Singapore Management University

Assessment Committee:

Prof. dr. M. Olaerts (Chair)

Prof. dr. L.C. Backer, Penn State University

Prof. mr. A.J.A.J. Eijsbouts

Prof. dr. F. Hendrickx, KU Leuven/Tilburg University 


\section{Table of Contents}

Chapter 1 Introduction $\quad 11$

1.1 Problem 13

1.1.1 Made in the USA Case 14

1.1.2 Cobalt Mining in the DRC Case 17

1.2 Research Question 21

1.3 Methodology 22

$\begin{array}{lll}\text { 1.3.1 Structure } & 22\end{array}$

1.3.2 Interdisciplinary Approach 23

1.3.3 Limitations 24

A. Primary Focus on the Private Sector and Private Law 24

B. Limited Assessment of Public or International Law 27

1.3.4 Preferences and Perspectives 29

A. International Perspective 29

B. Mediating between Keynes and Hayek 30

1.4 Normative Framework 33

1.4.1 Capabilities Approach 33

A. Capabilities Approach v. Economic and Utilitarian Arguments 34

B. Picking the Relevant Capabilities 37

1.4.2 Adapted Capabilities Approach 38

A. Right to Self-Preservation and Freedom of Choice 38

B. Opportunity to Participate in the Decision-Making Process 41

C. Ability to Learn, Think, and Adapt 41

Chapter 2 Labor/Employment Law Perspective 45

2.1 Sweatshops and Exploitative Labor Practices in New York 46

2.1.1 Relevant New York State Labor Laws 46

A. Relevant Laws 47

B. Apparel Industry Task Force 48

2.1.2 AITF: Facts and Figures 48

2.1.3 New York Labor/Employment Laws and Their Limitations 51

2.2 Sweatshops and Exploitative Labor Practices in the Netherlands 51

2.2.1 Relevant Dutch Labor Laws 53

A. Relevant Laws 53

B. Inspectie Sociale Zaken en Werkgelegenheid 54

2.2.2 Inspectie SZW: Facts and Figures 55

2.2.3 Dutch Labor/Employment Laws and Their Limitations 56

2.3 Problems with the Labor/Employment Law Approach 57

2.3.1 The Competence Problem 58

A. Laws Can Be Slow, Ineffective, and Unenforced 59

B. Lobbyists and Money's Corrupting Influence 61 
C. Governments' Conflict of Interest 63

D. Flawed Assumption of the Rational Actor 65

$\begin{array}{lll}\text { 2.3.2 The Goldilocks Problem } & 67\end{array}$

A. "We are operating in a U-shaped world" $\quad 68$

B. Risk of Overregulation and When Laws Backfire 70

C. Risk of Underregulation and Collective Laissez-Faire 72

2.3.3 Uberized Economy Case 73

A. Independent Contractor Classification as Labor Exploitation $\quad 74$

B. Labor/Employment Law v. Sharing Economy 75

C. Uber's Legal Battles $\quad 76$

2.4 Conclusion: Labor/Employment Laws Are Necessary, but Not Enough 83

Chapter 3 Tort Law Perspective $\quad 87$

3.1 Foreign Victims in US Courts $\quad 88$

3.1.1 Alien Tort Statute: Foreign Victims in US Federal Courts 88

A. Brief Summary of Seminal ATS Cases 90

B. Subject Matter Jurisdiction and Causes of Action Under the ATS 91

C. Personal Jurisdiction 95

D. Forum non Conveniens, Acts of State, and Political Question Doctrines $\quad 97$

E. Neutering the ATS: Kiobel v. Dutch Royal Petroleum (Shell) 100

F. The ATS Only has Limited Utility for Foreign Plaintiffs 104

3.1.2 California Civil Code: Foreign Victims in US State Courts 107

A. Applicable Law, Venue, and Other Preliminary Matters 107

B. Relevant California Tort Law 109

C. State Law Options are Limited as Well for the Alien Plaintiffs 112

3.1.3 Class Action and Representative Litigation for Transnational Cases 112

A. Class Action 113

B. Representative Litigation 114

3.1.4 US Tort Law and Their Limitations 115

3.2 Foreign Victims in Dutch Courts 116

3.2.1 "Dutch" Law: Foreign Victims in The Hague 116

A. Dutch Law and European Harmonization on Venue and Applicable Law 116

B. Shell and the Nigerian Farmers: Akpan v. Royal Dutch Petroleum 120

C. Respondeat Superior: Shell in Nigeria and Shell in the Netherlands 125

D. The Dutch Courts Allow More Access to Foreign Plaintiffs 128

3.2.2 Dutch Alternatives to US-Style Class Action Lawsuits 129

A. BW Article 3:305(a) and the Representative Groups 129

B. Wet Collectieve Afhandeling Massachade [Collective Settlement $\begin{array}{ll}\text { Procedure] } & 131\end{array}$

3.2.3 Dutch Tort Law and Their Limitations 132

3.3 Problems with the Tort Law Approach 133

3.3.1 The Territoriality Problem 133 
A. Globalization as a Disruptor of Traditional Governance 134

B. Difficulty of Enforcement at the International Level 136

C. Filing Claims Abroad is Cost-Prohibitive and Time Consuming 136

3.3.2 The Externalization Problem 137

A. Severing Liability: Outsourcing, Third Parties, and Respondeat $\begin{array}{ll}\text { Superior } & 138\end{array}$

B. Piercing a Different Type of a Corporate Veil 139

C. Firm Disaggregation and Fragmented Enterprises 142

$\begin{array}{lll}\text { 3.3.3 FIFA in Qatar Case } & 144\end{array}$

A. Exploiting Migrant Laborers for the Beautiful Game 144

B. Potential Implications of the Case 149

3.4 Conclusion: Tort Law Offers Limited Opportunities for Exploited Laborers 152

Chapter 4 Company Law/Corporate Governance Perspective 155

4.1 Corporate Social Responsibility Umbrella 156

4.1.1 What is Corporate Social Responsibility? 157

A. CSR: The Definition(s) 158

B. CSR as a Hybrid Regulatory Mechanism 160

C. Untangling Laws, Social Norms, Values, and Morals 161

4.1.2 Why Corporate Social Responsibility? 163

A. Businesses Have a Vested Interest in CSR 163

B. Grounds for Skepticism 165

4.2 Company Law/Corporate Governance Measures to Reduce Labor Exploitations 166

4.2.1 CSR and Its Impact on Corporate Governance 166

A. Shareholder Value Model and Its Focus on Share Value 168

B. Stakeholder Value Model and Stakeholder Involvement 171

C. Enlightened Shareholder Value Model and Shareholder Activism 173

$\begin{array}{ll}\text { 4.2.2 Incorporating as a Benefit Corporation } & 179\end{array}$

A. What is a Benefit Corporation? 180

B. The Benefits of a Benefit Corporation 180

4.2.3 Integrated Reports, ESG Metrics, and Sunshine Policies 182

A. What are Integrated Reports? 182

B. Stock Markets with ESG Listing Requirements 184

C. Transparency Legislations 185

4.3 Problems with the Company Law Approach 189

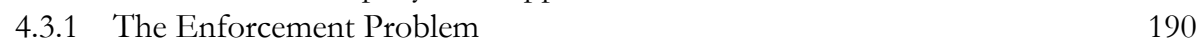

A. Costs of Implementing CSR > Benefits of CSR? 190

B. Risk of Isomorphic Mimicry and Greenwashing 191

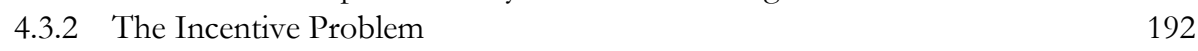

A. Matter of Extrinsic and Intrinsic Motivations 193

B. Ego Depletion: Being Socially Responsible Takes Continuous

C. Intrinsic Motivation through Telos and Phronesis 196

$\begin{array}{lll}\text { 4.3.3 The Causation Problem } & 198\end{array}$ 
A. Being Socially Responsible $\neq$ Better Working Conditions for Workers

B. Legalizing CSR Initiatives $\neq$ Higher Compliance and Better Outcomes

C. Laws can Crowd Out Voluntary Incentives and Much More

4.4 Conclusion: Plenty of Problems with the Company Law Approach

Chapter 5 Contract/Consumer Law Perspective

5.1 Ethical Consumerism and CSR

5.1.1 What is Ethical Consumerism

A. Consumerism and Capitalism in the Age of Proliferation

B. Reassessing Consumerism and Capitalism

5.1.2 Contract Law as the Enforcer of Justice?

A. Origins of Contracts and Notions of Justice

B. Proximus Egomet Mihi and the Corruption of Contracts

C. Redemption of Contracts?

5.2 Contract/Consumer Law Measures to Reduce Labor Exploitation

A. What are Codes of Conduct?

B. Codes of Conduct: Between Downstream and Upstream Businesses

C. Monitoring, Auditing, and Enforcing Codes of Conduct

D. Codes of Conduct: Between Downstream Businesses and Consumers

\subsubsection{Certification and Labeling Schemes}

A. Differentiating Between Standards, Certifications, and Labels

B. Certification and Labeling: The Cost Benefit Analysis

C. The Proliferation of Certifications and Labels

D. Preventing the Race to the Bottom with Smarter Logos?

E. Foreseeable Limitations of Certification and Labeling Schemes

5.2.3 Vitiating Factors and Consumer Protection Based Arguments

A. Defects of Consent: Fraud, Misrepresentation, and Mistake

B. Immoral Contracts Contrary to Public Policy

C. Consumer Protection Laws in the EU (The Netherlands)

D. Consumer Protection Laws in the US (California)

5.3.1 The Proliferation Problem

A. We are What We Own: Cathexis and Our Instinct of Acquisition 257

B. Cognitive Dissonance and How We Lie to Ourselves 261

C. Numb and Desensitized about Labor Exploitation 264

5.3.2 The Complexity Problem 266

A. Fundamentally Unidentified Questions 267

B. Bounded Rationality Revisited 268

C. System 1 and System $2 \quad 272$ 
D. Biases and Heuristics 274

E. "Companies are People Too" 280

5.3.3 The Communal Problem 281

A. Our Herd Mentality and the Various Shades of Conformity 282

B. We are Attention-Seekers: The Costly Signaling Theory 285

C. We Care Less About What We Do Not See 286

5.3.4 Proliferating Complexity: Emerging Trends 290

A. Emergence of Micropowers and the Shifting Power Paradigm 290

B. Consumers are Thinking Less Before Buying 297

C. Consumers from the East 300

D. Protean Supply Chains 303

5.4 Conclusion: Contract/Consumer Law Approaches are Double-Edged Swords 307

Chapter 6 Recommendations for the Path Forward 311

6.1 Lessons Learned from Our Existing Measures 312

6.1.1 Private Actors are Flawed 312

A. Our Framework Should Acknowledge Our Flaws Better 313

B. Our Framework Should Adopt a More Holistic Approach 314

6.1.2 Private Actors are Operating in a Sub-Utopian World 316

A. Our Framework Should Be Adaptive to an Increasingly Complex
Future

B. Our Framework Should Refrain from Absolutes 317

6.2 Call for an Alternative Framework 318

6.2.1 Private Global Norm Production, Reflexive Governance, and Adaptive Management 319

6.2.2 Adopting a More Holistic Approach that Employs Social Norms 321

A. What are Social Norms? 322

B. Benefits of Social Norms vis-à-vis Legal Norms 326

C. Cost of Over-Legalization: When the Law Crowds Out and Spills Over 329

D. Private Global Norm Production: Its Feasibility and Desirability 336

6.2.3 Adopting Reflexive Governance and Adaptive Management 341

A. What are Reflexive Governance and Adaptive Management Strategies? $\quad 342$

B. Benefits of Reflexive Governance and Adaptive Management 347

C. Reflexive Governance and Adaptive Management: Its Feasibility and Desirability 355

6.3 Pragmatic Application of the Alternative Framework 360

6.3.1 Recommended Role of the Governments 362

A. Strategic Use of the Law and Nudges 362

B. Ensuring a Level Playing Field 366

C. Special Districts, Charter Cities, and Seasteads 370

D. Open Source Governments 373

6.3.2 Recommended Role of the Businesses $\quad 375$ 
A. Rankings v. Emulating Industry Leaders

B. Synchronization of the Supply Chain and Automatization of Manufacturing

C. Capability Building Rather Than Monitoring and Punishing 383

6.3.3 Recommended Role of the Consumers 388

A. Learn How to Change Habits 389

B. Reconsider Boycotts and Naming-and-Shaming 391

C. Moral Reminders and Awareness Education 393

D. Collaborative Consumer Feedback Mechanism 396

E. Create Work Centers 400

6.4 The Swiss Cheese Theory 403

Chapter 7 Conclusion - Bringing Everything Together 407

$\begin{array}{lll}7.1 & \text { General Findings } & 409\end{array}$

7.1.1 A World Without a Panacea 409

7.1.2 Valorization and Reasons for Optimism 410

7.2 Validation of the Alternative Framework 411

7.2.1 Collaborative and Holistic 412

A. Necessity of Government Measures 412

B. Necessity of Private Initiatives 413

$\begin{array}{lll}\text { 7.2.2 Plurality and Polycentricity } & 414\end{array}$

A. Embracing the Romantics 414

B. Acceptance and Open-Mindedness 415

7.2.3 Flexibility and Adaptability 416

A. Getting Punched in the Mouth 417

B. Unknown Unknowns 417

$\begin{array}{lll}7.3 & \text { Final Remark } & 419\end{array}$

Acknowledgements \& Apologies $\quad 421$

Summary $\quad 425$

Samenvatting 427

Bibliography 429

1. Books 429

2. Articles 436

3. Newspaper \& Magazines 443

4. Reports 445

5. Online Content 448

6. Miscellaneous 452

7. Case Law 453

Appendix $\quad 457$ 


\section{Chapter}

\section{Introduction}

"The first thing we do, let's kill all the lanyers."

\section{Shakespeare's Henry VI, Part II}

According to the International Labour Organization ("ILO"), about 21 million people worldwide are victims of forced labor, ${ }^{1}$ which refers to instances where the laborers are coerced to work due to violence, the threat thereof, or by some other, more subtle means like debt bondage. ${ }^{2}$ A similar term to forced labor is "modern slavery," which according to the ILO, is a catchall phrase that not only includes forced labor, but sexual exploitation, human trafficking, and some of the worst forms of child labor. ${ }^{3}$ While there are conflicting reports about the exact figures and the methodology of calculating them, there are approximately 30 to 46 million people suffering from what the ILO refers to as modern slavery. ${ }^{4}$

1 International Labour Organization, ILO Global Estimate of Forced Labor: Results and Methodology, (2012), at p. 13 (specifying that $89 \%$ of the 20.9 million (18.7 million) are exploited by private individuals/enterprises, as opposed to state-imposed labor (i.e. prison labor) and about 68\% (14.2 million) are victims of forced labor exploitation excluding victims of forced sexual exploitation); see also, INTERNATIONAL LABOur OrGanizATION, Profits and Poverty: The Economics of Forced Labour, (2014), at p. 1.

2 International Labour Organization, ILO Global Estimate of Forced Labor: Results and Methodology, (2012), at p. 19 (referring to the ILO Forced Labour Convention, 1930 (No. 29) Article 2.1, which defines forced or compulsory labor as "all work or service which is exacted from any person under the menace of any penalty and for which the said person has not offered himself voluntarily"). This report also lists various examples of coercion, including but not limited to armed guards that prevent workers from leaving, locked premises, confiscation of identification documents, and threats of denunciation to authorities in case the worker is an illegal immigrant. Debt bondage is when a worker borrows money from the employer in advance and pledges repayment through his or her labor.

3 International Labour Organization, ILO Global Estimate of Forced Labor: Results and Methodology, (2012), at p. 13 (noting that the term "modern slavery" includes forced labor, human trafficking for labor and sexual exploitation, and even trafficking for organs and in some cases, forced marriages).

4 E.A. Posner, The Twilight of Human Rights Law, (Oxford: Oxford University Press, 2014), at p. 4 (citing that "nearly 30 million people are forced against their will to work" with an estimated "14 million people... enslaved in India, nearly 3 million in China, more than 2 million in Pakistan, and hundreds of thousands in Nigeria, Ethiopia, Russia, Thailand, Congo, and Myanmar" who are labeled as "the worst offenders"); cf. THE GLOBAL SLAVERY INDEX, Global Findings, (2016). Available at: http://www.globalslaveryindex.org/findings/ (last accessed 11 August 2016) (reporting that there are about 45.8 million people estimated to be "in some form of modern slavery"). 
An even broader term than forced labor or modern slavery is labor exploitation, which is an umbrella term that describes situations where laborers are not provided with just compensation on par with their labor, often as result of power asymmetries between the workers and the employers. ${ }^{5}$ So while forced labor or modern slavery generally falls under the labor exploitation umbrella, not all instances of labor exploitation are coercive or nefarious enough to warrant comparisons to slavery: For example, a worker can choose - of his own volition - to work in a sweatshop, which is an environment where the pay is below the minimum wage, the working hours excessively long, and the conditions often poor, unsafe, and undignified. ${ }^{6}$ While this hypothetical worker is indeed a victim of labor exploitation, absent any element of coercion, this would not constitute a case of forced labor or modern slavery. ${ }^{7}$ The ILO refers to these exploited laborers as those that are in "vulnerable employment" and they estimate that nearly 1.5 billion people - which is more than half of the developing world's workers - are stuck in these exploitative situations, where they are not compensated properly for their labor, are deprived of various social protections, and are in danger of becoming victims of forced labor or modern slavery. ${ }^{8}$ These figures substantiate the claim that the problem of labor exploitation is a collective action problem on a global scale with serious implications. ${ }^{?}$

Distinguishing these closely related terms at the onset is important because there are number of legal instruments that ban forced labor or modern slavery outright, but not everything that falls under the labor exploitation umbrella is as heavily regulated as "slavery" by most governments. ${ }^{10}$ For example, while companies located within the United States are required to pay their workers either the federal or the state mandated minimum wage, the law does not explicitly prevent these US companies from outsourcing the com-

See e.g., J. ELSTER, “Exploring Exploitation,” The Journal of Peace Research 15(2) (1978): 3-17.

6 There is no single feature that makes a workplace or a factory a "sweatshop," but some obvious indicators include the existence of fire, electrical or other health and safety hazards, wage violations, child laborers, and so on. See NEW York StATE DePARTMENT OF LABOR, A Guide for Manufacturers and Retailers. Available at: http://www.labor.ny.gov/workerprotection/laborstandards/workprot/sweatshp.shtm (last accessed 3 April 2017). International Labour Organization, Profits and Poverty: The Economics of Forced Labour, (2014), at p. 3 (stating that " $[\mathrm{t}]$ here is no question that slavery, in all its forms, is unacceptable and must be eradicated. However, not all children exposed to hazardous work are 'slaves', and not all labour that is not compensated with a fair wage is necessarily forced.”).

8 International Labour Organization, World of Work Report: Developing with Jobs [Executive Summary], (Geneva: ILO, 2014), at p. 4 (adding that [i]In sub-Saharan Africa, more than three out of four workers are in vulnerable forms of employment, with women disproportionately affected compared to men."); see also, INTERNATIONAL Labour Organization, ILO Global Estimate of Forced Labor: Results and Methodology, (2012), at p. 16 (noting that the "Asia-Pacific region accounts for by far the highest absolute number of forced labourers [at] 11.7 million or $56 \%$ of the global total," with the second highest number being Africa that of at 3.7 million (18\%). The developed economies and the European Union accounted for 1.5 million forced laborers, which is about $7 \%$ ).

9 A. Tocqueville, Democracy in America, Volume I, Part A (noting that slavery "dishonors labor [as] it introduces idleness into society, and with idleness, ignorance and pride, luxury and distress. It enervates the powers of the mind and benumbs the activity of man.”); see also, R. WILKINSON \& K. PICKETT, The Spirit Level: Why Equality Is Better for Everyone (London: Penguin Books, 2010), at p. x (noting that inequality has a corrosive effect on society); T. JUDT, Ill Fares the Land, (New York: Penguin, 2010), at p. 185 (stating that "[i]f we remain grotesquely unequal, we shall lose all sense of fraternity: and fraternity, for all its fatuity as a political objective, turns out to be the necessary condition of politics itself."); and, F. CAPRA \& U. MATTEI, The Ecology of Law: Toward a Legal System in Tune with Nature and Community, (Oakland: Berrett-Koehler, 2015), at p. 119 (observing that a system where "CEOs can make in a few hours what their employees make in a year of work," is not only "socially unacceptable," but this level of "inequality is the first foe of community.").

10 See e.g., ILO Forced Labour Convention, 1930 (No. 29), ILO Abolition of Forced Labour Convention 1957 (No. 105), and Worst Forms of Child Labour Convention 1999 (No. 182). 
pany's manufacturing to another country, where the minimum wage is substantially lower than that of the US. In other words, the law does not necessarily prevent companies from circumventing the payment of the US minimum wage, which increases the possibility of laborers being exploited somewhere abroad. This is because although most businesses would likely not challenge their governments from banning forced labor or slavery, many businesses would likely contest if their governments were to ban outsourcing all together. This is to suggest that while governments can play a significant role in addressing issues like forced labor or modern slavery, they might have a more difficult time in regulating the less coercive forms of labor exploitation especially if they are taking place abroad. ${ }^{11}$

What complicates matters for the governments is the issue of their limited territorial sovereignty in light of the ever-expanding global supply chain. Generally speaking, a supply chain is an operational network involving myriad of actors, including but not limited to laborers that gather raw materials and natural resources, processors and intermediaries that turn these resources into components and supplies, companies that use these supplies to manufacture commodities for the consumption of the consumers, and so on. A global supply chain is where various parts of this dynamic network are spread across multiple countries. While there are various benefits to an increasingly globalizing supply chain, this is where a large percentage of labor exploitations take place. Even with various regulations in place to prevent instances of labor exploitation - which will be discussed throughout this thesis - the ILO estimates that businesses operating in the global supply chain continue to earn annual profits of around $\$ 150.2$ billion just from their labor exploitation. ${ }^{12}$

The general topic of this thesis will be the plight of these laborers in vulnerable employment and how, even with the existence of laws that aim to prevent exploitative practices, businesses continue to make profit through exploitation. In short, there is a problem with the status quo and this introductory chapter will start by elaborating on what exactly this problem is (Section 1.1), followed by the presentation of the specific research question that this thesis will answer (Section 1.2), its methodology (Section 1.3), and finally its normative framework (Section 1.4).

\subsection{PROBLEM}

Reports of labor exploitations taking place within the global supply chain today are not uncommon: Apparel companies like Nike and Adidas are routinely scrutinized for the working conditions of their manufacturers' factories. Companies that deal in electronics like Apple and Sam-

11 J. Donnelly, Universal Human Rights in Theory and Practice [Second Edition], (Ithica: Cornell University Press, 2003), at p. 10 (stating that "we do not have human rights to all things that are good, or even all important good things" and that "we are not entitled - do not have (human) rights - to love, charity, or compassion.").

12 International Labour Organization, Profits and Poverty: The Economics of Forced Labour, (2014), at p. 13 (elaborating that " $[\mathrm{m}]$ ore than one third of the profits - $\$ 51.2$ billion - are made in forced labour exploitation, including nearly $\$ 8$ billion generated in domestic work by employers who use threats and coercion to pay no or low wages."). 
sung similarly are investigated for their relationship with contractors like Foxconn or their raw material suppliers in Africa. The agricultural sector is also rife with reports of labor exploitations, especially that of immigrant workers. In other words, there is no shortage of examples to depict the problem of labor exploitation and corporate malfeasance, but bearing this in mind, the two case studies below will provide a representative sample of the types of problems that this thesis will address. The first case will illustrate a problem of forced labor, while the second case will focus on the issue of labor exploitation that is less coercive in nature.

\subsubsection{Made in the USA Case}

In 1993, popular apparel brands including, but not limited to Tommy Hilfiger, Calvin Klein, and Levi's came under heavy scrutiny for tagging their products with the "Made in the USA" label, when in fact some of their products were manufactured in conditions that paralleled slavery in the Commonwealth of the Northern Mariana Islands ("CMNI"). ${ }^{13}$ Though technically a protectorate of the United States, the self-governing Commonwealth on the Pacific Ocean enjoys a covenant-based exemption from complying with various US federal regulations including minimum wage and immigration laws. ${ }^{14}$ Exploiting this loophole, companies set up factories on the islands and hired immigrant laborers at an average wage of around $\$ 2.15$ per hour (compared to the US federal minimum wage, which at the time was \$4.25), ${ }^{15}$ and advertised to their consumers that their products were "Made in the USA." This implied that their products were made in conformity with relatively high American standards and in compliance with the mandatory US regulations, when in fact they were not.

The migrant laborers on the Commonwealth were often lured to work there under false pretenses that they would be able to earn a decent wage while working in America. Many of the workers migrated from neighboring countries like Bangladesh and Sri Lanka by borrowing money from their soon-to-be employers, thus entering into a situation of debt bondage even prior to arriving on the islands. Upon their arrival, they were stuffed into labor camps, had their passports confiscated, and forced to live in captivity while producing clothes for the aforementioned brands. Their living quarters were rigged with barbed wires and uniformed guards patrolled the compound to prevent workers from escaping. ${ }^{16}$ For all intents and purposes, these migrant workers became forced laborers.

Furthermore, most of the workers working in the garment-manufacturing sector were women, who were often prostituted when they were not working in the factories. When the exploited women became pregnant, the factory managers forced them to have abor-

13 P. SHENON, "Made in the U.S.A.? Hard Labor on a Pacific Island/A Special Report: Saipan Sweatshops Are No American Dream," The New York Times, (18 July 1993).

14 See, 48 U.S. CoDE $\$ 1801$ (Approval of Covenant to Establish a Commonwealth of the Northern Mariana Islands in Political Union with the United States). Amongst various other exceptions, products manufactured in the CNMI can be shipped to the US without any tariff or quota.

15 U.S. Department of Labor Wages And Hour Division, History of Federal Minimum Wage Rates Under the Fair Labor Standards Act, 1938-2009. Available at: http://www.dol.gov/whd/minwage/chart.htm (last accessed 4 April 2017).

16 P. SHENON, "Made in the U.S.A.? Hard Labor on a Pacific Island/A Special Report: Saipan Sweatshops Are No American Dream," The New York Times, (18 July 1993). 
tions so that they could continue working to satisfy the demand of the consumers back in the West. ${ }^{17}$ The instinctive reaction to a systematic failure of this nature would be to call upon the government to intervene, to regulate, and to punish the perpetrators so as to deter events like this from repeating itself and that is - to a certain extent - what happened initially after the news broke of what was happening in the CNMI.

The first official government response to the news came from the US Department of Labor and the Occupational Safety and Health Administration ("OSHA"). They conducted investigations in Saipan - the capital of the Commonwealth - where many of these labor camps were located and discovered many atrocities, like the ones mentioned above, along with other instances of labor exploitation ranging from excessive working hours without just compensation to laborers being physically abused and falsely imprisoned. ${ }^{18}$ In the aftermath of the OSHA investigations, the legislature in the Commonwealth approved a law to increase the minimum wage on the islands by 30 cents a year for each of the subsequent seven years and proposed to establish a human rights commission to ensure that the rights of the workers were protected. ${ }^{19}$ Furthermore, in addition to measures that were being implemented locally in the CNMI, Senator Frank Murkowski (R-AK), at the federal level, proposed a bill to extend US federal minimum wage and labor protections to the workers in the Commonwealth. ${ }^{20}$

Alongside these legislative proposals, the investigations also brought about administrative sanctions and fines against several manufacturers based in the Commonwealth who were accused of exploitive labor practices. ${ }^{21}$ One particularly noteworthy factory owner was ordered to pay $\$ 9$ million in back wages to the exploited laborers under a settlement with the US Department of Labor. ${ }^{22}$ The initial reaction by the government, both at the local and at the federal level, showed signs of possible improvements to the working conditions in the Commonwealth.

However, for every member of the US Congress that sought to extend the US federal minimum wage to the CNMI, there were those that opposed the wage increase. The arguments made by those that opposed the increase was based primarily on the claim that the Commonwealth's ability to provide cheap labor and thus its competitive advantage would be stunted by the minimum wage increase, which would effectively decrease the incentive for businesses to stay on the islands, thus hurting the over-all economy of the Common-

T.B. EDSALL, “Another Stumble for Ralph Reed's Beleaguered Campaign,” The Washington Post, (29 May 2006).

18 U.S. Department OF THe InTERIOR OfFice OF Insular AfFairs, Report on the Commonwealth of the Northern Mariana Islands 1999. Available at: https://www.doi.gov/sites/doi.gov/files/migrated/oia/reports/upload/ islands.pdf (last accessed 4 April 2017).

19 P. SHENON, "Made in the U.S.A.? Hard Labor on a Pacific Island/A Special Report: Saipan Sweatshops Are No American Dream," The New York Times, (18 July 1993).

20 M. SHIELDS, "The Real Scandal of Tom DeLay," CNN, (9 May 2005). Available at: http://edition.cnn.com/2005/POLITICS/05/09/real.delay/ (last accessed 4 April 2017); see also, the internal government documents detailing the US-CNMI relationship, which has recently been unclassified and made available through the Clinton Library: http://www.clintonlibrary.gov/assets/storage/Research\%20\%20Digital\%20Library/formerlywithheld/batch1/2006-0167-F.pdf (last accessed 18 September 2015).

21 P. SHENON, "Made in the U.S.A.? Hard Labor on a Pacific Island/A Special Report: Saipan Sweatshops Are No American Dream," The New York Times, (18 July 1993).

22 P. SHENON, "Made in the U.S.A.? Hard Labor on a Pacific Island/A Special Report: Saipan Sweatshops Are No American Dream," The New York Times, (18 July 1993); see also, U.S. DEPARTMENT OF THE INTERIOR OFFICE OF INSULAR AFFAIRS, Report on the Commonwealth of the Northern Mariana Islands 1999. Available at: https://www.doi.gov/sites/doi.gov/files/migrated/oia/reports/upload/islands.pdf (last accessed 4 April 2017). 
wealth. Leaving aside the legitimacy of these economic development-based arguments for the moment, in an effort to fight against the demands to increase the minimum wage on the islands, the CNMI hired Jack Abramoff in 1995 as their chief lobbyist in Washington, DC. Abramoff - a prominent lobbyist who was subsequently sentenced to federal prison on charges of conspiracy, fraud, and tax evasion - successfully lobbied for the garment factories in the CNMI to continue being exempt from US labor laws. ${ }^{23}$

One of Abramoff's key arguments to prevent federal minimum wage and working regulations to be applied in the Commonwealth was based on notions of the free market and the benefits of laissez-faire governance as advocated by the Chicago school and personified by F.A. Hayek and Milton Friedman. ${ }^{24}$ Based on these arguments, Abramoff was able to proclaim that the CNMI was a champion of free enterprise and that government regulation ought to keep their hands off from this otherwise successful business environment. ${ }^{25} \mathrm{Ca}$ tering to a conservative US Congress at the time, Abramoff's arguments to keep "sweatshops safe from wage, hour, and immigration laws" proved persuasive. ${ }^{26}$ US Representative George Miller (D-CA), who was in favor of extending the minimum wage to the Commonwealth, characterized Abramoff's tactics in the following manner at the time: "He spent a lot of time, effort and money to protect a system that was a growth industry for sex shops, prostitution, abuse of women, slavery, illegal immigration, worker exploitation and narcotics, and he did it all in the name of freedom." 27

Although, the US Senate managed to unanimously pass Murkowski's bill to extend the minimum wage to the CNMI, ${ }^{28}$ Representative Tom DeLay (R-TX), who was the House Whip at the time and a close acquaintance of Abramoff, successfully blocked the vote on the bill in the House. This meant that the CNMI, even after all of the public outrage, still did not have to adhere to the federal minimum wage. ${ }^{29}$ Regarding the CNMI, DeLay is later quoted as saying that the Commonwealth - with its low-wages and anti-union condi-

S. Blumenthal, How Bush Rules: Chronicles of a Radical Regime, (New Jersey: Princeton University Press, 2006), at p. 155.

24 These arguments will be discussed in more depth in Chapter 1.4.1.

25 D. E. Rosenbaum, "At $\$ 500$ an Hour, Lobbyist's Influence Rise with G.O.P.," The New York Times, (3 April 2002).

26 S. Blumenthal, How Bush Rules: Chronicles of a Radical Regime, (New Jersey: Princeton University Press, 2006), at p. 155; see also, T.B. EDSALL, “Another Stumble for Ralph Reed's Beleaguered Campaign,” The Washington Post, $(29$ May 2006). According to some accounts, Abramoff's success was also in part due to his less-than-kosher tactics. For example, Abramoff's lobby received a lot of support from conservative Christians, who Abramoff - along with his friend Ralph Reed (the executive director of the Christian Coalition at the time) - galvanized by claiming that Senator Murkowski's bill was something that "the radical left, the Big Labor Union Bosses, and Bill Clinton want[ed] to pass" to prevent the "Chinese from coming to work on the Marianas [sic] Islands" so that they could be exposed to the "teachings of Jesus Christ" and "return to China with Bibles in hand."

27 D. E. Rosenbaum, “At $\$ 500$ an Hour, Lobbyist's Influence Rise with G.O.P.," The New York Times, (3 April 2002).

28 M. SHIELDS, "The Real Scandal of Tom DeLay," CNN, (9 May 2005). Available at: http://edition.cnn.com/ 2005/POLITICS/05/09/real.delay/ (last accessed 4 April 2017).

29 It is worth pointing out that prior to the House of Representatives blocking Senator Murkowski's bill, Abramoff had arranged for an all-expenses-paid visit for Tom Delay, his family, and his staff to visit Saipan, where he met with Willie Tan of Tan Holdings Corporation, who just so happened to be the noteworthy factory owner who had to pay the $\$ 9$ million in back wages and damages to laborers after the OHSA investigations; see, B. Ross, "DeLay's Lavish Island Getaway,” ABC Nens, (6 April 2005). Available at: http://abcnews.go.com/WNT/Investigation/ story?id=647725 (last accessed 4 April 2017). 
tions - was "a perfect petri dish of capitalism," which echoed the same laissez-faire arguments that Abramoff made a few years prior relying on Hayek and Friedman's arguments. ${ }^{30}$

To summarize this case, there was a public outcry immediately following the news about the labor exploitations taking place in the CNMI. Upon discovery, the US government conducted investigations and proposed various measures to remedy the situation, but some of the key proposals, which would have extended the application of US federal employment protections to the CNMI, failed to pass purportedly due in large part to questionable lobbying practices and dubious legislating by a handful of politicians. In the words of Representative Miller, an "awful lot of time and motion [was] wasted trying to give the appearance of reform instead of actually making real, structural changes." 31 This case illustrated how the US government addressed the issue of forced labor, the obstacles that they faced, and the difficulties that come with attempting to change the status quo. The next case will illustrate a different problem also associated with labor exploitation in the supply chain, which could prove even more difficult for governments to address.

\subsubsection{Cobalt Mining in the DRC Case}

Cobalt is a necessary component in making rechargeable lithium-ion batteries that power everything from mobile phones, tablets, laptops, and other portable electronic devices including smart cars. ${ }^{32}$ More than half of the world's total supply of cobalt comes from the Democratic Republic of Congo ("DRC"), which is also one of the poorest countries in the world. ${ }^{33}$ According to Amnesty International, this creates an environment rife for labor exploitation, with organizations such as UNICEF estimating that approximately 40,000 children work in mines across southern DRC under extremely harsh and toxic conditions. ${ }^{34}$ Furthermore, there are approximately 110,000 to 150,000 artisanal miners in this region called creuseurs - who mine for cobalt by digging out rocks from tunnels deep underground, many of them in areas unauthorized for mining. ${ }^{35}$ While there are regulations in place that prohibit mining in these areas, these creuseurs still dig, some even under their own homes, and the government of the DRC have been able to do very little about this problem. ${ }^{36}$

30 M. SHIELDS, "The Real Scandal of Tom DeLay," CNN, (9 May 2005). Available at: http://edition.cnn.com/ 2005/POLITICS/05/09/real.delay/ (last accessed 4 April 2017).

31 P. SHENON, "Made in the U.S.A.? Hard Labor on a Pacific Island/A Special Report: Saipan Sweatshops Are No American Dream," The New York Times, (18 July 1993).

32 See generally, Amnesty InTERnATIONAL \& AFrewatch, This is What We Die For: Human Rights Abuses in the Democratic Republic of the Congo Power the Global Trade in Cobalt, AFR 62/3183/2016 (London: Amnesty International, 2016) (reporting on findings based on interviews with 87 people including, but not limited to those who work, or have worked in these artisanal mines, cobalt traders, and businesses that purchase batteries, with cobalt sourced from the DRC).

33 See generally, AmNESTy InTERnATIONAL \& AFreWATCH, This is What We Die For: Human Rights Abuses in the Democratic Republic of the Congo Power the Global Trade in Cobalt, AFR 62/3183/2016 (London: Amnesty International, 2016).

34 AMnESTy InTERnAtIONAL \& AFrewatch, This is What We Die For: Human Rights Abuses in the Democratic Republic of the Congo Power the Global Trade in Cobalt, AFR 62/3183/2016 (London: Amnesty International, 2016), at p. 6 (reporting that they work on average about 12 hour days in dangerous mines for only about $\$ 1-2$ a day [1,0002,000 Congolese Francs]).

35 Amnesty International \& AFrewatch, This is What We Die For: Human Rights Abuses in the Democratic Republic of the Congo Power the Global Trade in Cobalt, AFR 62/3183/2016 (London: Amnesty International, 2016), at p. 4.

36 Amnesty International \& AFrewatch, This is What We Die For: Human Rights Abuses in the Democratic Republic of the Congo Power the Global Trade in Cobalt, AFR 62/3183/2016 (London: Amnesty International, 2016), at p. 7-8 
What is different from the CNMI case here is that in many of these cases, the miners including the child laborers - choose to mine for the cobalt. It is not as if their passports have been confiscated or that they cannot return home. Rather, they choose to work in these mines, because it is one of the very limited options that they have to make any income. While there are various measures - from laws to voluntary codes - that prohibit the practice of illegal mining and that deter Western companies to do business with intermediaries that deal with illegally mined cobalt, these measures have done little to curtail the problematic behaviors. ${ }^{37}$ For example, mining outside the authorized areas is illegal and as a deterrence measure, the DRC government imposes severe fines for those caught doing so. However, in many cases, these fines are so inconceivably exorbitant - relative to the miner's available income - that Amnesty International believes that they virtually serve no purpose as an effective deterrent. ${ }^{38}$ To be rather blunt, while there is increasing pressure by the international community for the DRC to address these matters more competently, the DRC simply lacks the political will and the resources to accomplish this feat. ${ }^{39}$

As hinted above, in light of the fact that governments like that of the DRC cannot help regulate these problematic practices, there are those that call upon businesses to help address this problem. ${ }^{40}$ There are, for instance, various measures in existence that attempt to incentivize businesses not to deal with socially irresponsible suppliers and manufactures (i.e. those intermediaries that purchase illegally mined cobalt): For example, the UN Guiding Principles on Business and Human Rights (“UNGP”), ${ }^{41}$ the OECD's Guidelines for Multinational Enterprises ("OECD Guidelines"), and the Due Diligence Guidance for Responsible Supply Chains of Minerals from Conflict-Affected and High-Risk Areas

(suggesting that there is evidence of government officials turning a blind eye to the illegal mining, while taking bribes or extorting illegal payments).

37 Just to list a few: Democratic Republic of Congo's Labour Code (2002), which in relevant parts include regulations on working hours, proper payment of wages, workplace safety, ban on child labor (prohibiting employment of children under the age of 16); DRC Mining Code (2002), which limits the mining of cobalt to Artisanal Mining Zones [Zones d'exploitation artisanle] and requiring the establishing of a "code of conduct for artisanal mining"; the DRC Child Protection Code (2009), the UN Guiding Principles on Business and Human Rights; and, International Labour Organization's Worst Forms of Child Labour Convention (No. 182) and ILO Recommendation 190, which require governments to take effective measures to prohibit and eliminate child labour by setting up guidance on how parties can do so.

38 AmNesty InTERnATIONAL \& AFREWATCH, This is What We Die For: Human Rights Abuses in the Democratic Republic of the Congo Power the Global Trade in Cobalt, AFR 62/3183/2016 (London: Amnesty International, 2016), at p. 18 (according to DRC Mining Code (2002), Article 220 and 302, any persons engaging in illegal mining activities or those purchasing or selling minerals in contravention of the law is liable for a fine between $\$ 10,000$ and $\$ 250,000$ ).

3 D. RoDriK, The Globalization Paradox: Democracy and the Future of the World Economy, (New York: Norton, 2011), at p. 245 (stating that "[p]oor countries argue that they cannot afford to have the same stringent standards in [the areas of labor and environmental standards] as the advance countries" because regulations against the use of child labor can backfire if they lead to fewer jobs and greater poverty.").

40 M. HoBBES, "The Myth of the Ethical Shopper," The Huffington Post, (2015). Available at: http://highline.huffingtonpost.com/articles/en/the-myth-of-the-ethical-shopper/ (last accessed 16 July 2015) (reporting that "[i]nstead of empowering domestic agencies with a mandate to prevent abuses, we rely on international corporations seeking to insulate themselves from bad publicity" to resolve these problems).

41 UN OfFice of The High Commissioner for Human Rights, Guiding Principles on Businesses and Human Rights: Implementing the United Nations "Protect, Respect and Remedy" Framework, UN DOC HR/PUB/11/04 2011) (requiring due diligence from companies "to identify, prevent, mitigate and account for how they address their impacts on human rights."). This is the guideline, which has been developed by former Special Representative of the Secretary-General on the issue of human rights, John Ruggie and an instrument that will be discussed in more detail below. 
$(2013)^{42}$ all preach the doctrine of "do no harm," but the problem is that companies often fail to take the necessary steps, as evidenced by the persistence of this problem to this day. ${ }^{43}$ While many companies claim that they do not condone any form of child labor or advertise that their supply chains are socially responsible, according to a recent Amnesty International report, many of these claims are untrustworthy, if not meaningless. ${ }^{44}$

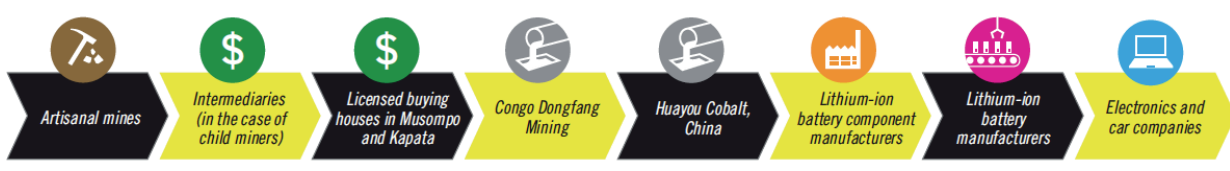

Figure 1: Flow Chart of the Cobalt Supply Chain ${ }^{45}$

This is a situation where the DRC government has failed to place an adequate system to reduce labor exploitation. Given this failure and the limit of what the government can actually do, the companies have been pressured to be more responsible as evidenced by the emergence of instruments such as the UNGP and the OECD Guidelines. ${ }^{46}$ The problem is that what the companies are doing is not enough either to resolve this problem. The more relevant question for the purposes of this subsection, however, is whether it is really the responsibility of companies like Apple and Samsung to determine whether the lithium-ion batteries that they use are actually sourced in a socially responsible manner, especially bearing in mind how complex the typical supply chain is as noted in Figure $1 .{ }^{47}$

42 These guidelines offer step-by-step guidance on how companies should behave with regards to sourcing of minerals that are mined from conflict areas such as the DRC.

43 Amnesty International \& Afrewatch, This is What We Die For: Human Rights Abuses in the Democratic Republic of the Congo Power the Global Trade in Cobalt, AFR 62/3183/2016 (London: Amnesty International, 2016), at p. 9, 41 (noting that the "purpose of the OECD Guidance is to ensure that companies are not profiting from, or contributing to, serious human rights abuses in the mines that they source from, or anywhere else along their supply chains."). The OECD Guidance has "been approved by all 34 OECD Member States and endorsed by nine nonOECD countries and the eleven member states of the ICGLR International Conference on the Great Lakes Region]" and is generally recognized as "the most instructive international standard on conducting responsible due diligence in mineral supply chains, it is not in itself legally-binding"; see, AMNESTY INTERNATIONAL \& Afrewatch, This is What We Die For: Human Rights Abuses in the Democratic Republic of the Congo Power the Global Trade in Cobalt, AFR 62/3183/2016 (London: Amnesty International, 2016), at p. 44.

44 Amnesty International, "Exposed: Child Labour Behind Smart Phone and Electric Car Batteries," Press Release, (19 January 2016). Available at: https://www.amnesty.org/en/press-releases/2016/01/child-labourbehind-smart-phone-and-electric-car-batteries/ (last accessed 20 February 2016) (quoting Mark Dummett, a Business \& Human Right Researcher at Amnesty International stating that they are "not worth the paper they are written on."').

45 Amnesty International \& AFrewatch, This is What We Die For: Human Rights Abuses in the Democratic Republic of the Congo Power the Global Trade in Cobalt, AFR 62/3183/2016 (London: Amnesty International, 2016), at p. 47.

46 Amnesty International \& AFrewatch, This is What We Die For: Human Rights Abuses in the Democratic Republic of the Congo Power the Global Trade in Cobalt, AFR 62/3183/2016 (London: Amnesty International, 2016), at p. 7, 67 (noting that " $[\mathrm{t}]$ here is a significant lack of capacity within governmental agencies to monitor and enforce safeguards and improve conditions for artisanal miners."). As a result, governments like that of the DRC, have been repeatedly chastised by UN human rights monitoring bodies, ILO expert bodies, and various other NGOs for their failure to "put in place an adequate labour inspection system[s]."

47 Amnesty International, "Exposed: Child Labour Behind Smart Phone and Electric Car Batteries," Press Release, (19 January 2016). Available at: https://www.amnesty.org/en/press-releases/2016/01/child-labourbehind-smart-phone-and-electric-car-batteries/ (last accessed 20 February 2016) (quoting Mark Dummett, a Business \& Human Right Researcher at Amnesty International stating that "[c]ompanies whose global profits total $\$ 125$ billion cannot credibly claim that they are unable to check where key minerals in their productions come from.”). 
On a related note, while instruments like the UNGP or the OECD Guidelines are just voluntary and soft law measures, to what extent should governments incentivize their companies to behave in a socially responsible manner while they are operating in foreign jurisdictions? The UN Committee on Economic, Social and Cultural Rights has declared that states have "a duty to prevent their parties - such as companies - from violating human rights abroad, if they are able to influence these third parties by legal or political means," 48 but do states really have an obligation to create such laws? To those that answer in the affirmative, there is an additional question of how meaningful such measures can actually be: To offer some perspective, \$1502 of the Dodd-Frank Act enacted in 2010, requires US companies to conduct due diligence investigations for certain conflict minerals that come out of the DRC to make sure that they were sourced in a socially responsible manner. ${ }^{49}$ As it stands, however, cobalt is not included in the list of "conflict minerals," 50 which once again evidences the shortcomings of some governmental regulations, but more importantly, it begs the question of what impact would the US government adding cobalt to this list have on the working conditions of the creuseurs and the child miners in the DRC. ${ }^{51}$ The US government might argue that adding cobalt to the list would be a prudent course of action, ${ }^{52}$ but the benefits of doing so, especially from the perspective of the creuseurs and the child miners in the DRC, remain unproven.

In sum, this case study presented the difficult question of how actors in the global supply chain can deal with instances of labor exploitation, which may not be categorized as forced labor per se, but is still problematic nonetheless. Considering that the creuseurs and the child miners in the DRC have no meaningful alternatives for income and the intermediaries take advantage of this situation by buying the cobalt ores at a price far below the cost of labor that went into mining them, this fits the broad definition of labor exploitation noted at the beginning of this Introduction, albeit a more subtle one. The conundrum here is that the blunt solution - say to ban all cobalt sourced from the DRC - is not necessarily a solution that would benefit the workers in the vulnerable position. Mining for cobalt, as dangerous as it may be, is one of the only ways available for these vulnerable miners to support themselves and their families. In light of this problem, we must first acknowledge that the conventional wisdomthat governments ought to regulate these exploitative practic-

UN COMmitTeE ON ECONOMic, Social and Cultural Rights, UN DOC E/C.12/GC/19, para. 54; see also, AMNESTY INTERNATIONAL \& AFREWATCH, This is What We Die For: Human Rights Abuses in the Democratic Republic of the Congo Power the Global Trade in Cobalt, AFR 62/3183/2016 (London: Amnesty International, 2016), at p. 67 (stating that "[u]nder international human rights law, all states have a duty to protect against human rights abuses by all actors, including businesses throughout their global operations.").

49 \$1502 of the Dodd-Frank Act also requires companies that fail to comply to provide an explanation as to why they failed to comply.

50 The list only considers tin, tantalum, tungsten, and gold as conflict minerals.

51 It is worth noting that the EU is currently debating similar legislation to Dodd-Frank, where if implemented, companies will be required to undertake due diligence measures similar to the one noted above. See, EUROPEAN COMMISSION, Proposal for a Regulation of the European Parliament and of the Council setting up a Union system for supply chain due diligence self-certification of responsible importers of tin, tantalum and tungsten, their ores, and gold originating in conflict-affected and bigh-risk areas, COM/2014/0111 final (2014).

52 AmNesty InTERNATIONAL \& AFrewatch, This is What We Die For: Human Rights Abuses in the Democratic Republic of the Congo Power the Global Trade in Cobalt, AFR 62/3183/2016 (London: Amnesty International, 2016), at p. 10, 43 (reporting that the companies they interviewed either directly stated or implied that they did not feel obligated to conduct supply chain due diligence because cobalt was not one of the listed minerals under Dodd-Frank). It is worth noting, as the Amnesty International report notes, that "[c]urrently, no country legally requires companies to publicly report on their cobalt supply chains." 
es by mandating corporate transparency and due diligence reporting might not be in the best interest of the exploited laborers. ${ }^{53}$

The story of the CNMI is just one example of what can happen to laborers in the global supply chain, even in a developed country like the United States, when profit-seeking corporations and corrupt government officials collude together to exploit the marginalized workers. ${ }^{54}$ The DRC case on the other hand, showed that even when well-meaning governments enact legislations and businesses sign on to adhere to voluntary guidelines, enforcement measures are often lacking and even the most well intended actions could bring questionable outcomes. The two case studies also raised many intriguing questions like what the lawmakers could have done differently to help the laborers, or whether multinational companies should do more to prevent such atrocities within their supply chain. Other questions such as whether the consumers bear some responsibility as well for creating the demand, albeit indirectly, for cheap labor, or whether the laborers themselves are to blame for their own predicament for not revolting against a system that exploits them also emerge.

To conclude this section, the problem of labor exploitation in the global supply chain is a complex one, which has metastasized throughout the world and impacting the lives of more than a billion workers. The even bigger concern, however, is the possibility that what the governments are currently doing or what conventional wisdom dictates might not be the solution to these problems at all.

\subsection{RESEARCH QUESTION}

Eliminating any and all forms of labor exploitation from the global supply chain would be a formidable task, if not an impossible one. Thus, the aim of this thesis will not be to "solve" the problem of labor exploitation, but to offer a reassessment of what those operating within the global supply chain can do differently, ${ }^{55}$ which starts with asking the right research question. Bearing in mind the problems posed above, the main research question of this thesis - in its broadest conception - is the following: What can private actors do differently to further reduce labor exploitations in the global supply chain? In order to answer this broad question, few sub-questions emerge: 1) what is the state of the art and what are private actors currently doing to reduce labor exploitation in the global supply chain, 2)

53 Amnesty International, "Exposed: Child Labour Behind Smart Phone and Electric Car Batteries," Press Release, (19 January 2016). Available at: https://www.amnesty.org/en/press-releases/2016/01/child-labourbehind-smart-phone-and-electric-car-batteries/ (last accessed 20 February 2016) (stating that "[g]overnments must put an end to this lack of transparency, which allows companies to profit from misery" by enacting laws that "require companies to check and publicly disclose information about where they source mineral and their suppliers.”); cf. InTERnational Labour OrGanization, World of Work Report: Developing with Jobs [Executive Summary], (Geneva: ILO, 2014), at p. 5 (stating that "[a]ccording to conventional wisdom, selective interventions and targeted support would be a source of distortions and economic inefficiency," but that "[i]n reality, success depends on careful diversification strategies in the context of gradual trade liberalization consistent with multilateral commitments.").

54 See, N. KLEIN, No Logo, (New York: Picador, 2000), at p. 338 (calling this type of a violation as a "collusion" between corporations and governments).

55 C. Hitchens, Thomas Paine's Rights of Man, (New York: Grove Press, 2006), at p. 122 (suggesting that addressing a problem of this nature requires "a mixture of sober practicality and sublime optimism."). 
what impacts are they having, 3) what problems and limitations are they encountering, and 4) what changes can they make to further contribute to the reduction of labor exploitation in the global supply chain? In order to answer these questions, the following sections will lay out the methodology and the normative framework that this thesis will employ.

\subsection{METHODOLOGY}

Having posed the research question above, this section on methodology will now present the basic structure of this thesis (Subsection 1.3.1), elaborate on the interdisciplinary approach that it will implement (Subsection 1.3.2), clarify the limitations of this thesis in terms of what it will and will not do (Subsection 1.3.3), and finally, layout some of the author's preferences, including but not limited to selecting specific jurisdictions that this thesis will focus on (Subsection 1.3.4).

\subsubsection{Structure}

After this introductory chapter, this thesis will layout the legal instruments and various strategies already in existence addressing the issue of labor exploitation in the fields of labor/employment law (Chapter 2), tort law (Chapter 3), company law (Chapter 4), and contract/consumer law (Chapter 5). Each of these substantive chapters will also highlight the main problems with the existing measures and in light of their flaws, this thesis will propose an alternative framework or strategy to better address the problem of labor exploitation in the global supply chain (Chapter 6). The final chapter will offer concluding remarks and the answer to the research question (Chapter 7).

The justification behind the selection of these various legal domains, in short, is to offer a thorough coverage of all the different instruments and strategies that various stakeholders are eclectically utilizing to address the labor exploitation problem. To elaborate further, the chapter on labor/employment law will focus on what governments are currently doing to protect the welfare of the workers within their territorial borders to prevent, detect, and/or remedy instances exploitation. The chapter on tort law, which has a slightly more extraterritorial reach than labor/employment laws, will focus on what laborers themselves can do to seek access to justice in foreign courts to remedy exploitations that they already suffered in another jurisdiction. Thus, the tort law measures are more expost, meaning that they are not measures that necessarily seek to detect or prevent instances of exploitation, but they are more concerned with remedying the exploitations that have already taken place through foreign direct liability claims that target multinational companies and their alleged torts in their countries of incorporation. ${ }^{56}$ The following chapters on company law and contract law will shift gears from focusing on what governments or laborers are doing to address the issue of what businesses and consumers are doing to alleviate the plight of the workers.

Foreign direct liability claims are popular option for plaintiffs seeking to addressing instances of corporate malfeasance because jurisdictions where many multinational corporations are registered, often offer laborers higher legal protection than that of the jurisdiction where the tort took place. Chapter 3 will elaborate on this in more detail. 
In doing so, these chapters will again present measures that aim to either prevent, detect, and/or remedy instances exploitation, thus offering both ex ante and expost strategies.

\subsubsection{Interdisciplinary Approach}

In short, this thesis will pursue an interdisciplinary - or a mixed-methodology - approach, which means that in addition to the traditional doctrinal - or intra-disciplincary - methodology, this thesis will incorporate observations and findings from a handful of non-legal sciences to help explain the impact and the limitations of existing legal measures and voluntary initiatives.

More specifically, each of the substantive chapters (Chapters $2-5$ ) will start with a descriptive overview of existing measures that aim to address the problem of labor exploitation by looking at statutes, case laws, enforcement measures, and so forth. In describing the state of the art, this thesis will pay particular attention to their problematic aspects, because determining the cause for why something is not working is the first step towards addressing that problem. ${ }^{57}$ To enhance the analysis of why some measures fail to reduce instances of labor exploitation, this thesis will rely on an eclectic range of non-legal fields such as behavioral economics, psychology, sociology, and anthropology. The remaining chapters will take the lessons obtained from these findings and propose an alternative or a complementary approach that will be in alignment with the normative framework to be established later on in this chapter.

The short justification for selecting an interdisciplinary approach is that it offers a more enriched explanation as to why some measures actually help to address the labor exploitation problem, while others do not. While some may doubt the utility or perhaps even the feasibility of incorporating non-legal sciences into a legal thesis, many scholars and practitioners alike note the importance of implementing a more holistic, multi- or interdisciplinary approach. ${ }^{58}$ Moreover, given that there are considerations and factors outside of the

57 This methodology is arguably similar to falsification in the sense that it will cherry-pick select instances of where the law is not contributing to the reduction of labor exploitation, thus proving that the status quo is unsatisfactory; see e.g., A. CALAPRICE (ED.), The New Quotable Einstein, (Princeton: Princeton University Press, 2005), at p. 291 (quoting Einstein stating that "[n]o amount of experimentation can prove me right, a single experiment can prove me wrong."). It is similarly difficult to argue that a particular law is the right way, because there will always be scenarios where the "best designed" laws render unintended consequences; see also, C.M. CHRISTENSEN, The Innovator's Dilemma: The Revolutionary Book That Will Change the Way You Do Business, (New York: Harper Business, 2011), at p. xxxvii (referring to Thomas Kuhn and noting that the "key to improving any theory is to surface anomalies - events or phenomena that the theory cannot explain. It is only by seeking to account for outliers exceptions to the theory - that researchers can improve the theory.").

58 The field of sociology of law, in particular, and the seminal works of scholars like Max Weber, Émile Durkheim, and Eugen Ehrlich, have long espoused the study of law with its impact on societies at large. See e.g. M. WEBER, Law in Economy and Society, M. RHEInSTEIN (ED.) \& E. SHILS (TRANS.) (Cambridge: Harvard University Press, 1954) (focusing more on the external or empirical impact of laws rather than their internal or moral considerations); and, E. EHrLiCH, Fundamental Principles of the Sociology of Law, (Cambridge: Harvard University Press, 1936) (noting the value of paying attention to how social networks and group norms shape societies - or what he calls "living law" - differently from positive law, which are generally compulsory norms imposed by the state). See also, M. Siems, Comparative Law, (Cambridge: Cambridge University Press, 2014), at p. 310 (noting that "[i]t is frequently suggested that research on human behavior can be helpful for the understanding of legal systems"); and, R.J. SHILlER, Irrational Exuberance, (Princeton: Princeton University Press, 2015), at p. 165-6 (advocating that "to understand the true nature... we must also turn to psychology" and other sciences that understand "character of human intelligence, reflecting its limitations as well as its strengths"). From a practical perspective, the American 
law that influence the way private actors behave, incorporating non-legal sciences and considering non-legal factors like social norms or our cognitive limitations, will offer answers that are more in alignment with reality. ${ }^{59}$ In the end, while laws are extremely important, they are not the final authority on who we are or how we operate as people. ${ }^{60}$

\subsubsection{Limitations}

The aim of this subsection is to establish the parameters of this thesis in terms of what this thesis will and, more importantly, will not cover. To elaborate, this subsection will layout the justifications for this thesis choosing to: a) focus mostly on the private sector and private law, and b) not to conduct any in-depth assessment of international treaties or human rights conventions, which are the instruments traditionally associated with issues of labor exploitation in the international context.

\section{A. Primary Focus on the Private Sector and Private Law}

For the purposes of this thesis, the term private actors or private sector will include, but is not limited to, non-governmental organizations, companies, their stakeholders, consumers, and the laborers themselves. This thesis will focus primarily on the role of these private actors in addressing the issue of labor exploitation in the global supply chain, which is a relatively unconventional approach, given that traditionally, governments are perceived as

Bar Association (“ABA"), for example, has long recognized the value of an interdisciplinary approach to law, especially with regards to psychology and behavioral sciences. As far back as 1930, the ABA declared that "the time has arrived when the grim hard facts of modern psychological inquiry must be recognized by our lawmakers despite the havoc they may create in the established institutions." See, N. CANTOR, "Law and Social Sciences," American Bar Association Journal 16 (1930): 385, at p. 386; cf, This is not to suggest that interdisciplinary approach does present some obstacles: For example, incorporating economics into a legal analysis presents a serious problem given that legal scholars are not necessarily experts on complex macro- or microeconomics and therefore, must rely on the expertise of others.

59 F. CAPRA \& U. MATTEI, The Ecology of Law: Toward a Legal System in Tune with Nature and Community, (Oakland: Berrett-Koehler, 2015), at p. 159 (arguing the need for an approach that "recognize[s] the fundamental interconnectedness of our global problems and enable us to find appropriate, mutually supportive solutions that, instead of distinguishing law, politics, and economics at the local, state, or even international level, would mirror the interdependence of the problems they address."); see also, M.C. NussBaum, "Beyond the Social Contract: Capabilities and Global Justice," Oxford Development Studies 32(1) (2004), at p. 14 (noting that "[i]n a rapidly changing world... any very concrete prescriptions for implementation need to be made in partnership with other disciplines." "[i]n a rapidly changing world... any very concrete prescriptions for implementation need to be made in partnership with other disciplines"); see also, M.C. NussBaum, Creating Capabilities: The Human Development Approach, (Cambridge: Belknap Harvard, 2013), at p. 167 (adding that the question of "how to assign the duties to specific groups and individuals is a difficult matter, and one requiring interdisciplinary theoretical cooperation, since history and political science offer important insights about changing global structures.").

60 M. Siems, Comparative Law, (Cambridge: Cambridge University Press, 2014), at p. 121 (stating that the likes of Montesquieu and von Savigny "argue that there is an organic connection between a particular people - its beliefs, culture, morals, as well as its social, political and economic forces - and its legal system"); citing, M. ANTOKOLSKAIA, Harmonisation of Family Law in Europe: A Historical Perspective, (Antwerp: Intersentia, 2006), at p. 37-9; see also, F. CAPRA \& U. MATTEI, The Ecology of Law: Toward a Legal System in Tune with Nature and Community, (Oakland: Berrett-Koehler, 2015), at p. 72, 105 (summarizing Freidrich Karl von Savigny that "law varies from place to place," and it "must be the product of the 'spirit of the people' (Volksgeist)," which is to suggest that "the law does not belong to the sovereign state, but like culture or language, to the people."). 
the appropriate institutions to manage our collective action problems. ${ }^{61}$ The problem of labor exploitation in the global supply chain, as we suggested earlier, is no doubt a global collective action problem, ${ }^{62}$ but there are two main justifications for choosing this rather unconventional approach: The first is that there are obvious limits to what governments can do, and second, private actors are becoming as influential, if not more powerful than some governments. This part of the subsection will elaborate on these two justifications.

The first reason for focusing on the private sector is due to the fact that there is a limit to what governments can do and what we can realistically expect from them. ${ }^{63}$ While there is a tendency - especially in the more developed economies - for the general public to rely on their governments to protect them and to address their collective action problems, ${ }^{64}$ the public cannot expect this reliance to be absolute. For example, consider the government regulation of the fashion industry, where instances of labor exploitation are quite high. On average, consumers purchase about 80 billion pieces of clothing annually worldwide, which is about $400 \%$ more than we used to purchase not only a decade ago. ${ }^{65} \mathrm{Next}$, think about how much chemicals are involved in the process of making these 80 billion pieces of clothing. Let us narrow down our scope to say only leather products like leather jackets or leather boots. A tannery is where they take the animal hides and make them more durable by treating it with an assortment of chemicals like anthracene, syntans, and glutaraldehyde. These chemicals are not only harmful to the environment, but also toxic for the tannery workers and dangerous for the locals living near the tannery if not properly disposed. When improperly disposed, these chemicals can seep into their local water system and increase the likelihood of the residents getting cancer just because they live near the tannery. ${ }^{66}$

One might assume that surely, governments must be testing these chemicals first, restricting the use of the toxic ones, and ensuring that they are being used and disposed in a safe manner so as to minimize their harm on the workers, the consumers, and the local residents. While this may indeed be true in many cases, especially in the more developed economies, take a moment to digest the fact that even in a developed economy like the US, where of the 84,000 chemicals commonly used to manufacture goods sold to consumers,

61 T. JudT, Ill Fares the Land, (New York: Penguin, 2010), at p. 167 (commenting that "[m]ost critics of our present condition start with institutions. They look at parliaments, senates, presidents, elections and lobbies and point to the way in which these have been degraded or abused the trust and authority placed in them.”).

62 A. Crane, D. Matten \& L. Spence, "Corporate Social Responsibility: In Global Context," in Corporate Social Responsibility: Reading and Cases in Global Context, A. CrAnE, D. MATTEN \& L. SPENCE (EDS.) (London: Routledge, 2013), at p. 14 (noting that resolving collective action problems of this nature has "traditionally been considered [as] a task for governments or [through] mandatory regulation.”).

63 The CNMI and the DRC case studies already offered glimpses of the governments' limitations and this thesis will provide more evidence to this claim in the subsequent chapters.

64 R.B. Cialdini, Influence: The Psychology of Persuasion, (New York: Collins Business, 2007), at p. 132 (stating that there are psychological reasons for people's inactions, especially when there are others aware of the problem, personal or individual responsibility is reduced and we succumb to the belief that "someone else will fix the situation").

65 B. MoOre, “The 'True Cost' Documentary Tallies Global Effect of Cheap Clothes," Los Angeles Times, (28 May 2015). Available at: http://www.latimes.com/entertainment/movies/la-et-mn-true-cost-cheap-clothesdocumentary-20150528-story.html (last accessed 25 March 2016) (noting some of the figures noted in Andrew Morgan's documentary "True Cost” (2015)).

66 See generally, M. MwinYIHijA, Ecotoxicological Diagnosis in the Tanning Industry, (New York: Springer, 2010) (providing a comprehensive overview of how chemicals used in tanneries are causing irreparable environmental harm and serious health damages for the workers in tanneries). 
only about 1,500 to 2,000 have thoroughly been tested for their carcinogenicity. ${ }^{67}$ This example and the two case studies noted in the beginning suggest that while government interventions, legislative enactments, and regulatory enforcements are all very much necessary, there is a limit to what governments and the laws can do. ${ }^{68}$

The second justification for focusing on the private sector has to do with the fact that some private actors are as influential or as powerful as governments. ${ }^{69}$ Multinational corporations ("MNCs"), for example, have accumulated significant amount of resources and influence, where according to an in-depth research conducted by Robert G. Eccles and George Serafem, about 1,000 businesses are responsible for $50 \%$ of the total market value of the world's more than 60,000 publicly traded companies or put more bluntly, these 1,000 businesses practically control the global economy. ${ }^{70}$ There are similar studies that corroborate the concentration of power among a group of corporations, ${ }^{71}$ all suggesting that some of the top MNCs operating within the global supply chain are almost as powerful, if not more so than some governments. ${ }^{72}$ This concentration of power and influence, which roughly employs 67 million workers, has tremendous potential that can be used to

67 J. De GraAf, D. WAnn \& T.H. NAYLor, Affluenza: How Overconsumption is Killing Us - And How We Can Fight Back [Third Edition], (San Francisco: Berrett-Koehler Publishers, 2014), at p. 88 (adding that of the "3,000 chemicals produced at the highest volume, roughly two-fifths have no testing data on basic toxicity"); citing, US Environmental Protection Agency, "Chemical Testing \& Data Collection," (8 August 2013). Available at: http://www.epa.gov/opptintr/chemtest (last accessed 25 March 2015).

68 T. JudT, Ill Fares the Land, (New York: Penguin, 2010), at p. 8, 206 (stating - with regards to the need for governments - that "the practical need for strong states and interventionist governments is beyond dispute," and that "[t]here are too many areas of life where we cannot be relied upon to advance our collective interests merely by doing what we think is best for each of us.”). Long story short, governments are absolutely necessary.

69 S.D. MurPHY, "Taking Multinational Corporate Codes of Conduct to the Next Level," Columbia Journal of Transnational Law 43(2) (2005), at p. 54 (noting that " $[\mathrm{t}]$ he rise of MNCs as a globally dominant economic forces has been characterized by an extensive movement of capital, goods and services across borders, which gives MNCs enormous influence on the working conditions of their laborers in developing countries and on the environmental effects of their operations without any countervailing power exercised by nation-states."); see also, F. CAPRA \& U. MATTEI, The Ecology of Law: Toward a Legal System in Tune with Nature and Community, (Oakland: BerrettKoehler, 2015), at p. 127 (stating that " $[\mathrm{t}]$ oday, for the first time since the birth of the modern state, the private sector is stronger than the government," and adding that the "result is a seemingly irreversible machine that produces inequality and ecological disaster...”); see also, N. HERTZ, The Silent Takeover: Global Capitalism and the Death of Democracy, (New York: Harper Business, 2001).

70 R.G. Eccles \& G. SerafeM, “Top 1,000 Companies Wield Power Reserved for Nations,” Bloomberg, (11 September 2012). Available at: http://www.bloomberg.com/news/2012-09-11/top-1-000-companies-wieldpower-reserved-for-nations.html (last accessed 4 April 2017).

71 S. Vitali, J.B. GlatTfelder \& S. BAtTison, "The Network of Global Corporate Control," PLoS One 6(10) (2011) (noting that there are 147 super companies like Barclays and JP Morgan \& Chase that wield tremendous amounts of influence and power to the extent that they control $40 \%$ of all the corporate wealth across the globe); see also, R. ANDERSON, Confessions of a Radical Industrialist, (New York: Random House Business Books, 2011), at p. 143 (observing that "[i]f Wal-Mart were a country, its $\$ 312$ billion in 2007 revenue would rank the company just behind the Netherland's economy.”). A slightly more updated data reveals that in 2013, Walmart's total revenue was an estimated $\$ 473$ billion, whereas the Dutch nominal GDP in 2013 was at $\$ 853$ billion. Walmart's $\$ 473$ billion in 2013 would still make the company "wealthier" than Austria ( $\$ 428$ billion), Thailand ( $\$ 387$ billion), South Africa ( $\$ 351$ billion), Denmark ( $\$ 336$ billion), and Bangladesh ( $\$ 149$ billion) just to name a few. See, Walmart, Corporate \& Financial Facts, (2014). Available at: http://news.walmart.com/walmart-facts/corporatefinancial-fact-sheet (last accessed 20 February 2015); The World Bank, GDP Ranking Table, (16 December 2014). Available at: http://databank.worldbank.org/data/download/GDP.pdf (last accessed 20 February 2015).

72 L.P. MARCUS, “The People's Corporation," Project Syndicate, (15 September 2014). Available at: http://www.project-syndicate.org/commentary/lucy-p--marcus-says-that-companies-have-more-power-thanever-before--but-so-do-people (last accessed 4 April 2017); see also, T. JuDT, Ill Fares the Land, (New York: Penguin, 2010), at p. 231 (noting that "If the world was becoming smaller and states more marginal to the daily operations of the international economy, what could social democracy hope to offer?”). 
deal with the problem of labor exploitation in the global supply chain. ${ }^{73}$ To only pay attention on what governments can do, and ignoring this potential would be a missed opportunity. ${ }^{74}$ Rather than portraying them as the problem, one can shift the paradigm by viewing these firms as being part of the solution instead, and this will be one of the core aims of this thesis.

Given that the primary focus of this thesis is on the private sector, none of the chapters will focus on public law, including tax law, although many believe that taxation of socially irresponsible actions or subsidizing socially responsible actions may be the best way to influence behavior of private actors. ${ }^{75}$ As the title of this thesis suggests, the reason for this exclusion is primarily due to the fact that this thesis chooses to place its focus on the private sector and private law. However, given that governments and their regulations inevitably influence private actors, this thesis will - albeit on a limited basis - address the role of governments and their regulations from time to time, as well.

\section{B. Limited Assessment of Public or International Law}

Placing our primary focus on private actors and private law also means that this thesis will avoid - for the most part - any in-depth analysis of various international treaties on human rights conventions that are primarily aimed towards the states. This approach is also an unconventional one, given that many existing literature suggests that the solution to an international problem like that of labor exploitation in the global supply chain ought to be addressed through global governance or international treaties and conventions. However, some justifications for avoiding an in-depth analysis of international law or human rights conventions can be found in the myriad of human rights literature that has already addressed this topic, to present the various limitation of this approach. ${ }^{76}$ For example, some limitations include, but are not limited to the following: 1) global governance solutions often tend to be soft law measures or mere aspirational guidelines and, as such, they are not self-enforcing, ${ }^{77}$ 2) politics and the legislative process at the international/global level are

73 R.G. Eccles \& G. SERAfEM, “Top 1,000 Companies Wield Power Reserved for Nations,” Bloomberg, (11 September 2012). Available at: http://www.bloomberg.com/news/2012-09-11/top-1-000-companies-wieldpower-reserved-for-nations.html (last accessed 4 April 2017).

74 M.C. Nussbaum, "Beyond the Social Contract: Capabilities and Global Justice," Oxford Development Studies 32(1) (2004), at p. 4 (noting that "[a]ny theory of justice that proposes political principles defining basic human entitlements ought to be able to confront these inequalities and the challenges they pose, in a world in which the power of the global market and of multinational corporations has considerably eroded the power and autonomy of nations.").

75 T. JuDT, Ill Fares the Land, (New York: Penguin, 2010), at p. 206 (stating that general taxation is the best tool for "aggregating individual desires to collective advantage.”).

76 G.R. STONE, "Editor's Note," in E.A. Posner, The Twilight of Human Rights Law, (Oxford: Oxford University Press, 2014), at p. x (noting that "as currently constituted, international human rights law has little real impact" and what is required is "a more modest and more realistic approach that focuses more on effectiveness than on symbolism.”); see also, D. RODRIK, The Globalization Paradox: Democracy and the Future of the World Economy, (New York: Norton, 2011), at p. 226-8 (noting that "[g]lobal governance offers little help in solving these challenges" because " $[\mathrm{w}] \mathrm{e}$ are dealing with problems rooted in deep divisions among different societies in terms of preferences, circumstances, and capabilities. Technical fixes don't help. Neither do networks of regulators, market-based solutions, corporate social responsibility, or transnational deliberations."); M.C. NussBAUM, "Beyond the Social Contract: Capabilities and Global Justice," Oxford Development Studies 32(1) (2004), at p. 15 (advocating that the "institutional structure at the global level ought to remain thin and decentralized.").

77 E.A. Posner, The Twilight of Human Rights Law, (Oxford: Oxford University Press, 2014), at p. 139. (stating that "human rights treaties are not self-enforcing" and that "relying on biased and interested states to enforcement 
more complicated than that at the national level, ${ }^{78}$ 3) there is a lack of real commitment by state actors, ${ }^{79} 4$ ) international organizations often lack the required resources to implement significant and meaningful changes, ${ }^{80} 5$ ) there are organizational problems with these international organizations, ${ }^{81}$ and stated bluntly 6) they are weak. ${ }^{82}$

While the main aim of this thesis is not to challenge or substantiate the veracity of these claims, many of the measures regarding labor exploitations at the international level do tend to be "softer" instruments that fail to offer tangible protection for the exploited workers. Take for instance, the aforementioned UNGP 83 or others like the Universal Declaration of Human Rights ("UNDHR"), ${ }^{84}$ European Union's Programme for Employment and Social Solidarity ("PROGRESS"), ${ }^{85}$ and the Ruggie Framework. ${ }^{86}$ While these instru-

may be self-defeating, and that human rights enforcement requires the involvement of independent international institutions...").

78 M. NAím, The End of Power: From Boardrooms to Battlefields and Churches to States, Why Being in Charge Isn't What It Used to Be, (New York: Basic Books, 2013), at p. 227, 237 (noting that "more and more 'small' countries veto, footdrag, demand special consideration, or generally undermine the efforts of the 'big' nations in one area after another..." and at the international level, "the level of paralysis is even more ominous. Global problems are multiplying while the capacity of the international community to contain them is stagnant or dwindling"); see also, E.A. PoSNER, The Twilight of Human Rights Law, (Oxford: Oxford University Press, 2014), at p. 107 (noting that "efforts to overcome collective action problems through the construction of international institutions have floundered because the collective action problem reemerges within the operation of those institutions."); and, E.A. POSNER, The Twilight of Human Rights Law, (Oxford: Oxford University Press, 2014), at p. 139 (noting that "an enormous menagerie of committees, councils, commissions, offices, and courts, with complexly overlapping jurisdictions and varying capacities - nearly all undermined by resources starvation or legal restriction on their authority.").

79 Y. SHANY, "The Effectiveness of the Human Rights Committee and the Treaty Body Reform," Hebrew University Faculty of Law International Law Forum Research Paper No. 02-13 (2013), at p. 21 (stating that [t]he unhappy situation of the UN treaty bodies may thus be explained in large part by a tension between superficial commitment by many state-parties to the goal of human rights promotion and a realpolitik aversion to actual treaty implementation"; see also, E.A. Posner, The Twilight of Human Rights Law, (Oxford: Oxford University Press, 2014), at p. 40 (opining that States are generally "reluctant about submitting to the jurisdiction of courts or other legal bodies" and " $t]$ he resulting international legal institutions are thus considerable weaker than domestic legal institutions.”).

80 E.A. POSNER, The Twilight of Human Rights Law, (Oxford: Oxford University Press, 2014), at p. 42 (stating that the "[p]art of the problem may be the sheer number of committees and their overlapping jurisdictions" but moreover "the committees have vast jurisdiction over most of the world while possessing few resources, which of course limits their effectiveness.”).

81 E.A. Posner, The Twilight of Human Rights Law, (Oxford: Oxford University Press, 2014), at p. 139 (stating institutions such as these often tend to be "an enormous menagerie of committees, councils, commissions, offices, and courts, with complexly overlapping jurisdictions and varying capacities - nearly all undermined by resources starvation or legal restriction on their authority.").

82 D. Bilchitz, "The Ruggie Framework: An Adequate Rubric for Corporate Human Rights Obligations," International Journal on Human Rights 7(12), (2010), at p. 199 (noting that international law on human rights agreed to by the States is the "lowest common denominator" and that corporations should "not only be required to avoid harm," but also "be required to contribute actively to the realization of such rights."); see also, E.A. POSNER, The Twilight of Human Rights Law, (Oxford: Oxford University Press, 2014), at p. 104 (stating that the "reason human rights law failed to improve respect for human rights is that the law is weak - the treaties are vague and inconsistent, and the institutions are balkanized, starved of resources, and unequipped with legal authority."); E.A. POSNER, The Twilight of Human Rights Law, (Oxford: Oxford University Press, 2014), at p. 42 (noting that "committees do not have the power to issue sanctions or remedies.").

83 Principle 11, which requires business enterprises to "respect human rights" and to "avoid infringing on the human rights of others and should address adverse human rights impacts with they are involved."

84 UNHR Article 23 (1): [Right] To work, to free choice of employment, to just and favorable conditions of work, and to protection against unemployment. (2) To equal pay for equal work. (3) To just and favorable remuneration ensuring for himself and his family an existence worthy of human dignity, and supplemented, if necessary, by other means of social protection. (4) To form and to join trade unions for the protection of his interest.

85 A. RÜHMkorf, Corporate Social Responsibility, Private Law and Global Supply Chains, (Cheltenham: Edward Elgar, 2015), at p. 81 (noting the importance of PROGRESS as a program that fosters companies creating and managing a responsible supply chain). 
ments are aspirational and important indeed, they are not necessarily binding, thus failing to offer a very pragmatic solution to answering our specific research question on what private actors can do differently.

Moreover, most of the international conventions or agreements on this subject are instruments that bind the states, and not individuals. So an individual seeking a remedy for being exploited as a laborer cannot base his or her claim on these so-called rights. For example, both the UNDHR and the International Covenant on Economic, Social and Cultural Rights ("ICESCR") recognize the "right to work" to the extent that it demands states to protect such rights, but that does not mean that all states do so or that an exploited worker can claim violation of these "rights" against his or her employer. After all, these international conventions were not designed with such purposes in mind. As a result, even though both the DRC and the United States are parties to the ICESCR, this does not necessarily mean that these international treaties actually protect the laborers from being exploited.

In the end, international treaties and conventions, especially those that extol human rights, while of great symbolic importance, often do not guarantee that the state actors will respect such rights, nor will it allow private actors to rely on them to make claims against those companies that exploit them. So rather than looking at our issue from an international law perspective, this thesis will focus on the more pragmatic approaches by looking at the role of private actors relying on private law and private initiatives.

\subsubsection{Preferences and Perspectives}

The aim of this subsection is to clarify the subjective preferences of this thesis for choosing to: a) maintain a rather international perspective, and b) not subscribe or pledge allegiance to any particular school of economic thought.

\section{A. International Perspective}

While this thesis will not address international treaties or human rights conventions in much detail as noted in the previous subsection, it will nevertheless maintain an international perspective. While traditional legal analysis observes laws of various different jurisdictions comparatively, thus taking a rather domestic perspective, ${ }^{87}$ this thesis will focus on the problem of labor exploitation from a more global perspective, given that our problem is one that has permeated through territorial borders. This is to suggest that the topic of legal jurisdiction in this thesis - while relevant in some varying instances - is not necessarily an issue of the utmost importance. This is particularly true in the later chapters of this

86 J.G. Ruggie, Guiding Principles on Business and Human Rights: Implementing the United Nations "Protect, Respect and Remedy" Framework, United Nations Report HR/PUB/11/04 (2011) (advocating for a three pillar model consisting of the state's duty to respect fundamental freedoms, companies to be socially responsible, and for the system to offer more effective access to remedies); see also, A.L. VYTOPIL, Contractual Control in the Supply Chain: On Corporate Social Responsibility, Codes of Conduct, Contracts and (Avoiding) Liability, (The Hague: Eleven, 2015), at p. 33 (describing that "[t]he Ruggie framework thereby sets out the responsibilities that - inter alia - businesses have with regard to their operations and human rights.”).

87 See e.g., D. RoDrik, The Globalization Paradox: Democracy and the Future of the World Economy, (New York: Norton, 2011), at p. 239 (admitting that while " $[\mathrm{t}]$ here is no 'one way' to prosperity" the "core institutional infrastructure of the global economy must be built at the national level..."). 
thesis (i.e. Chapters 4 and 5 that deal with issues of corporate social responsibility and ethical consumerism), as they will focus mainly on the role of private actors relying on private initiatives, non-legal measures, and the grey area where they are not legally obligated to act, but perhaps ought to.

Looking at the problem of labor exploitation from a global perspective is to acknowledge that there are some fundamental similarities in terms of how different actors currently deal with this global problem. However, to the extent that there are some lingering and noticeable differences, when presenting the state of the art in Chapters 2 through 5 , this thesis will pay particular attention to the laws of New York and the Netherlands. The justification for selecting these jurisdictions, aside from various pragmatic concerns, is that they are quite different and similar at the same time, which is interesting from a comparative perspective: First, one is a civil law jurisdiction whereas the other is a common law jurisdiction. Second, one is European and the other American. Third, both New York City and Amsterdam, the capital of the Netherlands, are metropolises of economic and cultural significance. They are both vital hubs of international commerce and a near integral part of the global supply chain. Additionally, looking at these two jurisdictions will allow us to consider various US federal regulations as well as EU Regulations and Directives that aim to curtail instances of labor exploitation.

The fact that the doctrinal part of this research is narrowed down to New York and the Netherlands does not mean, however, that these two jurisdictions will be the only jurisdictions that this thesis will observe. Other jurisdictions, including but not limited to California, the United Kingdom, Qatar, and Nigeria will also be considered to the extent that legislations within these jurisdictions will be relevant to the discussion at hand: For example, Chapter 3.1.2 will look to the tort law of California because within the US, California is known to be the most plaintiff-friendly jurisdiction, and many of the tort based cases that end up at the US Supreme Court traces back to the courts in California. Another example where this thesis will have to take laws of other jurisdictions into consideration can be found in Chapter 3.2.1, where the Dutch Tort Law on Conflict of Law (Wet Conflictenrecht Onrechtmatige Daad) ${ }^{88}$ will require us to look at the laws of Nigeria and England even for cases that are brought before the courts in the Netherlands, not to mention the relevant EU Regulations. ${ }^{89}$ The need to discuss this rather eclectic set of jurisdictions further stresses the importance of maintaining an international perspective in dealing with the global problem at the heart of this thesis.

\section{B. Mediating between Keynes and Hayek}

Before proceeding on to the substantive chapters, it is important to clarify at the onset, one particular clarification, which is that this thesis does not subscribe to one particular school of economic thought over another. It is important to state this outright, given that the phrasing of the research question - which focuses on the private sector - might give a

Note that Wet Conflictenrecht Onrechtmatige Daad has been effectively repealed and replaced by the Dutch implementation of subsequent EU Regulations. This will be discussed further in Chapter 3.2.1.

89 While this thesis primarily focuses on Western laws and remedies, to borrow the words of Ugo Mattei, "[ $\mathrm{t}]$ here is no ethnocentrism in this choice - only the urgency to place responsibility where it belongs.” See, F. CAPRA \& U. MATTEI, The Ecology of Law: Toward a Legal System in Tune with Nature and Community, (Oakland: Berrett-Koehler, 2015), at p. x. 
mistaken impression that this thesis supports the aforementioned Chicago school of thought.

In answering the question of whether governments should intervene to reduce instances of labor exploitation, a Keynesian will likely argue that they should, whereas Hayek, Friedman, and many others from the Chicago school traditional would argue that governments should refrain, preferring a laissez-faire approach instead, and opting for more market-oriented solutions. ${ }^{90}$ We already witnessed this debate in the context of whether the US should extend minimum employment protections to the CNMI or whether governments should mandate companies dealing with conflict minerals to be more transparent about their supply chains. This thesis answers this question by first suggesting that both Keynesian and Chicago schools of thought are not necessarily right or wrong, but their predictive values are quite circumstantial. ${ }^{91}$ To elaborate, this thesis is very suspicious of some the arguments advocated by the Chicago school, ${ }^{92}$ but it is equally skeptical of the view that a paternalistic government and their laws can resolve all of our problems at all times.

Admittedly, these statements do not answer the original question of whether governments ought to intervene to address our problem and where this particular thesis stands on the issue: First, this thesis acknowledges that government regulations and laws do and should incentivize individuals to behave in a particular way, which has some obvious Keynesian undertones. However, to the extent that our normative framework - which will be presented in the next section (Section 1.4) - will consider personal autonomy, freedom of choice, and self-preservation as vital factors to reducing labor exploitation, this thesis cannot completely divorce itself from the teachings of the Chicago tradition either. To mediate this predicament, it is worth noting that a fundamentalist view of any theory has flaws: The Kantian approach to universalizing a general principle or suggesting that we should always do something in a particular manner is sure to invite criticism. This is to suggest that we cannot survive in a pure market society, where social relations are embedded in the economy and market forces dictate our values and norms; ${ }^{93}$ but we also should not worship a state of unhindered legal paternalism, where the law overrides personal autonomy and individual choice based on the fact that individuals may fail to exercise choice wisely in a manner that harm others or even themselves. ${ }^{94}$

So where does this leave us in terms of how this thesis leans in terms of its preference between Keynes and Chicago? The short answer is that it does not really matter. Ultimately, the dichotomy between these two schools of thought is somewhat over-exaggerated.

T. JuDT, Ill Fares the Land, (New York: Penguin, 2010), at p. 103 (noting the tendency of the Chicago school to "dogmatically reject all central control").

91 Both Keynes and Hayek would agree that economics is an "interpretive science" that is "not amenable to prediction or precision." See, T. JuDT, Ill Fares the Land, (New York: Penguin, 2010), at p. 103.

92 See e.g. T. JuDT, Ill Fares the Land, (New York: Penguin, 2010), at p. 107, 109 (describing the likes of Friedman as the leader of the "cult of privatization" that worships the private sector and a staunch advocate for a movement to shift public responsibility onto the private sector to - at least according to Judt - "no discernible collective advantage."). Some of the popular arguments and their predilection for free market economics can be seen through there stance, including but not limited to no government interventions, cut taxes, reduce government spending and ownership, and increase privatization.

93 K. POLANYI, The Great Transformation: The Political and Economic Origins of Our Time, (Boston: Beacon Press, 2001), at p. 60; and, M. ZWOLINSKI, "A Libertarian Case for the Moral Limits of Markets," Georgetown Journal of Law and Public Policy 13(2) (2015): 275-290, 275.

94 A. OGus, "The Paradoxes of Legal Paternalism and How to Resolve Them," Legal Studies 30 (2010), at p. 61-2. 
For example, although the Chicago school claims that the market knows best and that governments should refrain from interfering, even they acknowledge that some rules and regulations are necessary. ${ }^{95}$ Moreover, the alleged restrictions of various freedoms that supposedly come as a result of government interventions are not necessarily libertyinhabiting as Joseph W. Singer notes:

"The free market model conceptualizes mandatory rules as interferences with freedom of contract and, hence, limitations on autonomy. But if these rules help the parties get what they want - and if the parties cannot get what they want without, then it makes no sense to characterize those rules as necessarily liberty-inhabiting; rather, although they limit freedom of action, they appear to be liberty-enhancing. "96

Singer's point suggests that there is already some consensus, or at least common denominator, between these two schools of thought that markets should be subject to some very minimum levels of regulation without being accused of restricting people's liberty or autonomy. ${ }^{97}$ The more pertinent question thus is not whether governments should intervene or not, but when and how they should intervene, which is a question that this thesis will address periodically as a way to figure out what private actors can do differently to reduce labor exploitations in the global supply chain.

To conclude this part of the subsection, we need more than just the invisible hand to reduce labor exploitations in the global supply chain. At the same time, excessive governance can become obstacles that get in the way of this objective as well. This is partly due to the fact that the typical command and control style regulation not only challenges our sense autonomy and freedom of choice, but it is not very flexible and is slow to adapt to rapidly changing realities. ${ }^{98}$ This hierarchical command and control structure, often utilized by governments, not only creates high transition costs and various inefficiencies, but often render mixed outcomes mired in series of tradeoffs. ${ }^{99}$

95 J. W. SingER, "Things that We Would Like to Take for Granted: Minimum Standards for the Legal Framework of a Free and Democratic Society," Harvard Law and Policy Review 2 (2008): 139, at p. 154 (noting that "[t]he "free market' describes a particular sort of social order, and that order is premised not only on freedom of contract but on the equal status of persons. This means that the liberty of each party to the deal must be limited in certain ways to protect the liberty of the other.").

96 J. W. SINGER, "Things that We Would Like to Take for Granted: Minimum Standards for the Legal Framework of a Free and Democratic Society," Harvard Law and Policy Review 2 (2008): 139, at p. 147.

97 J. W. SingER, "Things that We Would Like to Take for Granted: Minimum Standards for the Legal Framework of a Free and Democratic Society," Harvard Law and Policy Review 2 (2008): 139, at p. 149, 153; see also, J. W. SINGER, "Subprime: Why a Free and Democratic Society Needs Law," Harvard Civil Rights-Civil Liberties Law Review 47 (2012): 141, 142 (stating that "markets function because we have the rule of law, and liberty is possible only if we have a robust regulatory state."); J.E. STIGLITZ, Freefall: Free Markets, and the Sinking of the World Economy, (New York: W. W. Norton \& Co, 2010), at p. x (stating that "markets do not work well on their own.”).

98 R.H. Thaler \& C.R. SunsteIN, Nudge: Improving Decisions About Health, Wealth, and Happiness, (New York: Penguin, 2009), at p. 186 (stating that "[t]ypically regulators have chosen some kind of command-and-control regulation, by which they reject free choices and markets entirely and allow people little flexibility...”).

99 For example, while laws are very much necessary to promote equality, in reality, there are often tradeoffs: In a zero-sum game where equality is pinned against economic gains and efficiency, often times, the efficiency side of the argument prevails. See e.g., S. DEAKIN, J. MALMBERG \& R. SARKAR, "Do Labour Laws Increase Equality at the Expense of Higher Unemployment? The Experience of Six OECD Countries, 1970-2010," University of Cambridge Faculty of Law Legal Studies Research Paper Studies No. 11, (2014), at p. 2 (citing to a World Bank report that suggests that "laws created to protect workers often hurt them"); see, World Bank, Doing Business in 2008 (Washington D.C.: World Bank, 2008). This issue of negative repercussions will be developed further in subsequent sections of the 
In the end, "[t] he kind of markets in which sweatshops exist doesn't look much like Libertarian Utopia. But they don't exactly look like Stalinist Russia, either.” ${ }^{100}$ Bearing this point in mind, this thesis will focus on the private sector, not because it subscribes to the Chicago school of thought or because it underscores the importance of governments, but because it acknowledges that private actors possess tremendous and untapped potential, perhaps above and beyond what governments are capable of doing. ${ }^{101}$ Before moving on to substantiate this point, this introductory section will present the aforementioned normative framework that this thesis will utilize.

\subsection{NORMATIVE FRAMEWORK}

Now that the problem, the research question, and the methodology of this thesis has been established, it is important to lay out a framework that will serve as our measuring stick when answering the research question: In other words, what is the criteria this thesis will rely on to claim that a particular measure is working or not working. In short, the normative framework for this thesis will be an adapted version of the capabilities approach. Before elaborating on this particular framework, this section will first present an overview of the traditional capabilities approach as constructed by Amartya Sen and Martha Nussbaum (Subsection 1.4.1). Based on the original capabilities approach, the second subsection will present our interpretation of the capabilities approach, which is specifically tailored to address the research question of what can private actors do differently to reduce labor exploitation in the global supply chain (Subsection 1.4.2). The final subsection (Subsection 1.4.3) will conclude this introductory chapter with a short caveat before moving on to the subsequent chapters.

\subsubsection{Capabilities Approach}

The capabilities approach asks the fundamental question of what are people capable of actually doing or what are they capable of becoming. ${ }^{102}$ Amartya Sen summarizes this approach in terms of whether or not people have opportunities to choose and to act in ways

thesis; see also, R.H. THALER \& C.R. SunSTEIN, Nudge: Improving Decisions About Health, Wealth, and Happiness, (New York: Penguin, 2009), at p. 186.

100 M. ZWOLINSKI, “A Libertarian Case for the Moral Limits of Markets," Georgetown Journal of Law and Public Policy 13(2) (2015): 275-290; see also, T. JuDT, Ill Fares the Land, (New York: Penguin, 2010), at p. 183 (stating that "[s]ome sort of mutual restraint will be required if we are to take seriously all of our desires: this is a truism for any consensual system”).

101 J. Norberg, In Defense of Global Capitalism, (Washington D.C.: Cato Institute, 2003), at p. 17 (arguing that "[w]hat I really believe in, first and foremost, isn't capitalism or globalization. It isn't the systems of regulatory codes that achieve all we see around us in the way of prosperity, innovation, community, and culture. Those things are created by people. What I believe in is man's capacity for achieving great things, and the combined forced that results from our interactions and exchanges.").

102 M.C. Nussbaum, Creating Capabilities: The Human Development Approach, (Cambridge: Belknap Harvard, 2013), at p. $\mathrm{x}, 14$ (noting that this approach is also referred to by the "capabilities approach" or the "human development approach"). 
that they want. ${ }^{103}$ Martha Nussbaum's interpretation of the capabilities approach is quite similar, where she states that our goal, as a society, is to ensure that we all "get above a certain threshold level of combined capability, in the sense not of coerced functioning but of substantial freedom to choose and act." 104 Nussbaum elaborates on her interpretation by emphasizing that the capabilities approach is about whether people are capable of minimally flourishing and realizing their goals. ${ }^{105}$ Thus, according to this normative framework, actions that increase the opportunities or capabilities available to people, which allow them to realize their goals are deemed to be good or successful. ${ }^{106}$ It is worth stressing here that the capabilities approach, as envisioned by Sen and Nussbaum is an outcome-oriented approach that focuses on the minimums and only when these minimums have been provided to people can a society be considered as a decent and minimally just.

\section{A. Capabilities Approach v. Economic and Utilitarian Arguments}

The capabilities approach is most commonly associated with the field of development studies, as the main normative framework that measures whether strategies are actually contributing to the development of nations and their people. ${ }^{107}$ To provide a bit of historical context, the capabilities approach was a critical response to the traditional development framework that primarily relied on aggregate economic factors like looking at the developing countries' gross domestic product ("GDP") to assess their achievements. Using these economic arguments, some portrayed sweatshops and labor exploitations as rites of passage or as necessary steppingstones in the economic development of third world economies. For example, Benjamin Powell concluded that companies are willing to outsource their manufacturing to developing countries, specifically because their labor costs are relatively low, and in return, the developing countries benefit from the technology and other resources that companies bring to them. ${ }^{108}$ This line of argument implies that a top down

103 A. SEN, Development as Freedom, (New York: Knopf, 1999) (elaborating on the notion of capabilities as "substantial freedoms," which "is a set of opportunities to choose and to act" that is created or enabled by "a combination of personal abilities and the political, social, and economic environment"); and, M.C. NussBAuM, Creating Capabilities: The Human Development Approach, (Cambridge: Belknap Harvard, 2013), at p. 20-1 (referring to what Sen calls "substantial freedoms" as "combined capabilities," is the "totality of opportunities [one] has for choice and action in [their] specific political, social, and economic situation.”).

104 M.C. Nussbaum, Creating Capabilities: The Human Development Approach, (Cambridge: Belknap Harvard, 2013), at p. 23-4, 125 (noting the heavy influence of Aristotle and the Stoics by acknowledging the importance of lawmakers "to understand what human beings require for a flourishing life" and the necessity of meaningful personal choice as a fundamental component of human dignity bestowed upon every human being by virtue of simply being human); cf. R. DwORKIN, Sovereign Virtue: The Theory and Practice of Equality, (Cambridge: Harvard University Press, 2002) (criticizing that " $[t]$ he idea that people should be equal in their capacities to achieve [their] desirable states of affairs, however, is barely coherent and certainly bizarre-why would that be good? — and the idea that government should take steps to bring about that equality-can you imagine what steps those would be? - is frightening.").

105 M.C. Nussbaum, Creating Capabilities: The Human Development Approach, (Cambridge: Belknap Harvard, 2013), at p. 23-4, 125.

106 M.C. Nussbaum, Creating Capabilities: The Human Development Approach, (Cambridge: Belknap Harvard, 2013), at p. 14.

107 S.L. ESQUiTH, "Introduction: Institutions and Urgency," in Capabilities, Power, and Institutions: Toward a More Critical Development Ethics, S.L. ESQUiTH \& F. GIFFORD (EDS.) (Pennsylvania: Pennsylvania State University, 2010), at p. 9 (quoting Ingrid Robeyns during the Third International Conference on the Capabilities Approach).

108 B. POwELL, "In Defense of 'Sweatshops'," Library of Economics and Liberty, (2 June 2008). Available at: http://www.econlib.org/library/Columns/y2008/Powellsweatshops.html (last accessed 4 April 2017) (stating that "[w]hen companies open sweatshops they bring technology and physical capital with them," and "as more sweatshops open, more alternatives are available to workers raising the amount a firm must bid to hire them"); see also, J. 
regulation to clamp down on sweatshops and measures that aim to eradicate labor exploitations in the developing economies are undesirable because it would increase their production costs and reduce their competitive advantage, which in the long run would stunt economic growth to the detriment of every worker. Some economists go as far as to suggest that to deny the sweatshop laborers the ability to work in sweatshops would only further exacerbate their plight, and as unpleasant as their working conditions may be, their collective sacrifice is the key to their nation's economic prosperity. ${ }^{109}$

The proponents of the economic approach rely on historical evidence to justify their position that many of today's developed nations have experienced a similar period in their own history characterized by awful labor conditions before developing into industrialized economies. Upton Sinclair's The Jungle, for example, illustrates the harsh working conditions in the US meatpacking industry during the early $20^{\text {th }}$ century, where many of the immigrant laborers had to endure not only hazardous and unsanitary working conditions, but also experienced abuse, torment, and hopelessness. Taking the economic arguments at face value, it was the sacrifice of these immigrant workers and their "willingness" to work in abhorrent conditions that allowed America to become the industrialized economy that it is today. If we were to deny developing countries of similar rites of passage, the proponents of this particular view would argue that we would be doing a great disservice to the developing nations by insisting that they reduce labor exploitations. These arguments take on a rather utilitarian view ${ }^{110}$ that for the sake of the country, for the sake of the greater good, for the sake of maximizing aggregate utility, and for the sake of increasing GDP, labor exploitations should be tolerated.

On the other hand, the proponents of the capabilities approach believe that measuring the health of a nation or of its people by measuring economic factors to be an inaccurate indication of how well off they actually are. ${ }^{111}$ This is to say that an increase in the GDP

Norberg, In Defense of Global Capitalism (Washington D.C.: Cato Institute, 2003), at p. 21 (claiming that it was because of globalization and capitalism that poverty level across the globe has diminished); and, THE ECONOMIST, “The Biggest Contract," (26 May 2005). Available at: www.economist.com/node/4008642 (last accessed 4 April 2017) (quoting Ian Davis, the former worldwide managing director of McKinsey \& Company noting how developing countries can benefit from "the entry of multinational companies," even in the context of labor exploitation, as they "often contributed critical capital, technology, skills and other poverty-reducing economic spillovers.").

109 P. KRugman, "In Praise of Cheap Labor: Bad Jobs at Bad Wages Are Better Than No Jobs at All," Slate Magazine, (21 March 1997) (stating that "you might as well deny them the prospect of continuing industrial growth, even reverse the growth that has been achieved.”). Available at: http://web.mit.edu/krugman/ www/smokey.html (last accessed 4 April 2017); see also, J. NORBERG, In Defense of Global Capitalism (Washington D.C.: Cato Institute, 2003), at p. 21, 64 (arguing "in the affluent world we have had capitalism in one form or another for a couple of centuries. That is how countries of the West became 'the affluent world.' Capitalism has given people both the liberty and the incentive to create, produce, and trade, thereby generating prosperity"); and, C. DuHigG \& D. BARBozA, "In China, Human Costs are Built into an iPad," The New York Times, (25 January 2012). Available at: http://www.nytimes.com/2012/01/26/business/ieconomy-apples-ipad-and-the-humancosts-for-workers-in-china.html (last accessed 18 December 2016) (noting a related argument against regulating sweatshops, which is that "radical overhaul could slow innovation").

110 See generally, J. BENTHAM, (arguing that we should always act so as to maximize our aggregate happiness); see also, J.S. MiLL, On Liberty, (1859).

111 See e.g. the Commission on the Measurement of Economic Performance and Social Progress conducted in 2008, which suggested that the average real household income was a "more pertinent" measurement of people's actual living standard rather than the increase of the nation's GDP; see also, M.C. NussBAum, Creating Capabilities: The Human Development Approach, (Cambridge: Belknap Harvard, 2013), at p. 48. For similar reasons, there are those that advocate for the replacement of the Gross Domestic Product with that of the Social Progress Index (SPI) as 
does not necessarily correlate with an increase in living standards for everyone. ${ }^{112}$ The general problem with looking at aggregate economic measurements like the GDP as a normative criterion is that it invites utilitarian justifications. While utilitarian solutions have their merits, ${ }^{113}$ they often fail to take into consideration notion of justice and fairness especially for those in the minority, ${ }^{114}$ and accordingly, both Sen and Nussbaum are critical of this particular approach. ${ }^{115} \mathrm{It}$ is also worth pointing out that even the creator of the GDP, Simon Kuznets, himself believed that the GDP is not a good indicator of a nation's wellbeing. ${ }^{116}$ Furthermore, adopting an economic normative criterion into a legal analysis makes it difficult to reach moral or ethical conclusions because illegal or immoral actions can often have great economic utility. This is to note that the purely economic framework is an inadequate way to measure or assess issues of social justice. ${ }^{117}$

Thus, a normative framework that prioritizes economic or market factors would not suit the purposes of this thesis, which is ultimately about justice, fairness, and reducing instances of labor exploitation. ${ }^{118}$ Therefore, we need a normative framework - like the

"a new way to measure social progress" given that "GDP is simply too one-dimensional to provide a complete measure of a nation's progress"; see, M. BISHOP, "Beyond GDP," The Economist, (18 April 2013) (quoting Michael Green, the head of the non-profit, Social Progress Imperative.). While later sections of this thesis will advocate for some of Simon Kuznet's creations (i.e. the Kuznet's curve or the so called the Inverted-U curve) this portion of the thesis will, ironically, challenge others (i.e. the GDP).

112 M.C. Nussbaum, Creating Capabilities: The Human Development Approach, (Cambridge: Belknap Harvard, 2013), at p. 1 (stating that "[i]ncreased GDP has not always made a difference to the quality of people's lives, and reports of national prosperity are not likely to console those whose existence is marked by inequality and deprivation"); see also, M.E.P. SELIGMAN, Flourish, (New York: Atria, 2011), at p. 96, 222 (criticizing the GDP because "every time we build a prison, every time there is a divorce, a motor accident, or a suicide, the GDP - just a measure of how many goods and services are used - goes up"); see also, E. DiENER \& M.E.P. SELIGMAN, "Beyond Money: Toward an Economy of Well-Being," Psychological Science in the Public Interest 5 (2004): 1-31 (noting that how well a nation is doing cannot be measured by GDP alone); see also, D. RODRIK, The Globalization Paradox: Democracy and the Future of the World Economy, (New York: Norton, 2011), at p. 55 (noting that "“If economics were only about profit maximization, it would be just another name for business administration. It is a social discipline, and society has other means of cost accounting besides market prices.”).

113 Utilitarian solutions are often touted as options that lead to risk and damage minimization. For example, if you can pull a lever that would kill only one person, but failing to pull the lever would result in the death of five people, a utilitarian would argue that pulling the lever is the right solution without necessarily addressing the issue of justice and fairness in pulling that lever. This is to suggest that under the utilitarian framework, so long as more people are happy, the level of misery suffered by the minority can, in one way or another, be justified.

114 C. Fried, An Anatomy of V alues: Problems of Personal and Social Choice, (London: Oxford University Press, 1970), at p. 218, 220 (noting that "[t]he most obvious objection to a pure efficiency argument is an argument from fairness.").

115 See e.g. M.C. Nussbaum, Creating Capabilities: The Human Development Approach, (Cambridge: Belknap Harvard, 2013), at p. ix (noting that "[b]ecause countries respond to public rankings that affect their international reputation, th[is] crude approach encouraged them to work for economic growth alone, without attending to the living standard of their poorer inhabitants..."); and, A. SEN, Development as Freedom, (New York: Knopf, 1999), at p. 3. (noting that the "development requires removal of major source of unfreedom: poverty as well as tyranny, poor economic opportunities as well as systematic social deprivation, neglect of public facilities as well as intolerance or over-activity of repressive states.").

116 S. KUZNETS, "National Income, 1929-1932," National Bureau of Economic Research 124 (1934), at p. 7 (noting that "the welfare of a nation can scarcely be inferred from a measurement like [GDP].").

117 M.C. Nussbaum, Frontiers of Justice: Disability, Nationality, Species Membership [Tanner Lectures of Human Values], (Belknap Press of Harvard University Press, 2007), p. 283; see also, T. JudT, Ill Fares the Land, (New York: Penguin, 2010), at p. 230 (noting that "[i]f we confine ourselves to issues of economic efficiency and productivity, ignoring ethical considerations and all reference to broader social goals, we cannot hope to engage it."); see also, M.J. SANDEL, What Money Can't Buy: The Moral Limits of Markets, (London: Allen Lane, 2012) (adding that in a market society, inequality is not just about luxury and material possessions, but about having access to basic rights).

118 J. W. SINGER, "Things that We Would Like to Take for Granted: Minimum Standards for the Legal Framework of a Free and Democratic Society," Harvard Law and Policy Review 2 (2008): 139, 148 (stating that "[t]he market does 
capabilities approach - that takes into consideration qualitative criteria like freedom, personal autonomy, and fraternity over economic growth. ${ }^{119}$ In the end, choosing the capabilities approach as the basis for a normative framework means that this thesis makes the conscious choice to treat human beings, not as some means to an end, but as the end itself. ${ }^{120}$

\section{B. Picking the Relevant Capabilities}

As noted above, the capabilities approach is about increasing opportunities and expanding the choices available to people to live a minimally flourishing and dignified life. ${ }^{121}$ While the aim of this approach is clear, what is less clear is what specific capabilities would allow or enable this outcome. This is one of the main points of differentiation between Nussbaum and Sen. ${ }^{122}$ While Sen does not provide a list of what he considers as basic capabilities, ${ }^{123}$ Nussbaum explicitly lists what she considers to be the central or basic capabilities, selecting capabilities like integrity and having control over one's environment. ${ }^{124}$

Given the narrow aim of this thesis - which is to find different ways private actors can contribute to reducing labor exploitation - simply adopting Nussbaum's list of basic capabilities for people to live a dignified life would not be an exact fit. On the other hand, hav-

not adequately reflect the interests of third parties or of society as a whole who bear the negative externalities of market transactions and who are barred from participating in those transactions because of obvious impediments to transacting."').

119 P. Alston, Labour Rights as Human Rights: Collected Courses of the Academy of European Law, (Oxford: Oxford University Press, 2005), at p. 13 (suggesting that the "[p]romotion of market participation through support for the equal formation of capabilities is welfare maximizing and thus consistent with neo-liberal economic criteria for social policy.”).

120 J. W. SingER, "Things that We Would Like to Take for Granted: Minimum Standards for the Legal Framework of a Free and Democratic Society," Harvard Law and Policy Review 2 (2008): 139, at p. 158 (noting that this "[n] ormative argument is based on the idea that people are of immeasurable importance and that they deserve to be treated like human beings, not merely as cogs in a wealth-producing machine - in Kant's words, as ends, not means.").

121 J. W. SINGER, “Subprime: Why a Free and Democratic Society Needs Law," Harvard Civil Rights-Civil Liberties Law Review 47 (2012): 141, 160 (elaborating that "[w]e must ensure that each person has the realistic opportunity to participate in social and economic life, and that all of us, are able to expect that market and... transactions will accord with minimum standards compatible with out justified expectations and deepest values."); see also, M.C. Nussbaum, "Beyond the Social Contract: Capabilities and Global Justice," Oxford Development Studies 32(1) (2004), at p. 4, 14-15 (comparing these basic human entitlements to to human rights, "as a minimum of what justice requires for all.").

122 M.C. Nussbaum, "Beyond the Social Contract: Capabilities and Global Justice," Oxford Development Studies 32(1) (2004), at p. 12-3 (adding that "[m]y capabilities approach," vis-à-vis that advocated by Amrtya Sen, "begins with outcomes: with a list of entitlements that have to be secured to citizens if the society in question is a minimally just one.").

123 A. SEN, Development as Freedom, (New York: Knopf, 1999) (refusing to provide a list of basic capabilities because they can change depending on the circumstances and opting to leave that substantive/normative question to the process of democratic deliberation instead); see also, T. BINGHAM, The Rule of Law, (New York: Penguin, 2010), at p. 68 (noting that "there is no universal consensus on the rights and freedoms which are fundamental, even among civilized nations," and that "[i]n some developing countries a higher premium is put on economic growth than on protection of individual rights, and in some Islamic countries little or no protection is given to some rights which are cherished elsewhere," therefore, "[i] $\mathrm{t}$ must be accepted that the outer edges of some fundamental human rights are not clear-cut.").

124 M.C. NussBaum, Creating Capabilities: The Human Development Approach, (Cambridge: Belknap Harvard, 2013), at p. 33-4 (listing ten central capabilities, including but not limited to things such as bodily health, bodily integrity, and control over one's environment); $c f$. A. SEN, Development as Freedom, (New York: Knopf, 1999) (refusing to provide a list of basic capabilities as Nussbaum does, rather opting to leave that substantive/normative question to the process of democratic deliberation). 
ing a normative framework that is too broad (i.e. the one normative criterion simply being "to increase opportunities and capabilities for the workers") would not be much of a framework because there are many ways private actors can contribute to increasing the worker's capabilities without necessarily empowering them to get out of their vulnerable positions: For instance, a company can increase the workers' wages by a few cents, which arguably increases the workers' spending capabilities, but the wage increase alone might not get the workers out of their vulnerable position. Thus, increasing capabilities, in and of itself, is too ambiguous of a criterion. Thus, we must come up with our own capabilities approach, that is not just as enumerated by Nussbaum, but also not too broad. For what it is worth, Nussbaum herself acknowledges that the capabilities that she lists are mere proposals, stressing the need for theoretical flexibility, and that the list is an open-ended list that invites revisions. ${ }^{125}$ Accordingly, the following subsection will present a revision, or rather an adaptation to Nussbaum's list of basic capabilities to better accommodate the focus of this thesis.

\subsubsection{Adapted Capabilities Approach}

If the standard capabilities approach is about giving people the bare necessities for a chance at a dignified life, ${ }^{126}$ our normative framework will be an adaptation of this, which will focus on providing minimum capabilities to the workers that will give them the possibility to have a dignified working life and to be empowered so that they can help themselves get out of their vulnerable position. Thus, our capabilities approach will not be about whether people should have a certain minimum wage or whether they should be prohibited from working however many hours, but about giving them a choice and a voice to have their preferences heard on what their wage should be or how long they should work. This is, as Nussbaum noted, about having some element of control over their work life. Accordingly, the bare minimum capabilities of our adapted approach will consist of a) the right to selfpreservation and freedom of choice, b) opportunity to participate in the decision-making process, and c) the ability to learn and grow. When subsequent chapters refer to whether the workers' capabilities have been increased or not, it will be referring to whether particular measures or actions have enhanced these factors or not.

\section{A. Right to Self-Preservation and Freedom of Choice}

One of the most fundamental capabilities is that of right to self-preservation. Selfpreservation has to do with not having one's freedom arbitrarily infringed or for an individual to be compelled to act in a way that goes against his or her will. Nussbaum elaborates on this capability by referencing Grotius and proclaiming that individuals have sovereignty or sui juris and while we forfeit some of these rights through social contract, no hu-

125 M.C. Nussbaum, Creating Capabilities: The Human Development Approach, (Cambridge: Belknap Harvard, 2013), at pp. 15, 108-9; see also, J. RAwLS, The Law of Peoples, (Cambridge: Harvard University Press, 1999) (portraying this as a "partial moral conception" rather than a grandstanding metaphysical idea).

126 M.C. Nussbaum, "Beyond the Social Contract: Capabilities and Global Justice," Oxford Development Studies 32(1) (2004), at p. 14-15; see also, M.C. Nussbaum, Creating Capabilities: The Human Development Approach, (Cambridge: Belknap Harvard, 2013), at p. 31 (these bare minimums being "areas of freedom so central that their removal makes a life not worthy of human dignity."). 
man being should be forced to work against his or her will. ${ }^{127}$ So actions that liberate forced laborers or victims of modern slavery would be considered as measures that protect and enhance the worker's right to self-preservation.

However, this criterion becomes convoluted when dealing with instances of labor exploitation that are not coercive. Earlier in this chapter, we distinguished forced labor and modern slavery from labor exploitation by noting that there are people that choose to work in sweatshops, whereas forced laborers, like those in the CNMI case, have been deprived of their liberty and any meaningful choice. Workers that choose to work in sweatshops are making a voluntary decision to work there for the sake of self-preservation much like the child miners in the DRC. While discussions about sweatshops and labor exploitations often tend to vilify MNCs - labeling them with a variety of less-than-favorable monikers like modern day slave owners or colonial imperialists - this particular normative criterion acknowledges that the reality is more complicated than that.

The arguments against sweatshops, however, are likely more popular than those in support of sweatshops. After all, sweatshops are associated with exploitation of laborers, where they are underpaid and overworked in environments that are often undignified and hazardous. Arguments to save workers from such situations could be argued as capabilityenabling, but this is not necessarily true. The argument in support of sweatshops is neatly summarized by Nobel Prize winning economist Paul Krugman, who essentially calls out those that advocate for better working conditions and treatment of workers in developing economies by villainizing companies, globalization, and capitalism as being stupid. ${ }^{128}$ An example that he provides to substantiate his claim is the promulgation of the Child Labor Deterrence Act in the US and its impact on Bangladeshi sweatshop laborers in 1993. As a result of this American legislation, child laborers were released (read: fired) from many sweatshops in Bangladesh, but rather than getting a better job or getting an education, many of them were forced into prostitution instead because better alternatives were not available to them. ${ }^{129}$

The lack of better alternatives in cases like this means that working in a sweatshop is the best they can do given their difficult circumstances, much like the creuseurs and the child miners in the DRC. It is their way of self-preservation. Krugman's position, which is contrary from that of popular public sentiments, is that "third world countries desperately need their export industries" and that "they can't have those export industries unless they are allowed to sell goods produced under conditions that Westerners find appalling, to workers

M.C. Nussbaum, "Beyond the Social Contract: Capabilities and Global Justice," Oxford Development Studies 32(1) (2004), at p. 13.

128 P. KRUGman, "Reckonings, Hearts and Heads," The New York Times, (22 April 2001). Available at: http://www.nytimes.com/2001/04/22/opinion/reckonings-hearts-and-heads.html (last accessed 4 April 2017) (noting that anyone who blames third world poverty on multinational corporations is simply wrong); see also, P. KRUGMAN, "In Praise of Cheap Labor: Bad Jobs at Bad Wages Are Better Than No Jobs at All," Slate Magazine, (21 March 1997). Available at: http://web.mit.edu/krugman/www/smokey.html (last accessed 4 April 2017) (noting any improvement that the developing countries have experienced is not because of "benign policies of national governments, which are as callous and corrupt as ever," but it is the "direct and unintended result of actions of soulless multinationals and rapacious local entrepreneurs, whose only concern was to take advantage of the profit opportunities offered by cheap labor.").

129 P. KRUGMAN, "Reckonings, Hearts and Heads," The New York Times, (22 April 2001). Available at: http://www.nytimes.com/2001/04/22/opinion/reckonings-hearts-and-heads.html (last accessed 4 April 2017) (citing to a report conducted by Oxfam). 
who receive very low wages." 130 These were the exact sentiments we heard in the CNMI case study and the reason why the conservative US Congress opposed the application of the US federal minimum wage in the CNMI. These types of arguments paint sweatshops as a necessary evil, with Krugman noting that "for an impoverished Indonesian or Bangladeshi woman with a handful of kids who would otherwise drop out of school and risk dying of mundane diseases like diarrhea, $\$ 1$ or $\$ 2$ a day can be a life-transforming wage." 131 To clarify, as noted above, this thesis is not convinced by attempts to assess the welfare of people based on aggregate economic factors like the GDP, but it is more sympathetic to Krugman's line of arguments that government measures that deprive people of their ability to work - even if it is in sweatshops - is depriving them of self-preservation and the ability to minimally flourish, if done so in a manner that simply bans them from working in sweatshops without providing alternative means for income.

These arguments in support of sweatshops can obviously be cut-and-pasted into debates about raising the minimum wage, reducing working hours, enhancing social protections, and a variety of other measures that mean well and is intended to protect or empower the workers. As with simply banning sweatshops, there often appears to be unintended consequences that end up indirectly reducing the choices available to the workers. For example, increasing the minimum wage could force companies to lay off workers, thus causing them to be in further poverty. At a more macro level, even if one particular factory increases the wage it pays to its workers thus arguably increasing their capabilities, if other factories do not follow, companies doing business with the first factory will likely move to the other factories or another country all together where labor is cheaper. Moreover, the imposition of minimum wage - which could indirectly raise the expectations of the workers - renders yet another obstacle for unskilled workers, making it even more difficult for them to find work thus reducing their capabilities in the process. ${ }^{132}$ This problem is summarized in the continuing debate between organizations like the ILO and the World Bank, where the ILO supports the continued promulgation of labor law in order to "ensure a just share of the fruits of progress to all," whereas the World Bank argues that protectionist laws are "upsetting the competitive process and distorting market outcomes," which end up hurting the workers in the long run. ${ }^{133}$ Similar to the debate between Keynes and the Chicago traditions, at the theoretical level, neither is right nor wrong.

In sum, this normative criterion of self-preservation and freedom of choice is essentially about providing workers the freedom to have a say in terms of what work they choose to

130 P. KRUgman, "Reckonings, Hearts and Heads," The New York Times, (22 April 2001). Available at: http://www.nytimes.com/2001/04/22/opinion/reckonings-hearts-and-heads.html (last accessed 4 April 2017).

131 N.D. KRISTOF \& S. WuDunN, Half the Sky: How to Change the World, (London: Virago Press, 2010), at p. 276.

132 B. POWELL, "In Defense of 'Sweatshops'," Library of Economics and Liberty, (2 June 2008). Available at: http://www.econlib.org/library/Columns/y2008/Powellsweatshops.html (last accessed 4 April 2017) (arguing that "[e]mployers will meet health and safety mandates by either laying off workers or by improving health and safety while lowering wages against workers' wishes. In either case, the standards would make workers worse off.").

133 S. Deakin, J. MALmberg \& R. SARKaR, "Do Labour Laws Increase Equality at the Expense of Higher Unemployment? The Experience of Six OECD Countries, 1970-2010," University of Cambridge Faculty of Law Legal Studies Research Paper Studies No. 11, (2014), at p. 2 (citing to the ILO's Philadelphia Declaration (1944) and World Bank's Doing Business in 2008); see also, World Bank, Doing Business in 2008 (Washington D.C.: World Bank, 2008); 
do and to walk away from it if they so choose to. ${ }^{134}$ Accordingly, measures that simply ban certain practices like sweatshops without providing workers a meaningful alternative or suggestions to raise the minimum wage that could end up getting them fired in the long run, could be considered as a reduction in the worker's capabilities, and therefore, a measure that this thesis will likely not advocate for.

\section{B. Opportunity to Participate in the Decision-Making Process}

The right to self-preservation requires that the worker's actions can actually have some impact on his or her environment, which leads to our next capability: the opportunity to participate in the decision-making process at their work. This capability has to do with whether or not the workers can have their voices heard or is given a platform to speak, which is capabilities-enhancing. It is not necessarily the ability to actually change the situation per se, but the opportunity to at least have their say and to be given a chance to collaborate and participate in the decision-making process along with the others. ${ }^{135}$ Providing an opportunity for one to voice their opinion fosters an open and inclusive process, which increases the chances that whatever outcome they reach is a more fair and equal one. ${ }^{136}$

This capability is crucial because tackling a problem like labor exploitation in the global supply chain requires collective will and concerted efforts by each and every stakeholder including the workers themselves and this normative criterion acknowledges this reality. ${ }^{137}$ Thus, strategies that encourages participation of the workers in the decision-making process or somehow enhances the voice of the workers will be deemed a positive one, whereas those that shun or mute their voice as a negative one. It is worth noting here that this capability for the workers to participate will ideally be on a fair and equal basis, however, while this thesis acknowledges that these criteria are extremely important, ${ }^{138}$ it is more of a goal and not necessarily a prerequisite to meet this particular capability.

\section{Ability to Learn, Think, and Adapt}

As noted in the previous subsection, the capabilities approach is an outcome-oriented approach with a rather consequentialist perspective, which insists that the only way to

A. SEN, "The Idea of Justice," Journal of Human Development 9(3) (2008): 331-42; see also, S.L. ESQUITH, "Introduction: Institutions and Urgency" in Capabilities, Power, and Institutions: Toward a More Critical Development Ethics, S.L. ESQUITH \& F. GIFFORD (EDS.) (Pennsylvania: Pennsylvania State University, 2010), at p. 9 (referring to Sen).

135 M.C. Nussbaum, "Beyond the Social Contract: Capabilities and Global Justice," Oxford Development Studies 32(1) (2004), at p. 4 (stating that "[w]e cannot solve the problems of global justice by envisaging international cooperation as a contract for mutual advantage among parties similarly placed in a state of nature. We can solve them only by thinking of what all human beings require to live a richly human life - a set of basic entitlements for all people - and by developing a conception of the purpose of social co-operation that focuses on fellowship as well as self-interest.").

136 M.C. Nussbaum, "Beyond the Social Contract: Capabilities and Global Justice," Oxford Development Studies 32(1) (2004), at p. 12 (suggesting that "we ought to think of ourselves as people who want to live with others. A central part of our own good, each and every one of us, it to produce, and live in, a world that is morally decent, a world in which all human beings have what they need to live a life with human dignity.").

137 M.C. Nussbaum, "Beyond the Social Contract," in The Political Pbilosophy of Cosmopolitanism, G. BrocK \& H Brighouse (EDS.) (Cambridge: Cambridge University Press, 2005), at p. 211 (stressing, "we are all under a collective obligation to provide the people of the world with what they need... [the] answer to the question 'who has the duties?' is that we all do.").

138 T. JuDT, Ill Fares the Land, (New York: Penguin, 2010), at p. 184 (noting that "of all the competing and only partially reconcilable ends that we might seek, the reduction of inequality must come first," because "[u]nder conditions of endemic inequality, all other desirable goals become hard to achieve."). 
determine whether a particular plan or measure is adequate is by actually looking at the outcomes. ${ }^{139}$ In other words, it is a framework that is hesitant to evaluate an action prior to seeing the outcome of that particular action first. The capabilities approach, at least as adapted in our context, insists that people be allowed, upon seeing the outcomes of their actions, to continually learn, change, and adapt in search for better outcomes. By choosing a capability that enables workers to learn and to grow ensures that they accumulate knowledge, which further increases the chances for the workers to be more self-reliant and to make better informed decisions for themselves and perhaps even for others. The importance of learning and thinking as a capability cannot be understated, because increasing capabilities in its purest sense comes from education. ${ }^{140}$

The application of this particular normative criterion should not be limited to the workers only, but should also be extended to other actors within the global supply chain as well. For example, in order to really determine what private actors can do differently to reduce labor exploitation in the global supply chain, they must be given the capability to try different approaches, to be open-minded and flexible, to learn from their failures, and to continuously adapt to try new and improved strategies. ${ }^{141}$ This means that we must accept some level of trial and error, not to mention embracing pluralism, which is to imply that the world is too diverse of a place for a one-size-fits-all solution. ${ }^{142}$ Moreover, as it pertains to this thesis, this normative criterion is particularly important because it justifies the interdisciplinary approach that this thesis selected as its methodology: As Nussbaum notes, "[c]apability theorists need to learn all they can from experimental work in psychology, but they also need to become readers of novels, biographies, autobiographies, and psychological case histories - anything that can enhance their grasp of those complicated elements of human experience on which our hope of political achievement and stability depends." 143 Learning, thinking, trying, and adapting are key capabilities that is not only important for workers, but for private actors and academics as well.

While we are on the subject of learning, we must also address a related issue of our cognitive limitations and our bounded rationality here. While this thesis will address these two related topics throughout the following chapters, some preliminary definitions must be presented here at the onset. Our bounded rationality can be explained in the following manner:

"Full rationality requires unlimited cognitive capabilities. Fully rational man is a mythical hero who knows the solutions to all mathematical problems and can immediately perform all computa-

139 M.C. Nussbaum, Creating Capabilities: The Human Development Approach, (Cambridge: Belknap Harvard, 2013), at p. 95 (admitting that the capabilities approach, at least her version of it, is a "cousin of consequentialism").

140 M.C. NussBaum, Creating Capabilities: The Human Development Approach, (Cambridge: Belknap Harvard, 2013), at p. 60 (noting other factors such as distribution of resources that enhance health, love, care and support from family and the broader community).

141 M.C. Nussbaum, "Beyond the Social Contract: Capabilities and Global Justice," Oxford Development Studies 32(1) (2004), at p. 17 (noting that "[a]ll institutions and individuals have a responsibility to support education, as key to the empowerment of currently disadvantaged people. Education is a key to all the human capabilities.").

142 D. RoDrik, The Globalization Paradox: Democracy and the Future of the World Economy, (New York: Norton, 2011), at p. 226; see also, C.M. ChrisTENSEN, The Innovator's Dilemma: The Revolutionary Book That Will Change the Way You Do Business, (New York: Harper Business, 2011), at p. 230 (noting that “[ $\mathrm{t}]$ here is no one best strategy.”).

143 M.C. Nussbaum, Creating Capabilities: The Human Development Approach, (Cambridge: Belknap Harvard, 2013), at p. 184. 
tions, regardless of how difficulty they are. Human beings are in reality very different. Their cognitive capabilities are quite limited. For this reason alone, the decision-making behavior of human beings cannot conform to the ideal of full rationality."

In short, our cognitive capabilities - our abilities to process information, to digest them, and to make decisions based on careful analysis of the available information - are somewhat limited, which is why we must be given the freedom to try new ideas and to learn from our mistakes in the hopes of making gradual progress. Accordingly, proposals that this thesis will endorse must enable private actors to learn, grow, and adapt while bearing in mind the reality that we do not possess unlimited cognitive abilities. The more a particular strategy or measure is cognizant of this fact, while allowing workers and other private actors to keep learning and evolving, the better that approach will be deemed according to our normative framework. Implied in this criterion is the reality that our world is complex and the acknowledgment that it is difficult to get things right in the first try. ${ }^{145}$

In the end, whether a particular course of action can be supported, for the purposes of this thesis, will be determined in accordance with the adapted capabilities approach laid out in this subsection. Achievements will not be measured in terms of increasing GDP, guaranteeing absolute justice, or ensuring equal and fair outcomes, but in terms of whether that particular course of action actually increased the capabilities of the workers. ${ }^{146}$ This is a modest framework that focuses on giving workers the very basic tools necessary to attempt to achieve these end results and how private actors can facilitate this process.

This introductory chapter presented the basic outline of this thesis and what it intends to accomplish. In doing so, it hinted on several occasions to the complexity of the problem that we are dealing with and how exercising conventional wisdom may not produce the intended or desired outcomes. In concluding this introductory chapter, the words of renowned American theoretical physicist Richard Feynman resonate heavily: "I have approximate answers, and possible beliefs, and different degrees of certainty about different things, but I'm not absolutely sure of anything." 147 When grappling with a complex issue of this magnitude, Feynman's understanding of his limitations and his humility is worth bearing in mind. In sum, this thesis will attempt to reassess and reconceptualize how all of the different stakeholders - the corporations, the consumers, the workers, and the collective alliances that they form - can collaborate to reduce labor exploitations in the global supply

R. SELTEN, "What is Bounded Rationality," in Bounded Rationality: The Adaptive Toolbox, G. GigerenZER \& R. SELTEN (EDS.) (Cambridge: The MIT Press, 2001), at p. 14.

145 F. CAPRA \& U. MATTEI, The Ecology of Law: Toward a Legal System in Tune with Nature and Community, (Oakland: Berrett-Koehler, 2015), at p. 24 (arguing the importance of realizing "that all scientific models and theories are limited and approximate"); see also, A.K. SHAH \& D.M. OPPENHEIMER, "Heuristics Made Easy: An EffortReduction Framework," Psychological Bulletin 134(2) (2008): 207-222, at 207 (suggesting that “[p]eople must operate within the constraints imposed by both their cognitive resources and the task environment - a concept known as bounded rationality"); see generally, H.A. SIMON, "Invariants of Human Behavior," Annual Revien of Psychology 41 (1990): 1-19.

146 M.C. NussBaum, "Beyond the Social Contract: Capabilities and Global Justice," Oxford Development Studies 32(1) (2004), at p. 4 (noting that thinking about justice through this approach "provides us with a promising way of thinking about the goals of development in this increasingly interdependent and interconnected world.").

147 R. Feynman, The Pleasure of Finding Things Out: The Best Short Works of Richard P. Feynman, J. RoBBINS (ED.) (New York: Basic Book, 1999), at p. 24. 
chain by empowering the exploited laborers. ${ }^{148}$ In doing so, this thesis will not only look at this problem from a purely legal perspective, but address the grey areas, where private actors may not have a legal obligation to act, but perhaps should or ought to in order to answer the question of what private actors can do differently to reduce instances of labor exploitation. As the UN sees it, any solution to a problem of this nature calls for an "expansive rethinking of the role of the state and communities and their capacity to identify and exploit emerging opportunities." 149 This includes not just relying on governments and preconceived notions of "common" wisdom, but incorporating an interdisciplinary methodology and keeping an open-mind about different ideas and possibilities. What follows in this contribution is an attempt at this so-called expansive rethinking.

International Labour Organization, "Profits and Poverty: The Economics of Forced Labour," (2014), at p. 47 (agreeing that in order to end forced labor, "[c]omprehensive measures are required that involve governments, workers, employers and other stakeholders working together...”).

149 United Nations Human Development Report (2011). Available at: http://www.undp.org/content/dam/undp/ library/corporate/HDR/2011\%20Global\%20HDR/English/HDR_2011_EN_Complete.pdf (last accessed 4 April 2017), at p. 81. 


\title{
2
}

\section{Labor/Employment Law Perspective}

\begin{abstract}
"I often wonder whether we do not rest our hopes too much upon constitutions, upon laws, and upon courts. These are false hopes; believe me, these are false hopes. Liberty lies in the hearts of men and women; when it dies there, no constitution, no law, no court can save it; no constitution, no law, no court can even do much to help."
\end{abstract}

\section{Learned Hand}

In order to answer our research question - what can private actors do differently to further reduce labor exploitations in the global supply chain - this first substantive chapter will present how employers are complying with labor/employment laws of New York and the Netherlands (Section 2.1 and Section 2.2 respectively) and how governments are enforcing compliance to these measures at the domestic level. ${ }^{150}$ Each of these sections will showcase the impact the labor/employment laws are having on labor exploitation within their territorial boarders, followed by highlighting some of their underlying problems and limitations (Section 2.3). This chapter will conclude by answering whether or not these measures are actually increasing the capabilities of the workers in accordance with our normative framework (Section 2.4).

Before diving into the discussion of labor/employment law, however, it is worth reiterating here that to the extent that governments do impact the way private actors behave, this

It is worth mentioning here that while labor law and employment law are often used interchangeably in some circles, there are various technical differences between the two fields of law one of which is that labor law tends to focus on unionized workers, whereas employment law covers a more general field of workers. See e.g. K. EDWARDS \& S. RoBINSON, "Labor and Employment Law: A Career Guide," Bernard Koteen Office of Public Interest Advising Harvard Law School, C. PATTANAYAK (ED.) (2012). Available at: http://hls.harvard.edu/content/uploads/ 2008/06/laboremployment2012.pdf (last accessed 22 February 2016) (noting that labor law has "traditionally encompassed the relationships among unions, employers, and employees," whereas employment law is defined "more broadly as the negotiated relationships between employers and employees... [a]lthough employment lawyers deal with many of the same parties as labor lawyers..."). Many jurisdictions also distinguish service contracts from an employment relationship, and independent contractors from employers, which is a subject that will be discussed in much more detail in Chapter 2.3.4A. 
chapter will also elaborate on government measures like minimum wage laws to assess what the current level of government intervention is in light of the question, how and when should governments intervene. Thus, in comparison to the other substantive chapters, this chapter will be an outlier as it pays more attention to what governments are doing within their own jurisdictions rather than focusing on the private sector and the global supply chain. As a result, this chapter will have a more domestic focus rather than the international perspective described back in the methodology section. ${ }^{151}$ Nevertheless, the labor/employment perspective is still a very relevant part of this thesis as 1) the domestic supply chain is still technically part of the global supply chain, and 2) the private sector can influence when and how governments ought to intervene through the democratic process.

\subsection{SWEATSHOPS AND EXPLOITATIVE LABOR PRACTICES IN NEW YORK}

According to the now declassified documents released by the US General Accounting Office ("GAO"), there were at least 4,500 sweatshops employing more than 50,000 workers in New York City in the 1990's. ${ }^{152}$ Today, many observers fear that this problem has not only persisted, but due in large part to increasing demands fostered by globalization, these numbers have actually gone up. ${ }^{153}$ Although New York City is one of the biggest hubs for international commerce and an environment with various guaranteed social protections, the GAO report depicts a less glamorous view of a city populated by an alarming number of exploited workers. ${ }^{154}$ To elaborate on this issue, the following subsections will be structured in the following manner: The first subsection will present the relevant regulations that businesses operating within New York must meet with regards to the treatment of their employees (Subsection 2.1.1), which will be followed by a presentation of some facts and figures that provide a frame of reference in terms of the number of businesses that violate these requirements (Subsection 2.1.2). The last subsection will draw some preliminary observations in terms of whether these measures are working to reduce instances of labor exploitation in New York or not (Subsection 2.1.3).

\subsubsection{Relevant New York State Labor Laws}

This subsection will: a) list the various legal protections that are available to the employees working in the state of New York and how the exploited workers can seek redress if their

151 This is mostly due to the fact that the application of labor/employment laws extend only to those working within the jurisdiction and generally does not apply to those located abroad.

152 United States General Accounting Office, “'Sweatshops' in New York City: A Local Example of a Nationwide Problem," Briefing Report to the Honorable Charles E. Schumer, House of Representatives. GAO/HRD-89-101 BR (B231284).

153 United States General Accounting Office, “'Sweatshops' in New York City: A Local Example of a Nationwide Problem," Briefing Report to the Honorable Charles E. Schumer, House of Representatives. GAO/HRD-89-101 BR (B231284); see also, A. FEUER, "New York State Calls It a Sweatshop," The New York Times, (20 May 2009).

154 A. BernhardT, D. POlson \& J. DeFilippis, "Working Without Laws: A Survey of Employment and Labor Law Violations in New York City," National Employment Law Project (2010), at p. 39 (indicting that more often than not, the victims of these labor violations are "foreign-born" and minorities of Latino or Asian decent). 
rights are violated; followed by b) the introduction to the task force that has been deputized by the New York State Department of Labor to enforce these measures especially in the garment sector where labor exploitations are rampant.

\section{A. Relevant Laws}

At the onset, it must be mentioned that the labor laws of New York work hand in hand with the federal Fair Labor Standards Act ("FLSA") to ensure that the workers are at least paid the minimum wage, ${ }^{155}$ that overtime pay is given for any work over the 40 hours a week, ${ }^{156}$ and that the employment of children is restricted, ${ }^{157}$ to list a few of the key protections offered to the workers of New York. In addition, the so-called "hot goods" provision $^{158}$ entitles the Department of Labor to confiscate and destroy products produced in a prohibited manner thus serving as a deterrent measure against businesses operating or working with sweatshops. In addition to the various legislative measures and the "hot goods" provision, businesses must also comply with state and federal occupational safety and health laws to ensure that employees are working in a safe environment. ${ }^{159}$ For companies that repeatedly fail to comply with these regulations, administrative sanctions can be imposed on them, which include, but are not limited to $\$ 1,000$ for each wage related violation and/or a fee of $\$ 10,000$ for each unauthorized underage worker found within the premise. ${ }^{160}$ These fines arguably incentivize businesses to treat employees fairly and not to work with sweatshops.

Not only are businesses fined in the event of wage violations or for having a hazardous workplace, but in the event that a worker is injured or harmed while at work, New York has a compensation scheme that makes it relatively easy for the workers to seek just compensation from their employers for the injuries suffered. ${ }^{161}$ The Worker's Compensation scheme is a no-fault framework, meaning that once a worker is injured on the job, they are quickly compensated without having to take the employer to court, which arguably empowers the workers by ensuring that they are adequately compensated for medical expenses

155 See 29 U.S.C. $\$ 206$ (Minimum wage); see also NY CLS Labor, Article $19 \$ 652$ (Minimum wage).

156 See 29 U.S.C. $\$ 207$ (Maximum hours); see also NY CLS Labor, Article 5 (Hours of work).

157 See 29 U.S.C. $\$ 212$ (Child labor provisions), see also NY CLS Labor, Article 4 (Child labor).

158 See 29 U.S.C. $\$ 215$ (Prohibited acts; prima facie evidence); see also NY CLS Labor, Article 12A §341-a (Special Task Force for the Apparel Industry).

159 See NY CLS Labor, Article 11 \255-316 (Factories: Accident Prevention, Fire Hazard, Sanitation, Foundries and Duties of Owners and Occupiers); See also, Department of Labor's Occupational Safety \& Health Administration (henceforth "OSHA"), although this falls slightly outside of the scope of this thesis.

160 See 29 U.S.C. $\$ 216$ (Prohibited acts; prima facie evidence). As a short side note, it is worth noting that the selection of the value of these fines is somewhat arbitrary: For example, the amount of fine for a "serious violation of regulations concerning worker safety is capped at $\$ 7,000$, while violation of the Wild Bird Conservation Act can result in a fine of up to \$25,000"; see, D. KAHNEMAN, Thinking, Fast and Slow, (London: Penguin Book, 2013), at p. 361-2 (observing that the "system of administrative penalties is coherent within agencies but incoherent globally.").

161 The state of New York requires employers to carry Worker's Compensation insurance to cover for their employee's work related accidents that cause injuries or illnesses. See NY CLS Worker's Compensation, Article 2 $\$ 10$ (Compensation) and The state of New York requires employers to carry Worker's Compensation insurance to cover for their employee's work related accidents that cause injuries or illnesses. See NY CLS Worker's Compensation, Article $2 \$ 10$ (Compensation). In most cases, receiving benefits is as simple as filing a claim (a C-3 form) and presenting the case to the Worker's Compensation Board, although there are various exceptions, for example in cases of contributory negligence, when the worker's behavior was grossly negligent, reckless, or intentional. The businesses in the apparel industry are required to pay into the Worker's Compensation scheme if they wish to be registered as a business annually. 
and partial reimbursement for lost wages. While this particular scheme overlaps with insurance and tort laws (the latter of which will be covered in more depth in the next chapter), the compensation scheme arguably empowers workers by making it easier for them to have their voices heard and being able to support themselves even when they can no longer work. ${ }^{162}$

\section{B. Apparel Industry Task Force}

With regards to the actual task of monitoring suspected sweatshops or detecting instances of labor exploitation and imposing fines for violations, the NYS Department of Labor has deputized - in accordance with the powers vested to them by Article 12 of New York's labor law ${ }^{163}$ - a special task force to carry out the enforcement of these measures in the garment industry, where labor exploitation is particularly rife. In New York City, the agency tasked with this mission is the Apparel Industry Task Force ("AITF”). ${ }^{164}$ Employees working for a company in New York may file complaints with the AITF to seek redress against their employers for the violation of the aforementioned provisions. Upon receiving a complaint, the AITF will investigate the matter, hold meetings with the factory representatives, carry out interviews, and conduct audits. At the conclusion of its investigation, they will prescribe a set of corrective actions, and order the payment of back wages (if necessary) for the underpaid or overworked laborers. ${ }^{165}$ The AITF also conducts random, surprise visits to suspected or targeted areas, thus leaving sweatshops guessing as to when the AITF could raid their facility. In short, the AITF has strung together series of successful raids for over two decades, confiscating goods made in violation of the law, and ordering back wages to be paid to workers. ${ }^{166}$ Moreover, when the violation is severe enough or when illegal immigrants are found on the business premises, the task force also refers the matter to the appropriate government authorities. ${ }^{167}$

\subsubsection{AITF: Facts and Figures}

To provide some context, a decade ago, the NYS Department of Labor and the AITF reported that on average they were collecting approximately $\$ 3.75$ million a year from

162 There are tradeoffs, however, because the no-fault system also means that while the workers get access to compensation right away, they are prevented from subsequently suing the employer, which depending on the circumstances, can be argued as capability-inhibiting.

163 Special Task Force for the Apparel Industry, Annual Report 2005 (henceforth "AITF Annual Report 2005"). Available at: www.labor.ny.gov/agencyinfo/PDFs/AITF\%20Annual\%20Report $\% 202005$.pdf (last accessed 4 April 2017), at p. 6.

164 Given the relative "success" of the AITF since its inception in 1987, New York State Department of Labor has subsequently emulated the AITF model and established various offshoots such as the Fair Wages Task Force and the Misclassification Task Force that serve similar purpose as the AITF, but in areas not limited to the garment industry.

165 AITF Annual Report 2005, at p. 11 (stating that "[t] he AITF investigators make every effort to bring firms into compliance without penalties, since their goal is to encourage firms to operate legitimately.”).

166 New York State Department of Labor Press Release, "State Raids New York City Sweatshops: Department Issues First-Ever Order of Confiscation Against Manufacturer and Tags Contractor's Products; Garments May not be Moved or Sold Until Full Restitution is Made to Workers.” (2009). Available at: http://www.labor.state.ny.us/ pressreleases/2009/April29_2009.htm (last accessed 4 April 2017).

167 AITF Annual Report 2005, at p. 6. This issue of involving other authorities and the problems that this can create will also be addressed in Chapter 2.1.3. 
businesses found to be in violation of labor/employment laws, which they distributed back to 6,750 workers. ${ }^{168}$ The most recent report available in 2010 showed that these numbers have increased quite significantly, reporting that the AITF collected an estimated $\$ 28.8$ million in owed wages, which is more than 7 times what the figure was five years prior, and distributed them to an estimated 18,000 exploited workers. ${ }^{169}$ Even taking into account inflation, this is quite a significant increase. The report does not offer explanations as to why the amount of unpaid wages collected on behalf of the workers increased so much in a five-year span. Granted, the number of workers they paid back also increased significantly during the same period, but in short, an unpaid worker got back about $\$ 555,56$ on average in 2005 due in part to the AITF enforcement, whereas in 2010, an unpaid worker got back about $\$ 1,600$ on average. It must be stressed that these are just general averages of estimated figures, but it shows that the AITF is enforcing measures that are paying exploited workers back and doing so more successfully than in the past, at least in terms of unpaid wages collected. One could interpret this to suggest that the AITF and the NYS Department of Labor are working to ensure that exploited workers are being compensated more justly and that they are righting a wrong that had been committed.

Table 1: Unpaid Wages Collected by the AITF for the Exploited Workers

\begin{tabular}{lllll}
\hline Year & $2002-2005$ (Average) & 2006 & 2009 & 2010 \\
\hline $\begin{array}{l}\text { Unpaid Wages Collected on } \\
\text { Behalf of Workers (Mil) }\end{array}$ & $\$ 3.75$ & $\$ 12.2$ & $\$ 20.3$ & $\$ 28.8^{*}$ \\
$\#$ of Workers Owed Wages & 6,750 & 10,674 & 15,424 & $18,000^{*}$ \\
\hline
\end{tabular}

* Estimated

It must be acknowledged, however, that the figures on Table 1 are sporadic and slightly outdated, but this is due to the fact that the NYS Department of Labor does not conduct these assessments on a regular basis and the most recent survey, as noted above, was conducted in 2010. ${ }^{170}$ To elaborate on these numbers a bit further, the AITF does provide a further breakdown of these figures: For example, in a one year span, they conducted 1,320 investigations and detected roughly 1,740 violations, meaning that some investigations revealed multiple violations. ${ }^{171}$ Of these violations, about $68 \%$ (around 1180 violations) were related to record-keeping and business registration issues, while about $30 \%$ (around 520 violations) were related to unpaid wages or wages below the minimum wage. In New

168 AITF Annual Report 2005, at p. 19. This amounted to roughly $\$ 556$ per worker on average.

169 A. BernhardT, D. POlson \& J. DeFilippis, "Working Without Laws: A Survey of Employment and Labor Law Violations in New York City," National Employment Law Project (2010), p. 46; see also, D. MASSEY, "Labor Law Violations Seen Costly for City Workers," Crain's New York Business, (28 January 2010).

170 See Appendix A: Freedom of Information Law Request Letter from the New York State Department of Labor. According to the Records Access Officer of the New York State Department of Labor more complete or updated records do not exist. Series of other requests were made to the Department and to the AITF for them to release more recent figures, but such requests were refused or responded to with an answer that no such records were kept. Moreover, the Department of Labor stopped publishing reports on this in 2006. See, New York State Department of Labor Website, “Annual Reports." Available at: bttps:// wmm.labor.ny.gov/agencyinfo/annualpt.shtm (last accessed 22 February 2016).

171 AITF Annual Report 2005, at p. 19; Special Task Force for the Apparel Industry, Annual Report 2004. Available at: www.labor.ny.gov/agencyinfo/PDFs/AITF_2004_web.pdf (last accessed 5 June 2015), at p. 8. 
York, instances of child laborers made up only a handful (about 23 violations) per year. ${ }^{172}$ Although the task force follows a set protocol for their sweeps and raids, the outcome of the sweep differs from one to another. One particular noteworthy sweep was a joint sweep by the NYS Department of Labor, spearheaded by the AITF, and the United States Department of Labor, where 39 investigators from the two departments investigated nine supermarkets in Queens, New York and found 5 out of the 9 markets that they raided to be in violation of several labor laws, owing approximately 270 workers $\$ 1$ million in back pay. ${ }^{173}$

While these numbers suggest that the task force is accomplishing its mission to enforce the labor/employment laws of New York with some success, we must bear in mind two crucial points: First, our normative framework focuses on increasing the workers' capabilities and not necessarily about whether the AITF is detecting all instances of labor violations; and second, these numbers do not paint a complete picture. For example, a survey conducted by the National Employment Law Project ("NELP") 174 revealed that workplace violations in New York were still "severe and widespread" especially in the low-wage labor markets like the garment industry monitored by the AITF. This NELP survey, which surveyed 1,432 workers in various low-wage markets, ${ }^{175}$ found convincing evidence that what the Department of Labor and the AITF is doing may not be enough and not necessarily capability-enhancing either: Of the people surveyed, $21 \%$ of the workers were regularly paid below the minimum wage (with at least $51 \%$ of them receiving more than $\$ 1$ less than the minimum wage per hour); more than $33 \%$ worked for more than 40 hours a week without receiving overtime pay (with the average violation working 13 hours of overtime without appropriate compensation); $23 \%$ of the workers attempted to file a complaint or attempted to form a union, but within that subgroup, $42 \%$ of them stated that they experienced illegal retaliation from their employer; and 23\% stated that they did not make a complaint within the year of being surveyed, even when they had valid reasons to do so, either due to the fear or retaliation or because they did not believe that filing a complaint would make any difference. ${ }^{176}$

These numbers only provide a small sample of the plight that the laborers face but, at the very least, it substantiates the claim that within the United States, even in a metropolis like New York City, labor exploitation is rather prevalent and common. Moreover, these figures, along with the anecdotes narrated by the workers, suggest that while there are minimum protection measures established by both federal and state governments along with a vigilant task force in place to enforce them, many adamant businesses and employers still continue to exploit their workers. While some of the exploited laborers are being compensated due in part to the work of the NYS Department of Labor and the AITF, there are just as many exploited laborers who are apprehensive to come forth or wish that the AITF

172 AITF Annual Report 2005, at p. 17; AITF Annual Report 2004, at p. 20.

173 AITF Annual Report 2005, at p. 16-17.

174 A. Bernhardt, D. POlson \& J. DeFilippis, "Working Without Laws: A Survey of Employment and Labor Law Violations in New York City," National Employment Law Project (2010).

175 The National Employment Law Project defines "low wage" workers as workers, 18 years or older that are "frontline" workers (i.e. non-managerial, non-professional, non-technical workers) in suspected sectors (i.e. sewing and garment workers, delivery drivers, food preparers, etc.) that are making less than $\$ 13.07$ per hour.

176 A. Bernhardt, D. POlson \& J. DeFilipPIS, "Working Without Laws in New York City," Challenge 54(2) (2011), at p. 2-4. 
not intervene for the fear of losing their work or face deportation, thus putting into question how capability-enhancing the existing labor/employment laws actually are in New York.

\subsubsection{New York Labor/Employment Laws and Their Limitations}

The sweeps conducted by the AITF serve to keep most businesses in line and incentivize them to refrain from operating a sweatshop or conducting business with one. However, whether these government regulations and randomized sweeps actually enhance the capabilities of the workers enough for them to have a dignified working life remains less clear. An argument that these regulations and enforcement measures do reduce labor exploitations by increasing the capabilities of the workers can rely on the fact that the Compensation scheme or the AITF gives the workers additional outlets to voice their problem, which arguably is empowering. However, as the NELP survey documented, many workers are apprehensive of reporting any violations for the fear of retaliatory tactics from the employer, which could cost them their jobs or for the undocumented immigrants, the risk of being deported. This means that while there are laws and task forces that aim to protect these exploited workers, it does not mean that the workers' capabilities are necessarily being enhanced through their implementation and enforcement.

In the end, lowly skilled workers will always be willing to work at near intolerable conditions if that is their only possible source of income. In this sense, workers working in the sweatshops of New York and the child miners of the DRC have some commonalities in their lack of better alternatives. Businesses interested in simply maximizing profits can still risk operating a sweatshop or working with one, given that the task force sweeps are not entirely thorough and some violations go undetected. So long as the profit that comes from breaking the law outweighs the probability of being sanctioned, these labor exploitations will likely continue, but as we saw in the DRC example, increasing the fines alone does not necessarily address the issue of incentives. ${ }^{177}$ While labor/employment laws will likely keep most businesses in check, it does not address the core issue, which is the fact that people need money to survive and in many cases, regardless of whether they are lowly skilled laborers or executives in multinational corporations, they are willing to do what it takes to make it. Before reaching any preliminary conclusions, however, the next subsection of this chapter will conduct a similar review of the Dutch approach to this problem to compare various similarities and difference between the two jurisdictions.

\subsection{SWEATSHOPS AND EXPLOITATIVE LABOR PRACTICES IN THE NETHERLANDS}

It is of some interest to see, as this section will show, that when it comes to the measures being implemented to curtail exploitative labor practices, the system of monitoring, con-

177 Perhaps even when the risks do not outweigh the benefits, employees and employers alike may still continue to operate against the law, if it is the "only way" for them to make an earning. 
ducting randomized sweeps, and fining the violators appears to be a very common approach. For example, the Dutch way of dealing with the problem of labor exploitation within their jurisdiction is remarkably similar to the strategies adopted by the AITF and the NYS Department of Labor. Similar to the structure of the last section on New York labor/employment laws, this section will first present the relevant regulations that businesses operating within the Netherlands must meet with regards to the treatment of their employees (Subsection 2.2.1). This will be followed by a presentation of relevant facts and figures that will provide a frame of reference in terms of the number of businesses that violate these requirements (Subsection 2.2.2). The last subsection will draw preliminary observations in terms of whether these measures are reducing labor exploitations in alignment with our normative framework (Subsection 2.2.3).

Before moving on to the substance of Dutch labor/employment law, it is worth pointing out first that labor exploitations do really take place even in an economically developed country like the Netherlands with their various social welfare and protection programs. According to the European Parliament, there are roughly 1.1 million "slaves" in Europe of which an estimated 2,175 are located within the Netherlands. ${ }^{178}$ In 2013 alone, there were 993 confirmed reports of slavery or slavery-like working conditions. ${ }^{179}$ Recall here that the term "modern slavery" or what the Dutch Ministry of Social Affairs and Employment [Ministerie van Sociale Zaken en Werkgelegenheid] refers to as "modern form of slavery" [moderne vorm van slavernij], is a very specific subset of labor exploitation and other instances of "shameless exploitation" [schaamteloze nitbuiting. ${ }^{180}$ This suggests that the number of exploited laborers is significantly larger than the estimated number of "slaves" working within the Netherlands noted by the European Parliament.

One common example of shameless exploitation that we have already witnessed in this thesis is what the European Parliament refers to as "contract slavery." Contract slavery occurs when the so-called employers, say in the Netherlands, guarantee employment to immigrant workers, but upon their arrival to the Netherlands, their identification documents are confiscated and they are exploited to work in less than pleasant conditions. ${ }^{181}$ In one relatively recent case of reported contract slavery, an asparagus farm in the Dutch

See generally, European Parliament Directorate-General for External Policies of the EU Briefing Paper, "Addressing Contemporary Forms of Slavery in EU External Policy,” (2013) Available at: http://www.europarl.europa.eu/ RegData/etudes/note/join/2013/433703/EXPO-DROI_NT(2013)433703_EN.pdf (last accessed 4 April 2017). The briefing paper defines "contemporary slavery" as the "exercise of the powers attaching to the right of ownership-control over a person by another such as a person might control a thing". Cf. More recently, the European Parliament's Organized Crime, Corruption and Money Laundering Committee projected a lower number, estimating that there are approximately 880,000 "slaves" in the European Union.

179 See generally, European Parliament Directorate-General for External Policies of the EU Briefing Paper, "Addressing Contemporary Forms of Slavery in EU External Policy,” (2013) Available at: http://www.europarl.europa.eu/ RegData/etudes/note/join/2013/433703/EXPO-DROI_NT(2013)433703_EN.pdf (last accessed 4 April 2017), at p. 34 (citing to the research conducted by M. NARAYAN DATTA \& K. BALES, "Slavery in Europe: Part 1, Estimating the Dark Figure," Human Rights Quarterly 35(3) (2013)).

180 Meerjarenplan 2013-2014: Inspectie Social Zaken en Werkgelegenheid [Term Plan 2013-2014]. Available at: https://www.inspectieszw.nl/Images/Meerjarenplan\%202013-2014\%20Inspectie\%20SZW_tcm335-334154.pdf (last accessed 4 April 2017); see also, Inspectie SZW, De bestrijding van slavernijachtige vitbuiting [The Fight against Slavery-like exploitation]. Available at: www.inspectieszw.nl/onderwerpen/arbeidsverhoudingen/ arbeidsuitbuiting/de_bestrijding_van_slavernijachtige_uitbuiting/(last accessed 3 March 2015).

181 See generally, European Parliament Directorate-General for External Policies of the EU Briefing Paper, "Addressing Contemporary Forms of Slavery in EU External Policy,” (2013) Available at: http://www.europarl.europa.eu/ RegData/etudes/note/join/2013/433703/EXPO-DROI_NT(2013)433703_EN.pdf (last accessed 4 April 2017), at p. 7. 
village of Someren was found to be exploiting Polish and Romanian immigrant workers when a fire safety inspector conducted a random work place safety inspection. ${ }^{182}$ Typical to many other contract slavery cases, these migrant workers had their passports confiscated by the employer when they first arrived in Someren and they were forced to sleep in dingy rooms, similar to the experiences of the migrant laborers brought to the CNMI, ${ }^{183}$ not to mention the fact that they were overworked and paid well below the minimum wage (about $€ 50$ per week). ${ }^{184}$ These cases are not just isolated incidents, but are not uncommon. For example, a total of 35 Indonesian migrant workers were discovered working in multiple sweatshops located in The Hague, Rotterdam, and Gouda, where they were forced to work 14 hour days, cramped up in cockroach-infested sweatshops while making rice cakes and chili paste for well below the minimum wage. ${ }^{185}$ Bearing in mind these cases, the first subsection will start by presenting the Dutch labor/employment laws that technically should have protected these workers from being exploited.

\subsubsection{Relevant Dutch Labor Laws}

This subsection will: a) list the various protections that are available to the employees working in the Netherlands; followed by b) the introduction of the task force that monitors compliance to these laws in the Netherlands.

\section{A. Relevant Laws}

The relevant Dutch labor/employment laws in our context are the following: Minimum Wage and Minimum Holiday Allowance Act [Wet minimumloon en minimumvakantiebijslagen or WML], the Placement of Personnel by Intermediaries Act [Wet allocatie arbeidskrachten door intermediairs or $W$ aadi], the Foreign National Employment Act [Wet arbeidvreemdelingen or $W a v$, and the Working Conditions Act [Arbeidsomstandighedenwet], and the Working Hours Act [Arbeidstijdenwet]. ${ }^{186}$ Although there are some differences between these laws and that of the New York state labor laws noted above, they serve the same goals, which is to ensure that workers are getting paid a certain minimum wage, have regulated working hours in a safe work environment, and to prevent those who should not be working from doing so.

R. KIEVIT, “A Slavery Drama in the Dutch Village of Someren," Radio Netherlands Worldwide, (22 May 2009). Available at: http://www.rnw.nl/english/article/slavery-drama-dutch-village-someren (last accessed 4 April 2017); see also, V. Mallet \& G. DinMore, "Europe: Hidden Economy," Financial Times, (8 June 2011). Available at: http://www.ft.com/intl/cms/s/0/efc3510e-9214-11e0-9e00-00144feab49a.html\#axzz2vI729dEv (last accessed 4 April 2017) (noting that European cities such as Tuscany have "transformed into an example of how economic globalization and weak government have combined to fuel the development of black economies on the southern and eastern fringes of Europe.”).

183 R. KIEVIT, "A Slavery Drama in the Dutch Village of Someren," Radio Netherlands Worldwide, (22 May 2009). Available at: http://www.rnw.nl/english/article/slavery-drama-dutch-village-someren (last accessed 4 April 2017).

184 R. KIEviT, “A Slavery Drama in the Dutch Village of Someren," Radio Netherlands Worldwide, (22 May 2009$).$ Available at: http://www.rnw.nl/english/article/slavery-drama-dutch-village-someren (last accessed 4 April 2017).

185 S. GotTlieb, "Golden Promises End in a Sweatshop in The Hague," Radio Netherlands Worldwide, (9 April 2010). Available at: http://www.rnw.nl/english/article/golden-promises-end-a-sweatshop-hague (last accessed 4 April 2017). While the human trafficking aspect of these cases are particularly sinister, the issue falls outside the scope of this particular thesis.

186 They are relevant in the sense that these are the laws that the Inspectie SZW monitors compliance to. See, Inspectorate SZW, "2012 Annual Report." Available at: www.inspectieszw.nl/Images/2012-Annual-ReportInspectorate-SZW-Summary_tcm335-341803.pdf (last accessed 17 December 2016). 
Without getting bogged down on too much detail, some of the minor differences between the labor related legislations in New York and the Netherlands are as follows: 1) the minimum age for children to be allowed to work in the US is generally 14 (not including farm labor) but 15 in the Netherlands; 2) the minimum wage in New York is $\$ 7.25$, whereas the Dutch have a system where the minimum wage depends on the worker's age, which ranges from roughly $€ 2.50$ at 15 to roughly $€ 8.50$ for ages 23 and over; and 3) the various civil fines for violation of these labor laws are quite different, where the fine in New York for employment related violations is $\$ 1,000$ for the first violation, $\$ 2,000$ for the second violation, and $\$ 3,000$ for the third violation, in the Netherlands, different violations amount to different fees, ranging from $€ 12,000$ for each illegal immigrant found working on the premises or $€ 10,000$ for each underpaid employee. Again, while there are other differences, the New York and Dutch approach to implementing labor/employment laws is strikingly similar: They impose certain minimum restrictions about who can work and how much they should get paid in a workplace that is minimally safe. Even in their enforcement measures, these two jurisdictions employ a similar approach, which will be addressed in the next part of this subsection.

\section{B. Inspectie Sociale Zaken en Werkgelegenheid}

Compliance to the aforementioned Dutch labor/employment laws are enforced by the Dutch equivalent of the AITF, the Inspectie SZW [Inspectie Sociale Zaken en Werkgelegenheid], although the inspectorate's coverage is not limited to the garment and fashion industry like the AITF. The Dutch Ministry of Social Affairs and Employment created the Inspectie SZW by merging three labor-related inspectorates in January of 2012 and ever since, the inspectorate has been tasked to monitor and enforce the labor/employment laws noted above. The Inspectie SZW, like the AITF, conducts randomized sweeps and surprise inspections and when it detects violations, they impose administrative fines to the breaching businesses: For example, if a company was employing a foreign national without the necessary permit, the employer would be fined up to $€ 12,000$ per illegal laborer ( 6,000 in the event that the employer is a private individual rather and not a legal entity). ${ }^{187}$ If the employer was in breach of the Minimum Wage and Minimum Holiday Allowance Act, the fine for each of the underpaid employee would be up to $€ 10,000$, and so forth. ${ }^{188}$

The inspectorate's enforcement of the minimum standards imposed by the Dutch government serves as deterrent measures (i.e. threat of surprise inspections and imposition of fines). In cases where there are severe or gross violations or in the event of repeat offenders, the inspectorate can recommend that criminal charges be brought against the viola-

187 The amount of fines imposed have changed since January 2014, where as before, it used to be $€ 8,000$ for an alien worker without payment ( $€ 4,000$ in the event that the employer is a private individual rather and not a legal entity). Inspectie SZW, "Fines for Violating Minimum Wage Act." Available at: https://www.inspectieszw.nl/ onderwerpen/arbeidsverhoudingen/toezicht_eerlijk_werk/sancties_bij_overtreden_wav_wml_waadi/boetes_wml/index.aspx (last accessed 17 December 2016).

188 The amount of fines imposed changed in January 2014, whereas before, the fine was capped at $€ 6,700$ for minimum wage violations, which can be increased for repeat offenders. Available at: http://www.inspectieszw.nl/onderwerpen/arbeidsverhoudingen/toezicht_en_handhaving/sancties_bij_overtrede n_wav_wml/ (last accessed 22 February 2016); see also, Inspectorate SZW, "Inspections by the Inspectorate SZW on the employment of foreign workers and the payment of the minimum wage". Available at: www.inspectieszw.nl/Images/Inspections-by-the-Inspectorate-on-the-employment-of-foreign-workers-and-thepayment-of-the-minimum-wage_tcm335-326481.pdf (22 February 2016). 
tors. ${ }^{189}$ In addition to these endeavors, the Inspectie SZW and the Ministry of Social Affairs and Employment are working on implementing a new "naming-and-shaming" initiative, which would publish the names of companies that have been found guilty of labor/employment law violations in an attempt to increase the deterrence effect of these legislations. ${ }^{190}$ The possible benefits (or the lack thereof) of this type of a measure will be detailed in a subsequent chapter, but for the time being, the next subsection will present some facts and figures as published by the Inspectie SZW.

\subsubsection{Inspectie SZW: Facts and Figures}

In 2014, the number of labor market violations (violations of the relevant Dutch labor/employment laws noted above in Subsection 2.2.1A) that the Inspectie SZW detected, was 5,054, compared to 4,930 in 2013, 7,7160 in 2012, 9,655 in 2011 and 9,629 in 2010. ${ }^{191}$ Table 2 below lays out the other relevant figures like the number of cases where fines were imposed, how much fines the inspectorate collected, and how many of these cases were referred to criminal investigations. Given that the figures provided by the Dutch Ministry of Social Affairs and Employment are more comprehensive and thorough than that of the AITF and the NYS Department of Labor, we can extrapolate more meaningful observations in an attempt to assess the impact the Inspectorate SZW is having on labor exploitations in the Netherlands.

Table 2: Number of Inspections Conducted by Inspectie SZW and Amount of Fines Collected

\begin{tabular}{llllll}
\hline Year & 2010 & 2011 & 2012 & 2013 & 2014 \\
\hline Labor Market Fraud (Wav, WML, etc. violations) & 9,629 & 9,655 & 7,160 & 4,930 & 5,054 \\
Cases with Fines Imposed & 3,943 & 3,501 & 3,376 & 3,793 & 2,912 \\
Fines Collected (Million $€$ ) & 26.0 & 27.9 & 29.4 & 30.4 & 29.6 \\
Referrals to Criminal Investigations & 40 & 62 & 61 & 67 & 65 \\
\hline
\end{tabular}

This is similar to the approach taken by the AITF and the Department of Labor as exemplified in the aforementioned bust of the supermarkets in Queens.

190 Ministerie van Sociale Zaken en Werkgelegenheid, "Gegevens gecontroleerde bedrijven stapsgewijs openbaar," Niensbericht, (last accessed 22 February 2016). Available at: www.inspectieszw.nl/actueel/ nieuwsberichten/gegevens_gecontroleerde_bedrijven_stapsgewijs_openbaar.aspx (last accessed 4 April 2017).

191 SZW INSPECTORATE, "Annual Report of the Social Affairs and Employment Inspectorate: Summary," Ministry of Social Affairs and Employment (2014). Available at: http://www.inspectieszw.nl/Images/Annual-Report2014_tcm335-365558.pdf (last accessed 22 February 2016); SZW InSPECTORATE, "Annual Report of the Social Affairs and Employment Inspectorate: Summary," Ministry of Social Affairs and Employment (2012). Available at: http://www.inspectieszw.nl/Images/2012-Annual-Report-Inspectorate-SZW-Summary_tcm335-341803.pdf (last accessed 22 February 2016); SZW INSPECTORATE, "Annual Report of the Social Affairs and Employment Inspectorate: Summary," Ministry of Social Affairs and Employment (2013). Available at: http://www.inspectieszw.nl/ Images/Summary\%20Annual\%20Report\%202013\%20Inspectorate\%20SZW_tcm335-350953.pdf (last accessed 22 February 2016); SZW INSPECTORATE, "Annual Report of the Social Affairs and Employment Inspectorate: Summary," Ministry of Social Affairs and Employment (2011). Available at: http://www.inspectieszw.nl/ Images/Summary $\% 202011 \% 20$ Annual $\% 20$ Report $\% 20$ Social $\% 20$ Affairs $\% 20$ and $\% 20$ Employment $\% 20$ Inspectorate_tc m335-329873.pdf (last accessed 22 February 2016); SZW InSPECTORATE, "Annual Report of the Social Affairs and Employment Inspectorate: Summary," Ministry of Social Affairs and Employment (2011). Available at: http://www.inspectieszw.nl/Images/Summary $\% 202011 \% 20$ Annual $\% 20$ Report $\% 20$ Social $\% 20$ Affairs $\% 20$ and $\% 2$ 0Employment\%20Inspectorate_tcm335-329873.pdf (last accessed 22 February 2016). 
For example, Table 2 shows that after the merger of the three labor-related inspectorates that became the Inspectorate SZW in January of 2012, the number of labor market violations noticeably declined from 9,655 in 2011 to 5,054 in 2014. The amount of fines that the Inspectie SZW collected from the violators, however, increased since the formation of the Inspectie SZW from €27.6 million in 2011 to $€ 29.6$ million in 2014 . One possible way to interpret this trend is to conclude that the number of violations have actually decreased due, in some part, to the efforts of the Inspectorate SZW.

An alternative theory, however, is that although the number of violations the Inspectie SZW detected have decreased, the actual number of violations (including those that were undetected by the Inspectie SZW) have not changed either because: 1) the capacity for the Inspectorate SZW to conduct thorough sweeps have been reduced due to austerity based constraints, ${ }^{192}$ or 2) the violators have adapted to the inspections and have learned to conceal their violations more cleverly. The truth behind these figures probably lies somewhere in between with an assortment of various factors influencing these figures, which makes it difficult for this thesis to conclude one way or another about what the true impact of the Inspectie SZW is on labor exploitation in the Netherlands.

While this thesis cannot reach any meaningful conclusion regarding the impact of the Inspectie SZW and the relevant Dutch labor/employment laws that they enforce from these figures, it is worth repeating here that the aim of this thesis is not to figure out how the Inspectie SZW can increase or decrease the number of labor exploitations that they detect. The more relevant question is whether the laws and the Inspectie SZW enforcing them is actually leading to the reduction of labor exploitation in a manner that is increasing the capabilities of the workers. In other words, looking at these figures alone does not clearly indicate whether labor exploitations are being reduced in a way that is actually empowering workers, which will be addressed in the next section (Section 2.3) of this chapter, but before getting to that discussion, this subsection on Dutch labor/employment law must be concluded with some preliminary observations specific to the Dutch context.

\subsubsection{Dutch Labor/Employment Laws and Their Limitations}

It must be noted that even with the continuous work of the Dutch Ministry of Social Affairs and Employment and the Inspectie SZW, labor violations continue to persist in the Netherlands. This realization brings us back to the same concern that emerged at the end of our analysis of NYS Department of Labor and the impact of AITF enforcement measures: Can the current approach to establishing minimum safety nets through labor/employment laws and enforcing them through randomized sweeps conducted by task forces really lead to a meaningful reduction of labor exploitation in the supply chain in a manner that fits our normative framework? Although the dataset presented in the subsections above cannot lead us to any conclusive statements about the real impact and the effectiveness of the Inspectie SZW on the capabilities of the workers, one inescapable fact is that labor exploitations seem to persist regardless of the efforts exhausted by these task

192 Strengthening enforcement measures through "proactive investigations," providing "outreach to community groups" and educating employers and employees are all noble causes, but they all have costs that drains government resource. See e.g. A. BERnHARDT, D. POLSON \& J. DeFilipPis, at p. 6. 
forces. The figures presented in Subsections 2.1.2 and 2.2.2 proved, if nothing else, that malicious employers will continue to exploit their laborers, even in the existence of labor/employment laws that prohibit them from doing so, as long as the incentives to exploit laborers continue to exist (i.e. saving costs by not paying the minimum wage).

Moreover, from the perspective of the laborers, this particular enforcement approach also does not incentivize them to blow the whistle on their employers. The truth of the matter, as already hinted in the introduction, is that if the exploited laborers had the skill set and the possibility to work for better wages under better conditions, they would likely leave their exploitative employers behind. In many cases, however, it is the lack of this alternative that keeps the laborers working for low wages in exploitative conditions. In other words, in the absence of a better alternative, minimum wage laws and random sweeps alone do not intrinsically incentivize the laborers to cooperate with the governments and their enforcement of labor/employment laws as doing so would not necessarily be in their best interests. In many cases, the exploited workers would rather be working for below the minimum wage in unfavorable working conditions than to not be paid at all or even worse, be deported. Therefore, any proposals to improve, enhance, or complement the existing framework would have to address this root problem of how private actors should go about incentivizing businesses and laborers alike to intrinsically want a socially responsible supply chain.

\subsection{PROBLEMS WITH THE LABOR/EMPLOYMENT LAW APPROACH}

Having described the common approach that the New York and Dutch governments take to enforce their labor/employment laws, this section will now raise some underlying problems associated with their attempts, relative to the stated aims of this thesis, which is to find different ways private actors can reduce labor exploitation in the global supply chain. One of the justifications for focusing on the private sector that we already noted in the introduction was that government measures that aim to reduce labor exploitations have their limits in terms of what they can and cannot do. ${ }^{193}$ To further substantiate this specific point, this section will first address the governments' competence problem (Subsection 2.3.1), followed by what this thesis will refer to as the Goldilocks problem, which has to do with the difficulty that comes with attempting to determine when and how governments should intervene (Subsection 2.3.2). The final subsection will present a case study that illustrates how these two problems manifest themselves in reality (Subsection 2.3.3).

193 J. DE GraAf, D. WANn \& T.H. NAYlor, Affluenza: How Overconsumption is Killing Us - And How We Can Fight Back [Third Edition], (San Francisco: Berrett-Koehler Publishers, 2014), at p. 75 (noting that even with various governmental efforts, “[o]ne-fifth of the world's people - 1.2 billion human beings - live in 'extreme poverty,' on income of $\$ 1.25$ day or less, slowly dying of hunger and disease," and adding that "[ $\mathrm{t}$ ]hree billion others also desperately need more material goods"); see also, F. FuKUYAmA, Trust: The Social Virtues and the Creation of Prosperity, (New York: Free Press Paperbacks, 1995), at p. 5 (noting that "[a] strong and stable family structure and durable social institutions cannot be legislated into existence the way a government can create a central bank or an army.”). 


\subsubsection{The Competence Problem}

Left to our own devices, the choices that we - as individuals - make tend to be rather myopic, which means that individuals are generally not very good at addressing collective action problems. ${ }^{194}$ This was the very reason why governments were traditionally seen as the antidote for the tragedy of the commons in the first place. ${ }^{195}$ We pay taxes and elect our representatives so that they can resolve our shared problems. Accordingly, we expect our governments and our elected leaders to be competent, well intentioned, and effective enough to resolve our collective action problems. ${ }^{196}$ The main concern here is that at times, elected officials and governments fail to meet our lofty expectations. Lack of funding, resource constraints, and the need for politicians to be elected and re-elected, have all contributed in some ways to the growing myopathy of politicians and the declining legitimacy of our system of governance and the rule of law. ${ }^{197}$ It is almost as if governments have now become part of the commons and thus our tragedy. The competence problem that will be detailed below is not just about governments dealing with the specific issue of labor exploitation in the global supply chain, but about their inherent limitations in general. To illustrate and substantiate this point, this subsection will: a) show how inadequate laws can be; b) suggest that lobbyists and money have corrupting influences on our politicians; c) demonstrate how governments, as bureaucratic and democratic institutions, must perpetually deal with series of various conflicts of interests; and finally, d) note that governments rely on wrong or faulty assumptions. By presenting these flaws, this subsection will ulti-

T. JuDT, Ill Fares the Land, (New York: Penguin, 2010), at p. 135 (suggesting that individuals are generally poor at dealing with collective action problems due to the "fragmented individualism of our concerns"); See e.g., O. BARGill, Seduction by Contract: Law, Economics, and Psychology in Consumer Markets, (Oxford: Oxford University Press, 2012), at p. 2-4 (noting that "consumers often have a poor sense of their future use patterns" and tend to be myopic and overly optimistic); see also, A. OFFER, The Challenge of Affluence, (Oxford: Oxford University Press, 2006); T. JACKSON, Prosperity without Growth: Economics for a Finite Planet, (New York: Earthscan, 2009), at p. 160; A. SMITH, The Theory of Moral Sentiments, D.D. RAPHAEL \& A.L. MACFIE (EDS.), (Indianapolis: Liberty Classics, 1759), at p. 190; and, R.H. ThALER, Misbehaving: The Making of Behavioral Economics, (New York: Norton, 2015), at p. 88 (elaborating on Smith's idea in the following manner: "The crucial feature of Smith's conception of our passions is that they are myopic, that is, shortsighted.").

195 T. JACKSON, Prosperity without Growth: Economics for a Finite Planet, (New York: Earthscan, 2009), at p. 166 (noting that the "principal role of government," at least initially, was to "ensure that long-term public goods are not undermined by short-term private interests.”); B. SCHWARTZ, The Paradox of Choice: Why More is Less, (New York: Harper, 2004), at p. 25 (quoting utility industry expert Edward A. Smeloff that "[i]n the past we trusted that the state regulators who were appointed by our elected officials were watching out for us, which may or may not have been true").

196 T. HARForD, Adapt: Why Success Always Starts with Failure, (London: Abacus, 2012), at p. 5-6 (cautioning that "we have an inflated sense of what leadership can achieve in the modern world"); see generally, P.E. TETLOCK, Expert Political Judgment, (New York: Princeton University Press, 2005).

197 R.M. LOCKE, The Promise and Limitations of Private Power: Promoting Labor Standards in a Global Economy, (Cambridge: Cambridge University Press, 2013), at p. 169 (noting that "labor laws and regulations are often violated, and the labor inspectorates/ministries charged with inspecting workplaces and enforcing labor laws are weak, underfunded, and at times, prone to politicization or even corruption"); see also, M. NAÍM, The End of Power: From Boardrooms to Battlefields and Churches to States, Why Being in Charge Isn't What It Used to Be, (New York: Basic Books, 2013), at p. 15 (observing that there has been a corrosion of the government's "moral authority and legitimacy"); D. ARIELY, The (Honest) Truth About Dishonesty: How We Lie to Everyone - Especially Ourselves, (New York: Harper Collins, 2012), at p. 209 (noting that political action committees and ever-aggressive lobbyists have corrupted our system of governance as a whole); see also, L. Lessig, Republic, Lost: How Money Corrupts Congress-And a Plan to Stop It, (New York: Twelve, 2011). 
mately stress the need for the private sector to remain vigilant and involved, thus once again validating this thesis' focus on the private sector in the subsequent chapters.

\section{A. Laws Can Be Slow, Ineffective, and Unenforced}

First, the legislative process - in and of itself - often tends to be reactionary or ex post, meaning that legislators are sometimes reluctant to move away from the status quo. ${ }^{198}$ As a result, laws take time before they can actually be implemented. Even when legislatures are actually willing and able, drafting a law is an extremely difficult and time-consuming process because even on their best days, lawmakers cannot predict everything that lies ahead. ${ }^{199}$ This means that laws generally cannot remove every and all ambiguities, which could invite multiple interpretations and thus some confusion to its end users. ${ }^{200}$ In order to minimize these ambiguities, legislatures take time to review and revise drafts before submitting it as a bill, thus contributing to the lagging pace at which laws are promulgated.

Second, not only does the lawmaking process tend to be reactionary and sometimes slow, but even when a law is passed, the content of the law - as hinted above - can be ambiguous, lacking, or even ineffective. ${ }^{201}$ The confusion that these ambiguities create can significantly undermine the impact of the law. While the rule of law holds that laws ought to be accessible, intelligible, clear, and predictable, ${ }^{202}$ the law in reality is not necessarily

198 T. Harford, Adapt: Why Success Always Starts with Failure, (London: Abacus, 2012), at p. 29, 172 (adding that "government regulations, by their very nature, tend to be somewhat impervious to the possibility of improvement" because politicians have limited terms and "[e]ven more politically inconvenient is the fact that half of the pilot schemes will fail [as] many things do in a complex world...”). The government's reluctance can also be characterized in terms of the endowment effect, see e.g. E.A. POSNER, The Twilight of Human Rights Law, (Oxford: Oxford University Press, 2014), at p. 95; B. SCHwARTZ, The Paradox of Choice: Why More is Less, (New York: Harper, 2004), at p. 71 (explaining that "[o]nce something is given to you, it's yours. Once it becomes part of your endowment, even after a very few minutes, giving it up will entail a loss.”); see also, R.H. THALER, Misbehaving: The Making of Behavioral Economics, (New York: Norton, 2015), at p. 17-8 (explaining that "people value things that were already a part of their endowment more highly than things that could be part of their endowment; for example, "[g]iving up the opportunity to sell something does not hurt as much as taking the money out of your wallet to pay for it."); and, R.H. THALER, Misbehaving: The Making of Behavioral Economics, (New York: Norton, 2015), at p. 18, 131 (explaining that "people [value] things that were already part of their endowment more highly than things that could be a part of their endowment..."; for example, "[r]emoving a discount is not nearly as objectionable as adding a surcharge.").

199 E.A. Posner, The Twilight of Human Rights Law, (Oxford: Oxford University Press, 2014), at p. 95 (noting that "[t]he major reason that ambiguous laws exist in the first place is that the legislature finds it difficult to anticipate future events that it seeks to regulate."); see also, T. HARFORD, Adapt: Why Success Always Starts with Failure, (London: Abacus, 2012), at p. 174-7 (observing that people can exploit "the crucial difference between the letter and the spirit of the law").

200 E.A. Posner, The Twilight of Human Rights Law, (Oxford: Oxford University Press, 2014), at p. 86 (noting that " $[\mathrm{w}]$ hen legal rules are vague... one can easily argue that one complied with them even when one's conduct does not seem to advance the underlying purpose of the rules, which people will disagree about.").

201 S.V. Coslovsky \& R. LOCKE, "Parallel Paths to Enforcement: Private Compliance, Public Regulation, and Labor Standards in the Brazilian Sugar Sector," Politics \& Society 41(4) (2013): 497-526, 518 (stating that governments are often "not embedded within the sector [that they regulate], so they possess limited understanding of business practices or the reforms that might help targeted firms comply with labor standards without damaging their ability to compete"); citing to M.W. TOFFEL, J.L. SHORT \& M. OuELLET, "Reinforcing Regulatory Regimes: How States, Civil Society, and Codes of Conduct Promote Adherence to Global Labor Standards," Harvard Business School Technology \& Operations Management Unit Working Paper 65 (2013).

202 T. Bingham, The Rule of Law, (New York: Penguin, 2010), at p. 6; see also, United Nations, "Secretary General's Report on the Rule of Law in Conflict and Post-Conflict Societies," S/2004/16, (23 August 2004), at para. 6 (defining rule of law in the following manner: "[Rule of law is] a principle of governance in which all persons, institutions and entities, public and private, including the State itself, are accountable to laws that are publicly promulgated, equally enforced and independently adjudicated, and which are consistent with international human rights norms 
so. ${ }^{203}$ Lowly skilled laborers, for instance, generally lack the ability to read, understand, and utilize the law to their benefit, thus depriving them of the benefits that the law affords them. Even for more highly skilled private actors, the law is not necessarily something that can be processed and clearly understood without the help of hired legal professionals. The reality is that the principle behind Lord Mansfield's often cited quote about how the law ought to be based on common sense and how they should be easy for one to learn and retain is quite often violated in reality. ${ }^{204}$ For example, the late Justice Scalia of the US Supreme Court admitted that he did not read the legislation he was ruling on - the socalled Obamacare legislation, which was well over two thousand pages long - and joked that to be forced to read the law would be tantamount to cruel and unusual punishment. ${ }^{205}$ In short, the law can be pages and pages of legal jargon that even a Supreme Court Justice is reluctant to read in its entirety, which is to suggest that it is inaccessible, and thus possibly inadequate or ineffective.

Third, even if legislatures are able to draft concise and clear laws that are easy to understand without delay, there will always be an enforcement problem when it comes to the law. As the AITF and Inspectie SZW figures noted above, even when laws are relatively simple and the punishment for its violation clear and predictable, it does not guarantee that private actors will always comply. Moreover, task forces charged with enforcing the law realistically cannot be expected to detect and punish all instances of labor exploitations, given that such an expectation would be cost-prohibitive and highly unrealistic. ${ }^{206}$ In short, even if the legislatures can draft the perfect law - whatever such a hypothetical instrument would look like - there will always be an enforcement problem.

In sum, while governments and their laws provide very necessary minimum protections for the workers, they cannot guarantee that laborers will not be exploited. Moreover, there

and standards. It requires, as well, measures to ensure adherence to the principles of supremacy of law, equality before the law, accountability to the law, fairness in application of the law, separation of powers, participation in decision making, legal certainty, avoidance of arbitrariness and procedural and legal transparency.”).

203 T. Bingham, The Rule of Law, (New York: Penguin, 2010), at p. 6 (acknowledging the comment that the rule of law is "too uncertain and subjective an expression to be meaningful"); see also, B.Z. TAMANAHA, On the Rule of Law, (Cambridge: Cambridge University Press, 2004), at pp. 8-9 (stating that the rule of law is "'an exceedingly elusive notion' giving rise to 'rampant divergence of understandings' and analogous to the notion of the Good in the sense that 'everyone is for it, but have contrasting convictions about what it is'."); J. SHKLAR, "Political Theory and the Rule of Law," in The Rule of Law: Ideal or Ideology, A. HutCHINSON \& P. MONAHAN (EDs.) (Toronto: Carswell, 1987), at p. 1 (criticizing the rule of law as "one of those self-congratulatory rhetorical devices that grace the public utterances of Anglo-American politicians”); as cited by, T. BINGHAM, The Rule of Law, (New York: Penguin, 2010), at p. 5) (continuing to state that "No intellectual effort need therefore be wasted on this bit of ruling class chatter.").

204 Hamilton $v$ Mendes (1761) 2 Burr 1198, 1214; see also, Vallejo $v$ Wheeler (1774) 1 Cowp 143, 153 (holding that "[ $t$ ] he daily negotiations and property of merchants ought not to depend upon subtleties and niceties; but upon rules easily learned and easily retained, because they are the dictates of common sense, drawn from the truth of the case.")

205 National Federation of Independent Business v. Seblius. Oral Arguments (28 March 2012). Available at: http://www.supremecourt.gov/oral_arguments/argument_transcripts/11-393.pdf (last accessed 22 February 2016), at p. 38 (asking the Deputy Solicitor General Edwin Kneedler, "[w] hat happened to the Eight Amendment? You really want us to go through these 2,700 pages? Do you really expect the Court to do that?”).

206 T.P. GLYNN, "Taking the Employer Out of Employment Law? Accountability for Wage and Hour Violations in an Age of Enterprise Disaggregation," Employee Rights and Employment Policy Journal 5(1) (2011): 101-135, at p. 102 (noting that "[e]nsuring a decent life requires not only the laws that ensure minimum wages and protections, but "social and legal systems that promote effective enforcement."). see also, C. EsTLUND, "Who Mops the Floors at the Fortune 500? Corporate Self-Regulation and Low-Wage Workplace," Lewis and Clark Law Review 12 (2008): 671, at p. 678-9. 
is an increasing expectations gap between what we think the law should be doing and what the law is actually doing, which is contributing to the perception that governments are not getting the job done. ${ }^{207}$

\section{B. Lobbyists and Money's Corrupting Influence}

As noted above, governments face budgetary constraints, electoral concerns, and constant pressures from their constituents pulling them in various different directions. The legislative process, by its very nature, demands lawmakers to balance and mediate between conflicting interests to reach a compromise in terms of how they allocate their limited resources to various groups. This means that, at times, governments must cater to business interests and not just be preoccupied with protecting the interests of the laborers. What complicates this reality is the growing presence of lobbyists and the corrupting influence of money in politics.

The lobbyist problem, at its core, has to do with the fact that while we acknowledge that governments must balance the interests of multiple parties and constituents, money can have a tantalizing effect on lawmakers, which could incentivize them to pay more attention to those with money rather than to those without. ${ }^{208}$ The unavoidable reality is that some politicians do indeed cater to lobbyists, even if it means ignoring what is in the best interests of their constituents, as we saw in the CNMI case and how Jack Abramoff fought off the imposition of the minimum wage regulation extending to the Commonwealth. ${ }^{209}$ According to Lawrence Lessig, money in politics is the root of all social problems because lobbyists that can offer the biggest capital contributions gets the most say, and initiatives for positive social change (i.e. empowering workers in the lower echelons of the global supply chain) generally fail to make any progress. ${ }^{210}$ There are series of reports and studies that confirm Lessig's claim, ${ }^{211}$ which only adds to the growing number of reasons for why

M. NAím, The End of Power: From Boardrooms to Battlefields and Churches to States, Why Being in Charge Isn't What It Used to Be, (New York: Basic Books, 2013), at p. 64 (stating that "the fundamental cause of social and political instability in developing countries... was that people's expectations expanded much faster than the capacity of any government to satisfy them"); citing to, S.P. Huntington, Political Order in Changing Societies, (Connecticut: Yale University Press, 2006); see also, T. BIngham, The Rule of Law, (New York: Penguin, 2010), at p. 6, 26 (citing to Commission Communication to the Council and Parliament, 12 March 1998, COM (98) 146) (noting that while the European Commission has "consistently treated democratization, the rule of law, respect for human rights and good governance as inseparably linked," it fails to uphold them consistently).

208 M.C. Nussbaum, "Beyond the Social Contract: Capabilities and Global Justice," Oxford Development Studies 32(1) (2004), at p. 6 (observing that "many nations of the world do not have governments that represent the interests of the people taken as a whole. Even when a nation has a government that is not a mere tyranny, large segments of the population may be completely excluded from governance.”).

209 See generally, J.H. BIRnBaum, The Lobbyists: How Influence Peddlers Work. Their Way in Washington, (New York: Three River Press, 1993); see also, M.C. Nussbaum, Creating Capabilities: The Human Development Approach, (Cambridge: Belknap Harvard, 2013), at p. 180 (accusing lobbying groups as being "powerful civil society organizations that often work against the equal empowerment of all citizens.").

210 J. SHAw, "A Radical Fix for the Republic: Lawrence Lessig thinks American Democracy Requires a Constitutional Overhaul to Counter the "Economy of Influence," Harvard Magazine, (July-August 2012). Available at: http://harvardmagazine.com/2012/07/a-radical-fix-for-the-republic (last accessed 4 April 2017).

211 See e.g. M. GiLENS, "Inequality and Democratic Responsiveness," Public Opinion Quarterly 69(5) (2005): 778-796, at 778 (observing that there is a "vast discrepancy" between the government's responsiveness to the rich when compared to the poor, meaning that at least in the US, Congress caters to those with higher incomes vis-à-vis those with lower incomes); F. CAPRA \& U. MATTEI, The Ecology of Law: Toward a Legal System in Tune with Nature and Community, (Oakland: Berrett-Koehler, 2015), at p. 114, 118, 122 (adding that "[c]orporate money determines the behavior of states, and often nongovernmental organizations," not to mention the fact that "[g]overnments simply 
governments should not be perceived as the sole institution in charge of addressing our collective action problems. ${ }^{212}$

Moreover, there are signs that the symbiosis between the legislatures and the lobbyists is getting stronger, ${ }^{213}$ which is increasing the conflicts of interests that the legislatures face. ${ }^{214}$ The influence of lobbyists and special interests are exacerbated by the relatively short election cycles in the more developed economies and the need for politicians to raise enough money to run a successful campaign to remain in politics. According to James Buchanan's Nobel Prize winning work on rational choice theory, a conscientious politician advocating for social and environmental justice could be considered as being irrational, as doing so "does not maximize their chances of being re-elected" in light of corporate interests that may oppose such considerations. In addition, Naomi Klein observes that we are witnessing "a very disturbing mix of big corporate power and big state power cooperating in the interests of the elites," 215 which will increase instances like the one from the CNMI case study, where government officials colluding with businesses and their lobbies, become reluctant to take appropriate actions to reduce instances of labor exploitation at the government level. While one could find multiple points of objection in The Communist Manifesto, there is one interesting bit worth extrapolating and applying in this specific context: In their manifesto, Marx and Engels suggested that "governments in capitalist society [are] political extensions of the interests of business owners," where "[t] he executive of the state [is] nothing more than a committee for managing the affairs of the whole bourgeoisies." 216 While this cannot be the absolute truth about all capitalistic societies, it is an interesting

do not have the teeth to bite the corporations. They can only bark"); R. REICH, "Big Government isn't the Problem," Salon, (31 December 2014). Available at: http://www.salon.com/2014/12/31/robert_reich_big_govern ment_isnt_the_problem_partner/?utm_source=facebook\&utm_medium=socialflow (last accessed 2 February 2015) (noting that " $[\mathrm{t}]$ he larger problem is that much of government is no longer working for the vast majority it's intended to serve. It's working instead for a small minority at the top"); L. LESSIG, Republic, Lost: How Money Corrupts Congress-And a Plan to Stop It, (New York: Twelve, 2011); J. SHAw, "A Radical Fix for the Republic: Lawrence Lessig thinks American Democracy Requires a Constitutional Overhaul to Counter the 'Economy of Influence'," Harvard Magazine, (July-August 2012). Available at: http://harvardmagazine.com/2012/07/a-radical-fixfor-the-republic (last accessed 4 April 2017) (reporting that in 2009 alone "lobbyists spent $\$ 3.5$ billion, or about $\$ 6.5$ million per each elected member in [the US] Congress.”).

212 D. Goleman, Ecological Intelligence: The Coming Age of Radical Transparency, (London: Penguin, 2010), at p. 236 (stating that “[w]e can't always wait for government solutions. Political realities may make promises of beneficial shifts attractive, but not the pain of those shifts - politicians too often defer the pain until they will be out of office," not to mention the fact that "governments are notoriously slow and awkward when they try to regulate commerce."); see also, D. ARIELY, The (Honest) Truth About Dishonesty: How We Lie to Everyone - Especially Ourselves, (New York: Harper Collins, 2012), at p. $94-95$ (noting that "[w]hen regulation by the government... does not materialize, we as [people] should recognize the danger that conflicts of interest bring with them and do our best to seek service providers who have fewer conflicts of interest (or, if possible, none).").

213 See e.g. Citizens United v. Federal Election Commission, 558 U.S. 310 (2010) (holding that campaign contributions and donations is a form of free speech that should not be limited by the governments).

214 D. ARIELY, The (Honest) Truth About Dishonesty: How We Lie to Everyone - Especially Ourselves, (New York: Harper Collins, 2012), at p. 93 (writing that this quid pro quo relationship between the lawmakers and the lobbyists is putting the lawmakers "into terrible conflicts of interest").

215 M. NAím, The End of Power: From Boardrooms to Battlefields and Churches to States, Why Being in Charge Isn't What It Used to $B$ e, (New York: Basic Books, 2013), at p. 40-2 (quoting N. Klein from an interview given on 18 November 2009); see, Naomi Klein and Joseph Stiglitz on Economic Power. Available at: https://www.youtube.com/ watch?v $=\mathrm{qkErO}-$ TwOeo (last accessed 15 May 2015).

216 M. NAím, The End of Power: From Boardrooms to Battlefields and Churches to States, Why Being in Charge Isn't What It Used to Be, (New York: Basic Books, 2013), at p. 40-2 (citing to The Communist Manifesto); see generally, K. MARX \& F. ENGELS, The Communist Manifesto, (1848). 
point to consider nevertheless in light of current affairs. In short, money can have a corrosive effect not just on people, but on governments as well. ${ }^{217}$

In justifying the focus of this thesis being on the private sector, the introduction used the argument that private actors are becoming as powerful and influential as some governments. The irony here is that while this is indeed true, ${ }^{218}$ some of these private actors are using this influence purely for their own benefit and not in a way to enhance the capabilities of the exploited workers. Upton Sinclair neatly summarized the essence of the lobbyist problem in the following manner: "It is difficult to get a man to understand something when his salary depends on his not understanding it." 219 In other words, if enough corporate interest exists to keep the laborers in the global supply chain where they stand, relying on the public sector to protect their interests may also be equally irrational.

\section{Governments' Conflict of Interest}

While the normative framework of this thesis is the adapted capabilities approach, many governments still measure their successes and achievements primarily by looking at economic indicators like the GDP. ${ }^{220}$ To be clear, this is not to suggest that governments only care about economic considerations, which is simply not true; however, governments do have some preferences for measurable or quantifiable factors over qualitative ones simply because quantitative factors are easier to measure and compare. Moreover, if we assume for the moment that a government's primary objective is to advance the public good, the normative framework that that government relies on could drastically impact the its priorities and actions. Eric Posner suggests that part of the reason why governments are not capable of rooting out social problems like labor exploitation is that doing so does not necessarily increase the public good, if that government's focus is on economic indicators. ${ }^{221}$ As we mentioned in the limitation section of the introduction (Section 1.3), if a particular government's main normative criterion is to increase its GDP, creating laws to protect laborers at the bottom echelons of the supply chain could be argued as being detrimental to the overall public good. In short, a measuring stick that weighs economic and financial considerations more heavily than social considerations will likely produce outcomes that reflect such preferences: For example, there is empirical research to show that inequality is higher

M.J. SANDEL, What Money Can't Buy: The Moral Limits of Markets, (London: Allen Lane, 2012), at p. 122.

F. CAPRA \& U. MATTEI, The Ecology of Law: Toward a Legal System in Tune with Nature and Community, (Oakland: Berrett-Koehler, 2015), at p. 114, 118, 122 ("[a] number of corporations are now so large and powerful that they, rather than politicians, are able to determine law and policy.”).

219 T. JUDT, Ill Fares the Land, (New York: Penguin, 2010), at p. 168 (quoting Upton Sinclair's I, Candidate for Governor: And How I Got Licked); see, U. SINCLAIR, I, Candidate for Governor: And How I Got Licked, (Berkley: University of California Press, 1934), at p. 107.

220 Cf. A. HAYDEN, Sharing the Work, Sparing the Planet: Work, Time, Consumption, and Ecology, (London: Zed Books, 1999), at p. 36 (quoting the former Dutch Prime Minister Ruud Lubbers stating that "the Dutch are not aiming to maximize gross national product per capita. Rather we are seeking to attain a high quality of life, a just, participatory and sustainable society"); as cited in, J. DE GRAAF, D. WANN \& T.H. NAYLOR, Affluenఇa: How Overconsumption is Killing Us - And How We Can Fight Back [Tbird Edition], (San Francisco: Berrett-Koehler Publishers, 2014), at p. 213 (adding that other countries like the Scandinavian countries do not rely on GDP as their key indicator for wealth, and as a result, appear to be enjoying a higher quality of life as a whole).

221 E.A. Posner, The Twilight of Human Rights Law, (Oxford: Oxford University Press, 2014), at p. 122 (noting that "[o]ne reason governments do not pay much attention to human rights treaties is that they are responsible for advancing the public good, and the treaties themselves do not provide guidance as to what promotes the public good.”) 
in liberal market economies that focus more on economic indicators than in regulated market economies that focus more on social indicators. ${ }^{222}$

To continue this line of argumentation, let us consider the fact that what GDP essentially measures is how much consumers are spending, ${ }^{223}$ which means that the more people consume, the higher the GDP. Moreover, businesses operating in the global supply chain exist in large part because there is a demand from consumers and other businesses for more and more goods. This creates increased demands for cheaper and faster labor, which as the ILO noted earlier, creates a situation that is rife for laborers to be exploited, which is another conflict of interest that governments must address. ${ }^{224}$ On the one hand, governments have an interest in incentivizing consumers to be materialistic and for them to consume more as that increases the governments' GDP. On the other hand, governments also have an interest in reducing over consumption as it leads not only to situations of labor exploitation, but also to other collective action problems like environmental degradation caused by accumulation of waste.

Furthermore, governments interested in increasing economic indicators might not only be reluctant to enact laws that protect workers, but they could actively attempt to invite foreign businesses to come set up operations within their jurisdictions by advertising "business friendly" environments. ${ }^{225}$ This is often associated with deregulation and the race to the bottom, where in order to attract more and more businesses, governments create laws in favor of businesses or refrain from implementing restricting regulations, which would be beneficial to the businesses, but necessarily for their employees or other stakeholders. This phenomenon is a relatively common occurrence, enough for people to have coined the term Delaware Effect, to refer to this regulatory race to the bottom.

In sum, it has been said that globalization is the expansion of capitalism worldwide that governments can either welcome and benefit from, or fail to adapt and lose out in the

222 Scholars have observed that inequality tends to be higher in liberalized markets (UK and US) rather than coordinated market economies (Germany and Denmark). See, T. JACKSON, Prosperity without Growth: Economics for a Finite Planet, (New York: Earthscan, 2009), at p. 164; see also, R. WILKINSON \& K. PICKETT, The Spirit Level: Why Equality Is Better for Everyone (London: Penguin Books, 2010); and, T. JuDT, Ill Fares the Land, (New York: Penguin, 2010), at p. 13 (stating that " $\mathrm{t}$ ] he greatest extremes of private privilege and public indifference have resurfaced in the US and the UK: epicenters of enthusiasm for deregulated market capitalism.").

223 The International Monetary Fund defines GDP as follows: "GDP measures the monetary value of final goods and services - that is, those that are bought by the final user - produced in a country in a given period of time." See, T. CAllen, “Gross Domestic Product: An Economy's All," International Monetary Fund, (28 March 2012). Available at: http://www.imf.org/external/pubs/ft/fandd/basics/gdp.htm (last accessed 26 August 2016).

224 T. JACKSON, Prosperity without Growth: Economics for a Finite Planet, (New York: Earthscan, 2009), at p.164 (observing that " $[\mathrm{g}]$ rowth calls on us to be myopic, individualistic novelty seekers, because that's exactly what's needed to perpetuate the economic system... [and] there will inevitably be a tendency for governments to support social structures that reinforce materialistic, novelty-seeking individualism. Because that's what it takes to keep the economy afloat"); see also, S. ANHOLT, Places: Identify, Image and Reputation, (New York: Palgrave Macmillan, 2010), at p. 3-4 (stating that "[t]oday, the world is one market; the advance of globalization means that every country, city and region must compete with every other for its share of the world's commercial, political, social and cultural transactions.”); F. CAPRA \& U. MATTEI, The Ecology of Law: Toward a Legal System in Tune with Nature and Community, (Oakland: Berrett-Koehler, 2015), at p. 169 (describing this as the "shadow side of progress.").

225 J.M. SMITS, "The Future of Contract Law in Europe," in Research Handbook on EU Consumer and Contract Law. C. TwiGG-FLESNER (ED.) (Cheltenham: Edward Elgar, 2016): 549-565, 550 (observing that "governments and semiofficial institutions now try to attract foreign parties to their jurisdiction" by citing to the brochures issued by the Law Society of England and Wales titled "England and Wales: The Jurisdiction of Choice" (2007) and by the German Ministry of Justice's "Law - Made in Germany" (2008)). 
process. ${ }^{226}$ While we cannot fault the governments for wanting to ride with the wave of globalization to accrue its benefits - thus arguably advancing the public good - we cannot ignore the fact that partaking in this endeavor and encouraging materialistic consumption for the sake of increasing economic indicators comes with a cost. Bearing this in mind, one fundamental change that the private actors can push for through the democratic process would be to incentivize their governments to shift their normative framework from one that prioritizes economic factors to one that prioritizes social considerations more instead. However, it must be noted that while there are various alternatives to the GDP already in existence, ${ }^{227}$ this option has a low success rate considering the fact that governments and legislatures, as noted earlier in this subsection, are often reluctant or very slow to adapt.

\section{Flawed Assumption of the Rational Actor}

Similar to how governments prefer to measure their achievements based on economic indicators like the GDP, lawmakers also often rely on law and economic methodologies to justify their policies or laws that they promulgate because numbers provide some sense of reliability and objectivity. ${ }^{228}$ However, the problem with lawmakers relying on economic models to justify their actions is that traditionally, economic models make flawed assumptions. For example, the rational choice theory assumption, as advocated by Gary Becker, considers private actors to be rational, reasonable beings with unbound rationality and clear preferences. ${ }^{229}$ In reality, however, we do not always conduct reasoned, calculated costbenefit analysis prior to making every decision and private actors can be quite irrational about their preferences. ${ }^{230}$ This is partially due to the fact, at least according to Richard Thaler, that people are constrained by the "three bounds" of "bounded rationality, bounded willpower, and bounded self-interest," and the assumption that we are thoroughly unbounded is incorrect. ${ }^{231}$

D. RoDRIK, The Globalization Paradox: Democracy and the Future of the World Economy, (New York: Norton, 2011), at p. 233. For example, the Genuine Progress Indicator ("GPI") that includes in its calculations factors such as parenting and volunteer work, or more uniquely, the Gross National Happiness (GNH) that Bhutan utilizes to measure the people's happiness.

228 F. CAPRA \& U. MATTEI, The Ecology of Law: Toward a Legal System in Tune with Nature and Community, (Oakland: Berrett-Koehler, 2015), at p. 8 (noting that "all political debates [today] are firmly anchored in the powerful academic discipline of economics, which, by successfully claiming to be an exact science, determines policy making and legislation."); see also, G. CALABRESI, "Some Thoughts on Risk Distribution and the Law of Torts," Yale Law Journal 70(499) (1961); and, R.A. PosNER, Economic Analysis of the Law [Seventh Edition], (New York: Aspen Publishers, 2007).

229 A theory, at the most basic level, presumes that given series of options, actors choose rationally by weighing the pros and cons, through a reasoned cost-benefit analysis. Similar concept is the economic theory of the firm, which "stipulates that firms will act to maximize profits (or the value of the firm)"; see, R.H. THALER, Misbehaving: The Making of Behavioral Economics, (New York: Norton, 2015), at p. 27; see generally, G.S. BECKER, "Investment in Human Capital: A Theoretical Analysis," Journal of Political Economy 70(5) (1962): 9-49.

230 R.H. ThalER, Misbehaving: The Making of Behavioral Economics, (New York: Norton, 2015), at p. 48 (noting that this is a serious problem for the proponents of neoclassical economics, because "[e]conomic textbooks would stop on the first page if the assumption of well-ordered preferences had to be abandoned, because without stable preferences there is nothing to be optimized”); see also, B. SCHWARTZ, The Paradox of Choice: Why More is Less, (New York: Harper, 2004), at p. 138 (noting that something as small as "[i]nducing people to give reasons for their preferences, even if only to themselves, seemed to change their preferences" thus how unpredictable and irrational our preferences can be).

231 R.H. THALER, Misbehaving: The Making of Behavioral Economics, (New York: Norton, 2015), at p. 257-8 (suggesting that "the field of law and economics, as currently practiced, should be modified to accommodate recent findings in behavioral economics.”). 
While economists relying on faulty assumptions to create their models might not be a problem in and of itself, when lawmakers start to create laws and policies based on these models, what ends up happening is that laws are created that, at times, ignore our bounded rationality, which renders mixed outcomes. For example, relying on the rational choice theory, laws and regulations have been designed with the idea of deterring private actors from committing undesirable social acts by sanctioning them through fines or other forms of punishment and incentives, often characterized either as the carrot or the stick. ${ }^{232} \mathrm{By}$ imposing fines or increasing the amount thereof, lawmakers believe that they can deter undesirable actions, and while this is indeed the case to a certain extent, the first two sections of this chapter has already shown that there are limits to this approach, thus requiring a rethinking of this particular approach and our overall reliance on traditional economic models and assumptions. ${ }^{233}$

In thinking of better alternatives moving forward, what this thesis will eventually advocate for is to replace - or at least add to - the laws' current reliance on traditional economic models with an emerging field of behavioral economics, which questions the validity of the rational choice theory. ${ }^{234}$ While the discussion of this approach and a full description of what it entails will be tabled until subsequent chapters, in wrapping up this part on law's reliance on traditional economic models, it must be stated that the current labor/employment approach is not necessarily in alignment with our normative framework, which values amongst other factors, learning and growing not only for the workers, but for all relevant actors in the global supply chain. This is due to the fact that governments might be able to make better laws and policies if they were to take into consideration our flaws and bounded rationality, but at this current juncture, by looking at how labor/employment laws are designed and enforced, we can observe the governments' hesitance to adapting and changing at a rate on par with reality, thus reaffirming their competence problem. ${ }^{235}$

To conclude this subsection, governments, legislatures, and the laws that they pass all have various inherent flaws, which limit their ability to reduce labor exploitations in a manner consistent with the adaptive capabilities approach. ${ }^{236}$ In the words of the late Tony Judt, there is a "blurring of the distinction between law and justice," and although the law

232 G.S. BECKER, The Economic Approach to Human Behavior, (Chicago: University of Chicago Press, 1978), at 8, 17; see also, D. ARIELY, The (Honest) Truth About Dishonesty: How We Lie to Everyone - Especially Ourselves, (New York: Harper Collins, 2012), at p. 7; see also, G.W.L. Low, European Contract Law between the Single Market and the Law Market: A Behavioural Perspective, (Nijmegen: Wolf Legal Publishers, 2011), at p. 176 (noting that "to the extent that people are price-sensitive, "law as a regulatory function may be used as a carrot or a stick: to encourage or discourage certain activities by subsidizing the price or imposing costs on their actions, and thereby altering the price or character of these actions"); citing, R.A. POSNER \& F. PARISI, Economic Foundations of Private Law, (Edward Elgar Publishing, 2002), at 7.

233 E.H. ATIQ, "Why Motives Matter: Reframing the Crowding Out Effect of Legal Incentives," Yale Law Journal 123 (2014): 1070-1116, 1077; see also, D. ARIELY, The (Honest) Truth About Dishonesty: How We Lie to Everyone - Especially Ourselves, (New York: Harper Collins, 2012), at p. 14.

234 R.H. THALER, Misbehaving: The Making of Behavioral Economics, (New York: Norton, 2015), at p. 5, 7 (arguing that "[w]e need an enriched approach to doing economic research," which is an approach that takes into account people's bounded rationality).

235 See Generally, S. DEAKIN \& F. WiLkINSON, The Labour Market: Industrialization, Employment, and Legal Evolution, (Oxford: Oxford University Press, 2005).

236 H. Collins, "Conformity of Goods, the Network Society, and the Ethical Consumer," European Review of Private Law 5 (2014): 619-640, at p. 627 (noting that "in reality, a national government cannot exercise much influence over foreign business under a different jurisdiction.”). 
was once thought to be just, this is no longer true in all instances. ${ }^{237}$ Furthermore, there is a growing 'mismatch between the 'highly legalistic' and rigid enforcement practices of government regulatory agencies and the dynamic and evolving reality of supply chain factories." ${ }^{238}$ Hugh Collins believes that this gap is so large, especially in the context of international or global commerce, that he has even gone as far as to conclude that many government based regulatory strategies to address issue like labor exploitation in the global supply chain are "destined for ineffectiveness." 239 While this thesis is more positive towards the role that governments and their regulations, the main takeaway from this subsection is indeed to suggest that private actors cannot necessarily rely on them.

\subsubsection{The Goldilocks Problem}

The question of when and how governments should intervene, given their competence problem, comes back again in the context of this subsection. The Goldilocks problem, based on the fable of the same name, deals with the question of over-regulation, underregulation, and finding the "right" level of governmental regulation. Even if we presume, just for the time being, that the majority of legislatures are completely uninfluenced by money or overly swayed by economic considerations, and are only interested in faithful executing the duties of their office, this still leaves open the question of whether this majority can create the "right" set of rules that - for the purposes of this thesis - will lead to the reduction of labor exploitations in the global supply chain in a manner that is consistent with the adapted capabilities approach.

As suggested in the previous subsection, the actual impact that any legislation can have is often difficult to predict prior to its implementation. Not only can the most well intended legislation or court decision produce disastrous outcomes and unintended consequences, but history has shown time and time again, the fallibility of experts. ${ }^{240}$ Given that the capabilities approach is an outcome-oriented approach, this thesis believes that it is important, not just for private actors, but even for governments to continually assess and evaluate how the measures that they have implanted is actually working out to determine if that particular measure needs to be reevaluated. Admittedly, this obligation can prove diffi-

T. JudT, Ill Fares the Land, (New York: Penguin, 2010), at p. 182.

R.M. LOCKE, The Promise and Limitations of Private Power: Promoting Labor Standards in a Global Economy, (Cambridge: Cambridge University Press, 2013), at p. 169; see also, F. CAPRA \& U. MATTEI, The Ecology of Law: Toward a Legal System in Tune with Nature and Community, (Oakland: Berrett-Koehler, 2015), at p. 105 (paraphrasing an argument often associated with Freiderich Karl von Savigny and stating that "[a]ny codification of law was a top-down act of authority of the state in a given historical moment that necessarily made law less adaptable to subsequent historical circumstances.”).

239 H. Collins, "Conformity of Goods, the Network Society, and the Ethical Consumer," European Review of Private Law 5 (2014): 619-640, at p. 627, 639 (adding that "the ILO remains fundamentally a voluntary organization without powers of inspection and enforcement.").

240 For example, prior to the financial collapse of 2008, less government regulation in the financial sector was believed - by most experts - to be a better path to prosperity and the legislatures ran with this philosophy. See generally, R.A. POSNER, A Failure of Capitalism: The Crisis of '08 and the Descent into Depression, (Massachusetts; Harvard University Press, 2011); see also, C.M. CHRISTENSEN, The Innovator's Dilemma: The Revolutionary Book That Will Change the Way You Do Business, (New York: Harper Business, 2011), at p. 178 (noting that "[a]mid all the uncertainty surrounding disruptive technologies, managers can always count on one anchor: Experts' forecasts will always be wrong. It is simply impossible to predict with any useful degree of precision how disruptive products will be used or how large their market will be."). 
cult for various government entities, given their highly legalistic and rigid enforcement practices that were noted in the previous subsection.

Adaptability and flexibility is particularly essential in addressing a complex problem like labor exploitation in the global supply chain because we can never know with absolute certainty what the outcome of a particular law or action will have on a large population, or for governments to know what the right level of regulation really is ex ante. It is even conceivable that laws promulgated by governments intending to help workers in the bottom echelons of the supply chain cannot only

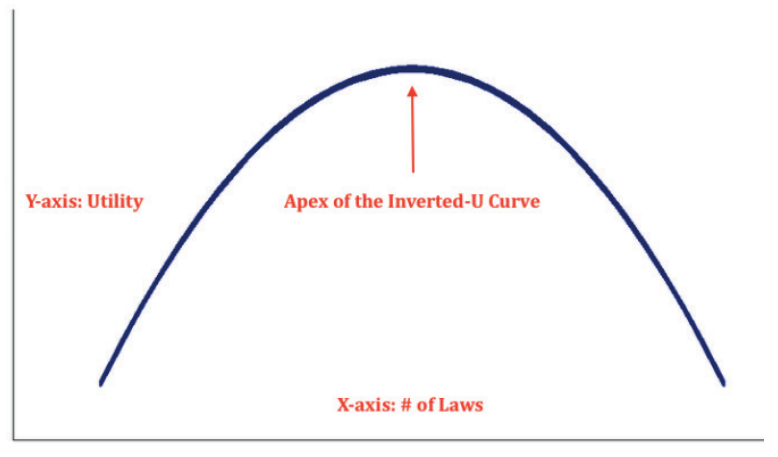

Figure 2: The Inverted-U Curve fail to help them, but actually exacerbate their situation. With this in mind, this subsection will: a) demonstrate why it is so important to strike the right balance of regulation/enforcement and why this is such a difficult task by introducing the concept of the Inverted-U curve; b) provide an example of where the law promulgated by governments actually make the lives of workers more difficult; and c) present instances where less government regulation can lead to better outcomes for the workers.

\section{A. "We are operating in a U-shaped world"241}

Psychologists Barry Schwartz and Adam Grant noted that great many things of any consequence obey the Inverted-U curve: “Across many domains of psychology, one finds that X increases $\mathrm{Y}$ to a point, and then it decreases $\mathrm{Y}$... There is no such thing as an unmitigated good. All positive traits, states, and experiences have costs that at high levels may begin to outweigh their benefits." 242 The concept of the inverted-U curve is closely related to the economic law of diminishing marginal utility, ${ }^{243}$ which is applicable in the case of government regulations as well: For example, if laws are introduced to a state of complete anarchy, some sense of order may be restored so long as the laws are efficiently enforced. ${ }^{244} \mathrm{By}$

241 M. Gladwell, David and Goliath: Underdogs, Misfits, and the Art of Batting Giants, (London: Little Brown \& Company, 2013), at p. 52.

242 B. SCHWARTZ \& A. GRANT, "Too Much of a Good Thing: The Challenges and Opportunity of the Inverted U," Perspectives on Psychological Science 6(1) (2011): 61-76, as cited by M. GLADwELL, David and Goliath: Underdogs, Misfits, and the Art of Batting Giants, (London: Little Brown \& Company, 2013), at p. 52.

243 J.D. Gwartney, R.L. Stroup, R.S. Sobel \& D.A. MAcPherson, Economics: Private and Public Choice, (Ohio: Cengage Learning, 2008) at p. 45 (noting the following: "The law of diminishing marginal utility states that the marginal (additional) utility derived from consuming successive units of a product will eventually decline as the rate of consumption increases. For example, the law says that even though you might like ice cream, your marginal satisfaction from additional ice cream will eventually decline as you eat more and more of it.").

244 The absence of law or government does not, however, mean that there will be no order: "In a world with no law and rudimentary government, order of some sort would exist. So much is clear from anthropological studies. The order would appear as routine compliance with social norms and the collective infliction of sanctions on those 
collecting taxes from the people and enhancing these enforcement measures, the anarchy could transition into some form of governance adhering to the principle of social contract. However, when there is too much law or when enforcement becomes excessive (and people are forced to pay more and more taxes as a result), the decent down the Inverted-U curve begins and additional laws or enforcements thereafter could be more detrimental to maintaining that sense of order and utility that the law had brought about initially. This is the point where government regulations start interfering with our normative criterion of personal autonomy and freedom of choice without offering meaningful returns that would justify the sacrifice of the people. ${ }^{245}$ This could potentially lead to disobedience of authority, a revolution, and possibly a return to the initial state of anarchy. The aforementioned expectations gap between what people expect from their governments and what they currently perceive to be getting could be an early indication that we are nearing or perhaps we are even past the apex of the Inverted-U curve, though this could be debated in perpetuity. On this matter, historian Tony Judt notes the following: "The only thing worse than too much government is too little: in failed states, people suffer at least as much violence and injustice as under authoritarian rule, and in addition their trains do not run on time."246

In the context of reducing labor exploitations in the global supply chain, governments could, in theory, create more draconian laws that provide harsh and strict incentives for businesses to think twice before supplying components from questionable suppliers or ban consumers from buying clothes that have been made in sweatshops all together: For example, governments can significantly increase the fines that they would impose on businesses found to be in violation of labor laws, but this thesis has already presented two cases - the DRC case and the Dutch increasing their fines for labor law violations - where imposing harsher punishments did not necessarily address the underlying exploitation nor did they increase the capabilities of the workers. ${ }^{247}$

In sum, the fundamental problem with these draconian measures is that they infringe upon various freedoms, not to mention the increased difficulty of enforcing and implementing such measures. The lesson to be extrapolated from the Inverted- $U$ curve is that governments must be careful not to overregulate but still make sure that they have mini-

who violate them, including stigmatization, of the deviant and ostracism of the incorrigible." See, E.A. POSNER, Law and Social Norms, (Cambridge: Harvard University Press, 2000), at p. 3.

245 Lochner v. New York, 198 U.S. 45 (1905) (holding, at the time, that "common law rights to property and contractual autonomy could not be overridden by legislative attempts to regulate working hours and conditions, such as minimum wages); see also, P. Alston, Labour Rights As Human Rights: Collected Courses of the Academy of European Law, (Oxford: Oxford University Press, 2005), at p. 4 (noting how the laws and judicial interpretation has changed since Lochner, where governments are more willing to infringe upon contractual freedoms for the sake of ensuring minimum safety nets); S. DEAKIN, "Contracts and Capabilities: An Evolutionary Perspective on the AutonomyPaternalism Debate," Erasmus Law Review 3(2) (2010), at p. 141 (commenting that while state interventions may seem to be the dominant force in this arena, it is actually the market forces and the business interest in profit maximization that is actually the dominant force); see also, W. VAN BOOM, "Introduction," Workshop on Juxtaposing Autonomy and Paternalism in Private Law, Erasmus University, Rotterdam (25 February 2010) (noting that "legal systems of western liberal democracies contain innumerable paternalistic rules and doctrines.”).

246 T. JuDT, Ill Fares the Land, (New York: Penguin, 2010), at p. 145.

247 As an interesting addition to this discussion, it is worth mentioning here that the fine imposed for a wage related violations in the Netherlands $(€ 6,700)$ is significantly higher than the fine imposed for wage violations in New York $(\$ 1,000)$. Using today's conversion rate (10 February 2014) $€ 6,700$ amounts to roughly $\$ 9,000$. However, the higher fines have not necessarily deterred labors from exploitative behaviors, above and beyond what is happening in New York. 
mum safety nets in place, all the while, being sensitive to the actual needs of their constituents. ${ }^{248}$

\section{B. Risk of Overregulation and When Laws Backfire}

One obvious problem with overregulation beyond the apex of the inverted-U curve is the legal pollution problem, which suggests that having too much law or making the law too dense and convoluted could not only be contrary to the aforementioned rule of law and Lord Mansfield's adage, but it would actually reduce the effectiveness of the law itself. ${ }^{249} \mathrm{~A}$ different kind of a problem that can occur as more and more laws are implemented comes back to the point that legislatures cannot predict with absolute certainty what the impact of even the most well intended law will be ex ante. Thus, the problem of overregulation and the problem of when the law backfires share a commonality in that they are both instances of when people would have been better off without certain laws coming into existence. For example, consider the following:

"L L Jabour law rules may allow employers scope to use self-employment, part-time work, fixed-term employment and temporary agency work in ways which avoid costs associated with the 'standard employment relationship' of permanent and full-time work. However, these laws... create divisions within the workforce between 'atypical' and 'standard' employment forms, may create new rigidities: in particular, atypical employment forms are associated with reduced training and lower levels of investment in human capital, so it is not clear that, overall, their encouragement via the legal system results in a net economic benefit. "250

Simon Deakin's point above can be illustrated through the Dutch legislature's recent attempt to incentivize companies to hire more permanent employees rather than temporarily or flexible workers. The Flexibility and Security Act [Wet flexibiliteit en zekerheid] or flexwet, as the Act is now referred to, created a variety of measures that the Dutch government believed would empower or help the flex workers; for example, by offering them transitional allowances [transitievergoeding] or by shortening the time that the employers have to decide whether to hire flexible workers on a more permanent basis. With regards to the latter measure, the rule on temporary workers used to be that if a flex worker was given 3 temporary contracts [tijdelijke contracten] or have been working for a particular employer for a peri-

L.C. BACKER, "Economic Globalization and the Rise of Efficient Systems of Global Private Lawmaking: WalMart as Global Legislator," University of Connecticut Law Review 39(4) (2007), at p. 4 (stating that "[t]he most successful producers of law are sensitive to their consumers, are efficient producers of reliable product that can be purchased, and can deliver stability, and production efficiencies, at a cost lower than their competitors.").

249 T. EhrLiCH, "Legal Pollution," New York Times Magazine (8 February 1976) as cited in G. TeubNER, "Juridification - Concepts, Aspects, Limits, Solutions," in Juridification of Social Spheres: A Comparative Analysis in the Areas of Labor, Corporate, Antitrust and Social Welfare Law, G. TEubner (ED.) (Berlin: Walter de Gruyter, 1987), at p. 1; see also, F.H. EASTERBROOK, "Cyberspace and the Law of the Horse," University of Chicago Legal Forum 207 (1996) (arguing against the increasing specialization and subdivision of laws - using examples of cyber law and what Gerhard Casper referred to as the 'law of horses' - and instead, suggesting that general rules can adequately address these 'special' situations); $f$. L. Lessing, "The Law of the Horse: What Cyberlaw Might Teach," Harvard Law Review 113 (1999): 501-546 (disagreeing with Easterbrook and emphasizing the importance of teaching law of cyberspace).

250 S. Deakin, J. Malmberg \& R. SARKar, "Do Labour Laws Increase Equality at the Expense of Higher Unemployment? The Experience of Six OECD Countries, 1970-2010," University of Cambridge Faculty of Law Legal Studies Research Paper Studies No. 11, (2014), at p. 2 (citing to the ILO's Philadelphia Declaration (1944) and World Bank's Doing Business in 2008); see also, World Bank, Doing Business in 2008 (Washington D.C.: World Bank, 2008); 
od of three years, the employer had to decide whether to hire them as a full time employee or they were forced to let the employee go. The new rule now pushed the employer's decision-making requirement up to 2 years, in other words, employers had to decide after only 2 years whether to convert a flex worker into a permanent employee. The assumption made by the Dutch legislatures here was that given the choice between having to let go of a flex worker that they liked or having to hire them, the employers would choose the latter rather than the former. Unfortunately, since the law has entered into force in July 2015, many flex workers claim that things have simply gotten worse, with many of them being fired after the two years, whereas in the old system, they would have been allowed to stay employed for at least one more year. ${ }^{251}$

While the aim of the flexwet, to close the gap between flex workers and permanent employees, ${ }^{252}$ was indeed well intended, the new law simply bred different ways in which companies went about circumventing the law, which ended up causing more harm to the very people that the law was attempting to empower. For example, some Dutch institutions came up with what is now referred to as the knutselcontracten or a hybrid/combination contract. $^{253}$ This is a type of a contract where an employer offers a permanent contract but for a job that is one day a week and for the rest of the week, this permanent contract is supplemented by series of temporary contracts. While activists have argued that this practice not only goes against the spirit of the new flexwet, but against some collective labor agreements [CAO's], they have failed to actually empower the flew workers that are either getting fired sooner or having to settle with hybrid contracts that simply does not offer the kind of protection that the law thought it would.

The impact of these failed legislations are long lasting. For example, Statistic Netherlands [Centraal Bureau voor de Statistiek] noted that one in five workers in the Netherlands now have some form of flexible employment contracts with that number steadily increasing with seven out of ten lowly educated workers finding only flex works in the last year. ${ }^{254}$ Flexible employment, while possibly beneficial for some, often comes with low job security, high work pressure, limited autonomy, and fewer opportunities for job training and professional development. Ultimately, the new Dutch flexwet legislation is yet another example of how even well-intended legislation, aimed at empowering and protecting workers by incentivizing businesses to hire more permanent workers, can backfire and cause significant unintended consequences. Examples of laws that intended to protect workers prone

251 NOS, "Hoe Flex is de Flexwet," (25 June 2015). Available at: http://nos.nl/op3/artikel/2043352-hoe-flex-is-deflexwet.html (last accessed 22 February 2016) (quoting Martin van Gelderen, an employment lawyer, as stating that many employers will simply let the old flex worker go and hire another, new flex worker instead ["De voortekenen zijn niet heel gunstig. Veel werkgevers laten weten dat als ze gedwongen worden al na twee jaar de keuze te maken, toch afscheid van die flexwerker te nemen en een nieuwe inburen."]);

252 J. ZWETSLOOT, "Universiteit ontduikt flexwet met 'knutselcontracten'," de Volkskrant (12 November 2015) Available at: http://www.volkskrant.nl/economie/universiteit-ontduikt-flexwet-met-knutselcontracten a 4184 222/ (last accessed 25 February 2016) (reporting the following: "Deze zogeheten 'flexwet' is een speerpunt van minister Lodewijk. Asscher van Sociale Zaken, die de groei van tijdelijke contracten wil stoppen en mensen in alle sectoren sneller aan een vaste baan wil belpen.").

253 J. ZWETSLOOT, "Universiteit ontduikt flexwet met 'knutselcontracten'," de Volkskerant (12 November 2015) Available at: http://www.volkskrant.nl/economie/universiteit-ontduikt-flexwet-met-knutselcontracten a 4184 222/ (last accessed 25 February 2016) (reporting that allowing every employee to request for flex work could "make it harder for those more in need of flexible working, increase risk of discrimination that could lead to more employment discrimination cases, and add unnecessary tape").

254 Centraal Bureau voor De Statistiek, "Dutch Labour Market Dynamics,” Press Release, (17 May 2013). 
to exploitation actually backfiring is somewhat more common than the general public realizes: For example, the increased popularity of flexible working hour legislations that aim to facilitate a more healthy work like balance have created series of various spillover effects in a number of other jurisdictions ${ }^{255}$ and the increasing trend of laws that "allow" workers to be labeled as "independent contractors" 256 rather than acknowledging them as full time employees, (a problem that will be elaborated in the next subsection) are creating a system in which workers and employees are losing more and more power, and thus autonomy and freedom of choice, which does not fit in with our normative framework.

This part of the subsection showed that there are times when some laws are better left unpromulgated using the Dutch flexwet example. The problem of overregulation and when laws backfire both originate from the fact that prior to implementation, legislatures cannot predict with absolute certainty what impact the law will have. This does not mean, however, that governments should always refrain from intervening, as the next part of this subsection will address.

\section{Risk of Underregulation and Collective Laissez-Faire}

From the Chicago school perspective, laws and regulations are generally perceived as detriments that unnecessarily tinker with the free market. ${ }^{257}$ So their response to concerns regarding overregulation or laws backfiring would simply be for governments to stop regulating and refrain from interfering. A proponent of this view, Otto Kahn-Freund coined the term "collective laissez-faire," 258 in asserting his case that government imposed labor laws, only play a minor role in the standing of labor rights. Kahn-Freund's contention was based on the underlying assumption that government regulations on this matter need not be excessive, given that laborers and unions have the incentive and the will to collectively bargain without external interventions. The added benefit of this regulation-free method, at least in theory according to Kahn-Freund, was that it would allow laborers and their employees to flexibly negotiate the ideal terms that they can both agree to without trampling on their freedom of choice and autonomy.

The fundamental problem with this claim, however, is that in jurisdictions where many of the sweatshops exist and where laborers are exploited, formation of a union or the collective bargaining process is outright prohibited. Even in the absence of such prohibitions, employers go out of their way to obstruct employees from unionizing. So while collective

S. TulETT, "Flexible Working Rights for All - Could They Backfire?," BBC (30 June 2014) Available at: http://www.bbc.com/news/business-26436131 (last accessed 25 February 2016) (reporting that allowing every employee to request for flex working schedule could "make it harder for those more in need of flexible working, increase risk of discrimination that could lead to more employment discrimination cases, and add unnecessary tape").

256 R.M. LOCKE, The Promise and Limitations of Private Power: Promoting Labor Standards in a Global Economy (Cambridge: Cambridge University Press, 2013), at p. 160 (observing that "[m]any Mexican electronics suppliers hire agency workers on multiple sequential short-term contracts so that workers fail to accumulate employment benefits afforded to full-time workers as required by the national labor code."). Locke notes that while there are various laws to prevent companies from circumventing these rules, it is often difficult to enforce. If anything, the original law that was meant to help workers have created a situation, a spillover of sorts, where workers are hired sequentially on the basis of short-term contracts or hired as mere contractors in the first places.

257 A.C.L. DAvieS, Perspectives on Labour Law, (Cambridge: Cambridge University Press, 2004), at p. 3.

258 O. KAHN-FreUnd, "Legal Framework," in The System of Industrial Relations in Great Britain: Its History, Law, and Institutions, A.D. FlaNDERS \& H.A. CLEGG (EDS.) (Oxford: Blackwell, 1964). 
laissez-faire may indeed be the right solution when there are healthy and strong unions already present protecting the rights of the laborers, the utility and the feasibility of KahnFreund idea is extremely limited in jurisdictions where the workers cannot unionize and there is a noticeable absence of other organizations that are supporting their interests. ${ }^{259}$ Furthermore, even if laws of developing countries change to allow for the formation of unions, there is no guarantee that the bargaining power of the newly formed unions will equal that of the businesses, which means that in certain cases, underregualtion and the collective laissez-faire approach pose serious risks to the empowerment of workers and the reduction of labor exploitation. While the focus of the two previous sections were on two relatively developed economies of New York and the Netherlands, the situation is more dire in developing economies where labor exploitation is more rampant, but regulations and enforcement measures are severely lacking: For example, according to a report conducted by journalist Michael Hobbes, Bangladesh only has 125 labor inspectors to protect the interests of their 75 million workers and Cambodian inspectors earn less than half of what an average garment worker makes, whose conditions the inspectors are actually supposed to be safeguarding. ${ }^{260}$ In these cases, more government intervention and increasing regulatory measures (i.e. increasing the number of the auditors or increasing their wages), could still bring about positive benefits that could outweigh their costs, meaning that in these jurisdictions are still to the left of the Inverted-U curve's apex.

While overregulation and laws backfiring raise their own set of problems, simply leaving it in the hands of the market, as already noted in the introduction, is not the ideal solution either. Having elaborated on the pitfalls of overregulation and underregulation, the next subsection will present another case study to show how the competence problem and the Goldilocks problem manifest themselves in reality and just how complicated of a task it is for governments and the courts to legislate or rule in a manner that reduces labor exploitation while empowering the workers. The following case study will also serve as yet another justification for this thesis to focusing its attention on the private sector that is more adaptable and flexible.

\subsubsection{Uberized Economy Case}

Uber, a company managing the ride-sharing app of the same name, and the legal battles that they are embroiled in worldwide is an interesting case study on how government interventions can not only produce problematic outcomes, but how the courts can be put between a rock and a hard place with no clear indication of the "right" answer. First of all, Uber is an app that allows users with a push of a button on their smartphones to get a ride from Uber drivers operating nearby. According to the company, Uber drivers are considered as independent contractors rather than Uber employees, thus illustrating Simon Deakin's point from before. The problem at the core of Uber's legal battle has to do with the fact that independent contractors - just like Dutch flex workers - are generally not entitled

259 After an illustrious career as a comparative law and labor law professor at Oxford, Otto Kahn-Freund passed in 1979 .

260 M. HobBEs, "The Myth of the Ethical Shopper," The Huffington Post, (2015). Available at: http://highline.huffing tonpost.com/ articles/en/the-myth-of-the-ethical-shopper/ (last accessed 16 July 2015). 
to benefits afforded to full time employees. ${ }^{261}$ This subsection will: a) lay out the problem that the independent contractor classification creates; b) describe the conflict between the highly rigid legal system and the emerging sharing economy; and finally, c) illustrate some of the relevant cases involving Uber and other apps of similar design and the difficulties that they impose upon the judicial system.

\section{A. Independent Contractor Classification as Labor Exploitation}

Former US Labor Secretary, Robert Reich, recently noted that the growth of the sharing economy and services like Uber is creating a problematic rise in the number of independent contractors that suffer from low job security and lack of social protections, which was also noted in the data published by Statistic Netherlands [Centraal Bureau voor de Statistiek]. ${ }^{262}$ In addition, Reich states the following about this emerging trend:

"This is the logical culmination of a process that began thirty years ago when corporations began turning over full-time jobs to temporary workers, independent contractors, free-lancers, and consultants. It was a way to shift risks and uncertainties onto the workers - work that might entail more hours than planned for, or was more stressful than expected. And a way to circumvent labor laws that set minimal standards for wages, hours, and working conditions. And that enabled employees to join together to bargain for better pay and benefits. ${ }^{, 263}$

The crux of his argument is essentially the very point that Deakin raised earlier and it lies in the fact that independent contractors, free-lancers, and other temporary workers provide businesses not only with flexibility, but ways to circumvent laws aimed at holding businesses accountable. If by simply classifying workers as independent contractors, employers can avoid laws aimed to protect employees, Reich asks rhetorically, what the point of having labor/employment laws are in the first place.

While businesses like Uber have attempted to persuade their drivers that being an independent contractor offers them flexibility and personal autonomy, many independent contractors have a hard time accepting the fact that as contractors, they lack many of the employment benefits and protections that they would otherwise be entitled to and labor activ-

R. REICH, "Why We're All Becoming Independent Contractors," The Huffington Post, (22 February 2015). Available at: www.huffingtonpost.com/robert-reich/why-were-all-becoming-independent-contractors_b_6731760.html (last accessed 22 February 2015) (noting that "Social Security, a 40-hour workweek with time-and-a-half for overtime, worker health and safety, worker's compensation if injured on the job, family and medical leave, minimum wage, pension protection, unemployment insurance, protection against racial or gender discrimination, and the right to bargain collectively"); see also, U.S. DEPARTMENT OF LABOR WAGE AND HOUR Division," "The Application of the Fair Labor Standards Act's 'Suffer or Permit' Standard in the Identification of Employees Who Are Misclassified as Independent Contractors" (15 July 2015). Available at: http://www.dol.gov/whd/workers/Misclassification/AI2015_1.pdf (last accessed 29 July 2015), at p. 1 (noting that "[w]hen employers improperly classify employees as independent contractors, the employees may not receive important workplace protections such as the minimum wage, overtime compensation, unemployment insurance, and workers' compensation.”).

262 R. REICH, "Why We're All Becoming Independent Contractors," The Huffington Post, (22 February 2015). Available at: www.huffingtonpost.com/robert-reich/why-were-all-becoming-independent-contractors_b_6731760.html (last accessed 22 February 2015) (stating that "[t]he rise of 'independent contractors' is the most significant legal trend in the American workforce - contributing directly to low pay, irregular hours, and job insecurity.").

263 R. REICH, "The Sharing Economy is Hurting Us Backwards," Salon, (4 February 2015). Available at: www.salon.com/2015/02/04/robert_reich_the_sharing_economy_is_hurtling_us_backwards_partner/?utm_sour $\mathrm{ce}=$ facebook\&utm_medium $=$ socialflow (last accessed 9 February 2015). 
ists believe that this is just another form of labor exploitation. ${ }^{264}$ The emergence of the sharing economy has brought to the forefront the problem of laws distinguishing employees from temporary workers, where business have a clear and vested interest in labeling their workers as contractors, rather than employees.

\section{B. Labor/Employment Law v. Sharing Economy}

Distinguishing independent contractors from employees is a particularly sensitive issue for businesses in the sharing economy as their business model relies heavily on contractors, temporary workers, or to bring back the Dutch term, flex workers. As the sharing economy continues to grow, we are witnessing increasing friction between this new economy and the law, which once again substantiates the aforementioned claim that there is a mismatch between highly legalistic and rigid enforcement practices of governments and their regulation and the dynamic and evolving reality of global business in reality. Leaving aside the legal issue of distinguishing employees from independent contractors for the moment, consider the demand for these services that rely on flexible workers: Uber, for example, is a collective public response for addressing the inadequacies of the public transportation system and traditional taxis that are often regulated by the government: "[D]isruptors [like Uber] challenge the way these powerful and lucrative businesses have operated for a very long time" 265 by offering the consumers an arguably better alternative (or at least another option to complement the existing system).

In short, services like Uber offer a great benefit to the general public. While this alone does not justify the exploitation of the drivers, it is worth noting that there are drivers that actually enjoy driving for Uber because it allows them to make extra income at a relatively flexible schedule. Thus, an argument could be made that this is capability-enhancing for some drivers. Many legislators, however, appear to be more apprehensive of this emerging trend, opting instead to restrain companies like Uber that compete with the taxi industry. ${ }^{266}$ The government's key argument is based on their interest to protect the passengers by regulating these emerging business models as if they are traditional for-hire transportation vehicles. The drivers that work for the Ubers of the world also want to be paid adequately and protected, but doing so would effectively neuter Uber's business model and its service will likely fail to function if their drivers were deemed as employees rather than independent contractors.

Whether one supports the government's view, Uber's view, or the drivers' view, each of the views have their merits and flaws. Ultimately, the issue of regulating the shared economy is about appropriately balancing governmental regulation, innovation and technology,

264 M. ISAAC \& N. SINGER, “California Says Uber Driver is Employee, Not a Contractor,” The New York Times, (17 June 2015). Available at: http://www.nytimes.com/2015/06/18/business/uber-contests-california-labor-rulingthat-says-drivers-should-be-employees.html (last accessed 22 July 2015) (reporting that labor activitsts believe companies like Uber are exploiting these workers by labeling them as contractors, because doing so allows them to minimize costs while maintaining “considerable control over drivers' workplace behavior.”).

265 R. Botsman, “Why the Law Won't Stop Uber,” Financial Review, (11 July 2014). Available at: http://m.afr.com/ p/boss/why_the_law_won_stop_uber_bQzVtcCASGPKkEl2lqDItN (last accessed 6 January 2015).

266 B.R. SMiTH, "City Hall and Uber Clash in Struggle Over New York Streets," The New York Times, (16 July 2015). Available at: http://www.nytimes.com/2015/07/17/nyregion/city-hall-and-uber-clash-in-struggle-over-new-yorkstreets.html (last accessed 22 July 2015) (reporting that the reason for New York City Mayor Bill de Blasio's reluctance to accept Uber is due to the fact that is "appears to be clogging Manhattan traffic"). The article also reports about how the "yellow-cab industry" was one of Mayor de Blasio's "most prolific campaign contributors."). 
worker empowerment, and labor protection all mashed into one big conflagration with each party believing that they are in the right. The problem is that this fire is spreading as Uber is going global, along with their legal problems, which is creating a very difficult situation for many governments. ${ }^{267}$

\section{Uber's Legal Battles}

Uber's legal battles, especially in its "home state" of California, perfectly illustrate the government's competence problem and the Goldilocks problem as described in Subsections 2.3.1 and 2.3.2. The main legal issues for Uber comes down to two important questions: 1) Is Uber a "for-hire" transportation company or merely a technology company that offers an innovative app; and 2) are Uber drivers employees or independent contractors? With regards to the first question, in July of 2015, Administrative Law Judge Robert Mason of the California Public Utilities Commission answered that Uber is more than just a technology company and in ruling so, decided to fine Uber $\$ 7.3$ million and ordered their operations to be suspended in California on the basis that Uber, as a for-hire transportation service has failed to comply with state laws "designed to ensure that drivers are doling out rides fairly to all passengers." 268 In other words, California Public Utilities Commission categorized Uber, not just as a tech company offering an app, but a company that offers traditional transportation services. Accordingly, the Utilities Commission deemed that Uber must obey and comply with the various laws regulating for-hire transpiration services.

With regards to the second question of whether Uber drivers ought to be classified as employees or independent contractors, the California Labor Commission recently hinted that Uber drivers ought to be classified as employees and not as independent contractors. ${ }^{269}$ In Uber $v$. Berwick, the Labor Commission of the State of the California awarded Barbara Berwick, a former Uber driver, compensation for about 470 hours of work driving for Uber. ${ }^{270}$ The relevant law at the center of the case was California Labor Code \$2802, which requires an employer to indemnify or reimburse an employee for necessary expenses in order for the employee to discharge his or her duties, including reimbursements for toll charges and taxes incurred while discharging a service for the employer. Thus, Berwick's claim - that Uber should reimburse her for the costs she incurred as an Uber driver (plus interests) - hinged on the assumption that she was actually an Uber employee and not an independent contractor.

L.J. Nelson, A. Chang \& P. Dave, "Uber Should be Suspended in California and Fined $\$ 7.3$ million, Judge Says," Los Angeles Times, (15 July 2015). Available at: http://www.latimes.com/business/la-fi-uber-suspended20150715-story.html\#page=1 (last accessed 22 July 2015) (reporting that "[a]round the world, cities have grappled with the incursion of Uber and its competitors. There have been lawsuits in San Francisco and bans on the app across Spain, roadway-blocking driver protests in London and vehicles overturned in Paris.").

268 L.J. Nelson, A. Chang \& P. DAve, "Uber Should be Suspended in California and Fined \$7.3 million, Judge Says," Los Angeles Times, (15 July 2015). Available at: http://www.latimes.com/business/la-fi-uber-suspended20150715-story.html\#page=1 (last accessed 22 July 2015).

269 M. ISAAC \& N. SINGER, "California Says Uber Driver is Employee, Not a Contractor," The New York Times, (17 June 2015). Available at: http://www.nytimes.com/2015/06/18/business/uber-contests-california-labor-rulingthat-says-drivers-should-be-employees.html (last accessed 22 July 2015).

270 Before the Labor Commissioner of the State of California, Barbara Ann Berwick v. Uber Technologies, Inc. et al. Case No. 11-46739 EK (3 June 2015). After the decision by the Labor Commissioner, Uber promptly filed for an appeal on 16 June 2015 with the Superior Court of California (County of San Francisco) CGC-15-546378. 
During the proceedings before the Commission, Uber insisted that Berwick was merely an independent contractor, which meant that she was not entitled to any reimbursements or compensation. ${ }^{271}$ In determining the question of employer or independent contractor, the Labor Commission relied on the precedent established by the California Supreme Court in S.G. Borello \& Sons, Inc. v. Department of Industrial Relations, which created a list of various factors the courts ought to consider in order to determine the nature of the employment relationship, including but not limited to factors such as the length of time for which the service was provided, method of payment, and whether the work was done under the direction of the principal or by a specialist without supervision. ${ }^{272}$ While multiple factors must be taken into account, one factor has received more attention above others in recent years, which is the question of whether the employer exerted or had the right to exercise control over the worker.

This attention on the sole factor of control, however, is somewhat misguided according to the US Department of Labor, which admonished in a recent statement that "although the common law control test was the prevalent test for determining whether an employment relationship existed at the time that the FLSA [Fair Labor Standard Act] was enacted, Congress rejected the common law control test in drafting the FLSA." 273 Adhering to this standard, the California Court of Appeals in Yellow Cab Cooperative v. Workers Compensation Appeals Board, a case similar to Berwick, which was also cited by the Labor Commission, held that workers that solicited potential clients on behalf of a delivery service ought to be classified as employees even though there was no element of actual control. The court argued that the solicitors must be considered as employees even in the "absence of control over the details," because "an employee employer relationship will be found if the [Defendants] retain pervasive control over the operation as a whole, the worker's duties are an integral part of the operation, and the nature of the work makes detailed control unnecessary." 274

Fighting an uphill battle in light of these precedents, Uber's Product Manager Brian Tolkin reiterated during the Berwick pleading that Uber is merely "a technological platform, a smart phone application that private vehicles drivers ('Transportation Providers') and passengers use to facilitate private transactions." 275 Tolkin continued that Uber also does not "exert any control over the hours [their drivers] worked" nor are there "minimum number or required trips" for the drivers. ${ }^{276}$ The Law Commission did not find these ar-

271 Before the Labor Commissioner of the State of California, Barbara Ann Berwick v. Uber Technologies, Inc. et al. Case No. 11-46739 EK (3 June 2015), at p. 6.

272 S.G. Borello \& Sons, Inc. v. Department of Industrial Relations, 48 Cal. 3d 341, (1989). This "multi-factor test" is the standard test for establishing an employment relationship not just in California, but in most other States and event abroad. See e.g. Chandler v. Cape Plc. [2012] EWCA Civ 525.

273 U.S. Department of LABOR WAGE AND Hour Division, "The Application of the Fair Labor Standards Act's 'Suffer or Permit' Standard in the Identification of Employees Who Are Misclassified as Independent Contractors," (15 July 2015). Available at: http://www.dol.gov/whd/workers/Misclassification/AI-2015_1.pdf (last accessed 29 July 2015), at pp. 1-2 (citing to Walling v. Portland Terminal Co., 330 U.S. 148, $150-51$ (1947) and U.S. $v$. Rosenwasser, 323 U.S. 360, 362-63 (1945)).

274 Yellow Cab Cooperative v. Workers Compensation Appeals Board, 226 Cal.App.3d (1991).

275 Before the Labor Commissioner of the State of California, Barbara Ann Berwick v. Uber Technologies, Inc. et al. Case No. 11-46739 EK (3 June 2015), at pp. 4-5.

276 Before the Labor Commissioner of the State of California, Barbara Ann Berwick v. Uber Technologies, Inc. et al. Case No. 11-46739 EK (3 June 2015), at pp. 4-5. 
guments convincing, citing to Borello that it is "not necessary that a principal exercise complete control over a worker's activities in order for that worker to be an employee." 277 In addition, the Labor Commission was quick to dismiss Uber's claim that they are nothing more than a "neutral technological platform, designed simply to enable drivers and passengers to transact the business of transportation," by citing to the fact that Uber "vet[s] prospective drivers," "controls the tools the drivers use by requiring that the driver's register their vehicle with Uber and pass background checks," and so forth. ${ }^{278}$ Taking into account these factors, the Law Commission declared that Barbara Berwick was indeed an employee of Uber and thus should be reimbursed for expenses (along with interests) in accordance with California Labor Code $\$ 2802$.

It is worth mentioning here that the Labor Commission's ruling on Berwick, unlike a court decision, cannot be used as a precedent as the ruling by the Commission applies only to Berwick. This non-binding nature of the Commission's rulings can be illustrated by juxtaposing the Berwick case to an earlier case by the same Commission in Alatraqchi v. Uber Technologies that was decided in 2012. ${ }^{279}$ In Alatraqchi, the same California Labor Commission - albeit with a different hearing officer - determined that Uber was just a technology company, and that their drivers were independent contractors based on various factors: including, but not limited to the fact that the drivers can set their own working hours, the drivers did not have their work supervised by Uber, and that the drivers were not paid until they submitted their invoice to Uber. Again, this case did not set a binding precedent as the ruling by the Labor Commission only applied to the parties involved in the hearing, but it is interesting to see how two hearing officers working for the same institution (California Labor Commission) reached almost antithetical conclusions based on very similar circumstances. $^{280}$

What is even more concerning is the fact that Berwick and Alatraqchi are rather specific examples of how not only the California legislatures, but the judiciary, can sometimes be poorly-equipped to handle "innovative" changes taking place such as the emergence of the sharing economy, thus validating the competence problem presented in Subsection 2.3.1. While the US Department of Labor has attempted to standardize and clarify its stance on the employee/independent contractor distinction by stating that "most workers are employees under the FLSA's broad definitions," 281 there is still plenty of lingering confusion

Before the Labor Commissioner of the State of California, Barbara Ann Berwick v. Uber Technologies, Inc. et al. Case No. 11-46739 EK (3 June 2015), at p. 8 (citing to Borello, supra, at 355-360 that " $\mathrm{t}]$ he minimal degree of control that the employer exercised over the details of the work was not considered dispositive because the work did not require a high degree of skill and it was an integral part of the employer's business. The employer was thus determined to be exercising all necessary control over the operation as a whole.").

278 Before the Labor Commissioner of the State of California, Barbara Ann Berwick v. Uber Technologies, Inc. et al. Case No. 11-46739 EK (3 June 2015), at p. 9.

279 Before the Labor Commissioner of the State of California, Alatraqchi v. Uber Technologies, Inc., Case No. 11-42020 CT (1 August, 2012).

280 For what it is worth, California District Court Judge Edward Chen noted in response to the Labor Commission's decision in Alatraqchi to call services like Uber or Lyft as nothing more than a technology company as "plainly wrong" and "fatally flawed." See e.g. Patrick Cotter et al. v. Lyft Inc. et al., U.S. District Court for the Northern District of California, Case Number 3:13-cv-04065, Order Denying Cross-Motions for Summary Judgment, (11 March 2015).

281 U.S. Department of Labor Wage and Hour Division, “The Application of the Fair Labor Standards Act's 'Suffer or Permit' Standard in the Identification of Employees Who Are Misclassified as Independent Contractors," (15 July 2015). Available at: http://www.dol.gov/whd/workers/Misclassification/AI-2015_1.pdf (last 
and uncertainty. ${ }^{282}$ US Department of Labor's stance might curve the growing trend of companies increasingly characterizing their workers as contractors, but it remains unseen whether this guidance alone will shift the trend enough to quell Secretary Reich's concerns.

While various labor laws serve a valid purpose, the attempt to label Uber in the same category as a traditional for-hire transportation service, erodes the unique benefits that Uber offers to the general public and therein lies our conflict and the substantiation of the Goldilocks problem presented in Subsection 2.3.1.283 The current attempt by regulators to suppress the growing expansion of Uber, as some would argue, is a very necessary step in order to protect the rights of the Uber drivers and other independent contractors operating within the sharing economy. Others see this as an unnecessary intervention by the government that stifles a growing industry that enables people with free time to become drivers to make extra income, thus enhancing their capabilities. It is quite difficult to conclude that one side of the argument is more right than the other given that both arguments could be said to be capability-enhancing.

Whichever side one falls into, the main takeaway from this subsection is that the existing system of governance, its regulatory framework, and the judicial system is poorly equipped to understand and properly handle the emerging sharing economy: As Senator Mark R. Warner (D-VA) noted, "[the Berwick] ruling from the California labor regulators demonstrates why federal policy makers need to re-examine the $20^{\text {th }}$ century definitions and employment classification we're attempting to apply to a $21^{\text {st }}$ century work force." 284 In addition, the New York City Taxi Commissioner's statement noted that when it comes to the emergence of Uber and its impact on the city of New York, "[w]e're seeing unprecedented growth... [and] it's difficult to study anything when the landscape is changing so dramatically and so quickly." ${ }^{285}$ In other words, while lawmakers and judges are trying to

accessed 29 July 2015), at p. 15 (adding that the courts ought to bear in mind the "very broad definition of employment under the FLSA as 'to suffer or permit to work' and the Act's intended expansive coverage for workers must be considered when applying the economic realities factors to determine whether a worker is an employee or an independent contractor.").

282 Part of the lingering confusion has to do with the nature of the multifactor test that the courts use: "the multifactorial 'economic realities' test, which focuses on whether the worker is economically dependent on the employer or in business for him or herself... The factors should not be analyzed mechanically or in a vacuum, and no single factor, including control, should be over-emphasized"; see, U.S. DEPARTMENT OF LABOR WAGE AND HOur Division, “The Application of the Fair Labor Standards Act's 'Suffer or Permit' Standard in the Identification of Employees Who Are Misclassified as Independent Contractors," (15 July 2015). Available at: http://www.dol.gov/whd/workers/Misclassification/AI-2015_1.pdf (last accessed 29 July 2015), at p. 2, 15; see also, Tony \& Susan Alamo Foundation v. Secretary of Labor, 471 U.S. 290 (1985) (establishing the employment test under the Fair Labor Standards Act).

283 R. Botsman, “Why the Law Won't Stop Uber,” Financial Review, (11 July 2014). Available at: http://m.afr.com/ p/boss/why_the_law_won_stop_uber_bQzVtcCASGPKkEl2lqDItN (last accessed 6 January 2015) (observing that " $[\mathrm{t}]$ he history of the car shows how a new technology fundamentally changes the way people do things and how policymakers and regulators are faced with the vexing challenge of figuring out how to protect the public and resist pressure from players with a vested interest in protecting the status quo.").

284 M. ISAAC \& N. SINGER, "California Says Uber Driver is Employee, Not a Contractor," The New York Times, (17 June 2015). Available at: http://www.nytimes.com/2015/06/18/business/uber-contests-california-labor-rulingthat-says-drivers-should-be-employees.html (last accessed 22 July 2015).

285 B.R. SMiTH, "City Hall and Uber Clash in Struggle Over New York Streets," The New York Times, (16 July 2015). Available at: http://www.nytimes.com/2015/07/17/nyregion/city-hall-and-uber-clash-in-struggle-over-newyork-streets.html (last accessed 22 July 2015) (quoting Meera Joshi, New York City's Taxi Commissioner speaking about New York City Mayor de Blasio's attempt to place a cap on Uber's growth and relying on traffic studies to suggest that Uber leads to congestion and slower traffic speeds). 
figure out a solution for this conundrum, businesses are pushing forward. Moreover, while the lawmakers and our courts are playing catch up, disruptors like Uber are aggressively entering into new markets abroad with reckless disregard for the legal chaos it is creating. ${ }^{286}$

As Rachel Botsman notes, "ultimately, regulation should enable innovation that disrupts a market for the benefit of the majority," 287 but there are reasons to doubt whether our legislators are up to for this task because the Uber case presents a predicament for the governments: Should they or should they not meddle? If they do, how should they do so in a way that actually protects or empowers workers, while still trying to not neuter this growing market? Is there a way to please everyone or is this a zero-sum game? While the proponents of the sharing economy like Botsman believe in the possibility of technology, labor advocates like Reich see the sharing economy as a problem, stating that the Uberized sharing economy is operating outside the labor laws to the detriment of many workers. ${ }^{288}$ The ideal scenario would be to enable companies like Uber to continue its services while empowering their drivers, but it remains to be seen, whether governments and courts can present a solution that would meet both of these criteria. According to California District Court Judge Edward Chen, who is presiding over one of the case against Lyft - Uber's main competitor - noted that the courts currently do not possess the prerequisite competence to resolve this matter in a satisfactory manner:

"As should now be clear, the jury in this case will be handed a square peg and asked to choose between two round holes. The test the California courts have developed over the $20^{\text {th }}$ Century for classifying workers isn't very belpful in addressing this 21st Century problem. Some factors point in one direction, some point in the other, and some are ambiguous. Perhaps Lyft drivers who work more than a certain number of hours should be employees while the others should be independent contractors. Or perbaps Lyft drivers should be considered a new category of worker altogether, requiring a different set of protections. But absent legislative intervention, California's outmoded test for classifying workers will apply in cases like this." 289

So Judge Chen is left wanting and waiting for the legislatures to update the law so that the benefits of the sharing economy can be preserved, while at the same time, ensuring that businesses are prevented from exploiting independent contractors, against the spirit of labor laws. This is the real life manifestation of the Goldilocks problem and substantiation to the competence problem that governments face.

L.J. Nelson, A. Chang \& P. Dave, "Uber Should be Suspended in California and Fined $\$ 7.3$ million, Judge Says," Los Angeles Times, (15 July 2015). Available at: http://www.latimes.com/business/la-fi-uber-suspended20150715-story.html\#page=1 (last accessed 22 July 2015) (repoting that "[Uber] has become known for aggressively barreling into new regions without much consideration for existing rules and norms, and has subsequently faced widespread pushback... More than a dozen lawsuits have been filed in recent months in countries across the continent, where some analysts say the company is in danger of being shut down or becoming so entangled in legislation as to be neutered.").

287 R. Botsman, “Why the Law Won’t Stop Uber,” Financial Review, (11 July 2014). Available at: http://m.afr.com/ p/boss/why_the_law_won_stop_uber_bQzVtcCASGPKkEl2lqDItN (last accessed 6 January 2015).

288 R. REICH, "Why We're All Becoming Independent Contractors," The Huffington Post, (22 February 2015). Available at: www.huffingtonpost.com/robert-reich/why-were-all-becoming-independent-contractors_b_6731760.html (last accessed 22 February 2015).

289 Patrick Cotter et al. v. Lyft Inc. et al., U.S. District Court for the Northern District of California, Case Number 3:13cv-04065, Order Denying Cross-Motions for Summary Judgment, (11 March 2015), at p. 19. 
In attempting to predict which way the wind will blow, two factors are worth bearing in mind: First, there are two federal class action lawsuits currently pending (one against Uber and one against Lyft) in the Northern District of California in addition to the Berwick appeal. ${ }^{290}$ Depending on the outcome of these cases, companies invested in the sharing economy like Uber, Lyft, Instacart, Homejoy, and Postmates (just to name a few) that rely on independent contractors to deliver groceries, run errands, lend tools to neighbors, or clean houses must proceed with caution as new legislations and precedents can - for better or for worse - effectively dismantle the sharing economy (sometimes also referred to as the gig economy). The second point worth bearing in mind is that many of the recent cases where the question of the employment relationship was at issue, the courts have, more often than not, held the workers to be employees rather than independent contractors by holding that the term employment should be considered rather broadly. ${ }^{291}$ This trend is not just limited to the state of California, but elsewhere like in the UK, where the London Employment Tribunal recently held that 40,000 Uber drivers operating in the UK should be classified as employees and be paid the national living wage. ${ }^{292}$ This test case, initiated by GMB union on behalf of two Uber drivers - highlighted the argument that sharing economy, however convenient for the end-users may be perpetuating worker exploitation and tax avoidance, which in the end only benefits multinational corporations. ${ }^{293}$

Taking into consideration the aforementioned statement released by the US Department of Labor about how most workers are considered as employees under the FLSA's broad definitions facts seem to suggest that the sharing economy's growth could face a legal setback in the near future. While this might be promising series of developments for labor law advocates and former Labor Secretaries, their optimism must be curbed as "[u]nder California law, if reasonable people could differ on whether a worker is an employee or an independent contractor based on the evidence in the case, the question is not for a court to decide [but for] ... the jury." ${ }^{294}$ The irony of it all would be that the members of the jury will likely rely on services like Uber and Lyft - especially in California - to get to court.

In sum, the discussion over how governments and the judicial system is dealing with the Uberized economy evidences the reality that even when governments, or their judiciary, mean well and attempt to improve the working conditions of the workers, similar to the problem of the Dutch flexwet case, there are no guarantees that the law will solve the problem. When dealing with disruptive issues like the sharing economy and whether to classify Uber drivers as independent contractors or not, the legal system is left attempting to cram a

O'Connor v. Uber Technologies, Inc., Case No. 13-cv-03826 and Cotter v. Lyff, Inc., Case No. 13-cv-04065.

291 See e.g. Patricke Cotter et al. v. Lyft Inc. et al., U.S. District Court for the Northern District of California, Case Number 3:13-cv-04065, Order Denying Cross-Motions for Summary Judgment, (11 March 2015), at p. 17 (citing to JKH Enterprises v. Department of Industrial Relations, $48 \mathrm{Cal}$. Rptr. 3d at 568-70 and Air Couriers International v. Employment Development Department, 59 Cal. Rptr. 3d at 38-39, which were two cases the courts held that freelance package delivery drivers ought to be classified as employees).

292 S. HiCKEY, "Uber Tribunal Judges Criticise 'Fictions' and 'Twisted Language'," The Guardian, (28 October 2016). Available at: https://www.theguardian.com/technology/2016/oct/28/uber-tribunal-judges-fictions-twistedlanguage-appeal (last accessed 30 October 2016).

293 J. KOLLEWE, “Uber Awaits Tribunal Ruling Over Drivers' Status as Wrokers," The Guardian, (28 October 2016). Available at: https://www.theguardian.com/business/2016/oct/28/uber-awaits-tribunal-ruling-over-driversstatus-as-workers (last accessed 30 October 2016).

294 See Angelotti v. Walt Disney Co., 121 Cal. Rptr. 3d 863, 870 (Ct. App. 2011). 
square peg into a circular hole. The reality of the world in which we reside in is that it is so complex that the governments' approach to reducing labor exploitations could end up actually hurting the workers and inhibiting their capabilities. In this sea of uncertainty, one thing is for sure: The dilemma over when and how governments can help the exploited independent contractors is far more complicated and difficult to figure out than the one Goldilocks faced in her fable.

In concluding this section on the problems with the current labor/employment approach and the various limitations of the public sector, one could argue that the existing laws - especially in the more developed economies - are reaching near the apex of the Inverted-U curve, where simply increasing the fines for violations is not necessarily adding to the deterrence effect of the laws. Accordingly, the main take away from this section is that even when there is indeed a problem, the default solution should not necessarily be to create more and more laws or to simply increase the fines and punishments in the hopes that there will be a corresponding decrease in the number of violations. ${ }^{295}$ The Inverted-U curve and a number of case studies have shown that this is often not the case. Moreover, the same can be said in terms of how governments can deal with the problem of empowering independent contractors and flex workers, which is to suggest that governments should resist designating all Uber and Lyft drivers as employees rather than independent contractors, as such a declaration could have unintended consequences. ${ }^{296}$

Therefore, rather than risking overregulation or dealing with the unintended consequences, one possible solution would be for governments to avoid making drastic and sweeping changes across the board. Instead, governments can take the path of cautious incrementalism, ${ }^{297}$ as illustrated by the approach the Californian authorities have taken; choosing to deal with this issue on a case-by-case basis and taking into careful consideration circumstantial factors specific to each case. The private sector can support this path of cautious incrementalism, by resisting the urge to demand that governments create more laws or various judicial bodies to rule definitively on a particular issue in a manner that creates binding precedents that could lock in the unintended consequences.

R.J. SHILler, Irrational Exuberance, (Princeton: Princeton University Press, 2015), at p. 227 (stating that "new government agencies to deal with systematic risk... are not automatically solved by these new agencies," because "[b]ureaucratic organizations may find it hard to muster the courage and conviction to deal with them.").

296 S. Deakin, J. Malmberg \& R. SARkAR, "Do Labour Laws Increase Equality at the Expense of Higher Unemployment? The Experience of Six OECD Countries, 1970-2010," University of Cambridge Faculty of Law Legal Studies Research Paper Studies No. 11, (2014), at p. 26 (stating that it is difficult to produce "empirical evidence to support or refute hypotheses concerning the economic effects of labour laws.").

297 M.C. Nussbaum, Creating Capabilities: The Human Development Approach, (Cambridge: Belknap Harvard, 2013), at p. 175-6 (defining cautious incrementalism as the process of "building up a structure through the years, as one case advances upon, or confirms and deepens the insights of, another case. Often the contours of an abstractly specified right are exceedingly unclear at the outset," but as "time goes on and new cases come forward, we understand more clearly what we are protecting, and the protection is nailed down more firmly."). 


\subsection{CONCLUSION: LABOR/EMPLOYMENT LAWS ARE NECESSARY, BUT NOT ENOUGH}

This chapter first presented how the governments of New York and the Netherlands deal with the problem of labor exploitations taking place within their jurisdictions in Sections 2.1 and 2.2. These two sections evidenced that the approach that these two jurisdictions take to address the labor exploitation problem within their jurisdiction - by imposing minimum protections for the workers and enforcing them through fines and randomized sweeps by task forces - is remarkably similar. Based on the observations made in these two sections, this chapter reached a preliminary conclusion that governments, their labor/employment laws, and their enforcement measures are essential to deterring businesses from exploiting their workers. ${ }^{298}$

However, in pointing out some of the inherent problems and limitations with the existing system of governance in Section 2.3, this chapter also suggested that the private sector's reliance on their governments cannot be absolute. This is due to the fact that while the central aim of labor/employment laws is to create a level playing field between workers and their employers thus reduce chances of labor exploitation, ${ }^{299}$ there are reasons to suspect that governments might not be able to effectively do so given their competence problem and their various conflicts of interests. This concern was substantiated by describing the very nature of the legislative process, the governments' tendency to prioritize economic indicators to measure their achievements, and the increasing symbiosis between lawmakers and lobbyists. As Lawrence Lessig noted, the reason why change at the governmental level is so sclerotic, is because money is so inherent and tied to the decisions that governments make and corporations are the ones with the money and thus, influence. ${ }^{300}$

Moreover, the limitations of governments and their regulatory measures were further showcased by figures of persisting labor exploitations even in developing economies such as New York and the Netherlands. These figures and surveys indicated that there are significant portions of the workforce that: 1) do not know about the protections that are afforded to them by law, 2) are afraid to voice their complaints for the fear of employer retaliation, and/or 3) simply deal with being exploited without raising a complaint because they lack better or meaningful alternatives. The solution to address the plight of laborers in

S. Deakin, J. MAlmberg \& R. SARKar, "Do Labour Laws Increase Equality at the Expense of Higher Unemployment? The Experience of Six OECD Countries, 1970-2010,” University of Cambridge Faculty of Law Legal Studies Research Paper Studies No. 11, (2014), at p. 1 (concluding that "worker protective labour laws in general... are positively correlated with equality" and that "[1]aws relating to working time and employee representation... have beneficial impacts on both efficiency and distribution."). This study used "longitudinal data on labour law in France, Germany, Japan, Sweden, the UK, and the US for the four decades after 1970, [to] estimate the impact of labour regulation on unemployment and equality, using labour's share of national income as a proxy for the latter... employ[ing] a dynamic panel data analysis which distinguishes between short-run and long-run effects of legal change.").

299 S. Deakin, J. Malmberg \& R. SARKar, "Do Labour Laws Increase Equality at the Expense of Higher Unemployment? The Experience of Six OECD Countries, 1970-2010," University of Cambridge Faculty of Law Legal Studies Research Paper Studies No. 11, (2014), at p. 1 (noting that "legal protection of workers is often justified on the grounds that it reduces or mitigates the effects of the inequality of bargaining power which is inherent in the employment relationship.”).

300 J. SHAw, "A Radical Fix for the Republic," Harvard Magazine, (12 September, 2012). Available at: http://www.law.harvard.edu/news/spotlight/faculty-research/lessig-a-radical-fix-for-the-republic.html (last accessed 4 April 2017). 
these categories is not for governments to simply create more laws or to increase the fines for violations as the Inverted-U curve suggested. This is not only because there is a fear or legal pollution or the possibility that laws can backfire - as illustrated by the Dutch flexwet example and the lessons from the law in an Uberize economy case study - but for the very fundamental reason that this particular approach does not fit with our normative framework: For example, even if increasing the fines imposed to businesses actually increased the deterrence effect of the law, which studies suggest that it may not, this measure is not necessarily capabilities-enhancing for the workers. Furthermore, while legislative measures that attempt to increase the minimum wage or court precedents that hold all independent contractors should receive employment protections on par with that of a full time employee could be argued as capability-enhancing in one way, it fails to take into account the possible unintended consequences, which could actually be detrimental to the capabilities of the workers in the long run. This is all to suggest that while efforts exhausted by governments are contributing to some noticeable improvements in the living standards and the working conditions of workers in the global economy, ${ }^{301}$ too much of a good thing can be counterproductive. This is partly due to the fact that laws in general are not designed to eliminate labor exploitation in its entirety (and the aim of this thesis is not to offer proposals that would claim such grand ambitions), as the law must balance the interests of multiple stakeholders, including but not limited to workers, businesses, consumers, investors, etc., and though creating more and more legal protections for workers might benefit the workers, doing so could infringe upon some protections afforded to businesses and vice-versa.

In light of this realization, this chapter offered a starting point of discussion in terms of what private actors can do differently to reduce instances of labor exploitation, which is for them to start by acknowledging that while governments are important and necessary that does not mean that the private sector can rely on them to simply resolve all of their problems. ${ }^{302}$ This chapter also hinted to the capabilities of the private sector and their ability to influence the status quo. Moving forward, the private sector must reassess how they can harness this potential to address collective action problems like labor exploitation in the global supply chain. According to Jan Smits, "[t]here is a clear need for a new theory of sources of private law that puts less emphasis on the national States and that allows us to decide not only at which geographical level of regulation private relationships are best dealt with (the local, regional, national, European or supranational level), but also by whom (legis-

M. NAím, The End of Power: From Boardrooms to Battlefields and Churches to States, Why Being in Charge Isn't What It Used to Be, (New York: Basic Books, 2013), at p. 55 (noting, for example that "according to the World Bank, between 2005 and 2008, from sub-Saharan Africa to Latin America and from Asia to Eastern Europe, the proportion of people living in extreme poverty (those with incomes under $\$ 1.25$ day) plunged - the first time that has happened since statistics on global poverty became available."); see also, K.A. ELLIOT \& R.B. FrEEMAN, "White Hats or Don Quixotes? Human Rights Vigilantes in the Global Economy," National Bureau of Economic Research Working Paper 8102 (2001). Available at: http://www.nber.org/papers/w8102.pdf?new_window $=1 \% 20$ white $\% 20 \mathrm{~h}$ (last accessed 4 April 2017), at p. 32.

302 C.M. Christensen, The Innovator's Dilemma: The Revolutionary Book That Will Change the Way You Do Business, (New York: Harper Business, 2011), at p. 35 (noting that simply because an organization has accumulated a variety of skills and knowledge does not necessarily mean that that are capable of resolving every type of problems); see also, P. Anderson \& M. Tushman, "Technological Discontinuities and Dominant Designs," Administrative Science Quarterly (35) (1990): 604-633. 
lators, regulatory agencies, courts or the parties themselves) and for which topics." 303 Taking his words to heart, the next chapter of this thesis will start by focusing more on the private sector and what they are currently doing and what they can do differently, as promised in the introduction. In closing, the main take away to extrapolate from this chapter is that rather than holding our collective breaths for governments to change the way in which we operate, the private sector can become the catalyst for change themselves from a more grassroots level.

303 J.M. SMITS, "Plurality of Sources in European Private Law, or: How to Live with Legal Diversity?," in European Legal Method - in a Multi-Level EU Legal Order, U. NEERGAARD \& R. NiELSEN (EDS.), (Copenhagen: Djøf Forlag, 2012): 71-86, 77 . 
Page left intentionally blank 


\section{3}

\section{Tort Law Perspective}

"A truly virtuous man would come to the aid of the most distant stranger as quickly as to bis own friend."

\section{Montesquieu}

While the previous chapter focused on the issue of how governments are dealing with the problem of labor exploitation within their own jurisdictions through labor/employment laws, this chapter will address whether tort laws are enabling private actors to deal with the problem of labor exploitation taking place outside of their home jurisdictions. This chapter will show that while the reach of labor/employment laws are generally limited to the confines of their home jurisdictions, tort law offers a slightly more extraterritorial reach, which is relevant given the businesses' propensity to increasingly outsource their operations abroad, externalize their liabilities to third party foreign legal entities, and circumvent their domestic labor/employment laws in the process. While Bangladeshi or Cambodian laborers working for subsidiaries or suppliers of Western companies abroad may not be entitled to claim minimum wages of New York or the Netherlands, in the event that they are exploited by their employers, the workers may nevertheless seek justice in US or Dutch courts for torts that occurred abroad to initiate what is commonly referred to as a foreign direct liability case. ${ }^{304}$ In the process, tort law could potentially give the exploited workers grounds to not only bring a claim against their direct employers, but potentially their parent companies as well.

Accordingly, this section will illustrate how foreign workers, as alien plaintiffs, have been able to initiate legal proceedings based on tort law claims in the US (Section 3.1) and in the Netherlands (Section 3.2) for torts that occurred in foreign jurisdictions. By enabling

J.M. SMITS, “The Expanding Circle of Contract Law," Maastricht European Private Law Institute Working Paper 3 (2016), at p. 4 (noting that "so-called foreign direct liability claim aims to hold a wealthy party located in the United States liable for a wrong committed by one of its suppliers or sub-suppliers in another country"); see also, L.F.H. ENNEKING, "Crossing the Atlantic? The Political and Legal Feasibility of European Foreign Direct Liability Cases," George Washington International Law Review 40 (2009): 903-938. 
foreign victims of corporate malfeasance access to justice in US/Dutch courts, the tort laws that will be addressed in this chapter could be argued as capabilities-enhancing for the exploited workers. However, similar to the structure of the previous chapter, this chapter will also raise various limitations and problems associated with the tort law approach (Section 3.3), before concluding with an analysis of whether these tort law measures are actually contributing to the reduction of labor exploitation in a manner that is in alignment with our normative framework (Section 3.4).

\subsection{FOREIGN VICTIMS IN US COURTS}

The objective of this first section is to provide an overview of relevant US tort laws and to determine how useful they are at actually providing foreign plaintiffs access to justice in US courts. The first subsection will look at how the Alien Tort Statute contributes to this endeavor at the federal court level (Subsection 3.1.1), followed by a discussion of state tort law based claims that could also give foreign plaintiffs access to justice in US state courts (Subsection 3.1.2). These subsections will be followed by a discussion of whether foreign plaintiffs can join class action lawsuits or representative litigations as yet another strategy that could potentially give foreign plaintiffs a chance to seek redress in US courts (Subsection 3.1.3). This section will finally conclude with an assessment of how realistic or feasible these tort law based claims are and whether they actually reduce instances of labor exploitation by considering their limitations in practice (Subsection 3.1.4).

\subsubsection{Alien Tort Statute: Foreign Victims in US Federal Courts}

One of the more interesting developments in the area of tort law for the purposes of this thesis was the emergence - or more appropriately the reemergence - of the Alien Tort Statute ("ATS") in the US. ${ }^{305}$ Since its reemergence in the 1980's, there have been many cases where alien plaintiffs, relying on the ATS, have not only succeeded in having their cases heard before US federal courts, ${ }^{306}$ but have actually managed to experience victory. ${ }^{307}$ At the onset, however, it must be clarified that while many of these cases did involve corporate malfeasance and the defendants were indeed major MNCs, some of the plaintiffs were not victims of labor exploitation per se, nor were they directly employed by the MNCs or their subsidiaries. Rather, some of the claims alleged human rights violations or

28 U.S.C. $\$ 1350$.

306 Over 154 cases against corporations have been filed under the ATS since the Karadzic decision. According to Michael Goldhaber, of the 150 or so legitimate ATS cases, it is estimated that 14 ended in settlements or default judgments for a success rate of about $9.5 \%$ and although the terms of the settlement are confidential, of the 6 cases in which the terms were leaked, the settlements total for about $\$ 80$ million, see e.g. M.D. GOLDHABER, "Alien Tort Backup Plan," The American Lawyer, (1 January 2013).

307 Admittedly, most of these victories come in the form of out of court settlements as multinational corporations accused of human rights violations seek to mitigate their reputational damage. See e.g. Doe v. Unocal, 963 F. Supp.

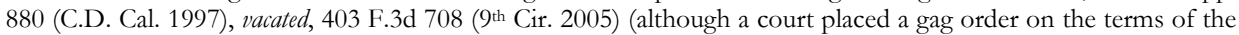
settlement, an insider leak revealed that the settlement figure was in the area of $\$ 30$ million); see also, "A Milestone for Human Rights," Bloomberg Business Week, (23 January 2005); and, J. MOUAWAD, "Shell to Pay \$15.5 Million to Settle Nigerian Case," The New York Times, (8 June 2009). 
some variation thereof, framed in the context of MNCs breaching a duty that was owed to the plaintiffs. This does not necessarily present a problem for this thesis because what is important in our analysis of the ATS - and subsequent laws - is whether or not alien plaintiffs can gain access to US courts, which could be argued as capabilities-enhancing as suggested above. Therefore, while this subsection will discuss some cases relating to allegations of human rights violations and not specifically issues of labor exploitation, what is important in the context of our normative framework is whether the ATS - and subsequent laws - increases the workers' capabilities by giving them increased access to justice and to having the opportunity to have their voices heard.

Before elaborating on the uniqueness of the ATS, practical considerations of jurisdiction and competence must be addressed first. In a very straightforward tort claim, a tortfeasor and a tort victim will be a resident of the same jurisdiction and the alleged tort would have taken place in that particular jurisdiction as well. This scenario describes a typical Worker's Compensation claim noted back in Chapter 2, where an employee living in New York sues an employer operating in New York, for a work incident that occurred in New York. In this case, the choice of forum and the governing law will most likely be that of New York. An attempt by the tort victim to forum shop and to bring a suit in a different jurisdiction, perhaps in another state without a Worker's Compensation scheme, will likely be dismissed by the other state on the grounds of forum non conveniens given that their shared jurisdiction is likely the most appropriate one based on witness/evidence availability and other relevant considerations. ${ }^{308}$

In a slightly different scenario, where the tortfeasor and the tort victim reside in the same jurisdiction, but the tort in question occurred in another jurisdiction, the issue of appropriate forum and possibly even the question of applicable law become slightly more complicated, with the answer likely depending on where the plaintiff initiates the proceeding (i.e. whether in the shared home jurisdiction of the tortfeasor and the tort victim, or in the alternative, the jurisdiction where the tort actually occurred). For that matter, if the tortfeasor and the tort victim were from two different jurisdictions and the tort occurs in a third jurisdiction, the question of forum and the appropriate governing law could quickly become a jurisdictional quagmire with parties and courts having to look at various applicable rules on conflict of laws. In other words, in the absence of a multi-jurisdictional treaty, ${ }^{309}$ legislation with an extraterritorial reach/universal jurisdiction, or an international civil claims court, it would be very difficult for plaintiffs to seek remedy in a jurisdiction other than their own: If the plaintiffs, hypothetically, are workers in the lower echelons of the global supply chain suing a MNC, the workers will not only need the proper incentive to sue - which we already noted in the previous chapter that not all workers have - but they will need capital to hire legal representation and to pay for court costs in a foreign jurisdiction.

Other basis for forum non conveniens include, but are not limited to undue hardship for the defendants, availability of alternative forums and public policy considerations to list just a few.

309 See e.g. Regulation (EU) No 1215/2012 of the European Parliament and of the Council of 12 December 2012 on jurisdiction and the recognition of judgments in civil and commercial matters (Recast) OJEC (L 351/1). 
The ATS was relevant in this context because it was thought to have an extraterritorial reach, ${ }^{310}$ which made it easier for a plaintiff domiciled outside of the US to bring a tort claim in US federal courts even for a tort that occurred outside of the US against a non-US defendant. The language of this short, but notable statute states that: "[ $\mathrm{t}]$ he district courts shall have original jurisdiction of any civil action by an alien for a tort only, committed in violation of the law of nations or a treaty of the United States." 311 After its resurgence in the 1980's, the ATS quickly became a source of nuisance to many MNCs and was lauded by human rights advocates as an unparalleled statute that authorized US federal courts to exercise universal civil jurisdiction over alleged extraterritorial human right abuses to which the US had no connection or nexus.

To present an overview of the ATS and its utility, this subsection will: a) offer a brief summary of seminal ATS cases; b) explain the requirement for the alien plaintiffs relying on the ATS to establish subject matter jurisdiction, as well as c) personal jurisdiction; d) analyze how concerns of forum non conveniens, act of state doctrine, and the political question doctrine all contributed to the weakening of the ATS; e) discuss the impact of the Kiobel $v$. Dutch Royal Petroleum case on the ATS, and how f) it effectively neutered the ATS.

\section{A. Brief Summary of Seminal ATS Cases}

The intended purpose of the ATS, as it was originally conceived within the Judiciary Act of 1789, was to provide a cause of action for visiting foreign dignitaries in the event that they were injured or attacked while on US soil. ${ }^{312}$ In other words, the initial aim of this statute was not to give foreign plaintiffs legal standing to sue for a tort that occurred outside of the US, but for torts that occurred within the US. The statute laid relatively dormant without receiving much spotlight until 1980 when it was first used as the legal basis for seeking remedies for human rights violations that took place abroad in Filartiga v. Peña-Irala. ${ }^{313}$ The Second Circuit Court held then that the ATS granted jurisdiction for US federal courts to hear cases regarding human rights violations of foreign citizens for violations of international norms, even if that violation occurred outside of the United States. ${ }^{314}$ In Filartiga, the Second Circuit Court reasoned that: "the international community has come to recognize the common danger posed by the flagrant disregard of basic human rights" 315 and continued to state that:

"[C]ivilized nations have banded together to prescribe acceptable norms of international behavior" and that "bumanitarian and practical considerations have combined to lead the nations of the world to recognize that respect for fundamental human rights is in their individual and collective in-

\footnotetext{
310 Though the extent of this jurisdictional reach was significantly narrowed by Sosa and Kiobel as it will be described in full detail later.

31128 U.S.C. $\$ 1350$.

312 Sosa v. Alvarez-Machain, 542 U.S. 692, 712, 716 (2004) (noting that during the 1780s, there were incidents where foreign dignitaries were attacked on US soil - the Marbois incident of 1784 where a member of the French legation was attacked in Philadelphia and another incident in 1789 where a Dutch Ambassador was assaulted in New York in 1789 - and needed the matter adjudicated in the US courts).

313 Filártiga v. Peña-Irala, 630 F.2d 876 (2d Cir. 1980).

314 Filártiga v. Peña-Irala, 630 F.2d 876 (2d Cir. 1980).

315 Filártiga v. Peña-Irala, 630 F.2d 876, 890 (2d Cir. 1980).
} 
terest... our holding today... is a small but important step in the fulfillment of the ageless dream to free all people from brutal violence." 316

This was the language that opened up the floodgates for foreign victims to bring their cases to the US federal courts even for alleged torts that took place abroad committed by foreign alien defendants. Although the language of the Second Circuit Court's holding in Filartiga and its subsequent cases ${ }^{317}$ were seen as positive developments for human rights activists, this momentum shifted rather drastically with the US Supreme Court's ruling in Sosa v. Alvarez-Machain. ${ }^{318}$ Under Sosa, the Court significantly limited what the ATS authorized the US federal courts to actually do by holding that the ATS was a mere jurisdictional statute that did not create any new rights of action. ${ }^{319}$ Moreover, Sosa's holding clarified that the ATS only "enabled federal courts to hear claims in a very limited category defined by the law of nations and recognized at common law." 320

The following two parts on subject matter jurisdiction (part b) and personal jurisdiction (part c) will provide an overview of what these "limited categories" are and will attempt to describe the items on the checklist that the alien plaintiffs must check off in order for them to pursue an action based on the ATS in the aftermath of Sosa, but prior to Kiobel.

\section{B. Subject Matter Jurisdiction and Causes of Action Under the ATS}

Although the ATS was unique in various ways, even during its heyday, the parties still had to establish both subject matter jurisdiction and personal jurisdiction in order to have standing before the US federal courts. In the most basic sense, subject matter jurisdiction requires the particular court to have the authority to hear the subject matter of the case (i.e. courts specializing in human rights do not have subject matter jurisdiction to hear cases involving purely commercial interests that do not impact human rights). With regards to subject matter jurisdiction, the Supreme Court in Sosa significantly limited the authority of the federal courts by narrowing the causes of action that the courts can hear based on the ATS. ${ }^{321}$ As it will be discussed in more detail below, in order for the plaintiff to establish subject matter jurisdiction according to the Sosa decision, the alien plaintiff must show that

316 Ibid

317 Filartiga was followed by a series of cases that broadened the scope of the ATS, though in some cases, the courts did not explicitly hold so, but due mainly to the fact that defendants settled the cases, thus giving the perception that the ATS could be applied more broadly. See e.g. Kadic v. Karadric, 70 F.3d 232 (2nd Cir. 1995) (expanding the reach of ATS to non-state, private actors); see also, Doe v. Unocal, 963 F. Supp. 880 (C.D. Cal. 1997), vacated, 403

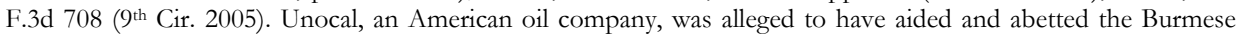
military in the commission of forced labor and other atrocities during the construction of their pipeline in Burma. Although the parties ultimately settled and the case dismissed, Unocal hinted to other victims seeking redress that the ATS could be used as a leveraging mechanism to force companies to settle; see J. C. DRIMMER \& S.R. LAMOREE, "Think Globally, Sue Locally: Trends and Out-of-Court Tactics in Transitional Tort Actions," Berkeley Journal of International Law 29(2) (2012) (noting the rise in out-of-court tactics that surround ATS claims); see also, C. Holzmeyer, "Human Rights in an Era of Neoliberal Globalization: The Alien Tort Claims Act and Grassroots Mobilization in Doe v. Unocal," 43 Law and Society Review 271 (2009), at p. 291 (describing the variety of grassroots tactical options available).

318 Sosa v. Alvarez-Machain, 542 U.S. 692 (2004).

319 Sosa, 542 U.S. at 710.

320 Sosa, 542 U.S. at 712.

321 Sosa, 542 U.S. at 724,729 (holding that "the ATS is jurisdictional statue creating no new causes of action" and that "all Members of the Court agree that $\$ 1350$ is only jurisdictional."). 
the violation in question was a violation of an international customary norm that is "specific, universal, and obligatory." 322

The first prerequisite for the courts to exercise ATS-based jurisdiction over a case is specificity, in that the international norm must be specific. While this requirement might seem reasonable prima facie, the manner in which the Supreme Court defined "specificity" is rather archaic to say the least. In establishing the parameters of specificity, the Court held that "we think courts should require any claim [to be] defined with a specificity comparable to the features of the $18^{\text {th }}$ century paradigms we have recognized," or stated differently:

"Whatever the ultimate criteria for accepting a cause of action subject to jurisdiction under $\int 1350$ [ATS], we are persuaded that federal courts should not recognize private claims under federal common law for violations of any international law norm with less definite content and acceptance among civilized nations than the historical paradigms familiar when $\int 1350$ was enacted. ${ }^{, 323}$

In other words, in order for a foreign litigant to have standing in the US federal courts on the grounds of the ATS, the alien must - at a threshold level - be able to argue and successfully establish that their claim of human rights violation must have been specifically defined and recognized by the international community in 1789 , or at least comparably so. ${ }^{324}$ One example of such an international norm, according to the Court's ruling in United States $v$. Smith 325 was the norm against piracy: "In Smith, a statute proscribing 'the crime of piracy (on the high seas) as defined by the law of nations,' 3 Stat. 510(a) (1819), was held sufficiently determinate..." ${ }^{326}$ In coming to the conclusion that piracy at sea was a violation of a norm recognized by the international community in the late $18^{\text {th }}$ century, the Supreme Court in Smith took into consideration works by Lord Bacon, Grotius, Bochard, and other renowned legal commentators of the time, which allowed them to rule that a genuine international consensus existed to hold that the crime of piracy was indeed "sufficiently and constitutionally defined." 327

The example of piracy illustrates the rather difficult task of determining what could have been considered as universal in the $18^{\text {th }}$ century paradigms. It is worth noting here that according to this archaic definition, slavery would not be considered as a violation of international customary norm, given that slavery in the US was not constitutionally abolished until the adoption of the Thirteenth Amendment in 1865. This would suggest that any claims related to labor exploitation has a slim chance of meeting the "specificity" requirement.

Even if the plaintiffs can successfully argue that a violation of some labor related law meets the specificity requirement, the second criterion that they would have to establish is

Sosa, 542 U.S. at 725, 732 (quoting In re Estate of Marcos Human Rights Litigation, 25 F.3d 1467, 1475 (9th Cir. 1994)). 542 U.S, at 725,732 . This is in direct contrast to what the lower court held in Filartiga, which held that "courts must interpret international law not as it was in 1789, but as it has evolved and exists among the nations of the world today." See, Filartiga, 630 F.2d at 881.

324 See e.g. Sosa, 542 U.S. at 724 (using examples of "violation of safe conducts, infringement of the rights of ambassadors, and piracy" as examples of "certain torts in violation of the law of nations" most likely recognized by the First Congress).

325 United States $v$. Smith, 18 U.S. 71 (1820).

326 Smith, 18 U.S. at 162.

327 Ibid., (holding that "whether we advert to writers on the common law, or the maritime law, or the law of nations, we shall find, that they universally treat of piracy as an offence against the law of nations, and that its true definition by that law is robbery upon the sea."). 
that the norm must be universal. In other words, a particular right in question must be recognized by law of nations, including but not limited to treaties, customary practice, and jus cogens. More specifically, the Court in Sosa held that "federal courts may recognize claims 'based on the present-day law of nations' provided that the claims rest on 'norm[s] of international character accepted by the civilized world." 328 Given the US' allergy to binding itself to international treaties, the decision by its highest court to base a cause of action on this point is somewhat perplexing. Take for instance, the assortment of international treaties that is noticeably missing the US signature or conventions that they have yet to ratify: For example, the Convention on the Rights of the Child, the Convention on the Elimination of All Forms of Discrimination Against Women, the Convention on the Rights of Persons with Disabilities, and the Intentional Convention for the Protection of All Persons from Enforced Disappearance, just to list a few. This list does not, in any way, imply that the US does not care about children or women, but it does put the US federal courts in a rather awkward position. For instance, if an alien plaintiff files an ATS based claim for the violation of her basic rights relating to work place discrimination based on her gender that took place abroad, the US courts would likely not consider the Convention on the Elimination of All Forms of Discrimination Against Women as a valid international treaty as US is not a signatory to that convention. The question of what can be considered as a norm of "international character accepted by the civilized world" also creates problems with regards to the third requirement as well.

The third and the final criterion is that the norm must be binding and not hortatory, or to use the exact phrasing of the Supreme Court, the norm must be at or near "full realization... as binding law" as judges do not have the authority to create any "private cause of action." 329 Coming back to the previous issue of international treaties, there is some doubt as to whether the Court would likely consider an international treaty that has not been signed by the US to be fully realized as binding law. This language of the Supreme Court also seems rather restrictive in that according to this definition, the courts would likely not recognize the UN's Universal Declaration of Human Rights ("UDHR") as having an obligatory nature and many of the "rights" the Declaration lists would be insufficient grounds to establish the obligatory element of establishing subject matter jurisdiction under the ATS. ${ }^{330}$ Only certain human rights listed under the UDHR, such as the prohibition of genocide and torture that overlap with principles of jus cogens, would likely be deemed as "preemptory and mandatory norms of international law that no nation may violate." 331

Other hortatory or aspirational rights, like Article 23 of the UDHR, for example, which recognizes the right to work in just and favorable conditions, will most likely not be considered to be on par with jus cogens. The aforementioned issue of slavery and whether there was a recognized prohibition of it in 1789 is also a lingering concern. This would suggest that there are different levels of international customary norms, some that attain the status

Kiobel v. Royal Dutch Petroleum Co., 621 F.3d 111 (2d Cir. 2010) (referencing Sosa v. Alvarez-Machain, 542 U.S. 692, 725 (2004).

329 Sosa, 542 U.S. at 738.

330 Sosa, 542 U.S. at 735.

331 Black's Law Dictionary (8th Ed. 2004), at p. 876. 
of jus cogens, ${ }^{332}$ and some - or rather most - that do not. This makes it so that truly universally binding norms are hard to establish, not to mention that on their own, most of these international norms are non-binding. ${ }^{333}$ The ATS framework is unique in that the cause of action is determined, not by the law of the host jurisdiction or by the law of where the tort occurred, but by the application of the law of nations (i.e. customary international law) or a treaty of the United States. ${ }^{334}$ In other words, there is no black letter law that the court must refer to when considering an appropriate cause of action under the ATS scheme, but instead, the courts must look to historic documents to determine what constituted a customary international law back in 1789 because of their holding in Sosa.

An illustration of just how the Court's ruling in Sosa restricted the access of foreign plaintiffs from having legal standing in the US federal courts based on the ATS can be seen through the Ninth Circuit Court case, Doe v. Unocal. ${ }^{335}$ Bear in mind that the Ninth Circuit Court heard this case, prior to Sosa, and as result, the Ninth Circuit Court noted that the ATS "not only confers jurisdiction but also creates a cause of action." 336 The Supreme Court would eventually overturn this interpretation with their Sosa decision, 337 but for a short period of time prior to Sosa, at least in the Ninth Circuit, judges were deemed to have the authority to establish "private cause of action." One of the private causes of action that the Ninth Circuit Court acknowledged in Unocal was the right to work in just and favorable conditions, as laid out in Article 23 of the UDHR.

In Unocal, ${ }^{338}$ a group of Burmese ${ }^{339}$ villagers brought a suit against Unocal and its parent company, Union Oil (a company based in California) seeking relief under the ATS and California State law for allegations that the defendants were involved in various human rights violations including but not limited to forced labor, murder, rape, false imprisonment, and wrongful death during the construction of a gas pipeline in Burma, which involved violent interventions by the Burmese military. ${ }^{340}$ To offer a bit of what lies ahead later in the next subsection (Subsection 3.1.2), it is worth clarifying here the importance of separating the analysis of forced labor and genocide in the context of customary international law and the ATS framework on one side and the state law claim of false imprisonment and wrongful death in the California tort law framework on the other. Even if a court was to dismiss the plaintiff's ATS claim that does not automatically defeat their state law

332 See e.g. B. Stephens, "Sosa v. Alvarez-Machain: The Door is Still Ajar from Human Rights Litigation in U.S. Courts," Brooklyn Law Review 70 (2004): 533, 537 (including "cruel and inhumane or degrading treatment" as one of the "violations of the law of nations").

333 Take for example covenants or declarations such as the Universal Declaration of Human Rights; International Covenant on Economic, Social and Cultural Rights, (January 3, 1976) 993 U.N.T.S. 3; International Covenant on Civil and Political Rights, (March 23 1976) 999 U.N.T.S. 171.

334 As previously above in this subsection this is because in order for the court to establish subject matter jurisdiction, the Supreme Court in Sosa noted that the international norm that the plaintiffs are relying on to establish their cause of action must be "specific, universal and obligatory".

335 Doe v. Unocal, 395 F.3d. 932 (Doe II) (9 $9^{\text {th }}$ Cir. 2002).

336 Doe v. Unocal, 395 F.3d. at 949; see also, Papa v. US, 281 F.3d 1004, 1013 (2002) and Hilao v. Marcos, 25 F.3d 1467, 1474-75 (1994).

337 Sosa, 542 U.S. at 738 .

338 Doe v. Unocal, 395 F.3d. 932 (Doe II) (9 $9^{\text {th }}$ Cir. 2002).

339 Burma is present day Myanmar.

340 Formerly Burma. 
claim, which is precisely what happened in Unocal, ${ }^{341}$ and will be addressed separately in the next Subsection 3.1.2.

Keeping the focus strictly on the ATS framework for now, the Ninth Circuit in Unocal held that "forced labor is so widely condemned that it has achieved the status of a jus cogens violation" 342 citing to the Universal Declaration of Human Rights. While the courts reliance on the UDHR seemed logical at the time, if this argument had been made after the Supreme Court's ruling in Sosa, the Ninth Circuit Court's reliance on UDHR would have been met with scrutiny as UDHR fails to meet at least one prong of Sosa's "specificity, universality, and binding nature" test, if not all of them. ${ }^{343}$ However, because the Unocal decision preceded the Supreme Court's Sosa decision, the defendants did not argue that forced labor was not a violation of customary international norm. In other words, prior to Sosa, plaintiffs could have reasonable argued that violations of rights enumerated in the UDHR were valid causes of action to establish subject matter jurisdiction under the ATS.

As a result, Unocal felt that the petitioners had legitimate enough of a claim and thus decided to settle prior to the court reaching its decision. This means that prior to Sosa, alien plaintiffs were able to rely on principles found in the UDHR such as the right to work in just and favorable conditions and to use these arguments as leverage for the defendants to settle. ${ }^{344}$ But because Sosa narrowed the definition of what constitutes as customary international norms, this dismantled the ability to rely on the UDHR and other "softer" measures as a source of leverage that the petitioners may have had at one point. Essentially, Sosa put an end to a useful strategy that was available to the plaintiffs and made it easier for defendants to have the claims dismissed. In other words, after Sosa, only "serious" jus cogens violations such as genocide and torture became sufficient causes of action under the ATS and other "softer" rights such as the right to work in just and favorable conditions were effectively removed from possible claims available under the ATS. This is to suggest that the US Supreme Court's decision in Sosa was capability-reducing given that it restricted the opportunities available for the alien plaintiffs to have their voices heard in the US federal courts.

\section{Personal Jurisdiction}

As if the requirement to establish subject matter jurisdiction and to have a valid cause of action was not difficult enough for the alien plaintiffs, once subject matter jurisdiction is established, the plaintiff must also establish personal jurisdiction, which essentially comes down to the question of whether the courts can enforce their rulings upon the parties. In the US, generally speaking, in order for the court to establish personal jurisdiction, the plaintiff

341 The issue of state law based claims will be addressed later in subsection 2.2.2.

342 Doe v. Unocal, 395 F.3d. 932 (Doe II) (9th Cir. 2002).

343 In addition, given that forced labor and slavery was not universally prohibited in the United States until 1865 when the Thirteenth Amendment took effect, it could prove difficult for the court to rely on most of the provisions found within the UDHR as satisfying the specificity and the universality requirement. The Thirteenth Amendment of the U.S. Constitution states that "either slavery nor involuntary servitude, except as a punishment for crime whereof the party shall have been duly convicted, shall exist within the United States, or any place subject to their jurisdiction."

344 B. QugLEY, a spokesman for the U.S. Chamber of Commerce, as noted in R. HAMILTON, "A History of the U.S. Alien Tort Statute," Reuters, E. Evans (ED.) (30 September 2012) (quoting the spokesman who noted that "these lawsuits come with a massive cost and are designed to leverage reputational damage on the company in order to extract a huge settlement or judgment."). 
must be able to show that the defendant either had "continuous and systematic" 345 contact to the jurisdiction or show certain "minimal contact" with the jurisdiction and that the particular suit does not offend "traditional notions of fair play and substantial justice." 346 Assuming that these elements are met and in the event that the defendant is an individual, the plaintiff can establish personal jurisdiction by serving the defendant in person while they are within the US territories, or in the alternative, at their place of residence. ${ }^{347}$ In the event that the defendant is a corporation, the threshold question is whether the corporation has a US office or a branch. If the corporation has a US branch, the petitioner may serve the corporation's agent or officer at that location to establish personal jurisdiction. ${ }^{348}$ If the corporation does not have a US office or the individual is not within the US territories, establishing personal jurisdiction becomes more difficult. ${ }^{349}$ These procedural requirements show that even under the ATS framework (and even prior to Kiobel), it was difficult for the alien plaintiffs to have legal standing and thus access to the US federal courts. In Filartiga, for example, the defendant, Peña-Irala, was physically present in the United States, which made establishing personal jurisdiction relatively easy. In reaching this conclusion regarding the issue of personal jurisdiction, the Second Circuit Court held that "[c]ommon law courts of general jurisdiction regularly adjudicate transitory tort claims between individuals over whom they exercise personal jurisdiction, wherever the tort occurred." 350

While the introductory paragraphs of this chapter suggested that the ATS offered some extraterritorial reach, we must be careful not to suggest that the ATS offers universal jurisdiction, which it does not. As noted above, the parties must establish some minimal contact with the US territories if the petitioners are to successfully rely on the ATS to establish their legal standing in US federal courts. While this issue of universal jurisdiction will be elaborated further below, it suffices to note here that the ATS does not have universal jurisdiction given that the statute itself does not expressly state that it does. ${ }^{351}$ Ultimately, what this suggests is that if only the plaintiff is located within the US and the tortfeasor is not and lacking any contact with the US, the ATS claim - even prior to Kiobel - would likely have been dismissed by the courts on the grounds that it failed to establish personal jurisdiction, especially if the tort in question occurred abroad.

International Shoe Co. v. Washington, 326 U.S. 310, 316 (1945); see also, Helicopteros Nacionals de Colombia S.A. v. Hall, 466 U.S. 408, 414 (1984); Goodyear Dunlop Tires Operations, S.A. v Brown, 564 U.S. (2011). International Shoe Co., 326 U.S. at 316.

347 See generally, Federal Rules of Civil Procedure Rule 4.1 and 5.

348 Federal Rules of Civil Procedure Rule 4(h).

349 See generally, Asabi Metal Industries Co. v. Superior Court, 480 U.S. 102 (1987) (holding that a foreign company selling motorcycle parts that eventually ended up in the stream of commerce in the US did not meet the minimum contact requirement and therefore insufficient to establish personal jurisdiction based on fairness and the reasonableness standard); see also, Helicopteros Nacionales de Colombia, S.A. v. Hall, 466 U.S. 408 (1984) (holding that contract negotiations taking place on US soil alone is insufficient to establish personal jurisdiction); $C$ f. Presbyterian Church of Sudan v. Talisman Energy, Inc., 244 F. Supp. 2d 289 (S.D.N.Y. 2003) (holding that the defendants listing on the New York Stock Exchange is sufficient to establish jurisdiction).

350 Filártiga v. Peña-Irala, 630 F.2d 876, 880 (2d Cir. 1980).

351 Morrison v. Nat'l Australia Bank Ltd, 561 U.S. an extraterritorial application, it has none."). 


\section{Forum non Conveniens, Acts of State, and Political Question Doctrines}

Even if the alien plaintiff somehow met the three Sosa requirements to establishing subject matter jurisdiction and if the circumstances were so that personal jurisdiction was also established, the Court further cautioned in Sosa that the federal courts would also consider possible consequences of granting an alien plaintiff legal standing in determining whether or not they will do so. ${ }^{352}$ The lower courts have interpreted this to mean that the federal courts should not grant legal standing to foreign plaintiffs if doing so meddles with foreign policy or other interests of the Executive branch. ${ }^{353}$ This essentially means that the federal courts will be reluctant to hear cases that are of a sensitive political nature especially if the act in question is conducted by another sovereign state. ${ }^{354}$ Although the logic behind this reverence, called the political question doctrine, is sound, it provides little to no relief for those victims seeking access to justice and substantive remedy. ${ }^{355}$ As the Unocal example illustrated above, many human right violations that occur in the extractive sector involve foreign governments and their militaries, which makes it more likely for the US federal courts to refrain from hearing such cases on the ground that it is politically charged and sensitive.

In this context, Sarei v. Rio Tinto Plc. ${ }^{356}$ exemplifies the hurdles that alien plaintiffs must overcome in a case where the relief is based on the ATS, but the facts involve politically sensitive issues. The plaintiffs in Rio Tinto, residents of Papua New Guinea, filed a suit against a multinational mining company, Rio Tinto, which is headquartered in London, for polluting their islands, which harmed the health and livelihood of the people living on the

Sosa, 542 U.S. at 732-33 (holding that "the determination [of] whether a norm is sufficiently definite to support a cause of action should (and, indeed, inevitably must) involve an element of judgment about the practical consequences of making that cause available to litigants in the federal courts.").

353 Khulumani v. Barclay National Bank LTD., 504 F.3D 254, 261 (2 ${ }^{\text {nd }}$ Cir. 2007) (referring to Sosa, 542 U.S. at 733 n. 21 and noting that "views of the Executive Branch on the issue of the case's impact on foreign policy should be given 'serious weight'.").

354 Act of state doctrine generally holds that US courts are prohibited form adjudicating claims dealing with official acts of a foreign sovereign; see e.g., Underbill v. Hernandez 168 US 250, 252 (holding that "the courts of one country will not sit in judgment on the acts of the government of another, done within its own territory."); see generally, K. JAWGER, "Environmental Claims under the Alien Tort Statute," Berkeley Joumal of International Law 28(2) (2010), at p. 7.

355 In addition, as mentioned earlier, the Second Circuit Court in Kiobel held that the courts lack subject matter jurisdiction for cases involving corporate defendants. Some of the most convincing arguments for this point were made by Shell's counsel, Kathleen Sullivan during the second round of oral arguments for Kiobel. She argued that no customary international law throughout the world holds corporations liable for the human rights offenses, making repeated references to the Rome Treaty, ICC, and their distinctions of persons from corporations. Sullivan's biggest punch was when she argued that even in during the international military tribunals for the war atrocities, including but not limited to the Nuremberg trials, ICTY, and ICTR, only corporate officers have been prosecuted and not the corporations themselves. John Ruggie subsequently argued that Kathleen Sullivan, who relied on Ruggie's UN report during her oral arguments, mischaracterized his report, correcting her that his main conclusion from the report was that the most consequential legal development in business and human rights "is the gradual extension of liability to companies for international crimes, under domestic jurisdiction but reflecting international standards"; see, Report of the Special Representative of the Secretary General on the issue of human rights and transnational corporations and other business enterprises, "Business and Human Rights: Mapping International Standards of Responsibility and Accountability for Corporate Acts," UN Document A/HRC.4/035 (19 February 2007). It is interesting to note here that even Justice Ginsburg seemed to have issues with Kathleen Sullivan, stating that "you are just representing the corporations to say what is in the interests of the United States, when the United States representative told us they think that individuals and corporations are both subject to suit"; see, Kiobel, Oral arguments.

356 Sarei v. Rio Tinto, Plc. (Sarei I), 221 F.Supp. 2d 1116 (C.D. Cal. 2002), Sarei v. Rio Tinto, Plc. (Sarei II), 456 F.3d. 1069 (9 th $^{\text {th }}$ Cir. 2006); Sarei v. Rio Tinto Plc., 487 F.3d 1193 (9 (th $^{\text {th }}$ Cir. 2007). 
islands. ${ }^{357}$ In addition to the environmental damages, during a series of protests by the residents against Rio Tinto, the tension escalated to the point where the residents sabotaged the mining areas with sit-ins and in one particular incident, used explosives. In retaliation, the Papua New Guinea government sent defense forces to Bougainville, the area of the conflict, to put down the uprising. ${ }^{358}$ The plaintiffs alleged that Rio Tinto was complicit in the crimes that the Papua New Guinea military perpetrated by providing economic and tactical assistance to them during the retaliation, where the military shot and killed a number of Bougainvilleans in what became known as the St. Valentine's Day massacre. This sparked a civil war, which lasted for decades with estimated casualties totaling more than 10,000. ${ }^{359}$ Sarei, the named plaintiff personally experienced this tragedy, but subsequently moved to California and filed a claim based on the ATS together with 21 co-plaintiffs that still resided in Papua New Guinea.

The suit itself claimed crimes against humanity, war crimes and cruel, inhumane and degrading treatments in violation of customary international law as the basis of their ATS claim and the District Court held that they were cognizable claims under the ATS. ${ }^{360}$ The Court of Appeals would later agree with the District Court's ruling that the claims of war crimes, violations of the laws of war and racial discrimination "all implicate 'specific, universal and obligatory norm[s] of international law' that properly form the basis for [ATS] claims." 361 The District Court even went as far as to state that if the allegations were proven, Rio Tinto would even have been held liable for certain acts committed by the Papua New Guinea government. ${ }^{362}$ However, the District Court had to respect the fact that Rio Tinto and the government of Papua New Guinea had an agreement where the company would share $19.1 \%$ of the mining profits with the government in exchange for the government to remove people living near the mining area. Based on this agreement, the defendant, Rio Tinto, invoked the act of the state doctrine and the political question doctrine in order to get the US federal courts to back off. 363

The standard for the political question doctrine, established in Marbury v. Madison ${ }^{364}$ and opined by Chief Justice Marshall emphasized the importance of the Court to avoid entanglements with the legislative and the executive branches of the government: "questions, in their nature political, or which are, by the constitution and laws, submitted to the executive, can never be made in this court." 365 With regards to Rio Tinto, the US Department of State publicly made a statement that for the courts to continue hearing this case "would risk a potentially serious adverse impact... on the conduct of [United States'] foreign relations"366

Sarei, 221 F.Supp. 2d at 1123-4. The plaintiffs, black Bougainvilleans, also alleged discriminatory hiring practices by Rio Tinto for discriminatory hiring practices and paying them "slave wages".

358 Sarei, 221 F.Supp. 2d at 1126.

359 Sarei, 221 F.Supp. 2d at 1127.

360 Sarei, 221 F.Supp. 2d at 1139-63.

361 Sarei, 221 F.Supp. 2d at 1132. It is worth noting here that the District Court's holding here about war crimes and racial discrimination as being specific, universal and binding could be challenged. Although war crimes would likely constitute jus cogens, whether racial discrimination would amount to jus cogens or whether it is even as specific and universal could be challenged.

362 Sarei, 221 F.Supp. 2d at 1148-49.

363 Sarei, 221 F.Supp. 2d at 1121.

364 Marbury v. Madison, 5 U.S. 137 (1803).

365 Ibid.

366 Sarei v. Rio Tinto Plc., 487 F.3d 1193, 1197 (9 ${ }^{\text {th }}$ Cir. 2007). 
and urged the court to dismiss the case. In the end, the trial court agreed with the defendants and dismissed the suit in 2002 on the grounds that the subject matter dealt with nonjusticiable political question and acts of a state. ${ }^{367}$

A few years after the dismissal, the plaintiffs subsequently appealed when the government of Papua New Guinea changed their position and stated that they no longer objected to the plaintiffs continuing their litigation in the US. ${ }^{368}$ The question that the Ninth Circuit then had to address was whether in light of the new position by the government of Papua New Guinea, genuine issues of political doctrine remained. In accordance with the political doctrine test established in Baker v. Carr, ${ }^{369}$ the Ninth Circuit Court held that the facts no longer presented a political question. ${ }^{370}$ The Ninth Circuit also affirmed the District Court's holding that the plaintiffs did not have to exhaust their local remedies in Papua New Guinea before seeking a remedy in the US, which was another challenge that was brought by Rio Tinto. The Ninth Circuit ultimately held that no such requirement existed and that it was "up to Congress or the Supreme Court to alter the status quo if warranted." 371 Accordingly, the dismissal of the plaintiff was reversed and the case was remanded for further proceedings. ${ }^{372}$ It is also worth adding here, that another argument that the Rio Tinto could have raised even in the absence of a political question, was the issue of forum non conveniens, where they could have appealed to the US court that the appropriate venue of the case would have been Papua New Guinea and that not all local remedies were exhausted by the plaintiff there, but it is conceivable that Rio Tinto did not take this approach, perhaps preferring the US federal courts to that of Papua New Guinea's. ${ }^{373}$

On remand, the defendants provided supporting documents - ranging from the International Covenant on Civil and Political Rights, the Universal Declaration of Human Rights, and the European Convention for the Protection of Human Rights, in an attempt to prove that acts that violate "right to life" and "right to health" ought to be specific and universally accepted norms equivalent to the law of nations in 1789. The District Court, however, disagreed, holding that these rights did not constitute specific, universal, and binding norms that could be considered as law of nations in the aftermath of Sosa. ${ }^{374}$ The District Court did, however, strangely held that the plaintiffs had a valid ATS claim on the basis of the fact that Rio Tinto allegedly polluted the marine ecology in violation of the United Nations Convention on the Law of the Sea ("UNCLOS"), which the court recognized as customary international law and "law of nations" even though the United States

Sarei, 221 F.Supp. 2d at 1183-93, 1193-99 and 1199-1209.

368 Sarei v. Rio Tinto Plc., 456 F.3d 1069, 1076 (embedding a quote by Papua New Guinea's Chief Secretary Joshua Kalinoe stating that "[t]he government is not a party to this case. Accordingly, it does not see the case presently before the courts affecting diplomatic and bilateral relations between our two countries nor does it see it affecting the peace process on the island of Bougainville.").

369 Baker v. Carr, 369 U.S. 186 (1962) (establishing a six-factor test for the courts to apply when determining whether there is a valid political question and thus for the court to avoid adjudicating on the matter).

370 Sarei v. Rio Tinto Plc., 456 F.3d, at 1084.

371 Sarei v. Rio Tinto Plc., 456 F.3d 1069, 1074 (9th Cir. 2006).

372 Sarei v. Rio Tinto Plc., 456 F.3d, at 1099.

373 International law generally requires that before a plaintiff can assert a claim in a foreign jurisdiction, the plaintiff must have exhausted all remedies available in their domestic jurisdiction or other possible forums such as international claims tribunals; see e.g. Sosa, 542 U.S. at 733; see also, Sarei v. Rio Tinto, Plc., 550 F.3d 822, 824 (9 th Cir. 2008) (holding that "[s]imply because universal jurisdiction might be available, does not mean that [the Court] should exercise it" but also recognizing that local remedies do not have to be exhausted in all cases).

374 Sarei v. Rio Tinto, Plc., 221 F.Supp. 2d 1116, 1156 (C.D. Cal. 2002). 
was not a signatory of the convention. ${ }^{375}$ This answers our earlier question, at least at the lower federal court level, of whether or not the US has to be a signatory to the international treaty in order for the courts to consider it as a recognized norm: The answer is that they do not and accordingly, the Ninth Circuit held that the plaintiff's claim of environmental damage based on UNCLOS was a proper basis for an ATS based claim. The revelation of what happened in Rio Tinto and what became of the Bougainvilleans, however, must be tabled until after the discussion of Kiobel as the resolution of Rio Tinto cannot be described without first elaborating on Kiobel.

For the time being, it suffices to conclude that Rio Tinto illustrated just some of the obstacles that confront alien plaintiffs: For example, in addition to the substantive and procedural obstacles that the US Supreme Court created through Sosa, foreign plaintiffs must still be able to overcome a handful of traditional challenges often linked to transnational litigations (i.e. jurisdictional constraints, the political question doctrine, forum non conveniens arguments, state actor doctrine, etc.). However, this subsection also showed that it was still possible for the alien plaintiffs to reach some level of success with their ATS claim. The next part of this subsection, however, will discuss how even this lingering utility of the ATS has now been stripped away by the Supreme Court's decision in Kiobel, which makes the relative success that was achieved in Rio Tinto or Unocal no longer replicable today. In short, the likelihood of an alien plaintiff succeeding on their ATS claim in the US federal courts, even prior to Kiobel was relatively low. In the aftermath of Kiobel, the subject of the next part of the subsection, the chances of success became even more slim for the alien plaintiffs.

\section{E. Neutering the ATS: Kiobel v. Dutch Royal Petroleum (Shell)}

As if the Court's ruling in Sosa along with the other legal and political obstacles did not create enough confusion and hardship for the alien plaintiffs, Kiobel added yet another setback for the alien plaintiffs seeking access to justice in the US federal courts. ${ }^{376}$ One of the questions that were left unanswered by the Court in Sosa that Kiobel addressed, at least initially, was whether corporations could be held liable under the ATS. While there are those that believe MNCs, just like states or individual citizens, ought to be held liable for violating international customary norms such as genocide, torture, slavery, and other crimes against humanity, ${ }^{377}$ there are those that strongly reject this notion of a legal entity being treated as if it was a living entity. In other words, the latter school of thought would impose vicarious liability or respondeat superior to the company's officers who may have violated a law, but not hold the companies themselves liable. This very issue of whether corporate

375 Sarei, 221 F.Supp. 2d at 1161.

376 See e.g. Kiobel, 456 F. Supp. 2d (stating that Sosa "provides little guidance concerning which acts give rise to a claim"). Other questions such as whether plaintiffs must exhaust their local remedies prior to filing an ATS claim. Exhaustion, whether the courts have subject matter jurisdiction to review corporate liability issues, or at a more fundamental level, whether extraterritorial application is a violation of international law were all left unanswered by the court in Sosa.

377 M.T. KAMMINGA \& S. ZiA-ZARIFI, “An Introduction,” in Liability of Multinational Corporations Under International Law, M.T. KAMminga \& S. ZIA-ZARIFI (EDS.) (Dordrecht: Springer, 2000), at p. 8 (note 23); see also, N.M.C.P. JÄGERS \& M.J.C. VAN DER HEIJDEN, "Corporate Human Rights Violations: The Feasibility of Civil Recourse in the Netherlands," Brooklyn Journal of International Law 33(3) (2008): 833-870, 835 (noting many international conventions and soft law instruments such as the International Convention on the Suppression and Punishment of the Crime of Apartheid and Basel Convention on the Control of Transboundary Movements of Hazardous Wastes and Their Disposal as some examples of instruments that deal with corporate liabilities). 
defendants can be sued under the ATS, or whether the federal courts have subject matter jurisdiction over corporate malfeasance was the central question raised in Kiobel v. Royal Dutch Petroleum Co., or at least that was the case initially. ${ }^{378}$ The Second Circuit in Kiobel ultimately held that under customary international law, tort liability does not extend to corporations and accordingly, ruled that the US federal courts lack the necessary subject matter jurisdiction to consider cases where corporations have been accused of violating human rights. ${ }^{379}$ Although the petitioners argued that the respondents, British and Dutch petroleum companies, aided and abetted the Nigerian government in carrying out mass human rights violations, ${ }^{380}$ their arguments did not succeed as the circuit court held that they did not have the jurisdiction to hear a case of this nature. In regards to this holding, the dissenting opinion conveyed that this interpretation dealt a "substantial blow to international law and its undertaking to protect fundamental human rights." 381

After the petitioners appealed and the Supreme Court granted certiorari in October 2011, the Court was inundated with amicus briefs. Almost a hundred amicus briefs were filed for Kiobel, most of which were to comment, if not to criticize, the extraterritorial overreach of the ATS and not necessarily on the issue of whether corporations ought to be held liable for violations of international law. The essence of these briefs appeared to have reached the Justices, with Justice Breyer expressing rather bluntly that the Court was not a "United States Supreme Court of the World." 382 Some of the more noteworthy briefs were penned by the European Commission, United Kingdom, and the Netherlands all discussing the inappropriateness - at least according to them - of the ATS and its extraterritorial element. The European Commission's amicus brief, for example, relied heavily on the idea of the Charming Betsy doctrine 383 and the requirement for plaintiffs to exhaust all local remedies before seeking justice in another jurisdiction. In its brief, the Commission requested the Court to "interpret the ATS with reference to the jurisdictional framework and limitations of international law," or in other words, apply the ATS only in cases where "the defendant is a United States national or the conduct implicates United States security interests of fundamental importance." 384 Regarding the exercise of the previously mentioned universal jurisdiction, the Commission further requested that the US only apply such measures "over a narrow category of the most grave international law violations involving conduct of universal concern so long as the ATS claimant demonstrates that those States with a nexus to the case are unwilling or unable to provide a forum and no international remedies are available." 385 The Commission's amicus brief, at least from an international relations and comity

Kiobel v. Royal Dutch Petroleum Co., 621 F.3d 111 (2d Cir. 2010). Keep in mind that in Unocal, the parties settled, thus never actually reaching a final hearing on the issue of corporate liability.

379 Kiobel v. Royal Dutch Petroleum Co., 621 F.3d at 118, 147.

380 Similar to the facts of the other cases, the Nigerian victims in Kiobel were protesting Shell and its Nigerian subsidiary's extractive operations in Ogoniland, which was met with aggressive and violent retaliation from the Nigerian government, which was allegedly aided and abetted by Shell's Nigerian subsidiary.

381 Ibid., at $149,151$.

382 Kiobel, Oral arguments at p. 8.

383 Murray v. Schooner Charming Betsy, 6 U.S. 64, 118 (1804) (holding that "an act of Congress ought never be construed to violate the law of nations...').

384 Brief of the European Commission on Behalf of the European Union as Amicus Curiae in Support of Neither Party, regarding Kiobel v Royal Dutch Petroleum Co. (13 June 2012), at p. 36.

385 EC Amicus Brief, at p. 36. 
perspective, presented a reasonable approach to the ATS quandary, ${ }^{386}$ but this presented another conflict of interest for the US government: That is to say that respecting international relations and notions of comity also meant that the US federal courts had to abandon the practice of offering foreign plaintiffs access to justice in the US federal courts, which from the perspective of the victims was capability-reducing and contrary to the normative framework of this particular thesis.

Not to be outdone by the Commission, the governments of the United Kingdom and the Netherlands penned an amicus brief as well in which they made it a point to stress that the US was overstepping its boundaries and declared that "just as international law imposes human rights obligations on States, it imposes restraints on the assertion of jurisdiction by one State over civil actions between persons that primarily concern another State." 387 The UK and the Netherlands made a further point that "[f]or the U.S. to allow the ATS to provide the basis for such claims would clearly interfere with other nations' sovereignty and be plainly inconsistent with international law and the concept of international comity..." 388 As evidenced by the amicus briefs filed by the Commission, the UK, the Netherlands and many others, the consensus of foreign jurisdictions at the time was clear: the ATS should not only be used sparingly, if at all, but only under extremely limited circumstances.

Given the international nature of these problems, the critics of the ATS argued that the adjudication of these problems would be best handled at the international level, through the ICJ, the OECD, or the UN. Similarly, with regards to the application of international law, the Ninth Circuit in Unocal cited to the Restatement (Second) of Conflict of Laws $\$ 6$ (1969), which notes that the application of international law is indeed appropriate when "the needs of the... international system" are better served by applying international rather than national law. ${ }^{389}$ However, as already mentioned in the introduction, relying on organizations like the ICJ, the OECD, or the UN to handle issues of labor exploitation is unsatisfactory, at least for the purposes of this thesis that considers the capabilities of the workers in its normative framework. If anything, it was the ineffectiveness of these institutions to address problem like Unocal and their general lack of civil remedies and enforcement measures that called for the reemergence of the ATS in the first place.

At the risk or rehashing some of the points already made in the introductory chapter, even if a uniform set of internationally applicable principles were created (which arguably already exist), the enforcement measures, at least at the civil or private level, will ultimately be left up to individual nations that must implement these principles into their domestic legislations, which will be adjudicated by their domestic courts. As evidenced by some the amicus briefs from Kiobel and the US' general reluctance to sign prominent international treaties previously mentioned, sovereignties are often reluctant to share or abdicate authority to another, especially when that authority can be turned against them. To suggest that

386 The amicus brief submitted by Germany shares similar sensibilities; see e.g. Brief of the Federal Republic of Germany as Amicus Curiae in Support of Respondents, regarding Kiobel v Royal Dutch Petroleum Co. (2 February 2012), at p. 15-16 (stating that "[t]he Federal Republic of Germany urges this Court to continue its cautious application of the ATS, as in Sosa...”).

387 Brief of the Governments of the Kingdom of the Netherlands and the United Kingdom of Great Britain and Northern Ireland as Amici Curiae in Support of Neither Party, regarding Kiobel v Royal Dutch Petroleum Co. (henceforth, the "UK \& Dutch Amicus Brief”) (13 June 2012), at p. 2.

388 UK \& Dutch Amicus Brief, at p. 6.

389 Doe v. Unocal, 395 F.3d. at 949. 
supranational organizations like the UN will be able to provide adequate remedy for civil or private law violations seems rather unrealistic at this point, but this particular objection will be tabled at least until Section 3.3.

Getting back to the Kiobel case, the Justices ruled almost as if they were influenced by the amicus briefs, as the Supreme Court shifted the central question in Kiobel from whether a corporation can be held liable under the ATS, 390 to a much broader question on the extraterritorial aspect of the ATS. To address this new question, in October 2012, the Court called for a second round of oral arguments to discuss whether the statute should permit federal courts from hearing cases that occurred outside of the United States in the first place. On 17 April, 2013, in a unanimous 9-0 opinion, the Supreme Court answered in the negative, holding that the ATS is indeed subject to the presumption against extraterritoriality and does not entitle a claim brought by alien plaintiffs against a foreign corporation for a tort that occurred on a foreign soil to be heard in US federal courts, thus answering the hypothetical question posed at the very beginning of this section. ${ }^{391}$

In delivering the opinion of the Court, Chief Justice Roberts held that in order for plaintiffs to establish jurisdiction based on the ATS, their case must "touch and concern the territory of the United States" and "must do so with sufficient force to displace the presumption against extraterritorial application." 392 A "mere presence" by corporations, whether it is in the form of a branch or an office located within the US, as the Chief Justice clarifies, is insufficient. ${ }^{393}$ Although this opinion leaves the question of what exactly can be construed as "sufficient force" open to interpretation, Justice Breyer's concurring opinion sought to establish a more concrete test to determine whether plaintiffs can establish jurisdiction. The three factors that Justice Breyer's established were as follows: "(1) the alleged tort occurs on American soil, (2) the defendant is an American national, or (3) the defendant's conduct substantially and adversely affects an important American national interest." ${ }^{394}$ According to Justice Breyer, absent one of these factors, federal courts lack the jurisdiction to hear the case. Given that Kiobel did not meet any of these requirements - as the tort occurred on Nigerian soil between a Nigerian plaintiff and a British/Dutch corporation and the defendant's conduct did not substantially and adversely affect American interests (although Royal Dutch Petroleum does have some corporate presence in the US) - it was relatively easy for the Court to dismiss Kiobel by affirming the Court of Appeal.

It would be appropriate to recall Rio Tinto into the discussion here as the previous part of subsection tabled the outcome of the case until this subsection first dealt with Kiobel. As a reminder, prior to the Supreme Court's holding in Kiobel, the Ninth Circuit had held that the district court's recognition of the UN Convention on Law of the Sea ("UNCLOS") was a valid basis for an ATS claim, which was upheld during the appeal, 395 and that the political question challenge was overcome based on the fact that Papua New Guinea withdrew their contention. So while the case showed signs of promise for the alien plaintiffs, in the after-

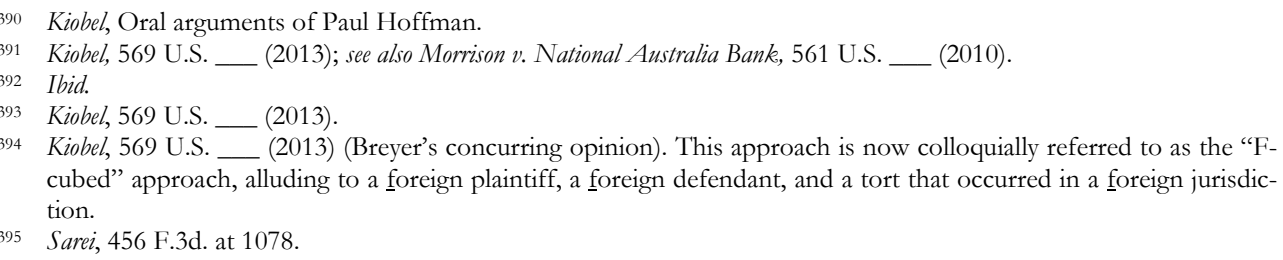


math of the Kiobel decision, however, Rio Tinto appealed to the Supreme Court based on the fact that the Ninth Circuit's ruling improperly relied on ATS's extraterritorial reach, which the Court held that there was a presumption against. The Court granted certiorari for Rio Tinto, but vacated and remanded the case without a full hearing for the lower courts to consider the case in light of Kiobel. What this meant was that because the case involved foreign plaintiffs suing a foreign defendant for a tort that occurred in Papua New Guinea, the ATS could no longer be considered as a basis for a valid claim. Accordingly, the case was dismissed once again, but this time with prejudice. ${ }^{396}$ The victims of Bougainville, as if they had not suffered enough from their livelihood being destroyed and enduring a decade long civil war, did not have anything to show for after jumping through obstacles for a litigation that continued on for 13 years in the US due in preponderant parts to the Kiobel decision.

In the end, Kiobel effectively authorized federal courts to dismiss alien plaintiffs that had a case under the ATS against a foreign defendant for a tort that took place abroad. Similar to Rio Tinto, in Linde v. Arab Bank, ${ }^{397}$ for example, the plaintiffs - a group of around 6,500 victims - alleged that the Arab Bank financed terrorism, which facilitated the terrorists to carry out suicide bombings in Israel and Palestinian territories with American casualties. The District Court initially held that Arab Bank had the duty to disclose information in accordance with the Federal Rules of Civil Procedure 37(b), but the Bank did not do so arguing that Jordanian privacy laws prohibited them from disclosing private banking information and a violation thereof could result in criminal sanctions back in Jordan. Some members of the plaintiffs were American citizens while some were foreign nationals. The basis of the claim for the US-based plaintiffs was the Anti-Terrorism Act, ${ }^{398}$ while the foreign nationals sought relief under the ATS.

What the Kiobel decision did effectively was to undercut the foreign nationals seeking relief under the ATS, which meant that with the exception of a few hundred or so American plaintiffs in the suit, the remainder of the foreign plaintiffs' case had to be dismissed in light of Kiobel. According to a statement by Arab Bank, Kiobel eliminated $90 \%$ of the claims against the bank, ${ }^{399}$ clearly illustrating the impact of Kiobel. Cases like Rio Tinto and Arab Bank illustrate the difficulties that lie ahead for foreign victims seeking access to justice in US federal courts under the post-Kiobel ATS regime. Whereas the ATS once enabled foreign plaintiffs to use the threat of a lawsuit as a possible leverage against MNCs - as exhibited by Unocal - even that limited option no longer seems to be available to the alien plaintiffs today as such options have since been stripped away by the US Supreme Court after its decisions in Sosa and Kiobel.

\section{F. The ATS Only has Limited Utility for Foreign Plaintiffs}

The story of the ATS - at least during the Filartiga era - was that of optimism, where some US courts attempted to breakdown the traditional procedural limitations to protect human rights and to provide remedy for those whose rights had been violated abroad, but had no

\footnotetext{
Sarei v. Rio Tinto Plc. No. 02-56256 (9 th $^{\text {th }}$ Cir. 2013) (order affirming the district court's dismissal of the case).

Linde v. Arab Bank Plc., 706 F.3d 92 (2 ${ }^{\text {nd }}$ Cir. 2013).

18 U.S.C. $₫ 2333$.

D. FISHER, "New York Federal Court Dismisses Alien Tort Claims Against Arab Bank,” Forbes, (26 August 2013).
} 
clear path to justice. Though it may have provided some with relief between the postFilartiga and pre-Kiobel era, the continued reliance on the ATS as a valid legal basis for an alien plaintiff - say an exploited laborer from Bangladesh - to seek justice in the US courts now seems unreasonable. ${ }^{400}$ Moreover, looking at the outrage that the ATS debate sparked at the international level speaks volumes of the state actors' allergy to the notion of universal jurisdiction and the idea that a foreign country would intervene and adjudicate their citizens (including corporate citizens) in another jurisdiction for a tort that occurred abroad. This was likely the most significant contributing factor to the ATS's premature demise and yet another evidence to substantiate the claims made earlier about the limitations of the so-called international law approach. While there are those that still continue to advocate for the extraterritorial adjudication of cases like John Ruggie, they are also quick to acknowledge the political infeasibility of such an approach. ${ }^{401}$ Although some speculate that corporate defendants could one day end up missing the ATS ${ }^{402}$ given the possibility that, due to forum non conveniens ground, they could end up being dragged into a litigation in far more difficult jurisdictions than in the US, for the time being, the corporations that are exploiting laborers appear to be "safe" from the extraterritorial reach of the ATS.

Before wrapping up the analysis of the ATS as a possible avenue of approach for exploited laborers to seek justice in the US federal courts and to ultimately curtail instances of labor exploitation in the global supply chain, it is worth pointing out for the sake of due diligence, one lingering issue that has not been discussed thus far. The source of this lingering issue comes from Justice Kennedy's concurring opinion in Kiobel, which stated rather cryptically that "the Court is careful to leave open a number of significant questions regarding the reach and interpretation of the Alien Tort Statute." 403 Justice Kennedy, however, did not specify what these "significant questions" were or what that means for future alien plaintiffs basing their claims on the ATS. The likely answer, based on the analysis presented in this subsection, is that Bangladeshi laborers bringing a claim against their Bangladeshi employer for labor exploitation that occurred in Bangladesh based on the ATS will likely lack standing even if the Bangladeshi employer had contractual relations with a US based company. The simple reason for this conclusion is that if we are to interpret the Court's language in Sosa and realize that customary international law did not - in 1789 - recognize labor exploitation as a violation of jus cogens or corporate liability for that matter, the answer to the question of whether the ATS would ever be able to restrict corporate malfeasance and their perpetuation of labor exploitation seems almost out of the question. As one judge keenly noted, "plaintiffs' imaginative view of this Court's power must face the reality that

B. STEPHENS, "Translating Filártiga: A Comparative and International Law Analysis of Domestic Remedies for International Human Rights Violations," Yale Journal of International Law 27(1) (2002), at p. 24 (stating that jurisdictional restrictions and other prudential considerations "make core human rights lawsuits impossible in many legal systems.").

401 J.G. RuggIE, Just Business: Multinational Corporations and Human Rights, (New York: W.W. Norton \& Company, 2013), at p. 117 (supporting extraterritorial adjudication of cases "where claimants face a denial of justice in a host state and cannot access home state courts regardless of the merits of the claim." However, Ruggie also recognizes that it is "not possible to reach a consensus on [extraterritorial adjudication] among governments at this time...").

402 J.C. Drimmer \& S.R. LamoreE, "Think Globally, Sue Locally: Trends and Out-of-Court Tactics in Transitional Tort Actions," Berkeley Journal of International Law 29(2) (2012), at p. 456, 472.

403 Kiobel v. Royal Dutch Petroleum, 569 U.S. __ (2013) (Justice Kennedy's concurring opinion). 
United States district courts are courts of limited jurisdiction. While their power within those limits is substantial, it does not include a general writ to right the world's wrongs." 404

The aim of this subsection was to describe an existing tort law framework in the US, which could possibly help exploited laborers empower themselves, by giving them access to justice in the US federal courts through the ATS. While this tort law based approach was - at least for some time - an approach that had more extraterritorial reach than labor/employment laws that focus purely on domestic matters, it seems that even the tort law based claims, at least those based on ATS, are still confined to its territorial boarders as well. 405 There is, however, one positive knock-on effect that came as a result of the series of ATS cases, which John Ruggie notes was the "growth of voluntary corporate social responsibility initiatives... at least in part to avoid ATS-type liability." 406 This issue of corporate social responsibility initiatives and its impact on curtailing labor exploitation in the global supply chain will be addressed in subsequent chapters as measures that really allow private actors to have an impact in order to reduce labor exploitations in the global supply chain.

Before addressing the growth of corporate social responsibility, for the time being, what will likely happen is that future alien plaintiffs will no longer seek access to justice under the ATS framework in the US federal courts, but will opt to seek relief in state courts based on state tort law claims as demonstrated by the plaintiffs in Unocal. 407 As briefly mentioned during the Unocal discussion above, it is common for victims to seek relief not only under the ATS in federal courts, but for them to also to seek remedies under the relevant state tort law claims in state courts. This is due to the fact that one violation, say torture, which could be considered as a violation of customary international law can also be categorized as simple assault and battery under a state tort law framework. ${ }^{408}$ While the Kiobel decision significantly reduced the likelihood of success under the ATS framework, the impact on the plaintiffs seeking access to justice in state courts under state law must be considered in and of its own, which will be the topic of discussion in the next subsection. damages, the damages were never actually paid as there were no enforcement measures that went after Peña-Irala ensured that he paid; see also, R. HAMiLTON, "A History of the U.S. Alien Tort Statute," Reuters, E. Evans (ED.) (30 September 2012); A.L. VYTOPIL, Contractual Control in the Supply Chain: On Corporate Social Responsibility, Codes of Conduct, Contracts and (Avoiding) Liability, (The Hague: Eleven, 2015), at p. 52 (stating that because the Supreme Court held that there is "a presumption against extraterritorial application under the ATS... virtually all pending ATS cases will likely be dismissed.”).

406 J.G. RugGIE, "Kiobel and Corporate Social Responsibility: An Issues Brief," Harvard John F. Kennedy School of Government Working Paper (4 September 2012), at p. 4.

407 H. L. BUXBAUM, “Transnational Regulatory Litigation,” Virginia Journal of International Law 46(2) (2006): 251-317, a p. 271 (stating that "[i]n an era in which unchecked corporate power often results in economic misconduct on a global scale, civil proceedings in US courts could help provide meaningful regulation of economically harmful behavior"); see also, EARTHRights InTERnATIONAL, "Out of Bounds: Accountability for Corporate Human Rights Abuse After Kiobel," (2013), at pp. 78-9.

408 EARThRights InTERnATIONAL, "Out of Bounds: Accountability for Corporate Human Rights Abuse After Kiobel," (2013), at p. 79. 


\subsubsection{California Civil Code: Foreign Victims in US State Courts}

The previous subsection hinted to the fact that many of the alien plaintiffs that sought relief based on the ATS also file tort law based claims at the US state court level in conjunction with their federal ATS claims. This strategy is relevant in the broader context of this thesis as it could possibly provide another avenue of approach for the exploited laborers in the bottom echelons of the supply chain to fight back against corporate malfeasance and labor exploitations in the US courts. Accordingly, this subsection will: a) present an overview of the applicable law regarding preliminary matters such as the issue of venue; b) elaborate on substantive laws that alien plaintiffs can base their claims upon; and finally, c) discuss the feasibility and the impact of this approach in light of our normative framework.

\section{A. Applicable Law, Venue, and Other Preliminary Matters}

During the analysis of Unocal at the federal level, ${ }^{409}$ the previous subsection mentioned that Unocal's parent company, Union Oil, was a company based in California and as a result, the alien petitioners brought a tort law based claims in the Superior Court of California, separate from their federal claim based on the ATS. ${ }^{410}$ Bearing in mind that this subsection is still dealing with the question of what alien petitioners can do to seek remedy in US courts for a tort that occurred abroad against companies that have connections to the US, this subsection will now briefly go over the facts from Unocal and assess whether a tort law based claim at the state level would be a feasible option for an alien petitioner in the future.

California, generally known as a plaintiff-friendly jurisdiction, is often the preferred jurisdiction for many plaintiffs, both foreign and domestic, as already evidenced by the series of aforementioned cases such as Rio Tinto and Unocal. Before getting to the substantive law aspect of a state based labor exploitation/tort claim, the preliminary issues of applicable law and venue must be addressed once again. Given that the plaintiffs in Unocal brought the case to a court in California, let us focus on the laws of California for this analysis. ${ }^{411}$ Though parties, in general, can opt to have a law of another jurisdiction apply, absent consent from both of the parties, even the question of the applicable law can become a contentious issue. In cases where the parties do not agree, determining the applicable law ${ }^{412}$ (or as the Superior Court refers to as the "choice of law") follows a 3-step governmental interest analysis in accordance with the precedent established in Washington Mutual Bank, ${ }^{413}$ which lays out the following framework: 1) "the foreign law proponent must identify the applicable rule of law in each potentially concerned state and must show it materially differs

Doe v. Unocal, 395 F.3d. 932 (Doe II) (9th Cir. 2002).

410 It is worth reiterating here that as a threshold matter, it is important to separate the analysis of forced labor and genocide in the context of customary international law under the ATS framework from claims such as negligence, false imprisonment, and wrongful death under the state tort based claims. Given that these are two different approaches to dealing with the same incident, even if the court dismisses the plaintiff's ATS claim, the plaintiff still has the chance to be heard on their state law claims, as was the case in Unocal.

411 Based on the principle of lex fori; Cf. A.L. VYTOPIL, Contractual Control in the Supply Chain: On Corporate Social Responsibility, Codes of Conduct, Contracts and (Avoiding) Liability, (The Hague: Eleven, 2015), at p. 276 (noting, with regards to the issue of choice of law, that the law of the home state of the MNC will "frequently not apply... in practice" as the Restatement (Second) of Conflict of Laws will deem the applicable law to be the law where the tort occurred).

412 Lex causae.

413 Washington Mutual Bank v. Superior Court, 24 Cal. 4th 906, 919 (2001). 
from the law of California"; 2) "if a material difference is found, the court must then determine what interest, if any, each state has in having its own law applied"; and 3) taking into consideration the existence of a material difference and each jurisdiction's interests, the court must "select the law of the state whose interests would be 'more impaired' if its law were not applied." 414

In Unocal, for example, the defendants argued that the law of Myanmar ought to apply in accordance with Washington Mutual Bank. ${ }^{415}$ Unocal, as the proponent of the foreign law and having the burden to identify applicable law, submitted a ten-page summary of the law of Myanmar by an expert to support its claim. ${ }^{416}$ The Superior Court ruled, however, that the ten-page summary was insufficient as it only presented "snippets and portions" of the Myanmar law and was therefore not extensive enough to establish that Myanmar's interests would be more impaired if the court applied California law. ${ }^{417}$ Because the proponents of the foreign law could not pass muster, the applicable law (choice of law) in Unocal was deemed to be that of California's. ${ }^{418}$

Not only is the applicable law a contentious subject in many cases, but in many transnational cases, the venue or the forum where the litigation will take place is also a frequent source of quarrels, with defendants making forum non conveniens based challenges to move the venue away from California to another jurisdiction such as the defendant's home jurisdiction or in the jurisdiction of there the tort allegedly took place. With regards to this point, alien plaintiffs must be aware that there is a presumption of forum shopping in most transnational cases against the plaintiffs, who usually file the claim in the US courts. This is due mostly to the fact that the differences in the discovery process and the availability of punitive damages in the US often allow foreign plaintiffs to claim remedies that they may not be entitled to in their home jurisdictions. ${ }^{419}$ The foreign jurisdiction might find this objectionable as we already witnessed during the Kiobel discussion. Another source of concern related to forum shopping is the availability of class action lawsuits in the US, which may not be available in the plaintiff's home jurisdiction. As evidenced by cases such as Unocal, Rio Tinto, and Kiobel, many of these transnational cases are class action lawsuits. While this topic of class action lawsuits will be tabled until the next subsection (Subsection 3.1.3), it is worth already pointing out here laws that enable class action lawsuits ought to be considered as capabilities-enhancing as it invites victims to form groups to augment their voices and to balance their collective power against the alleged tortfeasor. Before

414 Washington Mutual Bank v. Superior Court, 24 Cal. $4^{\text {th }}$ 906, 919-20 (2001).

415 Note that that in 1989, Burma officially changed their name to Myanmar.

416 Doe v. Unocal, Superior Court of California County of Los Angeles (No. BC 237980 and BC 237 679) (2004) p. 5, at para. $10-11$.

417 Doe v. Unocal, Superior Court of California County of Los Angeles (No. BC 237980 and BC 237 679) (2004) p. 5, at para. 10-11; see also, Sommer v. Gabor, 40 Cal. App. $4^{\text {th }} 1455,1469-1470$ (1995) (holding that snippets and portions of a foreign law is not adequate to make meaningful conclusions).

418 Doe v. Unocal, Superior Court of California County of Los Angeles (No. BC 237980 and BC 237 679) (2004) p. 6, at para. 4.

419 For example, the US is renowned for their protracted discovery phase and the availability of sometimes exorbitant punitive damages that may entice foreign plaintiffs to bring their suits in the US, even when there are more appropriate venues to adjudicate the question at hand; see, H. L. BUXBAUM, "Transnational Regulatory Litigation," Virginia Journal of International Law 46(2) (2006): 251-317, a p. 305 (noting that "transnational litigation creates a tension between two goals: increased effectiveness in regulating economic misconduct and maintenance of order within the international community"); see also, A.L. VYTOPIL, Contractual Control in the Supply Chain: On Corporate Social Responsibility, Codes of Conduct, Contracts and (Avoiding) Liability, (The Hague: Eleven, 2015), at p. 276. 
elaborating on the issue of class action lawsuits, however, the analysis of alien plaintiffs seeking access to the California courts must be completed first.

While the courts in California, with their reputation of being a plaintiff-friendly jurisdiction, may be perceived as being "more willing" to provide a forum for these types of cases, in the aftermath of Kiobel and in light of these possible tensions, even the California state courts are increasingly becoming cautious about not over-extending their jurisdiction and ensuring not to grant alien plaintiffs with legal standing unless the case actually "touches or concerns" the California. ${ }^{420}$ In other words, in order for the California courts to hold that they have jurisdiction over the case, the alien plaintiff will still have to establish personal jurisdiction against the defendant similar to the process of establish personal jurisdiction in federal cases, where the defendant must somehow be connected to California in a significant way. Absent that connection, even the California state courts will most likely dismiss the plaintiff's case. In sum, it must be noted that even with the state tort based claims in the state courts, the alien plaintiffs will still face series of procedural challenges like establishing personal jurisdiction or fighting off forum non conveniens claims even before getting to their substantive arguments.

\section{B. Relevant California Tort Law}

Having described some of the preliminary issues that the alien plaintiffs can encounter, this part of the subsection will now proceed with the substantive concerns that come with alien plaintiffs bringing claims based on a state tort law claims for torts that occurred abroad in Californian courts. Before getting into the details, however, a brief differentiation of intentional torts from unintentional torts must be made in the context of an exploited worker seeking redress against their employer, who is a subsidiary of a company based in California, as was the case in Unocal.

With regards to unintentional torts, say that of negligence, the duty not to cause harm either by an act or an omission is a duty that both the parent and subsidiary companies must adhere to. If, for example, a subsidiary causes harm to its workers in the course of conducting its operation outside of the US, the failure of the parent company to exercise due diligence and to prevent that foreseeable damage by its subsidiaries could potentially be grounds for a negligence action directly against the parent company.

With regards to intentional torts such as false imprisonment or wrongful death claims, generally speaking, the element of intent by the parent company must be established by the plaintiffs, which could prove difficult if the actual wrongdoing was carried out by the subsidiary based in a foreign jurisdiction and not the parent company based in California. While directly going after the subsidiary in the jurisdiction where the tort occurred would be an easier case to establish for various threshold issues noted above, it is often the case that the plaintiffs want to go after the big fish or the parent company based in places like California in US state courts for the reasons mentioned above (i.e. US courts allow for punitive damages and class action lawsuits). While there are clear benefits for the alien

420 A.L. VYTOPIL, Contractual Control in the Supply Chain: On Corporate Social Responsibility, Codes of Conduct, Contracts and (Avoiding) Liability, (The Hague: Eleven, 2015), at p. 276 (noting that "the courts have severely restricted the application of [ATS] in respect of cases that fall within its scope" and adding that the reason for this restriction is based on the recent reinterpretation of the "touch and concern" standard and what types of actions can be considered as touching and concerning the territory of the US). 
plaintiffs to initiate proceedings in US courts against the parent company based in California, this process could present a serious legal obstacle for the plaintiffs who must establish a connection between the parent company and its subsidiaries (or possibly contractors or other separate legal entities with only contractual ties).

The plaintiffs in Unocal, however, were able to establish a connection with the US rather easily based on the fact that Unocal and its parent company, Union Oil, were both based in California. During the trial court stage in the Superior Court of California (County of Los Angeles), the plaintiffs made claims based on California tort law for battery, false imprisonment, assault, intentional infliction of emotional distress, conversion, negligence, negligent infliction of emotional distress, negligence per se, and negligent hiring and supervision by Unocal, ${ }^{421}$ but as noted earlier, the parties settled out of court, after the defendant's motion for judgment was rejected. Therefore, this thesis will not elaborate on the elements of all of these torts, but to the extent that the claim of negligence is the most common claim in scenarios where plaintiffs are attempting to hold the parent corporation liable for abuses carried out by its subsidiaries for the reasons noted above, the remainder of this part of the subsection will focus on this particular cause of action.

The traditional elements of negligence are duty, breach, causation, and damage, but many jurisdictions across the US make subtle changes to these core elements. ${ }^{422}$ California, for example, differentiates legal cause from proximate cause while incorporating the damage element into the causal requirement. ${ }^{423}$ First, with regards to the duty requirement, California's Civil Code \$1714(a) is a catch all, which establishes a general duty of care for "everyone" to not cause injury to others. For the sake of our purposes, this general duty can be relied on as the relevant duty on which a claim of negligence can be built upon. ${ }^{424}$ With regards to the other elements, the California courts have held that the elements of negligence are: "(a) legal duty to use due care; (b) a breach of such legal duty; [and] (c) the breach as the proximate or legal cause of the resulting injury." ${ }^{25}$ The difference between proximate cause and legal cause can be simplified as follows: cause in fact or legal cause is an inquiry into whether the defendant's wrongdoing actually caused the harm that the plaintiff has suffered, whereas proximate cause inquiries about the proximity of the wrongdoing and the damage caused. So in the context of proximate cause, determining the causal link has to do with the issue of foreseeability. ${ }^{426}$

421 See, The RobBins Collection, "The Common Law and Civil Law Traditions," University of California at Berkley School of Law (2010), at p. 4 (noting that "California has a state civil code organized into sections that echo traditional Roman civil law categories pertaining to persons, things, and actions..."); Doe v. Unocal, Superior Court of California County of Los Angeles (No. BC 237980 and BC 237 679) (2004) p. 2, at para. 16-21.

422 Restatement (Third) of TORTs: Liability for Physical and EMOtional Harm $\$ 6$ recognizes five elements for negligence: "duty," "failure to exercise reasonable care," "factual cause," "physical harm" and "harm within the scope of liability (which historically has been called 'proximate cause')".

423 Ladd v. County of San Mateo, 911 P.2d 496 (Cal. 1996) (citing Evan F. v. Hughson United Methodist Church, 8 Cal.App. $4^{\text {th }} 828,834(1992)$.

424 "Everyone is responsible, not only for the result of his or her willful acts, but also for an injury occasioned to another by his or her want of ordinary care or skill in the management of his or her property or person, except so far as the latter has, willfully or by want of ordinary care, brought the injury upon himself or herself...The extent of liability in these cases is defined by the Title on Compensatory Relief."

425 Ladd v. County of San Mateo, 911 P.2d 496 (Cal. 1996) (citing Evan F. v. Hughson United Methodist Church, 8 Cal.App. $4^{\text {th }} 828,834$ (1992).

426 Burns v. Neiman Marcus Group, 173 Cal.App.4th 479, 488, fn. 8 (2009) (noting that "[f]irst, the [trier of fact] may consider the likelihood or foreseeability of injury in determining whether, in fact, the particular defendant's con- 
Having established the basic elements of negligence in California, let us apply these rules to a series of hypotheticals to help illustrate the kind of uphill battle that the alien plaintiffs can expect to encounter even at the state court level: An employee working for a construction company falls from a poorly maintained scaffolding equipped by the company and suffers a broken hip. To successfully claim negligence based compensation in California, the employee must first establish that the employer had the duty to properly maintain the scaffolding (a duty that was breached). The fall was both the proximate cause and the legal cause of the damage that the employee suffered (i.e. broken hip), because it was foreseeable that if the construction company failed to maintain the scaffolding properly, an employee who gets on the scaffolding could fall from it, which is precisely what happened. In this simple hypothetical, all of the elements of negligence have been met and the employee can thus claim compensation from the employer (i.e. the construction company). ${ }^{427}$

By adding an extra actor to this hypothetical, say a subcontractor who is now in charge of solely setting up the scaffolding, the question becomes slightly more complex. The employee, who is still working for the construction company, can now sue the subcontractor for breaching its duty (i.e. failing to properly maintain the scaffolding) and claim compensation for damages suffered, but the question of whether the employee can still sue the construction company for negligently hiring the subcontractor becomes an entirely separate analysis. For example, what is the duty of the construction company now (i.e. perhaps to conduct due diligence to ensure that the subcontractor is competent) or whether there was legal or proximate cause (i.e. was it foreseeable for the construction company that if they hired the subcontractor, the subcontractor could breach its duty, which in turn could cause harm to the employee). In this second scenario, the outcome of whether the employee can claim that the construction company was negligent becomes a bit more complicated.

In the next variation of the hypothetical, imagine if the employee was no longer an actual employee of the construction company, but an independent contractor that the subcontractor hired to facilitate the construction company's business. In this case, what duty does the construction company owe to the independent contractor that was hired by the subcontractor? Though no definitive answer can be offered without painting a more complete picture, one answer, relatively speaking, would be that it will be far more difficult for that independent contractor in the third scenario to claim negligence against the construction company compared to the employee from the first scenario.

Now imagine a real world supply chain, where there are even more players involved (recall Table 1 from Chapter 1 that illustrated the cobalt supply chain) and add to that the fact that not all of the parties are even located on the same continent. Faced with this reality, the analysis of what is foreseeable or the question of what duty a parent company owes to the contractor hired by a company that supplies a component to one of its subsidiaries becomes extremely difficult to answer. Faced with this complexity, the courts will likely hold that the parent company owed no meritable duty of care to the supplier's contractor.

duct was negligent in the first place. Second, foreseeability may be relevant to the [trier of fact's] determination of whether the defendant's negligence was a proximate or legal cause of the plaintiff's injury.”).

27 Issues of contributory negligence and damage calculations could always arise to complicate matters, but alas. 


\section{State Law Options are Limited as Well for the Alien Plaintiffs}

As noted earlier, in many of these cases, the parties either settled out of court or the case was simply dismissed. This is to point out that looking at case laws do not offer us much guidance in terms of the options that are available to the alien plaintiffs and the likelihood of their success. However, perhaps the very lack of successful cases to recite here, suggests that for the alien plaintiffs seeking to bring claims against corporations for a tort that occurred abroad, US state courts may not be the approach that offers high probability of success either.

Speaking of increasing the chances of their success in court, however, one sure way to do so is by bringing a class action lawsuit against the alleged corporate tortfeasor, which is at least an attempt to level the unbalanced bargaining power between the resource-strapped plaintiffs and the often affluent corporations through the adage that there is power in numbers. The next subsection will address this issue of class action lawsuits and representative mass litigations, to answer the question of how workers can rely on these measures to enhance their voice, thus increase their capacity to challenge those that have exploited them.

\subsubsection{Class Action and Representative Litigation for Transnational Cases}

What many of the transnational litigations based on allegations of human rights violations (including accusations of forced labor) presented above have in common is the plurality of plaintiffs in each of the cases. These cases generally take the form of class action lawsuits, where there are multiple plaintiffs suing a corporation and its subsidiaries. Moreover, it is not uncommon to see non-governmental organizations like the Center for Constitutional Rights or EarthRights International play important support roles by facilitating these resource-strapped plaintiffs navigate the often expensive and complicated litigation process. In some very special cases, these NGOs can even represent the interest of the plaintiffs in court by being designated as a representative plaintiff. ${ }^{428}$ This is to suggest that any laws or measures that allow or enable a group of individuals to collectively act for a shared purpose - to right a wrong that has allegedly been committed - is surely capabilities-enhancing.

This begs the question of whether these litigation mechanisms can actually be utilized as yet another way for exploited laborers in the bottom echelons of the global supply chain to seek access to justice in US courts by either joining a class action or by having their interests represented by an NGO that is based in the US, thus giving the plaintiffs a connection - though arguably tenuous - with the US. In other words, can NGOs based in the US sue on behalf of foreign plaintiffs for a tort that occurred abroad in US courts? Bearing this question in mind, this subsection will address whether foreign plaintiffs can actually circumvent the jurisdictional restrictions that may bar them otherwise from having their cases heard in US courts and whether this could possibly lead to abusive forum shopping practices, which could potentially irk other sovereign nations in a similar way that the ATS did. 


\section{A. Class Action}

In the US, for federal class actions, Federal Rules of Civil Procedure (“FRCP”) Rule 23 in conjunction with 28 U.S.C. 1332(d) outline the requirements for filing a class action lawsuit. ${ }^{429}$ Under its provisions, the party seeking the class action must establish in the complaint the following elements: 1) numerosity, 2) commonality, 3) typicality, and 4) adequacy of representation of the class. ${ }^{430}$ Class action certification requirements at the state level, say in California, are very similar to the federal certification requirements: For example, California's Code of Civil Procedure Section $382^{431}$ and Rule 3.764 of the California Rules of Court establish the certification requirements that the class must be "ascertainable" and that there must be a "well defined community of interest in the question of law and fact involved in the case." 432 This requires - at the very least - that the class must share a common question of law or fact, that there is a typicality of the claims within the class, and that the class can adequately represent all members of the class as a whole. ${ }^{433}$ Essentially, the federal and state (i.e. California) requirements for certification are almost identical.

What is implicit in these rules is the general reluctance by the courts to accept class action lawsuits, even for domestic plaintiffs. ${ }^{434}$ However, this does not mean that they are precluded from doing so as evidenced by the existence of various class action tort claims such as Rio Tinto and Arab Bank - both at the federal and state level. Actually establishing class certification, however, is difficult under FRCP Rule 23 and its state counterparts, especially when foreign plaintiffs are involved, usually due to insufficient typicality and commonality. ${ }^{435}$ What this means is that foreign plaintiffs and US-based plaintiffs may form a class to target the same defendant and its alleged wrongful conduct, but that is not to say that the damages that each of the groups suffered is common enough to certify all of the victims under one classification, especially when one group of plaintiffs are US-based and the others are not.

As cases such as Arab Bank illustrated earlier, the courts have no problem separating the classes into two, one with US-based plaintiffs and the other consisting of alien plaintiffs, and simply dismissing the latter due to lack of legal standing. ${ }^{436}$ This lack of commonality and typicality is one of the biggest challenges that could prevent foreign plaintiffs from joining a class with US-based plaintiffs thus denying them access to justice through the US

Other threshold requirements for a federal class action are: 1) diversity (this element requires that the parties must reside in different States, which in the context of a transnational litigation will likely be a given) and 2) amount in controversy (the requirement that the amount of controversy is at least $\$ 75,000$ ) in addition to the 4 requirements set forth by FRCP Rule 23.

430 FRCP Rule 23(a).

431 California Code of Civil Procedure Section 382 states: "[W] hen the question is one of common or general interest, of many persons, or when the parties are numerous, and it is impracticable to bring them all before the court, one or more may sue or defend for the benefit of all."

432 Lindner vs. Thrifty Oil, 23 Cal.4th 429, 435 (2000).

433 See generally, Judicial Council of California (Administrative Office of the Courts), "Class Certification in California: Second Interim Report from the Study of California Class Action Litigation" (February 2010). Available at: http://www.courts.ca.gov/documents/classaction-certification.pdf (last accessed 4 April 2017).

434 This is assumed on the basis of the fact that in order for a class to be certified, they must also state in the complaint the justification of the class action, whether that reason is that the individual adjudication would prejudice the party opposing the class or some reason as to why the class action is a better mechanism than individual adjudication of the claims. See e.g. FRCP Rule 23(b)(1)(A), (b)(1)(B), (b)(2) and (b)(3).

435 H. L. BuxBAum, “Transnational Regulatory Litigation,” Virginia Journal of International Law 46(2) (2006): 251-317, a p. 311.

436 See e.g. Linde v. Arab Bank, 706 F.3d 92 (2 $2^{\text {nd }}$ Cir. 2013). 
courts even if they initiate a class action lawsuit together with domestic plaintiffs. In other words, while class action lawsuits permit plaintiffs in similar situations to join forces and to collectively seek redress, its application does not extend to all nor does it allow basic jurisdictional requirements to be circumvented.

\section{B. Representative Litigation}

If joining a class proves to be too difficult for the reasons stated above, the other possibility available to the foreign plaintiffs could be to have their interests represented by an organization based in the US instead. Particularly if what the foreign plaintiffs are seeking is either declaratory or injunctive relief (and not financial compensation or damages), this could potentially provide a satisfactory outcome for the foreign plaintiffs. While it is possible for organizations to represent a case on behalf of plaintiffs in the US - at least in theory - the procedural requirements could, in practice, prevent foreign plaintiffs from relying on US based associations or organizations to represent their interests in US courts.

First of all, the relevant case law in the US that established the standard for whether an organization or an association has standing to bring a suit on behalf of its members is Hunt v. Washington State Apple Advertising Commission. ${ }^{437}$ Hunt held the following elements to be the requirement for representative litigation: An organization or an association has standing if "(a) its members would otherwise have standing to sue in their own right; (b) the interests it seeks to protect are germane to the organization's purpose; and (c) neither the claim asserted nor the relief requested requires the participation of individual members in the lawsuit." ${ }^{438}$ By reading these requirements even in the most lenient way possible, here again, it would be difficult for a US based NGO to represent a group of foreign plaintiffs as the first prong of Hunt requires that individual members have standing in their own right.

One of the more notable examples of a failed attempt at representative litigation can be found in Bhopal incident, ${ }^{439}$ where plaintiff organizations attempted to bring damage claims on behalf of its members who were all victims of the Bhopal disaster in India. The contentious series of litigations, which lasted for decades, arouse from one of the worst industrial disasters in India, where a gas leak at a pesticide plant owned by an American corporation in Bhopal exposed over 500,000 people to toxic gas that ultimately lead to the deaths of more than 3,000 residents that lived near the chemical plant. ${ }^{440}$ The plaintiffs initially brought a suit under the ATS, but subsequently amended their complaint to include New York state law as well for environmental pollution related claims.

In addition to individual plaintiffs, several organizations representing residents of Bhopal such as Bhopal Gas Peedit Mabila Udyog Sangathan, Bhopal Gas Peedit Mabila Stationery Karmachari Sangh, and a handful of other organizations applied to be considered as plaintiff organizations representing the interest of Bhopal victims. Their claims, however, were all denied due to the fact that the groups could not establish the requirements of individual

437 Hunt v. Washington State Apple Advertising Commission, 432 U.S. 333 (1977).

438 Hunt, 432 U.S. at 343.

439 Bano v. Union Carbide Corporation, 361 F.3d 696 (2nd Cir. 2004); Bano v. UCC, No 99 Civ. 11329 (JFK) (S.D.N.Y. 2003); Bano v. Union Carbide Corporation, 273 F.3d 120 (2 $2^{\text {nd }}$ Cir. 2001); In re Union Carbide Corp. Gas Plant Disaster, 634 F.Supp. 842 (S.D.N.Y. 1986).

440 See generally, In re Union Carbide Corp. Gas Plant Disaster, 634 F.Supp. 842, 844 (S.D.N.Y. 1986). 
standing, representativeness, and the commonality of the relief being sought amongst its members. ${ }^{411}$ Similar to the limitations of the class action approach, even for representative actions, legal standing for the individual members of the group is the minimum requirement, which means that a representative action is also not a feasible way for alien plaintiffs to circumvent the jurisdictional requirements.

To summarize this brief subsection, class action lawsuits and representative actions, while advantageous for most plaintiffs, especially when individual members of a class cannot afford to litigate against a multinational corporation on their own, does not offer much solace to alien plaintiffs attempting to establish legal standing in US courts. While class action lawsuits and representative actions could, in theory, serve important functions that would help the plaintiffs navigate through the US legal system both at the federal level and state level, these mechanisms simply do not allow jurisdiction or standing requirements to be circumvented. Thus, the answer to the question posed in the beginning of whether foreign plaintiffs can join the same class as that of the domestic plaintiffs is an almost certain no, as classifying a foreign plaintiff and a domestic plaintiff in the same class would violate at various requirements necessary to form a class. Foreign plaintiffs would likely have to form their own class consisting only of foreign plaintiffs - as witnessed in Arab Bank - and that class will have to establish standing and jurisdiction on its own, which could prove to be an almost impossible task. Similarly, with regards to representative actions, foreign plaintiffs will also encounter obstacles given the requirements established in Hunt that in order for an association or a group to have standing, each of its members would have to have standing to sue on their own right. In short, while possibly capabilitiesenhancing in theory, class action and representative litigations are not so in reality, at least for the alien plaintiffs seeking access to justice in US courts.

\subsubsection{US Tort Law and Their Limitations}

In light of the fact that the ATS has been neutered to a point where it is useful only in extremely limited circumstances, alien plaintiffs seeking access to justice in US courts must therefore switch strategies to file their complaints in state courts. However, this section also showed that even this approach is becoming increasingly difficult even in plaintiff-friendly jurisdictions like California especially if the defendant's connection to the state is tenuous or if the tort that was committed abroad was carried out not by the US-based company but by its subsidiary, or worse, some third party. The fragmented nature of the global supply chain, in other words, is what is making it more difficult, not only for alien plaintiffs, but for petitioners in general to establish connections between the actual tortfeasor and the companies that have control over them. While Section 3.4 will elaborate on this particular problem of increasing fragmentation, this section will conclude, at least for the moment, by noting that alien plaintiffs will find it extremely difficult to gain access to justice in US courts for torts that occurred abroad especially when the alleged defendant's connection to the US is tenuous. While class action lawsuits or representative lawsuits could empower the plaintiffs in theory, the practical limitation of legal standing prevents alien plaintiffs from 
benefiting from these capabilities-enhancing mechanisms. The next subsection will address whether foreign plaintiffs face similar difficulties in Dutch courts.

\subsection{FOREIGN VICTIMS IN DUTCH COURTS}

We now shift gears to address the issue of whether the Dutch legal system offers better access to justice within their courts for alien plaintiffs relying on tort law claims. Accordingly, this section will first present an overview of how alien plaintiffs can seek access to justice in Dutch courts by following the Akpan v. Royal Dutch Petroleum case (Subsection 3.2.1). Then, the next subsection will analyze the Dutch approach to collective redress that is slightly different from that of the US (Subsection 3.2.2), and the last subsection section will conclude by addressing whether Dutch courts enabling alien plaintiffs to seek access to justice in their courts can actually enhance the capabilities of exploited laborers in a manner that will reduce labor exploitations in the global supply chain. (Subsection 3.2.3).

\subsection{1 "Dutch" Law: Foreign Victims in The Hague}

The focus of this subsection is still on whether tort laws are enabling private actors to deal with the problem of labor exploitations taking place outside of their territorial boarders. This section in particular will address whether Dutch tort law is enabling laborers exploited abroad to seek justice in Dutch courts against Dutch companies, and what private actors can do to facilitate this process. Accordingly, this section will: a) start by explaining preliminary matters such as determining venue and applicable law under the Dutch legal system as influenced by EU law; b) present the most recent and relevant cases that illustrate how alien plaintiffs can seek justice in Dutch courts; c) elaborate on some of the difficulties that still lie ahead for alien plaintiffs seeking access to justice in Dutch courts; and finally, d) conclude by assessing whether Dutch tort law is enabling foreign victims of labor law to empower themselves in a manner that would contribute to the reduction of labor exploitation in the global supply chain.

\section{A. Dutch Law and European Harmonization on Venue and Applicable Law}

As already noted in the introduction, the analysis of Dutch law inevitably requires a functional understanding of various EU legislations as they impact both substantive and procedural application of Dutch law. Generally speaking, Dutch law allows "foreign" plaintiffs better access the Dutch courts for tort claims even if the incident occurred abroad than the US courts, although to what extent depends on whether the plaintiffs are residents of other EU Member States or not. In this context, it is important to remember the impact that the EU and its harmonizing measures have on Dutch law through measures such as the Brussels ${ }^{442}$ and Rome Regulations, ${ }^{443}$ as they affect the issue of venue and applicable law within

Regulations that deal with jurisdiction and enforcement issues for civil matters within the EU Member States. Regulation (EU) No 1215/2012 of the European Parliament and of the Council of 12 December 2012 on jurisdiction and the recognition of judgments in civil and commercial matters (Recast) OJEC (L 351/1) replaced its predecessor, Brussels I Regulation Council Regulation (EC) No. 44/2001 of 22 December 2000 on Jurisdiction 
the EU, especially in transnational cases. With regards to the matters of venue and jurisdiction, the Brussels Regulation Recast gives us guidance: Article 1 notes the Regulation applies to civil and commercial matters, but noting very clearly that it will not extend to matters that could implicate other sovereignties (acta iure imperii). More relevant to our discussion, Article 4 notes that, in general, the court where the defendant has its habitual residence is deemed as the appropriate jurisdiction. ${ }^{444}$ Article 7 further enumerates instances where a person domiciled in a Member State may be sued in another Member States other than where they are domiciled: For example, in cases of a contractual dispute, the courts where the performance or the obligation in question was to take place can have jurisdiction, ${ }^{445}$ or in tort cases, the courts of the place where the harmful event occurred or may occur is the appropriate venue. ${ }^{446}$ Yet another exception to the general rule, one that is perhaps more favorable to employees can be found in Article 21(b)(i) of the Recast, which notes that an employer may be sued in a Member State other than the one they are domiciled, including, but not limited to the court in a jurisdiction where the employee habitually carries out his work, which has the potential of reducing the costs that an exploited laborer could bring against his employers in the Member State jurisdiction in which he resides.

There are two additional articles worth noting in our context, which could potentially be useful for foreign plaintiffs: The first is Article 8 of the Recast, which states that a person domiciled in a Member State to be sued in another jurisdiction in the event that there are multiple defendants and a court in the other Member State, where any one of the other defendants are domiciled. ${ }^{447}$ The second is Article 34, which explicitly mentions third

and the recognition and enforcement of judgments in civil and commercial matters. OJEC (L12/1), and went into force in January 2015. Parts of the recast now applies to non-EU residents in some cases as well; see also, A.L. VYTOPIL, Contractual Control in the Supply Chain: On Corporate Social Responsibility, Codes of Conduct, Contracts and (Avoiding) Liability, (The Hague: Eleven, 2015), at p. 276 (noting that "[ $[\mathrm{t}]$ he question of jurisdiction is governed by Brussels I regulation, which - most importantly - holds that the court of the state in which the defendant has its domicile will have jurisdiction (although alternative grounds for jurisdiction exist).").

443 Regulation (EC) No. 593/2008 of 17 June 2008 (Rome I) applied to contractual situations and Regulation (EC) No. 864/2007 of 11 July 2007 (Rome II) applies in conflict of law situations of a non-contractual obligation scenario; see also, A.L. VYTOPIL, Contractual Control in the Supply Chain: On Corporate Social Responsibility, Codes of Conduct, Contracts and (Avoiding) Liability, (The Hague: Eleven, 2015), at p. 276 (stating that "in contract cases, the Rome I regulation determines that choices of law will be respected" but in the absence of a choice of law clause, "the law of the state with which the contract is most closely connected to is applicable, although exceptions apply."). Rome II, in relevant parts, stating that in cases of tort, the law of the state where the tort took place will be applicable.

444 Article 4(1) notes that "[s]ubject to this Regulation, persons domiciled in a Member State shall, whatever their nationality, be sued in the courts off that Member State." Article 4(2) elaborates that "[p]ersons who are not national of the Member State in which they are domiciled shall be governed by the rules of jurisdiction applicable to nationals of that Member State." There is not much difference between the original Regulation and the Recast with regards to this issue, and determining whether a foreign plaintiff can sue in the court of a particular Member State depends on the law of that Member State. Council Regulation (EC) No 44/2001 of 22 December 2000 on Jurisdiction and the Recognition and Enforcement of Judgments in Civil and Commercial Matters; Prior to the Recast, Brussels I Article 2(1) noted that "persons domiciled in a Member State shall, whatever their nationality, be sued in the courts of that Member State." See also, A. RüHMkORF, Corporate Social Responsibility, Private Law and Global Supply Chains, (Cheltenham: Edward Elgar, 2015), at p. 84. Brussels I Regulation Recast Art 7(1)(a).

446 Brussels I Regulation Recast Art 7(2).

447 Brussels I Regulation Recast Art 8(a) (adding that this is possible "provided the claims are so closely connected that it is expedient to hear and determine them together to avoid the risk of irreconcilable judgments resulting from separate proceedings"). Article 20(1) of the Recast deals with the issue of jurisdiction with issues regarding employment matters, but it specifically notes that jurisdiction shall be determined "without prejudice" to the aforementioned Article 7 and 8 . 
states (non-EU states), but in the context of how Member States may stay the proceedings, if legal proceedings have already initiated in a third state. The relevance and the application of these articles will be addressed in the next subsection.

With regards to the question of applicable law, both Rome Regulations pay respect to party autonomy and the choice of law that the parties agree to, ${ }^{448}$ but in tort cases where there are no choice of law clauses, Rome II Article 4(1) generally states that "the law applicable to a non-contractual obligation arising out of a tort/delict shall be the law of the country in which the damage occurs irrespective of the country in which the event giving rise to the damage occurred and irrespective of the country or countries in which the indirect consequences of that event occur. In short, Rome II generally abides by the lex loci damni principle, or the law of the country where the injury took place. ${ }^{449}$

Bearing in mind the impact of Rome and Brussels Regulations, with regards to proper venue for an individual litigant, the appropriate forum for adjudication, generally speaking would be the jurisdiction where the defendant resides, especially if the tort in question occurred there as well. This is so given that the defendant's place of residence usually determines the venue. In cases where the defendant is a legal entity like a corporation, their place of incorporation or business headquarters will be considered as the appropriate venue. ${ }^{450}$ In the Netherlands, which incorporated the Brussels Recast into its revised Civil Code, a corporation is domiciled in the place of its incorporation. ${ }^{451}$ Therefore, even if the company has its headquarters elsewhere, so long as they incorporated in the Netherlands, they are subject to be sued in the Netherlands and the Dutch courts have jurisdiction over them. ${ }^{452}$ Essentially, if a company is "domiciled" in the Netherlands, then the Dutch courts will not dismiss the case on the grounds of forum non conveniens. 453

448 For example, Rome I Article 3(1) emphasizes that the "parties have the freedom of choice to determine the law applicable to their contract." See, Regulation (EC) No 593/2008 of the European Parliament and of the Council of 17 June 2008 on the law applicable to contractual obligations. A. RüHMKORF, Corporate Social Responsibility, Private Law and Global Supply Chains, (Cheltenham: Edward Elgar, 2015), at p. 84

449 Rome II Article 4(2) if the victim and the tortfeasor reside in the same Member State, then the law of that Member State ought to apply.

450 Brussels Recast Article 63(1) (or formerly Brussels I Article 60(1)), noting the following: "For the purposes of this Regulation, a company or other legal person or association of natural or legal persons is domiciled at the place where it has its (a) statutory seat, or (b) central administration, or (c) principal place of business."

451 A.L. VyTOPIL, Contractual Control in the Supply Chain: On Corporate Social Responsibility, Codes of Conduct, Contracts and (Avoiding) Liability, (The Hague: Eleven, 2015), at p. 276 (noting that " $[\mathrm{i}] \mathrm{f}$ the defendant is a Dutch MNC, a Dutch court will have jurisdiction."); see also, BW Article 1:10(2) (stating that "the domicile of a legal person is located at the place where he has his seat according to law or his articles of incorporation or by-laws.”); and, BW Article 1:14 (stating that a "person who keeps a head office has, for all matters related to his enterprise, his domicile also at the place of this head office. A person who keeps a branch office has, for all matters related to this specific branch, his domicile also at the place of this branch office.").

452 Cf. Some of the other Member States (i.e. Germany and France) apply the "real seat" doctrine. This is not to suggest that the only forum where the company can be sued is where the company was incorporated. In the European context, Brussels (I) Article 5(3) also a "[A person domiciled in a Member State may, in another Member State, be sued] in matters relating to tort, delict or quasi-delict, in the place where the harmful event occurred or may occur..."; see also Article 5(5): ““"[A person domiciled in a Member State may, in another Member State, be sued] as regards a dispute arising out of the operations of a branch, agency or other establishment, in the courts for the place in which the branch, agency or other establishment is situated..."

453 See generally, Case 281/02, Owusu v. Jackson [2005] ECR I-1383; see also, N.M.C.P. JÄGERS \& M. J. VAN DER HeIjDEN, "Corporate Human Rights Violations: The Feasibility of Civil Recourse in the Netherlands," Brooklyn Journal of International Law 33(3) (2008): 833-870, 850. 
Cases where all the parties are Dutch residents do not, relatively speaking, present any jurisdictional or forum issues, as Dutch law and Dutch courts will be the appropriate law and venue. Even when there are non-Dutch parties involved, so long as they are still residents of a EU Member State, Brussels Recast, would extend the court's jurisdiction to these non-residents so long as there is a close connection between the claims and adjudicating the matter in the Netherlands would be expedient. ${ }^{454}$ The more intriguing scenario is what happens when the litigants are not Dutch and do not reside in any EU Member States. Essentially, Brussels outlines the framework at a supranational level for establishing jurisdiction within the Member State's courts, but unlike the ATS framework of yesteryears, Brussels does not have an extraterritorial reach and would require plaintiffs to establish some territorial connection to the Member States where the suit is brought, whether it be that the violation occurred within their territory or that the claim is against a defendant residing within the EU. In other words, Brussels would not allow a foreign petitioner to bring a claim regarding a violation that occurred abroad, which was committed by an alien defendant with no connection to the EU into their courts. If some connection can be established, then it is up to the Member States to decide, as Brussels does not explicitly provide guidance when the plaintiffs are non-EU members.

With regards to the issue of applicable law, the relevant legislation in the EU context is the Rome regulation. Rome II Article 14(1), for example, states that if the parties can agree on the applicable law "by an agreement entered into after the event giving rise to the damage occurred" then that choice prevails. ${ }^{455}$ If the parties cannot agree on the applicable law, lex loci deliciti would hold that the law of where the harm occurred ought to be the applicable law. Accordingly, Rome II Article 4 (1) states that "the law applicable to a noncontractual obligation shall be the law of the country in which the damage arises or is likely to arise, irrespective of the country in which the event giving rise to the damage occurred and irrespective of the country or countries in which the indirect countries of that event arise." ${ }^{456}$ Given that the Rome Regulations apply to the Netherlands, the Dutch courts will generally apply "foreign law in transnational human rights litigation that seeks to hold a parent company accountable for acts or omissions in violation of a duty of care by the parent company itself." 457

To summarize this part of the subsection, the law does not preclude a foreign plaintiff from filing a complaint in Dutch courts so long as there is a "close connection" to the

454 Brussels I Regulation Recast Art 8(a) (adding that this is possible "provided the claims are so closely connected that it is expedient to hear and determine them together to avoid the risk of irreconcilable judgments resulting from separate proceedings"). Formerly Brussels I Article 6(1), noting that "a person domiciled in a Member State may also be sued where he is one of a number of defendants, in the courts for the place where any one of them is domiciled, provided the claims are so closely connected that it is expedient to hear and determine them together to avoid the risk of irreconcilable judgments resulting from separate proceeding...").

455 Regulation (EC) No 864/2007 of the European Parliament and of the Council of 11 July 2007 on the Law Applicable to Non-Contractual Obligations (Rome II) Article 14(1); see also, 2001 Bill on Conflicts of Law in Tort [Wet Conflictenrecht Onrechtmatige Daad] ("WCOD") Article 6(1).

456 For cases regarding claims of environmental damages, Rome II Article 7, the "polluter pays" doctrine allows for an interesting twist to the choice of law analysis: "the law applicable to a non-contractual obligation arising out of environmental damage shall be the law determined pursuant to Article 4(1), unless the person seeking compensation for damage chooses to base his or her claim on the law of the country in which the event giving rise to the damage occurred."

457 N.M.C.P. JÄGERS \& M. J. VAN DER HEIJDEN, "Corporate Human Rights Violations: The Feasibility of Civil Recourse in the Netherlands,” Brooklyn Journal of International Law 33(3) (2008): 833-870, 852. 
Netherlands and depending on where the tort occurred, the plaintiff may seek to have the law of that jurisdiction apply. The following part of this subsection will provide a case study of how these issues all work in practice by discussing the Akpan case.

\section{B. Shell and the Nigerian Farmers: Akpan v. Royal Dutch Petroleum}

In January 2013, right around the time the US Supreme Court was deliberating Kiobel, the Dutch district court in The Hague issued three decisions all revolving around the oil pollution created by Shell Petroleum Development Company ("SPDC") - a wholly owned Nigerian subsidiary of Royal Dutch Shell ("RDS") - and the damages it caused to Nigerians living near the pipeline maintained by SPDC. 458 Of the three cases that were brought before the court, the court in The Hague ordered compensation to be paid to one particular plaintiff, Friday Akpan, for environmental damages caused by the oil spillage that contaminated the habitat and destroyed the livelihood of the nearby farmers and fishermen.

This is, as The Hague court stated, a case involving Nigerian plaintiffs, relying on Nigerian law, for a tort that took place in Nigeria by a Nigerian subsidiary of a Dutch company being adjudicated in the Netherlands. ${ }^{459}$ The Akpan case, in other words, would be a case that would immediately be dismissed if brought in the US courts in the aftermath of Kiobel. The applicable law was determined, at least at the time of this case, in accordance with Dutch Tort Law on Conflict of Law [Wet Conflictenrecht Onrechtmatige Daad]. As already noted back in the Introduction, WCOD has since been repealed and replaced by the aforementioned EU regulations, but at the time of Kiobel, the court held that because the tort was committed on Nigerian soil, in accordance Article 3(1) and (2) of WCOD, Nigerian law, especially the laws applicable in the Nigerian state of Akwa Ibom, where the two oil spills took place ought to be the applicable law. Note that this is in conformity with lex loci deliciti and Rome II Article 4 (1) noted above, which has since replaced the WCOD.

In addition to conflicts of law, there were venue issues as well. The oil spill in question was only one of many, as there were numerous instances of similar spillage that occurred back in June 2005, which caused significant delays before The Hague district court could rule on the venue issue in December 2009. After the court in The Hague ruled that it did have jurisdiction over this case, ${ }^{460}$ the Nigerian plaintiffs, along with a co-plaintiff, Friends of the Earth [Milieudefensie], added Royal Dutch Shell's other subsidiaries, Shell Transport and Trading Company and Dutch Shell Petroleum N.V. (the Dutch subsidiaries of RDS), to the case as well. There were no jurisdictional issues with regards to The Hague court presiding over RDS and its Dutch subsidiary, but what allowed the court to gain jurisdiction over SPDC (the Nigerian subsidiary) for the alleged tort, which took place in Nigeria

See e.g. Rechtbank Den Haag, 1 januari 2013, LJN BY9854 (case of Friday Alfred Akpan v. Shell); see also Rechtbank Den Haag, 1 januari 2013, LJN BY9845 (case of Barizaa Manson Tete Dooh v. Shell); and, Rechtbank Den Haag, 1 januari 2013, LJN BY9850 (case of Fidelis Ayoro Oguru and Alali Efanga v. Shell). It is worth noting that in the past, Shell has been accused of worse. For example, after Shell requested increased security from the commissioner of police in Ogoniland in 1990, the police 80 villagers were killed and 494 homes were destroyed; see, D. Vogel, The Market for Virtue: The Potential and Limits of Corporate Social Responsibility, (Washington D.C.: Brookings Institution Press, 2006), at p. 141. Similarly, other Nigerian activists like Ken Saro-Wiwa who waged a non-violent campaign against Royal Dutch Shell's operation in the Niger Delta ended up being executed by the Nigerian government. Here again, corporate action backed by government corruption has created a serious incident (similar to the CNMI mentioned in the introduction).

459 Rechtbank Den Haag, 1 januari 2013, LJN BY9854, para. 4.6, 4.8 and 4.9.

460 Rechtbank Den Haag, 1 januari 2013, LJN BY9854, para. 4.6, 4.8 and 4.9. 
was Article 7 of the Dutch Code of Civil Procedure [Wetboek van Burgerlijke Rechtsvordering. ${ }^{461}$ Given that the Dutch court had jurisdiction over at least one defendant (RDS), Article 7 enabled the Dutch court to treat the other defendants involved in the same proceeding in the same manner as the first defendant for the sake of expediency/efficiency [doelmatigheid], provided that there was some link or connection between the defendants. ${ }^{462}$ Note that this is in conformity with Article 8 of Brussels Recast mentioned above. In this case, because SPDC was a subsidiary of RDS, the court found a sufficient link between the defendants. Article 7 of the Dutch Code of Civil Procedure is particularly interesting as it gives the Dutch court the authority and jurisdictional competence over foreign subsidiaries of Dutch companies anywhere in the world, so long as the parent company incorporated in the Netherlands.

As noted above, Nigerian law was deemed applicable in accordance with WCOD Article 3(2) 463 and lex loci deliciti in order to "ensure redress in accordance with the expectations of the society where the harm occur[ed]," 464 but lex loci deliciti creates its own set of problems and difficulties. For example, under lex loci deliciti, judges in the Netherlands and their clerks must not only become proficient in the laws of the Netherlands and the transposition of relevant EU legislations, but depending on the case, they must familiarize themselves with the laws of a completely unfamiliar jurisdiction such as that of Nigeria as was the case in Akpan. Compare this to the California example from earlier, where if the parties were interested in applying a foreign law in US courts, Washington Mutual Bank ${ }^{465}$ required the moving party to identify the relevant rule, explain to the court the material difference with that of the laws of the host jurisdiction, and justify using the foreign law in US courts. ${ }^{466}$ In this sense, the Dutch approach to determining the applicable law is more straightforward.

Having said that, however, what added an extra element of complexity to the case in Akpan was the fact that the Nigerian legal system was based on the English common law and as a result, English cases have persuasive authority in Nigeria. ${ }^{467}$ This can be evidenced by the Nigerian legal system's incorporation of English case law such as Donoghue v. Steven$\operatorname{son}^{468}$ to determine issues relating to the tort of negligence and whether a duty of care has

Article 7.1 Wetboek van Burgerlijke Rechtsvordering states: "Indien in zaken die bij dagvaarding moeten worden ingeleid de Nederlandse rechter ten aanzien van een van de gedaagden rechtsmacht heeft, komt hem deze ook toe ten aanzien van in hetzelfde geding betrokken andere gedaagden, mits tussen de vorderingen tegen de onderscheiden gedaagden een zodanige samenhang bestaat, dat redenen van doelmatigheid een gezamenlijke behandeling rechtvaardigen."

462 Article 7.1 Wetboek van Burgerlijke Rechtsvordering [the Dutch Code of Civil Procedure].

463 WCOD Article 3(2) holds that "when the harmful effect of an act is felt in a place other than where the act takes place, the law of the country in which the effect is felt applies unless the corporation could not reasonably foresee this harmful effect." As translated by N.M.C.P. JÄGERS \& M. J. VAN DER HEIJDEN, "Corporate Human Rights Violations: The Feasibility of Civil Recourse in the Netherlands," Brooklyn Journal of International Law 33(3) (2008): 833-870, 851.

464 N.M.C.P. JÄGERS \& M. J. VAN DER HEIJDEN, "Corporate Human Rights Violations: The Feasibility of Civil Recourse in the Netherlands, ” Brooklyn Journal of International Law 33(3) (2008): 833-870, 851.

465 Washington Mutual Bank v. Superior Court, 24 Cal. $4^{\text {th }} 906,919$ (2001).

466 Washington Mutual Bank v. Superior Court, 24 Cal. 4th 906, 919-20 (2001).

467 Rechtbank Den Haag, 1 januari 2013, LJN BY9854, para. 4.22.

468 Donoghue v. Stevenson [1932] AC 562 UKHL is the seminal tort case that established the modern parameters of the negligence doctrine and the duty of care in England. The case involved a customer in a pub, Mrs. Donoghue, who drank a bottled beer that allegedly contained a dead snail. She subsequently fell ill and sued Stevenson, the beer manufacturer. The House of Lords held that manufactures owe a duty of care to its foreseeable consumers to 
been breached. In short, in order for us to understand the Akpan case in its entirety, we must understand Dutch procedural law as influenced by the EU as well as Nigerian tort law, which is heavily influenced by English case law. While a lot can be said with regards to the aforementioned issue of rule of law suggesting that laws ought to be accessible and intelligible, this particular concern will be tabled until Section 3.3 about some of the problems with tort law approach. For the time being, however, we must first understand the seminal English case on negligence, Donogbue v. Stevenson, which was cited by the Dutch court in Akpan, to determine if RDS and SPDC were indeed negligent. ${ }^{469}$ In Donoghue, Lord Akin, writing for the majority held that:

"The liability for negligence, whether you style it such or treat it as in other systems as a species of 'culpa,' is no doubt based upon a general public sentiment of moral wrongdoing for which the offender must pay. But acts or omissions which any moral code would censure cannot, in a practical world, be treated so as to give a right to every person injured by them to demand relief." 470

Lord Akin follows this summation up with the formulation of the "neighbor principle," which states that the defendant ought to have taken a reasonable care to avoid acts or omissions that they could have reasonably foreseen would injure their "neighbor." According to Lord Akin, a "neighbor" is anyone who is so closely and directly affected by the act of the defendant that they reasonably ought to have them in contemplation as being so affected. ${ }^{471}$ If the neighbor principle was still in effect today, Akpan can reasonably argue that SPDC owed them this duty of care. Now juxtapose the neighbor principle with the rebuttable presumption that there is no general duty for companies to prevent third parties from causing damage to another that is unless a particular relationship between the parties can give rise to the imposition of liability against the defendant. ${ }^{472}$ Combining these two creeds, the rule that can be extrapolated from Donoghue is that finding a defendant liable for damages caused by negligence is an inquiry that requires the courts to consider the "totality of circumstances," similar to the approach taken in the US.

Although the spirit of the neighbor principle established in Donogbue still exists to this day, the determination of whether tort liability exist has evolved over the subsequent decades in the UK to what is now commonly referred to as the "three-stage" test. ${ }^{473}$ As The Hague court confirmed, English/Nigerian law relies on the three criteria as formulated by Lord Keith of Kinkel and exemplified in Caparo Industries Plc. v. Dickman, which was also cited by the Dutch court. ${ }^{474}$ The three criteria for establishing liability are: 1 ) the foreseea-

provide a safe product, or in this specific case, to ensure that snails do not end up in their beers. Writing for the majority, Lord Akin established the neighbor principle and a duty of care for negligence.

Donoghue v. Stevenson [1932] AC 562, 580.

Donoghue $v$. Stevenson [1932] AC 562, 580.

2 See e.g. Smith v. Littlewoods Ltd [1987] AC241, 270-2.

473 It is worth mentioning here that in other common law jurisdictions such as Canada, New Zealand and Australia they rely on a two-prong approach, which incorporates policy considerations.

474 Caparo Industries Plc. v. Dickman [1990] UKHL 2. The case involved a takeover of Fidelity Plc. by Caparo Industries, based on statements made by an accountant, Dickman, who although informed Caparo of Fidelity's poor financial situation, failed to convey the true severity of Fidelity's account. Caparo sued Dickman for negligence in preparing the accounts for the takeover. Bingham LJ and Taylor LJ of the Court of Appeal held that Dickman did owe a duty given Caparo's position as a stakeholder, vis-à-vis an outside investor, which fulfilled the proximity prong of the three stage. Lord Bridge of Harwich delivering the lead judgment for the House of Lords, however, held that 
bility of the defendant that the plaintiff would suffer a loss; 2) the proximity between the plaintiff and the defendant; and 3) whether it is fair, just and reasonable to assume that the duty existed. ${ }^{475}$ Traces of the neighbor principle and the Donoghue precedent is still evident within the three prong test, but as Lord Reid in Home Office v. Dorset Yacht Co ${ }^{476}$ noted, it has become more of statement of principle than an actual test practiced by the courts. Although the case laws present a clear equation, there are those that suspect that regardless of whether it is the three-prong test, the two-prong test or the totality of circumstances test, the courts may sometimes do just what they please, paying only lip-service to these formulations. ${ }^{477}$

Leaving aside the cynic's view for the time being, applying these precedents to the case at hand, The Hague court started with the presumption that there is no general duty of care for corporations, especially with regards to preventing injuries to third parties that is unless they fit into a particular set of exceptions. ${ }^{478}$ The direct application of this general rule would suggest that under Nigerian law, RDS nor SPDC had an obligation to prevent the pipelines from injuring third parties, but the plaintiffs claimed that there was indeed a set of special circumstances that should preclude the defendants from benefiting from this general rule.

Essentially, the plaintiffs argued that SPDC owed them a duty of care not to spill oil on their habitat, thus ruining their lives as they knew it. The defendants argued back that the spill was caused by sabotage and not due to their negligence or the poor maintenance of the pipeline. The plaintiffs then counter-argued that 1) these sabotages were common in the area and thus foreseeable; 2) that there was proximity between SPDC and the local residents whose livelihoods have been ruined by the spill; and 3) that it would be fair, just, and reasonable for SPDC to impose a duty on SPDC to protect the pipeline from sabotage, thus protecting the local residents from the oil spill. ${ }^{479}$

Although the court did accept Shell's claim that the spill was indeed caused by sabotage and not due to poor maintenance, ${ }^{480}$ it nevertheless held that the plaintiff's claims met the three prongs of foreseeability, proximity, and fairness. ${ }^{481}$ What made Akpan's case successful, where the other two failed, was due to the fact that the pipeline in Ibibio, the location

no duty was owed regardless of Caparo's position as a stakeholder, vis-à-vis an outside investor. Lord Bridge of Harwich, did however, endorse the three-prong test, restating the Court of Appeal's formulation and providing additional analysis of his own regarding the principle of proximity; see also, R. STEVENS, "Torts," in The Judicial House of Lords: 1876-2009, L. BLOM-COOPER, B. DiCKSON \& G. DREWRY (EDS.) (Oxford: Oxford University Press, 2009), at p. 638.

475 See e.g. Caparo; see also, Rechtbank Den Haag, 1 januari 2013, LJN BY9854, para. 4.23.

476 Home Office v. Dorset Yacht Co. [1970] AC 1004, 1027 (noting that Donoghue "is not to be treated as if it were a statutory definition... but... that the time has come when we can and should say that it ought to apply unless there is some justification or valid explanation for its exclusion."); see also, R. STEVENS, "Torts," in The Judicial House of Lords: 1876-2009, L. BLOM-COOPER, B. DiCKSON \& G. DREWRY (EDS.) (Oxford: Oxford University Press, 2009), at p. 638.

477 R. STEvens, "Torts" in The Judicial House of Lords: 1876-2009, L. BlOM-COOPER, B. Dickson \& G. DrEwRY (EDS.) (Oxford: Oxford University Press, 2009), at p. 639 (stating that "One does not have to be temperamentally cynical to take the view that the change from one test to another was obfuscatory. Today although lip service is paid to the three-state test, it plays hardly any substantive role in the analysis of the courts.").

478 Smith v. Littlewoods Ltd. [1987] AC 241, at 270; see also, Rechtbank Den Haag, 1 januari 2013, LJN BY9854, para. 4.24.

479 Rechtbank Den Haag, 1 januari 2013, LJN BY9854, para. 4.39.

480 Rechtbank Den Haag, 1 januari 2013, LJN BY9854, para. 4.39.

481 Rechtbank Den Haag, 1 januari 2013, LJN BY9854, para. 4.42 and 4.43. 
of the oil spill in Akpan's case, was particularly lacking in security. Whereas in the other areas, the pipelines were buried under ground or had steel pipes that made it more difficult for people to sabotage, the court held that in Ibibio, the pipeline was extremely easy to sabotage, stating that not only was it above ground, but a simple wrench could have sabotaged the pipeline. ${ }^{482}$ Therefore, the court deemed that there was indeed a duty of care owed by SPDC, which was a special relationship between the plaintiff and the defendant, where the defendant had created a dangerous situation that gave "rise to an imposition or assumption of responsibility" on the defendant. ${ }^{483}$

In the end, The Hague court held that SPDC was negligent against Akpan when they failed to sufficiently protect the oil pipelines in 2006 and 2007 from sabotage and as a result, was ordered to compensate for damages that the plaintiff suffered from the oil spills. ${ }^{484}$ Experts in the field lauded this decision that " $\left.\mathrm{t}\right]$ he fact that a subsidiary has been held responsible by a Dutch court is new and opens new avenues." ${ }^{85}$ More importantly, this was a significant step to remedy a wrongdoing of a MNC for torts committed abroad, as this was "the first time a Dutch-registered company ha[d] been sued in a domestic court for offences alleged to have been carried out by a foreign subsidiary." 486 It must be clarified here, however, that while the court in The Hague held that SPDC was negligent, it did not extend this ruling to RDS.

As a side note, it is worth mentioning here that even if Dutch tort law was applied, as opposed to Nigerian/English tort law, the outcome may not have been drastically different as the analysis would have been essentially similar. The elements of negligence under BW Article 6:162 states that (1) "a person who commits an unlawful act towards another which can be imputed to him, must repair the damage which the other person suffers as a consequence thereof" 487 and BW Article 6:162 (2) defines an "unlawful act" as "an act or omission violating a statutory duty or unwritten duty of care." 488 The question that remains, regardless of whether the analysis is under Nigerian/English law or Dutch law, is whether there is a way that the parent company and not just the subsidiary can be held liable for torts committed by its subsidiaries. In other words, how can we hold RDS responsible for the wrongdoings of its subsidiary, SPDC, which was something the Dutch court refused to do. This will be addressed in the next part of the subsection.

482 Rechtbank Den Haag, 1 januari 2013, LJN BY9854, para. 4.43.

483 Smith v. Littlewoods Ltd. [1987] AC 241, at 272D, see also, Rechtbank Den Haag, 1 januari 2013, LJN BY9854, para. 4.24.

484 Rechtbank Den Haag, 1 januari 2013, LJN BY9854, para. 5.1. One of the claims that the court did not accept was the human rights violation claim, where Akpan (para. 4.56) argued that SPDC damaged the physical integrity of Akpan by living in a polluted environment [SPDC aansprakelijk is voor de aantasting van de lichamelijke van Akpan door het leven in een vervuilde leefomgeving]. In order for courts to find an "actual" human rights abuse, it would have to meet the standards established in Gbemre v. Shell Petroleum Development Company and Others, AHRLR 151 (NgHC 2005), which involved a "flaring" process rather than a "mere" oil spill caused by negligence, which lead to a polluted environment that created a "cocktail of toxins" [para. 4.7.a] that lead to premature death and respiratory illness.

485 I. Sekularac \& A. Deutsch, "Dutch Court says Shell responsible for Nigeria Spills,” Reuters (30 January 2013 ) Available at: http://uk.reuters.com/article/2013/01/30/uk-shell-nigeria-lawsuit-idUKBRE90T0DC20130130 (last accessed 4 April 2017).

486 Ibid.

487 BW 6:162(1) states: "Hij die jegens een ander een onrechtmatige daad pleegt, welke hem kan worden toegerekend, is verplicht de schade die de ander dientengevolge lijdt, te vergoeden."

488 BW 6:162(2), in relevant part, states: “...en een doen of nalaten in strijd met een wettelijke plicht of met hetgeen volgens ongeschreven recht in het maatschappelijk verkeer betaamt..." 


\section{Respondeat Superior: Shell in Nigeria and Shell in the Netherlands}

The Hague court's decision to hold SPDC liable was a capabilities-enhancing outcome, not only for Akpan but for other potential victims that could feel empowered from this decision to come out of the woodwork to make a stand again Shell or other Dutch companies operating around the world in Dutch courts. A lingering concern, however, and a point of contention with the Akpan ruling was the fact that RDS, the parent company controlling its wholly owned subsidiary, was not held liable at all. This particular aspect of the decision irked several members of the plaintiff party given that RDS owns 100\% of SPDC shares and its profits (estimated at $€ 1.8$ billion annually) are transferred to the Netherlands, suggesting that orders are coming from the Netherlands and the RDS has control over SPDC and its operation in Nigeria. ${ }^{489}$ For example, Geert Ritsema of the Friends of the Earth International is quoted as saying the following: "Apparently, our justice system allows a company to pocket the profits from a foreign subsidiary without being held liable for the damages it causes while producing those profits." 490 This part of the subsection will now attempt to answer the question of why RDS was not held liable for anything, when the circumstantial evidence suggested to the fact that SPDC was simply following orders passed down from RDS in the Netherlands.

Before jumping into the discussion of how to hold the parent companies liable for the actions of its subsidiaries, a brief overview of respondeat superior is necessary. Respondeat superior is a legal doctrine, which states that if an employee commits a tort in the course of or within the scope of his employment, the employer can be held vicariously liable for the tort committed by the employee. The problem, however is that the concept of respondeat superior does not apply when attempting to hold parent companies vicariously liable for the torts committed by its subsidiary because the law generally considers the subsidiary as a separate legal entity from the parent company. ${ }^{491}$ In the Netherlands, parent companies cannot be held automatically liable for the wrongdoings of their subsidiaries ${ }^{492}$ or that of their foreign business partners, ${ }^{493}$ and this reality is no different in the US. There are, however, two ways to get around this limitation: One way is to prove that the parent company was actually in control of the subsidiary's day to day operation; or in the alternative, the plaintiffs can make a negligence claim (also referred to as establishing direct liability) based on the fact that the parent company failed to exercise due diligence in dealing with its subsidiary.

With the basics of respondeat superior and its limitations in mind, we begin our analysis of how RDS could have been held liable in Akpan. Given that the court in The Hague relied on Nigerian law, we must once again look to English common law to answer the issue of liability as it relates to the parent company and the wrongdoing of its subsidiaries. The legal question presented to the court hinged on whether Shell's subsidiary in Nigeria

FriendS OF THE EARTh INTERnATIONAL, "Dutch Court ruling against Shell a Partial Victory," (30 January 2013). Available at: http://www.foei.org/press/archive-by-year/press-2013/dutch-court-ruling-against-shell-apartial-victory (last accessed 4 April 2017).

490 Ibid.

491 N.M.C.P. JÄGERS \& M. J. VAN DER HeijDEN, "Corporate Human Rights Violations: The Feasibility of Civil Recourse in the Netherlands," Brooklyn Journal of International Law 33(3) (2008): 833-870, 841 (noting that "[t]he doctrine of limited, meant to encourage individual entrepreneurship, has resulted in corporations establishing complicated corporate structures consisting of numerous legal entities with multiple layers of limited liability.”).

493 BW Article 2:20. 
(SPDC) acted negligently by allowing the spillage to occur and to what extent the parent company had knowledge or the ability to influence the situation. ${ }^{494}$ The relevant English case law that the Dutch court cited in Akpan was Chandler v. Cape, ${ }^{495}$ which asked the more specific question of whether a parent company has the duty of care towards employees of a subsidiary with regards to health and safety policies. Chandler v. Cape established that under certain circumstances, employees working for a subsidiary can successfully seek damages from a parent company. ${ }^{496}$ The facts of the case were as follows: Chandler was employed by a wholly owned subsidiary of Cape, when he was exposed to asbestos and subsequently contracted asbestosis. ${ }^{497}$ By the time Chandler had brought the suit, however, the subsidiary no longer existed so he sued Cape, the parent company, instead by alleging that they owed a duty of care to him that they breached. The judgment of the Court of Appeal, written by Arden LJ, used Caparao's three-stage test, and in ruling that Cape was in fact liable, demonstrated that the parent companies can be held liable for the actions (or inactions) of their subsidiaries. ${ }^{498}$ In Cape, Arden LJ explicitly mentions Connelly v. Rio Tinto Zinc Corporation and Ngcobo v. Thor Chemicals Holds as other examples of cases where parent company owed a duty of care to employees of subsidiaries and that there is no requirement for parent companies to have absolute control of the subsidiary in order for the parent company to be held liable. ${ }^{499}$

This English/Nigerian approach in determining liability against the parent company is not far removed from the Dutch approach. As Dutch courts have held that even when there are two separate legal entities, if a company influences the day-to-day operations of another and exerts some type of control over the other, Dutch courts will impose vicarious liability against the controlling company for the tort committed by the other. ${ }^{500}$ For example, in the case where the Ministry of Social Affairs and Employment took to court several newspaper publishers for hiring illegal immigrants for the delivery of their newspapers (in violation of the Foreign National Employment Act, Article 2), 501 the publishers used the defense that the actual delivery of their newspapers was conducted by a separate legal entity, or what they

494 The threshold issue of the court's jurisdiction had already been ruled in the interim back in February 2010; see Rechtbank 's-Gravenhage, 24 februari 2010, LJN BM1469.

495 Chandler v. Cape Plc. [2012] EWCA Civ 525.

496 A. RÜHmkorf, Corporate Social Responsibility, Private Law and Global Supply Chains, (Cheltenham: Edward Elgar, 2015), at p. 178 (noting that "the precedent set by Chandler v. Cape makes the CSR principle of providing a safe workplace a much more important consideration for parent companies within corporate groups as they are not able to avoid liability in tort purely by setting up several subsidiaries.”).

497 Chandler v. Cape Plc. [2012] EWCA Civ 525, at para. 1.

498 Chandler v. Cape Plc. [2012] EWCA Civ 525, at para. 80 (holding the following: "[T] his case demonstrates that in appropriate circumstances the law may impose on a parent company responsibility for the health and safety of its subsidiary's employees. Those circumstances include a situation where, as in the present case, (1) the businesses of the parent and subsidiary are in a relevant aspect the same; (2) the parent has, or ought to have, superior knowledge on some relevant aspect of health and safety in the particular industry; (3) the subsidiary's system of work is unsafe as the parent company knew, or ought to have known; and (4) the parent knew or ought to have foreseen that the subsidiary or its employees would rely on its using that superior knowledge for the employee's protection.”)

499 Chandler v. Cape Plc. [2012] EWCA Civ 525, at para. 66 (noting that thought the control need not be absolute, the liability that the parent company will have will be limited to damages caused "in relation to what might be called high level advice or strategy.").

500 See e.g., Raad van State, 17 maart 2010, LJN BL7835 (the case against De Volkskrant, Trouw, Algemeen Dagblad and De Telegraaf).

501 Artikel 2, Wet arbeidureemdelingen. 
referred to as a network of distributors [een network van distributeurs]. ${ }^{502}$ Based on this claim, the publishers argued that they should not be held liable if the distributors hired illegal immigrants. However, the Dutch Administrative Court [Raad van State] did not consider this argument to be valid, holding that the publishers had an influence on how the deliveries were to be made for the door-to-door service and in doing so, exerted control over the delivery operation. This issue of parent company's control over its subsidiaries is the key to determining whether alien plaintiffs can sue the parent companies, thus opening the door of Dutch courts. This is to suggest that if the plaintiffs seek to go after an entity higher up in the hierarchy with no contractual privity, they must attempt to establish that the parent company or some downstream company had influence or some control over the actions of its subsidiary or some other company like manufacturers or suppliers.

In order to successfully evidence this influence or control, internal documents that exhibit the business relationship between the parent company and its subsidiary or another third party legal entity become necessary. The problem here is that the respondent businesses do not have an overwhelming incentive to willingly provide these documents to the plaintiffs. Whereas this task might be easier in the US, where there are specific discovery rules in place, Dutch litigations generally do not have a prolonged discovery phase, if at all. To illustrate this point, we refer back to the Akpan, where the plaintiffs made requests to obtain RDS internal documents but RDS refused to provide them: Although Dutch law (Article $843 \mathrm{a} \mathrm{Rv}$ ) permits parties to request documents relevant to the case to be presented by parties, as Friends of the Earth did in order to obtain internal Shell documents to establish an element of control, the court denied this request (citing to Article $22 \mathrm{Rv}$ ). ${ }^{503}$ As it could be expected, partially due to Shell's refusal to produce the relevant documents, the plaintiffs could not establish RDS' involvement in the day-to-day operation of SPDC and as a direct result. The fact that the court in The Hague did not order RDS was one of the main reasons why the plaintiffs could not establish a connection between RDS and SPDC, which was the reason why RDS was not held responsible for the pollution caused by its Nigerian subsidiary. ${ }^{504}$ Going after the parent company for the wrongdoings of its subsidiaries in another jurisdiction is a formidable task in and of itself, but when the courts are reluctant to force the parent companies to disclose their internal documents that the plaintiffs need to establish the relationship between the parent company and its subsidiary, this task becomes almost impossible.

Although Akpan demonstrated how courts can empower foreign plaintiffs by allowing them to file their grievances against corporate malfeasance in the Netherlands, the case also highlighted some of the limitations with this approach. In short, the plaintiffs will still face

Raad van State, 17 maart 2010, LJN BL7835 (the case against De Volkskrant, Trouw, Algemeen Dagblad and De Telegraaf); see also, "Hoge boetes wegens illegale krantenbezorgers"” de Volkskrant (4 May 2010). Available at: http://www.volkskrant.nl/recensies/hoge-boetes-wegens-illegale-krantenbezorgers $\sim$ a981799/ (last accessed 4 April 2017).

503 Rechtbank Den Haag, 1 januari 2013, LJN BY9854, para. 4.61; see also, M.J. VAN DER HeIJDEN, "Class Actions/Les Actions Collectives," Electronic Journal of Comparative Law 14(3) (2010), at p. 2 no. 2 (noting that "in case a party shows a legitimate interest the court can order the other party to produce specific documents related to the parties' legal relationship. In practice, these orders are not often issued").

504 Rechtbank Den Haag, 1 januari 2013, LJN BY9845, para. 4.39 (holding that " $[\mathrm{g}$ ] elet op al het voorgaande bebben de moedervennootschappen in Den Haag en Londen daarom naar het oordeel van de rechtbank. naar het toepasselijke Nigeriaanse recht in dit geval geen tort of negligence jegens Milieudefensie en Dooh gepleegd."). 
resistance and obstacles, including but not limited to the difficulty that comes with obtaining necessary documents from the defendants. Though possible in theory, Dutch courts rarely demand that the defendants turn over all the relevant documents to the plaintiffs. ${ }^{505}$ One policy shift that the private sector can push to change would be to flip the script and to place the burden of proof on the corporations (that readily have the necessary information available) to prove that there is indeed no connection or element of control between the parent company and the subsidiary. This would make it easier, not only for foreign plaintiffs, but even for domestic victims of labor exploitation to go after the parent companies that regularly claim they have no control or influence over their subsidiary or another third party legal entity. Implementing this proposal would require a complete paradigm shift, not to mention that it would be against the self-interest of many corporations; this reality suggests that the chances of this proposal ever manifesting is quite low. ${ }^{506}$

\section{The Dutch Courts Allow More Access to Foreign Plaintiffs}

To summarize this subsection, there are two ways the foreign plaintiffs can access the Dutch courts. First is if the tort occurred in the Netherlands, and the second, more interesting way would be if the tort occurred abroad, but the wrongdoing was carried out by a company incorporated in the Netherlands or by its subsidiary as demonstrated by Akpan. This latter scenario is made possible by Dutch Code of Civil Procedure [Wetboek van Burgerlijke Rechtsvordering] Article 7, which allows Dutch courts to string together co-defendants for the sake of expediency/efficiency [doelmatigheid] so long as there is some link or connection between the defendants. ${ }^{507}$ This means that in the aftermath of the US Supreme Court's decision in Kiobel, foreign plaintiffs will have an easier time seeking access to justice in Dutch or other EU Member State courts than in the US courts: In accordance with Dutch law, "bringing suit against a Dutch parent company before a Dutch court for harmful activities abroad will not present major judicial problems" 508 In the US, however, not only must the case in question "touch and concern the territory of the United States" and "must do so with sufficient force to displace the presumption against extraterritorial application," 509 but more importantly, there is a presumption that companies cannot be considered as valid defendants in the context of the ATS.

Though admittedly, some concerns remain such as the very real possibility that the Dutch courts will have to interpret and apply a foreign law. Another drawback of going Dutch as opposed to American is the limitations the Dutch place on their class actions.

M.J. vAN DER HEIJDEN, “Class Actions/Les Actions Collectives,” Electronic Journal of Comparative Law 14(3) (2010) (observing that " $[\mathrm{t}]$ he court may reverse the burden of proof where a party fails to comply with a court order obliging the party at any stage of proceeding to provide access to the records or documents that party is obliged to draw up and to keep.").

506 R.H. THALER, Misbehaving: The Making of Behavioral Economics, (New York: Norton, 2015), at p. 169 (stating that "[a] paradigm shift is one of the rare cataclysmic events in science when people make a substantial break with the way the field has been progressing and pursue a new direction.”); see also, T.S. KUHN, The Structure of Scientific Revolutions, (Chicago: University of Chicago Press, 1962).

507 Article 7.1 Wetboek van Burgerlijke Rechtsvordering; see also, Brussels I Regulation Recast Art 8(a) (adding that this is possible "provided the claims are so closely connected that it is expedient to hear and determine them together to avoid the risk of irreconcilable judgments resulting from separate proceedings").

508 N.M.C.P. JäGERS \& M. J. VAN DER HEIJDEN, "Corporate Human Rights Violations: The Feasibility of Civil Recourse in the Netherlands," Brooklyn Journal of International Law 33(3) (2008): 833-870, 853. 
Although this is not to suggest that no collective redress (vis-à-vis class action lawsuits) is available in the Netherlands, but as the next subsection will show, collective redress mechanisms available in the Netherlands that could facilitate the plaintiffs' collective efforts to seek justice against corporate malfeasance is not as robust as that the US.

\subsubsection{Dutch Alternatives to US-Style Class Action Lawsuits}

As mentioned earlier, what many of these foreign direct liability cases seem to have in common is the number of plaintiffs in each of the cases. The US approach to addressing this issue was by permitting class action lawsuits and to bundle multiple claims into a single large mass so long as they could meet certain classification requirements. The Dutch approach differs significantly in a sense that class actions claims are somewhat different under Dutch law when compared to its US counterpart. ${ }^{510}$ This is not to say, however, that no option for collective legal action exists in the Netherlands as there are two ways that collective actions can facilitate the victims of corporate malfeasance in the Netherlands: 1) via a representative group or collective action in accordance with BW Article 3:305 that allows foundations to seek injunctions and declaratory judgments; and 2) through a collective settlement procedure in accordance with the 2005 Dutch Act on Collective Settlements of Mass Damages [Wet collectieve afhandeling massachade] (henceforth "WCAM"). ${ }^{511}$ These two options, implemented to provide plaintiffs more opportunities to access justice, ${ }^{512}$ are very often used in conjunction, though usually the representative action commences the proceeding followed by WCAM settlements. This subsection will now address how Dutch law deals with instances where there are groups of victims arising out of the same or factually similar incidents and how, by consolidating their voices, the victims can seek remedies that may not be available when left to their individual devices.

\section{A. BW Article 3:305(a) and the Representative Groups}

In Akpan, Friends of the Earth played a significant part in assisting and facilitating the plaintiffs' proceedings against Shell, but what exactly is the limit of what these NGOs and other associations can do to facilitate, or perhaps litigate on behalf of the plaintiffs? Can NGOs sue on behalf of sweatshop laborers in Bangladesh? ${ }^{513}$ This part of the subsection will address this very question.

510 Here again, the impact of the European Commission on Dutch law must be noted and the role European Commission Recommendation 2013/396/EU and Communication (2013) 401 final have made.

5112005 Dutch Act on Collective Settlements Mass Damages [Wet collectieve afhandeling massachade] (henceforth "WCAM") as implemented by BW Article 7:907-910 and Rv Article 1013-1018; see also, BRITISH INSTITUTE OF INTERNATIONAL AND COMPARATIVE LAW, "Report II on Collective Redress," (November 2014), at pp. 38-43. There is a possible third option, which is currently a legislative proposal that if enacted, would allow legal entities to represent individual claimants and to seek damages. As it stands, compensatory collective redress is limited to "mass harm situations."

512 M.J. van DER HeijDEN, “Class Actions/Les Actions Collectives,” Electronic Journal of Comparative Law 14(3) (2010), at p. 3 .

513 J. BoumA, "Waarom Urgenda de Klimaatzaak kan Winnen," Trouw, (14 April 2015). Available at: http://www.trouw.nl/tr/nl/13110/Klimaatverandering/article/detail/3953028/2015/04/14/Waarom-Urgendade-klimaatzaak-kan-winnen.dhtml (last accessed 2 May 2015) (reporting that on the issue of climate change, NGOs have been permitted to sue on behalf of "future generations: "In 2001 bepaalde de rechtbank in Den Haag dat Greenpeace namens toekomstige generaties tegen de staat mocht procederen over het tempo van de aardgaswinning in Nederland.") 
BW Article 3:305(a)(1) permits associations [verenigingen] or foundations [stichtingen] to bring collective action on behalf of individuals on any assortment of issues including but not limited to labor or employment related issues. ${ }^{514}$ Even a special purpose vehicle ("SPV") can be created for the sole purpose of bringing a representative claim under this framework. ${ }^{515}$ Dutch law appears to be cognizant of the fact that in many cases, individual victims may not be willing to bring suits because they are otherwise unable to do so due to financial constraints or general lack of knowledge for recourses available to them. ${ }^{516} \mathrm{BW}$ Article 3:305(a) does, however, require similar classification requirements seen earlier in the US context, such as the representativeness requirement and commonality requirement. ${ }^{517}$ Another interesting feature of the Dutch group representation option is that BW Article 3:305(c) explicitly allows for organizations established outside of the Netherlands under the Directive $98 / 27 / \mathrm{EC}$ regime to bring an action to protect the residents of their country in Dutch courts. ${ }^{518}$ This suggests that the Dutch are more open to foreign plaintiffs seeking class actions in Dutch courts, especially if they are from another EU Member State.

One significant drawback of the group representation action in accordance with the BW Article 3:305 framework, however, is that monetary claims are generally not permitted. ${ }^{519}$ This means that only injunctive or declaratory relief is available under this scheme, which may not be beneficial for those that are seeking monetary compensation for a harm that has already befallen them. In addition, these actions only bind the group itself against the defendant and not the individual members against the defendant. In other words, there is no remedy or right arising out of the group representation action that the individuals can then claim or seek to enforce against the defendant. In order for the individuals to do so, the individuals must go after the defendants themselves, which for some could defeat the purpose of joining a representative group. ${ }^{520}$ Although group representation only provides injunctive or declaratory relief, the assumption is that what is good for the group should be beneficial to the individuals whose interests the group is representing. To summarize, though the Dutch representative actions might be more accommodating than its US counterpart, given its prohibition for monetary claims, it may only have limited use, especially given that the relief only binds the group and not the individuals themselves.

See e.g. Hoge Raad November 1997, NJ 1998, 268 (Kuipers Logistics); see also, M.J. VAN DER HeIJDEN, "Class Actions/Les Actions Collectives," Electronic Journal of Comparative Law 14(3) (2010)

515 See e.g. Court of Appeals (The Hague) Vie d'Or, 27 May 2004, LJN: AP0151, 01/1086.

516 N.M.C.P. JÄGERS \& M. J. VAN DER HEIJDEN, "Corporate Human Rights Violations: The Feasibility of Civil Recourse in the Netherlands," Brooklyn Journal of International Law 33(3) (2008): 833-870, 849 (noting that "[v]ictims of corporate misconduct will often be dependent on non-governmental organizations to bring legal proceedings against the corporation because they lack the resources on their own to do so.").

$517 \mathrm{BW}$ Article 3:305(a)(1) requires that the groups must be representative of the group members, as indicated by their articles of incorporation and actual practice; see also, BRITISH INSTITUTE OF INTERNATIONAL AND COMPARATIVE LAW, "Report II on Collective Redress," (November 2014), at p. 39 (adding that Dutch courts set standing of representative organizations on an ad-hoc basis).

518 British institute of International and Comparative Law, "Report II on Collective Redress," (November 2014), at p. 41 (stating that "Dutch law allows foreign representative entities to initiate or participate in a procedure on the same basis as national entities.").

519 BW Article 3:305(a)(3) (noting that " " $v$ ij kean niet strekken tot schadevergoeding te voldoen in geld.").

520 BW Article 3:305(a) (5): "Een recbterlijke uitspraak, heeft geen gevolg ten aanzien van een persoon tot bescherming van wiens belang de rechtsvordering strekt en die zich verzet tegen werking van de uitspraak ten op zichte van hem..." 


\section{B. Wet Collectieve Afhandeling Massachade [Collective Settlement Procedure]}

Once the representative group action is concluded, or in some cases as an alternative to the group representative process, the WCAM measures can be pursued. Codified in part under BW Article 7:907(1), WCAM measures give binding force to settlements in cases where there is compensation for damages "caused by an event or similar events entered into by a foundation or association with full legal capacity with one or more other parties." WCAM essentially is a procedure in which after the two parties reach a settlement, the court will declare the settlement legally binding. The obvious benefit of this mechanism is that it authorizes the courts to make legally binding an otherwise non-binding settlement and in that sense, it could be seen as a measure that enhances alternative dispute resolution mechanisms.

In terms of threshold requirements, the WCAM procedure shares similar requirements to that of the group representation action as there are representativeness and commonality requirements. ${ }^{521}$ One key difference between the group representation and the WCAM procedure, besides the fact that under the WCAM scheme monetary compensations are not prohibited, is the fact that it is an opt-out system as opposed to the BW Article 3:305(a) based claims, which are opt-in. As a result of this, WCAM procedure has a more hefty notification requirement to notify the possible members of the group. With regards to jurisdiction, WCAM is also unique in the sense that all cases relating to WCAM will be heard in the Amsterdam Court of Appeals as this is the court that has the exclusive jurisdiction. ${ }^{522}$

Cases where all the members are Dutch residents do not, relatively speaking, present any jurisdictional or standing issues. ${ }^{523}$ When there are non-Dutch, but still an EU Member State residents within the settlement group, Article 6(1) Brussels I, as mentioned earlier would extend the courts' jurisdiction to these non-residents so long as there is a "close connection" between the claims and combining the claims would be "expedient." 524 The more intriguing scenario is what happens to members that are non-Dutch and not a resident of any EU Member States? As with the BW Article 3:305(a) group representation, WCAM also has a rather lenient view on foreign plaintiffs accessing justice through Dutch courts as they have held that foreign plaintiffs can be a part of the settlement procedure. ${ }^{525}$ In other words, WCAM settlement allows for international plaintiffs (even those who are from non-EU Member States) to be a part of the settlement. The relevant case to make this point is Shell v. Dexia Bank Nederland, a case in which multiple foundations formed as the plaintiff-side party (where five out of the six members were groups located in the Netherlands). As previously noted, Rv. Article 3 allows for non-Dutch residents to have standing in the Dutch courts, so long as at least one of the parties is domiciled in the Netherlands:

521 BW Article 7:907(1), similar to the representativeness inquiry for the group representative claim stage, courts will look at objectives of the foundations, their articles of association, their practices, etc., see also, M.J. VAN DER HeijDen, "Class Actions/Les Actions Collectives," Electronic Journal of Comparative Law 14(3) (2010), at p. 9.

522 Rv. Article 1013(3).

523 Brussels (I) Article 2(1), noting that "persons domiciled in a Member State shall, whatever their nationality, be sued in the courts of that Member State.").

524 Brussels (I) Article 6(1), noting that "a person domiciled in a Member State may also be sued where he is one of a number of defendants, in the courts for the place where any one of them is domiciled, provided the claims are so closely connected that it is expedient to hear and determine them together to avoid the risk of irreconcilable judgments resulting from separate proceeding...”).

525 Court of Appeals (Amsterdam) 29 May 2009, LJN: BI5744 (Shell Petroleum N.V. and the Shell Transport and Trading Comp. Ltd et al v. Dexia Bank Nederland N.V. et al). 
"So, even if the case is substantially unconnected to the Netherlands, but one of the parties to the settlement is a Dutch foundation or association, or a special purpose foundation or association is ad hoc established, the Amsterdam Court of Appeals will have jurisdiction." 526 In other words, the Dutch court can declare a settlement binding for a group even if it includes members outside of the Netherlands or the EU. This characteristic of WCAM, used in conjunction with the BW Article 3:305(a), has been recognized by some as the Dutch version of the ATS in the US. ${ }^{527}$

Although the WCAM procedure seems rather promising, there are few noteworthy drawbacks, the biggest one being that the WCAM procedure does not provide any incentives for the parties to actually settle. Moreover, unlike the damages available in the US, in the Netherlands, the amount of damages that the defendants are willing to settle for could be limited because the Dutch do not permit punitive damages. Moreover, the general assumption with group litigation is that it could lower the amount that each individual would receive in the end, as any settlement figure will obviously have to be divided amongst the group. In the end, although the representative action under BW Article 3:305 and WCAM in the Netherlands provide an interesting alternative to the US style class action suits, they pack a weaker punch given the lack of punitive damages and the lack of any incentivizing force that would otherwise compel the corporations to settle in the first place.

\subsubsection{Dutch Tort Law and Their Limitations}

The previous parts of this subsection showed that the Dutch courts and their collective redress mechanisms have a lower threshold when it comes to allowing foreign plaintiffs to have standing before their courts or for joining a representative group, which allows for interesting cases to be initiated in Dutch courts. ${ }^{528}$ While this is a very enticing aspect of the Dutch system for foreign plaintiffs, this strong point is counterbalanced by several shortcomings, including but not limited to the fact that BW Article 3:305(a)(3) prohibits representative claims from seeking pecuniary damages (not to mention punitive damages), and these measures only serve as weak incentives for businesses to initiate settlement procedures in the first place. The Dutch system, although a more inclusive one, packs less punch relative to its American counterpart. The lingering question that arises in this context though is whether a stronger punch (i.e. allowing for the imposition of pecuniary fines or allowing for punitive damages) would actually incentivize businesses to change their practices. The small sample size from the previous subsection (Chapter 2.1) suggests that there is no strong correlation between an increase in the fines and a decrease in the number

526 M.J. van DER HeijDEN, “Class Actions/Les Actions Collectives,” Electronic Journal of Comparative Law 14(3) (2010), at p. 11.

527 M.J. van DER HeijDEN, “Class Actions/Les Actions Collectives,” Electronic Journal of Comparative Law 14(3) (2010), at p. 5 (noting that " $[\mathrm{t}]$ ransnational aspects of the WCAM as the Court transformed the Dutch procedure into a global collective settlement mechanism.").

528 See e.g. District Court (The Hague) 24 June 2015, ECLI:NL:RBDH:2015:7145 (Sticbting Urgenda v. Staat der Nederlanden). A case where an NGO bourght a representative claim on behalf of 886 individuals and sued the Netherlands based on the argument that state's climate policy was detrimental to future generations and the court actually ordred that the Netherlands to reduce their carbon emissions. The appeal is currently pending. 
of labor violations, if at all. ${ }^{529}$ For similar reasons as to why imposing the death penalty for certain crimes does not eradicate such crimes, simply raising the fines or imposing harsher punishments may also fail to prevent businesses from continuing to exploit workers or committing torts against them in the global supply chain.

\subsection{PROBLEMS WITH THE TORT LAW APPROACH}

This chapter on tort law focused on how laws in the US and the Netherlands are enabling alien plaintiffs - like Bangladeshi sweatshop laborers - to seek access to justice in American or Dutch courts for a tort that occurred abroad (i.e. Bangladesh). The assumption made at the beginning of this chapter was that by giving these alien plaintiffs access to justice in US or Dutch courts, these exploited laborers will have another platform or a better opportunity to have their grievances heard, thus empowering them in a way that could possibly lead to the reduction of labor exploitations in the global supply chain. However, as the two previous subsections showed, this particular tort law approach might not be the most feasible strategy to reduce instances of labor exploitation. This section will address the two main problems inherent in this approach: First, the territoriality problem, which is linked to the competence problem from Chapter 2 (Subsection 3.3.1), and second, the externalization problem, which is about how businesses are adapting to the existing legal frameworks in a manner that reduces their exposure to liability while still retaining the profits (Subsection 3.3.2). Finally, this section will conclude by describing the FIFA case (Subsection 3.3.3), which illustrates just how the territoriality problem and the externalization problem is manifesting in reality.

\subsubsection{The Territoriality Problem}

Chapter 2 already addressed the competence problem that governments face when attempting to restrict the actions of businesses operating at the domestic level through their labor/employment laws. When governments are tasked to regulate corporate malfeasance at a global level, the government's competence problem becomes even more noticeable. This is partially due to the fact that globalization has put into overdrive the ability for businesses to operate globally, unlimited by geographical constraints, with subsidiaries, manufactures, and suppliers all scattered around the globe. ${ }^{530}$ While the business end has evolved at a rapid pace in light of globalization, the law - still generally conceived at the national level - has not kept up with the businesses. ${ }^{531}$ In order to elaborate on how the territoriality

529 If anything, there is anecdotal evidence from the Amnesty International that if the fines become arbitrarily high, people may start to simply ignore them. See e.g., AMNESTY INTERNATIONAL \& AFREWATCH, This is What We Die For: Human Rights Abuses in the Democratic Republic of the Congo Power the Global Trade in Cobalt, AFR 62/3183/2016 (London: Amnesty International, 2016), at p. 18 (reporting that when fines are so large, and goes beyond the means of the people to pay, they become "essentially meaningless" and fails to serve as an effective deterrent).

530 See e.g., L.E. READ, I, Pencil, (New York: The Foundation for Economic Education, 1958) (describing the complicated and global process of making a simple wooden pencil from the perspective of... the pencil).

531 T. JuDT, Ill Fares the Land, (New York: Penguin, 2010), at p. 197 (noting that "[w]e should by now have learned that politics remains national, even if economics does not."). 
problem exacerbates the government's competence problem, this subsection will: a) address the issue of international comity, b) discuss the difficulty of American and Dutch courts enforcing their rulings upon entities located abroad, and finally, c) touch upon the issue of costs for the alien plaintiffs to litigate claims abroad.

\section{A. Globalization as a Disruptor of Traditional Governance}

As noted above, globalization weakens the sovereignty of national governments and their regulations, or at the very least, it exposes their limitations. ${ }^{532}$ For example, globalization has highlighted that while business can operate globally, most laws and its enforcement are bound by territorial limitations. ${ }^{533}$ Although the systematic process of "eliminating" barriers can be beneficial for some (i.e. businesses), globalization is almost akin to denationalization and the weakening of national sovereignty. According to Larry Catá Backer, there are structural failures of political entities like states when exercising their power through government regulations because while our borders may be porous with citizens moving with relative ease back and forth, the authority of the national government often does not extend past the border. ${ }^{534}$ This is also a substantive limitation in a sense that governments or states can be "characterized by a failure to conform regulation to the current consensus of value maximizing activity among those subject to the regulation." 535 Related to the point on substantive limitation, this is where the reality that many governments often tend to rely more on economic indicators rather than qualitative considerations - which are often more difficult to measure - can exacerbate the problem.

The essence of Backer's point was demonstrated in the international dialogue that took place during Kiobel, when discussing whether the ATS should have universal jurisdiction or extraterritorial reach. ${ }^{536}$ Granted, these concepts could be considered as rather "out-of-thebox" from a traditional legal perspective, but the level of animosity that was directed towards the ATS and the possibility that the US might have jurisdiction over foreign entities

532 J.M. SMITS, Private Law 2.0: On the Role of Private Actors in a Post-National Society, (Maastricht; HiiL, 2011). Available at: http://www.hiil.org/data/sitemanagement/media/Publication_Smits_250211(1).pdf (last accessed 4 April 2017), at p. 16 (noting that "[i]n a post-national society, the traditional lawgivers can no longer fulfill the functions of codification...”); See also, N. LuHmann, Law as a Social System, (Oxford: Oxford University Press, 2004) (noting the declining relevance of the law in the era of globalization); F. CAPRA \& U. MATTEI, The Ecology of Law: Toward a Legal System in Tune with Nature and Community, (Oakland: Berrett-Koehler, 2015), at p. 116 (arguing that "[s]tates, limited as they are by the borders of their jurisdictions, are not strong enough to place limits on the global roaming of extractive corporations"); see also, M. HARDT \& A. NEGRI, Empire, (Cambridge: Harvard University Press, 2000).

533 T. JuDT, Ill Fares the Land, (New York: Penguin, 2010), at p. 121 (noting that "politics is a function of space - we vote where we live and our leaders are restricted in their legitimacy and authority to the place where they were elected.").

534 L.C. BACKER, "Economic Globalization and the Rise of Efficient Systems of Global Private Lawmaking: WalMart as Global Legislator" in University of Connecticut Law Review 39(4) (2007), at p. 8 (noting that "objects of regulation may freely enter and leave regulatory territories.”).

535 L.C. BACKER, "Economic Globalization and the Rise of Efficient Systems of Global Private Lawmaking: WalMart as Global Legislator," in University of Connecticut Law Review 39(4) (2007), at p. 8 (citing to P. ALLOTT stating that the "[1]egal systems and legal services have become commodities in international trade, as legal experience is transferred from one country to another. It is now possible to get an economic advantage in international trade by ensuring that your trading partner's legal system is more like your legal system than like that of your competitors."); see also, P. AlLOTT, The Health of Nations: Society and Law Beyond the State, (Cambridge: Cambridge University Press, 2002), at p. 60.

536 See e.g. P. WeISS, "Run, Rummy, Run," Global Policy Forum, (8 December 2006). Available at: http://www.globalpolicy.org/component/content/article/97/32136.html (last accessed 4 April 2017). 
brought a plethora of criticisms and complaints disguised as amicus briefs. This reality suggests that sovereign entities like government do not like being told what to do by others or to be judged by them. Moreover, courts are very reluctant to involve itself in political matters embodied by the political question doctrine: Particularly in the American courts, where the separation of powers prevents the judiciary from intervening and answering political questions, relying on tort law to change the political landscape of international relations and commerce is, strictly speaking, a violation of the political question doctrine. ${ }^{537}$ Bearing in mind this point, it is not likely that the courts will intervene in cases where Bangladeshi sweatshop laborers would be given access to US courts for a tort that occurred in Bangladesh, simply becomes their employers were suppliers to a company based in the US. This again proves the international comity problem and the general reluctance that governments have to having their citizens adjudicated by a court of another. This territoriality problem further exacerbates the governments' competence problem; but moreover, it suggests that governments are generally change adverse and cannot be fully relied upon to producing innovative solutions for a problem as complex and international as that of labor exploitations taking place in the global supply chain. 538

Solving or addressing an international problem of such a nature requires laws that can be effective between borders, but countries are hesitant to accept laws with extra-territorial reach or universal jurisdiction, which makes this particular approach politically infeasible. This is part of the reason why most traditional perspectives on human rights violations or labor exploitations in the global context rely on international law as the appropriate instrument for change. However, as the introduction of this thesis already noted, international law is not the focus of this thesis and they are not without their set of limitations and problems. For example, while some private international law instruments at the EU level - like Brussels and Rome Regulations mentioned in this chapter - are having some positive impact in opening up domestic courts to citizens of other Member States or at times even third state plaintiffs, the Regulations' authority and jurisdiction do not extend to all nooks and crannies of the globe. Moreover, even these seemingly harmonizing private international laws are contributing to increasing tensions between Member States in terms of what the EU can dictate to the Member States and how Member States must comply and change their own legal systems accordingly. ${ }^{539}$ In short, the reverence to international or supranational comity suggests that sovereign entities and domestic courts will continue to be reluctant to hear cases brought by alien plaintiffs against foreign corporations for a tort that allegedly occurred in some foreign territory.

537 See e.g. Marbury v. Madison, 5 US 137 (1803) (holding that the United States Supreme Court did not have the authority to judge the discretionary actions of the Secretary of State); see also, Baker v. Carr, 369 US 186 (1962) (holding that there was no political question regarding the apportionment of state legislatures).

538 Cf. M. Mazzucato, The Entrepreneurial State: Debunking Public vs. Private Sector Myths, (London: Anthem, 2013) (arguing against claims that governments are not innovators, holding that the private sector would not be as successful with innovative R\&D, if not for government backing and investments).

539 R. Rogowski, Reflexive Labour Law in the World Society, (Cheltenham: Edward Elgar, 2013), at p. 244 ; see G. TEUBER, (1998) (noting that " $[\mathrm{t}$ ransnational labour regulations open national labour law order to external concerns [and thus] has the potential to be an irritating factor within national labour law orders."); see also, J.M. SMITS, "Private Law 2.0: On the Role of Private Actors in a Post-National Society," (Maastricht; HiiL, 2011). Available at http://www.hiil.org/data/sitemanagement/media/Publication_Smits_250211(1).pdf (last accessed 4 April 2017), at p. 16 (noting that "natural reaction of States when confronted with a globalizing society is to try to regain what they lost, which means States will try to domesticate the new types of rules."). 


\section{B. Difficulty of Enforcement at the International Level}

Chapter 2 already discussed the problem of enforcement in the context of whether businesses are actually complying with labor/employment laws, but in the context of transnational tort law litigation, there is an entirely different kind of an enforcement problem: In other words, what happens after a US or a Dutch court rules in favor of the alien plaintiffs? Take for example, what is happening in the Niger Delta. Even though Shell was ordered to clean up their act by the Dutch court for destroying the livelihood of the Ogoni people and many others, there is still much work to be done as " $[\mathrm{t}]$ he government of Nigeria and Shell have taken almost no meaningful action" even though the court in Hague reprimanded them in Akpan: According to a spokesperson from Friends of the Earth spokesperson, " $[t]$ he lack of meaningful action in the face of incontrovertible scientific evidence is outrageous. The Nigerian government and Shell are quite simply getting away with environmental and human rights abuses in the Niger Delta." 540 This is to suggest that even if alien plaintiffs were permitted to seek access to justice in foreign courts and managed to win their case against all odds, there is no guarantee that the defendants will remedy the issue in a manner satisfactory to the alien plaintiffs. According to Amnesty International, Shell has not changed their practices nor cleaned up the environmental damage after the court's ruling in $A$ kpan ${ }^{541}$ So even after victories won by Akpan, there continues to be a "systematic failure of the Nigerian government and oil giant Shell to clean up the horrendous oil pollution in the Niger Delta, despite recommendations made by a major UN study..." 542 In short, the enforcement in transnational tort law cases is lacking, which suggests that this particular tort law approach may not be the most promising way to stop corporate malfeasance abroad and to reduce instances of labor exploitation in the global supply chain.

\section{Filing Claims Abroad is Cost-Prohibitive and Time Consuming}

Litigations, especially transnational litigations, where alien plaintiffs are seeking access to justice in foreign courts, while possibly capabilities-enhancing, is still cost-prohibitive and extremely time consuming. The discussion earlier about laws that enable class action or representative litigations suggested that there is power in numbers and that some of these concerns can be overcome, but there is some room for doubt: For example, even if NGOs like Amnesty International or Friends of the Earth support the victims abroad by filing representative litigations or assisting the plaintiffs in filing class action lawsuits in their

540 O. TiCKeld, "Niger Delta Oil: Shell Ignores Horrendous Pollution," Ecologist, (4 August 2014). Available at: www.theecologist.org/News/news_round_up/2501331/niger_delta_oil_shell_ignores_horrendous_pollution.htm 1 (last accessed 4 April 2017) (quoting Godwin Ojo of Friends of the Earth Nigeria).

541 O. TiCKELl, "Niger Delta Oil: Shell Ignores Horrendous Pollution,” Ecologist, (4 August 2014). Available at: http://www.theecologist.org/News/news_round_up/2501331/niger_delta_oil_shell_ignores_horrendous_polluti on.html (last accessed 4 April 2017) (quoting Audrey Gaughran of Amnesty International that "[n]o matter how much evidence emerges of Shell's bad practice, Shell has so far escaped the necessity to clean up the damage it has caused.").

542 Friends of The EArTh Europe, “No Progress: An Evaluation of the Implementation of UNEP's Environmental Assessment of Ogoniland, Three Years On,” (4 August 2014). Available at: http://www.foeeurope.org/ sites/default/files/publications/foee-no-progress-040814_0.pdf (last accessed 4 April 2017); see also, UNITED NATiOns Environment Programme, "Environmental Assessment of Ogoniland," (2011). Available at: http://postconflict.unep.ch/publications/OEA/UNEP_OEA.pdf (last accessed 4 April 2017). It is worth adding here, that while it is easy for some of us to criticize MNCs such as Shell, it is worth considering that companies like Shell - even with all of their negative press on this matter - is providing some structure and benefits to the local community. 
domestic courts, there is no guarantee that justice will be swift. Recall the Rio Tinto case and how the victims of Bougainville fought in US courts for over 13 years, only to come away with nothing in the end. So while this particular tort law approach might give exploited laborers a different platform to voice their grievances and increase the choices that they have to seek redress, the outcomes are often not necessarily contributing to the reduction of labor exploitation in the global supply chain. Therefore, while private actors like NGOs can continue to support and back these transnational cases, given the limitations noted in this chapter, perhaps it would be more prudent for private actors to reassess their continued reliance on this particular strategy.

Is sum, the territoriality problem, which is linked to the government's competence problem, significantly reduces the feasibility and the impact of the particular tort law approach discussed in this chapter. Not only are courts reluctant to hear cases for torts that occurred in another sovereign territory, but they are even more hesitant to adjudicate matters between foreign parties, as they need to pay reverence to international comity. Moreover, even if the domestic courts do take on foreign cases, which could possibly add on to an already congested docket, there is no guarantee that the judgments will be effectively enforced in the other sovereign territories. Last but not least, the cost of initiating lawsuits in a different sovereign territory, even if possible, could be cost-prohibitive and time consuming for the exploited laborers even with the assistance of various private actors that could facilitate the process. What adds to the limitation of our tort law approach is not just limited to the competence of the governments or the lack of resources available to the exploited laborers, but what the businesses are doing in order to externalize their liabilities, which will be the topic of our next subsection.

\subsubsection{The Externalization Problem}

We noted in the beginning that giving alien plaintiffs access to justice in US or Dutch courts will offer them another platform to have their grievances heard, thus empowering them in a way that could possibly lead to the reduction of labor exploitations in the global supply chain. However, their ability to gain access or to seek redress from US or Dutch companies is significantly limited by the externalization problem. The externalization problem refers to the tendency of businesses to minimize their risks by externalizing their liabilities. Given their primary interest in maximizing profits, it is in the interest of businesses to establish subsidiaries or outsource parts of their operations elsewhere as we have seen throughout this thesis. More importantly, there are laws that facilitate this operation and protect the companies and their shareholders. In short, in the event that a foreign subsidiary commits a tort, it is very difficult for the plaintiffs to hold the parent company legally liable as the Akpan case exemplified. In an increasingly globalizing economy, not only is the question of establishing a duty of care on the parent company extremely difficult, but various conflict of law issues arise as well, given that many of these subsidiaries are located in jurisdictions all around the globe. ${ }^{543}$ To elaborate on the externalization problem further,

543 See e.g. Adams v. Cape Industries Plc [1990] Ch 433 (involving a principle company in the UK with materials (asbestos) mined through subsidiaries in South Africa and Texas, which caused damages to workers in the subsidiary based in Texas). 
this subsection will: a) discuss the ways in which companies are severing their liabilities, b) illustrate how plaintiffs can attempt to still hold these companies labile, and c) note how the increasing firm disaggregation and fragmentation of the global supply chain is making this task more difficult for the plaintiffs.

\section{A. Severing Liability: Outsourcing, Third Parties, and Respondeat Superior}

Many businesses go to some lengths to conceal their exploitations and violations, making it difficult for the task forces mentioned in Chapter 2 to detect and punish the violators. While some methods of concealment are more sinister and obvious than others (i.e. blackmailing employees to not speak to inspectors conducting audits, maintaining multiple accounting books, etc.), there are other, more "legitimate" ways for employers, especially corporations, to attempt to distance themselves from liabilities. One common way is for companies to outsource or contract out parts of their operation to separate legal entities and deny any liability for the acts of those third parties (i.e. subsidiaries, subcontractors, and the aforementioned independent contractors). ${ }^{544}$ This not only allows them to externalize various parts of their production, but it reduces their exposure to liability, not to mention the fact that they can also avoid paying for the benefits of the workers also mentioned back in Chapter 2. ${ }^{545}$ By outsourcing various parts of their operation to another legal entity, the parent company can still benefit from their services, but in the event that the subsidiary or the supplier is found to be exploiting their workers, the parent company can claim that they were not aware of such dealings by the other legal entity as we also witnessed in the Akpan case.

Traditionally, the doctrine of respondeat superior or vicarious liability - regardless of whether in a civil jurisdiction or a common law jurisdiction - states that employers can be held liable for the actions of their employees or workers for actions undertaken during the course of their employment. This could apply in a similar manner to hold parent companies liable for the actions of its subsidiaries or other legal entities, but whether or not vicarious liability can be applied to the parent company depends on the question of how much control the parent company had over the other legal entity. This issue of determining control is very similar to the aforementioned discussion of how much control Uber had over its drivers or how much control the Dutch newspaper companies had over the operation of its distributers discussed back in Chapter 2.546

544 A. RÜHmkOrF, Corporate Social Responsibility, Private Law and Global Supply Chains, (Cheltenham: Edward Elgar, 2015), at p. 101 (stating that sub-contracting "poses a significant challenge for the promotion of CSR policies in the supply chain through contract law, especially if there are diversified suppliers and sub-suppliers.").

545 A. RüHmkorf, Corporate Social Responsibility, Private Law and Global Supply Chains, (Cheltenham: Edward Elgar, 2015), at p. 172 (noting that "[m]any companies create sophisticated group structures consisting of a parent company with several subsidiaries," in order to "reduce their liability risk"); see also, B. HANNIGAN, Company Law, (Oxford: Oxford University Press, 2012), at para. 3-44; and, T.P. GLYNN, “Taking the Employer Out of Employment Law? Accountability for Wage and Hour Violations in an Age of Enterprise Disaggregation," Employee Rights and Employment Policy Journal 5(1) (2011): 101-135, at p. 114.

546 T.P. GLYNN, "Taking the Employer Out of Employment Law? Accountability for Wage and Hour Violations in an Age of Enterprise Disaggregation," Employee Rights and Employment Policy Journal 5(1) (2011): 101-135, at p. 108 (stating that this determination often depends on whether the parent company had the "right to exercise over the manner or details of the [subsidiary's] work"); see also, RESTATEMENT (THIRD) OF AGENCY \$7.07 (3)(a) (2006) (stating that the principal could be held liable for the actions of the agent if the principal controls or has the right to control the manner and means of the agent's performance or work). 
This requirement for the employer or the parent company to have control and/or influence over the third party before establishing vicarious liability is similar in the Netherlands as it is in the US, but in the Dutch case, the courts have been more broad and lenient in their interpretation of an employer and have imposed upon them, additional liabilities depending on the circumstances, as exemplified by the Dutch newspaper case noted back in Chapter 2. To recall its main points, this case was a clear example of how the Dutch courts interpret the term "employer" broadly in the context of the Foreign National Employment Act, thus denying companies from avoiding liabilities by simply contracting tasks out to third parties. This broadened definition of an employer and the residual imposition of liabilities even when responsibilities are partially outsourced is an area where the Dutch have gone beyond its American counterparts to prevent the exploitation of laborers in the domestic context, but the more relevant question presently, is whether this is the same in the international context.

While the Dutch courts might be more willing to extend liability against the principal businesses seeking to avoid liability by outsourcing various tasks to agents and other third party legal entities relative to the US courts, as we witnessed in Akpan, this general observation is not always true, especially when the parent company and its subsidiary are located in different territorial sovereignties. For example, recall here that in Akpan, the Dutch courts did not extend Shell Petroleum Development Company's liability (Royal Dutch Shell's wholly owned Nigerian subsidiary) to Royal Dutch Shell in the Netherlands. This can be partially explained by an argument that it is far more difficult for employers or parent companies to control their employees, subsidiaries, suppliers, and contractors if they are located in a different country. Thus, outsourcing - especially at an international scale - could have an added benefit for companies to not only lower costs, but decrease the chances that they will be held liable for the torts or other offences caused by their subsidiaries or contractors abroad. The answer to how the plaintiffs can attempt to overcome this problem will be addressed next.

\section{B. Piercing a Different Type of a Corporate Veil}

Similar to the debate surrounding the issue of outsourcing, legal mechanisms like "limited liability" were created initially for legitimate reasons, but have been prone to abuse in subsequent practice. Limited liability, for example, was created supposedly to encourage entrepreneurships and we often see, especially in company law or law of agencies, other types of legal mechanisms that nurture entrepreneurships in favor of business growth. ${ }^{547}$ As noted in the introduction, we cannot fault the governments for wanting to foster a business friendly atmosphere for the sake of soliciting businesses to come to their territories, but the governments must also recognize that doing so can have consequences. For example, outsourcing and limited liabilities can make the task of victims seeking redress against corporate malfeasance rather difficult. To reiterate a previous point made back in Chapter 2, the unavoidable reality is that governments must protect and balance the interests of multiple parties, and so do companies, who must not only cater to diverse shareholder interests, but that of their stakeholders as well. Accordingly, the aim of this part of the subsection is to 
highlight that although companies should, at least according to our normative framework, balance and protect the interests of their stakeholders and the laws should enable that, many existing laws tend to prioritize a certain class of stakeholders more so than the rest, as exemplified by legal mechanisms such as limited liability and the protections afforded to shareholders and director-level stakeholders by the corporate veil.

Generally speaking, the corporate veil protects and shields shareholders and the board of directors acting on behalf of the company - as a separate legal entity - from incurring personal liability. At the most basic level, this means that a hypothetical plaintiff cannot directly sue the shareholders and the board of directors for an alleged wrongdoing of the company that they are suing. This protection is also afforded to parent companies being shielded from the liabilities of their subsidiaries to the extent that the subsidiaries are separate legal entities. This means that in most cases, a plaintiff suing the subsidiary for an alleged wrong doing generally cannot directly go after the parent company as exhibited earlier in the Akpan case the Dutch court's refusal to hold Royal Dutch Shell liable for the wrongdoings of its Nigerian subsidiary. While there are certain exceptions when parties can indeed pierce or lift the corporate veil, this is often a very tall order, especially in cases when plaintiffs are seeking to hold the parent companies liable for the wrongdoings of its subsidiaries, even when they are wholly-owned subsidiaries.

Proponents of limited liability and the corporate veil will quickly note that their liabilities are only partially limited and that it is not as if corporations and their shareholders can do as they please without any consequences. For example, in the event that a wholly owned subsidiary causes a violation, the victims can - at least in theory - directly go after the parent company so long as various requiremetns are met, which will be discussed further below. In short, while possible in theory, piercing the corporate veil - particularly in the case of trying to hold a parent company liable for its subsidiaries actions -is extremely difficult in practice, given that there is a heavy presumption that parent companies are completely separate legal entities from its subsidiaries.

Recall here in this context, the Cape case also from Subsection 3.2.1, in which the court held that the parent company owed a duty of care for the employee of its subsidiaries who suffered asbestosis. Although this was a case where the employee of the subsidiary was actually able to seek damages from the parent company, Arden LJ was adamant that this was not because the plaintiff was able to pierce the corporate veil:

"I would emphatically reject any suggestion that this court is in any way concerned with what is usually referred to as piercing the corporate veil. A subsidiary and its company are separate entities. There is no imposition or assumption of responsibility by reason only that a company is the parents company of another company. " 548

As Arden LJ noted, the corporate veil, more commonly used to protect shareholders of companies from the debts that the company incurs, can also be relied upon by parent companies from severing liabilities from their subsidiaries. To her point, the fact pattern in Chandler v. Cape was different in a sense that the subsidiary, Cape Products, where Chandler worked no longer existed when the suit was filed and as a result, Cape had assumed the responsibilities of caring for its former subsidiary's employees directly. This was evidenced 
in the case by Cape's involvement in the asbestos business of Cape Products. ${ }^{549}$ In essence, Arden LJ was making the point that this is an issue where the parent company had hands on knowledge of the dangerous working conditions with asbestos. The Court also held that Cape had significant control over Cape Products, as evidenced by the fact that it hired scientific and medical specialists to look after the working conditions of their plants. 550 This control was what made this issue not necessarily a vicarious liability issue, but an assumption of responsibility and a simple negligence issue. So while the plaintiff won, it was not because he was able to pierce the corporate veil.

There have been cases, unlike in Cape, when the corporate veil has indeed been pierced in instances where the subsidiary owed debts and obligations to third parties, which the parent company was held liable for: For example, the Dutch courts have pierced the corporate veil so that the creditors of the subsidiaries can collect the debts owed by the subsidiary from the parent company. ${ }^{551}$ However, the likelihood of success for claims made by an employee of the subsidiary or someone like Akpan against the parent company would most likely be quite low. Moreover, even in the Netherlands, parent companies are often held liable, not because the plaintiffs were able to successfully pierce the corporate veil in the strictest sense of the word, but more likely on the basis that the parent company violated a duty of care just like in Cape.

Furthermore, it is worth nothing here that if the plaintiffs seek to pierce the corporate veil, "the applicable law will be the law of the country where the subsidiary is incorporated because this will be considered the lex societatis of the subsidiary," 552 which in Akpan was Nigerian/English law. It is also worth reiterating here the significance of the Dutch courts' openness to adjudicate matters in the Netherlands, even when dealing with foreign laws. 553 Yet, the problem for the plaintiffs still remain in that even when they are able to overcome procedural issues, the substantive matter of piercing the corporate veil is a rather tall order in any jurisdiction. If cases like Akpan illustrated anything, it is that victims will even have difficulties obtaining relevant documents that would allow them to argue that the parent company had control and influence over its subsidiary.

In sum, plaintiffs can technically pierce the corporate veil for the parent company's failure to prevent foreseeable damages by its subsidiaries, which acknowledges the fact that parent companies do have some duty of care even against the workers of their subsidiar-

Chandler v. Cape Plc. [2012] EWCA Civ 525, at para. 28 (referring to Cape's board meeting minutes where decisions about the expansion of Cape Products business were discussed and how there were directors of both companies in common).

550 Chandler v. Cape Plc. [2012] EWCA Civ 525, at para. 75.

551 Hoge Raad, 21 december 2001, NJ 2005, 96 (Sobi.Hurks II) and Hoge Raad, 12 juni 1998, NJ 1998, 727 (Coral/Stalt); see also, N.M.C.P. JÄGERS \& M. J. VAN DER HEIJDEN, "Corporate Human Rights Violations: The Feasibility of Civil Recourse in the Netherlands," Brooklyn Journal of International Law 33(3) (2008): 833-870, at p. 842 (adding, however, that "profound (financial) involvement of the parent company and knowledge of the infringement of rights is required for the courts to allow the corporate veil to be pierced.").

552 N.M.C.P. JÄGERS \& M. J. VAN DER HEIJDEN, "Corporate Human Rights Violations: The Feasibility of Civil Recourse in the Netherlands," Brooklyn Journal of International Law 33(3) (2008): 833-870, at p. 852.

553 N.M.C.P. JÄGERS \& M. J. VAN DER HEIJDEN, "Corporate Human Rights Violations: The Feasibility of Civil Recourse in the Netherlands," Brooklyn Journal of International Law 33(3) (2008): 833-870, at p. 849 (noting that the "parent companies can be sued in the Dutch courts concerning activities abroad if the Netherlands is the country where the corporation has been established."); see also, G. BETLEM, "Transnational Litigation Against Multinational Corporations Before Dutch Civil Courts" in Liability of Multinational Corporations Under International Law, M.T. KAMMINGA \& S. ZIA-ZARIFI (EDS.) (Dordrecht: Springer, 2000): 283-305, 302. 
ies. ${ }^{554}$ However, in practice, plaintiffs will have a very difficult time overcoming the presumption that parent companies and their subsidiaries are separate legal entities especially in a transnational context. ${ }^{555}$

\section{Firm Disaggregation and Fragmented Enterprises}

John Maynard Keynes once noted that "remoteness between ownership and operation is an evil." ${ }^{556}$ If this is indeed true, we should reconsider the consequences of outsourcing at the global level. Ultimately, the existing system of allowing employers to limit their legal liability through outsourcing is incentivizing firms to disaggregate, which creates "fragmented enterprises" (i.e. series of suppliers and subcontractors working for the multinational corporations as illustrated by Figure 1 from Chapter 1) that is increasing the separation between ownership and operation. This makes it easier for actors operating in the global supply chain to not be held accountable for their actions, because in some cases, they themselves are not entirely sure what the impact of their actions are. ${ }^{557}$

What increases the complexity of this respondeat superior discussion is that business incentives for outsourcing production and hiring third party subcontractors is not necessarily about dodging liabilities, as there are legitimate incentives for companies to move their production to a third party jurisdiction. ${ }^{558}$ But even if the sole reason for firms to outsource is to dodge liabilities, not only would it be prohibitively difficult for regulators to decipher corporate intentions, but options in terms of what they can actually do about it, is likely limited. ${ }^{559}$ Considering the high-reward, low-risk aspect of these types of arrangements from a purely business perspective, outsourcing - which increased firm disaggregation and creates further fragmented enterprises - is a relatively risk-adverse option for many companies.

Thus, from a purely fiduciary perspective, it would even be negligent for the firm's decision-makers not to outsource, thus increasing profits, reducing their liabilities, and keep-

554 See e.g. Hoge Raad, 21 december 2001, NJ 2005, 96 (Sobi/Hurks II).

555 N.M.C.P. JÄGERS \& M. J. VAN DER HEIJDEN, "Corporate Human Rights Violations: The Feasibility of Civil Recourse in the Netherlands," Brooklyn Journal of International Law 33(3) (2008): 833-870, at p. 859 (suggesting that "a parent company has a duty of care to prevent foreseeable damages. For example, in terms of injury that may occur when working with hazardous materials, it has been argued that if workers fall ill as a result of working with such materials, this may give rise to direct liability for the parent company if the company had the opportunity to intervene in its subsidiary's activities.").

556 J.M. KeYNES, "National Self-Sufficiency," The Yale Review 22 (1933): 755-769; see also, J. DE GRAAF, D. WANN \& T.H. NAYLOR, Affluenza: How Overconsumption is Killing Us - And How We Can Fight Back [Third Edition], (San Francisco: Berrett-Koehler Publishers, 2014), at p. 187 (adding that " $[\mathrm{t}]$ he lack of connection is convenient for corporate managers who don't have to see the life cycle of their profits - remote sweatshops, strip mines, and toxic waste landfills.”).

557 T.P. GLYNN, "Taking the Employer Out of Employment Law? Accountability for Wage and Hour Violations in an Age of Enterprise Disaggregation," Employee Rights and Employment Policy Journal 5(1) (2011): 101-135, at p. 104, 135 (noting that firm disaggregation and fragmented enterprises "pose significant challenges for enforcement of wage and hour mandates.").

558 Y.S. ANG, "Ethical Outsourcing and the Act of Acting Together," in Empowering Organizations through Corporate Social Responsibility, R. WOLF, T. ISSA \& M. THIEL (EDS.) (Pennsylvania: IGI Global, 2015), at p. 120 (noting that outsourcing is cost effective given the economies of scale).

559 T.P. GLYNN, "Taking the Employer Out of Employment Law? Accountability for Wage and Hour Violations in an Age of Enterprise Disaggregation," Employee Rights and Employment Policy Journal 5(1) (2011): 101-135, at p. 103 (noting the "limitations on liability for work-law violations"); see also, C. BECKER, "Labor Law Outside the Employment Relation," Texas Law Review 74 (1996): 1527 (noting that employment related law and the liability that it imposes to businesses promote businesses to outsource contracts and to hire independent contractors). 
ing up the competitive advantage against other companies. ${ }^{560}$ In short, although outsourcing might increase firm disaggregation and reduce corporate accountability, it still makes economic sense, ${ }^{561}$ similar to how it makes more sense for politicians to cater to business interests if they seek reelection, as noted back in Chapter 2. Especially when the problem occurs abroad, beyond the state's territorial boarders, it is not the primary responsibility of that government to concern itself in the welfare of some overseas factory workers that is not within their sovereignty, nor to be active in championing the protection of some human rights causes. ${ }^{562}$

In the context of labor exploitation, companies are often portrayed as the wrongdoers, ${ }^{563}$ that they are driven by greed, and lack empathy or care for those they exploit while in the process of making profits; however, in most cases, companies outsourcing their operations and circumventing laws of their own jurisdiction are not breaking the law. As noted before, governments also have an incentive, if not a duty, to ensure that they are fostering a legal environment favorable to businesses incorporated within their jurisdiction as well to keep up competition with other countries. David Vogel notes that "[a]s US and European firms face pressures to behave more virtuously, they are simultaneously experiencing increasing competition from a growing number of Asian firms based in China, Korea, and Taiwan. At the same time, Western firms increasingly produce for a worldwide market, including many countries where public pressure to act more responsibility is typically low..." 564 So this is where problems noted back in Chapter 2 become entangled with some of the limitations of our tort law approach.

In short, given all of the ways in which businesses can lawfully externalize their liability, it does not make sense - at least business sense - for them to voluntarily take on more liability. Moreover, the governments have conflicting motives in terms of curtailing such corporate behaviors as well. What this means with regards to answering our research question is that private actors cannot rely on what governments are doing alone, but we must also - at

560 M. FrIEDman, "The Social Responsibility of Business Is to Increase Its Profits," New York Times Magazine, (September 13, 1970) (declaring that "the social responsibility of business is to increase its profits"). Bear in mind that Friedman's take on the matter is only one particular way of looking at the goal of a company. There are various alternative perspectives, which will be elaborated in more detail in Chapter 4.2.1.

561 T.P. GLYNN, "Taking the Employer Out of Employment Law? Accountability for Wage and Hour Violations in an Age of Enterprise Disaggregation," Employee Rights and Employment Policy Journal 5(1) (2011): 101-135, at p. 104 (arguing that "outsourcing does far more than shift legal responsibility from one entity to another: it allows enduser firms to avoid noncompliance risks while benefiting from labor at a price discounted by the low probability of enforcement of work law mandates"); see also, N.D. ZATZ, "Working Beyond the Reach or Grasp of Employment Law," in The Gloves-Off Economy: Workplace Standards at the Bottom of the Labor Market, A. BERNHARDT, H. Boushey, L. Dresser \& C. Tilly (EDS.) (Urbana-Champaign: Labor and Employment Relations Association, 2008), at p. 49.

562 T. JACKSON, Prosperity without Growth: Economics for a Finite Planet, (New York: Earthscan, 2009), at p. 159 (stating that "[p]olicy-makers are (perhaps rightly) uncomfortable with the idea that they have a role in influencing people's values and aspirations" especially those outside of their borders). Regardless of any inane hesitation, governments and policymakers influence our social structures in what Jackson calls "signals" and these signals create our social world. In this sense, the thought of the government intervening with our decision-making process is not problematic.

563 D. Ashiagbor, "Evaluating the Reflexive Turn in Labour Law," in The Autonomy of Labour Law, A. BoGG, C. Costello, A.C.L. DAVIES \& J. PRASsl (EDS.), (Berlin: Walter de Gruyter, 2015) (accusing companies of "domesticating legal norms to serve their own managerial needs"); see also, L. EDELMAN, S. RIGG FULLER \& I. MARA-DRITA, "Diversity of Rhetoric and the Managerialization of Law," American Journal of Sociology 106(6) (2001): 1589-1642.

564 D. VogeL, The Market for Virtue: The Potential and Limits of Corporate Social Responsibility, (Washington D.C.: Brookings Institution Press, 2006), at p. 94. 
the very least - reassess the existing framework and our current approach to dealing with the problem of labor exploitation. This will take us into the realm of corporate social responsibility and ethical consumerism in the subsequent chapters, but before moving on to address these topics, the next subsection will first present an interesting case to cement the points raised in this section. In October of 2016, a Dutch trade union and an exploited migrant worker filed a lawsuit against FIFA in a Swiss court for allegedly being complicit in the labor exploitations taking place in Qatar as the country prepares to host the 2022 World Cup. This case will illustrate how an exploited laborer can stand up against an international organization (albeit with some assistance), but also address how the territoriality problem and the externalization problem can present serious obstacles for such claimants.

\subsubsection{FIF A in Qatar Case}

The subsections above noted how the territoriality problem complicates the imposition of domestic laws in national courts for torts that have taken place beyond its territorial borders to foreign parties. In addition, the previous subsection also stressed how the externalization problem (i.e. where companies outsource problematic aspects of their operations to independent third parties abroad) can make remedying the exploited laborers in domestic courts a rather complicated ordeal.

Even against unfavorable odds, some private actors have taken a grand stand against multinational corporations or other international organizations in foreign courts as demonstrated by cases like Kiobel and Akpan with varying levels of success. One additional case worth mentioning in this context that can further showcase what private actors (i.e. exploited laborers) are capable of is a case that was recently filed - in October 2016 - in a Swiss court, which is the case of Federatie Nederlandse Vakvereniging ("FNV") and Nadim Shariful Alam v. Fédération Internationale de Football Association ("FIFA"). ${ }^{565}$ This case revolves around the labor exploitation that is currently taking place in Qatar as the country prepares to host the 2022 World Cup. An exploited migrant laborer from Bangladesh, Alam, is suing FIFA together with FNV, a Dutch trade union confederation of which Alam is a member of, alleging that FIFA is complicit in the labor exploitations taking place in Qatar, where Alam used to work. Accordingly, this subsection will: a) layout the main facts of the case; and b) discuss the implications of this case in the context of how tort-law based claims are being used by exploited migrant laborers to seek justice in foreign courts.

\section{A. Exploiting Migrant Laborers for the Beautiful Game}

Amnesty International has been critical for some time about the labor abuses taking place in Qatar as the country prepares to host the World Cup, noting in particular the failures of the Qatari government to take meaningful steps to improve the situation for the migrant laborers and the lack of corporate due diligence up and down the supply chain. ${ }^{566}$ Refusing

At the time of writing, the writ of summons was just filed with the Handelsgericht des Kantons Zürich (the Commercial Court of Zurich) so the case has yet to be assigned a case number. However, the writ of summons, drafted by the Dutch firm Prakken d'Oliveira is available at: https://www.fnv.nl/site/over-de-fnv/fnvinternationaal/1040331/ fnvnadimsharifulalamvfifaenglish.pdf (last accessed 28 October 2016).

566 According to Amnesty International, Qatar has hired 375 labor inspectors that conducted over 56,000 inspections in 2015 alone, but the government did not make detailed analysis of these inspections available; see, AMNESTY 
to wait around for the Qatari government or businesses operating in Qatar to tackle the labor exploitation problem, the plaintiffs in this case initiated a lawsuit against FIFA in Swiss courts for the labor exploitations taking place in Qatar. ${ }^{567}$

The basic facts surrounding the FIFA case is not drastically different from the facts of the CNMI case presented back in the Introduction: There are over 1.7 million migrant workers in Qatar being recruited from countries like Bangladesh and India, lured by promises of finding meaningful work in Qatar. ${ }^{568}$ The migrant laborers take out loans (usually from the recruiters themselves, thus being forced into debt bondage) to travel to Qatar, where upon arrival, their passports are confiscated and they are forced to work in harsh conditions while being severely underpaid; any infractions, attempts to unionize or to report these violations are not only frowned upon, but punished (e.g. deduction of pay, deportation, etc.). ${ }^{569}$ For example, the plaintiff, Alam - a Bangladeshi national - alleged that his passport was confiscated upon arrival and that he was subsequently forced into labor for a period of 18 months in harsh conditions, where was underpaid by an amount totaling 9,400 pounds; and when he reported these violations, he was promptly fired and deported without receiving proper compensation for his labor. ${ }^{570}$

InTERNATIONAL, The Ugly Side of the Beautiful Game: Exploitation of Migrant Workers on a Qatar 2022 World Cup Site, MDE 22/3548/2016 (London: Amnesty International, 2016), at p. 7, 67 (noting that the companies are not respecting various labor standards set up byt the UN Guiding Principles on Business and Human Rights and the Qatari government's measures to remedy the situation as being inadequate).

567 P. WALKER, "Dutch Union Suing FIFA over 'Modern Slavery' at Qatar 2022 World Cup Sites in Landmark Case," Independent, (11 October 2016). Available at: http://www.independent.co.uk/news/world/middle-east/fifaqatar-world-cup-2022-migrants-dutch-union-slavery-fnv-bangladesh-court-legal-action-a7356191.html (last accessed 28 October 2016). While Swiss or Qatari law falls outside the scope of this thesis, it is worth addressing the jurisdiction of the Swiss court to hear this case here: Given that FNV is a Dutch entity and FIFA is a Swiss entity, both parties are domiciled in States that signed on to the Lugano Convention. Article 2(1) of the Convention states that "[s]ubject to the provisions of this Convention, persons domiciled in a State bound by this Convention shall, whatever their nationality, be sued in the courts of that State." Establishing the Swiss courts jurisdiction for Alam is slightly more complicated given that as a Bangladeshi national, Alam cannot invoke the Lugano Convention. The plaintiffs argue that in accordance with Article 129(1) of the Swiss Private International Law ("IPRG"), for tort complaints, the defendant's forum, in this case Zurich, is the appropriate forum. FNV's claim in accordance to their complaint is that "as a trade union and member of the international trade union movement, it is a matter of concern for FNV that employees around the world are able to form trade unions..." and that the actions (or the inactions) of Qataris government, where migrant laborers are prevented from unionizing or protected by minimum labor standards are harmful to the interests of FNV, as well as to the interests of their members. It must be noted here that Alam, after being fired and deported from Qatar, joined FNV as a member. Swiss Code of Civil Procedure ("ZPO") Article 89(1) on "Group action" permits associations and other organizations "of national or regional importance... to protect the interests of a certain group of individuals may bring an action in their own name for a violation of the personality of the members of such group."

568 O. GIBSON, "FIFA Faces Legal Challenges Over Qatar Migrant Workers," The Guardian, (10 October 2016). Available at: https://www.theguardian.com/football/2016/oct/10/fifa-faces-legal-challenge-over-qatar-migrantworkers-world-cup-2022 (last accessed 28 October 2016).

569 P. WALKER, "Dutch Union Suing FIFA over 'Modern Slavery' at Qatar 2022 World Cup Sites in Landmark Case," Independent (11 October 2016). Available at: http://www.independent.co.uk/news/world/middle-east/fifaqatar-world-cup-2022-migrants-dutch-union-slavery-fnv-bangladesh-court-legal-action-a7356191.html (last accessed 28 October 2016).

570 P. WALKeR, "Dutch Union Suing FIFA over 'Modern Slavery' at Qatar 2022 World Cup Sites in Landmark Case," Independent (11 October 2016). Available at: http://www.independent.co.uk/news/world/middle-east/fifaqatar-world-cup-2022-migrants-dutch-union-slavery-fnv-bangladesh-court-legal-action-a7356191.html (last accessed 28 October 2016). 


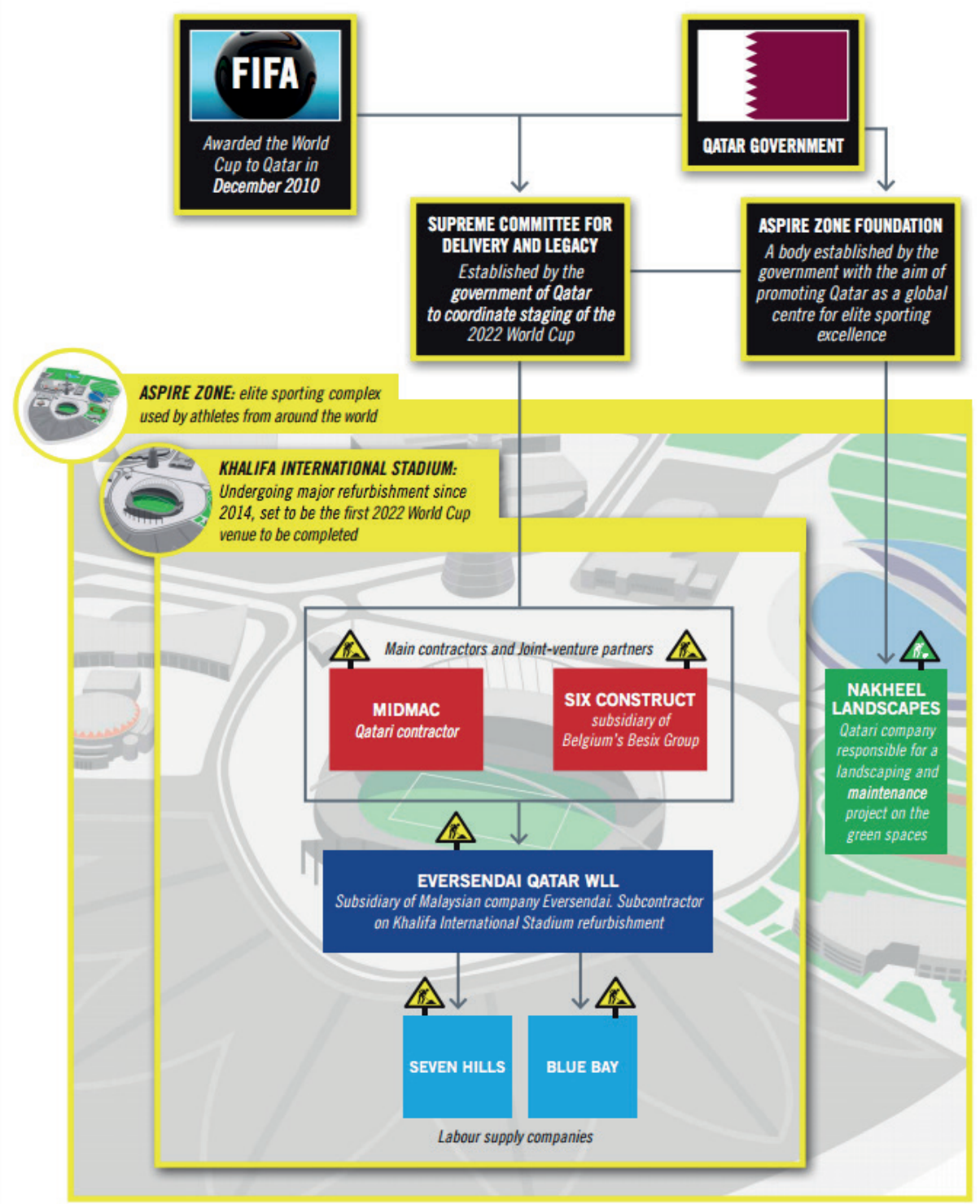

Figure 3: The Parties in the FIFA Case ${ }^{571}$

What is different about the FIFA case compared to the CNMI case is that rather than US legislatures and administrative authorities getting involved to resolve the labor exploitation

571 AmNESTy INTERNATIONAL, The Ugly Side of the Beautiful Game: Exploitation of Migrant Workers on a Qatar 2022 World Cup Site, MDE 22/3548/2016 (London: Amnesty International, 2016), at p. 49. 
problem taking place within its jurisdiction (as the case was in the CNMI), the Qatari government - at least according to Amnesty International - failed to adequately address this problem. ${ }^{572}$ This inaction led to the case at hand, where the plaintiffs initiated legal proceedings in a commercial court in Zurich against FIFA, an organization based in Switzerland. FNV and Alam's claim not only seeks compensation for unpaid wages, but in addition, alleges that FIFA - by awarding the World Cup to Qatar - was and continues to be complicit in perpetuating labor exploitation and various tortious acts in Qatar. ${ }^{573}$ Amnesty International concurs with this assessment as well, reporting that:

"In 2010, when FIFA awarded the 2022 World Cup to Qatar, it knew, or ought to have known, that most construction work in Qatar involves migrant workers and that migrant workers were subjected to serious and systematic labour exploitation. Yet, FIF A did not put in place any measures to ensure that the men who would build the World Cup infrastructure would not be exploited. $"{ }^{\prime 54}$

This case exemplifies how a migrant worker, with the backing of a Dutch trade union confederation, can attempt to change the labor standards of a foreign country by applying pressure on a large, international organization that has, in essence, vouched for the legitimacy of the said foreign country.

What makes this particular suit unique is that FIFA - for all intents and purposes - is not the entity that allegedly exploited Alam's labor. Although Alam's labor - and that of many other migrant laborers - is essential for Qatar to host a successful World Cup in 2022, which in turn would validate FIFA's selection of Qatar as the host for the profitable tournament, it would likely be difficult for the plaintiffs to hold FIFA accountable for all of the labor exploitations taking place at the World Cup venues. Moreover, the plaintiffs' claims are quite tricky not only because there is a territoriality issue here - which raises various political and comity related issues (i.e. a Swiss court adjudicating on a possible tort that occurred in Qatar against a Bangladeshi national with possible indictment of the Qatari government) - but more detrimentally to the plaintiffs' case, there is the issue of connecting the defendant, FIFA, to the possible tort committed in Qatar. In other words, the relationship between Alam and FNV with FIFA is extremely tenuous. ${ }^{575}$ For example, the main contract for getting the Khalifa International Stadium (one of the main venues for the 2022 World Cup) ready for the tournament was awarded to Midmac-Six Construct JV (a joint venture between a Qatari company and a subsidiary of a Belgian company), but various operations have been subcontracted to companies like Eversendai Qatar (a subsidiary

572 See generally, AMNESTY INTERNATIONAL, The Ugly Side of the Beautiful Game: Exploitation of Migrant Workers on a Qatar 2022 World Cup Site, MDE 22/3548/2016 (London: Amnesty International, 2016). Cf. The Qatari government did implement the 2009 Sponsorship Law and Law No. 21 of 2015 in an attempt to reduce the control that these sponsors have over the workers, but Amnesty International is skeptical of whether these measures will actually contribute to meaningful differences for the exploited laborers.

573 P. WALKER, "Dutch Union Suing FIFA over 'Modern Slavery' at Qatar 2022 World Cup Sites in Landmark Case," Independent (11 October 2016). Available at: http://www.independent.co.uk/news/world/middle-east/fifaqatar-world-cup-2022-migrants-dutch-union-slavery-fnv-bangladesh-court-legal-action-a7356191.html (last accessed 28 October 2016).

574 AMNESTY INTERNATIONAL, The Ugly Side of the Beautiful Game: Exploitation of Migrant Workers on a Qatar 2022 World Cup Site, MDE 22/3548/2016 (London: Amnesty International, 2016), at p. 10.

575 AMNESTy INTERNATIONAL, The Ugly Side of the Beautiful Game: Exploitation of Migrant Workers on a Qatar 2022 World Cup Site, MDE 22/3548/2016 (London: Amnesty International, 2016), at p. 4. 
of a Malaysian company) and Nakheel (a development company based in Dubai), who then divided and sub-subcontracted various parts of their operations to other smaller companies that ultimately hired migrant laborers from labor supply or recruitment companies like Seven Hills and Blue Bay. ${ }^{576}$ These labor supply companies are generally the entities directly responsible for recruiting the migrant laborers from abroad based on a sponsorship system, which gives the sponsors tremendous amounts of control over the lives of the migrant workers (e.g. deciding where they work, where they live, and whether they get fired or deported). ${ }^{577}$ This means that Midmac-Six Construct JV, Eversendai, and Nakheel do not technically "employ" the migrant laborers, similar to how Uber drivers are supposedly not Uber employees, but the migrant workers are sponsored by and work for the labor supply companies.

What this means is that legally speaking, it would be quite difficult for a plaintiff to even argue that the main contractor, Midmac-Six Construct JV in this case, ought to be held liable for the tortious acts and wrongdoings of an independent company (i.e. Seven Hills or Blue Bay) that sourced the migrant laborers to the main contractor's subsubcontractors. In the absence of clear and convincing evidence that the main contractor had some element of control or influence over the day to day operations of its subsubcontractors and/or that of the labor supply and recruitment companies, the plaintiffs will likely lose the case. The claim that FNV and Alam are making, however, is even more tenuous in that it attempts to hold FIFA, an organization that awarded the World Cup to Qatar, the country where these companies operate, to be complicit and thus responsible for the violations that the plaintiffs suffered.

While the plaintiffs' claim might be slightly overreaching, it is not entirely frivolous either. For example, the plaintiffs' complaint mentions violations of various legal and semilegal instruments as the basis for their claim against FIFA, including but not limited to violations of Qatari law, the UN Guiding Principles on Business and Human Rights, handful of ILO Conventions, and the Workers' Welfare Standard. ${ }^{578}$ It is worth noting here that

576 AmNESTy INTERNATIONAL, The Ugly Side of the Beautiful Game: Exploitation of Migrant Workers on a Qatar 2022 World Cup Site, MDE 22/3548/2016 (London: Amnesty International, 2016), at p. 5 (noting that labor supply companies "are small operations in which a sponsor brings a number of migrant workers to Qatar and then hired them out to other companies to do work.”).

577 The two relevant Qatari laws that enable this are Law No. 4 of 2009 regarding Regulation of the Expatriates Entry, Departure, Residence and Sponsorship and Law No. 14 of 2004, which in combination, essentially prohibit migrant laborers from leaving their job or the country without their sponsor's consent. This is referred to as the kafala system, which has been heavily criticized by various labor organizations such as the ILO. It is worth noting, however, that Qatar recently did approve Law No. 21 of 2015, which will replace the aforementioned 2009 Sponsorship Law from 14 December 2016 onwards, which supposedly increases the state's oversight into whether migrant laborers will be provided an exit visa, but as Amnesty International notes, "migrant workers will still be required to obtain their sponsor's approval to change jobs or leave the country," which is still the "key tool of control and coercion for abusive employers"; see, AMNESTY INTERNATIONAL, The Ugly Side of the Beautiful Game: Exploitation of Migrant Workers on a Qatar 2022 World Cup Site, MDE 22/3548/2016 (London: Amnesty International, 2016), at p. 67; see also, O. GIBSON, "FIFA Faces Legal Challenges Over Qatar Migrant Workers," The Guardian, (10 October 2016). Available at: https://www.theguardian.com/football/2016/oct/10/fifa-faces-legalchallenge-over-qatar-migrant-workers-world-cup-2022 (last accessed 28 October 2016).

578 For example, Qatar is a member of the ILO, which means that they are bound by various conventions that prohibit exploiting laborers (i.e. 1930 Forced Labour Convention (Convention No. 29), 1957 Abolition of Forced Labour Convention (Convention No. 105), etc.). Qatar is also a member of the Arab Charter on Human Rights, which condones exploitation of labor. Moreover, Qatari law (i.e. Article 65 of the 2004 Labour Law) also prohibits abusive contracts, which in relevant part holds that employees are entitled to wages designated to them by their contract and arbitrary deduction of wages by the employers are prohibited. 
the Workers' Welfare Standard is a private initiative created by the Supreme Committee for Delivery and Legacy - a governmental committee established by Qatar to plan and deliver the World Cup - that all companies awarded with contracts must follow and obey, which includes various minimum labor protections like prohibition of forced labor. ${ }^{579}$ While the impact of these types of private initiatives, standards, and codes of conduct will be discussed in more detail in Chapter 5, for the purposes of discussing our tort case, it suffices to simply note that there are various overlaps in terms of what the national laws, the soft law instruments, and the private initiatives require companies to do: in short, that is for companies not to exploit laborers and for companies to exercise due diligence so that their supply chain is also not perpetuating labor exploitation. As this thesis already noted in Chapter 2, however, just because laws and instruments exist, it does not necessarily mean that private actors adhere to them.

As a matter of fact, the basis of the plaintiffs' claim lies on this very point that FIFA failed to conduct their due diligence to ensure that the host country would not perpetuate labor exploitation on a massive scale when they awarded Qatar with the 2022 World Cup. More specifically, FNV and Alam allege that FIFA violated duties supposedly owed to migrant laborers, when it awarded Qatar to be the host and failed to impose various reforms to the Qatari government, even though they were - at least acceding to the plaintiffs - in a position to demand them, thus giving grounds for FIFA to be held liable. ${ }^{580}$

\section{B. Potential Implications of the Case}

Three general points are worth extracting from this ongoing case. First is the confirmation of the preliminary conclusion that this thesis reached at the end of Chapter 2, which is that there is a limit to what labor/employment laws can do because of the governments' competence problem. In addition, while international instruments like the UN Guiding Principles on Business and Human Rights have tremendous aspirational and normative functions, they are not directly reducing the instances of labor exploitation at least in a manner that is actually empowering migrant laborers in Qatar. For example, according to Liesbeth Zegveld, one of the attorneys working on the case against FIFA, while Qatari authorities are indeed trying to address their labor exploitation problem, their efforts are simply not good enough:

"We met with senior Qatari officials and they said they needed time to introduce new laws. They may say they need time but in reality they are just buying time. In any case, the new laws do too little to change the fundamental problems facing migrant workers and will mean little unless they are enforced." 581

579 AmneSTy INTERnATIONAL, The Ugly Side of the Beautiful Game: Exploitation of Migrant Workers on a Qatar 2022 World Cup Site, MDE 22/3548/2016 (London: Amnesty International, 2016), at p. 5 (noting that many of the protections enumerated on the Workers' Welfare Standards overlap with existing Qatari labor/employment laws.)

580 O. GiBSON, "FIFA Faces Legal Challenges Over Qatar Migrant Workers," The Guardian, (10 October 2016). Available at: https://www.theguardian.com/football/2016/oct/10/fifa-faces-legal-challenge-over-qatar-migrantworkers-world-cup-2022 (last accessed 28 October 2016).

581 O. GIBSON, "FIFA Faces Legal Challenges Over Qatar Migrant Workers," The Guardian, (10 October 2016). Available at: https://www.theguardian.com/football/2016/oct/10/fifa-faces-legal-challenge-over-qatar-migrantworkers-world-cup-2022 (last accessed 28 October 2016). 
Even if more stringent laws or comprehensive private standards were to be created with the intended aim of protecting laborers from being exploited, as the Amnesty International report confirms, exploited laborers almost never report violations of these laws and private standards for the fear of retaliation. ${ }^{582}$ Once again, this is to suggest that all the laws and rules do not make a difference, practically speaking, if they go unenforced or the laborers choose not to report the violations for the fear of retaliation or because they lack any meaningful alternatives.

Second, the likely outcome of this case will be that the commercial court in Zurich will be reluctant to hold FIFA liable given that while tort claims generally do not require privity, the argument that FIFA owed a duty to migrant laborers in Qatar that they breached by awarding the World Cup to Qatar, thus causing foreseeable harm and damages to the laborers, is objectively far-fetched. Moreover, the commercial court in Zurich is faced with a predicament similar to the ones faced by the US Supreme Court in Kiobel or by the Dutch Hoge Raad in Akpan. The quandary comes from the fact that the court must balance issues of human dignity and justice with that of commerce, international comity, and preserving various notions of the rule of law. In the end, Liesbeth Zegveld believes that it will take more than a year for the commercial court in Zurich to reach any sort of judgment, if at all. ${ }^{583}$ However, due to the various problematic aspects with cases of this nature that this chapter already flagged and noted, FNV and Alam face a difficult task ahead. Not only is there a territoriality problem (i.e. suing FIFA for an alleged wrongdoing that is taking place in Qatar against foreign victims), but the plaintiffs must also overcome the externalization problem, given that FIFA, in a manner of speaking, externalized the responsibility - and the liability - of hosting the 2022 World Cup to Qatar. Furthermore, given that the Supreme Committee, tasked with delivering the event, has contracted out the actual construction of the stadium to a joint venture company, who then subcontracted the construction to other companies, who then contracted out the sourcing of their laborers to recruitment companies, there is a severe case of fragmentation and disaggregation that obfuscates the legal arguments that the plaintiffs are trying to make.

Third, this case compels us to deal with the question of whether complicity is enough to go after an organization like FIFA for tort-based claims of labor exploitation, and if so, where the courts should draw the line. If the Swiss court was to say, hypothetically, that FIFA was indeed complicit and ought to be held liable, can the same argument then be used for multinational corporations like Apple or Samsung to be held liable for the exploitation of child laborers in the mines of the DRC? Can the same argument also be made that while many consumers are not directly supporting labor exploitation, when they actively choose to purchase from brands often associated with using exploited laborers, can these consumers also be held liable for being complicit in labor exploitation? FIFA has argued that they cannot be held accountable for a wide range of societal problems that continue to

582 AmNESTy InTERnATIONAL, The Ugly Side of the Beautiful Game: Exploitation of Migrant Workers on a Qatar 2022 World Cup Site, MDE 22/3548/2016 (London: Amnesty International, 2016), at p. 9 (stating that "none of the workers whose cases are documents in this report brought a complaint to the authorities about the human rights abuses they were experiencing."').

583 P. WALKER, "Dutch Union Suing FIFA over 'Modern Slavery' at Qatar 2022 World Cup Sites in Landmark Case," Independent (11 October 2016). Available at: http://www.independent.co.uk/news/world/middle-east/fifaqatar-world-cup-2022-migrants-dutch-union-slavery-fnv-bangladesh-court-legal-action-a7356191.html (last accessed 28 October 2016). 
exist in the host nations, ${ }^{584}$ but FNV and various other NGOs believe that FIFA can and should have been more influential in changing the status quo; however, this point of contention could equally apply to many companies and consumers as well. So where do private actors go from here?

John Ruggie recently published a report that - at least in part - praises FIFA as an organization that has "made an important start," while noting that there are still various areas that FIFA must change (i.e. it must shift its culture from "good-looking governance" to that of "good governance"). ${ }^{585}$ In his report, Ruggie offered 25 recommendations advising FIFA to be more proactive rather than reactive and to be more accountable rather than insular, but Ruggie did not provide any specific recommendation as to how FIFA ought to deal with cases like the one initiated by FNV and Alam. ${ }^{586}$ In a subsequent interview with the Guardian, however, Ruggie did note the following: "FIFA can't impose human rights on countries but in return for hosting a tournament there are certain human rights to which you should have to adhere to... If you can't, you have to make tough decisions. That may include having to terminate an existing relationship." 587 So while Ruggie partially challenges one of the plaintiffs' claims - that FIFA could have imposed Qatar to adopt new laws that better protect their migrant workers - Ruggie concedes that FIFA could be doing more by severing their ties with Qatar and finding a different host country that has a better track record of not exploiting their laborers. The problem with this suggestion, however, is that while FIFA severing ties with Qatar might send a strong message to other potential host countries to improve their track record of labor exploitation, it does not necessarily improve the working conditions of the migrant laborers in Qatar in a manner that conforms to our normative framework of the adapted capabilities approach. If anything, what is required is not for FIFA to abandon Qatar to show its seriousness about reducing labor exploitation, but for FIFA to stay and to hunker down, and attempt to find a way to work more closely with the Qataris to address the labor exploitation in a more meaningful and pragmatic way.

While the success of FNV and Alam's case against FIFA could - at least in theory empower the workers and improve their working conditions, creating such a lofty precedent could open up the floodgates, which could render unimaginable domino effects, both good and bad, as illustrated by the hypotheticals noted above. A judgment of such a nature

584 O. GIBSON, "FIFA Faces Legal Challenges Over Qatar Migrant Workers," The Guardian, (10 October 2016). Available at: https://www.theguardian.com/football/2016/oct/10/fifa-faces-legal-challenge-over-qatar-migrantworkers-world-cup-2022 (last accessed 28 October 2016) (quoting FIFA's head of sustainability, Federico Addiechi that FIFA "cannot and indeed does not have the responsibility to solve all the societal problems in a host country of a Fifa World Cup...”).

585 J.G. RugGIE, "For the Game. For the World: FIFA \& Human Rights," Harvard Kennedy School Corporate Responsibility Initiative (2016). Available at: https://www.hks.harvard.edu/centers/mrcbg/programs/ cri/research/reports/report68 (last accessed 28 October 2016), at p. 36; see also, M. ANDREWS \& P. HARRINGTON, "Off Pitch: Football's Integrity Weaknesses, and How to Strengthen Them," Harvard University Center for International Development Working Paper 311 (January 2016). Available at: https://www.hks.harvard.edu/ centers/cid/publications/faculty-working-papers/footballs-financial-integrity (last accessed 28 October 2016).

586 J.G. RugGIE, "For the Game. For the World: FIFA \& Human Rights," Harvard Kennedy School Corporate Responsibility Initiative (2016). Available at: https://www.hks.harvard.edu/centers/mrcbg/programs/cri/research/ reports/report68 (last accessed 28 October 2016), at p. 4.

587 O. GIBSON, "FIFA Faces Legal Challenges Over Qatar Migrant Workers," The Guardian, (10 October 2016). Available at: https://www.theguardian.com/football/2016/oct/10/fifa-faces-legal-challenge-over-qatar-migrantworkers-world-cup-2022 (last accessed 28 October 2016). 
would have serious implications not only to company laws but on how companies and other private actors operate, which will be the subject of the next chapter. However, before moving on to address those particular issues, we must first draw some preliminary conclusions about the tort law approach and what exploited laborers can do to reduce labor exploitation in the global supply chain by pleading their case in front of foreign courts.

\subsection{CONCLUSION: TORT LAW OFFERS LIMITED OPPORTUNITIES FOR EXPLOITED LABORERS}

This chapter first presented how American and Dutch courts are dealing with the issue of foreign plaintiffs that come to seek access to their courts in order to rectify a wrongdoing that took place abroad in Sections 3.1 and 3.2. The reason for pursuing this particular avenue of approach was under the assumption that if exploited laborers had an additional platform where they can file grievances or seek redress against their exploiters, this would not only empower the laborers in a manner conforming to our normative framework, but would have the added benefit of publicizing corporate malfeasance taking place abroad. In many cases, because the alien victims were not directly employed by the parent company, but often by its subsidiaries or contractors, they had to rely on tort law claims rather than a claim based on privity of contract, which presented series of additional complications. In addition, each of these sections also touched upon the various class action or representative litigation methods available in the two jurisdictions with the idea that there is power in numbers and that exploited laborers can band together in the hopes of balancing out the power asymmetry problem between the laborers and the corporations.

However, Section 3.3 described that while possible in theory, the current approach of exploited laborers initiating transnational litigation against Western corporations that rely on labor exploitation abroad through separate legal entities, may be an incredibly cumbersome approach for the alien plaintiffs, not to mention the fact that the probability of their success is relatively low. This is due in part to the fact that domestic courts are generally reluctant to give legal standing to foreign plaintiffs for the fear of violating international comity or overstepping their bounds into the realm of politics. Even from the perspectives of the laborers or the would-be foreign plaintiffs, initiating and litigating abroad is an extremely costly and time-consuming process, which could make this particular approach unfeasible in the absence of significant private sector support. Even with the support of various NGOs, however, as the Rio Tinto case demonstrated, it is entirely possible for the plaintiffs to end up with nothing, even after a decade long litigation. Part of the reason why alien plaintiffs often fail to successfully seek redress from parent companies is because there are laws that protect companies from being held liable for the actions of their subsidiaries or contractors like, and companies are relying on them to shield themselves from liability and externalizing their risks away.

From a broader perspective, it must be noted that the focus of tort liability analysis tends to be expost in that they attempt to remedy the victims once the violation has already taken place similar to that of labor/employment law enforcements. While declaratory judgments could be issued to prevent future violations, the trouble with this is that the 
businesses often take into consideration and incorporate these ex post costs into their risk calculation ex ante, which creates a significant perverse incentive. Especially for the extractive sector and for companies like Shell, Chevron, and Rio Tinto, being sued abroad is not a matter of if, but a matter of when, and accordingly, they take measures to address the issue whether by insurance or some pooling mechanisms that decrease the deterrence effect of various sanctioning measures. This begs the question of whether these ex post regulations and enabling victim plaintiffs to sue in foreign courts on the basis of tort law really serve as effective incentives for businesses to curtail their wrongdoings.

So these considerations lead us to the conclusion that while tort law based claims could be argued as being potentially capabilities-enhancing, by looking at the outcomes of various transnational tort law cases, they may not be the most feasible nor efficient approach that the private sector can take to reducing labor exploitation in the global supply chain. 
Page left intentionally blank 


\section{Chapter

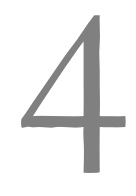

\section{Company Law/Corporate Governance Perspective}

"The value of an idea lies in the using of it."

\section{Thomas Edison}

The previous chapter elaborated on how exploited laborers can potentially seek justice in American or Dutch courts even for torts that took place abroad. In doing so, however, Chapter 2 concluded that the particular tort law approach - that of relying on transnational litigations - may not be as capabilities-enhancing or as feasible as once thought. In describing the plight of the laborers seeking justice abroad, the last chapter also noted how companies outsourcing operations and externalizing their liabilities are contributing to the territoriality and externalization problems that is preventing various attempts to reduce labor exploitations from succeeding. Bearing this last point in mind, this chapter will now shift our attention from what laborers themselves are doing to focusing on the role of companies, their stakeholders, and company law based measures that they are implementing. Given that many companies operate at a global level, as noted back in the methodology section, our analysis of what companies are doing will adopt a rather international and holistic perspective: What this means is that some of the measures that this and the subsequent chapters will discuss are not necessarily laws and regulations of one specific jurisdiction or another in particular, but moreover, we will be looking at various voluntary private initiatives as well.

This international and holistic approach requires one clarifying distinction before we can proceed: Laws are different from private initiatives or private rule making and they ought to be treated separately. The main difference between private law and private rulemaking comes down to the core difference that private law (i.e. tort law, contract law, etc.) is still mainly produced by the States, whereas private rule-making is a production of rules 
or norms by private actors themselves and not necessarily the government. ${ }^{588}$ While mandatory State made laws like labor/employment laws require legislative approval and must go through the gambit of various legislative procedures before being implemented, private rule-making or private initiatives are more flexible and do not require democratic consent in order to be considered legitimate: That is to suggest that private initiatives, often based on our fundamental freedoms to contract, can have far more reaching results, especially when dealing with matters that have trans-boundary effects and in a much more flexible and adaptive manner. ${ }^{589}$

With this in mind, the aim of this chapter is to reassess the role of company law based measures and what private actors are currently doing in our quest to answer the research question of what can private actors do differently to reduce instances of labor exploitation in the global supply chain. Accordingly, this chapter will have the following composition: The first section will define corporate social responsibility ("CSR") as this chapter will focus on company laws and corporate governance practices that fall under the CSR umbrella; and how various stakeholders within the company can influence or shape the role that companies play in the global supply chain (Section 4.1). The second section will then describe some very specific company law based measures that are currently being implemented voluntarily by private actors (Section 4.2), which will be followed by the third section that will address the various problems and limitations associated with these existing measures (Section 4.3). The final section of this chapter will draw preliminary conclusions about the impact of voluntary CSR initiatives and company law-based measures on the reduction of labor exploitations and what we can learn from their flaws (Section 4.4).

\subsection{CORPORATE SOCIAL RESPONSIBILITY UMBRELLA}

The previous chapters have noted that in the era of post-national governance, governments are handcuffed by an increasing number of constraints and limitations. ${ }^{590}$ While govern-

F. CAFAGGI, "Private Regulation in European Private Law," EUI Working Papers Robert Scbuman Centre for Advanced Studies Private Regulation Series (2009). Available at: http://www.estig.ipbeja.pt/ ac_direito/RSCAS_2009_31.pdf (last accessed 2 May 2015), at p. 2 (elaborating that "[p]rivate law and private rule-making are different yet related bodies of rules. Private law is publicly (mainly State) produced law, including mandatory and enabling provisions, which individual or collective private actors can specify and modify, when rules are enabling. Private rule-making is production of rules by private actors both in areas where there is enabling legislation and in those where public law-making has not (yet) emerged or cannot operate due to constitutional limitations."); citing to, D. LEVI-FAuR, "Regulatory Capitalism: The Dynamics of Change Beyond Telecom and Electricity," Governance 19(497) (2006); see generally, G. TEubner, Global Law without a State, (Brookfield: Dartmouth Publishing Co., 1997); and, J. BratTHWaite \& P. Drahos, Global Business Regulation, (Cambridge: Cambridge University Press, 2000), at p. 5 (citing to N. JANSEN \& R. MiChAelS, "Private Law Beyond the State? Europeanization, Globalization, Privatization," American Journal of Comparative Law 54 (2006), at p. 843.

589 J.M. SMITS, "Democracy and (European) Private Law: A Functional Approach," in Globalization and Private Law: The Way Forward, M. FAURE \& A. VAN DER WALT (EDS.) (Cheltenham: Edward Elgar, 2010), at p. 19 (noting the debate between Michaels and Jansen on one side and Rodl on the other and pointing that private rule making does "not necessarily have to find its legitimacy in the decisions of national parliaments.").

590 O.O. SCHACHTER, "The Decline of the Nation-State and its Implications for International Law," Columbia Journal of Transnational Law 36(7) (1997), at p. 23; see also, S.D. MURPHY, "Taking Multinational Corporate Codes of Conduct to the Next Level," Columbia Journal of Transnational Law 43(2) (2005), at p. 2 (noting that "states are continuing to do what they have always done, [but] they are just not keeping up with the surge in transnational commercial, financial, service, health and informational relations.”). 
ments and their legislations serve - and will continue to serve - a very important purpose in preventing uninhibited exploitation of laborers in the global supply chain, there is a limit to what they can do. This section will now address what companies can do to ameliorate the plight of the workers and the burdens placed on governments through various private initiatives that fit under the corporate social responsibility umbrella. ${ }^{591}$ Bearing in mind the great potential of companies and the significant amount of power that they wield - as evidenced by studies of Eccles and Serafem or Vitali, Glattfelder, and Battison that were mentioned in the Introduction - this section will devote our attention to the role of companies operating in the global supply chain that are trying to make a difference. ${ }^{592}$

Accordingly, this subsection will first discuss the role that corporate social responsibility plays in shaping the actions of companies and their stakeholders (Subsection 4.1.1), followed by addressing the question of why businesses are adopting and implementing CSR initiatives voluntarily even in the absence of legal obligations for them to do so (Subsection 4.1.2).

\subsubsection{What is Corporate Social Responsibility?}

This thesis mentioned back in the Introduction, the so called "grey area," where private actors may not have a legal obligation to act, but perhaps should or ought to as one of the areas that this thesis will pay particular attention to in answering the question of what private actors can do differently to reduce instances of labor exploitation. Focusing on the workers' capabilities serves as a reminder that we need to make special efforts to address the unequal needs of those are in vulnerable employments. ${ }^{593}$ Rather than focusing on the normative question of why or whether private actors ought to, this chapter will present a descriptive overview of what private actors are indeed already doing, above and beyond what government measures like labor laws require them to do. With regards to businesses and corporations, this grey area can be described in the context of corporate social responsibility. CSR, akin to business virtue, can generally be described as "practices that improve the workplace and benefit society in ways that go above and beyond what companies are legally required to do." 594 Recall John Ruggie's observation from back in Chapter 2, where he noted that in the aftermath of cases like Kiobel, there has been a "growth of voluntary corporate social responsibility initiatives," which suggests that, whatever their interests or

D. Vogel, The Market for Virtue: The Potential and Limits of Corporate Social Responsibility, (Washington D.C.: Brookings Institution Press, 2006), at p. 160 (suggesting that "[i]n many respects [companies] are in unchartered territory under pressure to assume obligations that have historically been the responsibilities of governments and international institutions.").

592 R.G. ECCLES \& G. SerAfem, "Top 1,000 Companies Wield Power Reserved for Nations," Bloomberg, (11 September 2012). Available at: http://www.bloomberg.com/news/2012-09-11/top-1-000-companies-wieldpower-reserved-for-nations.html (last accessed 4 April 2017) (noting that "the starting point for any strategy of institutional change toward a sustainable society" should be based on this corporate power).

593 M.C. Nussbaum, "Beyond the Social Contract: Capabilities and Global Justice," Oxford Development Studies 32(1) (2004), at p. 13 (adding the caveat that people are not expected, nor asked to help others and promote human capabilities to the point where they themselves become impoverish and their attempts establish a dignified life devoured).

594 D. VoGEL, The Market for Virtue: The Potential and Limits of Corporate Social Responsibility, (Washington D.C.: Brookings Institution Press, 2006), at p. 2. 
motivations may be, companies are indeed willing to go above and beyond what is required by the government measures. ${ }^{595}$

In order to carry out a detailed analysis of CSR and its contribution to answering our research question, this subsection will: a) provide a working definition of CSR, b) conceptualize CSR as a hybrid regulatory mechanism, and given the possible confusion that could arise from describing CSR as a hybrid mechanism, c) attempt to clarify the basic differences between laws, social norms, values, and morals in the context of our research question.

\section{A. CSR: The Definition(s)}

The most basic and common definition of CSR is the one already offered above, which includes any measure that a corporation takes that goes above and beyond what they are required to do by law for the benefit of society. ${ }^{596}$ This could be something as simple as paying laborers down the supply chain more than the legal minimum wage, or something more complex as creating an internal code of conduct, establishing various monitoring mechanisms, and conducting randomized audits to ensure compliance to the voluntary code. While these CSR measures are indeed voluntary (as in companies are not legally compelled to do so), companies can choose to supplement these voluntary initiatives with various private law instruments. ${ }^{597}$ For example, a company can volunteer to uphold itself to comply with soft law recommendations, guidelines, or other more normative instru-

J.G. RugGIE, "Kiobel and Corporate Social Responsibility: An Issues Brief," Harvard John F. Kennedy School of Government Working Paper (4 September 2012), at p. 4 (noting that this growth can partially be attributed to the wishes of companies to "avoid ATS-type liability").

596 The European Commission defines CSR as follows: "Corporate social responsibility refers to companies voluntarily going beyond what the law requires to achieve social and environmental objectives during the course of their daily business activities." Available at: http://ec.europa.eu/social/main.jsp?catId=331 (last accessed 4 April 2017); see also, European Commission, "Green Paper: Promoting a European Framework for Corporate Social Responsibility," COM (2001) 366 final, 20 (defining CSR in the following way: "a concept whereby companies integrate social and environmental concerns in their business operations and in their interactions with their stakeholders on a voluntary basis."). Note that this definition has since been adapted by a more recent EU Commission publication of CSR; see, European Commission, "Communication from the Commission to the European Parliament, the Council, the European Economic and Social Committee and the Committee of the Regions: A renewed EU strategy 2011-14 for Corporate Social Responsibility" COM (2011) 681 final; see also, A. RÜHMKORF, Corporate Social Responsibility, Private Law and Global Supply Chains, (Cheltenham: Edward Elgar, 2015), at pp. 3, 10. (noting that CSR is "by definition voluntary."); Confederation of British Industry, Issue Statement: Corporate Social Responsibility (2001) (using adjectives such as "voluntary," "business-driven" and "well-beyond what is required by legislation" to describe CSR); Cf. A. RÜHMKORF, Corporate Social Responsibility, Private Law and Global Supply Chains, (Cheltenham: Edward Elgar, 2015), at p. 11 (acknowledging that "the view that CSR is, by definition, a voluntary matter is far from settled."); D. VOGEL, The Market for Virtue: The Potential and Limits of Corporate Social Responsibility, (Washington D.C.: Brookings Institution Press, 2006), at p. 172-3 (arguing that "the definition of corporate social responsibility needs to be redefined to include the responsibilities of business to strengthen civil society and the capacity of governments to require that all firms act more responsibly" given that that "too few firms have undertaken or supported [labor empowering] political initiatives, in part because they are hesitant to promote expansions of government regulatory requirements"); C. GLINSKI, "Corporate Codes of Conduct: Moral or Legal Obligation," in The New Corporate Accountability: Corporate Social Responsibility and the Law, D. MCBARNET, A. Voiculescu \& T. CAmpBell (EDS.) (Cambridge: Cambridge University Press, 2007), at p. 147; K. CampBell \& D. VICK, "Disclosure Law and the Market for Corporate Social Responsibility," in The New Corporate Accountability: Corporate Social Responsibility and the Law, D. MCBARnET, A. VOICUlESCU \& T. CAMPBELl (EDS.) (Cambridge: Cambridge University Press, 2007), at p. 242 (including in their definition of CSR the following: "[t]he obligation to be socially responsible is usually conceived of as being over and above the minimum requirement imposed on companies by formal legal rules, although this is not invariably the case.").

597 A. RÜHmKOrF, Corporate Social Responsibility, Private Law and Global Supply Chains, (Cheltenham: Edward Elgar, 2015), at p. 12 (noting that "private law could provide told to enforce CSR principles, for example, through the use of consumer law, the enforcement of contractual CSR obligations or through liability in tort law.”). 
ments, ${ }^{598}$ which would be an example of the company implementing a CSR strategy in and of itself, but in addition, by contractually binding themselves either to the public or to other members of the supply chain that they will abide by these normative instruments, this voluntary CSR initiative now has legally binding force. This would suggest that CSR measures could be interpreted to include the law though not necessary limited to the law. ${ }^{599}$ For example, if a company contractually binds itself to a voluntary code of conduct that is not otherwise mandated by the law, this would be an example of a CSR initiative or private-rule making within our basic definition, but with an added backing of contract law. This particular understanding of CSR and private rule making will be the framework that this thesis will rely on moving forward. 600

While the selection of this particular definition of CSR does not necessarily undermine other interpretations or understandings of CSR, it is worth noting that the abundance of definitions for what CSR exactly is and the various divisions even amongst the proponents of CSR weakens the potential of what it can accomplish. The EU has also noted this concern, stating that the proliferation of CSR measures, however well intended they might be, is creating confusion and disorienting the masses. ${ }^{601}$ So while the debate over what CSR actually means or what it entails may be a fruitful academic exercise and a discourse that may ultimately contribute to the evolution of CSR, it is worth bearing in mind that the discussion over the proper definition of what CSR is, at the current juncture, can also be detrimental to what these initiatives are attempting to accomplish in the first place. ${ }^{602}$

One additional caveat, which must be made before proceeding, is that although CSR has been described as an American idea with its origins in the US, this is now a global phenomenon. ${ }^{603}$ This obviously does not mean that CSR measures are implemented with simi-

598 For example, instruments including but not limited to: Universal Declaration of Human Rights, UN Global Compact, UN Norms on the Responsibility of Transnational Corporations and Other Business Enterprises with regard to Human Rights Obligations, UN Guiding Principles, OECD Guidelines for Multinational Enterprises, ILO Declaration on Fundamental Principles and Rights at Work, ILO's Tripartite Declaration of Principles Concerning Multinational Enterprises and Social Policy, and many more.

599 A. RÜHMkORF, Corporate Social Responsibility, Private Law and Global Supply Chains, (Cheltenham: Edward Elgar, 2015), at p. 13; see also, J. BLACK, "Decentering Regulation: Understanding the Role of Regulation and SelfRegulation in a Post-Regulatory World," Current Legal Problems 54 (2001), at pp. 129.

600 A. RÜhmkorf, Corporate Social Responsibility, Private Law and Global Supply Chains, (Cheltenham: Edward Elgar, 2015), at p. 3 (suggesting that CSR initiatives are those that "advance the interests of those who are affected by their activities, focusing in particular on the social and environmental impact of their work.").

601 European Parliament Directorate-General for External Policies (Policy Department), "New Options for Strengthening Standards on Social and Environmental Responsibilities of Corporations and Their Implementation,” EXPO/B/DEVE/FWC/2009-01/Lot5/36 PE 457.138 (2013), at p. 4 (observing that "[t]he current proliferation of approaches and standards at various levels (national, international, generic, sector-specific) inevitably leads to a lack of orientation for consumers, investors and policy-makers," which is leading to a situation where there is a "lack of political will to consistently promote CSR"); see also, M.S. SCHWARTZ, Corporate Social Responsibility: An Ethical Approach, (London: Broadview, 2011), at p. 15 (noting that there is a "multitude of different definitions" for what CSR is and a "range of views on the appropriate scope and nature of a firm's social responsibilities.”); see also, D. MATTEN \& J. MOON, “Implicit' and 'Explicit' CSR: A conceptual framework for understanding CSR in Europe," ICCSR Research Paper Series 29 (2004) (defining CSR as "a cluster concept which overlaps with such concepts as business ethics, corporate philanthropy, corporate citizenship, sustainability, and environmental responsibility. It is a dynamic and contestable concept that is embedded in each social, political, economic and institutional context.").

602 The Inverted-U curve, mentioned in Chapter 2.3.4A could also be applicable in this context as well.

603 A. Crane, D. Matten \& L. Spence, "Corporate Social Responsibility: In Global Context," Corporate Social Responsibility: Reading and Cases in Global Context, A. CRANE, D. MATTEN \& L. SPENCE (EDS.) (London: Routledge, 2013), at p. 13. 
lar results all across the globe as various differences can be seen in whether CSR measures are even necessary. For example, let us compare the US and Europe from a very broad societal perspective: Americans generally espouse the idea of personal freedom, which engenders a relatively unregulated market and a reduced reliance on welfare provisions, whereas Europeans - and Asians for that matter - are more willing to sacrifice their individual autonomy for the sake of addressing their societal problems through collective action and a more involved government. ${ }^{604}$ What this means in the context of CSR and the need for such measures is that there is more room for CSR in American-like societies, and perhaps less need for such measures in European or Asian societies.

Another way to conceptualize this rather broad societal difference is to suggest that measures that a typical American might classify as a CSR measure can often be perceived as the task for the governments from a more European perspective. ${ }^{605}$ With these geographical and cultural considerations, it is important to keep in mind that although CSR will be discussed in this chapter rather generally, differences in its application and outcome could differ greatly depending on whether we are talking about it in the context of a developing economy or a developed economy, or whether we are dealing with MNCs or small-tomedium sized enterprises ("SMEs"), and so on. What this suggests is that CSR is somewhat of a fluid term, susceptible to varying interpretations and definitions, with some, even arguing that CSR is no longer purely voluntary, but a necessary feature for any business. This brings us to the conceptualization of CSR as a hybrid regulatory mechanism.

\section{B. CSR as a Hybrid Regulatory Mechanism}

As noted above, private law can add legally binding force to an otherwise voluntary CSR initiative, and together with the claim that CSR is quickly becoming a necessary feature in business, an idea has emerged that CSR is a form of private rule making that can equip MNCs with the power to create their own private legal systems. ${ }^{606}$ This portrayal of CSR as an instrument capable of creating a private legal system, answers the question of why CSR initiatives could be a useful tool to combat labor exploitations in the global supply chain, but it also raises other questions: For example, the issue of CSR as a regulatory instrument - vis-à-vis a voluntary initiative - have led some to further distinguish "private initiatives" from "private regulations." ${ }^{607}$ However, attempting to establish a clear line of demarcation

A. Crane, D. Matten \& L. Spence, “Corporate Social Responsibility: In Global Context,” Corporate Social Responsibility: Reading and Cases in Global Context, A. Crane, D. MATTEN \& L. SPENCE (EDS.) (London: Routledge, 2013), at p. 13-4 (noting that "American society is characterized by fairly unregulated markets for labour and capital, low levels of welfare state provision, and a high appreciation of individual freedom and responsibility," whereas Europeans and Asians have "a stronger tendency to address social issues through governmental policies and collective action.").

605 A. Crane, D. Matten \& L. Spence, “Corporate Social Responsibility: In Global Context," Corporate Social Responsibility: Reading and Cases in Global Context, A. CrAne, D. MATTEN \& L. SPENCE (EDS.) (London: Routledge, 2013), at p. 14.

606 N. KLEIN, No Logo, (New York: Picador, 2002), at pp. 437 (observing that CSR could give MNCs "unprecedented power" to draft their "own privatized legal systems, to investigate and police themselves, as quasi nation-states.").

607 A. RÜHmkorf, Corporate Social Responsibility, Private Law and Global Supply Chains, (Cheltenham: Edward Elgar, 2015), at p. 24 (noting that "[p]rivate regulations describes normative settings which are not provided for by statebased decision-making, but by voluntary decisions of non-profit actors such as corporations or NGOs which create general rules beyond single contracts. Private CSR Regulation, inter alia, consists of codes of conduct and labelling schemes"); see also, D. SCHIEK, "Private Rule-Making and European Governance - Issues of Legitimacy," European Law Review 32 (2007), at pp. 443-4. 
between private initiatives from private regulations, CSR initiatives from the law, what is public and what is private, or between what is legally required and what is voluntary in the context of CSR is a rather difficult and complicated task. The bottom line is that CSR and the law are inextricably linked: As experts in the CSR field often note, "the link between law and CSR remains unclear and contentious," and relationship between CSR and the law have, at the very least, the "potential to overlap in various ways." 608

One way to cope with this potential overlap is to present CSR as a hybrid regulatory mechanism, which is consistent with the definition established in the previous part of the subsection. For example, Fabrizio Cafaggi refers to a system, where issues such as workplace safety standards, payment of minimum wages, protection against child labor, freedom to collectively bargain, and so forth are inserted within the provisions of commercial contracts as a hybrid legal regime. ${ }^{609}$ In other words, the inclusion of regulatory provisions in commercial contracts makes it so that a breach of said provisions could trigger number of consequences including, but not limited to allowing the defendant to seek contractual remedies and then some. ${ }^{610}$ Experts in the field of CSR believe that the future of CSR lies in a bybrid regulatory approach, where supply chain management will not only require a multi-dimensional approach, but a collaboration between the private sector and the public sector. ${ }^{611}$

In the end, however, while the task of distinguishing voluntary CSR initiatives from private regulations could be a useful academic exercise, in reality, this demarcation is blurry at best and perhaps not entirely necessary to be answered for the purposes of this chapter, which is to provide a descriptive overview of what companies are currently doing to combat labor exploitations in the global supply chain. Before embarking on this particular endeavor, this subsection must briefly touch upon one last threshold issue, which is to distinguish laws or legal norms from that of social norms and individual values or morals. Given that this thesis will take a holistic approach moving forward, it is important to clarify some basic terms first, which will be the aim of the next part of this subsection.

\section{Untangling Laws, Social Norms, Values, and Morals}

Being that the research question of this thesis is what the private sector can do to reduce instances of labor exploitation in the global supply chain, focusing only on what they are legally compelled to do would only provide a partial answer. Accordingly, this thesis will also look for ideas or solutions where private actors may not have legal obligations to pro-

608 A. RÜHmkorf, Corporate Social Responsibility, Private Law and Global Supply Chains, (Cheltenham: Edward Elgar, 2015), at p. 3, 25.

609 F. CAfAGgi, "The Regulatory Functions of Transnational Commercial Contracts: New Architectures," Tekes Project, (2012) Available at: http://papers.ssrn.com/sol3/papers.cfm?abstract_id=2136632 (last accessed 4 April 2017), at p. 5 (stating that where "transnational commercial contracts have also become vehicles of implementation of public international regulation... [c]ommercial contracts [even] expand the effects of international public regulation and may increase their effectiveness using private law enforcement mechanisms.”).

610 T.H. Moran, Beyond Sweatshops: Foreign Direct Investment and Globalization in the Developing World, (Virginia: R. R. Donnelley and Sons, 2002), at p. 90 (referring to the variety of remedies as "simultaneous or sequential remedial systems").

611 A. RÜHMKORF, Corporate Social Responsibility, Private Law and Global Supply Chains, (Cheltenham: Edward Elgar, 2015), at p. 231-2 (defining the hybrid regulatory approach as the approach that takes different regulatory techniques such as public and private law, soft and hard law [interacting together to] promote CSR in the global supply chain.”); see also, F. CAFAGGI, “The Regulatory Functions of Transnational Commercial Contracts: New Architectures," Tekes Project, (2012) Available at: http://papers.ssrn.com/sol3/papers.cfm?abstract_id=2136632 (last accessed 4 April 2017). 
tect the laborers working on the other side of the world, but still attempt to do so based on some other incentivizing force. Whether that is social norms or individual values and morals, in answering our research question, these non-legal norms play a crucial role. Therefore, we must first distinguish legal obligations from obligations that arise from some other value or norm-based sentiments, which can be quite intertwined. ${ }^{612}$

Kelsen, Hart, Weber, Dworkin, and many other prominent scholars have already offered extensive explanations in their various attempts to classify and distinguish laws from norms, morals, and values. ${ }^{613}$ For example, Austin would likely argue that the law is something imposed by a sovereign that when broken, brings about punishments and sanctions and so on. While a comparative analysis of all of these theories would be an interesting academic contribution, this thesis, however, aspires to do no such thing nor will it replicate their debate here. For the sake of this thesis, their debates will be truncated, paraphrased, and adapted into the following: Values or morals are internal standards of behavior that people possess, when collectively manifested, become the foundation of societal or social norms. When these social norms are codified or given a legally binding force, these social norms become laws, which essentially means that the law ought to reflect our collective values. ${ }^{614}$ With regards to this last point, it must be noted that laws, from time to time, can influence the norms of the society, which in turn can influence our values, and morals. In other words, laws, norms, values, and morals are very much entangled and it is quite difficult to distinguish one of its effects from that of another.

It is also worth clarifying here that the "law" at least in our context, will not be limited to codifications of norms at the hands of sovereign governments in the legal positivist sense, but the definition will be expanded to include private agreements enforced by the law of obligations. Ultimately, what separates laws from social norms, values, and morals at least for the sake of this thesis - is that breaching the law brings about legally enforceable sanctions, where as non-codified norms, values and morals do not bring about such legally enforceable sanctions (albeit there are various other incentives that can come about,

612 S. SHAVELL, "Law versus Morality as Regulators of Conduct," American Law and Economics Review 4(2) (2002): $227-$ 257 , at p. 230 (noting that morals, generally speaking, are "rules of conduct that are associated with certain distinctive psychological and social attributes... a moral rule has the property that, when a person obeys the rule, he will tend to feel the sentiment known as virtue, and, if he disobeys the rule, he will tend to feel the sentiment known as guilt.").

613 See generally, H. KELSEN, Pure Theory of Law, (California: University of California Press, 1967) (coining the term grundnorm or "basic norm"); see generally, H.L.A HART, The Concept of Law, (Oxford: Oxford University Press, 1961), at p. 193 (stating that there is an inherent aspect of authority with the law as "those who voluntarily obey shall not be sacrificed to those who would not."); M. WEBER, Economy and Society: An Outline of Interpretive Sociology (Volume 2], (Berkeley: University of California Press, 1978); see generally, R. DworkIN, Taking Rights Seriously, (Massachusetts: Harvard University Press, 1978).

614 J. W. SiNGER, "Subprime: Why a Free and Democratic Society Needs Law," Harvard Civil Rights-Civil Liberties Law Review 47 (2012): 141, 142 (noting that "because we live in a free and democratic society (or aspire to do so), our regulations must be compatible with the norms, ideals, and values that democracies represent. This means that the question is not whether to regulate the free market but what legal framework best promotes the values of a free and democratic society that treats each person with equal concern and respect."); see also, M.J. HoPMAN, "Lipstick Law, or: The Three Forms of Statutory Law," The Journal of Legal Pluralism and Unofficial Law 49(1) (2017): 54-66, 61 (noting that "statutory law in fact can appear in three different forms, written formal law (A), law for the community (B) and non-public law (C)," where the latter two can be either written or unwritten). 
none of which are legal). ${ }^{615}$ It must be noted, however, that the law is not the only instrument in which our societies' ideals are reflected nor are they the only means to incentivizing the masses to change their behaviors. This becomes slightly tricky especially when answering a question like "what incentivizes people to behave in a certain manner?" The answer, in short, is some combination of the law, social norms, personal values, and morals. While this thesis need not clearly distinguishing where one ends and the other starts, in order to reassess the role of private actors to reducing labor exploitations in the global supply chain, relying on all of these forces will likely become necessary: In other words, to fully answer our research question and to reassess the role of the private sector, this thesis will not just rely on a strict legal analysis and recommend changes to the law, but as hinted in the Introduction, we will take a more holistic approach to changing our reality and to addressing this systematic challenge. ${ }^{616}$

Having elaborated on what CSR is and how the implementation of various CSR measures can be construed as a hybrid regulatory mechanism that intertwines laws, social norms, values, and morals, the next subsection will move on to addressing the question of why it is that some companies are voluntarily drafting and implementing CSR measures that the law does not require them to.

\subsubsection{Why Corporate Social Responsibility?}

Why is it that some companies voluntarily choose to treat their workers better, internalize their liabilities, and hold themselves accountable without governments breathing down on them? Asking why companies adopt voluntary CSR initiatives is relevant to answering our main research question because determining why some companies choose to go above and beyond what the law requires them to do, would enhance our reassessment of the private sector's role in addressing our labor exploitation problem. Accordingly, this subsection will: a) list various reasons why companies are interesting in adopting and implementing CSR initiatives, and b) whether there are grounds for skepticism with these stated reasons.

\section{A. Businesses Have a Vested Interest in CSR}

First, as Ruggie noted in the aftermath of Kiobel, the number of companies engaging in CSR has increased significantly in the recent decades. ${ }^{617}$ Leaving aside the important question of their impact for the time being, the proliferation of the various CSR initiatives validates our assumption that there are companies that are voluntarily attempting to be more socially

${ }_{615}$ See generally, M. Foucault, Discipline \& Punish: The Birth of the Prison [Second Vintage Books Edition], A. SHERIDAN (TRANS.) (New York: Random House, 1995) (noting the rather penal nature of our societies, which incentivize people to behave in a particular manner through coercion and extrinsic incentives like imprisonment and how this process of punishment has become normalized).

616 N.D. KRISTOF \& S. WuDunN, Half the Sky: How to Change the World, (London: Virago Press, 2010), at p. 36.

617 A. Crane, D. MatTen \& L. Spence, "Corporate Social Responsibility: In Global Context," Corporate Social Responsibility: Reading and Cases in Global Context, A. CrAnE, D. MATTEN \& L. SPENCE (EDS.) (London: Routledge, 2013), at p. 3 (observing that "corporations today are addressing their role in society far more coherently, comprehensively, and professionally," which evidences the "growing demands to legitimate its practices to society at large"); see also, D. VOGEL, The Market for Virtue: The Potential and Limits of Corporate Social Responsibility, (Washington D.C.: Brookings Institution Press, 2006), at p. 16 (stating that " $[\mathrm{m}]$ any executives genuinely care about conducting their businesses in ways that are more environmentally sustainable, that respect human rights, and that foster economic development."). 
responsible. Yet, the general public's perception towards businesses and multinational corporations is that they are simply not doing enough: For example, according to one survey, $58 \%$ of the general public across Europe believe that businesses are simply not doing enough to address their social and environmental responsibilities. ${ }^{618}$ This is particularly relevant to companies engaging in $\mathrm{B} 2 \mathrm{C}$ (business-to-consumer) transactions because " $[\mathrm{u}] \mathrm{p}$ to 90 per cent of consumers consider the social responsibility of companies in their purchase and consumption behaviour." 619

While the general public is still skeptical of corporations and their claims of corporate social responsibility, a UN backed study on corporate responsibility published in 2013, acknowledged that there is an indeed concerted effort by business leaders to change this negative public perception. ${ }^{620}$ Moreover, business leaders interviewed for this report agreed with the general public that businesses are not doing enough to meet its social and environmental obligations to ensure a sustainable future. ${ }^{621}$ What these business leaders envision is a business model where "the active management of social, environmental, and governance issues" are all integrated into their core business. With regards to what incentives the businesses have to turn this model into a reality, according to the same report, $76 \%$ of those interviewed believe that embedding CSR initiatives into their core business will increase revenue growth. ${ }^{622}$ Other reports also show similar levels of demand for businesses to be more socially responsible, not just from the consumers, but from executives running the businesses as well, which could impact even companies engaged in B2B (business-tobusiness) transactions. ${ }^{623}$

J. KeEBle \& D. Brown, “The Business Case for Corporate Citizenship,” Arthur D. Little, Inc. (2003), at p. 3.

A. RÜHMKORF, Corporate Social Responsibility, Private Law and Global Supply Chains, (Cheltenham: Edward Elgar, 2015), at p. 126; see also, N.C. SMITH, "Consumers as Drivers of Corporate Social Responsibility," in The Oxford Handbook of Corporate Social Responsibility, A. Crane, A MCWilliams, D. MATTEN ET AL. (EDS.) (Oxford: Oxford University Press, 2008), at p. 281; J. SMITH, “The Companies with the Best CSR Reputations," Forbes, (2 October 2013). Available at: http://www.forbes.com/sites/jacquelynsmith/2013/10/02/the-companies-with-the-best-csrreputations-2/ (last accessed 4 April 2017) (citing a study conducted by a consulting firm in New York, the Reputation Institute, suggesting that CSR initiatives "drive business growth, customer loyalty, and employee alignment" and also quoting CB Bhattacharya from the European School of Management and Technology that " $41 \%$ of how people feel about a company is based on their perception of the firm's corporate social responsibility practices"); see also, D. VogeL, The Market for Virtue: The Potential and Limits of Corporate Social Responsibility, (Washington D.C.: Brookings Institution Press, 2006), at p. viii (reporting that the "[p]otential marketing appeal of 'ethical' products" has prompted large corporations to purchase smaller brands identified with CSR including, but not limited to Cadbury Schweppes purchasing Green \& Black, L’Oréal purchasing Body Shop, and Colgate-Palmolive acquiring Tom's of Maine).

620 See, The UN Global Compact-Accenture CEO Study on Sustainability 2013: Architects of a Better World. Available at: https://www.unglobalcompact.org/docs/news_events/8.1/UNGC_Accenture_CEO_Study_2013.pdf (last accessed 4 April 2017) (basing its findings on in-depth interviews with over 100 global business leaders and online surveys of 1,000 CEOs with respondents drawn from 103 countries across 27 industries).

621 The UN Global Compact-Accenture CEO Study on Sustainability 2013: Architects of a Better World. Available at: https://www.unglobalcompact.org/docs/news_events/8.1/UNGC_Accenture_CEO_Study_2013.pdf (last accessed 4 April 2017), at pp. 5, 11 (noting that "business is not playing its part in forging a sustainable future.").

622 The UN Global Compact-Accenture CEO Study on Sustainability 2013: Architects of a Better World. Available at: https://www.unglobalcompact.org/docs/news_events/8.1/UNGC_Accenture_CEO_Study_2013.pdf (last accessed 4 April 2017), at p. 11; see also, S.D. MurPHY, "Taking Multinational Corporate Codes of Conduct to the Next Level," Columbia Journal of Transnational Law 43(2) (2005), at p. 45 (noting that offering a product made in a socially responsible manner is becoming a new way of product differentiation for businesses and a source of additional profit).

623 S. RoberTs, J. KeEble \& D. Brown, “The Business Case for Corporate Citizenship,” Arthur D. Little, Inc. (2003), at p. 9 (adding that " $78 \%$ of senior business leaders across Europe believe that only by fully integrating responsi- 
Taking these surveys at face value, the reason as to why companies engage in CSR initiatives seems to be twofold: 1) to meet the public's demand for companies to do more, and at the same time 2) to increase their reputation and revenue in the process. ${ }^{624}$ Again, taking these interviews and surveys at face value, there are indications that point to the fact that companies are interested in going above and beyond what laws require them to do because they believe that that is in their best interests moving forward. ${ }^{625}$ The important question is which instruments, strategies, or systems can take this assumed motivation and convert it into the reduction of labor exploitation in the global supply chain?

\section{B. Grounds for Skepticism}

The previous part of the subsection assumed the sincerity of the business leaders' willingness to embed or integrate various CSR initiatives into their core business. However, this sincerity likely does not extend across all businesses at all times, and even if businesses were indeed sincere, there is no guarantee that their thoughtful actions will lead to better outcomes for the exploited laborers: For example, Lori Forte Harnick, the general manager of citizenship and public affairs at Microsoft recently commented on the importance of being a responsible global corporate citizen and how Microsoft takes their social and communal responsibilities seriously. ${ }^{626}$ However, her statement must be juxtaposed with the reality that Microsoft, even with their socially responsible stance, was recently implicated by Amnesty International's report that they are sourcing their lithium-ion batteries from companies that have ties to the DRC, where their cobalt mines are inundated with child laborers working in unsafe and unregulated mines. The point of this observation is not to lambast Microsoft's operations, but to call to attention the difficulty for even the most well meaning companies to actually operate in a socially responsible manner given the complexities of the global supply chain, which is a problem that will be addressed in much more detail below. The take away for the time being is that there is some doubt about the current ways in which companies are relying on CSR initiatives and the impact that they are actually having on reducing labor exploitations.

Furthermore, while helping their workers and laborers might be a genuine part of the businesses' reason to implement CSR measures, their motivations may not be purely altruistic as the UN backed report revealed: At least part of the reason why a large percentage of businesses are implementing CSR initiatives has to do with the fact that they believe CSR

ble business practice will companies be more competitive and nearly $70 \%$ of CEOs say that Corporate Responsibility is 'vital' to profitability.").

624 S. Roberts, J. Keeble \& D. Brown, “The Business Case for Corporate Citizenship,” Arthur D. Little, Inc. (2003), at p. 9 (noting that "[o]ver half of chief executives across Europe argue that the business benefits of Corporate Responsibility are not exaggerated, and that $92 \%$ [of those executives interviewed] accept it is their responsibility to drive this through the business.”).

625 M.C. Nussbaum, "Beyond the Social Contract: Capabilities and Global Justice," Oxford Development Studies 32(1) (2004), at p. 16 (arguing that "[m]ultinational corporations have responsibilities for promoting human capabilities in the regions in which they operate" and that they "should undertake to promote good labour conditions, going beyond what local laws require" because "corporations do better with a stable, well-educated work-force.")

626 J. SMITH, "The Companies with the Best CSR Reputations," Forbes, (2 October 2013). Available at: http://www.forbes.com/sites/jacquelynsmith/2013/10/02/the-companies-with-the-best-csr-reputations-2/ (last accessed 4 April 2017) (quoting Harnick that "[b]eing a responsible global corporate citizen is a critical part of Microsoft's culture and business at all levels of the company. We take our responsibilities to the public seriously and believe it's more important than ever to serve the needs of people in communities worldwide."). 
to be instrumental in the company's long term profitability. In other words, companies could be motivated to incorporate CSR measures primarily to increase profits through enhanced brand reputation, which just so happens to have a secondary knock-on effect of improving the lives of laborers in their supply chain.

In sum, while the impact of these various CSR initiatives could generally be argued as capabilities-enhancing for the workers, this subsection will conclude for the time being without addressing this question and whether or not the companies' incentives actually matters or changes the outcomes of their initiatives. Before being able to answer these questions in an adequate manner, this chapter must first elaborate on the various company law-related CSR measures that the companies are implementing, which will be addressed in the following section.

\subsection{COMPANY LAW/CORPORATE GOVERNANCE MEASURES TO REDUCE LABOR EXPLOITATIONS}

The aim of this section is to present the most common ways in which companies and their stakeholders are attempting to deal with the labor exploitation problem by relying on various company law and corporate governance related measures that fall under the CSR umbrella. The assumption here is that if companies implement initiatives that hold themselves accountable and initiate strategies that attempt to be more socially responsible, this could somehow reduce the instances of labor exploitation even in the lower echelons of the global supply chain. Accordingly, this section will have the following composition: The first subsection will touch upon how CSR is affecting the very composition and internal decision-making processes of companies, which has led to various restructurings of how shareholders, directors, and other stakeholders are collaborating to be more socially responsible (Subsection 4.2.1); this will be followed by a description of an emerging trend of companies incorporating as Benefit Corporations (Subsection 4.2.2); and, 3) the last subsection will discuss how companies are attempting to be more transparent by adopting sunshine policies and requiring integrated reports that show the companies ESG (environmental, social, and governance) metrics in addition to their financial figures (Subsection 4.2.3).

\subsubsection{CSR and Its Impact on Corporate Governance}

CSR initiatives are particularly interesting because it presupposes that corporations, as legal entities, are capable of being held morally, ethically, or socially responsible for their actions as if they were conscious, living beings. Obviously, individuals run corporations and these individuals are the ones responsible for the actual decision-making. Moreover, recall our discussion from Kiobel in Chapter 3, where the US Supreme Court initially discussed whether corporations themselves could be found to be in violation of international law during the first round of oral arguments and how the Court was leaning towards the negative. ${ }^{627}$ In this context, it is important to clarify at the onset that even though CSR

To quote the affluent former US Presidential candidate Mitt Romney: “Corporations are people." 
measures are about corporations as the name suggests, it is ultimately about a group of individuals (from shareholders to stakeholders, and from board members to individual mangers) behind the veil of a legal entity that is making the ethical, moral, and socially relevant decisions.

Companies - at least as they were initially conceived - were entities that furthered or catered to the general public's interest first and foremost. ${ }^{628}$ Accordingly, companies were given licenses to operate on the basis that their existence and their actions would be beneficial to civil society. ${ }^{629}$ Although companies are now an indelible part of our society, what we now expect from companies has changed since the time of when companies first emerged. ${ }^{630}$ At its conception, companies, at least in theory, were expected to behave like good citizens that take into account the interests of others beside themselves and exercise informed and ethical judgment in deciding what to do. ${ }^{631}$ This normative notion, however, is not always in alignment with how companies are actually operating today as exemplified by the various examples noted above.

In addition, not only have companies changed since its creation, but company laws have evolved (or devolved) to a point where some scholars now note that "[i]n general, corporate law does not mandate corporate social responsibility," but instead, they "question whether the law even permits corporate social responsibility." ${ }_{332}$ While this particular suggestion will be elaborated in more detail immediately below, we must recall here that a company is an amalgam of various stakeholders operating's as a single legal entity: For example, Gary Low notes that a business or a firm is "a coalescence of boundedly rational

L.A. Stout, "The Shareholder Value Myth," The European Financial Review, (30 April 2013). Available at: http://www.europeanfinancialreview.com/?p=883 (last accessed 7 April 2017) (noting that when corporations first came into being, they "were created specifically to develop large commercial ventures like roads, canals, railroads, and banks. Investors in these early corporations were usually also customers. They structured their companies to make sure the business would provide good service at a reasonable price - not to maximize investment returns."). Stout continues by noting that "[f]or most of the twentieth century, large public companies followed a philosophy called managerial capitalism. Boards of directors in managerial companies operated largely as self-selecting and autonomous decision-making bodies, with dispersed shareholders playing a passive role. What's more, directors viewed themselves not as shareholders' servants, but as trustees for great institutions that should serve not only shareholders but other corporate stakeholders as well, including customers, creditors, employees, and the community."

${ }^{629}$ S. RoberTS, J. KeEble \& D. Brown, “The Business Case for Corporate Citizenship," Arthur D. Little, Inc. (2003), at p. 10 (noting that a company's license to operate historically depended on the unwritten authority granted by its stakeholders at large); see also, F. CAPRA \& U. MATTEI, The Ecology of Law: Toward a Legal System in Tune with Nature and Community, (Oakland: Berrett-Koehler, 2015), at p. 185-6 (stating that "[i]n the United States, for example, the idea that economic interests can be incorporated no matter what their purpose is quite recent and dates back to the late nineteenth century. Before then the legal benefits of incorporation were granted only for specific purposes and were limited in time. Once the purpose of a corporation had been achieved... the corporation would dissolve.").

630 T. HARFord, Adapt: Why Success Always Starts with Failure, (London: Abacus, 2012), at p. 244 (noting that "[c]orporations have become such a fixture of life that they seem more permanent to us than they were ever intended to be.").

631 UK CBI's WatKInson COMmission, The Responsibilities of the British Public Company, final report of the Company Affairs Committee (Watkinson Report), (London: Confederation of British Industry, 1973), at p. 23 (stating that "[a] company should behave like a good citizen in business. The law does not (and cannot) contain or prescribe the whole duty of a citizen. A good citizen takes account of the interests of others besides himself and tries to exercise an informed and imaginative ethical judgment in deciding what he should and should not do. This, it is suggested, is how companies should seek to behave.").

632 S.M. BAINBRIDGE, Corporate Law: Third Edition, (St. Paul: West Academic, 2015), at p. 245-6. 
individuals and group, each quite possibly with different aspirations." ${ }^{633}$ Ultimately, it is the stakeholders - ranging from the shareholders, directors, officers, managers, employees, etc. - that plot the course of what a company will do and to put that plan into action. In most cases, shareholders are the primary recipients of the profits but they generally do not intervene in the day-to-day operations of the company. That task is allocated to the directors and the officers who make the executive decisions on what the company will do and it is the employees' task to turn that vision into a reality: In other words, "it is a fundamental premise of corporate governance that managers manage... shareholders may be the beneficial owners of the corporation, but the separation of ownership and control is one of the key advantages of the corporate form." 634

This general rule does not mean that it is only the directors and the corporate officers of the company that have a say in how the business will be run. In the US, for example, "shareholder activism has always been one of the ingredients of... corporate governance," ${ }_{35}$ with shareholders recommending to the directors how the company ought to operate, or in some cases, the directors can include recommendations from the employees as well. In other words, depending on the company's particular corporate governance structure, who decides or how decisions are made will differ. Accordingly, this subsection will discuss how CSR interacts with the three main corporate governance models: a) the shareholder value model, b) the stakeholder value model, and c) the enlightened shareholder value.

\section{A. Shareholder Value Model and Its Focus on Share Value}

First and foremost, corporate governance, at the most basic level, is a "set of processes, customs, policies, laws, and institutions affecting the way a company is directed, administered, or controlled." 636 An example of a popular corporate governance model is the shareholder value model, which prioritizes increasing the company's value for the sake of their

G.W.L. LOw, European Contract Law between the Single Market and the Law Market: A Behavioural Perspective, (Nijmegen: Wolf Legal Publishers, 2011), at p. 239 (adding that “[j]ust as a man's limited cognition 'bounds' his rationality, the scarcity of resources that an organization has at its disposal constrains its ability to realize all that it may want to gain”); see also, R.M. CyERT \& J.G. MARCH, A Behavioral Theory of the Firm, (New Jersey: Prentice-Hall, 1963).

634 D.A.J. Telman, "Is the Quest for Corporate Responsibility a Wild Goose Chase? The Story of Lovenheim $v$. Iroquois Brands, Ltd.," Akron Law Review 44(2) (2011): 480-527, 484; citing, J.D. Cox \& T.L. HAZEN, Treatise on the Law of Corporations [Second Edition], (New York: Aspen Publishers, 2003), at p. 7 (noting that "centralized administration is a necessity in a large corporation and that shareholders as such do not participate in the day-to-day management of the corporations"); and, E.F. FAMA \& M.C. JENSEN, "Separation of Ownership and Control," Journal of Law and Economics 26 (1983): 301-2 (arguing that "separation of decision and risk-bearing functions survives... in part because of the benefits of specialization of management and risk bearing but also because of an effective common approach to controlling the agency problems caused by separation of decision and risk-bearing functions.").

635 D.A.J. TeLman, "Is the Quest for Corporate Responsibility a Wild Goose Chase? The Story of Lovenheim $v$. Iroquois Brands, Ltd.", Akron Law Review 44(2) (2011): 480-527, 484.

636 R. SMERdon, A Practical Guide to Corporate Governance, (London: Sweet \& Maxwell, 2010), at p. 1; see also, European Commission, “Corporate Governance Package - Frequently Asked Questions," MEMO/14/274 (9 April 2014). Available at: http://europa.eu/rapid/press-release_MEMO-14-275_en.htm?locale=en (last accessed 14 March 2016) (defining corporate governance and explaining is benefits in the following manner: "Corporate governance is the system of rules, practices and processes by which a company is directed and controlled. Good corporate governance ensures that companies and their management operate within a framework of checks and balances so they are accountable both to their owners and to society at large. Good corporate governance ensures the company's management makes decisions in the best interests of the company and thus significantly contributes to companies' competitiveness and long term sustainability and therefore to economic growth and jobs."). 
shareholders. ${ }^{637}$ This model, is part of the reason why running a corporation today is often associated with the process of simply attempting to maximize profits. ${ }^{638}$ Given the reputation of the shareholder value model and its prevalence, it is understandable that some have argued that this particular model of corporate governance is simply incompatible with CSR initiatives, a point which was hinted to earlier. ${ }^{639}$

The seminal case to substantiate this claim, at least in the US, is Dodge v. Ford Motor Co. ${ }^{640}$ In 1916, Henry Ford (who owned 58\% of the Ford Motor Company's stock) decided that the company was making too much money (with a surplus of over $\$ 60$ million) and rather than paying out dividends to the shareholders, Ford decided to 1) expand his business, 2) give a raise to his employees, and 3) lower the price of the Ford vehicles in order to "benefit the public and the firm's workers and customers." ${ }^{411}$ For his altruistic and socially considerate actions, Ford was sued by the Dodge brothers (who owned 10\% of the Ford Motor Company's stock) arguing that his actions were in violation of his duty to maximize the profit for the shareholders and the court agreed. In short, the court in Dodge held that "[a] business corporation is organized and carried on primarily for the profit of the stockholders. The powers of the directors are to be employed for that end..." 642 Due to this holding, Ford was ordered to pay out the dividends to his shareholders rather than giving his employees a raise or reducing the cost of the Ford vehicles, which would have enhanced the public good.

As the Dodge case demonstrated, if the aim of a company is indeed to maximize the shareholders' profits, such a culture fosters decisions that will cut costs by all means necessary for the sake of increasing their stock prices. ${ }^{643}$ This would suggest that there is no room for CSR measures that would voluntarily increase the company's liability by increas-

637 See e.g., L.A. STOUT, The Shareholder Value Myth: How Putting Shareholders First Harms Investors, Corporations, and the Public, (San Francisco: Berrett-Koehler Publishers, 2012); see also, F. GuerrerA, "Welch Condemns Share Price Focus," Finanical Times, (12 March 2009); and, F. CAPRA \& U. MATTEI, The Ecology of Law: Toward a Legal System in Tune with Nature and Community, (Oakland: Berrett-Koehler, 2015), at p. 112 (noting that corporations are "relentlessly pursuing shareholder interest, working as legally determined machines, and externalizing social costs" worldwide).

638 L.A. STOUT, The Shareholder Value Myth: How Putting Shareholders First Harms Investors, Corporations, and the Public, (San Francisco: Berrett-Koehler Publishers, 2012), at p. 6 (quoting GE's former CEO Jack Welch stating that the shareholder value model is "the dumbest idea in the world."); see also, A. RÜHMKORF, Corporate Social Responsibility, Private Law and Global Supply Chains, (Cheltenham: Edward Elgar, 2015), at p. 215 (noting that "[t]his model of the company according to which it is the purpose of the corporation to ultimately maximize the revenue of shareholders puts directors under a duty to prioritize the shareholders in their decision making"); see also, H. HANSMANN \& R. KRAAKMAN, "The End of History for Corporate Law," Georgetown Law Journal 89 (2001): 439-468, 448.

639 A. Rühmkorf, Corporate Social Responsibility, Private Law and Global Supply Chains, (Cheltenham: Edward Elgar, 2015), at p. 34 (noting that "[i]t has been argued that the shareholder value theory made claims that a company should act in a socially responsible manner irrelevant"); see also, D. MiLlon, “Theories of the Corporation," Duke Law Journal 39(2) (1990): 201-262, 225.

640 Dodge v. Ford Motor Co., 170 NW 668, 684 (Mich, 1919).

641 S.M. BAinbridge, Corporate Law: Third Edition, (St. Paul: West Academic, 2015), at p. 246.

${ }_{642}$ Dodge v. Ford Motor Co., 170 NW 668, 684 (Mich, 1919).

643 A. RüHmkorf, Corporate Social Responsibility, Private Law and Global Supply Chains, (Cheltenham: Edward Elgar, 2015), at p. 229; of. L.A. STOuT, "Why We Should Stop Teaching Dodge v. Ford," Virginia Law \& Business Review, 3(1) (2008): 163-176, 165, 176 (claiming that " $\mathrm{t}]$ eaching Dodge $v$. Ford as anything but an example of judicial mistake obstructs understanding" of the reality that in addition to maximizing profits for their shareholders, coroprations can and do "seek other things, as well, including specific investment, stakeholder benefits, and their own continued existence."). In short, Stout argues that Ford $v$. Dodge is a weak precent and the often-quoted language of the Michigan Supreme Court is nothing more than "an offhand remark."). 
ing their accountability, which would likely be considered as an unnecessary risk. What this means, at least under the shareholder value model, is that companies are willing to implement CSR initiatives up and to a point where costs associated with creating, implementing, and enforcing them do not outweigh any additional profits that the positive reputation from the CSR initiatives render. If at any point, the costs start outweighing the benefits, the shareholders could argue that the directors have a fiduciary duty to reduce or scrap their CSR initiatives all together, which for the purposes of this thesis would not be the ideal system. ${ }^{644}$

That is unless, having a reputation of being a socially responsible company could be argued as a profit maximizing course of action in the long run: As noted above, a large part of the reason why businesses are implementing CSR initiatives in the first place has to do with the fact that the implementation of a CSR strategy has been linked to the company's long term profitability, although there is no guarantee that this is a causal relationship or even a highly correlated one at that. ${ }^{645}$ However, so long as some plausible justification can be provided by the directors, the courts today will likely refrain from adjudicating on the manner. ${ }^{646}$ This deference is primarily due to the number of post-Dodge cases that established and strengthened the doctrine of the business judgment rule in the US: The business judgment rule, similar to the doctrine of political question noted in Chapter 3, restrains courts from judging or invalidating the actions of the corporate directors so long as they: 1) acted in good faith, 2) in the best interest of the corporation, 3) on an informed basis, and 4) their actions were neither wasteful, nor 5) conducted for the sake of self-interest. ${ }^{647}$ In other words, the director's duty to increase shareholders profits today must be balanced with the deference afforded to directors by the business judgment rule: For example, a director could justify that maintaining a CSR strategy is vital to any company's long term survival and prosperity, but if in doing so, the company cannot survive in the short run (possibly due to the fact that upholding its CSR initiatives are too cost prohibitive), shareholders may have legitimate grounds to displace that socially responsible director or at least

L.A. STOUT, The Shareholder V alue Myth: How Putting Shareholders First Harms Investors, Corporations, and the Public, (San Francisco: Berrett-Koehler Publishers, 2012), at p. 6 (noting that while sympathetic to the idea of moving away from the shareholder value model, Lynn believes that "one does not need to embrace either a stake-holderoriented model of the firm, or a form of corporate social responsibility theory, to conclude that shareholder value thinking is destructive.").

645 Cf. D. Vogel, The Market for Virtue: The Potential and Limits of Corporate Social Responsibility, (Washington D.C.: Brookings Institution Press, 2006), at p. 23 (stating that "discerning investors now recognize that a company managed according to interests broader than those of only shareholders is more likely to profit over the long term... Corporations with stakeholders focus have been shown to enjoy greater sales and value growth than companies with narrow shareholder focus"); citing, J. HOLLENDER \& S. FENICHELL, What Matters Most: How a Small Group of Pioneers Is Teaching Social Responsibility to Big Business, and Why Big Business Is Listening, (New York: Basic Books, 2004), at p. 163.

646 S.M. Bainbridge, Corporate Law: Third Edition, (St. Paul: West Academic, 2015), at p. 246 (stating that "[i]f a proposed course of action plausibly relates to long-term shareholder wealth maximization, courts will not intervene"); see also, A.P. Smith Manufacturing Co. v. Barlow, 98 A.2d 581 (N.J. 1953) (upholding charitable donations by companies as not a violation of fiduciary duty on the basis that "modern conditions require that corporations acknowledge and discharge social as well as private responsibilities as members of the communities within which they operate.")

647 S.M. Bainbridge, Corporate Law: Third Edition, (St. Paul: West Academic, 2015), at p. 247 (noting that by "[a]pplying the business judgment rule... many courts essentially presume that an altruistic decision was in the corporation's best interest”); see also, Sblensky v. Wrigley, 237 NE 2d 776 (Ill. App. 1968); Grobow v. Perot, 539 A.2D 180 (Del. 1988). 
be able to invalidate his actions. So for companies subscribing to the shareholder value model, CSR initiatives could make sense, but only to the point where it is creating profits or has the potential to create profits down the line. It must be noted though, that even when the director can actually implement CSR strategies, its impact on the exploited laborers could be minimal, as this model places its primary importance on the shareholders' profits and not on some stakeholders at the extreme opposite end of the power spectrum.

\section{B. Stakeholder Value Model and Stakeholder Involvement}

This brings us to the second corporate governance model, which is the more inclusive, stakeholder value model: The stakeholder value model, also known as the pluralist model, "proposes that a company should be run in the interest of all its stakeholders rather than just the shareholders" and the "underlying idea of this approach is that the company functions as a social institution whose conduct has an important impact on people's lives." 648 While this framework could be difficult to implement in the real world, at least the theory behind this model is more in alignment with our normative framework that seeks to empower the workers through autonomy, freedom of choice and the opportunity to participate in the decision-making process. Moreover, this model is more conducive to implementing CSR initiatives compared to the shareholder value model given that it takes into account the interests of the company's employees as stakeholders, and not just that of the shareholders: In the words of John Ruggie, "[a]lthough it remains contested, the principle is taking hold that transnational firms... ought to be held accountable not only to their shareholders, but also to a broader community of stakeholders who are affected by their decisions and behavior." ${ }_{449}$ This is to suggest that the stakeholder value model is more consistent with the traditional view of a company and the view that companies must not only cater to the interests of their shareholders, but consider and value the impact of the company on the larger community as a whole. ${ }^{650}$

The stakeholder approach is gaining in popularity, as further evidenced by various nonshareholder constituency statutes emerging across the US that explicitly permit directors to consider the interests of various stakeholders and the communities at large into the company's decision-making process. ${ }^{651}$ However, a foreseeable concern with this particular model is the coordination/organization problem that could arise from giving a voice to all

648 A. RÜHmkORF, Corporate Social Responsibility, Private Law and Global Supply Chains, (Cheltenham: Edward Elgar, 2015), at pp. 34-5; see generally, R. E. FreEmAN, Strategic Management: A Stakeholder Approach, (Cambridge: Cambridge University Press, 2010).

649 J.G. Ruggie, "Reconstituting the Global Public Domain: Issues, Actors and Practices," John F. Kennedy School of Government Faculty Research Working Paper (2004), at p. 21; as cited in, D. VoGEL, The Market for Virtue: The Potential and Limits of Corporate Social Responsibility, (Washington D.C.: Brookings Institution Press, 2006), at p. 3; see also, J.M. SMITS, "The Expanding Circle of Contract Law," Maastricht European Private Law Institute Working Paper 3 (2016), at p. 3 (arguing that laws should "expand the circle of people it seeks to protect.").

650 R. ANDERSON, Confessions of a Radical Industrialist, (New York: Random House Business Books, 2011), at p. 170, (noting that "sensitizing stakeholders is all about who we are, what can we offer our colleagues, our customers, other corporations, and our communities, [where t] he entire earth is our 'community of interest."').

651 The emergence of the stakeholder value model can be illustrated by number of states in the US adopting nonshareholder constituency statutes that have amended the directors duty of care so that they may "consider the impact a decision will have on not only shareholders, but also on a list of other constituency groups, such as employees, suppliers, customers, creditors, and the local communities in which firm does business... [and] to consider both the long-and short-term effects of the decision"; see, S.M. BAINBRIDGE, Corporate Law: Third Edition, (St. Paul: West Academic, 2015), at p. 249. 
of the stakeholders. In other words, some type of organization or structure will likely have to be put in place so that each of the stakeholders' voices and opinions will indeed be heard and evaluated appropriately. Until this mechanism or structure can be put in place, it could be difficult to translate this model into concrete results. One need not look further than a handful of proposals, suggestions, and policies that advocate for the stakeholder model, before realizing that some of them do not expressly outline how the organization aims to incorporate all of the stakeholders. For example, the European Parliament recently advocated for the multi-stakeholder approach to CSR, declaring that it "welcomes the idea of establishing multi-stakeholder CSR platforms," and elaborating that "the development of CSR should be driven through the multi-stakeholder approach assigning a leading role to businesses," 652 but without offering any specifics in terms of the how. While the inclusiveness of this approach and the EP's dedication to the stakeholder value model is one sign to show their commitment to CSR, the document is a bit vague on how to implement such a model at the European level. Similarly, CSR Europe, an NGO advocating for strengthening CSR in Europe suggests that companies must "put employees at the heart of the European CSR strategy," 653 but beyond the rhetoric, they do not layout a clear path to putting employees at the heart of the CSR strategy in reality.

The most generic approach to implementing the stakeholder model would be to get all of the stakeholders - or their representatives - together in a room, have them discuss a particular problem, and have them offer and agree on possible solutions or recommendations, which coincidentally would be capabilities-enhancing and in conformity with our particular normative framework. ${ }^{654}$ However, the fact that an employee representative gets to sit and discuss an issue with the company's CEO or one of the shareholders may not be enough. In order to truly implement CSR Europe's suggestion, the representative must feel empowered enough to present the views of the workers to the higher ups, without fears or retaliation. This is precisely why the stakeholder model must have some type of agreed upon decision-making process to go along with it. Even with such measures in place, whenever a group of people get together, there is always a risk of conformity and herd mentality problems, which will be discussed at length in Chapter 5; but to offer a bit of a preview here, studies in behavioral psychology and sociology have repeatedly shown that peer-pressure and the desire to fit into a group is often a strong motivator to compel people to simply follow the herd without even them realizing it, especially when certain groups

European Parliament, "Report on Corporate Social Responsibility: Accountable, Transparent, and Responsible Business Behavior and Sustainable Growth," Motion for European Parliament Resolution 2012/2098(INI) (28 January 2013) Available at: http://www.europarl.europa.eu/sides/getDoc.do?pubRef=//EP//TEXT+REPORT+A7-2013-0017+0+DOC+XML+V0//EN (last accessed 11 March 2016), at para. 13, 56

653 M. Migliorato, "EU CSR Strategy 2020 and the Work of CSR Europe," CSR Europe: Enterprise 2020 Presentation. Available at: http://www.sodalitas.it/public/allegati/EUCSRStrategy2020_2015213121453416.pdf (last accessed 11 March 2016), at p. 110.

654 European Commission, "How to Engage and Empower Stakeholders in Entrepreneurship Education," Ref. Ares 2917375 (2013) (noting that "[s]takeholder engagement process can be a participatory approach for policy making. It is a process that involves interest groups in agenda setting and decisions-making as well as in implementing, evaluating, and reviewing actions."); see also, C.S. DiTLEV-SIMONSEN \& F. WENSTøP, "How Stakeholders View Stakeholders as CSR Motivators," Social Responsibility Journal 9(1) (2013): 137-147; and M. EL ABBOUBI \& A. CORNET, “Towards a Dynamic Stakeholder Management Framework for CSR Certifications," International Journal of Business and Social Science 3(4) (2012): 1-12. 
of people are hierarchically ranked above the others. In order to not get too far ahead of ourselves, for the time being, this scenario can be equated to the previously discussed instances where illegal immigrant laborers do not blow the whistle on the sweatshop owner for the fear of retaliation. In other words, the incentive of a lowly employee challenging the authority of their bosses even in these multi-stakeholder proceedings is a lingering concern, which must be addressed. ${ }^{655}$ Moreover, even if the discussions are not contentious, but amicable, even then, there are no assurances that as soon as the meeting has been concluded that the actual decision makers of the company, the managers, officers, and the directors will pay any heed to what was said by the employees.

While there are various grounds for concern (as with everything else that has been discussed up until this point), organizations that adopt the stakeholder approach clearly have more potential to successfully implementing CSR initiatives and is in more alignment with our normative framework. Moreover, as Chapter 6 will address later, the diversity of opinions and the ideas that the different stakeholders can bring to the table (assuming that there is no conformity/peer-pressure issues) adds to the list of possible solutions that a group of only shareholders may not have been able to come up with. So from a purely CSR perspective, or in the context of our problem of reducing instances of labor exploitation in the global supply chain, the stakeholder value model seems to offer more potential than the shareholder value model. However, before reaching any preliminary conclusions, the last of the corporate governance model must be assessed first, which is the enlightened shareholder model.

\section{Enlightened Shareholder Value Model and Shareholder Activism}

Last, but not least, there is the enlightened shareholder value model that some refer to as the inclusive model, which attempts to blend the two previous corporate governance models. One way to conceptualize this relatively new model is to think of it as the shareholder value model with shareholder primacy intact, but with the caveat that the directors are now required to consider other factors, besides profits and increasing share values, including but not limited to the various interests of other stakeholders involved with the company. ${ }^{656} \mathrm{In}$ requiring directors to take various other factors besides profit into consideration, this model opens up the path for increased shareholder engagement and activism so as to suggest or propose to the board of directors what factors, besides profits, they ought to consider. For

See e.g., T. HARFORD, Adapt: Why Success Always Starts with Failure, (London: Abacus, 2012), at p. 30, 62; citing to, I.L. JANIS, Victims of GroupThink, (Boston: Houghton Mifflin Co., 1972) (explaining that "a strong team - a 'kind of family' - can quickly fall into the habit of reinforcing each other's prejudices out of simple team spirit and desire to bolster the group.”).

656 A. RÜHmkORF, Corporate Social Responsibility, Private Law and Global Supply Chains, (Cheltenham: Edward Elgar, 2015), at p. 37 (adding that the underlying view of this model is "premised on the belief that long-term profit maximisation can only occur through the fostering of co-operative relationships with the various non-shareholder constituents."); see also, L.A. STOUT, The Shareholder Value Myth: How Putting Shareholders First Harms Investors, Corporations, and the Public, (San Francisco: Berrett-Koehler Publishers, 2012), at p. 9 (arguing that while "many people are 'prosocial,' meaning that they are willing to sacrifice at least some profits to allow the company to act in an ethical and socially responsible fashion," there are those that "care only about their own material returns." This diversity of shareholders means that boards of public companies often must "balance and mediate among different shareholders' competing and conflicting demands.”); and, J. BAKAN, The Corporation: The Pathological Pursuit of Profit and Power, (New York: Free Press, 2004), at p. 2 (arguing that "the corporation is a pathological institution, a dangerous possessor of the great power it wields over people and societies."). 
example, the EU has recently lauded shareholder activism (or shareholder engagement) as the key to increasing corporate accountability, with owners engaging more actively with their companies and challenging the board in a meaningful and constructive way. ${ }^{657}$ This is to suggest that the enlightened shareholder model has the potential to not only resolve the coordination/organization problem of the stakeholder model, but curtail the incentive/greed problem of the pure shareholder model, at least in theory.

The enlightened shareholder value model could indeed be the popular corporate governance model moving forward, especially in Europe given the European Commission's recent decision to revise the existing Shareholders' Rights Directive. ${ }^{658}$ The aim of this revision is to "make it easier for shareholders to use their existing rights over companies and enhance those rights where necessary," by better holding "the management of the company to account and act in the long-term interest of the company." ${ }^{659}$ The revision to the Shareholders' Rights Directive, which was voted in favor of by the European Parliament in March of 2017 and is currently awaiting for final adoption before the European Council, aims to accomplish this task by: 1) "strengthening the transparency requirements for institutional investors and asset managers on their investment and engagement policies regarding the companies in which they invest [in]," 2) creating "a framework to make it easier to identify shareholder so [that] they can more easily exercise their rights like voting rights," and 3) introducing a "say on pay" scheme that would link management pay with their performance (i.e. "oblige companies to disclose, clear, comparable and comprehensive information on their remuneration policies"). 660

Although the introductory remarks of this subsection noted how shareholders generally do not meddle in the day-to-day operations of the company, the revised Directive would incentivize shareholders and institutional investors to shed their perception of being a passive investor and to start taking a more active role with in the operations of a company.

European Commission, “Corporate Governance Package - Frequently Asked Questions,” MEMO/14/274 (9 April 2014). Available at: http://europa.eu/rapid/press-release_MEMO-14-275_en.htm?locale=en (last accessed 14 March 2016) (adding that the current regulatory framework "inhibits investors from playing a more optimal role in the corporate governance of listed companies across borders, and companies, in turn, do not have the necessary means and information to engage with investors.").

658 Directive 2007/36/EC of the European Parliament and of the Council of 11 July 2007 on the exercise of certain rights of shareholders in listed companies, L 184/17 (listing the various rights of the shareholders, including but not limited to their right to put items on the agenda of the general meeting (Article 6), right to vote at the general meeting (Article 7), and their right to ask questions (Article 9)). On 9 December 2016, the EU's committee of permanent representatives (COREPER) approved the agreement between the Slovak presidency and the European Parliament representatives to "strengthen shareholder engagement in big European companies." See, European Council, "Shareholders' rights in EU companies: Presidency strikes deal with Parliament," Press Release, (16 December 2016). Available at: http://www.consilium.europa.eu/en/press/press-releases/2016/12/16-shareholdersrights-eu-companies/ (last accessed 7 April 2017) (noting that the aim of the agreement is to "encourage transparent and active engagement by shareholders of listed companies...").

659 European Commission, "European Commission proposes to strengthen shareholder engagement and introduce a ‘say on pay' for Europe's largest companies,” (9 April 2014). Available at: http://europa.eu/rapid/pressrelease_IP-14-396_en.htm?locale=en (last accessed on 14 March 2016); see also, European Commission, "Shareholders' Rights Directive Q\&A Fact Sheet," MEMO/17/592 (14 March 2017). Available at: http://europa.eu/rapid/press-release_MEMO-17-592_en.htm (last accessed 7 April 2017).

660 European Commission, "European Commission proposes to strengthen shareholder engagement and introduce a 'say on pay' for Europe's largest companies,” (9 April 2014). Available at: http://europa.eu/rapid/pressrelease_IP-14-396_en.htm?locale=en (last accessed on 14 March 2016) (suggesting that the proposal, if implemented would "improve the corporate governance of around 10,000 companies listed on Europe's stock exchanges"). 
While this course of action by the European Union could potentially be the necessary catalyst for creating a more socially responsible companies and governance structures, scholars like Lynn A. Stout would caution that empowering and enabling shareholders may not necessarily be an ideal course of action either. ${ }^{661}$

Also in the US, cases promoting shareholder engagement and empowering them through strengthening of their rights is on the uptick. The most seminal case that triggered this trend is likely Lovenheim v. Iroquois Brands, Ltd., which demonstrated just how an "enlightened" shareholder can influence the actions of the company to steer it towards a more socially responsible path. ${ }^{662}$ Iroquois Brands was a company that imported various products from abroad and distributed them in the US. One such product was a patté de foie gras that was imported from France. Peter Lovenheim, a minority shareholder whose day job was being the Government Relations Counsel for the Humane Society of the United States, suspected that this product was produced in an inhumane way (made by force feeding and overstuffing the geese) and proposed that Iroquois Brands investigate how its suppliers were producing them. ${ }^{663}$ The relevant rules that Lovenheim relied on were the Securities and Exchange Commission Rule 14a-8 and Securities Exchange Act of 1934, which empower shareholders to submit proposals or recommendations regarding matters pertaining to the company and its course of business. ${ }^{664}$ Lovenheim's proposal was for Iroquois Brands to investigate whether the patté de foie gras was made in an inhumane manner, and if so, to discontinue importing and distributing the product.

Rather than distributing Lovenheim's proposal, Iroquois Brands refused to incorporate this proposal into the proxy statement on the grounds that the sale of the paté de foie gras in question was such a minute part of their entire business that it did not warrant an investigation. The relevant rule that Iroquois Brands based their rejection on was SEC Rule 14a$8(1)(5)$, which stated that proposals relating to 'less than $5 \%$ of the firm's assets, earnings or sales, and that it not otherwise significantly relate to the firm's business, may be omitted from the proxy statement." 665 Given that the paté de foie gras sales only constituted "less than $0.05 \%$ " of Iroquois Brands' assets, Lovenheim had to rely on the argument that importing

661 D.A.J. Telman, "Is the Quest for Corporate Responsibility a Wild Goose Chase? The Story of Lovenheim $v$. Iroquois Brands, Ltd.," Akron Law Review 44(2) (2011): 480-527, 527 (arguing that viewing shareholders as "passive investors concerned only with maximizing the return on their investment [is] too narrow of a view" for what corporations are); see generally, L.A. STOUT, The Shareholder Value Myth: How Putting Shareholders First Harms Investors, Corporations, and the Public, (San Francisco: Berrett-Koehler Publishers, 2012).

662 Lovenheim v. Iroquois Brands, Ltd., 618 F. Supp. 554 (D.C. Dist. 1985); see also, S.M. BAINBRIDGE, Corporate Law: Third Edition, (St. Paul: West Academic, 2015), at p. 299-300 (noting that Lovenheim v. Iroquois Brands, Ltd. is the seminal case that illustrates how shareholders can impact how corporations behave).

663 Lovenheim v. Iroquois Brands, Ltd., 618 F. Supp. 554, 556 (D.C. Dist. 1985).

66417 C.F.R. \$240. Rule 14a-8(a) (2010) and Securities Exchange Act of 1934, Chapter 404, 48 Stat. 895 (1934) (codified as amended at 15 U.S.C. \$78n(a) (2010)); see generally, D.A.J. TELMAN, "Is the Quest for Corporate Responsibility a Wild Goose Chase? The Story of Lovenheim v. Iroquois Brands, Ltd.," Akron Law Review 44(2) (2011): 480-527, 480 (explaining that "these regulations provide that a corporation must include qualifying shareholder proposals in its proxy solicitation materials distributed in advance of annual or special shareholder meetings, along with the shareholder's statement in support of the proposal.”). From a comparative perspective, these rules serve the same functions to that of the EU's Shareholders' Rights Directive, 2007/36/EC, particularly Article 6, which allowed shareholders to put items on the agenda of the general meeting.

665 S.M. BAinbridge, Corporate Law: Third Edition, (St. Paul: West Academic, 2015), at p. 299 (noting that the "[p]âté sales constituted a mere $\$ 79,000$ per year, on which Iroquois Brands lost money, relative to annual revenues of $\$ 141$ million and profits of $\$ 6$ million" but the court held that the sale of the paté was "otherwise significantly related" to the business). 
and the distributing of the paté de foie gras was a socially irresponsible, cruel, and inhumane act that "significantly related to the firm's business," and the court eventually agreed with Lovenheim. ${ }^{666}$

While this allowed Lovenheim's proposal to be put on the proxy statement, the rest of the shareholders were not interested, and did not vote to implement the actions proposed. So while Lovenheim was indeed able to put his proposal to a vote, which was a win from a legal perspective, the other shareholders were not very much interested in being socially responsible. This would suggest that shareholder activism has its limits: "Judging by the few court cases that address social proposals, one could easily conclude that cases like Lovenheim are akin to nuisance suits that have no impact on corporate governance because the proposals never win anything approaching a majority of the shareholder vote." ${ }^{667}$ This suggests that while the law might provide a socially conscious shareholder the opportunity to propose to the other shareholders to guide the company in a more socially responsible direction, it does not actually help convince the shareholders to do so. Here again, while the law might be an instrument that facilitates shareholder activism, it does not incentivize the shareholders to actually be more socially responsible.

An alternative to making shareholder proposals would be for shareholders, especially large institutional investors, to divest from companies that are not socially responsible. In the words of Albert Hirschman, "people have two general classes of responses available when they are unhappy. They can exit the situation, or they can protest and give voice to their concern." ${ }^{668}$ With regards to shareholders and investors, shareholder proposal is the voice option, whereas divesting is the exit option. In this framework, the emerging trend of socially responsible investment ("SRI") could be considered as a way for investors to change the way they invest thus contributing to the reduction of socially irresponsible corporate practices. SRI can be defined as "an investment that is considered socially responsible because of the nature of the business the company conduct," which "uses environmental, social, and corporate governance criteria to generate long-term, competitive financial returns and positive societal impact." ${ }_{609}$ Though SRI has a long history, they "have recently grown in popularity in both the United States and Europe." 670 The intended goal of SRI is that if enough investors divest from companies involved in socially irrespon-

Lovenheim v. Iroquois Brands, Ltd., 618 F. Supp. 554, 559 (D.C. Dist. 1985).

667 D.A.J. Telman, "Is the Quest for Corporate Responsibility a Wild Goose Chase? The Story of Lovenheim v. Iroquois Brands, Ltd.," Akron Law Review 44(2) (2011): 480-527, $526-7$ (noting, however, that "it is clear from [Lovenheim's] subsequent experiences that social proposals can influence corporate decision-making processes," and quoting William Lerach who notes that "[c]orporations are overseen by boards of directors, but accountability to shareholders has long been overtaken by insider control and deference to management. Attempts by investors to improve corporate governance have produced only cosmetic improvements."); L.A. BEBCHUK, J.E. BACHELDER, W. LERACH \& ET AL., "Director Liability," Delaware Journal of Corporate Law 21(3) (2006): 1011-1045.

668 See generally, A.O. HiRschman, Exit, Voice, and Loyalty, (Cambridge: Harvard University Press, 1970); B. SChWARTZ, The Paradox of Choice: Why More is Less, (New York: Harper, 2004), at p. 111 (elaborating that "[i]n the marketplace, exit is the characteristic response to dissatisfaction.").

669 H. Kent BAKer \& J.R. NOFSINGer, "Socially Responsible Financing and Investing: An Overview," in Socially Responsible Finance and Investing, H. KENT BAKER \& J.R. NOFSINGER (EDS.) (New Jersey: Wiley, 2012), at p. 3.

670 D. VogeL, The Market for Virtue: The Potential and Limits of Corporate Social Responsibility, (Washington D.C.: Brookings Institution Press, 2006), at p. 37; W.H. CLARK \& E.K. BABSON, "How Benefit Corporations are Redefining the Purpose of Business Corporations," William Mitchell Law Review 38(2) (2012): 818-851, 821 (stating that SRI "has grown over the past 30 years to represent nearly $10 \%$ of U.S. assets under management, or roughly $\$ 2.3$ trillion."). 
sible practices, either those companies will go out of business or they will start behaving in a more socially responsible manner. ${ }^{671}$

There are handful of examples of investors and institutional investors divesting from companies that they believe are being socially irresponsible. For example, the largest pension fund in the Netherlands, ABP divested from Wal-Mart due to their labor and human rights concerns ${ }^{672}$ and one of the world's most renowned investors, Warrant Buffet, recently divested out of oil and gas companies. ${ }^{673}$ The relevant question worth asking, however, is whether or not these divestments actually influence the working conditions of the laborers. While investors can be satisfied with having a socially responsible portfolio, there is no guarantee that simply because investors divest, the working conditions of laborers will improve. Moreover, while some might believe that the stewardship of socially responsible investors - institutional or otherwise - could make corporations and their behaviors more socially responsible, there are various causes for skepticism: For example, according to Ivo Welch, professor of finance and economics at the Anderson Graduate School of Management at UCLA, "[i]ndividual divestments, either as economic or symbolic pressure, have never succeeded in getting companies or countries to change." 674 Using the empirical evidence collected from the divestment movement that took place against the apartheid South Africa, Welch noted that the divestment "had no discernible effect on the valuation of companies that were being divested, either short-term or long term." 675

A partial explanation for this could be the existence of other, less socially conscious investors who are willing to invest in companies that more socially responsible investors would divest from. An illustration that captures this very point was when deBeers, a company that used to control about $80 \%$ of the world's diamond sales, decided stop supplying their diamonds from mines associated with "blood diamonds," opting instead to "market only those it dug up itself." " ${ }^{76}$ Not only did their market share tumble as a result of this decision, but other companies quickly filled in the void that de Beers left: As Welch notes, "[f] or each investor and business that withdrew, there were others standing by ready to step in." 677 While advocates of SRI continue to claim that "socially informed investment funds will perform better because their managers are more aware of the significance of corporate

671 To support these socially responsible investors. there are various guidelines like the UN backed Principles of Responsible Investment ("PRI") and the Global Reporting Initiative ("GRI") that guide and support to invest more responsibility.

672 C. O'CONNOR, "How Angry Walmart Workers Helped Convince Foreign Investors to Dump Shares," Forbes, (7 October 2013). Available at: http://www.forbes.com/sites/clareoconnor/2013/10/07/how-angry-walmartworkers-helped-convince-foreign-investors-to-dump-shares/\#1a273f3a6bb6 (last accessed 12 March 2016) (reporting on various other institutional investors that have divested from Wal-Mart, which is a list that includes Sweden's largest state-backed pension fund AP Funds, Norway's state-run pension fund, Dutch asset managers PGGM and Mn Services).

673 J. CarrolL, "Buffett Dumping Exxon Points Investors to Review Oil Bets," Bloomberg, (18 February 2015). Available at: http://www.bloomberg.com/news/articles/2015-02-18/buffett-dumping-exxon-stake-pointsinvestors-to-rethink-oil-bets (last accessed 19 February 2015).

674 I. WELCH, "Why Divestment Fails," The New York Times, (10 May 2014), at p. A23.

675 I. Welch, "Why Divestment Fails," The New York Times, (10 May 2014), at p. A23; see also, S.H. TEOH, I. WELCH, \& C.P. WAZZAN, "The Effect of Socially Activist Investment Policies on the Financial Markets: Evidence from the South Africa Boycott," Journal of Business 72(1) (1999): 35-89, 79.

676 "Diamonds: Betting on De Beers," The Economist, (12 November 2011). Available at: http://www.economist.com/node/21538145 (last accessed 12 March 2016).

677 I. WELCH, "Why Divestment Fails," The New York Times, (10 May 2014), at p. A23 (noting that even if a company changes its behaviors, there will be plenty of other companies that are "ready, able and willing to step in."). 
social and environmental policies on long term financial performance," ${ }^{678}$ there are good reasons to doubt whether SRI will lead to any tangible improvements in the way laborers in the lower echelons of the global supply chain will be treated. Similar to the problem that Lovenheim faced, simply because one shareholder decides to be socially responsible, so long as the rest of the shareholders or other companies do not move in the same direction, meaningful difference could be difficult to achieve. ${ }^{679}$ This concern will be elaborated in more detail in Section 4.3

To conclude this subsection, some companies today are attempting to shed their reputation of being nothing more than a profit-maximizing entity by abandoning the shareholder value model and opting for the stakeholder or the enlightened shareholder value model instead. This movement "implies an obligation on the part of large companies to pursue objectives advancing the interests of all groups affected by their activities - not just shareholders but also stakeholders such as employees, consumers, suppliers, creditors and local communities." ${ }^{680}$ Moreover, in an attempt to convert companies (back) into being more responsible global citizens, there is growing public support for companies to adopt a corporate governance model that is more inclusive. The very emergence of the stakeholder value model, the enlightened shareholder value model, and the various non-shareholder constituency statues in the US validates this growing demand.

However, there are reasons for concern here as well, which will this thesis will elaborate further in Section 4.3, but suffice it to note here that shareholder primacy is still a large part of many companies' corporate governance framework, and while the law might facilitate enlightened shareholders to propose a change, it does not actually compel or incentivize shareholders to want to be more socially responsible as exemplified in Lovenheim: While " $[t]$ he enlightened shareholder value doctrine has at least, in theory, the potential to promote CSR," in reality " $[t]$ he interests of the stakeholders and the concept of CSR continue to be subordinated under the shareholder value prerogative." ${ }^{811}$ Two preliminary conclusions can be drawn from this observation: First, while laws that facilitate shareholder activism or stakeholder empowerment do play an important role in companies choosing to implement various CSR initiatives, these laws, in and of themselves do not address the underlying issue of incentives, which may not be the role of the law in the first place; and

678 D. VogeL, The Market for Virtue: The Potential and Limits of Corporate Social Responsibility, (Washington D.C.: Brookings Institution Press, 2006), at p. 38; see e.g. P. CAMEJO, The SRI Advantage: Why Socially Responsible Investing Has Outperformed Financially, (British Columbia: New Society, 2002); see also, S. ROBERTS, J. KEEBLE \& D. BROWN, "The Business Case for Corporate Citizenship," Arthur D. Little, Inc. (2003), at p. 8 (reporting that "86\% of institutional investors across Europe believe that social and environmental risk management will have a significantly positive impact on a company's long term market value," based on their survey conducted among 302 financial analysts and fund managers across Europe on SRI).

679 L.A. STOUT, The Shareholder Value Myth: How Putting Shareholders First Harms Investors, Corporations, and the Public, (San Francisco: Berrett-Koehler Publishers, 2012), at p. 8 (stating that the whole idea behind shareholder value ideology, even in the context of enlightened shareholders, is merely "based on wishful thinking," and "not reality.").

680 A. RÜHMkOrF, Corporate Social Responsibility, Private Law and Global Supply Chains, (Cheltenham: Edward Elgar, 2015), at p. 27; see also, K. CAMPBELL \& D. VICK, "Disclosure Law and the Market for Corporate Social Responsibility," in The New Corporate Accountability: Corporate Social Responsibility and the Law, D. MCBARNET, A. VOICULESCU \& T. CAmpbell (EDS.) (Cambridge: Cambridge University Press, 2007), at p. 242. For reasons noted in the introductory remark of this subsection, this emergence of ethical corporate governance, could be characterized as either an evolution of companies, or companies going back to its roots.

681 A. RÜhmkOrF, Corporate Social Responsibility, Private Law and Global Supply Chains, (Cheltenham: Edward Elgar, 2015), at pp. $77-8$. 
second, there are forces beyond the law that actually incentivizes people to change their views. For example, even though the shareholders did not vote for Lovenheim's proposal, Iroquois Brands did eventually discontinue the importing of the patte de foie gras. What this suggests, is that whether or not a company decides to implement CSR initiatives and to sincerely uphold them in a manner that actually reduces instances of labor exploitation in their supply chains comes down to the incentives and the motivations of the various stakeholders. The next subsection will address what some of the more socially responsible and motivated stakeholders are doing to affirm their commitment to CSR, by incorporating as a "benefit corporation," which is a unique development that is currently taking place in the United States.

\subsubsection{Incorporating as a Benefit Corporation}

As noted at the beginning of this section, when corporations first emerged, their existence was predicated upon the fact that they were serving a public purpose first and foremost, with any notion of profit being secondary. ${ }^{682}$ Moreover, there was no need for an elaborate legal framework that required them to consider their stakeholders because "[w]hen business first started up, they operated in the communities where they existed. This was where the executives lived," and with that proximity came some sense of communal responsibility: Back then, "legal structures that require[d] them to take into account all of their stakeholders" were not necessary because "social pressure served that role." ${ }^{883}$ With globalization, however, this proximity and the sense of communal responsibility waned, and as the shareholder value model discussion noted above, profits have all but become the sole objective for most companies, thus reaffirming Keynes' aforementioned remark that "remoteness between ownership and operation is an evil." ${ }^{684}$

The emergence of the stakeholder or enlightened shareholder value model, however, is incentivizing companies and their stakeholders to reassess the current status of corporations and for them to go back to the mentality of "purpose first and profit second." The rise of benefit corporations, the topic of this subsection, is yet another company law-based CSR initiative that is adding momentum to this movement. Bearing this in mind, this subsection will: a) describe what a benefit corporation actually is and what it attempts to accomplish, followed by b) noting how the benefit corporation legislation that is popping up across the United States is affecting the voluntary nature of this CSR initiative.

See generally, H. HANSMANN \& M. PARGENDLER, “The Evolution of Shareholder Voting Rights: Separation of Ownership and Consumption,” Yale Law Journal 123 (2014): 100-164; see also, L.A. STOUT, "The Shareholder Value Myth," The European Financial Review, (30 April 2013). Available at: http://www.europeanfinancialreview.com/ ? $\mathrm{p}=883$ (last accessed 7 April 2017); and, S. ROBERTS, J. KEEBLE \& D. BROWN, “The Business Case for Corporate Citizenship," Arthur D. Little, Inc. (2003), at p. 10.

683 C. Freeland, "Capitalism, but With a Little Heart," The New York Times, (18 July 2013). Available at: http://www.nytimes.com/2013/07/19/us/19iht-letter19.html (last accessed 4 April 2017) (quoting Governor Jack Markell from the state of Delaware after it signed a legislation recognizing the benefit corporation).

684 J.M. KEYNES, "National Self-Sufficiency," The Yale Review 22 (1933): 755-769; see also, J. DE GRAAF, D. WANN \& T.H. NAYLOR, Affluenza: How Overconsumption is Killing Us - And How We Can Fight Back [Third Edition], (San Francisco: Berrett-Koehler Publishers, 2014), at p. 187 (adding that "[t]he lack of connection is convenient for corporate managers who don't have to see the life cycle of their profits - remote sweatshops, strip mines, and toxic waste landfills.”). 


\section{A. What is a Benefit Corporation?}

A company can incorporate as a "benefit corporation," similar to how they can incorporate as a $\mathrm{C}$ corp or $\mathrm{S}$ corp, ${ }^{685}$ by filing the necessary paperwork with the appropriate state authorities, ${ }^{686}$ but in order for a company to incorporate as a benefit corporation, they must meet several unique requirements: First, not only do their corporate purposes have to state that they will "operate in a responsible and sustainable manner," but in order to "provide directors, stockholders, and ultimately the courts, some direction, they are also required to identify in their certificate of incorporation a specific public benefit purpose the corporation is obligated to pursue." ${ }^{687}$ These measures add a heighted sense of accountability for the directors whose fiduciary duty is no longer limited to maximizing profits, but they now must put their social and environmental objectives on par with their financial objectives. In short, the essence of a benefit corporation is to "take care of the people, the products, and the profits - in that order," 688 and they are backing up their claims by incorporating in a very special way. Currently 31 states in the United States permit and recognize this particular type of incorporation. ${ }^{689}$

\section{B. The Benefits of a Benefit Corporation}

The benefit, for the lack of a better word, of incorporating as a benefit corporation is that it shows the company's serious commitment to social responsibility, increases corporate transparency, and enhances the directors' accountability to the stakeholders and to society at large. There are over 500 registered benefit corporations currently operating in the US and according to a 2012 White Paper written by a group of US practitioners, a benefit corporation "is the most comprehensive yet flexible legal entity devised to address the needs of entrepreneurs and investors and, ultimately, the general public" because benefit corporations "offer clear market differentiation, broad legal protection to directors and officers, expanded shareholder rights, and greater access to capital than current alternative approaches." ${ }^{6} 90$

While the emergence of benefit corporation and a number of states changing their statutes to acknowledge this new type of incorporation method makes it easier for socially

In the US, incorporating as a C corp is the standard way to incorporate, which grants companies limited liability protections amongst other benefits noted back in Chapter 3, whereas S corps has similar benefits to C corps but are given special tax status.

686 Benefit Corp Information Center, "Benefit Corp vs. Certified B Corp”. Available at: http://www.benefitcorp.net/ what-makes-benefit-corp-different/benefit-corp-vs-certified-b-corp (last accessed 4 April 2017).

687 J. MARKELL, "A New Kind of Corporation to Harness the Power of Private Enterprise for Public Benefit," The Huffington Post, (22 July 2013). Available at: http://www.huffingtonpost.com/gov-jack-markell/public-benefitcorporation_b_3635752.html (last accessed 4 April 2017).

688 B. HorowiTz, The Hard Thing About Hard Things: Building a Business When There Are No Easy Answers, (New York: Harper Collins, 2014), at p. 93, 98 (quoting Jim Barksdale and commenting that "taking care of the people is the most difficult of the three by far and if you don't do it, the other two won't matter.”).

689 See, Benefit Corpation, "State by State Status of Legislation." Available at: http://benefitcorp.net/policymakers/ state-by-state-status (last accessed 17 April 2017) (noting that 31 US states have passed benefit corporation legislations and that 8 states are currently working on it). For example, New York and Califonia both passed Benefit Corporation Legislations back in 2012 (A4692-a/S79-a and AB361 respectively) that allow companies incorporating within New York or California to do so as benefit corporations.

690 W.J. Clark \& L. VRANKA, "Benefit Corporation White Paper," Benefit Corporation. Available at: http://benefitcorp.net/policymakers/benefit-corporation-white-paper (last accessed 18 December 2016). Wide variety of companies including clothing companies such as Patagonia or crowd-funding sites like Kickstarter have re-incorporated as benefit corporations. 
responsible companies to commit to their CSR initiatives, because the companies are not legally required to incorporate as benefit corporations, the problem of incentives creeps back in. If it is entirely up to the companies whether or not to incorporate as a benefit corporation, then the existence of enabling laws alone does not directly contribute to the reduction of labor exploitation. Similar to how the enlightened shareholder model can lead to the empowerment of workers and the reduction of labor exploitation, but only if the shareholders choose to be socially responsible, the necessary requirement for benefit corporations to succeed is the presence of motivated stakeholders that intrinsically believe in the importance of CSR. But similar to Lovenheim's proposal, just because the law offers ways for companies and stakeholders to be socially responsible, does not mean that private actors will take that opportunity to actually do so. In the end, socially conscious stakeholders, do not grow on trees and even if they did, the law is likely not the appropriate instrument that would incentivize them to grow.

From a business perspective, systems scientist and management expert Peter Senge and his colleagues note that there are several stages in the evolution of a business. ${ }^{691}$ In the earlier stages of the evolution, companies are reluctant to make socially responsible changes if they are costly and the law does not require them to change. They see such changes as unnecessary at least initially, but some gradually start seeing social responsibility as a potential competitive advantage, which evolves them to the "voluntary compliance" stage. Companies at this stage still see social responsibility in a view that is still linked to their bottom line and their hopes that the enhanced brand image/reputation might lead them to higher profits. The truly evolved company, at least according to Senge's framework, is the company that integrates social responsibility into the company's core strategies. ${ }^{692}$ The argument that this thesis supports is that benefit corporation could be the manifestation of this truly evolved company. Where we are at today is that companies are at various levels of this evolutionary framework, with some failing to comply even with the law, while others are going above and beyond what is required by law to incorporate as a benefit corporation.

So while one particular answer to our research question - of what private actors can do differently to reduce instances of labor exploitations in the global supply chain - could be to recommend companies to incorporate as a benefit corporation or at least for them to adopt a stakeholder value model, this observation offers up some food for thought: First, the existence of company laws that enable private actors to be socially responsible alone does not necessarily empower the exploited laborers in accordance with out normative framework nor directly reduce instances of labor exploitation; and second, the issue of incentives - and why private actors do the things that they do - seems to affect the outcome in one way or another. Bearing these two points in mind, the next part of the subsection will address yet another CSR initiative that is gaining in popularity, which is the filing of integrated reports with ESG metrics, along with other similar sunshine policies.

See generally, P.M. Senge, B. Smith, N. Kruschwitz, J. Laur, \& S. Schley, The Necessary Revolution: How Individuals and Organizations are Working Together to Create a Sustainable World, (New York: Doubleday, 2008).

${ }_{692}$ See generally, P.M. Senge, B. Smith, N. Kruschwitz, J. LAuR, \& S. SCHLEy, The Necessary Revolution: How Individuals and Organizations are Working Together to Create a Sustainable World, (New York: Doubleday, 2008). 


\subsubsection{Integrated Reports, ESG Metrics, and Sunshine Policies}

The previous subsection discussed how enlightened shareholders and investors can invest in a socially responsible manner citing to cases of shareholder activism like Lovenheim or ABP's divestment from Wal-Mart. What makes SRI possible in the first place, for investors to really determine whether a company is socially responsible or not, is if companies are transparent about their dealings and disclose an array of information above and beyond their mere financials. This could include any reports on the company's stance on environmental and social issues or information about the company's corporate governance structure. In the absence of this data, regardless of how responsible the investor wants to be, they will not be able to do so in a competent nor efficient manner. With this in mind, this subsection will discuss the existing CSR initiatives like a) filing integrated reports, or b) listing on markets with ESG listing requirements, followed by how c) governments are adopting transparency enhancing initiatives - commonly referred to as sunshine policies and converting these otherwise voluntary CSR initiatives into regulatory laws (i.e. California Transparency in Supply Chains Act, EU Directive on Disclosure of Non-Financial and Diversity Information).

\section{A. What are Integrated Reports?}

An integrated report is "a single document that presents and explains a company's financial and nonfinancial - environmental, social, and governance (ESG) - performance" ${ }^{693}$ and bares a close resemblance to John Elkington's triple bottom line framework, which states that companies should not only care about profits, but also about people and the planet. ${ }^{694}$ Incorporating as a benefit corporation, for example, requires directors to provide an integrated ESG report in addition to all of the other financial documents that they are obligated to report to their shareholders. By requiring directors to report their ESG practices, the idea is that the socially conscious investors will have the necessary tools to keep tabs on their investments and to make sure that the company is operating in a socially responsible manner. ${ }^{695}$ Moreover, as we noted in the Introduction, organizations - like businesses and governments - tend to prioritize considerations that are actually measured (i.e. economic or financial indicators), and by requiring ESG metrics along with the financials, the idea is that this forces directors to care about the companies social responsibilities, which could have benefits to the exploited laborers further down in the supply chain.

While being a benefit corporation shows serious intention and commitment above and beyond any form of incorporation, one need not be a benefit corporation to be transparent about their social and environmental performances. Even non-benefit corporations can disclose ESG related metrics to the investors and to the general public relying on any num-

R.G. ECCLeS \& D. SAlTZMAN, “Achieving Sustainability Through Integrated Reporting," Stanford Social Innovation Review, (Summer 2011): 56-61, 57.

694 See also, M.E.P. Seligman, Flourish, (New York: Atria, 2011), at p. 23 (noting that "[t]he new bottom line of the positive corporation in this view is profit... plus meaning... plus positive emotion... plus engagement... plus positive human relations.").

695 B Corps Annual Report (2012), at p. 6 (stating that to be a benefit corporation means that a company will be transparent regarding their social and environmental performance standards and meet higher legal accountability standards so that they can be a sustainable business). 
ber of voluntary guidelines. ${ }^{696}$ While these CSR initiatives and soft law guidelines have various differences in terms of what information the companies ought to disclose, they all have a common point, which is to stress the need for companies to report and inform their stakeholders above and beyond the mere financials. Although some companies might perceive these suggestions for additional information as an unnecessary burden, there are alleged benefits that could possibly outweigh the burden. For example, Eccles and Sutlzman note the following benefits: There are 1) internal benefits, where the work required to compile the ESG report could lead to better allocation of resources; 2) external market benefits where the ESG report would invite socially conscious investors; and 3) management and reduction of regulatory risk. ${ }^{697}$ More and more companies are providing ESG information in addition to their financial reports with information ranging from labor practices and corporate risk management on their own volition in an attempt to differentiate themselves from others and to improve their corporate reputation in attempts to attract more investors and consumers. ${ }^{698}$

While integrated reports that disclose more information have their benefits, there are at least three immediate concerns that emerge: First, in light of the Volkswagen emission scandal, the public must be on alert that there is no guarantee that the companies will always be truthful; second, even assuming their honesty, just because the companies release more information does not mean that every investor will read them and make competent decisions accordingly; ${ }^{699}$ and on a related point, third, some believe that the information that the aforementioned guidelines suggest that the companies disclose, are not necessarily the relevant indicators to determine whether a company is truly socially responsible or not. Combining the second and the third concern, some believe that "the steadily growing length of the GRI checklist may have made it more difficult for financial analysts to use these reports effectively." 700 Moreover, even if a socially responsible investor can get past these three concerns, as evidenced by Lovenheim's quixotic attempt, "shareholders' public interest proxy resolutions seeking changes in the corporate policies and practices are rarely adopted." 701 This reality suggests that even if we assume for the sake of the argument here

${ }^{696}$ For example, CSR initiatives suggested by Global Reporting Initiative's Sustainability Reporting Guidelines, UN Global Compact backed SDG Compass, UN Guiding Principles on Business and Human Rights, ISO 26000, OECD Guidelines for Multinational Enterprises, the ILO's Tripartite Declaration, and the Consultation Draft of the International Framework published by the International Integrated Reporting Council all stress the importance of integrated reporting and urge companies to be transparent and open in their reports about their ESG metrics.

697 R.G. ECCLES \& D. SALTZMAN, “Achieving Sustainability Through Integrated Reporting,” Stanford Social Innovation Review, (Summer 2011), at p. 59.

698 R.G. Eccles \& D. SAltZMAN, “Achieving Sustainability Through Integrated Reporting,” Stanford Social Innovation Review, (Summer 2011), at p. 58.

699 D. VOGEL, The Market for Virtue: The Potential and Limits of Corporate Social Responsibility, (Washington D.C.: Brookings Institution Press, 2006), at p. 65 (noting that only a "relatively small portion of investors" actually that take into account ESG factors in their financial analysis, which "clearly limits the impact of the SRI community on share prices and thus on corporate behavior"); see also, World Economic Forum, "Values and Value: Communicating the Strategic Importance of Corporate Citizenship to Investors," (2003) (noting the limited impact of SRI).

700 D. VOGEL, The Market for Virtue: The Potential and Limits of Corporate Social Responsibility, (Washington D.C.: Brookings Institution Press, 2006), at p. 69-70 (adding that not only are there too many factors for analysts to consider, but that "[n]o one has developed a way to calculate [corporate performance on environmental and social impact].”).

701 See generally, A. WILLIS, "The Role of the Global Reporting Initiative's Sustainability Reporting Guidelines in the Social Screening of Investments," Journal of Business Ethics 43(3) (2003): 233-237. 
that there are socially motivated companies willing to disclose honest integrated reports and conscious investors willing to read them and invest/divest accordingly, what impact they will actually have on reducing the instances of labor exploitation in the global supply chain remain largely unsubstantiated. Before reaching any preliminary conclusions here, however, the next part of the subsection will first address how some stock exchanges are incorporating the ESG metrics into their listing requirements.

\section{B. Stock Markets with ESG Listing Requirements}

In order for companies to be a publicly listed company on a stock exchange, they must comply with various reporting requirements of the particular stock exchange. Many of the world's stock exchanges currently do not offer guidance on non-financial reporting, ${ }^{702}$ but there are some like the New York Stock Exchange, Nasdaq, and the Johannesburg Stock Exchange that explicitly require their listed companies to submit integrated reports in addition to their financials. ${ }^{703}$ The incentive for companies to comply or to list in exchanges with such requirements, is the same reason why companies choose to implement any CSR initiative in the first place: As mentioned earlier during the discussion of the UN Global Compact-Accenture CEO Study on Sustainability, many CEOs and business leaders believe that "embedding sustainability into core business will drive revenue growth and new opportunities." 704 Taking this to heart, companies like Royal Philips Electronic take ESG factors very seriously and consider them as "driver[s] of growth" and an "integral" part of their businesses. ${ }^{705}$ In other words, some firms believe that listing on these socially conscious exchanges is yet another way to achieve market differentiation from their competitors that are less socially conscious.

Although there are various claims that suggest an almost causal relationship between the implementation of these CSR initiatives and long term profitability for the company, this is not necessarily true, at least not in all cases: For example, the London Stock Exchange's subsidiary FTSE Group's FTSE4Good Index and the Dow Jones Sustainability

R.G. ECCLES \& D. SALTZMAN, “Achieving Sustainability Through Integrated Reporting,” Stanford Social Innovation Review, (Summer 2011): 56-61, at 57 (noting that "only a handful of the world's top 30 stock exchanges provide guidance on non-financial reporting").

703 See e.g. NYSE Listed Company Manual. Johannesburg Stock Exchange, as a matter of fact, was the first stock exchange in the world to require listing companies to submit integrated reports. Other countries' stock exchanges (i.e. Nordic countries such as Denmark and Norway) require reports on environmental impacts of the companies and the UK have been stepping up requirements to include ESG metrics as well under the guise of transparency measures; see e.g. R.G. ECCLES \& D. SALTZMAN, "Achieving Sustainability Through Integrated Reporting," Stanford Social Innovation Review, (Summer 2011), at p. 59; see also, European Parliament Directorate-General For External Policies (Policy Department), "New Options for Strengthening Standards on Social and Environmental Responsibilities of Corporations and Their Implementation," EXPO/B/DEVE/FWC/2009-01/Lot5/36 PE 457.138 (2013), at p. 5

704 The UN Global Compact-Accenture CEO Study on Sustainability 2013: Architects of a Better World. Available at: https://www.unglobalcompact.org/docs/news_events/8.1/UNGC_Accenture_CEO_Study_2013.pdf (last accessed 4 April 2017), at p. 11; see also, R. G. ECCLES, I. IOANNOU \& G. SERAFEIN, "The Impact of Corporate Sustainability on Organizational Processes and Performance," Harvard Business School Working Paper Series 12-035 (2013) (noting that companies that manage their environmental and social performance could "significantly outperform their counterparts over the long-term, both in terms of stock market as well as accounting performance.").

705 Rudy Provoost, chairman of Philips' Sustainability Board and CEO of Philips Lighting, Philips Press Release (18 February 2011); as cited by, R.G. ECCLES \& D. SALTZMAN, "Achieving Sustainability Through Integrated Reporting," Stanford Social Innovation Review, (2011), at p. 60. 
Index, the "two major ethical stock indexes... since its inception... have underperformed the market by 3 percent and 8 percent, respectively." 706 This point brings us back to what previous subsections have suggested, which is that if the motivation for companies to engage in these CSR initiatives is primarily for the sake of profit, companies might find that the cost of adopting and implementing CSR initiatives may not be worth the benefits. As noted earlier, this is part of the very reason why incentives and motivations matter, because if a company that is investing in CSR is doing it only for the profits, their commitment could potentially wane if their CSR strategy is not returning profit. Section 4.3 will show how this particular concern can significantly undermine the effectiveness of various company law-based CSR initiatives on actually reducing labor exploitation in the global supply chain in a manner that conforms to our normative framework. Before moving on to this analysis, however, the next part of this subsection will address the increasing tendency of governments to turning otherwise voluntary CSR initiatives into mandatory regulations, and assess what impact such an approach has on our research question.

\section{Transparency Legislations}

The assortment of initiatives noted above was, for all intents and purposes, voluntary. ${ }^{707}$ After all, the very nature of CSR as voluntary initiative allows companies to embrace them or not; but for the companies that do, the supposed benefits included gaining a competitive advantage and market differentiation. ${ }^{708}$ This opportunity for differentiation and gaining a competitive advantage, however could be coming to an end as governments are increasingly adopting these voluntary initiatives and turning them into legislations that mandate corporate compliance: For example, the EU Directive on Disclosure of Non-Financial and Diversity Information, ${ }^{709}$ when it goes into effect on 1 January 2017, "will require large companies with more than 500 employees to disclose relevant and material environmental and social information in their annual reports." 710 The Commission stated that the aim of

D. Vogel, The Market for Virtue: The Potential and Limits of Corporate Social Responsibility, (Washington D.C.: Brookings Institution Press, 2006), at p. xvi (citing to findings by Stier); see, K. STIER, "Investing in Climate Change," Ethical Corporation, (2006).

707 For example, a company could choose not to integrate their reports in accordance with GRI's Sustainability Reporting Guidelines or refuse to incorporate as a benefit corporation. Similarly, a company could choose not to list on the NYSE or the Johannesburg Stock Exchange if they did not want to.

708 The UN Global Compact-Accenture CEO Study on Sustainability 2013: Architects of a Better World. Available at: https://www.unglobalcompact.org/docs/news_events/8.1/UNGC_Accenture_CEO_Study_2013.pdf (last accessed 4 April 2017), at p. 13.

709 Directive 2014/95/EU of the European Parliament and of the Council of 22 October 2014 amending Directive 2013/34/EU as regards disclosure of non-financial and diversity information by certain large undertakings and groups. See also, European Commission Press Release, "Statement: Disclosure of non-financial information: Europe's largest companies to be more transparent on social and environmental issues," (29 September 2014). Available at: http://europa.eu/rapid/press-release_STATEMENT-14-291_en.htm (last accessed 16 January 2016).

710 Directive 2014/95/EU of the European Parliament and of the Council of 22 October 2014 amending Directive 2013/34/EU as regards disclosure of non-financial and diversity information by certain large undertakings and groups. Preamble 6 and Article 4 (stating that the Directive will compel "certain large undertakings [to] prepare a non-financial statement containing information relating to at least environmental matters, social and employeerelated matters, respect for human rights anti-corruption and bribery matters."); see also, A. RÜHMKORF, Corporate Social Responsibility, Private Law and Global Supply Chains, (Cheltenham: Edward Elgar, 2015), at p. 59 (adding that in accordance with Article 1(1)(a), "the Directive stipulates that the annual report of these companies must include a non-financial statement containing information relating to at least environmental, social and employee matters, respect for human rights, anti-corruption and bribery matters.”). 
this Directive will be to "improve the kinds of information that companies need to provide on their socially responsible conduct." ${ }^{\prime 11}$ Given that it is a European Directive, all Member States are expected to transpose this requirement into their national legislations, but moreover, this Directive can significantly impact even foreign companies located outside of the $\mathrm{EU}$, to the extent that if they are conducting businesses within the EU or are listed in an EU exchange, this Directive could potentially require them to disclose integrated reports as well. ${ }^{712}$

While the Directive would indeed legalize and mandate the disclosure of integrated reports, the Directive does keep intact some element of CSR in that it adopts a comply or explain approach. ${ }^{713}$ That is to say, the Directive does give the opportunity for MNCs not to disclose an integrated report, but if they choose not to, they must explain and justify their refusal. In justifying this particular approach, the European Commission has stated the following:

"Most corporate governance is soft law and it is thus essential that the 'comply or explain' approach, whereby a company that chooses to depart from the applicable corporate governance code must give reasons for the departure, works well. This approach offers companies an important degree of flexibility, as it recognizes that, in certain circumstances, non-compliance with some recommendations might correspond better to the company's interest than $100 \%$ compliance with the code. ${ }^{, 714}$

While the comply or explain approach does indeed leave an element of flexibility and voluntarism intact, it has essentially changed the default setting of this previously voluntary initiative from an opt in to an opt out; whereas companies could opt in to a CSR initiative before, they will now have to explicitly opt out of complying with the law, which as the next subsection will show, can have an impact on companies' willingness to comply with this initiative. Suffice it to state here that companies opting out of compliance have more stigma attached to them than companies not opting into a voluntary initiative, especially from the perspective of consumers who might deem the company opting out of compliance to be a more socially irresponsible one. In a sense, this is paramount to naming and shaming, which could serve a similar purpose to the idea behind the Dutch Ministry of

711 A. RÜHMKORF, Corporate Social Responsibility, Private Law and Global Supply Chains, (Cheltenham: Edward Elgar, 2015), at p. 61.

712 Directive 2014/95/EU of the European Parliament and of the Council of 22 October 2014 amending Directive 2013/34/EU as regards disclosure of non-financial and diversity information by certain large undertakings and groups. Article 1. The Directive will be applicable, not only to companies incorporated in the EU that fit these elements, but possibly to foreign companies that are listed in an EU exchange or are conducting significant business within the EU.

713 Directive 2014/95/EU of the European Parliament and of the Council of 22 October 2014 amending Directive 2013/34/EU as regards disclosure of non-financial and diversity information by certain large undertakings and groups. Article 1 (1)(e) notes that " $[\mathrm{w}]$ here the undertaking does not pursue policies in relation to one or more of those matters, the non-financial statement shall provide a clear and reasoned explanation for not doing so." The "comply or explain" approach is also the preferred approach of the aforementioned proposal to amend the Shareholders' Rights Directive, where the companies that choose not to be transparent will have to explain why.

714 European Commission, "European Commission proposes to strengthen shareholder engagement and introduce a 'say on pay' for Europe's largest companies," (9 April 2014). Available at: http://europa.eu/rapid/pressrelease_IP-14-396_en.htm?locale=en (last accessed on 14 March 2016) (adding that "companies that depart from the applicable corporate governance code often fail to provide appropriate explanations for the departure, which makes it more difficult for investors to take informed investment decisions.”). 
Social Affairs and Employment's idea to publish the names of those found to be in violation of various labor laws by publishing the violators' names on a website (as described back in Chapter 2). ${ }^{715}$ While the European Commission's press release pays reverence to the importance of flexibility, requiring a company that decides not to submit an integrated report to explain their non-compliance is, at the very least, nudging companies towards compliance.

Although pressuring reluctant companies into compliance to these new legislations could indeed lead to more socially responsible practices, albeit fostered by shades of paternalistic libertarianism, there is a very real possibility that all of this legally required transparency and the disclosure of more and more information could actually be counterproductive to the cause of reducing instances of labor exploitation in the global supply chain. While the discussion of this particular topic will be tabled until next section of this chapter, we must bear in mind the possible dangers that lurk, not only with the comply or explain approach to incentivizing companies to be more transparent, but with the legalization of voluntary initiatives as a whole. Recall here the lessons extracted from the InvertedU curve back in Chapter 2, which noted that the answers to our problems does not necessarily lie in creating more and more laws or legalizing otherwise voluntary initiatives into legal requirements.

Similarly across the pond, the US government - both at the state level and at the federal level - are adopting previously voluntary CSR initiatives into legally mandated requirements as well: For example, the California Transparency in Supply Chains Act, which became effective in 2012, now requires companies doing business in California and making more than $\$ 100$ million (annual worldwide gross receipts), to publicly disclose their due diligence to root out modern slavery from their supply chain. ${ }^{716}$ Mandating disclosure of their due diligence not only requires companies to release various ESG metrics, but also to explain the steps they are taking to eradicate modern slavery from their supply chain. At the federal level, the previously mentioned $\$ 1502$ of the Dodd-Frank Wall Street Reform and Consumer Protection Act, which President Obama signed into law in 2010, now requires companies dealing with potential conflict minerals (i.e. tantalum, tin, tungsten, coltan, and gold) sourced from the DRC and surrounding areas, to conduct due diligence and to report their efforts to the SEC. ${ }^{717}$

715 K. RотH, "What are Human Rights For? Three Personal Reflections," in International Human Rights Law, D. MOECKLI, S. SHAH, \& S. SivaKuMARAN, (EDS.) (Oxford: Oxford University Press, 2014), at p. 8 (doubting the impact of "comply or explain" or "naming and shaming" approach because "there can be no shame if the public approves of the conduct in question.").

716 Senate Bill No. 657, Chapter 556; see also, A.L. VYTOPIL, Contractual Control in the Supply Chain: On Corporate Social Responsibility, Codes of Conduct, Contracts and (Avoiding) Liability, (The Hague: Eleven, 2015), at p. 92, 113 (summarizing that "CTSCA aims to increase transparency for consumers in respect of products tainted with human trafficking and slavery, thereby encouraging them to purchase responsibility with the hope of improving the lives of victims of human trafficking and slavery and has served as inspiration for other, similar acts in other jurisdictions.").

717 HR 4173 aiming to increase corporate transparency by implementing a due diligence framework regarding conflict minerals; see also, A.L. VYTOPIL, Contractual Control in the Supply Chain: On Corporate Social Responsibility, Codes of Conduct, Contracts and (Avoiding) Liability, (The Hague: Eleven, 2015), at p. 278 (summarizing the purpose of this section as requiring companies to be "transparent as to their policies in respect of issues covered by these acts (conflict minerals and slavery in supply chains, in short."). 
While laws that require supply chain traceability and auditing, in and of itself, can be argued as a welcoming development and a potentially capabilities-enhancing measures for the exploited laborers, as it relates to this thesis, there are two immediate concerns that arise: First is whether legalizing CSR initiatives and requiring companies to disclose ESG metrics actually leads to the reduction of labor exploitation in the global supply chain; and second, does the continued legalization of otherwise voluntary CSR initiatives have some kind of an effect on the effectiveness of CSR initiatives and the company's incentives to try and be a more socially responsible entity?

First and foremost, "empirical studies rarely report that disclosures lead disclosees to good decisions," 718 which is quite a huge concern in and of itself, but from a more practical side of the matter, the U.S. Government Accountability Office recently determined that most companies are simply not capable of determining the source of their conflict minerals, which was a concern already hinted to back in the Introduction of this thesis. ${ }^{719}$ If companies cannot competently determine or trace where their components come from, then what impact can they actually have to determine the instances of labor exploitation taking place in places like the DRC.

With regards to the second concern, we must introduce the concept of the crowding out effect here. The crowding out effect, at least in our context, occurs when the government increases their involvement to address a particular problem, which leads to a corresponding decrease in the involvement of the private sector to resolve the issue. ${ }^{720}$ In laymen's terms, if the government takes charge in dictating what companies must do in order to be socially responsible, it could potentially reduce the companies' incentives to take up other voluntary CSR initiatives. The crowding out of private initiatives due to an increasing government oversight can also be conceptualized by recalling the Inverted-U curve and the risks associated with overregulation discussed back in Chapter 2.

In the end, it is difficult to be critical of the European Parliament's assertion - a belief that is shared by many other stakeholders - that "disclosure of nonfinancial information is vital for managing change towards a sustainable global economy by combining long-term profitability with social justice and environmental protection." 721 It remains to be seen, however, what impact the legalization of voluntary CSR initiative will have, especially given the fact that even prior to the implementation of the various directives and legislations, a lot of companies were already disclosing ESG metrics and conducting due diligence as-

718 O. Ben-Shahar \& C.E. SCHNEIDER, More Than You Wanted to Know: The Failure of Mandated Disclosure, (Princeton: Princeton University Press, 2014), at p. 7-8; see also, C C. Winston, "The Efficacy of Information Policy: A Review of Archon Fung, Mary Graham, and David Weil's Full Disclosure: The Perils and Promise of Transparency," Journal of Economic Literature 46 (2008): 704, 713-4 (noting that "federal and state information policies, including but not limited to disclosure policies, suggests that they have not made consumers significantly better informed and safer".)

719 U.S. Government Accountability Office, "SEC Conflict Minerals Rule: Initial Disclosures Indicate Most Companies Were Unable to Determine the Source of Their Conflict Minerals," GAO-15-561, (18 August 2015). Available at: http://www.gao.gov/assets/680/672051.pdf (last accessed 12 March 2016).

720 This term is borrowed from economics and is usually used to describe instances where an increase in government spending, which is financed by increasing their debt, leads to corresponding decrease in private expenditures.

721 Directive 2014/95/EU of the European Parliament and of the Council of 22 October 2014 amending Directive 2013/34/EU as regards disclosure of non-financial and diversity information by certain large undertakings and groups. Preamble 3 (adding that "European Parliament acknowledge[s] the importance of businesses divulging information on sustainability such as social and environmental factors, with a view to identifying sustainability risks and increasing investor and consumer trust.”) 
sessments anyway: For example, 95\% of the world's 250 largest companies are already producing CSR reports that contained various ESG metrics. ${ }^{722}$ That is to say, even in the absence of regulations and legislations, many companies were already adopting these CSR initiatives voluntarily, but now that practically every MNC will have to do so, there is a possibility that the appeal of these CSR initiatives - as a source of market differentiation and/or competitive advantages - could be reduced. More alarmingly, the EU Directive and the California Transparency in Supply Chains Act, at least as they are drafted now, have failed to address at least two of the three aforementioned concerns: That is, whether the investors/consumers will actually bother to read the additional information now available to them, and even if they do, 2) whether they will be able to interpret and decipher the ESG metrics in a competent manner that will actually contribute to the reduction of labor exploitation bearing in mind the complexity of such a task and our bounded rationality, which was elaborated back in the Introduction. ${ }^{723}$ As noted above, simply offering more and more information could create an information overload problem for the investors and if governments continue to be more and more involved, there is also a possible risk of the crowding out problem, which can be visualized through the Inverted-U curve. These problems will be elaborated in more detail in the next section of this chapter.

\subsection{PROBLEMS WITH THE COMPANY LAW APPROACH}

The previous sections discussed an assortment of company law-based CSR initiatives, including but not limited to companies adopting a stakeholder value corporate governance model, companies incorporating as benefit corporations, and companies filing annual reports with ESG metrics. While these measures present a picture of what companies are currently doing to be more socially responsible, the previous sections also hinted to various problems with these existing approaches. This section will now elaborate on these problems in more depth: Accordingly, this section will address the enforcement problem (Subsection 4.3.1), the incentive problem (Subsection 4.3.2), and the causation problem (Subsection 4.3.3) to highlight some of the problems with the current way companies are attempting to reduce instances of labor exploitation in the global supply chain.

C. CASAZZA, “Oversight of Corporate Sustainability Activities," Director's Handbook Series 2014, (Washington D.C.: National Association of Corporate Directors with Ernest \& Young LLP, 2014), at p. 3.

723 For example, the Directive on Disclosure of Non-Financial and Diversity Information has not even specified what type of ESG metrics the companies are required to disclose. Article 2 of the Directive states that "[t]he Commission shall publish the guidelines by 6 December 2016," but it can be expected that the Directive will allow some flexibility, not to mention the number of existing instruments such as the UN Global Compact, ISO 26000, OECD Guidelines for Multinational Enterprises or the Global Reporting Initiative already provide guidance. Bear in mind the allegation made earlier that some of these guidelines and the information that they require companies to disclose could actually make matters more confusing for the investors. A. VACCARO \& J. FONTRODONA, "Academic View: The Myth of Corporate Transparency," The Economist, (7 September 2010). Available at: http://www.economist.com/blogs/newsbook/2010/09/myth_corporate_transparency (last accessed on 3 February 2016) (noting no amount of transparency laws will save society from "business malpractice and corporate psychopath"). 


\subsubsection{The Enforcement Problem}

The first reason why CSR initiatives can be problematic is because companies only have a limited amount of resources to invest in implementing and enforcing their CSR initiatives, which renders an assortment of enforcement problems similar to governments attempting to enforce their labor laws. What makes CSR initiatives even more difficult to "enforce" in some ways, is the fact that as voluntary initiatives, companies that lack the incentives to implement for enforce a CSR strategy, do not necessarily have to, unlike in the case of complying with labor laws or not committing torts. Accordingly, this subsection will: a) suggest that the cost for implementing CSR measures does not always outweigh the profits that the companies seek, which could diminish the resolve of some companies to actually becoming socially responsible, and as a result, b) note that there will be a risk of greenwashing, with companies only pretending to be socially responsible without actually making any difference in the lives of the exploited laborers.

\section{A. Costs of Implementing CSR > Benefits of CSR?}

Obviously, if more private actors cared about being socially responsible, "then they would bear the costs of enforcement; and if enforcement were cheap and easy, then people would bear the cost of enforcement even if they cared only a little." 724 The problem here is that adopting a CSR initiative, implementing it, and monitoring for continued compliance is often not cheap, but quite expensive. Add to this, the fact that for every research or report that extol CSR's profit enhancing potential, ${ }^{725}$ there are reports that dismiss the veracity of such claims. ${ }^{726}$ The unfortunate reality is that for businesses, being socially responsible does

724 E.A. Posner, The Twilight of Human Rights Law, (Oxford: Oxford University Press, 2014), at p. 107 (adding that "they don't care much and enforcement is hard, which is why serious efforts to enforce human rights are extremely rare...”).

725 C. CASAZZA, “Oversight of Corporate Sustainability Activities,” Director's Handbook Series 2014, (Washington D.C.: National Association of Corporate Directors with Ernest \& Young LLP, 2014), at p. 3 (reporting that "[i]n one recent survey, the number of companies reporting that their sustainability activities contributed to profits rose by 23 percent year over year, and nearly half of the respondents reported changing their business models in response to sustainability opportunities"); D. VoGEL, The Market for Virtue: The Potential and Limits of Corporate Social Responsibility, (Washington D.C.: Brookings Institution Press, 2006), at p. viii (stating that companies like Nike, Shell, and Wal-Mart have "responded [to CSR measures and various bad press] by changing some of its policies" and by “making modest improvements"); G. REIJN, "Verkoop van verantwoorde koffie stijgt explosief," De Volkskerant, $(8$ May 2013). Available

at: http://www.volkskrant.nl/vk/nl/2664/Nieuws/article/detail/3437913/2013/05/08/Verkoop-vanverantwoordekoffie-stijgt-explosief.dhtml (last accessed 26 January 2016) (reporting that an "explosive" increase in demand for socially responsible and fair trade products pointing, for example, to the $38 \%$ annual increase in the sale of UTZ fair trade coffee in 2013 alone; "dd]e wereldwijde verkoop van koffie met een UTZ-keurmerk groeide met 38 procent, en van keurmerk-cacao zelfs met 178 procent.”); Cf., Dutch National Rapporteur on Trafficking in Human Beings and Sexual Violence against Children, Trafficking in Human Beings: Ninth Report of the Dutch National Rapporteur, (2013), at p. 101 (noting that "[a]lthough there is growing demand for fair trade products, attention seems to focus mainly on possible exploitation in other countries rather than on exploitation that occurs or could occur in the Netherlands.").

726 T.M. Devinney, P. Auger, G. EcKhardt \& T. BirTChnell, "The Other CSR: Consumer Social Responsibility," Leeds University Business School Working Paper No. 15-04 (2006) (noting that "although consumer activism and pressure from NGOs led to Starbucks prominently displaying and selling fair trade coffee, the sales levels have been much lower than expected and demand has remained relatively flat since its introduction in 2001." All enthusiasm for "fair trade activities" aside, such products "rarely account for anything but a miniscule percentage of the market, normally $1 \%$ to $2 \%$ and where they do account for more market share, it is generally due to the activities of retailers rather than consumers."). 
not necessarily mean being profitable, but at times, being socially irresponsible does: Take for example the profitability of the shadow economy (also referred to as the black economy). ${ }^{727}$ The clandestine shadow economy of the Netherlands, for example, has been estimated to produce the equivalent of almost $10 \%$ of the Dutch GDP, and similarly, the size of the so-called shadow economy in the US is estimated to be hovering around $7 \%$ of the US GDP. ${ }^{728}$ These shadow economies that rely on the exploitation of laborers, while frowned upon by civil society, persist partly due to the fact that they are lucrative. If being socially responsible were similarly profitable, then companies would likely jump on such an opportunity, which suggests that in order for private initiatives like CSR to be implemented and enforced by companies, these measures have to be associated with value creation or market differentiation.

Enforcement could be made even more difficult, especially when businesses not only fail to increase profits as a result of implementing CSR initiatives, but when they result in loss of profits. The aforementioned de Beers example is a perfect illustration and a warning sign for other companies that not all socially responsible corporate decisions lead to profit, but it could potentially lead them to their demise. At times, similar to laws that aim to enhance worker protection, well-intended CSR initiatives can backfire, not only leading to financial losses for the companies, but leading to worse situations for the workers. To pile on the problems, businesses operating in the global supply chain "generally acknowledged that the costs of monitoring are becoming increasingly high and in the long run are not sustainable," 729 which suggests that it will become increasingly more difficult for companies to self-regulate themselves especially as firm disaggregation continues to make the global supply chain more fragmented. ${ }^{730}$

\section{B. Risk of Isomorphic Mimicry and Greenwashing}

Given the there are various risks associated with companies not investing in CSR strategies, but at the same time, realizing the cost-prohibitive nature of adopting and implementing them, companies are put in a position where they must make difficult decisions. One easy way out of this quandary, though not necessarily a path that leads to empowering workers or reducing labor exploitation, is for companies to fake it: In nature, there is a phenomenon called "isomorphic mimicry," when some non-venomous creatures evolve over time to

727 A term that broadly encompasses all of the unregistered workers, illegal immigrant laborers, sweatshop workers, working in unincorporated or unregistered businesses that pay their workers in cash, while not paying taxes or offering their workers any benefits or legally mandated minimum safety nets.

728 V. Mallet \& G. Dinmore, "Europe: Hidden Economy," Financial Times, (8 June 2011). Available at: http://www.ft.com/intl/cms/s/0/efc3510e-9214-11e0-9e00-00144feab49a.html\#axzz2vI729dEv (last accessed 4 April 2017). The research conducted by Friedrich Schneider continues to speculate that the size of the black economies range from $32.6 \%$ of its GDP in Bulgaria to $8.1 \%$ of its GDP in Switzerland, with the average across 31 European countries hovering around $20 \%$.

729 H.B. Jorgensen, P.M. PruZAn-Jorgensen, M. Jungk \& A. Cramer, "Strengthening Implementation of Corporate Social Responsibility in Global Supply Chains," World Bank Group - Corporate Social Responsibility Practice (2003), at p. 20; as cited in, D. VoGEL, The Market for Virtue: The Potential and Limits of Corporate Social Responsibility, (Washington D.C.: Brookings Institution Press, 2006), at p. 91.

730 The UN Global Compact-Accenture CEO Study on Sustainability 2013: Architects of a Better World. Available at: https://www.unglobalcompact.org/docs/news_events/8.1/UNGC_Accenture_CEO_Study_2013.pdf (last accessed 4 April 2017), at p. 11 (noting that there is a "sense of frustrated ambition" amongst the companies engaged in CSR). 
resemble venomous ones to fend off potential predators for the sake of survival. ${ }^{731}$ Reform dynamics, like the emergence of CSR, are often characterized by isomorphic mimicry, which is "the tendency to introduce reforms that enhance an entity's external legitimacy and support, even when they do not demonstrably improve performance." 732

In the CSR context, this is known as greenwashing, where companies establish their external legitimacy by claiming to be socially responsible, when in fact, they are not. These companies may even go as far as creating a code of conduct or private labels (two issues that the next chapter will address) that claim their products are eco-friendly or sweatshop free, without actually living up to their claims. News of companies making unsubstantiated or misleading claims - that substantiates the existence of these practices - are not uncommon. In other words, what makes CSR enforcement particularly difficult is the ease at which companies can claim to be socially responsible, without actually being committed to being socially responsible.

In sum, asking companies to strictly enforce their CSR strategies may be akin to asking a fox to guard the hen house. This is partially due to the aforementioned fact that some companies are only interested in adopting CSR initiatives for financial reasons, with the belief that incorporating CSR is a path to increasing their long term profits and gaining competitive advantage through market differentiation. If the companies' primary incentives for adopting these CSR initiatives are indeed purely financial, the risk of isomorphic mimicry and greenwashing increases and the likelihood of these measures making a positive impact on the working conditions of laborers decreases. This is why the issue of incentives and the reason why companies adopt CSR initiatives become important, which leads us to our next problem.

\subsubsection{The Incentive Problem}

Before diving into the issue of incentives, it is worth noting that some believe that the tools necessary - whether they be laws or voluntary initiatives - to eradicate labor exploitation from the global supply chain already exists, but what is currently lacking is the collective will to make use of these tools. ${ }^{733}$ The lack of our collective will is directly linked to the issue of incentives and our motivations to adopting and implementing various CSR initiatives. To develop this point further, this subsection will: a) differentiate extrinsic motivations from intrinsic motivations, b) explain why it is difficult for not only companies, but private actors in general to continue being socially responsible even after they make a commitment to do so if they rely only on extrinsic incentives, and c) discuss the importance of intrinsic motivations and how they can be harnessed.

731 For example, Eastern Coral snakes (non-venomous) have evolved to resemble Scarlet King snakes (venomous).

732 M. Andrews, L. PRitchetT \& M. WoOlCOCK, "Escaping Capability Traps Through Problem Driven Iterative Adaptation," World Development 51 (2013): 234-244, at pp. 234-5; see also, M. ANDREWs, L. PRITCHETT \& M. WOOLCOCK, "Capability Traps? The Mechanisms of Persistent Implementation Failure," Center for Global Development Working Paper 234 (2010) (citing to P. DiMAGgio \& W.W. Powell, "The Iron Cage Revisited: Institutional Isomorphism and Collective Rationality in Organizational Fields," American Sociological Review 48 (1983): 137-160 and J. MAHOney \& K. Thelen (EDS.), Explaining Institutional Change: Ambiguity, Agency, and Power, (New York: Cambridge University Press, 2010)).

733 N.D. KRISTOF \& S. WuDunN, Half the Sky: How to Change the World, (London: Virago Press, 2010), at p. 27 (specifying that it is the "political will" that is lacking in particular). 


\section{A. Matter of Extrinsic and Intrinsic Motivations}

Given the relative ease of greenwashing and isomorphic mimicry, the issue of incentives and motivations for why companies choose to implement CSR strategies in the first place must be brought back to the spotlight. The issue of incentives and the various flaws with the traditional understanding of Gary Becker's carrot or the stick approach was already noted back in the Introduction, but for the sake of this context, let us add to this analysis by asking the question of why companies choose to be socially responsible using this traditional framework: The carrot incentive here is the aforementioned possibility of increasing profits. In short, according to Becker's framework, companies - as rational actors - invest in CSR initiatives because they believe it will be profitable. The fear of the stick could be characterized by companies responding to external pressures, whether from investors or consumers that if the company does not implement CSR strategies, the consumers can boycott or the investors can divest from that company. These external pressures - what some have termed "civil regulation" - has been, and continues to be, a key component to making corporate behavior more socially responsible at least in terms of their external appearances. ${ }^{734}$

While these extrinsic incentives do play a major role in companies deciding to adopt CSR strategies, they contribute noticeably less when preventing companies from greenwashing and actually enforcing various CSR initiatives. For example, consider how and where many of our consumer goods are manufactured. While companies that sell the finished products - in the $\mathrm{B} 2 \mathrm{C}$ context - may be sensitive to their reputation and derive their value from having a clean and responsible brand image, most suppliers, manufactures, intermediaries, and contractors in the $\mathrm{B} 2 \mathrm{~B}$ context are not very brand conscious. ${ }^{735}$ So while the Nikes and Apples of the world may be conscious about their brand reputation, the businesses that manufacture the Nike shoes or the intermediaries that purchase cobalt ores from the child miners in the DRC generally do not care about their brand image. ${ }^{736}$ In

D. Vogel, The Market for Virtue: The Potential and Limits of Corporate Social Responsibility, (Washington D.C.: Brookings Institution Press, 2006), at p. 109; see also, A. Cowell, "A Call to Put Social Issues on Corporate Agendas," The New York Times (6 April 2000). Available at: http://www.nytimes.com/2000/04/06/business/ international-business-a-call-to-put-social-issues-on-corporate-agendas.html (last accessed 2 February 2016) (quoting Amnesty International's Sir Geoffrey Chandler stating that " $[\mathrm{t}]$ he increasing scrutiny of corporate behavior by the media, consumer groups, community organizations, local and international nongovernmental organizations and the immediacy of global communication leave companies with little, if any, hiding place.”); as cited in, D. VogeL, The Market for Virtue: The Potential and Limits of Corporate Social Responsibility, (Washington D.C.: Brookings Institution Press, 2006), at p. 158; see also, R.J. LIUBICIC, "Corporate Codes of Conduct and Product Labeling Schemes: The Limits and Possibilities of Promoting International Labor Rights Through Private Initiatives," Law and Policy International Business 30 (1998): 111, 116 (noting that "good public relations are vital to the bottom-line interests of companies with images to protect.").

735 R.J. LIUBICIC, "Corporate Codes of Conduct and Product Labeling Schemes: The Limits and Possibilities of Promoting International Labor Rights Through Private Initiatives," Law and Policy International Business 30 (1998): 111, 141 (showing examples such as tin, ingots, wood pulp, iron, resin, rubber, metals, palm oil, etc. as just some examples of products that do not derive value from brand image).

736 D. O’Rourke, “Outsourcing Regulation: Analyzing Nongovernmental Systems of Labor Standards and Monitoring," Policy Studies Journal 31(1) (2003): 10, 22 (noting that voluntary codes or monitoring regulations often fail to reach the informal-sector or home-based workers, where most of the developing country's workers are employed); see also, D. VOGEL, The Market for Virtue: The Potential and Limits of Corporate Social Responsibility, (Washington D.C.: Brookings Institution Press, 2006), at p. 89 (noting that "[a]n OECD survey of the garment industry estimates that two-thirds of the corporate and industry codes make no mention of monitoring systems" for its upstream subcontractors and suppliers). Take for example, the DRC's artisanal mines for cobalt discussed back in Chapter 1.1.2. While CSR initiatives like the Electronics Industry Code of Conduct, which standardizes, monitors, 
light of the fact that most entities in the global supply chain fall in this latter category, relying on extrinsic motivations may not lead to a significant decrease of labor exploitation in most parts of the global supply chain. Yet another reason why relying solely on extrinsic incentives may be insufficient is due to the fact that being socially responsible takes continuous effort and willpower, which are depletable resources.

\section{B. Ego Depletion: Being Socially Responsible Takes Continuous Effort}

For private actors to behave in a socially responsible manner or to operate in a way that minimizes their chances of exploiting laborers takes not just considerable amount of resources, but effort and willpower. If we were indeed perfectly rational, unbounded actors, the fact that it takes effort or willpower may not be prohibitive for us to keep being socially responsible at all times; but as this thesis has demonstrated time and time again, we are not always rational. In other words, being a good citizen, being a socially responsible company, or modifying one's behavior to be more ethical takes a surprising amount of discipline and will power that we may not possess: In what is known as "ego depletion," researchers have long known that resisting temptation takes considerable amount of awareness, effort, and energy. ${ }^{737}$ In our context, not buying a product or a supply manufactured by a certain company because of their ties to child laborer could be comparable to resisting the temptation to not smoking a cigarette when you are trying to quit. For better or for worse, “[w]illpower isn't just a skill. It's a muscle, like the muscles in your arms or legs, and it gets tired as it works harder, so there's less power left over for other things." 738 When stakeholders use up their willpower on other matters, (i.e. keeping the company afloat financially) it becomes more difficult for them to refrain from bad behaviors (i.e. failing to ensure that their suppliers are actually not exploiting their laborers), especially when they are not intrinsically motivated to being socially responsible, but only extrinsically motivated.

Behavioral economist, Richard Thaler notes that "[i]f you want to encourage someone to do something," you have to "make it easy,"739 and while measures like requiring companies to be more transparent and to produce more data could be argued as a step that makes it easier for investors to determine whether a company is truly socially responsible or not,

and audits labor practices of factories that make electronics for major brands such as Microsoft, Intel, and IBM have been around for well over a decade now, it has not had a noticeable impact. While increasing attention is being paid to the first-tier suppliers or manufacturers (i.e. Foxconn), progress has been slow with regards to lower in the supply chain.

737 N.L. Mead, R.F. Baumeister, F. Gino, M.E. Schweitzer \& D. Ariely, "Too Tired to Tell the Truth: SelfControl Resource Depletion and Dishonesty," Journal of Experimental Social Psychology 45(3) (2009): 594-597; see also, D. Ariely, The (Honest) Truth About Dishonesty: How We Lie to Everyone - Especially Ourselves, (New York: Harper Collins, 2012), at p. 100-1.

738 C. Duhigg, The Power of Habit: Why We Do What We Do in Life and Business, (New York: Random House, 2012), at p. 137 (quoting M. MURAVEN and citing to series of academic literature, including but not limited to: R.F. Baumeister, M. Muraven \& D.M. TiCe, "Self-Control as a Limited Resource: Regulatory Depletion Patterns," Psychological Bulletin 126 (1998): 247-59; R.F. BAumeister, M. Muraven \& D.M. TiCE, "Longitudinal Improvement of Self-Regulation Through Practice: Building Self-Control Strength Through Repeated Exercise," Journal of Social Psychology 139 (1999): 446-57; and, M.S. HAGGER ET AL., "Ego Depletion and the Strength Model of SelfControl: A Meta-Analysis," Psychological Bulletin 136 (2010): 495-25. There is a plethora of studies validating the veracity of this claim, the most famous of which is the cookie-radish experiment, but there are over "two hundred studies on this idea" all of which "found the same thing." See, C. DuHIGG, The Power of Habit: Why We Do What We Do in Life and Business, (New York: Random House, 2012), at p. 137.

739 R.H. THALER, Misbehaving: The Making of Behavioral Economics, (New York: Norton, 2015), at p. 337. 
there are theories that challenge this assumption: For example, there are some that argue measures that demand increased transparency and disclosure of more and more information like their ESG metrics lead to stakeholders making worse decisions. In the words of Omri Ben-Shahar, "disclosures compete with each other for people's time and attention... [they] can overburden the mind, both by offering too many options and by providing too much information about each option." ${ }^{440}$ In short, more information does not necessarily correlate with better outcomes, but it is entirely possible that it leads to even worse outcomes. ${ }^{741}$ This problem was earlier referred to as the choice overload problem and the manifestation of our bounded rationality and cognitive limitations. ${ }^{742}$ In the end, "all variants of voluntary effort - cognitive, emotional, or physical - draw at least partly on a shared pool of mental energy," 743 and requiring stakeholders to keep up with the ever changing dynamics of the law or various initiatives takes effort, awareness, and energy that many of us lack especially when they are being enforced only through extrinsic forces.

What can have a more significant impact on reducing instances of greenwashing or for companies to really commit to being socially responsible and maintaining their commitment even in light of ego depletion is for companies and other private actors to be more intrinsically motivated rather than being extrinsically incentivized. This is to suggest that the companies be socially responsible, not because it is profitable or because it gives them a competitive advantage, but because they truly want to be socially responsible for the sake of being socially responsible. Empirical data presented earlier in this chapter revealed that this is generally not the case today, with overwhelming majority of companies stating that their reason for enacting CSR measures is due to external or extrinsic pressures. ${ }^{744}$ If the private sector is to really tackle the problem of labor exploitation in the global supply chain in a different way and for them to overcome the incentives problem, the first step would be for private actors to focus less on extrinsic incentives and to start asking how companies can become intrinsically motivated by their Pollyannaish desire to do good. In short, this thesis will argue that harnessing the power of intrinsic motivation is the key to answering our question of what

740 O. Ben-Shahar \& C.E. SCHNEIDER, More Than You Wanted to Know: The Failure of Mandated Disclosure, (Princeton: Princeton University Press, 2014), at p. 95, 101.

741 R. CRASWELL, "Taking Information Seriously: Misrepresentation and Non-disclosure in Contract Law and Elsewhere," Virginia Law Review 92 (2006): 565, 584 (arguing that the availability of more information could "reduce the attention consumers pay to other information, conceivably leading to worse decisions.").

742 O. BEn-Shahar \& C.E. SCHNeIDER, More Than You Wanted to Know: The Failure of Mandated Disclosure, (Princeton: Princeton University Press, 2014), at p. 102 (noting that "[a]t the heart of the overload problem is the unpracticed mind's struggle to learn, remember, and use data.").

743 D. Kahneman, Thinking, Fast and Slow, (London: Penguin Book, 2013), at p. $41-3$ (citing to the work of Baumeister, noting that " $[\mathrm{w}] \mathrm{h}$ hen you are actively involved in difficult cognitive reasoning or engaged in a task that requires self-control, your blood glucose level drops.”).

744 R.J. LIUBICIC, "Corporate Codes of Conduct and Product Labeling Schemes: The Limits and Possibilities of Promoting International Labor Rights Through Private Initiatives," Law and Policy International Business 30 (1998): 111, 114 (noting that companies implement CSR initiatives due to "pressures from consumers, investors, the media, and non-governmental organizations" and the "fear of the effects of such pressure on profitability"); see also, H. Collins, "Conformity of Goods, the Network Society, and the Ethical Consumer," European Review of Private Law 5 (2014): 619-640, 626 (noting that "[t]he dominant motivation behind [codes of conduct] is presumably the concern that, if consumers believe that the processes by which the product was produced violate ethical standards, they may boycott a corporation's products in sufficient numbers to affect sales and profits"); D. VOGEL, The Market for Virtue: The Potential and Limits of Corporate Social Responsibility, (Washington D.C.: Brookings Institution Press, 2006), at p. 4 (noting that "precisely because CSR is voluntary and market-driven, companies will engage in CSR only to the extent that it makes business sense for them to do so... CSR only makes business sense if the costs of more virtuous behavior remain modest."). 
private actors can do differently to reduce instances of labor exploitation in the global supply chain. This realization leads us to two immediate follow up questions, which are 1) how can private actors go about harnessing intrinsic motivation, and 2) why most existing measures fail to achieve this goal. These questions will be addressed next.

\section{Intrinsic Motivation through Telos and Phronesis}

As hinted above, this thesis will ultimately argue that private actors finding intrinsic motivations to be socially responsible will be the key to addressing our labor exploitation problem, thus partially answering our research question of what private actors can do differently. While further details of how this could work will be tabled until Chapter 6, in order to validate our current point that there is an incentive problem with the existing company law/corporate governance approach, this part of the subsection will now touch upon what kinds of conditions are more conducive to fostering intrinsic motivation and how our existing measures are not necessarily focusing on creating intrinsic motivations. In short, we propose that the answer to creating or fostering intrinsic motivation lies in the Aristotelian concepts of telos and phronesis.

Let us start with some basic definitions: According to Aristotle's Nicomachean Ethics, telos is a sense of purpose or an end goal and phronesis is practical wisdom or collected intelligence. In terms of how these concepts relate to our general topic and the subject of intrinsic incentives, here is what this thesis will propose: In order to private actors to better address the problem of labor exploitation, being intrinsically motivated is crucial. In order for them to find or foster their intrinsic motivation, they must find their telos, or a sense of purpose (i.e. reducing labor exploitations or empowering workers). There are number of psychological and sociological studies that suggest having this sense of purpose is what leads to individuals accomplishing their goals. ${ }^{745}$ Concerning phronesis, Aristotle suggested that people simply obeying rules do not mean that they are exercising or gaining practical wisdom. ${ }^{746}$ That is to say that the solution to our collective action problems cannot be resolved through mere reliance on existing laws and rules, but we must continue to find practical ways of resolving our problems that is not just limited to the law or various CSR initiatives.

As we noted earlier, the current trend of how private actors are attempting to resolve the problem is through extrinsic incentives, creating more laws, and legalizing otherwise

745 M.E.P. Seligman, Flourish, (New York: Atria, 2011), at p. 12 (stating “[h]uman beings, ineluctably, want meaning and purpose in life."); and, C.P. NiEMIEC, R.M. RYAN \& E.L. DECI, "The Path Taken: Consequences of Attaining Intrinsic and Extrinsic Aspirations," Journal of Research in Personality 43 (2009): 291-306 (adding that purpose oriented people generally tend to do better than profit oriented people); see also, D.H. PINK, Drive: The Surprising Truth about What Motivates Us, (New York: Riverhead Books, 2009), at p. 145 (stating that " $\mathrm{t}$ ] he science shows that the secret to high performance isn't our biological drive or our reward-and-punishment drive, but... our deep-seated desire to direct our own lives, to extend and expand our abilities, and to make a contribution"); cf. N.D. KRISTOF \& S. WuDunN, Half the Sky: How to Change the World, (London: Virago Press, 2010), at p. 276 (stating that "[w]hile the main motivation for joining a global movement of this type to help others, the result is often to help oneself."). Point made by Kristoff and WuDunn is not necessarily to point out that we are all motivated by our selfish desires, but more to point out the fact that servings a greater purpose or fighting for a cause often brings positive benefits to the individual.

746 B. Schwartz \& K. Sharpe, Practical Wisdom: The Right Way to Do the Right Thing, (New York: Riverhead Books, 2010), at p. 5; see also, ARISTOTLE, Nicomachean Ethic, M. OSWALd (TRANS.) (New York: Library of Liberal Art, 1962), Book 4, Chapter 5 (1125b-1126a). 
voluntary CSR initiatives. According to the psychologist Barry Schwartz, this trend is not the way to generate telos, phronesis, intrinsic incentives, nor lasting solutions: In his own words, "[t]he rules and incentives that modern institutions rely on in pursuit of efficiency, accountability, profit, and good performance can't substitute for practical wisdom. Nor will they encourage it or nurture it. In fact, they often corrode it." 747 So our new framework that this thesis will propose in Chapter 6 to serve as an alternative to the existing measures and strategies will take these concepts and suggest various ways private actors can do things differently.

While it could be argued that companies already have a collective telos, which is to make profits and their phronesis is to do so by shareholder primacy, externalizing their liabilities, and focusing on economic or financial factors, this particular interpretation of telos and phronesis is not in alignment with how Aristotle conceptualized them, which was framed in the context of how one can live a virtuous life and to become an ethical being through telos and phronesis. This argument, however, relates back to our immediate concern of the incentive problem, and that is the point that as things stand, many companies are not intrinsically motivated to be socially responsible, because they lack the telos and phronesis as envisioned by Aristotle. Bear in mind that finding value in telos and phronesis is consistent with our normative framework, which places emphasis on empowerment of workers through discourse and learning.

In sum, the reason why private actors do what they do should be linked to their intrinsic motivations, but the law is not necessarily the best instrument to influence or stir people's intrinsic motivations. ${ }^{748}$ The incentive problem addressed here comes down to the fact that some companies, and other private sectors, lack the willpower or the intrinsic incentives to be socially responsible, as they may be cost-prohibitive or difficult to enforce. Although laws and legalized CSR initiatives do serve some aspirational or normative purposes that possibly affect or influence one's intrinsic motivations, they are generally extrinsic incentives, which does not contribute to fostering telos or phronesis. Moreover, many of the existing measures and initiatives discussed not only in this chapter, but also throughout this thesis fail at least in the context of our normative framework, not just because many of them fail to actually enhance the capabilities of the workers being exploited, but because they rely too heavily on extrinsic incentives. This is to suggest that creating more extrinsic incentives (i.e. laws or legalizing otherwise voluntary CSR initiatives) - or trying a different size stick or tastier carrots - as illustrated in various existing measures noted throughout the previous chapters, may not be the solution, but possibly the source of this incentive problem.

What this thesis will propose is for the workers and other private actors to find and harness their telos and to seek to gain phronesis, which increase the chances of creating, if not fostering, intrinsic motivation. After all, we must consider the possibility that "altruism, generosity, solidarity, civic duty, moral sentiments" and other intrinsic motivators are not

B. SCHWARTZ \& K. SHARPE, Practical Wisdom: The Right Way to Do the Right Thing, (New York: Riverhead Books, 2010), at p. 9-10 (adding that "tighter rules and regulations, however necessary, are pale substitutes for wisdom.”).

748 B.S. Frey, Not Just for the Money: An Economic Theory of Personal Motivation, (Vermont: Edward Elgar, 1997), at pp. 118-9 (stating that "[i]ntrinsic motivation is of great importance for all economic activities. It is inconceivable that people are motivated solely or even mainly by external incentives."). 
only "scarce resources that depletes with use," 749 but they can be crowded out by the presence of extrinsic incentives, which will be one of the issues discussed in the next subsection dealing with the causation problem.

\subsubsection{The Causation Problem}

One of the questions that this chapter posed time and time again with each of the existing CSR initiatives was whether the initiatives were actually reducing instances of labor exploitation and improving the working conditions of the marginalized workers, which is the focus of this thesis. The short answer is that more often than not, the answer was either inconclusive or not by much. One of the main reasons why this thesis found it difficult to claim any causal relationship between various CSR initiatives being implemented at one end of the supply chain and the reduction of labor exploitation at the other end, is due to the complexity of the global supply chain. In short, there are simply too many actors, variables, and factors involved in the global supply for one to be able to definitively state that a company attempting to be more socially responsible or governments enacting more laws are creating noticeable differences at the bottom echelons of the global supply chain. The only definitive statement that this thesis can make in this context is that labor exploitations continue to persist even with the presence of both government measures and private initiatives targeting to either reduce or eliminate labor exploitations. Above and beyond that, this part of the subsection will now attempt to suggest that: a) companies being socially responsible does not necessarily lead to better working conditions for the workers; b) legalizing CSR initiatives does not necessarily lead to higher compliance and better outcomes for the exploited workers; and c) laws, legalized CSR initiatives, and other extrinsic incentives can crowd out voluntary, intrinsic motivations that we noted previously, is the likely catalyst to bring forth a different type of private sector engagement.

\section{A. Being Socially Responsible $\neq$ Better Working Conditions for Workers}

While staunch advocates of CSR firmly believe that CSR initiatives empower all relevant stakeholders, ${ }^{750}$ any exuberance over CSR must be curbed to some degree. As this chapter noted on a few occasions, it is possible that the moment a company realizes that implementing CSR is not profitable, their incentive to continue implementing CSR initiatives

749 K.J. Arrow, "Gifts and Exchanges," Philosophy \& Public Affairs 1 (4) (1972): 343-62; cf. M.J. SANDEL, What Money Can't Buy: The Moral Limits of Markets, (London: Allen Lane, 2012), at p. 30 (stating that " $\mathrm{t}]$ hey are more like muscles that develop and grow stronger with exercise. One of the defects of a market-driven society is that it lets these virtues languish.”).

750 R.J. LIUBICIC, "Corporate Codes of Conduct and Product Labeling Schemes: The Limits and Possibilities of Promoting International Labor Rights Through Private Initiatives," Law and Policy International Business 30 (1998): 111,153 (suggesting that private initiatives may create an atmosphere conducive to unionization or reduce employee passivity); see also, S. ROBERTS, J. KEEBLE \& D. BROwn, "The Business Case for Corporate Citizenship," Arthur D. Little, Inc. (2002), at p. 8 (stating that "[c]ompanies that take corporate citizenship seriously can improve their reputations and their operational efficiency, while reducing their risk exposure and encouraging loyalty and innovation"); and, The UN Global Compact-Accenture CEO Study on Sustainability 2013: Architects of a Better World. Available at: https://www.unglobalcompact.org/docs/news_events/8.1/UNGC_Accenture_CEO_ Study_2013.pdf (last accessed 4 April 2017), at p. 13 (stating that at the heart of CSR "is a different approach moving beyond reactive, incremental responses to external pressures and toward a new understanding of sustainability as an opportunity for innovation, competitive advantage, differentiation and growth.”). 
could seriously diminish leading to greenwashing. ${ }^{751}$ Moreover, even for those companies that are intrinsically inspired to be socially responsible, it is difficult to determine whether the measures that they implement actually leads to the empowerment of workers and the reduction of labor exploitation at the other end of the supply chain. Take for example, the integrated reporting that was described in this Chapter. The fact that investors now have access to ESG metrics could serve as an extrinsic incentive for companies to clean up their acts, but what does this cleaning up act entail? If a company simply chooses to sever ties with suppliers or manufactures that have been accused of exploiting labor, do the workers that work at these facilities actually benefit from the company's decision to be socially responsible? The Introduction already touched upon arguments made by Krugman and other economist that investors simply divesting or companies severing ties with socially irresponsible suppliers or manufactures does not necessarily lead to the empowerment of workers, but instead, could end up reducing their autonomy, choice, and capabilities.

It is for this and various other reasons noted above in this thesis that many experts believe that CSR initiatives have clear limitations: The World Bank, for example, stated that it is entirely possible that CSR initiatives that require monitoring and auditing has "reached its limits, and may not be in a position to bring about further real and sustainable improvements in social and environmental workplace standards in developing countries." 752 Similarly, Richard Locke and his MIT research team concluded after reviewing more than 800 Nike subcontractors that CSR measures and their improvements "have hit a ceiling," and that any "improvements appear to be unstable in the sense that many factories cycle in and out of compliance over time." 753 Various other academics have voiced similar concerns stating that "CSR has much less impact on corporate reputation than 'bottom line issues such as increased sales and enhanced stock price" 754 or that "the role for both voluntary instruments and new legislation [are] rather limited." 755 So again, while it is difficult for us to reach definitive statements about how a company's CSR initiative leads to better working conditions for workers, it seems that there is plenty of skepticism within various circles, enough for private sectors to hit the pause button to question whether continuing to churn out various CSR initiatives really leads to the empowerment of the workers or to the reduction of labor exploitation.

This goes to show that even with our best intentions, with means and commitment to help those in need, there is no absolute guarantee that what we currently think will work, will actually work in reality. Therefore, at the very least, the causation problem leads us to

751 T. HARFord, Adapt: Why Success Always Starts with Failure, (London: Abacus, 2012), at p. 225 (arguing that even the most socially responsible companies need to make profits and quoting Whole Foods' CEO that "we can't fulfill [our] mission unless we are highly profitable.").

752 H.B. Jorgensen, P.M. PruZan-Jorgensen, M. Jungk \& A. Cramer, "Strengthening Implementation of Corporate Social Responsibility in Global Supply Chains," Corporate Social Responsibility Practice, (Washington D.C.: World Bank Group, 2003), at p. 20; as cited in, D. VoGEL, The Market for Virtue: The Potential and Limits of Corporate Social Responsibility, (Washington D.C.: Brookings Institution Press, 2006), at p. 91.

753 R.M. LOCKE, The Promise and Limitations of Private Power: Promoting Labor Standards in a Global Economy, (Cambridge: Cambridge University Press, 2013), at p. 174.

754 D. VogeL, The Market for Virtue: The Potential and Limits of Corporate Social Responsibility, (Washington D.C.: Brookings Institution Press, 2006), at p. 54 (quoting an excerpt from Ferry International Forbes CEO Forum).

755 A.L. VyTOPIL, Contractual Control in the Supply Chain: On Corporate Social Responsibility, Codes of Conduct, Contracts and (Avoiding) Liability, (The Hague: Eleven, 2015), at p. 284 (basing her conclusions on "insights from a number of CSR practitioners.”). 
accept that what is necessary to empower exploited workers and to increase their capabilities requires an understanding of the problem at a very local level, which means that companies cannot simply create CSR initiatives at one end of the supply chain in the hopes that it will somehow impact those in the other end of the supply chain in a positive way. They must actually put boots on the ground to see the impact of their actions, which is an approach that is in alignment with our outcome-oriented capabilities framework.

\section{B. Legalizing CSR Initiatives $\neq$ Higher Compliance and Better Outcomes}

Related to our first point about the uncertain causal relationship between various CSR initiatives and the empowerment of workers/reduction of labor exploitation, the causal effects of legalizing otherwise voluntary CSR initiatives or the impact of governments converting what used to be voluntary initiatives into mandatory regulation must also be questioned.

As this chapter noted in the beginning, various multi-stakeholder initiatives and CSR measures have traditionally been described as a "complex web of 'soft' law [that] has constructed new social norm[s]." 756 However, in order to add more teeth to this otherwise soft law instrument, governments have started to convert these soft, voluntary initiatives into hard regulations and legal or mandatory requirements. ${ }^{757}$ Their assumption is that by converting CSR initiatives into legal regulations or by adding the force of law to otherwise voluntary initiatives (i.e. by combining the voluntary initiative to incorporate as a benefit corporation with various legal obligations that come with it), companies will be more socially responsible. While this may in fact be the case in some instances, as this section already showed, there are two problems with this assumption: First, is what we already noted above, which is that companies making socially responsible decisions (i.e. severing ties with suppliers that exploited workers) does not necessarily lead to the empowerment of the workers and thus fails to meet our normative framework. Second, just because a voluntary initiative has been legalized or has the force of law by being paired with company law, does not mean that the companies will be more socially responsible or that their actions will reduce instances of labor exploitation at the other end of the global supply chain. Recall for a moment the lessons we extrapolated in reviewing the labor/employment law approach back in Chapter 2. Just because laws exist to prevent private actors behaving in a particular manner does not guarantee compliance; but moreover, Chapter 2 also cautioned against over-legalization in the context of the Inverted-U curve. If governments or private actors simply decide to legalize otherwise voluntary CSR initiatives, this thesis argues that there could be repercussions and unintended consequences that could potentially outweigh the benefits that such actions bring about.

D. VogeL, The Market for Virtue: The Potential and Limits of Corporate Social Responsibility, (Washington D.C.: Brookings Institution Press, 2006), at p. 162.

757 E.A. Duruigbo, Multinational Corporations and International Law: Accountability and Compliance Issues in the Petroleum Industry, (Leiden: Martinus Nijhoff, 2003), at p. 156 (calling for a strong regulatory mechanism and arguing that legalizing voluntary CSR initiatives could make them more "legitimate"); see also, D. VOGEL, The Market for Virtue: The Potential and Limits of Corporate Social Responsibility, (Washington D.C.: Brookings Institution Press, 2006), at p. 163 (calling CSR as a "second-best alternative" and pointing out that voluntary CSR measures are useful to the extent that when governments fail to protect their own people, then voluntary corporate initiatives are "better than nothing."). 
For example, recall our earlier discussion about the shadow economy. One of the reasons why these shadow economies continue to persist, where many employees are exploited and do not receive the social protection guaranteed to them by law, is to dodge taxes. ${ }^{758}$ As noted in the Introduction, this thesis will not discuss tax law in any detail, but just to make our current point, we must acknowledge the role of taxation in contributing to the shadow economy and the labor exploitation that takes place within it: In short, if the government intervenes too much in the affairs of private actors by demanding higher and higher level of social protection for the workers or move to increase taxation on companies or businesses, the unintended consequence of such an intervention could be the exacerbation of the labor exploitation problem. The unintended consequence of too much regulation or the continuance of legalizing otherwise voluntary CSR initiatives, therefore could be the increase of labor exploitation in the global supply chain. To use the shadow economy example once again, at a more macroeconomic level, exploited workers that operate in the shadow economy generally do not pay any taxes, which negatively impacts the governments' budget, which could "prompt higher taxes to make up for lost revenue, which in turn tempts more people into the black economy," and so goes the vicious cycle. ${ }^{759}$

In sum, while it is possible that governments converting voluntary initiatives into mandatory regulations or private actors legalizing CSR initiatives could have potential benefits, both governments and private actors should reconsider this approach, given the possibly that such actions could cause negative, unintended consequences. The reality of the global supply chain and the pockets of shadow economies that exist within it, are too complex to be directed in one way or the other with mere carrots and sticks. The next part of the subsection will elaborate on one specific unintended consequence of legalizing otherwise voluntary CSR initiatives, which is the crowding out effect.

\section{Laws can Crowd Out Voluntary Incentives and Much More}

The previous point suggested that governments converting voluntary private initiatives into mandatory regulation or private actors pairing company law with CSR initiatives to harden the otherwise soft law measures could potentially be detrimental to the exploited laborers. This part of the subsection will now attempt to link this observation with the possibility that the existence or emergence of laws and legalized CSR norms could crowd out the existing voluntary CSR initiatives or prevent new voluntary norms from emerging. Traditionally, the relationship between private initiatives and government intervention was the other way around. Companies often believed that creating private initiatives served as "disincentives for developing nations to enact stronger labor laws or prove enforcement of current standards." 760 In other words, the presence of private initiatives was often seen as

758 V. Mallet \& G. Dinmore, "Europe: Hidden Economy," Financial Times, (8 June 2011). Available at: http://www.ft.com/intl/cms/s/0/efc3510e-9214-11e0-9e00-00144feab49a.html\#axzz2vI729dEv (last accessed 4 April 2017) (quoting Pietro Reichlin stating that "[a]mong the main causes of the black economy is the level of taxation. The higher the tax and the regulatory burden the bigger the shadow economy of the country.").

759 V. Mallet \& G. Dinmore, "Europe: Hidden Economy," Financial Times, (8 June 2011). Available at: http://www.ft.com/intl/cms/s/0/efc3510e-9214-11e0-9e00-00144feab49a.html\#axzz2vI729dEv (last accessed 4 April 2017).

760 R.J. LIUBICIC, "Corporate Codes of Conduct and Product Labeling Schemes: The Limits and Possibilities of Promoting International Labor Rights Through Private Initiatives,” Law and Policy International Business 30 (1998): 111,157 (noting that "history appears to support a trend of societal concern about a problem caused in part by 
something that crowded out or kept out government measures and prevented them from creating mandatory laws. ${ }^{761}$ Thus, CSR initiatives were often seen as a way for businesses to pre-empt or prevent governments from enacting laws that would regulate their behaviors, thus the popularization of the analogy of a fox guarding the hen house. Be that as it may, many MNCs were already voluntarily implementing CSR initiatives like offering integrated reports to their investors, even prior to the emergence of EU Directives and transparency regulations that now mandate many companies to do so. ${ }^{762}$

The emergence of new transparency regulations and the codification of previously voluntary initiatives, however, is changing the traditional dynamic between laws and voluntary initiatives in terms of what is crowding out the other: In light of this trend towards legalization, it could be argued that the existence of too much regulation and hard laws are now crowding out otherwise softer, voluntary initiatives. Again, while some do not see any problem with this, arguing that if everyone is required to be more socially responsible, everything will be better, this assumption is entirely too optimistic, if not unrealistic. In short, "[t]he fact that a company has voluntarily adopted a particular social or environmental practice does not mean that public welfare would be enhanced if all other companies were required to do the same." 763

For example, not only does requiring private actors to be more and more socially responsible lead to the reduction or elimination of market differentiation for companies attempting to be socially responsible voluntarily, but linking this concern to the aforementioned issue of incentives, this trend could lead to the problem of extrinsic incentives crowding out intrinsic motivations. This is to suggest that "extrinsic prompts deprive the individual of that chance to exhibit her intrinsic motivations to others, which, in turn, undermines the value to the individual of having intrinsic motives." 764 As one author noted, the risk of extrinsic incentives crowding out intrinsic motivations is the following:

"Say you take people who are motivated to behave nicely, then give them a fairly weak set of ethical standards to meet. Now, instead of asking them to 'do it because it's the right thing to do,' you've essentially given them an alternate set of standards - do this so you can check off all these boxes. $" 765$

capital, capital self-regulation in order to pre-empt the creation of legal solutions, the failure of self-regulation, and the eventual enactment of public regulation"; citing, L. COMPA \& T. HINCHLIFFE-FARRICARRÈRE, "Enforcing International Labor Rights Through Corporate Codes of Conduct," Columbia Journal of Transnational Law 33 (1995): $663,687$.

761 R.J. LIUBICIC, "Corporate Codes of Conduct and Product Labeling Schemes: The Limits and Possibilities of Promoting International Labor Rights Through Private Initiatives," Law and Policy International Business 30 (1998): $111,149$.

762 D. VOGEL, The Market for Virtue: The Potential and Limits of Corporate Social Responsibility, (Washington D.C.: Brookings Institution Press, 2006), at p. 168 (stating that " $t$ t] he effectiveness of this effort to make soft law 'hard' remains to be seen...”).

763 D. VogeL, The Market for Virtue: The Potential and Limits of Corporate Social Responsibility, (Washington D.C.: Brookings Institution Press, 2006), at p. 169.

764 E.H. ATIQ, "Why Motives Matter: Reframing the Crowding Out Effect of Legal Incentives," Yale Law Journal 123 (2014): 1070-1116, 1081; see also, B.S. FrEY, "Crowding Out and Crowding In of Intrinsic Preference," in Reflexive Governance for Global Public Goods, E. Brousseau, T. DEDEURWAERdere \& B. SiebenhunTER (EDS.) (Cambridge: MIT Press, 2012), at pp. 75, 78.

765 D.H. PINK, Drive: The Surprising Truth about What Motivates Us, (New York: Riverhead Books, 2009), at 70 (citing to M.H. BAZERman, "Evaluating Your Business Ethics: A Harvard Professor Explains Why Good People Do 
Similar to how laws can crowd out private initiatives, extrinsic incentives can crowd out intrinsic ones. In the interest of full disclosure, the crowding out effect may not always take place; as a matter of fact, it is entirely possible that extrinsic incentives will not have any effect on some company's intrinsic incentives. However, the point that this part of the subsection is attempting to make, is not to substantiate the validity of the crowding out effect at all times, but merely to acknowledge it as a possibility and for private actors to reconsider its implications.

Bearing this point in mind, the key take aways from this section is threefold: First, various company law-based CSR initiatives run into similar problems that limit the impact of governments and their regulations like the enforcement problem. In addition, this section also suggested that even if the companies could overcome the enforcement problem, companies attempting to be socially responsible do not necessarily lead to the empowerment of exploited laborers or to the reduction in labor exploitation in accordance with our normative framework. Second, this section raised the problem of greenwashing, given that the cost of adopting and implementing CSR initiatives may be cost-prohibitive for some companies. This was part of the reason why this thesis stressed the importance of intrinsic motivations vis-à-vis extrinsic incentives, and to call upon private actors to reassess their current approach to dealing with the problem of labor exploitation, by focusing more on fostering and harnessing their intrinsic motivations. However, this section also observed that the current trend is going the other way, where stakeholders are relying more and more on extrinsic incentives, as evidenced by government codifications of previously voluntary CSR initiatives and private actors binding CSR initiatives with private law in their attempts to harden the otherwise softer approach that is CSR. Third, this section noted that one of the main problems with the emerging legalization trend is the potential crowding out effect that it has on voluntary initiatives and intrinsic motivations for companies to want to do good and to be socially responsible in a way that could actually increase the workers' capabilities.

In the end, what contributes to all of these problems is the reality that the problem of labor exploitation in the global supply chain is such a complicated problem that given our bounded rationality and cognitive limitations, it is extremely difficult - if not almost impossible - to accurately predict how private initiatives on one end of the supply chain will affect the conditions of workers at the polar opposite end of the chain ex ante. This issue of how our cognitive limitations and the complexity of the problem that we face will be further elaborated in the next chapter, but the next section will first offer some preliminary conclusions with regards to the existing company law/corporate governance approach.

Unethical Things," Gallup Management Journal, (12 June 2008); see also, B. HorowiTZ, The Hard Thing About Hard Things: Building a Business When There Are No Easy Answers, (New York: Harper Collins, 2014), at p. 132 (stating that "[a]t a basic level, metrics are incentives. By measuring quality, features and prioritizing them could make people too focused on those metrics "to the exclusion of other goals."). 


\subsection{CONCLUSION: PLENTY OF PROBLEMS WITH THE COMPANY LAW APPROACH}

In our continuing quest to answer our research question of what private actors can do differently to reduce instances of labor exploitation in the global supply chain, this chapter presented what companies are currently doing to address this problem through various company law/corporate governance measures that fall under the CSR umbrella. Section 4.1 explained at the onset what this CSR umbrella is and why companies choose to adopt and implement these voluntary initiatives that attempt to make their operations more socially responsible, even if it means incurring additional costs and liabilities. Section 4.2 followed up by presenting various CSR initiatives like: 1) how companies restructuring their corporate governance models to be more inclusive or enlightened, 2) how some companies are incorporating as benefit corporations thus voluntarily holding themselves to be more accountable with potential legal ramifications, and 3) how companies are attempting to be more transparent by offering investors ESG metrics or by listing on stock exchanges that require integrated reports. With regards to the integrated reports and ESG metrics, this section also discussed how investors, through socially responsible investing and divesting from socially irresponsible companies, can incentivize companies to behave in a more socially responsible manner. These sections showed the potential of various CSR initiatives and how it could potentially lead to the empowerment of workers by enhancing their capabilities. We noted in particular how the stakeholder model of corporate governance could be a successful initiative that would perfectly align with our normative framework, as it would incentivize companies to listen to their workers, enhance the workers' capabilities by allowing them to be a part of the companies' decision-making process, thus allowing workers to learn and contribute to their own personal autonomy.

While there were some promising aspects to what companies are currently doing through various CSR initiatives, Section 4.3 also presented some problems and limitations with the existing ways companies are attempting to be socially responsible. In doing so, this section listed and elaborated on the 1) enforcement problem, 2) the incentive problem, and 3) the causation problem. Broadly speaking, this section revealed that companies routinely fail to live up to their CSR goals for the reason that companies are cost conscious and cannot deplete all of their limited resources to ensuring their social responsibility. Part of the reason why this is the case, is just like governments that rely on GDP to measure the wealth of nations, private actors rely on increasing profits and decreasing costs as measures of success: For example, businesses - regardless of which corporate governance model they implement - need to make profits in order to continue operating and investors, regardless of how socially responsible they are, still need a return on their investment. ${ }^{766}$ What makes the enforcement problem with private initiatives even more difficult than the enforcement of government measures is the fact that as voluntary initiatives, private actors can design a system where compliance is not always necessary and or lack thereof, even

766 T. HARFORD, Adapt: Why Success Always Starts with Failure, (London: Abacus, 2012), at p. 83 (noting that people invest money "in the hope of payoffs later" or in terms of "a return on our investment," but this idea of ROI, "is simply not a useful way of thinking about new ideas and new technologies.”). 
tolerated. ${ }^{767}$ This means that while CSR initiatives are indeed less intrusive to the company's autonomy relative to governmental regulations, the very fact that they are voluntary makes it easier for companies to abandon CSR initiatives or weasel out of their commitments absent some binding force.

In light of this perceived weakness, governments are starting to codify what once used to be purely voluntary initiatives into mandatory regulations, as evidenced by instruments like the EU Directive on Disclosure of Non-Financial and Diversity Information and the California Transparency in Supply Chains Act. In addition, private actors are also legalizing their voluntary CSR initiatives by pairing them with various company law based measures, like incorporating as benefit corporations, which legally commits the companies to being more accountable. While there are some benefits that can come from this legalization and codification process, Section 4.3 also noted the importance of intrinsic incentives and how creating and fostering them could be the key to what private actors can do differently to further reduce instances of labor exploitation in the global supply chain. The legalization and codification trend not only runs counter to this goal, but there is an even larger concern that the overabundance of these extrinsic incentives could cause the intrinsic motivations to crowd out.

With regards to the concern of the crowding out effect, it is important to recall that extrinsic incentives, like monetary incentives or fear of legal sanctions, can undermine intrinsic ones. This could manifest problems in several different ways in our context. For example, companies focused on the profit making incentive of CSR will likely lose their intrinsic motivation, ${ }^{768}$ but moreover, if the reason for why companies act in a socially responsible manner is because that is what the law requires them to do, this is an entirely different motivation compared to companies that intrinsically want to be socially responsible for the sake of being good. Here in lies the fundamental paradox when it comes to CSR initiatives: Given that CSR is voluntary, companies need incentives in order to implement them. However, given that businesses need profits in order to continue existing, any measure that they implement must not be cost-prohibitive. In other words, prior to companies implementing any CSR initiatives, they must conduct a cost-benefit analysis and the likely financial impact of that initiative. The problem with this is that once companies start thinking about profits and costs, all of which are extrinsic motivators, there is a risk that their intrinsic motivation (to be socially responsible) could be crowded out; and if the reason for why companies are being socially responsible is due to extrinsic motivations, then the likelihood of compliance and enforcement being stringent or effective significantly decreases. This paradox is part of the reason why CSR and self-regulation has been characterized as the fox guarding the hen house and while it may lead to the empowerment of workers in some limited instances, the process as a whole does not actually seem to be capabilitiesenhancing.

N. KLEIN, No Logo, (New York: Picador, 2002), at p. 437 (referring to CSR as a "less threatening alternative to externally imposed regulation.").

768 M.J. SANDEL, What Money Can't Buy: The Moral Limits of Markets, (London: Allen Lane, 2012), at p. 61, 64. (citing to the Israeli Day Care study and stating that "economists often assume that markets do not touch or taint the goods they regulate. But this is untrue. Markets leave their mark on social norms. Often, market incentives erode or crowd out nonmarket incentives."). 
Last but not least, the causation problem led us to conclude that there is no guarantee that a company's socially responsible practices actually result in the empowerment of workers at the other end of the supply chain. While stakeholder involvement could address problem locally, the question of how much impact companies behaving in a socially responsible manner by releasing integrated reports for example, can have on exploited laborers on the other side of the world, remains inconclusive. Similarly, just because investors have more information in part to integrated reports does not mean that they will use that information in a manner that will benefit the exploited laborers at the other end of the supply chain. ${ }^{769}$ The example that this chapter provided was the example of a company severing ties with one of its supplier that has been accused of exploiting their laborers abroad. While severing ties with the supplier may increase the reputation of the company as a business that refuses to do business suppliers exploit laborers, simply severing ties with them does not necessarily mean that the working conditions of the supplier's laborers will improve. In other words, private actors must reassess whether their various CSR initiatives that companies are implementing are actually making a difference in the lives of the exploited laborers, or if they are simply claiming to be socially responsible for the sake of profitability, market differentiation, or just to quiet the external pressures. ${ }^{770}$

In conclusion, while the existing company law-based CSR initiatives have some potential, there are lingering concerns about their effectiveness and whether the continuation of these CSR initiatives and the governments continuing efforts to codify them will actually lead to the reduction of labor exploitation in the global supply chain. ${ }^{771}$ In terms of what private actors can do differently in this context, they can start by applying pressure on their governments to reassess their efforts to codify various voluntary measures and perhaps request governments to be more strategic about adopting and implementing CSR initiatives into laws, ${ }^{772}$ which as extrinsic incentives could crowd out the intrinsic motivations of the private actors. In terms of what the private actors themselves can do is to reassess their claims about being socially responsible and what impact their operation is really having on the workers on the other side of the world, at the lower echelons of the global supply chain. Doing so is not necessarily an easy task, and one that is made even more difficult by our bounded rationality and cognitive limitations, which make it very difficult to grasp all of the unintended consequences of our actions.

769 See e.g., D. Ariely, The (Honest) Truth About Dishonesty: How We Lie to Everyone - Especially Ourselves, (New York: Harper Collins, 2012), at p. 93; see also, D.M. CAIN, G. LOEWEnSTEIN \& D.A. MoORE, "The Dirt on Coming Clean: The Perverse Effects of Disclosing Conflicts of Interest," Journal of Legal Studies 34 (2005): 1-25 (noting that disclosure does not always lead to beneficial outcomes).

770 T.H. MORAn, Beyond Sweatshops: Foreign Direct Investment and Globalization in the Developing World, (Virginia: R. R. Donnelley and Sons, 2002), at p. 90 (noting that getting it "right" is indeed difficult task).

771 A.L. VyTOPIL, Contractual Control in the Supply Chain: On Corporate Social Responsibility, Codes of Conduct, Contracts and (Avoiding) Liability, (The Hague: Eleven, 2015), at p. 284 (noting that "perhaps the law, as it currently stands does not have all that much to offer when it comes to bringing about long-term improvement for CSR in supply chains.").

772 E.H. ATIQ, "Why Motives Matter: Reframing the Crowding Out Effect of Legal Incentives," Yale Law Journal 123 (2014): 1070-1116, 1072; see also, S.D. MuRPHY, "Taking Multinational Corporate Codes of Conduct to the Next Level," Columbia Journal of Transnational Law 43(2) (2005), at p. 55 (commenting on the need for a "synergy between government regulation and... self-regulation.”). 


\title{
Chapter
}

\section{Contract/Consumer Law Perspective}

\begin{abstract}
"If people could see that change comes about as a result of millions of tiny acts that seem totally insignificant, well then they wouldn't hesitate to take those tiny acts."
\end{abstract}

\section{Howard Zinn}

This thesis now moves on to offer an analysis of what private actors are doing with contract/consumer law-based measures in their attempts to reduce labor exploitation in the global supply chain. By presenting the existing approach, the aim of this chapter is to continue reassessing what the private actors are currently doing and what they can do differently to better address the problem of labor exploitation in a manner that conforms to our adapted capabilities normative framework. This chapter will continue to focus mainly on what companies are doing - as one of the more powerful and influential group of private actors - but rather than looking at how investors or shareholders can influence their behaviors, this chapter will now look to how consumers can affect corporate behavior in a way that would lead to the empowerment of the exploited laborers. Accordingly, many of the instruments covered in this chapter will also fall under the CSR umbrella, where companies choose to go above and beyond what they are required to do by labor/employment laws, by contractually binding themselves to a higher standard, thus making them more accountable for their actions.

Bearing these points in mind, this chapter will have the following composition: The first section will elaborate on the interplay between CSR and ethical consumerism and how the combination thereof affects the various contract/consumer law-based measures that will be discussed in this chapter (Section 5.1). This discussion will be followed by a presentation of various contract/consumer law-based measures that private actors are currently relying on to reduce labor exploitation (Section 5.2), followed by the various problems and limitations associated with these measures (Section 5.3). The final section of this chapter will draw preliminary conclusions about the impact that the contract/consumer law-based 
measures are having on reducing labor exploitations in the global supply chain and what lessons can be learned from them (Section 5.4).

\subsection{ETHICAL CONSUMERISM AND CSR}

Before diving into the analysis of various contract/consumer law-based measures, the first section of this chapter will discuss the interplay between CSR, which was already introduced in the previous chapter, and the concept of ethical consumerism. In order to do so, this section will first define ethical consumerism along with mentioning various concerns related to consumerism and capitalism more broadly (Subsection 5.1.1). This will be followed by our initial discussion about how contract law - in the context of CSR umbrella can go about restoring a sense of justice back into our consumption habits (Subsection 5.1.2).

\subsubsection{What is Ethical Consumerism}

Similar to CSR, ethical consumerism or consumption is not "a clearly defined set of practices, but is rather a convenient catch-all phrase for a range of tendencies within contemporary consumer culture today." 773 While the parameters of what actions amount to ethical consumption is rather vague, ${ }^{774}$ the general consensus is that consumer choices that display some element of "care, solidarity and collective concern" for the purposes of this thesis will be considered as choices that fit under the ethical consumerism umbrella. ${ }^{775}$ In recent times, the popularity of ethical consumerism has been on the rise, similar to the emergence of CSR. ${ }^{776}$ To the extent that the aim of these two ideas is to make companies and consumers more accountable and more socially responsible, putting these ideas into practice should lead, at least in theory, to a more socially responsible supply chain and a corresponding decrease in the instance of labor exploitation. In reality, however, even with the proliferation of various CSR measures and ethical consumer practices, labor exploitation remains within the global supply chain. Thus, one of the main goals of this chapter will be to determine why this is indeed the case.

A possible explanation to the persistence of labor exploitation can be attributed to the general trend that we see of over-consumption and the growing consumer demand, which is putting more pressure on companies to produce more goods cheaper and faster, which

773 T. LEWIS \& E. POTTER, "Introducing Ethical Consumption," in Ethical Consumption: A Critical Introduction, T. LEWIS \& E. POTTER (EDS.) (New York: Routledge, 2011), at p. 4 (using examples of buying Fair Trade chocolate, minimizing consumption of energy and water to save the planet, or recycling or swapping goods with other consumers as a way to reduce overall consumption all as manifestations of ethical consumption).

774 T. LEWIS \& E. POTTER, "Introducing Ethical Consumption," in Ethical Consumption: A Critical Introduction, T. LEWIS \& E. POTTER (EDS.) (New York: Routledge, 2011), at p. 5 (noting that " $[\mathrm{t}]$ he diversity and breadth of popular manifestations of concerns about contemporary materialism and overconsumption points to the limitations of definitional approaches to ethical consumption...").

775 C. Barnett, N. Clarke, P. Cloke \& A. Malpass, “The Political Ethics of Consumerism," Consumer Policy Review 15(2) (2005): 45-51, 45.

776 T. LEWIS \& E. POTTER, "Introducing Ethical Consumption," in Ethical Consumption: A Critical Introduction, T. LEWIS \& E. POTTER (EDS.) (New York: Routledge, 2011), at p. 4. 
as we noted before, creates situations rife for labor exploitation. What this suggests is that while companies are the group of private actors often accused of perpetuating labor exploitations in the global supply chain, ${ }^{777}$ it must be noted that the increasing demand created by the consumers is at least partially contributing to the labor exploitations taking place in our supply chain. Tony Judt stated the following in his opus, Ill Fares the Land on this matter:

"Something is profoundly wrong with the way we live today. For thirty years we have made a virtue out of the pursuit of material self-interest: indeed, this very pursuit now constitutes whatever remains of our sense of collective purpose. We know what things cost but have no idea what they are worth. We no longer ask of a judicial ruling or a legislative act: Is it good? Is it fair? Is it just? Is it right? Will it help bring about a better society or a better world? Those used to be the political questions, even if they invited no easy answers. We must learn once again to pose them.",778

What is implied in Judd's observation is that people in general, and not just as consumers or businesses, are contributing to the labor exploitation problem, but at a more fundamental level, private actors as a whole have often been failing to even ask questions about how our actions are impacting the societies in which we reside. Keeping this point in mind, this subsection will a) discuss how consumerism and capitalism in the age of proliferation is contributing to the labor exploitation problem, and b) discuss why private actors can benefit from reassessing their current ways of consumption.

\section{A. Consumerism and Capitalism in the Age of Proliferation}

We are now living in what journalist Moisés Naím refers to as the age of proliferation: "There is simply more of everything now. There are more people, countries, cities, political parties, armies; more goods and services, and more companies selling them; more weapons and more medicines, more students and more computers, more preachers and more criminals." 779 It is this availability of things and the increase in our options that is not only titillating our instinct of acquisition, but what is leading to a number of collective action problems that we as a society face today, including but not limited to the labor exploitation problem. This "materialistic and selfish quality of contemporary life," which has often been blamed on the increasingly growth of unadulterated capitalism, to quote Tony Judt once again, "is not inherent in the human condition... [and] we cannot go on living like this." 780 Before getting to how ethical consumerism and CSR initiatives can potentially facilitate private actors to change this paradigm, thus reduce labor exploitation in the global supply

777 R. Anderson, Confessions of a Radical Industrialist, (New York: Random House Business Books, 2011), at p. 143 (noting that "[i]f our collective passion for too much stuff is at the root of the problem in achieving true sustainability, Wal-Mart is likely where much of that stuff comes from.").

778 T. JUDT, Ill Fares the Land, (New York: Penguin, 2010), at p. 21 (stating how the "inequality" exacerbated by capitalism, consumerism and indifference is "corrosive," which "rots societies from within"; see also, R. WILKINSON \& K. PICKETT, The Spirit Level: Why Equality Is Better for Everyone (London: Penguin Books, 2010).

779 M. NAím, The End of Power: From Boardrooms to Battlefields and Churches to States, Why Being in Charge Isn't What It Used to Be, (New York: Basic Books, 2013), at p. 54.

780 T. JuDT, Ill Fares the Land, (New York: Penguin, 2010), at p. 2 (adding that "[m]uch of what appears 'natural' today dates from the 1980s: the obsession with wealth creation, the cult of privatization and the private sector, the growing disparities of rich and poor. And above all, the rhetoric that accompanies these: uncritical admiration for unfettered markets, disdain for the public sector, and the delusion of endless growth.").; see also, B. SCHWARTZ, The Paradox of Choice: Why More is Less, (New York: Harper, 2004), at p. 22 (addressing the concern that the point of revulsion where consumers have simply accumulated too much stuff "seems to recede endlessly into the future."). 
chain, let us first observe how consumerism and capitalism in the age of proliferation is actually contributing to the problem of labor exploitation in more detail.

Let us start with some facts and figures first. In this age of proliferation, Americans "now spend 71 percent of [their] \$15 trillion economy on consumer goods," a list that includes vital items such as shoes and mobile phones. ${ }^{781}$ With the emergence of the World Wide Web, digital consumerism around the globe has also skyrocketed: For example, "[t]en years ago, consumers spent $\$ 50$ billion online, nearly double what they had spent four years earlier. By 2012, online sales had topped $\$ 200$ billion, and they continue to double every four years. Although they are still only a fraction of total retail sales ( $\$ 4.4$ trillion), the trend is clear." 782 In order to support or finance our increasing consumption habits, people generally tend to work more hours than they did in the past: For example, the US Labor Department statistics indicate that workers, on average, are working at least 160 hours longer per year than they were only a few decades ago. ${ }^{783}$

This trend of people working more and for longer can be evidenced even in Europe with handful of governments increasing the age of retirement in recent years. ${ }^{784}$ While some economists might praise this increased productivity, what comes as a result of this increased workload is "a tremendous erosion of the nuclear family - a doubling of the divorce rate, a drop in parents' time available to children, and an increase in mobility." 785 Bear in mind that these events are taking place in the so-called developed economies; but now imagine what the impact of the age of proliferation has on the developing economies, where labor exploitation is already taking place at a higher frequency. To provide just a glimpse of what the age of proliferation is having on workers in the developing economies, consider the following:

"To produce goods at the lowest prices, we are willing to lay off thousands of workers and transfer their workplaces from country to country in search of cheap labor. We shatter the dreams of those

781 J. DE GraAf, D. WANN \& T.H. NAYlor, Affluen₹a: How Overconsumption is Killing Us - And How We Can Fight Back [Third Edition], (San Francisco: Berrett-Koehler Publishers, 2014), at p. 15 (observing anecdotally that Europe is "far more relaxed, less consumptive attitude toward life in contrast to that of the United States"); citing, US Census Bureau, Statistical Abstract of the United States: 2004-2005 (Washington D.C.: US Census Bureau, 2004), at p. 431. Available at: http://www.census.gov/prod/2004pubs/04statan/income.pdf (last accessed 26 March 2015).

782 J. DE GraAf, D. WANN \& T.H. NAYLOR, Affluenza: How Overconsumption is Killing Us - And How We Can Fight Back [Third Edition], (San Francisco: Berrett-Koehler Publishers, 2014), at p. 18; Balboa Capital, "E-Commerce Sales Top $\$ 50$ Billion in First Quarter," (30 May 2012). Available at: http://balboacapital.com/e-commerce-sales-top-50billion-in-first-quarter (last accessed 26 March 2015).

783 J. DE GRAAF, D. WANN \& T.H. NAYLOR, Affluenza: How Overconsumption is Killing Us - And How We Can Fight Back [Third Edition], (San Francisco: Berrett-Koehler Publishers, 2014), at p. 38, 41 (quoting economist Juliet Schor and contrasting the American "work ethic" to that of Europeans who "work nearly nine weeks less per year"); see also, J.B. SCHOR, Born to Buy: The Commercialized Child and the New Consumer Culture, (New York: Simon \& Schuster, 2004).

784 The Dutch, for example, is increasing the age of retirement (the age when they will be entitled to receive the state pensions AOW [algemene ouderdomswet]) from 65 to 66 by the year 2019, and up to 67 by the year 2023 .

785 D. Goleman, Emotional Intelligence, (New York: Bantam Books, 2005), at p. 241 (quoting Frederick Goodwin, the director of National Institute of Mental Health adding that “[y]ou don't grow up knowing your extended family much anymore. The losses of these stable sources of self identification mean a greater susceptibility to depression."). 


\section{workers who are discarded, and often shatter their families as well. The security of whole communi- ties is considered expendable. Lives are disrupted without a second though."}

This is all to suggest that the age of proliferation and our instinct of acquisition are having a dividing impact not just between developed economies and developing economies, but within our societies and within our families as well. Moreover, the age of proliferation has created what sociologist refers to as the "hourglass effect," 787 where societies are increasingly becoming polarized into those that have and those that do not. ${ }^{788}$ The hourglass effect is not only marked by the disappearance of the middle class, but by increasing inequality within our societies, ${ }^{789}$ to the extent that the so-called "one percenters" are no longer subject to the same laws and regulations as that of the other ninety-nine percent. ${ }^{790}$

The polarizing effect of the hourglass effect can be seen not only with regards to our societies, but with regards to the types of commodities available to the consumers, where consumer goods are marked by increased number of goods at the opposite ends of the price spectrum: that is to say that there are more extremely expensive goods and more extremely cheap goods being made in the market today. ${ }^{791}$ What these observations suggest

786 J. DE GraAf, D. WANn \& T.H. NAYLOR, Affluenza: How Overconsumption is Killing Us - And How We Can Fight Back Third Edition], (San Francisco: Berrett-Koehler Publishers, 2014), at p. 45.

787 Meaning that the society is split between an upper class and a lower class, with the middle class moving to one side or the other; see e.g., A. LEONARD, "The Hourglass Economy," Salon, (13 September 2011). Available at: http://www.salon.com/2011/09/13/the_hourglass_economy/ (last accessed 4 April 2017).

788 T. JudT, Ill Fares the Land, (New York: Penguin, 2010), at p. 14 (noting that "[i]n 2005, 21.2 percent of US national income accrued to just 1 percent of earners... [and t]oday, the CEO of Wal-Mart earns nine hundred times the wages of his average employee"); see also, J. DE GRAAF, D. WANN \& T.H. NAYLOR, Affluenza: How Overconsumption is Killing Us - And How We Can Fight Back /Third Edition], (San Francisco: Berrett-Koehler Publishers, 2014), at p. 71-2 (noting that the "[a]verage CEO pay has continued to increase at double-digit rates. Nike CEO Mark Parker earned \$35.2 million in 2012, up 219 percent from just a year earlier. By 2012, CEOs earned 354 times what their average workers made, up from 42 times as much I 1982 and 84 times as much in 1990.”) By comparison, Japanese and German CEOs earn "only 20 times" as much as average workers; citing, S. BHATT, "Cashing In," Seattle Times, (23 June 2013).

789 See generally, R. WILKINSON \& K. PICKETT, The Spirit Level: Why Equality Is Better for Everyone (London: Penguin Books, 2010); see also, PEW ReSEARCH CENTER, "The American Middle Class is Losing Ground," (9 December 2015). Available at: http://www.pewsocialtrends.org/2015/12/09/the-american-middle-class-is-losing-ground/ (last accessed 25 March 2016) (noting the decline of the middle class); Cf, J. DORFMAN, "The Death of the American Middle Class has been Greatly Exaggerated," Forbes, (15 December 2015). Available at: http://www.forbes.com/sites/jeffreydorfman/2015/12/15/the-death-of-the-american-middle-class-has-beengreatly-exaggerated/\#1d4212625e5b (last accessed 25 March 2016) (arguing that there is no agreed upon definition of the middle class, and that depending on the definition, the data can be manipulated to reach a different conclusion).

790 See generally, B. HARrington, Capital without Borders: Wealth Managers and the One Percent, (Cambridge: Harvard University Press, 2016) (analyzing that the extremely affluent are not subject to various laws or constrained by borders).

791 T. JACKSON, Prosperity without Growth: Economics for a Finite Planet, (New York: Earthscan, 2009), at p. 184 (suggesting that the goods made today, generally speaking, are becoming either cheaper and cheaper, or more and more expensive; with regards to the increasingly cheaper good, there is a corresponding decrease in the quality of the products available, which makes it easier for consumers to simply throw them away and to replace with another). Jackson adds that laws should "systemically address the durability of consumer products" because "[p]lanned and perceived obsolescence are one of the worst afflictions of the throw-away society and undermine both the rights and the legitimate interests of people as consumers and citizens."). There is a term for this, which is "planned obsolescence," which means that more and more products in our market today are products that were "either made to last only a short time so that they would have to be replaced frequently (adding to sales) or they were continually upgraded, more commonly in style than in quality"; see, J. DE GRAAF, D. WANN \& T.H. NAYLOR, Affluenza: How Overconsumption is Killing Us - And How We Can Fight Back, (San Francisco: Berrett-Koehler Publishers, 2014), at p. 134. 
is that consumerism and capitalism have combined forces to usher in the age of proliferation, which has contributed to the hourglass effect and the growing inequality that our societies are facing. Moreover, the increasing demand for cheaper goods incentivizes companies to continue searching for cheaper laborers, which increases the chances of labor exploitation and further polarizing our societies.

According to social epidemiologists Richard Wilkinson and Kate Pickett, the growing inequality within our societies are creating a variety of risks for private actors operating within these societies and even those that are doing better off - the affluent and the elite have an interest in working towards a more equal status quo. ${ }^{792}$ For example, the psychological impact of the age of proliferation is that it is increasing "the gap between what one has and wants" and "the gap between what one has and things others have," 793 which is creating a situation of almost guaranteed disappointment, where "[t]he circumstances of modern life seem to be conspiring to make experiences less satisfying than they could and perhaps should be, in part because of the richness against which we are comparing our own experiences." 794 Given these observations, many experts - from diverse and eclectic fields - are concerned about the current state of affairs. ${ }^{795}$

In sum, the growing inequality - ushered in by unadulterated capitalism and insatiable consumerism in the age of proliferation - is one of the main reasons why labor exploitations in our global supply chain continue to persist. Therefore, if we are to reassess the role

792 R. WiLkinson \& K. PicketT, The Spirit Level: Why Equality Is Better for Everyone (London: Penguin Books, 2010) (arguing that even the wealthy are better off and more happy in "equal" societies, relative to the wealthy in "unequal" societies). This state of affairs cannot be ideal for the $1 \%$ either, at least according to Nick Hanauer, a selfconfessed " 0.01 percenter," who argues that if the current state of inequality persists "the pitchforks are coming," suggesting that people will revolt against the $1 \%$ in a similar manner to the French Revolution; see, N. HANAUER, "Beware, Fellow Plutocrats, the Pitchforks are Coming," TED Talk, (August 2014). Available at: https://www.ted.com/talks/nick_hanauer_beware_fellow_plutocrats_the_pitchforks_are_coming?language=en (last accessed 25 March 2016).

793 A. Michalos, "Job Satisfaction, Marital Satisfaction, and the Quality of Life," in Research on the Quality of Life, F.M. ANDREWS (ED.) (Ann Arbor: Institute of Social Research, 1986), at p. 75; as cited in, B. SCHWARTZ, The Paradox of Choice: Why More is Less, (New York: Harper, 2004), at p. 183.

794 B. SChwARTZ, The Paradox of Choice: Why More is Less, (New York: Harper, 2004), at p. 181 (adding that these superficial comparisons have become "the only meaningful benchmark" in which we determine our happiness, satisfaction, and status).

795 S. Anholt, Brand New Justice: How Branding Places and Products Can Help the Developing World, (Oxford: Elsevier, 2005), at p. 164 (noting that "the degree to which shopping values have become the dominant force in Western society is worrying: the atmosphere of commercialism and materialism is rapidly becoming stifling, and the principle which, in a very different but not very distant age, was simply known as greed, is now pre-eminent to a degree which simply doesn't seem healthy”); see also, D. Goleman, Emotional Intelligence, (New York: Bantam Books, 2005), at p. 241 (paying tribute to M.E.P. Seligman and stating that " $[\mathrm{f}]$ or the last thirty or forty years we've seen the ascendance of individualism and waning of larger beliefs in religion, and in supports from the community and extended family. That means a loss of resources that can buffer you against setbacks and failures. To the extent you see a failure as something that is lasting and which you magnify to taint everything in your life, you are prone to let a momentary defeat become a lasting source of hopelessness"); J. DE GRAAF, D. WANN \& T.H. NAYLOR, Affluenza: How Overconsumption is Killing Us - And How We Can Fight Back [Third Edition], (San Francisco: BerrettKoehler Publishers, 2014), at p. 50 (quoting President Reagan's former adviser, Edward Luttwak as followed: "The contradiction between wanting rapid economic growth and dynamic economic change and at the same time wanting family values, community values, and stability is a contradiction so huge that it can only last because of an aggressive refusal to think about it"); E. LUTTWAK, Turbo-Capitalism: Winners and Losers in the Global Economy, (New York: HarperCollins, 1999); and, B. SCHWARTZ, The Paradox of Choice: Why More is Less, (New York: Harper, 2004), at p. 188 (noting that "upward comparisons," brought on by the gap between what we have and want or what others have, "produce jealousy, hostility, negative mood, frustration, lowered self-esteem, decreased happiness, and symptoms of stress."). 
of private actors and what they can do differently to reduce labor exploitations in the global supply chain, private actors can do much worse than to start by reconsidering their consumption habits and capitalistic tendencies. In this context, adopting ethical consumerism may be one possible option moving forward at least for the consumers, which brings us to the next part of this subsection.

\section{B. Reassessing Consumerism and Capitalism}

There is a popular Russian joke that "everything Marx said about communism was false, but everything he said about capitalism was true."796 Looking at the combined impact of unadulterated capitalism and over-consumption in the age of proliferation, with effects ranging from the "increasing commoditization of public goods [to] the rising social inequalities," 797 this joke is too close for comfort to elicit laughter. Some academics believe that the capitalistic system that we operate in is indeed susceptible to abuse, as capitalism often suffers from "auto-corrosive tendencies," 798 and the corruptibility of governments noted back in Chapter 2 or the profit-mindedness of businesses even at the risk of causing third party harm noted in Chapters 3 and 4 add some veracity to this claim.

This is not to suggest, however, that in order to answer our research question and to find different ways that private actors can address the problem of labor exploitation in the global supply chain, they must somehow "fix" capitalism and consumerism. Not only would such a topic fall far beyond the scope of this thesis, but in order to address our labor exploitation problem, this thesis will argue that private actors do not need to completely dismantle or abandon capitalism nor consumerism. As this thesis will argue, private actors simply need to find different ways to operate and consume in capitalistic societies, while bearing in mind the auto-corrosive tendencies of capitalism and consumerism as well as their bounded rationality and cognitive limitations. While capitalism or consumerism in a vacuum may not be neither good nor bad, the manner in which the private actors have been abusing them has undoubtedly contributed to an assortment of problems that we face today. Similarly, it is not just the evil corporations or selfish consumers that have contributed to this problem, but even private actors with good intentions may unconsciously be contributing to the labor exploitation problem and are oblivious of their impact. ${ }^{799}$ To the

796 J. DE GRAaf, D. WANn \& T.H. NAYLOR, Affluenza: How Overconsumption is Killing Us - And How We Can Fight Back [Third Edition], (San Francisco: Berrett-Koehler Publishers, 2014), at p. 9 (attributing this to a popular joke in Russia).

797 T. JACKSON, Prosperity without Growth: Economics for a Finite Planet, (New York: Earthscan, 2009), at p. 144; see also, J J. RUTHERFORD, "Wellbeing, economic growth and recession," Think-piece for the SDC Workshop: "Living WellWithin Limits, (London: Sustainable Development Commission, 2008); and, J. Norman, K Ussher \& D. ALEXANDER, From Here to Fraternity: Perspectives on Social Responsibility, (London: CentreForum, 2007).

798 L. OsBerg, "Markets, Morality, and the Auto-Corrosive Tendencies of 'Standard Economics'," in The Moralization of the Markets, N. STEHr, C. Henning \& B. Weiler (EDS.) (New Jersey: Transaction Publishers, 2006), at p. 155 (noting that current economic policies undermine the morality which underpins the efficiency of market process); see also, A. FALK \& N. SZECH, "Morals and Markets," Science 340 (2013): 707 (noting that "market interaction causally affects the willingness to accept severe, negative consequences for a third party."); cf. J.A. SCHUMPETER, Capitalism, Socialism and Democracy [Third Edition], (New York: Harper Perennial Modern Classics, 2008) (choosing to characterize capitalism and the business cycle as the process of "creative destruction" instead, and portraying this as a way societies can evolve).

799 D. ARIELY, The (Honest) Truth About Dishonesty: How We Lie to Everyone - Especially Ourselves, (New York: Harper Collins, 2012), at p. 70 (noting that "people don't need to be corrupt in order to act in problematic and sometimes 
extent that changing the way we consume (i.e. by adopting ethical consumerism) could be a possible catalyst for change, the next subsection will start by looking at contract law, which affects assortment of transactions that take place within the global supply chain, thus enable both consumerism and capitalism.

\subsubsection{Contract Law as the Enforcer of Justice?}

The previous subsection mentioned the growing inequality brought on by unadulterated capitalism and over-consumption in the age of proliferation. What contributes to this growing inequality is the fact that companies are able to externalize their liabilities to third parties, while still retaining their profits (as noted back in Chapter 3). What this means is that the profits that companies make are not being distributed equally to the stakeholders. Not only are people in the lower echelons of the supply chain not being compensated properly for the arduous work that they do, but those higher up in the hierarchy are making exorbitantly more. ${ }^{800}$ According to Sean D. Murphy, "[w] hile capitalism, at its core, entails freedom to pursue economic self-interest, it is equally true that capitalism in developed states only survived the challenge of socialist and communist movements by developing a distributive system of social benefits that was perceived as equitable, fair, and just." 801 The problem here is that the system of capitalism and liberalized economies that we operate in today is not distributing social benefits in a way that can be characterized as equitable, fair, or just.

While the principle of autonomy is something to be valued, whether in the context of capitalism or even in the context of our own normative framework, it is worth reconsidering this concept of autonomy and freedom of choice in the context of contract law. Contracts were once considered as instruments that respected a certain sense of distributive and commutative justice. While freedom of contract (i.e. respecting party autonomy) is considered as one of the fundamental principles of contract law today - meaning that instances where the law prevents parties from entering into contracts are somewhat limited (i.e. contracts can be (a)voided on the grounds that they are illegal/immoral or in cases of defects of consent like abuse of circumstances) - freedom of contract was not as "free" as they are today. ${ }^{802}$ Before elaborating on the various contract/consumer law-based CSR measures in

damaging ways. Perfectly well-meaning people can get tripped up by the quirks of the human mind, make egregious mistakes, and still consider themselves to be good and moral.”).

800 T. JuDT, Ill Fares the Land, (New York: Penguin, 2010), at p. 14 (noting that "[i]n 2005, 21.2 percent of US national income accrued to just 1 percent of earners... [and t]oday, the CEO of Wal-Mart earns nine hundred times the wages of his average employee.").

801 S.D. MurPHY, "Taking Multinational Corporate Codes of Conduct to the Next Level," Columbia Journal of Transnational Law 43(2) (2005), at p. 2. For example, cereal tycoon A.K. Kellogg, who was a "paternalistic capitalist" did "right" by his workers and treated them in a fair and respectable manner, offering them offered "thirty-five hours' pay for a thirty-hour week, and he built parks, summer camps, nature centers, garden plots, sports fields, and other recreational facilities for them"; see, J. DE GRAAF, D. WANN \& T.H. NAYLOR, Affluenza: How Overconsumption is Killing Us-And How We Can Fight Back, (San Francisco: Berrett-Koehler Publishers, 2014), at p. 130.

802 J.M. SMITS, Contract Law: A Comparative Introduction, (Cheltenham: Edward Elgar, 2014), at p. 10 (noting that freedom of contract "gives legal application to the idea that each individual should be allowed the autonomy to make choices they desire"); at p. 172 (translating abuse of circumstances (misbruik van omstandigheden) in the context of Article 3:44 (4) BW as when "someone knows or should understand that another person is induced to execute a juridical act as a result of special circumstances, such as state of necessity, dependency, wantonness, abnormal mental condition or inexperience, and promotes the realization of that juridical act, although what he knows or 
the next section of this chapter, this subsection will first a) describe the origins of contracts and how it entailed notions of justice in the past, b) explain how over time, this notion of justice in contract law was replaced with notions of party autonomy and contractual freedom, and in light of emerging CSR initiatives and surge of ethical consumerism that we are beginning to see, c) suggest that perhaps contracts can be redeemed to its original state where it considered notions of justice more prominently.

\section{A. Origins of Contracts and Notions of Justice}

Aristotelian and Thomistic philosophies have been credited and recognized as the origin of present-day contract doctrine. ${ }^{803}$ Both Aristotle and Aquinas emphasized the importance of intellectual order and moral virtue in contracts and believed that binding oneself to a contract was in and of itself an "exercise in virtue and commutative justice." 804 Nussbaum adds that this conception of contracts is consistent with the capabilities approach, noting that "[w]e think about human dignity and what it requires. My approach suggests that we ought to do this in an Aristotelian/Marxist way, thinking about the prerequisites for living a life that is fully human rather than subhuman, a life worthy of the dignity of the human being." 805 This is to suggest that intellectual order and moral virtue are not just important in terms of contracts, but as ideals that can lead to enabling workers to have a dignified working life.

It is worth noting here that there are two types of justice that we must consider: distributive and commutative. Distributive justice is about ensuring that everyone has the necessary resources, whereas commutative justice is about enabling people to obtain the necessary resources without jeopardizing other's ability to do the same. ${ }^{806}$ According to the Aristotelian tradition, contracts were "voluntary acts of commutative justice requiring equality so that at the moment of the transaction, neither party was enriched at the other's expense." 807 In other words, these fair and voluntary transactions not only benefited the parties, but more importantly, they ensured that they did not benefit one party at the expense of another. While some notions of contractual fairness or commutative justice still exist in today's contract law, by observing the cascade of contracts involved in the global supply chain - whether between a downstream buyer and an upstream supplier or between sweatshop operators and the sweatshop workers - it appears that the notion of commutative justice in contracts has deteriorated since the days of Aristotle and Thomas Aquinas.

should understand should lead him to refrain from doing so.”); at p. 178-180 (citing to Art 3:40 (1) BW that “a juridical act that its contents or implications violates good morals or public policy, is null and void"); and at p. 12 (noting that "[i]n the heyday of Roman civilization," for example, "only certain types of contact could be enforced.").

803 J. GordLey, The Philosophical Origins of Modern Contract Doctrine, (Oxford: Oxford University Press, 1991), at p. 3.

804 J. GordLey, The Philosophical Origins of Modern Contract Doctrine, (Oxford: Oxford University Press, 1991), at pp. 7, 9 .

805 M.C. Nussbaum, "Beyond the Social Contract: Capabilities and Global Justice," Oxford Development Studies 32(1) (2004), at p. 13 (listing some of these basic entitlements such as "adequate nutrition, education of the faculties, protection of bodily integrity, liberty for speech and religious self-expression, and so forth.”).

806 J. GORDLEY, The Philosophical Origins of Modern Contract Doctrine, (Oxford: Oxford University Press, 1991), at p. 14.

807 J. GordLey, The Philosophical Origins of Modern Contract Doctrine, (Oxford: Oxford University Press, 1991), at p. 287. 


\section{B. Proximus Egomet Mibi and the Corruption of Contracts}

At some point in time between the days of Aristotle and Aquinas, the reverence towards commutative justice in contracts waned. ${ }^{808}$ Legal scholars attribute this to the development of the natural lawyers and the emergence of "will theories" 809 in the $17^{\text {th }}$ and $18^{\text {th }}$ centuries that advanced the "will of the party" 810 approach, elevating the importance of party autonomy in the process. The emphasis on freedom of contract and allowing parties to enter into contracts even if one party clearly benefits at the expense of the other, arguably has contributed to the perception that contracts are instruments that companies can use to their advantage to legally bind those in weaker bargaining positions. ${ }^{811}$

The legitimacy of the will theory grew in the centuries following its emergence to a point, where in the early $20^{\text {th }}$ Century, the application of the theory may have gone perhaps too far, at least in the US. This overreach can be best exemplified by the US Supreme Court's holding in Lochner v. New York. 812 The case involved a New York law, amiable called the Bakershop Act, which established various workplace sanitary requirements and limited the number of hours bakers could work to 10 hours a day (and no more than 60 hours a week). Lochner, a baker, challenged the legitimacy of the Bakershop Act contending that it restricted his right to make his employees work more than 10 hours a week in violation of the Fourteenth Amendment's Due Process Clause. The Due Process Clause generally prohibits states from depriving "any person of life, liberty, or opportunity without due process of law." The Court held that the New York law was an "unreasonable, unnecessary and arbitrary interference with the right and liberty of the individual to contract" and held that "common law rights to property and contractual autonomy could not be overridden by legislative attempts to regulate working hours and conditions, such as minimum wages." 813 In a nutshell, the Court in Lochner took the Otto Kahn-Freund's path of collective laissez-faire and made that the supreme law of the land, holding that if an employee agreed to work for an employer at below the minimum wage, the legislature should not interfere with the parties' autonomy.

Lochner ushered in an era in the US commonly referred to as the Lochner era, which brought on cases like Adkins v. Children's Hospital, ${ }^{814}$ where the Court continuously held

F. CAPRA \& U. MATTEI, The Ecology of Law: Toward a Legal System in Tune with Nature and Community, (Oakland: Berrett-Koehler, 2015), at p. 68 (adding that distributive justice today is something "located in the domain of politics or of morals," and as a result has been "completely eliminated from the domain of legal science and has been abandoned for more than three hundred years.").

809 J. Gordley, The Philosophical Origins of Modern Contract Doctrine, (Oxford: Oxford University Press, 1991), at p. $287-$ 288 (describing the will theory as a contract theory that "every rule was to be traced back to the will of the parties" at least in regards to contract under civil law, but also something that is "now out of fashion in both common law and civil law jurisdictions because there is too much they did not explain.").

810 J. Gordley, The Philosophical Origins of Modern Contract Doctrine, (Oxford: Oxford University Press, 1991), at p. 8 (noting that "making a contract" where the parties "regarded simply as an act of will, not as the exercise of a moral virtue. The parties were bound simply to what they willed, not to obligations that followed from the essence or nature of their contract.").

811 F. CAPRA \& U. MATTEI, The Ecology of Law: Toward a Legal System in Tune with Nature and Community, (Oakland: Berrett-Koehler, 2015), at p. 186 (noting that "[f]reedom of contract, like the shield of limited liability for corporate investment, was one of the most powerful institutions developed by lawyers at the dawn of modernity to facilitate the transformation of commons into capital.").

812 Lochner $v$. New York, 198 U.S. 45 (1905).

813 P. Alston, Labour Rights As Human Rights: Collected Courses of the Academy of European Law, (Oxford: Oxford University Press, 2005), at p. 4.

814 Adkins v. Children's Hospital, 261 U.S. 525 (1923). 
laws establishing minimum wage or work hour restrictions violated the Due Process Clause and thus unconstitutional. The Lochner decision has been criticized, not just by liberals, but even by some conservatives as well, validating the point that giving parties too much autonomy and adamantly catering to notions of freedom of contract while striking down labor laws could lead to instances where parties with a bigger bargaining power exploit those with lesser means and legally bind them to unfair situations. ${ }^{815}$ One particular illustration of this type of power asymmetry and exploitation based on bargaining power was already noted in the context of choice of law and choice of forum issue back in Chapter 3. Even laws that appear prima facie neutral (i.e. the aforementioned Rome I Article 3 that gives "parties have the freedom of choice to determine the law applicable to their contract") can be exploited by private actors that have more bargaining powers to take advantage of the weaker party. ${ }^{816}$

The Lochner era came to an eventual end, at least in the US, when the US Supreme Court in Nebbia v. New York recognized that the freedom of contract is not a constitutionally protected right and that the states were entitled to enact laws that restrict the freedom of contract, so long as the legislation is not unreasonable or arbitrary. ${ }^{817}$ The Court's decision in Nebbia was followed by West Coast Hotel Co. v. Parrish, which overturned Adkins v. Children's Hospital, holding that States enacting minimum wage laws is not unconstitutional. ${ }^{818}$ While the legitimacy and the need for labor/employment laws discussed back in Chapter 2 are recognized today in most of the developed economies, cases like Lochner are stern reminders that freedom of contract and respecting the will of the parties, while important considerations, also need to be balanced with the interest of protecting those who cannot protect themselves. The Court in West Coast Hotel Co. encapsulated this fundamental problem by illustrating a typical power dynamic between employers and employees in the following manner: Given that employers usually want to get as much as possible out of their employees and the employees, fearing retaliation, tend to comply with the wishes of their bosses, a situation is created where the employees are practically constrained to obey the employers; and in such cases, the authorities may intervene - at the expense of party autonomy and contractual freedom - because the employees' "self-interest" in such cases are often "unsafe guides." 819

This idea that laws can quell unmitigated self-interest is a very relevant point to our discussion about the reduction of labor exploitation in the global supply chain. While party autonomy or contracts for that matter, in and of themselves may present itself as being neutral, in practice, they are not and those that wield a bigger bargaining power can use the principal of contractual freedom to their advantage and use it as a weapon against those

815 A. RÜHmkOrF, Corporate Social Responsibility, Private Law and Global Supply Chains, (Cheltenham: Edward Elgar, 2015), at p. 84.

816 A. RÜHmkORF, Corporate Social Responsibility, Private Law and Global Supply Chains, (Cheltenham: Edward Elgar, 2015), at p. 93 (stating that "[i]n commercial practice, due to the strong economic bargaining power of the buyer in international supply contracts, one can expect that buyers can often impose their CSR policies on their suppliers as prerequisite to trading... Multinational buyers from Western companies are usually in a position where they can choose between numerous potential suppliers.").

817 Nebbia v. New York, 291 U.S. 502 (1934).

818 West Coast Hotel Co. v. Parrish, 300 U.S. 379 (1937). It is worth noting here that this case only overturned Adkins and not Lochner.

819 West Coast Hotel Co. v. Parrish, 300 U.S. 379, interpose its authority."). 
who cannot defend themselves. That is to suggest that in the age of proliferation and the aggressive individualism that it has fostered, individuals are adopting a mindset of proximus egomet mihi, which says that it is every man for himself. ${ }^{820}$ In this framework, contracts are no longer virtuous instruments that espouse ideas of commutative justice that they once were. Rather, as noted back in Chapters 2 and 3, they have become instruments that allow for the externalization of one's liabilities on to others and shifting the burden further down the supply chain to laborers who must ultimately pay the price. So what can private actors do to shift this paradigm, where contracts are no longer being used as a tool for companies to exploit their workers or some third parties, but back to an understanding of contracts more akin to the way Aristotle and Aquinas envisioned them? This brings us back full circle to the main topic of this section about ethical consumerism and CSR.

\section{Redemption of Contracts?}

As noted at the beginning of this subsection, contract law today still values notions of fairness and justice to the extent that it prevents parties from entering into contracts that are contrary to public morals or in cases where one party gains grossly disproportionate advantage at the expense of another. ${ }^{821}$ However, the application of these measures in reality is quite limited as the following sections will illustrate. One possible way to address this limitation could be to call upon a more widespread implementation of the "hot goods" legislation discussed in Chapter 2, or something similar to it, which would serve not only to invalidate a commercial transaction involving goods made in sweatshops or manufactured in circumstances that would appall the general public's sense and sensibilities, but to go one step further and to have governments confiscate goods made in such manners. However, in the context of balancing the interests of various parties (including that of businesses) and the wisdom of the Inverted-U curve, Chapter 2 also acknowledged that excessively stringent or draconian laws that significantly curb party autonomy and freedom of contract might not be desirable either. ${ }^{822}$

So there must be a middle ground between governments dictating what private actors can and cannot contract about on one end and at the other end, private actors having complete autonomy to do what they want, even if that means the contract completely disregards the interest of the other party or the negative externalities and the third party harm that the contract could cause. ${ }^{823}$ One possible way to moderately redeem contracts, to rehabilitate its reputation as being perceived as an instrument that corporations rely on to exploit laborers to being perceived - once again - as an instrument to promote commutative justice, is for private actors to start drafting contracts in a manner that takes into con-

More accurately, "the closest one to me is myself."

821 L.K.L. TJON SOEI LEN, "European Contract Law and the Capabilities Approach: On Distributive Responsibility for Contract Law," Centre for the Study of European Contract Law Working Paper Series (00) (2010): 156, 168 (stating that "immoral contracts, are usually not enforced. Hence, contract law reflects rules of decent conduct between private parties (e.g. consumers and corporations).").

822 J.M. SMITS, "The Expanding Circle of Contract Law," Maastricht European Private Law Institute Working Paper 3 (2016), at p. 12 (concluding that "[d]eclaring the multinational's contract with a local supplier unenforceable means throwing away the baby with the bathwater," which could also have the effect of "gravely undermin[ing] the willingness of parties to conclude contracts if their bindingness is debatable.").

823 J.M. SMITS, "The Expanding Circle of Contract Law," Maastricht European Private Law Institute Working Paper 3 (2016), at p. 10 (noting that the "current contract law has no well-defined concept of externalities."). 
sideration negative externalities and third party harm. ${ }^{824}$ This is where various CSR initiatives and ethical consumer practices can combine forces and attempt to facilitate the rehabilitation process. In short, the remainder of this chapter will address how CSR and ethical consumerism can lead private actors to reassess various contract/consumer law-based measures differently to not only empower workers and reduce instances of labor exploitation in the global supply chain, but to redeem contracts in the process.

\subsection{CONTRACT/CONSUMER LAW MEASURES TO REDUCE LABOR EXPLOITATION}

The previous section suggested that one path to redeeming contracts, which incidentally also leads to yet another partial answer to our research question, is for private actors particularly businesses and consumers - to start drafting or demanding commercial or consumer contracts that bear in mind ethical values or some sense of commutative justice. The assumption here is that if consumers demand this from companies through various ethical consumption practices, and companies are open to adopting and implementing various CSR initiatives, this could lead to a possible reduction in labor exploitation in the global supply chain in a manner that conforms to our normative framework.

Accordingly, this section will present some of the more popular contract/consumer law-based measures that could potentially contribute to reducing labor exploitation: The first subsection will discuss codes of conduct, which is a very popular CSR initiative that could potentially be the catalyst for contracts to once again become an instrument that fosters social justice and enhances the capabilities of the laborers (Subsection 5.2.1). ${ }^{825}$ This will be followed by a related concept of certification and labeling schemes that many companies are starting to use to better inform socially conscious or ethical consumers (Subsection 5.2.2). The last subsection will elaborate further on the previously mentioned idea of how consumers can incentivize companies to be more socially responsible by relying on various consumer protection measures (Subsection 5.2.3). What these measures all have in common is that they are all attempts to restore some sense of commutative justice back into contracts, albeit with mixed levels of success. ${ }^{826}$

J.M. SMITS, "The Expanding Circle of Contract Law," Maastricht European Private Law Institute Working Paper 3 (2016), at p. 16 (suggesting that in order to expand the circle of contract law and for contractual parties to bear in mind the externalities that affect third parties, we would have to move away from contractual autonomy).

825 L.K.L. TJON SOEI LEN, "European Contract Law and the Capabilities Approach: On Distributive Responsibility for Contract Law," Centre for the Study of European Contract Law Working Paper Series (00) (2010): 156, 168 (arguing that "[b]ringing contracting options between consumers and corporations in line with a standard of minimum social justice can have significant influence on capabilities"); see also, H. KÖTZ \& A. FLESSNER, European Contract Law, (Oxford: Clarendon Press, 1997).

826 J. GORDLEY, The Philosophical Origins of Modern Contract Doctrine, (Oxford: Oxford University Press, 1991), at p. 230 (noting that while "[t]here is widespread agreement that any viable theory of contract will have to take the fairness of a contract into account, there is no agreement as to how to do so."). 


\subsubsection{Codes of Conduct}

Regardless of whether they promote some sense of justice or not, contracts are irreplaceable instruments in both commercial and consumer transactions: For example, a network of commercial contracts govern the relationships between the downstream companies - the Nikes and the Apples of the world - with their upstream suppliers/manufacturers not to mention the chain of sales contacts that bind the downstream companies to their consumers. While the primary purpose of a code of conduct is to establish a company's internal set of values and standards, through these commercial and sales contracts, a company's internal code can be externalized to hold upstream companies accountable to them, as well as influencing the purchasing decisions of the consumers by marketing to them, not only the products that they sell, but by convincing them of the socially responsible manner in which the products were made. This subsection will further discuss how these codes are contributing to the reduction of labor exploitation in the global supply chain and how in this context, contracts can once again serve as the enforcer of commutative justice, not only with the interests of the parties involved, but also by expanding the area of their coverage to include larger societal considerations as well.

Accordingly, this subsection will have the following composition: The first part of the subsection a) will define what codes of conduct are, followed by b) an analysis of how they can be implemented in a B2B context. These two sections will be followed by c) illustrations of various difficulties that come with monitoring and enforcing these codes. The last part of the subsection will d) offer an analysis of how codes of conduct can be utilized in a $\mathrm{B} 2 \mathrm{C}$ context, which could potentially lead to the reduction of labor exploitations and the empowerment of workers.

\section{A. What are Codes of Conduct?}

The most basic definition for codes of conduct, as sketched above, is that they are a set of rules that prescribe the expected standard of behavior of a company to its employees that often go above and beyond what the law (i.e. labor/employment law) requires. A code can be specific and custom-tailored for a company, or it can simply be cut-and-pasted from a variety of sources, which is to suggest that sources for inspiration is not only mixed, but plentiful. ${ }^{827}$ In this sense, codes of conduct can overlap with the law as well, and as the introductory remark at the beginning of this subsection hinted, the application of the code is not just limited for internal use within the company, but can be attached as a provision within a commercial contract. This creates a legally binding obligation for external parties

See generally, T.H. MORAN, Beyond Sweatshops: Foreign Direct Investment and Globalization in the Developing World, (Virginia: R. R. Donnelley and Sons, 2002), at p. 89. For example, there is an abundance of private codes of conduct where companies like Coca Cola, Nike, and Nestle have created their own code of conduct. There are codes that have been created by a group of private actors such as the SA8000, which is a code governing labor standards for suppliers and contractors was developed by a group of nineteen companies and organizations, the likes of Reebok, the Body Shop, and Amnesty International in 1996. Another example is the Global Manufacturing Principles that the toymaker Mattel spearheaded back in 1997, which established minimum standards that the suppliers of Mattel must comply with from specific standards regarding wages, hours, safety, health, freedom of association and protections from discrimination. There are also more market-driven standards created by organizations like the International Organization for Standardisation ("ISO"), which will be discussed further in the context of standardization and certification schemes in Chapter 3.2.3. 
to comply with a company's code that can include aspects of performance outside of traditional provisions (i.e. price, quantity, and delivery date) to include something more CSR oriented (i.e. maintaining a certain level of standard for the treatment of their workers). ${ }^{828}$

Academics and practitioners alike believe that voluntary codes of conduct in combination with the legally binding force of a contract can make meaningful contributions to reducing labor exploitation while enhancing the capabilities of workers in the lower echelons of the global supply chain. ${ }^{829}$ Part of this belief comes from the fact that as a voluntary private initiative, codes of conduct offer more autonomy to companies than a top down regulation of what governments require them to do in a much more fluid, adaptable manner similar to the other CSR measures noted back in Chapter $4 .{ }^{830}$ The opportunity that this unique combination presents is that codes of conduct can be utilized by companies to regulate activities of businesses in other, more developing countries, by requiring their business partners to uphold a higher labor standard than that of the country in which they operate. ${ }^{831}$

One of the first codes of conduct implemented by a multinational corporation ("MNC") was the Sullivan Principal in 1977 - created by a member of General Motor's Board of Trustees, Reverend L.H. Sullivan - to ensure that MNCs operating in South Africa were not complicit in the apartheid regime. ${ }^{832}$ This code ensured that those who opted to follow the Principal did not racially segregate their facilities, and although no conclusive evidence can be offered to establish a causal link between the emergence of the Principal and the collapse of the apartheid regime, the fact that the apartheid regime did

L.C. BACKER, "Economic Globalization and the Rise of Efficient Systems of Global Private Lawmaking: WalMart as Global Legislator," University of Connecticut Law Review 39(4) (2007), at pp. 14-15 (noting that "[w]ith respect to the management of suppliers, multinational corporations tend to focus regulatory efforts through contracts and agreements with individual suppliers that incorporate the multinational corporation's framework for ethical standards.”).

829 E.J. SCHRAGE, "Promoting International Worker Rights Through Private Voluntary Initiatives: Public Relations or Public Policy?" A Report to the U.S. Department of State on behalf of the University of Iowa Center for Human Rights (2014). Available at: http://www.cfr.org/pdf/Schrage-DOS.pdf (last accessed 4 April 2017), at xii (highlighting the importance of code of conduct and its "potential to generate direct improvements in the conditions of workers and communities in the global supply chains of major industries."). Speaking of combining codes of conduct with the law, there are specific instances where the law requires companies to establish codes of conduct for certain key stakeholders. See e.g., US Congressional Federal Sentencing Guidelines for Organizations (FSGO) of 1991 [15 U.S.C. \$ 7264] requires listed companies to adopt a code of ethics for senior financial officers, which relates back to the legalization problem discussed back in Chapter 4 .

830 S.D. Murphy, "Taking Multinational Corporate Codes of Conduct to the Next Level," Columbia Journal of Transnational Law 43(2) (2005), at p. 40 (noting that "[a]t the heart of this approach is the notion that MNCs are not required to adopt a particular code; the code remains a voluntary set of normative constraints that the MNC may embrace or not as it wishes.").

831 R. LOCKE, F. QIN \& A. BRAUSE, "Does Monitoring Improve Labor Standards?: Lessons from Nike," MIT Sloan School of Management Working Paper No. 4612-06 (2006). Available at: http://ssrn.com/abstract=916771 (last accessed 4 April 2017), at p 35 (stating that the limited ability of many developing countries to regulate labor and employment issues and their failure to enforce their laws is the reason why "monitoring for compliance with codes of conduct is ... the principal way both global corporations and labor rights NGOs address poor working conditions in global supply chain factories"); see also, S.D. MurPHY, "Taking Multinational Corporate Codes of Conduct to the Next Level," Columbia Journal of Transnational Law 43(2) (2005), at p. 3 (stating that "these codes of conduct seek to promote socially-responsible MNC conduct, largely in the developing world, so as to prevent harm or mistreatment of persons or things caused by MNC operations...”).

832 S.D. MurPhy, "Taking Multinational Corporate Codes of Conduct to the Next Level," Columbia Journal of Transnational Law 43(2) (2005), at pp. 4-5. 
collapse in the end, is an encouraging sign of the codes' possible potential. ${ }^{833}$ Following the precedent set by the Sullivan Principal, most, if not all, Fortune 500 companies today have adopted their own voluntary codes of conduct, which often include provisions not only about how workers should be treated, but other issues including environmental sustainability and elimination of work place discrimination. ${ }^{834}$

Another way to conceptualize codes of conduct can be when companies agree to participate in a framework such as the UN Global Compact and pledge to be a socially responsible corporate citizen. ${ }^{835}$ They are essentially making a promise to be more socially responsible and increasing their accountability by publicly joining a group of like-minded companies. With over 13,000 businesses across 170 countries signed on to reduce instances of labor violations ${ }^{836}$ and respecting its core principals, ${ }^{837}$ the UN Global Compact could be argued as being one of the most far reaching contract-based CSR initiatives around.

Whether by creating its own code of conduct or by joining a pact, MNCs today can not only hold itself to a higher standard, but can contractually compel upstream suppliers/manufactures to abide by their codes as well. To elaborate on this point, the next part of this subsection will focus specifically on the relationship between the downstream businesses with their upstream suppliers/manufacturers.

\section{B. Codes of Conduct: Between Downstream and Upstream Businesses}

For the purposes of this thesis, upstream businesses will include, but are not limited to, subsidiaries, manufacturers, and suppliers, whereas the downstream businesses will be the aforementioned Nikes and the Apples of the world. The downstream companies, who often draft the commercial contracts, include or attach their codes of conduct into these commercial contracts. ${ }^{838}$ Even when corporate codes are incorporated into general terms

833 S.D. Murphy, "Taking Multinational Corporate Codes of Conduct to the Next Level," Columbia Journal of Transnational Law 43(2) (2005), at pp. 5 (citing to S. PRAKASH SETHI \& O.F. WiLLIAMS, "Creating and Implementing Global Codes of Conduct: An Assessment of the Sullivan Principles as a Role Model for Developing International Codes of Conduct - Lessons Learned and Unlearned," Business \& Society Review 169 (2000)). There were approximately $150 \mathrm{MC}$ that pledges to support the principal.

834 T.H. Moran, Beyond Sweatshops: Foreign Direct Investment and Globalization in the Developing World, (Virginia: R. R. Donnelley and Sons, 2002), at p. 90. As noted above, this is partially because there are laws like 15 U.S.C. S 7264 noted above that specifically require publicly listed companies to have codes of conduct.

835 G. Kell \& D. Levin, “The Global Compact Network," in Learning to Talk: Corporate Citizenship and the Development of the UN Global Compact, M. McInTOSH, S. WadDock \& G. KeLL (EDS.) (Sheffield: Greenleaf, 2004), at p. 62 (explaining that the UN Global Compact can be characterized as a code of conduct for the signatories, given that it eschews core values for companies to be "participants engaged in a multi-stakeholder network, not members of a club that have met some performance standard to gain entry.")

836 D. VOGEL, The Market for Virtue: The Potential and Limits of Corporate Social Responsibility, (Washington D.C.: Brookings Institution Press, 2006), at p. 83, 139 (adding that "SA8000 is based on International Labor Organization standards but goes beyond them in requiring a 'living wage'... and the facilitation of 'parallel means of association and bargaining."'); see also, J. EsBENSHADE, Monitoring Sweatshops: Workers, Consumers, and the Global Apparel Industry, (Philadelphia: Temple University Press, 2004).

837 Some of the principles enumerated in the UN Global Compact, include but are not limited to businesses making sure that they are not complicit in human right abuses, but upholding the freedom of association and the effective recognition of the right to collective bargaining; the elimination of all formed of forced and compulsory labor the effective abolition of child labor; and the elimination for discrimination in employment and occupation.

838 D. MCBARnET \& M. KURKCHIYAN, "Corporate Social Responsibility Through Contractual Control? Global Supply Chains \& 'Other Regulation'," in The New Corporate Accountability: Corporate Social Responsibility and the Law, D. MCBarnet, A. Voiculescu \& T. Campbell (EDs.) (Cambridge: Cambridge University Press, 2007): 59-92, 65 (observing that the "[b]est practice is increasingly being treated as setting up a contractual obligation on suppliers to meet specified CSR standards."); see also, A. RÜHMKORF, Corporate Social Responsibility, Private Law and Global 
and conditions, ancillary documents, or umbrella agreements, their enforceability and applicability remain relatively unquestioned, thus serving as a strong incentive for the upstream businesses to actually comply with the code of the downstream business. ${ }^{839}$ Once the upstream businesses (usually the sellers), sign the contract with the downstream businesses (usually the buyers), the buyers can not only claim breach of contract in the event that the seller fails to deliver conforming goods on time, but if the goods were made in a manner in violation of the code.

The buyer's claim against the upstream businesses, however, can be complicated by a number of issues given the nature of the global supply chain: First, Western companies imposing codes of conduct on their upstream supplier located in non-Western jurisdiction, for example, could be akin to legally transplanting a Western law to a non-Western jurisdiction and expecting that they produce similar outcomes. Transplanting legislations that disregard cultural sensitivities of the host jurisdiction or fail to consider how the code and the existing law of the host country relate to one another is likely to bring about unintended consequences - at the very least - as already noted back in Chapter $4 .{ }^{840}$ In other words, Western corporations should not expect their non-Western business partners to simply accept, adapt, and internalize Western ideologies or the specific views of the company, simply because of the code without proper guidance, support, and adjustments.

The second major issue has to do with how the buyers go about detecting the seller's breach, which requires the buyers to establish not only a code of conduct, but adequate monitoring and auditing mechanisms to ensure compliance (this will be the main topic of the next part of the subsection). Another complication for the buyer's possible claim has to do with the very nature of the global supply chain and the important issue of contractual privity. Privity, which was already addressed back in Chapter 3, means that third parties that are not parties to the contract cannot base any potential claims on the basis of that contract, even if negative externalities generated as a result of the contract harmed the third parties. ${ }^{841}$ To illustrate this point, imagine the following hypothetical: A seller, who signed a commercial contract with the buyer and agreed to comply with the buyer's code of conduct, subsequently subcontracts parts of the contract to a third party who breaches the

Supply Chains, (Cheltenham: Edward Elgar, 2015), at p. 82 (adding that "[c]odes of conduct are "documents which state a number of social and environmental standards and principles that a firm's suppliers are expected to fulfill"); I. MAMic, "Managing Global Supply Chain: The Sports Footwear, Apparel and Retail Sectors," Journal of Business Ethics 59 (2005): 81-100, 81; and, H. Collins, "Conformity of Goods, the Network Society, and the Ethical Consumer," European Review of Private Law 5 (2014): 619-640, 625-6 (noting that "[1]arge corporations like Apple manage their network by insisting that their partners conform not only to business efficiency requirements such as Total Quality Management but also to code of conduct that are largely concerned with labour standards...").

839 These codes of conduct have been incorporated even into terms and conditions of purchase order forms or by incorporating them through references to their company's websites where their code is displayed. See, A. RÜHMKORF, Corporate Social Responsibility, Private Law and Global Supply Chains, (Cheltenham: Edward Elgar, 2015), at p. 87 (citing to the purchase order forms of companies such as Rio Tinto, Unilever, and GlaxoSmithKline); see also, A. BECKERS, Enforcing Corporate Social Responsibility Codes. On Global Self-Regulation and National Private Law, (Oxford: Hart Publishing, 2015) (defining the code as a voluntary instrument companies use to externalize their standards regarding their CSR practices).

840 M. Siems, Comparative Law, (Cambridge: Cambridge University Press, 2014), at p. 279.

841 A. RÜHmkOrF, Corporate Social Responsibility, Private Law and Global Supply Chains, (Cheltenham: Edward Elgar, 2015), at p. 89, 98 ("noting that it is generally the parties to that contract who can enforce that contractual effect," which generally means that third parties "cannot be subjected to a burden by a contract to which they are not a party." 
code of conduct. In this case, the buyer lacks the contractual privity to sue the seller's subcontractor. As noted back in the Introduction, the global supply chain is even more complicated with subcontractors further outsourcing parts of the original contract to subsubcontractors. Recall here in this context, the aforementioned phenomenon of firm disaggregation and the increasing fragmentation of enterprises discussed back in Chapter 3. Given that many Western brands "cannot bind companies further down the supply chain that are not its contractual partners... [t] he ability of contract law to promote CSR throughout the supply chain is therefore limited in practice." 842

There are, however, two practical ways to circumvent this problem for the downstream buyer, which would be to: 1) impose a duty to the initial supplier in the contract to "implement the buyer's CSR policy further down its own supply chain," 843 which is what is known as the perpetual clause or in the alternative; 2) to expressly prohibit initial suppliers to sub-contact parts of the contract to a third party without the buyer's express, prior written consent. ${ }^{844}$ While these measures resolve problems associated with establishing contractual privity between the MNC and its supplier's subcontractors, as noted before, in order to enforce the code on to the upstream businesses, the MNCs still must establish an adequate monitoring and auditing system to detect the breach in the first place, which brings us to the next part of the subsection.

\section{Monitoring, Auditing, and Enforcing Codes of Conduct}

The manner in which companies go about enforcing compliance to their codes of conduct throughout their supply chains bears a striking resemblance to how governments go about ensuring compliance to their labor/employment laws discussed back in Chapter 2. Many businesses attempt to enforce compliance to their codes through monitoring and randomized audits at the factories of their upstream business partners. In the event that the auditors detect violations, the buyers can reduce their orders or cancel their contractual relationship with the breaching seller thus creating extrinsic incentives for the seller to ensure compliance. In short, the functionality of auditing and monitoring resemble that of governments promulgating laws and having various agencies (i.e. AITF or Inspectie SZW) to enforce compliance and collect fines in the event of a violation.

The difference between the government enforcement of labor/employment laws and the corporate measures to ensure compliance to the code has to do with the variety of different monitoring and auditing mechanisms available in the private sector, where some monitoring mechanisms are clearly more strict and effective than others. For example, at one end of the spectrum, there is self-monitoring, which leaves it up to the upstream entities to regulate themselves and to submit the occasional reports to the downstream company. Self-reporting is a very popular approach given the low cost of implementation, but its

842 A. RÜHmkOrF, Corporate Social Responsibility, Private Law and Global Supply Chains, (Cheltenham: Edward Elgar, 2015), at p. 101.

843 A. RÜHMKORF, Corporate Social Responsibility, Private Law and Global Supply Chains, (Cheltenham: Edward Elgar, 2015), at p. 99 (noting also that "[i]f the first-tier supplier fails to incorporate the buyer's CSR policy into its contracts with its own contractors, then this failure constitutes a breach of the first-tier supplier's contractual duties to the buyer.’).

844 A. RÜHmkORF, Corporate Social Responsibility, Private Law and Global Supply Chains, (Cheltenham: Edward Elgar, 2015), at p. 100 . 
effectiveness - as an enforcement measure - is quite weak. ${ }^{845}$ At the other end of the spectrum, companies can hire independent inspectors to conduct routine audits. While hiring companies such as PricewaterhouseCoopers and Ernst \& Young to conduct audits is a more costly approach, compared to self-reporting, it is generally acknowledged as the better approach. That is not to say that hiring of the independent inspectors is without its problems: For example, even if the inspectors are supposedly independent, "a system that relies solely on monitors who are financially dependent on the companies being monitored cannot be considered autonomous." 846 To the extent that the inspectors are indeed being paid by the downstream corporations, their relationship could become symbiotic. So while the key factor that separates successful monitoring mechanisms from those that are not is the presence of frequent and independent monitoring, "when monitors and those being monitored develop a relationship, the effectiveness of that monitoring can dwindle, or possibly lead to a worse situation." 847

To resolve this symbiosis problem, other mechanisms of monitoring include forming a blind trust funded by various corporate members (i.e. Global Alliance of Workers and Communities) or to invite and give access to NGOs (i.e. GoodWeaves International) to come inspect the supply chains. While some codes, especially those monitored by independent third parties do "generate meaningful improvements for some workers or communities... compliance [still] remains highly uneven and violations pervasive" given the sheer complexity of the global supply chain. ${ }^{848}$ Depending on the frequency or the thoroughness of the auditing process, the compliance level changes accordingly. ${ }^{849}$ Moreover, an in-depth research conducted by a team from MIT of over 800 Nike suppliers in 51 countries showed that compliance is not only influenced by the frequency of auditing, but a variety of factors, including, but not limited to the location of the factory, its legal environment, and the relationship of the factory with the downstream company. ${ }^{850}$ This finding

845 A. RÜHmkOrF, Corporate Social Responsibility, Private Law and Global Supply Chains, (Cheltenham: Edward Elgar, 2015), at p. 120 (noting that "[s]elf-auditing still seems to be a popular tool in practice, perhaps because of the high number of suppliers which many Western companies have" or given the fact that "it facilitates the auditing process for them and reduces cost of monitoring.").

846 T.H. MORAn, Beyond Sweatshops: Foreign Direct Investment and Globalization in the Developing World, (Virginia: R. R. Donnelley and Sons, 2002), at p. 94.

847 D. ARIELY, The (Honest) Truth About Dishonesty: How We Lie to Everyone - Especially Ourselves, (New York: Harper Collins, 2012), at p. 227, 231.

848 D. Vogel, The Market for Virtue: The Potential and Limits of Corporate Social Responsibility, (Washington D.C.: Brookings Institution Press, 2006), at p. 76 (noting that "[c]ompliance remains highly uneven and violations pervasive"); see also, R. LOCKE, F. QIN \& A. BRAUSE, "Does Monitoring Improve Labor Standards?: Lessons from Nike," MIT Sloan School of Management Working Paper No. 4612-06 (2006). Available at: http://ssrn.com/abstract=916771 (last accessed 4 April 2017), at pp. 1-2 (discovering that "some factories appear to be in or close to full compliance with Nike's code of conduct while others appear to suffer from persistent problems with wages, work hours and health and safety issues.").

849 Cf. D. ArIELy, The (Honest) Truth About Dishonesty: How We Lie to Everyone - Especially Ourselves, (New York: Harper Collins, 2012), at p. 234 (noting that "[i]ncreased monitoring alone is unlikely to completely overcome our ability to justify our own dishonesty-particularly when others stand to gain from our misbehavior (not to mention the high financial costs of compliance with such regulations).”).

850 R. LOCKE, F. QIN \& A. BRAuSE, "Does Monitoring Improve Labor Standards?: Lessons from Nike," MIT Sloan School of Management Working Paper No. 4612-06 (2006). Available at: http://ssrn.com/abstract=916771 (last accessed 4 April 2017), at pp. 35-36 (listing factors such as "country effects (the ability of the labor inspectorate to enforce labor laws and standards in the country in which the factory is locate), factory characteristics (the age and size of the factory) and the relationship between Nike and the particular supplier (whether or not the supplier is a 
of how companies can increase compliance to the code - above and beyond establishing stricter and more frequent auditing frameworks - will be taken into consideration when proposing our own framework, but this discussion will be tabled until Chapter 6 . It is worth noting here, however, that this MIT study reveals a possible answer - or at least a partial answer - to our research question of what private actors can do differently to reduce instances of labor exploitation in the global supply chain: Companies seeking to be truly socially responsible must not just focus on higher code compliance as such, but must promote interactions at a more human level and not to treat workers as means to achieve a certain end. ${ }^{851}$

Before this thesis can expand or elaborate on this particular notion and attempt to answer our research question more fully, the more immediate issue of this subsection - what companies are currently doing - must be answered first. The short answer to this question is that while the emergence of codes of conduct and legally binding its compliance by relying on contract law show what companies are capable of, these measures have not rooted out labor exploitation from the global supply chain at least through its current implementations. ${ }^{852}$ This is partially due to the fact that codes of conduct, similar to the government enforcement of labor/employment laws, have the potential to improve the quality of life for the workers, but they are neither the panacea nor an adequate solution in and of itself. 853

In the end, the main problem with codes of conduct at least as they are being implemented now in the B2B context is the same problem that arises when government agencies attempt to enforce their labor/employment laws: It all comes back to the competence problem and the enforcement problem already noted back in Chapters 2 and 3 respectively. ${ }^{854}$ As it stands, codes of conduct are "not producing the significant and sustained improvements in workplace conditions that many had hoped it would." 855 Therefore, private actors must reassess their current approach, but before offering any reassessments, a discussion about the role of the consumers or ethical consumerism in this equation - as the driving force of companies perpetuating CSR strategies - must be addressed first.

strategic partner), how often Nike's non-compliance staff visit[ed] and interact[ed] with the factory, and who else is sourcing product from the same factory.").

851 S.J. FrenKEL \& D. SCOTT, "Compliance, Collaboration, and Codes of Labor Practice: The Adidas Connection," California Management Review 45(1) (2002): 29-49; see also, R. LOCKE, F. QIN \& A. BRAUSE, "Does Monitoring Improve Labor Standards?: Lessons from Nike,” MIT Sloan School of Management Working Paper No. $4612-06$ (2006). Available at: http://ssrn.com/abstract=916771 (last accessed 4 April 2017), at pp. 1-2.

852 E.J. SCHRAGE, "Promoting International Worker Rights Through Private Voluntary Initiatives: Public Relations or Public Policy?" A Report to the U.S. Department of State on behalf of the University of Iowa Center for Human Rights (2014). Available at: http://www.cfr.org/pdf/Schrage-DOS.pdf (last accessed 4 April 2017), at xii.

853 H. Collins, "Conformity of Goods, the Network Society, and the Ethical Consumer," European Review of Private Law 5 (2014): 619-640, 626 (noting that "we must remain skeptical about the effectiveness of much hyped corporate codes of conduct and similar measures in upholding minimum labour standards, for even well-intentioned western corporations cannot properly supervise the daily conduct of management in foreign business in the context of the 'organized irresponsibility' of business networks.').

854 R. LOCKE, F. QIN \& A. BRAUSE, "Does Monitoring Improve Labor Standards?: Lessons from Nike," MIT Sloan School of Management Working Paper No. 4612-06 (2006). Available at: http://ssrn.com/abstract=916771 (last accessed 4 April 2017) (noting that "notwithstanding the significant efforts and investments... to improve working conditions among its suppliers monitoring alone appears to produce only limited results.”).

855 R. LOCKE, F. QIN \& A. Brause, "Does Monitoring Improve Labor Standards?: Lessons from Nike," MIT Sloan School of Management Working Paper No. 4612-06 (2006). Available at: http://ssrn.com/abstract=916771 (last accessed 4 April 2017), at p. 36. 


\section{Codes of Conduct: Between Downstream Businesses and Consumers}

While the main focus of this chapter is on the role of corporations and various CSR initiatives that they can implement to reduce labor exploitation in the global supply chain, we already noted the vital role of the consumers and ethical consumerism in this context; to the extent that collective actions of consumers heavily influence what companies do and will continue to do so in the future, consumers are important pieces to our puzzle. ${ }^{856} \mathrm{Tra}-$ ditionally, "people have two general classes of responses available when they are unhappy. They can exit the situation, or they can protest and give voice to their concern." 857 In our context, consumers can exit by refusing to buy from companies that do not have a code of conduct (i.e. boycott), or in the alternative, voice their concern by calling out companies to adopt and implement codes that insist on not exploiting laborers. In what is often referred to as proxy accountability, consumers cannot only incentivize businesses to adopt a code of conduct, but through their purchasing decisions hold companies accountable on behalf of exploited laborers. ${ }^{858}$ While there are no laws banning consumers from shopping at stores associated with sweatshops or labor exploitation, through proxy accountability and holding themselves to a higher standard, ethical consumers can incentivize companies to be more socially responsible. ${ }^{859}$ However, there are two foreseeable concerns here: First, while consumers and consumer organizations can boycott companies or raise public awareness about companies violating their CSR policies, these private actors generally lack legal standing or have valid causes of action to go after companies directly for the way they exploit their laborers. ${ }^{860}$ As discussed back in Chapter 3, it would be difficult for consumers to sue the companies on behalf of their workers for their mistreatment and exploitation.

Second, while many acknowledge that the consumers are indeed the drivers of CSR activities, we also noted in the previous section that ironically it is the "purchase behaviour of many customers who buy cheap clothes without asking questions" in the first place that has "contributed to the widespread ignorance of human rights by suppliers in the developing world." ${ }^{861}$ In other words, not only do consumer lack legal standing to sue on behalf of the exploited laborers, but given the choice, many consumers do not hold themselves to a

856 A. RÜHMkORF, Corporate Social Responsibility, Private Law and Global Supply Chains, (Cheltenham: Edward Elgar, 2015), at p. 126 (noting that "[c]onsumers are increasingly a driver of CSR activities of companies"); see also, N.C. SMITH, "Consumers as Drivers of Corporate Social Responsibility," in The Oxford Handbook of Corporate Social Responsibility, A. Crane, A MCWilliams, D. MatTen et AL. (EDs.) (Oxford: Oxford University Press, 2008), at p. 281; and, D. VOGEL, The Market for Virtue: The Potential and Limits of Corporate Social Responsibility, (Washington D.C.: Brookings Institution Press, 2006).

857 See generally, A.O. Hirschman, Exit, Voice, and Loyalty, (Cambridge: Harvard University Press, 1970 ); B. SCHWARTZ, The Paradox of Choice: Why More is Less, (New York: Harper, 2004), at p. 111 (elaborating that "[i]n the marketplace, exit is the characteristic response to dissatisfaction.").

858 S. BRENTON, "The Political Motivations of Ethical Consumers," International Journal of Consumer Studies 37(5) (2013): 490-497, 490.

859 Proxy accountability is closely related to the idea of ethical consumerism, which is often characterized with catch phrases such as "voting with your wallet," but it is essentially a way for consumers to express their views and beliefs by selective shopping, boycotting, or a combination of the two.

860 A. RÜHMKOrF, Corporate Social Responsibility, Private Law and Global Supply Chains, (Cheltenham: Edward Elgar, 2015), at p. 219 (adding that "[e]thical consumerism is still more theory than practice"); see also, M. CARRINGTON, B. Neville \& G. Whitwell, "Why Ethical Consumers Don't Walk Their Talk: Towards a Framework for Understanding the Gap between the Ethical Purchase Intentions and Actual Buying Behaviour of Ethicallyminded Consumers," Journal of Business Ethics 97(1) (2010): 139-158.

861 A. RÜHmkorf, Corporate Social Responsibility, Private Law and Global Supply Chains, (Cheltenham: Edward Elgar, 2015), at p. 219. 
higher standard, thus only providing weak incentives for the businesses to actually implement and enforce CSR initiatives. Recall the incentive problem discussed back in Chapter 4 , in the context of what incentives companies have to be socially responsible: The same argument applies equally to consumers and their incentives to be ethical or socially responsible. While governments have obligations to protect those within their jurisdictions and corporations have the duty to provide wages and a safe working environment for their workers as required by the law, consumers generally have no similar legal obligation. ${ }^{862}$ Even if groups of consumers do in fact care about the impact of corporations on the exploited laborers, there is a bounded rationality problem in that there is a limit to what consumers - at least at an individual level - can do in terms where they obtain accurate information about corporate malpractices and what they can do about them. While interested consumers may rely on the information released by companies or read the news, there is no guarantee that the information that the consumers obtain is accurate, unbiased, or even complete. ${ }^{863}$ If the consumers, generally speaking, will not or cannot hold the companies accountable and they are the supposed drivers of CSR, there is a fundamental flaw with the system.

To conclude this subsection on codes of conduct, it is safe to suggest that while codes of conduct can indeed increase the reputation of a company's social responsibility, just because companies have implemented a corporate code does not mean that this actually improves the working conditions of the laborers at the other end of the supply chain. ${ }^{864}$ This was a point that was already made in the context of the causation problem back in Chapter 4, but it also applies in the context of codes of conduct as well. Take for example the aforementioned UN Global Compact, which has been hailed as the "most ambitious effort to develop norms for global corporations" that attempts to fill "the governance void of the global economy" and to "humanize the globalization process." 865 While aspirational indeed, the actual impact of the Global Compact has been mixed, with some commenting that the difference it has made as being incremental. ${ }^{866}$ Take another example, that of Ap-

862 One could argue that the consumer has an assortment of moral obligation towards the worker, but there are generally speaking - no legal obligations that a Western consumer owes to a worker say, in Bangladesh.

863 B. SCHWARTZ, The Paradox of Choice: Why More is Less, (New York: Harper, 2004), at p. 54 (suggesting that "[i]f people want real information, they have to go beyond advertisement to disinterested sources such as Consumer Reports. Its publisher, Consumer Union, is an independent, nonprofit organization whose mission is to help consumers."). This problem will be elaborated further in Chapter 3.4.

864 Amnesty International, "Exposed: Child Labour Behind Smart Phone and Electric Car Batteries," Press Release, (19 January 2016). Available at: https://www.amnesty.org/en/press-releases/2016/01/child-labourbehind-smart-phone-and-electric-car-batteries/ (last accessed 20 February 2016) (quoting Mark Dummett, a Business \& Human Right Researcher at Amnesty International stating that "[c]ompanies must not simply discontinue a trading relationship with a supplier or embargo [the problematic component] once human rights risks have been identified in the supply chain. They must take remedial action on the harm suffered by people whose human rights were abused.”).

865 G. KeLL \& D. LEvIN, "The Global Compact Network," in Learning to Talk: Corporate Citizenship and the Development of the UN Global Compact, M. MCINTOSH, S. WADDOCK \& G. KELL (EDS.) (Sheffield: Greenleaf, 2004), at p. 44.

866 M. TURner, "Effort to Bury Mistrust," Financial Times, (24 JuNE 2004). Available at: http://www.ft.com/ cms/s/0/d1395dc0-c57d-11d8-bfb1-00000e2511c8.html\#axzz40bysBPkm (last accessed 2 February 2016) (describing that the companies' motives for joining the pact as "a defensive response by trans-national corporations to public pressure" and "[b]y establishing this blue chip minimalism, they hope to avoid something that would lead to a more serious and effective means of accountability/regulation at the global level"); citing, McKinsey \& Co., "Assessing the Global Compact's Impact," UN Global Compact Office, (2004); see also, E.A. PoSNER, The Twilight of Human Rights Law, (Oxford: Oxford University Press, 2014), at p. 82 (stating that "[b]ecause NGOs lack the power to coerce, they ultimately depend on their ability to persuade governments, voters, businesses, and other 
ple, where the company has invested in various social responsibility initiatives over the years, but have not been able to completely root out persistent problems such as increasing low wages or reducing excessive working hours throughout their supply chain. ${ }^{867}$ Part of the reason why this is the case is because monitoring and auditing measures that attempt to enforce compliance through extrinsic incentives are generally paperwork exercises that focus primarily on quantitative analysis: "Inspectors typically spend one day - two, tops at each factory, mostly in the back office, checking time sheets for shift lengths, birth certificates for child labor, pay stubs for wages and overtime." 868 In other words, just because companies pass the auditing, does not necessarily mean that they are socially responsible or that the laborers are not being exploited.

While contracts do allow downstream buyers to bind upstream sellers to comply with their codes of conduct, thus making it is possible for a buyer to terminate the contract in the event that a seller breaches the code (i.e. by hiring sweatshop labor), it is conceivable that this only exacerbates the working conditions of laborers that work at the upstream seller's factory. ${ }^{869}$ While the buyer may claim that it did the socially responsible thing - by severing ties with a supplier who was exploiting laborers - just because the buyer severed ties with the seller does not actually mean that labor exploitation magically disappears. As already noted throughout this thesis, there are various spillover effects and unintended consequences that come with businesses simply severing ties with sweatshops, which could put the exploited laborers into even worse scenarios. ${ }^{870}$

In the end, simply because companies stop doing businesses with "bad companies" by strictly enforcing their codes of conduct does not mean that sweatshop labors will be better off, at least not in accordance with our normative framework of the adapted capabilities approach. Similarly, just because an ethical consumer decides to boycott a particular company accused of exploiting its laborers these actions alone do not cause the instances of labor exploitation to decrease as already noted in Chapter 4 and our analysis of the causation problem. This is even assuming that differentiating the "good companies" from "bad companies" is something that we are even capable doing in the first place, given our

people and institutions to take action against those whom the NGOs identify as human rights violators. Occasionally, boycotts and other forms of pressure follow from those efforts, but their overall effectiveness is clearly limited.”).

867 R.M. LOCKE, The Promise and Limitations of Private Power: Promoting Labor Standards in a Global Economy (Cambridge: Cambridge University Press, 2013), at p. 8 (noting that "[e]ven after several years of intense auditing of their suppliers, Apple's most recent Supplier Responsibility Report found that although most if its suppliers were improving their compliance on key issues such as underage labor, involuntary labor, and antidiscrimination, many of these same suppliers continued to struggle with excessive working hours and low wages.").

868 M. HobBes, "The Myth of the Ethical Shopper," The Huffington Post, (2015). Available at: http://highline. huffingtonpost.com/articles/en/the-myth-of-the-ethical-shopper/ (last accessed 16 July 2015); see also, D. VOGEL, The Market for Virtue: The Potential and Limits of Corporate Social Responsibility, (Washington D.C.: Brookings Institution Press, 2006), at p. 90 (noting that "[f]actory audits are typically based on written policies, on-site interviews with managers or workers, and the appearance of the factory during inspections. Yet such visits provide only a snapshot of factory practices, which may be misleading, especially when factories are notified of upcoming inspections.").

869 Cf. R.J. LIUBICIC, "Corporate Codes of Conduct and Product Labeling Schemes: The Limits and Possibilities of Promoting International Labor Rights Through Private Initiatives," Law and Policy International Business 30 (1998): 111,153 (suggesting that private initiatives may create an atmosphere conducive to unionization or reduce employee passivity).

870 See e.g. P. KRUGMAN, "Reckonings; Hearts and Heads" The New York Times, (22 April 2001). Available at: http://www.nytimes.com/2001/04/22/opinion/reckonings-hearts-and-heads.html (last accessed 4 April 2017). 
bounded rationality. In sum, there is no shortage of problems and limitations with the current ways in which the private sector is addressing the labor exploitation problem through the implementation of codes of conduct. Before elaborating further on the various problems with the existing contract/consumer law-based measures, let us analyze another popular CSR initiative first, which brings us to our next subsection on certification and labeling schemes.

\subsubsection{Certification and Labeling Schemes}

This subsection will discuss certification and labeling mechanisms, which are two very common CSR tools that aim to increase transparency of businesses by informing the public that the company in question and the goods or services that they provide are in compliance with a certain set of standards. Certification schemes and codes of conduct are similar in that they are both tools that establish some heighted standard that the companies aspire to meet, which often goes above and beyond what the law requires. They are related in the sense that a code of conduct could, for example, stipulate that all of their suppliers be certified in some manner or conversely, certain certification schemes could require that a company implement a code of conduct if they wish to be certified.

The basic idea behind certification and labeling is to provide transparency for the consumers and to signal to them that the company is socially responsible, that the product was made without exploitative labor, or that the product was made in an environmentally sustainable way. This could range from GMO-free produce labels to "Made in__" labels, the latter of which indicate that the product was manufactured in a jurisdiction with some minimum wage and labor standards (of course as the CNMI example in the Introduction already revealed that companies can exploit this mechanism as well).

Accordingly, this subsection will: a) differentiate between standards, certifications, and labels; b) offer a typical cost benefit analysis for companies seeking to implement certification and labeling schemes; c) discuss the issue of certification and labeling proliferation; d) elaborate on how private actors can prevent a race to the bottom from taking place in light of the proliferation problem; and finally, e) note some preliminary limitations with the certification and labeling schemes.

\section{A. Differentiating Between Standards, Certifications, and Labels}

One of the most commonly used certification schemes is the ISO 9001:2008, which is a guideline for quality management established by the International Organization for Standardisation ("ISO") based in Switzerland. ${ }^{871}$ The ISO also publishes other standards such as ISO 14001 (for environmental management standards) and ISO 26000 (for social responsibility). Although they are all related terms of art, it is important to distinguish here the differences between standards, guidelines, certifications, and labels at the onset. For example, the ISO 9001:2008 is essentially a document that lists series of standards and require-

International Organization for StAndardization, The ISO Survey of Management System Standard Certifications 2012, (2012). Available at: http://www.iso.org/iso/iso_survey_executive-summary.pdf (last accessed 4 April 2017) (noting that ISO 9001:2008 “is used in global supply chains to provide assurance about suppliers' ability to satisfy quality requirements and to enhance customer satisfaction in supplier-customer relationships."). 
ments on issues such as management responsibility (Section 5) and resource management (Section 6). Companies interested in becoming ISO 9001:2008 certified must first work to meet the standards published in the document. ${ }^{872}$ After the company has worked to meet the published standards, they must go through the certification process and to be officially ISO 9001:2008 certified, the company must be inspected by an independent auditor or assessor (not the ISO), who conducts a review and actually certifies the company. If the audit is successful, the company receives a certificate stating that the company is in compliance with ISO 9001:2008 standard. This does not, however, mean that this company can label all of their products with an "ISO 9001:2008 Certified" labels. As a matter of fact, the ISO specifically prohibits this practice. ${ }^{873}$

ISO 9001:2008 illustrates the point that although standards, certifications, and labels are all related, they are not the same. Certification refers to "the issuing of written assurance (the certificate) by an independent external body that has audited your management system and verified that it conforms to the requirements specified in the standard." 874 Certification in and of itself does not mean that they are entitled to label this accomplishment on their products. Labels, which are different from certifications, are essentially logos that are placed on the product or elsewhere that is visible to the consumers: "If designed well and tested for effectiveness, they are a very good tool to convey use, quality, health safety or environmental information or direct [consumers] to it." 875 What it comes down to is that just because a company meets a particular set of standard does not mean that they can be officially certified or be entitled to put a label on their goods. For example, ISO 26000 (which deals with social responsibility and issues that are more directly relevant to this thesis) is merely a list of standards - a guideline of sorts for companies - and even if companies follow this guideline to the tee, they cannot be certified because ISO 26000 is not a certifiable framework. ${ }^{876}$ On the other hand, it is entirely possible for a particular label not to have any meaningful certification or standard associated with it. For instance, companies can make their own self-regulated labels, but may not have any stringent certification process behind it. There are various other issues related to the certification process, such as the costs associated with them or how some certifications only allow certain types of companies or groups to certify, but this will be covered in more detail later.

872 As a quick side note, it is worth noting that although ISO 9001:2008 does not have a standard specifically regarding human rights violations in the supply chain, it deals with how businesses are operated at the management level from auditing procedures to implementation of internal measures to deal with issues relating to suppliers and customers, which indirectly affects the treatment of workers in their supply chain.

873 International Organization for Standardization, Publiciæing Your ISO 9001:2008 or ISO 14001:2004 Certification, (2010). Available at: http://www.iso.org/iso/publicizing_iso9001_iso14001_certification_2010.pdf (last accessed 4 April 2017) (noting the "unacceptable use of the ISO logo would include use on products, product labels and product-related information, on Web sites, in marketing materials, advertisements and company letterheads.").

874 International Organization for Standardization, Publicizing Your ISO 9001:2008 or ISO 14001:2004 Certification, (2010). Available at: http://www.iso.org/iso/publicizing_iso9001_iso14001_certification_2010.pdf (last accessed 4 April 2017).

875 European Commission, A Joint AIM-BEUC Initiative on Smarter Logos for Better Informed Consumers, (23 March 2014). Available at: http://ec.europa.eu/digital-agenda/en/news/joint-aim-beuc-initiative-smarter-logos-betterinformed-consumers (last accessed 4 April 2017); see also, AIM-BEUS initiative on Smarter Logos.

876 Other prominent "guidelines" or standards include OECD guidelines, UN Global Compact, UN Guiding Principles on Business and Human Rights just to highlight a few. 
Before getting to the cost benefit analysis and some of the issues associated with certifications and labels, a quick survey of just how prevalent these certifications are might be worthwhile. In 2012 alone, 11,417 ISO 9001 certificates were distributed in the Netherlands, 26,177 in the US and 1,101,272 in 184 countries worldwide, which demonstrates the popularity of this particular certification and the extent of its application. ${ }^{877}$ Since it was first published in 1987, ISO 9001 has enjoyed a steady - and generally increasing - support by companies who pay for the privilege to be certified.
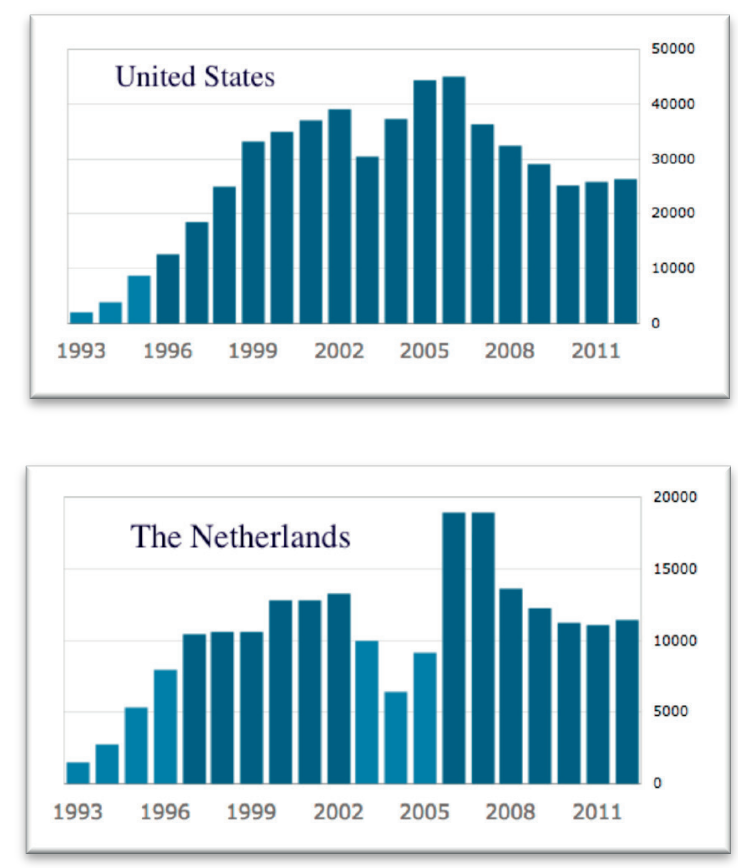

Figure 4: Number of ISO 9001 Certification Distributed in the US \& the Netherlands

While the ISO certification is one of the most commonly used schemes, there are many other certification and labeling schemes. Just to prove some context, the most recent figures indicate that there are more than 449 recognized labels in 197 countries across 25 industry sectors, ${ }^{878}$ and many more that are not recognized either because they are selfregulated and/or because they do not publicly disclose their certification requirements. So what incentivizes companies to join these schemes? This question leads us to the next part of this subsection.

INTERNATIONAL ORGANIZATION FOR STANDARDiZATION, ISO Survey 2012, (2012). Available at: www.iso.org/iso/home/standards/certification/iso-survey.htm (last accessed 4 April 2017).

878 ECOLABEL INDEX. Available at: http://www.ecolabelindex.com/ (last accessed 4 April 2017); see also, J. ENTINE, "Ecolabels - The wild west of labeling," Ethical Corporation, (7 March 2013). Available at: http://www.ethicalcorp.com/environment/ecolabels-wild-west-labelling (last accessed 4 April 2017); and, H. MAK, "Eco-labels: Radical Rethink Required," Ethical Corporation, (17 January 2012). Available at: http://www.ethicalcorp.com/environment/eco-labels-radical-rethink-required (last accessed 4 April 2017). 


\section{B. Certification and Labeling: The Cost Benefit Analysis}

Given the increasing number of businesses that are buying into the certification and labeling schemes, it is important to raise two fundamental questions in the context: 1) is being certified worth it for the companies; and 2) does it actually improve the treatment of its workers? The following part of this subsection will attempt to answer these two questions by listing some of the pro and cons of certifications and labeling schemes, and also attempt to answer the question of why companies are interested in voluntarily upholding their actions to a higher standard, above and beyond what is prescribed by the law.

The starting assumption here is that certifications and labels bring about some benefits for businesses or else ISO and other schemes would not have proliferated to the extent that they have today. However, when it comes to the question of whether certification actually improves the quality of the businesses, the products that they sell, or the way businesses treat their workers, the answers are somewhat unclear. Proponents of certification and labeling schemes are quick to note that businesses benefit from companies embedding CSR measures to their core business. Eccles, Ioannou, and Serafeim have conducted empirical studies where they have shown a correlation between publicly owned companies implementing sustainability initiatives - like labeling - with better stock performance. ${ }^{879}$ In addition to the financial incentives, the proponents claim that certification and labeling schemes actually help the workers in the supply chain: For example, groups like the Fair Trade USA or Fairtrade International ("FLO") offer certifications and labels for commodities such as coffee and sugar to businesses and claim that their certification and labeling programs are designed to improve the working conditions and wages for poor farmers. Fairtrade International does so by creating a price floor for products such as coffee and selling them at "a higher price than ordinary food, with subsidy passed back to the farmer." 880 The cost of this premium is mostly shifted to the consumers, but even with the inflated price, there is some evidence to suggest that companies can still make a profit, given that there are ethical consumers that prefer to buy the more socially responsible goods. ${ }^{81}$ On paper, this seems like a win-win-win situation for the coffee farmers, the coffee businesses, and the consumers, who supposedly get some sense of intrinsic egoboost for being an ethical consumer, but that is not an entirely accurate picture of reality.

Related to the aforementioned concept of proxy accountability, Chris Willie of the Rainforest Alliance - yet another organization that offers a certification and label for products such as coffee - notes that consumers at one end of the supply chain "really do have the power to send a message back all the way through the complicated supply chain" that impacts the lives of farmers at the opposite end of the supply chain "[i]f the message is

R.G. ECCLES, I. IOANNOU \& G. SERAFEIM, "The Impact of Corporate Sustainability on Organizational Processes and Performance," Harvard Business School Working Paper 12-035 (2013). Available at: http://www.hbs.edu/ faculty/Pages/item.aspx?num=47307 (last accessed 4 April 2017).

880 "Good Food?," The Economist, (7 December 2006). Available at: http://www.economist.com/node/8381375 (last accessed 4 April 2017).

881 British ASSESSMENT BUREAU, "ISO 9001 Proven to Help Win New Business." Available at: http://www.british-assessment.co.uk/guides/iso-9001-opens-doors-for-uk-businesses/ (last accessed 18 December 2016) (stating that according to their survey, " $44 \%$ of respondents said that they had won business as a result of becoming certified to the ISO 9001 quality management standard."). 
frequent, loud and consistent enough..." 882 In other words, consumers, through activism, can actually change business practices. Hugh Collins concurs that "the role of consumption as an expression of allegiances and values" can be a catalyst for change, ${ }^{883}$ and CSR measures like labels can - at least in theory - empower consumers by giving them information that can affect their consumption habits to be more in alignment with that of their values and beliefs. ${ }^{884}$

Businesses in turn can use labels are a tool to measure consumer demand, assuming that there is some demand for socially conscious products and services, and supply that demand efficiently. The assumption that some consumers are willing to pay more - a premium - in order to satisfy their need to be socially responsible is an opportunity that businesses can capture. The fact that products with certain CSR labels can be sold at a higher price and the fact that there are consumers who willing to buy them presents a possibility of the private sector.

Part of the reason why consumers are willing to pay a premium is based on their assumption that certified companies are more socially responsible, which has a certain appeal not just some consumers, but also to potential investors as well. The subject of how socially responsible investors may prefer to invest in socially responsible companies was already discussed back in Chapter 4 (i.e. in the context of investing in benefit corporations). ${ }^{885}$ While Chapter 4 discussed benefit corporations in the context of a company law-based approach, where companies incorporate with certain social responsibility embedded into their articles of incorporation, there is a contract law-based instrument that is quite similar, which is the B Corp certification. While there are similarities between incorporating as a benefit corporation and certifying as a B Corp, there are some differences: For example, any company that meets the certification requirements listed by B Lab (a nonprofit organization that certifies companies with the B Corps certification) and completes an assessment review along with submitting the relevant supporting documents can become a B Corps certified company. 886 The basic aim of B Corps according to B Lab is to "build a more inclusive, resilient, and sustainable economy [by] voluntarily meeting higher standards of transparency, accountability, and performance." 887 According to B Lab, there are over 990 companies from 32 countries in over 60 industries that are currently registered as being B Corp certified. 888 These companies unify under the motto of "make money and make a difference," and are aspiring to use "business as a force for good." It has been said that "B

882 The Economist, "Voting with your trolley" (7 December 2006). Available at: http://www.economist.com/ node/8380592/print (last accessed 4 April 2017).

883 H. COLLins, "Conformity of Goods, the Network Society, and the Ethical Consumer," European Review of Private Law 5 (2014): 619-640, at p. 639.

884 The Economist, "Voting with your trolley" (7 December 2006). Available at: http://www.economist.com/ node/8380592/print (last accessed 4 April 2017) (noting that "labels make a political act out of consumption").

885 See e.g. P. CAMEJO, The SRI Advantage: Why Socially Responsible Investing Has Outperformed Financially, (British Columbia: New Society, 2002); see also, S. RoberTs, J. KeEble \& D. Brown, "The Business Case for Corporate Citizenship," Arthur D. Little, Inc. (2003), at p. 8 (reporting that " $86 \%$ of institutional investors across Europe believe that social and environmental risk management will have a significantly positive impact on a company's long term market value," based on their survey conducted among 302 financial analysts and fund managers across Europe on SRI).

886 Performance Requirements to become B Corps certified can be found here: http://www.bcorporation.net/ become-a-b-corp/how-to-become-a-b-corp/performance-requirements (last accessed 4 April 2017).

887 B Corps Annual Report (2012), at p. 6.

888 Available at: http://www.bcorporation.net/what-are-b-corps (last accessed 4 April 2017). 
Corp is to business what Fair Trade certification is to coffee," 889 and similar to how some consumers might be willing to pay a premium for a Fair Trade coffee, some investors are more inclined to invest in a B Corp certified company relative to their non-certified competitors.

While focusing only on the proponents' arguments paints a rather rosy picture, at the other end of the spectrum, however, there are those that argue that: 1) certification is not worth the cost, 2) certification does not make any meaningful impact in the lives of the laborers, and 3) certification could even make matters worse, not only for the workers, but for the companies that implement them. ${ }^{890}$ First and foremost, compliance to a set standard does not come for free: In fact, the certification process is usually expensive and timeconsuming. For this and various other reasons, there are those that believe that private actors should resist the urge to certify everything or always rely on labels. ${ }^{891}$ One of the most often cited criticism for certification and labeling schemes in literature is an economic one, especially for labels like Fair Trade that imposes a price floor. The essence of this argument can be summarized as follows:

"The low price of commodities such as coffee is due to overproduction, and ought to be a signal to producers to switch to growing other crops. Paying a guaranteed Fairtrade Premium - in effect, a subsidy - both prevents this signal from getting through and, by raiding the average price paid for coffee, encourages more producers to enter the market." 1892

While this might be beneficial for Fairtrade coffee farmers, this phenomenon various experts have suggest that certifications that impose price floors exacerbate the situation for the non-certified coffee farmers, who are then forced to drop their prices to maintain their competitive advantage. ${ }^{893}$ Moreover, the argument that typically comes with implementing a price floor also applies here, which is that when a minimum price is implemented, it could potentially curtail business incentives to improve the quality of the product. Obviously there are other certification and labeling schemes that do not impose a price floor, but this goes to prove that: 1) not all certifications are created equal, 2) many private actors - especially consumers - may be unaware of what the label stands for, and 3) even for private actors that do know what certification criteria a particular label claims, what impact the certification and labeling scheme actually has on the exploited workers in the global supply chain, is - at times - murky, once again validating the causation problem mentioned in Chapter 4.

The causation problem in the context of what kind of impact certifications like Fairtrade that impose price floors have on the working lives of the laborers is worth a closer inspection. The truth of the matter is that while the average consumer believes Fairtrade products to be more sustainable and better for the farmers, the reality - as sug-

889 Available at: http://www.bcorporation.net/what-are-b-corps (last accessed 4 April 2017).

890 See generally, J. SEDDON, The Case Against ISO 9000, (Cork; Oak Tree Press, 2000) (noting that although companies that fail to be ISO 9000-certified are shun from the market, obtaining the certificate does not ensure quality).

891 See e.g., H. MAK, "Eco-labels: Radical Rethink Required," Ethical Corporation, (17 January 2012) (noting that "we can't [and] we shouldn't... certify and label everything.").

892 The Economist, "Voting with your trolley," (7 December 2006). Available at: www.economist.com/ node/8380592/print (last accessed 4 April 2017).

893 See generally, T. HARFORD, The Undercover Economist, (New York: Random House, 2007) (explaining that this process "drives down the price of non-Fairtrade coffee even further, making non-Fairtrade farmers poorer.") 
gested above - is not that simple. To argue this point, let us assume for the sake of argument that some consumers are indeed willing to pay a premium for Fairtrade coffee in the hopes that the extra cost will lead to the improvement in the coffee farmers' quality of life. If the premiums that the consumers pay go directly into the pockets of the farmers that would be one thing; however, the premium does not go from the consumers' wallets directly into the farmers' pockets. According to an expose by The Economist, Fairtrade is ultimately "an inefficient way to get money to poor producers [as] [r] etailers add their own enormous mark-ups to Fairtrade products and mislead consumers into thinking that all of the premium they are paying is passed on," when in fact only about " $10 \%$ of the premium paid for Fairtrade coffee in a coffee bar trickles down to the producer." ${ }^{994}$ If we approach this from a "glass is half full" approach, that is at least $10 \%$ more than the coffee farmers would have had, which might actually improve the lives of the coffee farmers working with Fairtrade certified companies.

A more cynical way - the "glass is half empty" view - is to see these certification and labeling mechanisms as yet another marketing tool that gives businesses the "means of identifying price-insensitive consumers who will pay more," but without actually improving the working life of the exploited laborers. ${ }^{895}$ In this context, recall the CNMI case study from the Introduction and how upstream manufacturers were able to manipulate the downstream brands and the general public by using the "Made in the USA" label. This is to suggest that consumers can be easily manipulated by some of these certifications and labeling schemes. Moreover, Cass Sunstein and Richard Thaler warn that "[i]f consumers have a less than fully rational belief, firms often have more incentive to cater to that belief than to eradicate it." ${ }^{896}$ In other words, if consumers automatically assume that "Made in the USA" means the goods were made well, or if Consumers think paying a premium for Fairtrade will benefit the coffee farmers, companies can choose to exploit people's misbeliefs and use psychological behaviors against consumer's interests. ${ }^{897}$ In other words, the Fairtrade example not only illustrates how these certification and labeling mechanisms can disproportionately benefit businesses relative to the coffee farmers, but it calls attention to the fact that companies might use labeling mechanisms into luring consumers into a false sense of security that they are being a socially responsible consumer, when in fact their purchasing decision failed to remedying the labor exploitation problem in a manner that aligns with our normative framework of empowering workers and increasing their capabilities.

Taking a step away from the price floor-specific concerns, there are many other issues that make the opponents of certification and labeling schemes question the effectiveness of these mechanism, which companies interested in engaging in CSR initiatives should bear in mind. For example, there is the issue of certification measures that only allow certain qualified businesses or groups to be even considered for certification. Sticking with our coffee

894 The Economist, "Voting with your trolley," (7 December 2006). Available at: www.economist.com/ node/8380592/print (last accessed 4 April 2017).

895 T. HARFORD, The Undercover Economist, (New York: Random House, 2007), at pp. 42, 46; see also, "Voting with Your Trolley," The Economist, (7 December 2006). Available at: http://www.economist.com/node/8380592/print (last accessed 4 April 2017).

896 R.H. Thaler \& C.R. SunsteIn, Nudge: Improving Decisions About Health, Wealth, and Happiness, (New York: Penguin, 2009), at pp. 81-82.

897 R.H. Thaler \& C.R. SUnSTEIN, Nudge: Improving Decisions About Health, Wealth, and Happiness, (New York: Penguin, 2009), at p. 79. 
example, for every certification and labeling schemes like the Rainforest Alliance, which allows producers of all sizes and kinds to be certified, there are those like Fairtrade International that only allows co-operatives of small producers to be certified and not plantations or large family operations. ${ }^{898}$ Given that the "vast majority of farm workers work on plantations," ${ }^{999}$ limiting certification to only a small group of businesses could mean that many of the laborers that work on large plantations are not being helped by the Fairtrade International certification and labeling mechanism. While this fact alone is not a good enough reason to discredit Fairtade products all together, when taking in combination with the aforementioned fact that Fairtrade certification has the spillover effect of incentivizing non-certified companies to lower their coffee prices even further, private actors cannot just assume that Fairtrade products are beneficial for everyone in the global supply chain, because the reality is not that simple. For example, one could arguably claim that the Rainforest Alliance certification, which does not guarantee a price floor, but opts instead to train and facilitate the farmers' access to credit, is better than the Fairtrade International's certification and labeling scheme, ${ }^{900}$ but then again, it is difficult to make a convincing argue that this type of a training based certification is "better" than those that do not, given that these types of arguments are too reductionist and they over-simplify the complex nature of reality. In short, for businesses attempting to conduct a cost benefit analysis of whether they should certify or which certification is better for them, the analysis requires a certain set of subjective criteria that is entirely too circumstantial for any in-depth analysis, at least for the purposes of this thesis.

This brief analysis addressed the two main issues of whether being certified is worth it for companies and whether certification and labeling measures actually improve the treatment of workers in the global supply chain. ${ }^{901}$ While the answer depends on multitude of factors, such as which certification and labeling schemes we are talking about, the general answer is that there is indeed some potential for these schemes to actually improve the lives of the exploited laborers (i.e. getting $10 \%$ of the premiums consumers pay if they work for companies that are certified by Fairtrade), but there is also a serious risk that they can exacerbate the plight of the workers, not to mention the fact that these mechanisms disproportionately benefit the businesses vis-à-vis the laborers. Therefore, similar to the preliminary conclusion that this thesis reached with regards to codes of conduct, this part of the subsection will conclude that while certification and labeling schemes have the potential to reduce instances of labor exploitation in the global supply chain, this approach is also not a panacea or the silver bullet.

\section{The Proliferation of Certifications and Labels}

898 "Voting with Your Trolley," The Economist, (7 December 2006). Available at: http://www.economist.com/node/ 8380592/print (last accessed 4 Apri 2017).

899 "Voting with Your Trolley," The Economist, (7 December 2006). Available at: http://www.economist.com/node/ 8380592/print (last accessed 4 April 2017).

900 "Voting with Your Trolley," The Economist, (7 December 2006). Available at: http://www.economist.com/node/ 8380592/print (last accessed 4 April 2017).

901 For an in-depth look on certifications and labels see, A.M. GANDARA, The Law and Economics of Eco-labels, European Doctorate in Law and Economics (2013). 
As previously mentioned, the idea behind certifying and labeling is that, in theory, it adds more transparency to the products or services being offered by businesses, which in turn allows consumers to make informed choices about their consumption. Proponents of labels believe that this increase in informed consumption not only enhances the businesses' willingness to adopt CSR initiatives, but possibly even improve the working conditions of laborers in the bottom echelons of the global supply chain. The lingering question worth asking, however, is whether consumers are really willing - or even capable - of making that "informed decision" given the hundreds of different types of labels that are in existence: These labels range from regional labels to global labels. They can be single-issue or multiissue. They can be self-regulated or regulated by an independent third party. They can be aimed towards consumers or towards other businesses. More importantly, the criteria required to "earn" these label differ greatly from one to another as already noted above (i.e. FairTrade certification versus Rainforest Alliance certification). This means that labeling schemes are generally not standardized and more importantly, given the proliferation of these labels, there is a very real possibility that both consumers and businesses are unaware of what some of these labels actually mean. Moreover, any further proliferation of labels could become counter-productive (perhaps yet another example of an Inverted-U curve at work). Although some consumers might actually have familiarity with these labels (see Figure 5), majority of private actors do not know what many of these labels actually signify: For example, Ecolabel Index's Anastasia O'Rouke noted that the "sea of stylized leaves and bean sprouts is confusing not only to individual consumers but to major purchasers like universities trying hard to do the right thing." 902 The general lack of awareness amongst even the most motivated private actors about what these labels actually entail is a major point of contention for those claiming that these labels lead to private actors making informed consumption

choices and thus improve the working conditions of the workers at the other end of the global supply chain.

Not only are these labels seemingly multiplying exponentially, but some of the labels go through periodic design changes or even alter what the companies must do to earn the labels: For example, one of the most frequently used agricultural label in the US is Fair Trade USA, which was formerly known as TransFair USA. As

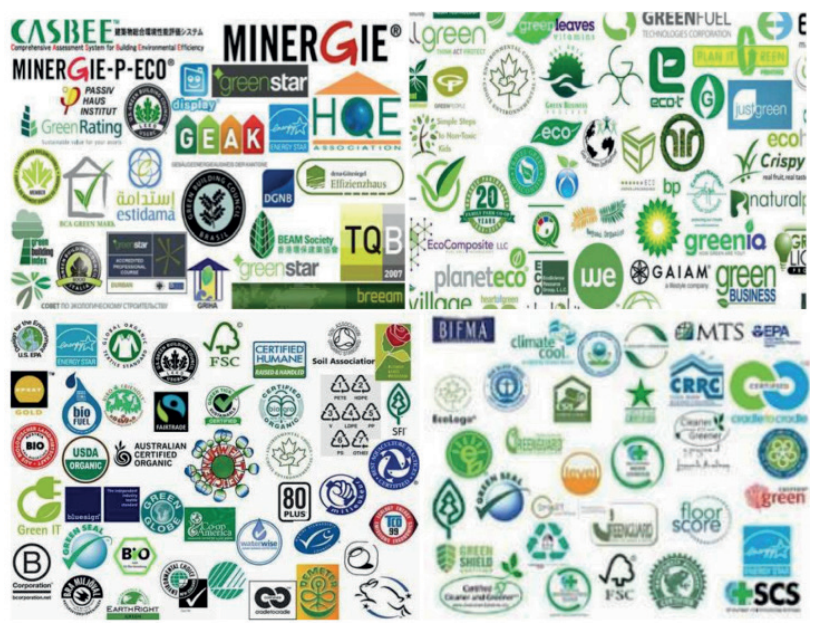

Figure 5: Sample CSR Labels

902 S. Overgaard, “As U.S. States Look to Add Food Labels, Denmark Looks to Subtract Some,” NPR, (29 October 2012). Available at: http://www.npr.org/blogs/thesalt/2012/10/29/163869580/as-u-s-states-look-toadd-food-labels-denmark-looks-to-subtract-some (last accessed 3 April 2017). 
the name suggests, Fair Trade USA is a regional labeling system, unlike the Fairtrade International (formerly known as the Fair Trade Labeling Organization) that has a more global reach compared to Fair Trade USA. Although the names sound similar, they are two different labeling schemes. Many of these labels do share similar goals, but attempt to further these goals through various different methods (i.e. some labels impose price floors as opposed to other labels that impose price ceilings), which could lead to drastically different outcomes. Bearing this in mind, is an average consumer really capable of deciphering these labels? For example, sticking to our example of coffee, can consumers really tell the difference between USDA Certified Organic, Fair Trade Certified, Shade Grown, Smithsonian Migratory Bird Center Bird-Friendly Coffee, and Rainforest Alliance Certified coffees? ${ }^{903}$ If anything, the further proliferation of these labels could lead to fragmentation, which could lead to a choice overload problem and prove to be counter-productive. The next section of this Chapter (5.3) will address this choice overload problem in more detail, but for now, it suffices to consider where there are too many labels already in existence, and whether this proliferation could incentivize consumers to stop taking the time to learn about them all together. If this is indeed a possibility, this could significantly weaken the claim that labeling leads to a more informed choice by the consumers.

What could exacerbate this already concerning situation is the potential race to the bottom that it can trigger amongst companies that realize that the majority of their consumers are unaware of what the labels actually signify as Sunstein and Thaler predicted earlier: For example, if consumers are unaware of the fact that meeting the certification requirements of a C4G label is cheaper and less demanding than the Fairtrade International label, is there an incentive for the companies to pick the more expensive label when they can simply go with the cheaper, and possibly equally good option? More critical of certification in general is environmentalist, Jennifer Jacquet, who notes that as certifications become more popular, it places greater responsibility on individual consumers rather than putting the pressure where it belongs, on companies and societies at large. ${ }^{904}$ Again, this is part of the reason why the incentive behind why companies implement CSR initiatives in the first place is important because if the company's primary interest is profit, then that company could very possibly "settle" for the C4G label. This kind of a scenario is a breeding ground for a race to the bottom type of a scenario, where the companies might simply opt for the cheapest, easiest label to get and in the process check off the box for meeting their CSR goals, without ever having to look under the hood and to determine what impact that decision has at the other end of the supply chain. For some less than honest businesses, this proliferation of labels and the confusion that it creates for the consumers could be perceived as a "good" thing because better informed customers could potentially jeopardize their sales. ${ }^{905}$

903 The answer to this particular question can be found here: http://www.eco-coach.com/blog/2008/12/04/ecofriendly-coffee-not-just-fair-trade/

904 J. JACQUet, Is Shame Necessary: New Uses for an Old Tool, (London: Penguin Books, 2016), at p. 7 (adding that collective action problems cannot be resolved simply by "changing the psychology and therefore the behavior of individuals," as problems of this nature often require "larger, often structural changes.").

905 C. HAunhorst, "Food from Nowhere: Producers Reject Calls for Stricter Labels," Spiegel Online International, (17 October 2012). Available at: http://www.spiegel.de/international/business/consumer-watchdogs-call-for-moredetail-on-processed-food-labels-a-861411.html (last accessed 4 April 2017). 


\section{Preventing the Race to the Bottom with Smarter Logos?}

Once again, the debate surrounding the utility of certification and labeling schemes and how they can be improved is nothing new. As a matter of fact, ideas to remedy the issue of label proliferation by having a more clear and transparent labeling system - in an effort to avoid such a downward spiral - have been around for some time, but have been met with some resistance from various industries that have hired lobbyists to block such movements. ${ }^{906}$ However, continuing attempts to better improve these labels so that they can actually inform consumers is an initiative that is gaining some renewed traction worldwide. At the EU level, one of the main issues on the EU Consumer Agenda is to enhance consumer knowledge through the use of better logos. ${ }^{907}$ For example, research conducted by the European Brand Association ("AIM"), together with European Consumer Organization ("BEUC") tested existing labels and reached similar conclusions as the one we reached above: The Director General of the BEUC, Monique Goyens, noted the following:

"Logos exist in all forms and shapes. Consumers are often unfamiliar with them, misinterpret their meaning or are even confused by their message. There is a large body of literature on design and testing of logos. We urge that any new logo which is part of a EU law is tested within a representative group of uses. Only this could guarantee its added value."

A slightly different approach, an approach taken by the Danish Consumer Council, is to simply get rid of overlapping labels in order to reduce the number of labels in circulation to the extent possible. ${ }^{909}$ While it might be tempting to simply regulate the number and types of labels allowed, some governments might be reluctant to overregulate what private companies can and cannot do and so long as claims being made by businesses on their labels are not grossly false or fraudulent, this approach of restricting permissible labels might not be the recommended approach for all.

Across the Atlantic in the US, there are similar dialogues taking place about standardizing labels and creating better labels at both the state and federal level. ${ }^{910}$ For example, the US Fair Trade Commission ("FTC") recently published a revised Green Guide to ensure that the claims made on sustainability labels are "truthful and non-deceptive." 911 In coming up with the revised Green Guide, the FTC stated that it collected a wide range of public

C. HAunhorst, "Food from Nowhere: Producers Reject Calls for Stricter Labels," Spiegel Online International, (17 October 2012). Available at: http://www.spiegel.de/international/business/consumer-watchdogs-call-for-moredetail-on-processed-food-labels-a-861411.html (last accessed 4 April 2017).

907 European Commission, A Joint AIM-BEUC Initiative on Smarter Logos for Better Informed Consumers, (23 March 2014). Available at: http://ec.europa.eu/digital-agenda/en/news/joint-aim-beuc-initiative-smarter-logos-betterinformed-consumers (last accessed 4 April 2017).

908 European Commission, A Joint AIM-BEUC Initiative on Smarter Logos for Better Informed Consumers, (23 March 2014). Available at: http://ec.europa.eu/digital-agenda/en/news/joint-aim-beuc-initiative-smarter-logos-betterinformed-consumers (last accessed 4 April 2017).

909 S. OvergaArD, “As U.S. States Look to Add Food Labels, Denmark Looks to Subtract Some," NPR (29 October 2012). Available at: http://www.npr.org/blogs/thesalt/2012/10/29/163869580/as-u-s-states-look-toadd-food-labels-denmark-looks-to-subtract-some (last accessed 3 April 2017).

910 M. BitTman, "My Dream Food Label," The New York Times, (13 October 2012). Available at: http://www.nytimes.com/2012/10/14/opinion/sunday/bittman-my-dream-food-label.html?_r=0 (last accessed 4 April 2017).

911 Federal Trade Commission, "FTC Issues Revised 'Green Guides',' (1 October 2012). Available at http://www.ftc.gov/sites/default/files/attachments/press-releases/ftc-issues-revised-greenguides/greenguides.pdf (last accessed 4 April 2017). 
input from both consumers and businesses. It is important to bear in mind the potential benefit of public and private collaboration as we move towards the subsequent chapters, but with regards to these initiatives that attempt to make labels smarter, there is potential for opportunity here, which could benefit not only the consumers, but aid their efforts to alleviate the plight of the exploited laborers at the other end of the supply chain.

However, any sense of optimism must be curbed with a healthy dose of reality: Regardless of how smart these labels become or how convenient it becomes for consumers to check whether the products and services that they are buying involve any human rights violations or not, the issue still remains that the average consumer might not care (or cannot afford to care) and therein lies the limitation of CSR initiatives and proxy accountability of consumers, which brings us to the next part of the subsection.

\section{E. Foreseeable Limitations of Certification and Labeling Schemes}

One of the main implications that emerged from this subsection was that certification and labeling schemes are not without its flaws: First, some certification and labeling schemes simply do not contribute to making the businesses more socially responsible. Second, the certification and labeling process is cost prohibitive for smaller businesses, which means that even if some of their practices are more socially responsible than that of the MNCs, consumers could be misled into thinking that the product with the label is more socially responsible. Third, the overabundance of these labels can lead to a choice overload problem, leading consumers to simply ignore the labels. Fourth, there are those that believe that certification and labeling schemes not only dupe consumers into a false sense of security by suggesting that "guilt-ridden shoppers could avoid their uneasy feelings by simply changing their buying habits," but that these measures generally do not transform businesses into a socially responsible entities by themselves. ${ }^{912}$ Fifth, from the perspective of the exploited laborers, just because some consumers pay more for goods with labels on them, does not necessarily mean that the premium goes directly into the pockets of the exploited laborers. Based on these observations, there is a strong argument that certification and labeling schemes, as they exist today, is a source for more confusion, rather than clarity and transparency.

Ultimately, certification and labeling schemes might give a competitive advantage to certified businesses that place labels on their products, ${ }^{913}$ but the answer to the question of whether they really reduce instances of the labor exploitation in the global supply chain remains heavily contested. One thing is for certain, which is that for every proponent of certification and labeling scheme that allege their unquestionable benefits, there are those equally convinced of their limitations. In the end, the likely answer is that certifying all the companies or labelling all of the products in the world is not necessarily going to end labor 
exploitation as we know it. ${ }^{914}$ This is precisely why certification and labeling, like codes of conduct, is not the panacea, which suggests that private actors can benefit from reassessing their over-reliance on such mechanisms.

The next subsection will address how contract/consumer law-based claims can support these CSR initiatives or at least incentivize companies to take these measures more seriously. In doing do, the next subsection will address whether these measures can actually affect the working conditions of the laborers in the lower echelons of the global supply chain.

\subsubsection{Vitiating Factors and Consumer Protection Based Arguments}

The previous subsections suggested that consumers take into consideration a company's CSR initiatives in their purchasing decisions and to the extent that downstream buyers select their upstream sellers based on their willingness to comply with their code of conduct, the law should protect both these consumers and downstream buyers from false information and broken promises. ${ }^{915}$ This subsection will now focus on these legal arguments that private actors can make, not only to provide them with remedies, but also to hold companies more accountable to the various CSR initiatives noted above. This subsection, accordingly, will address potential claims based on defects of consent, breach of contract, consumer protection, and arguments based on immorality and public policy. In addition, this subsection will also provide an analysis of what impact - if any - the success of these potential claims have on the working conditions of the upstream laborers.

Accordingly, this subsection will have the following composition: This subsection will first a) attempt to assess the feasibility and the desirability of consumers invalidating unethical contracts using arguments based on defects of consent, followed by b) arguments based on claims that the underlying contract was either immoral or contrary to public policy. These two parts will be followed by the analysis of claims based on c) consumer protection laws of the EU and d) consumer protection laws in the US to see whether they are feasible and desirable ways for consumers to hold companies more accountable to their claims of social responsibility.

\section{A. Defects of Consent: Fraud, Misrepresentation, and Mistake}

This chapter already noted how contracts can be used to legally bind upstream sellers to the downstream buyers' otherwise voluntary codes of conduct. This part of the subsection, will now detail how downstream buyers (and even consumers) can get out of their contracts with companies that exploit their laborers or misled the consumers by looking at vitiating factors such as defects of consent and prohibited contracts. While the binding nature of contracts can incentivize businesses to adhere to various voluntary CSR initiatives, companies can similarly be motivated to behave in accordance with a certain code, if failure to accessed 4 April 2017) (noting that "[n]o amount of Fairtrade coffee will eliminate poverty, and all the organic asparagus in the world will not save the planet.").

915 A. RÜHMKORF, Corporate Social Responsibility, Private Law and Global Supply Chains, (Cheltenham: Edward Elgar, 2015), at p. 129 (stating that "consumers are influenced in their purchase decisions by the CSR commitment of companies”); S.D. MuRPHY, "Taking Multinational Corporate Codes of Conduct to the Next Level," Columbia Journal of Transnational Law 43(2) (2005), at p. 45. 
comply with a code means that the buyer can refuse payment for goods or services rendered. ${ }^{116}$ The relevant question in this part of the subsection therefore, is how can private actors rely on these contract/consumer law-based arguments to make corporations more accountable? This part of the subsection will start answering this question by looking at defects of consent claims such as fraud, misrepresentation, and mistake.

The first of the possible defects of consent-based claims is fraud or fraudulent misrepresentation. ${ }^{917}$ If a company claims that their products were made in a socially responsible manner, knowing full well that that was not the case (thus willful deception), a consumer or the downstream buyer who relied on that claim could seek to invalidate the contract based on fraud or fraudulent misrepresentation: "All civil codes and international instruments... make clear that fraud (dol, arglistige, täuschung, bedrog) is grounds for avoidance of the contract or other juridical act." 918 More specifically, in the Netherlands, BW Article 3:44 (1) states that "a juridical act may be annulled when it has been entered into as a result of threat, fraud or abuse of circumstances" $" 919$ and similarly in New York, both statutory provisions and case laws hold that fraud is a valid basis to invalidate a contract. ${ }^{920}$ In addition to invalidating the contract, parties can also claim for damages if the circumstances call for it. ${ }^{921}$ In other words, if the downstream buyer purchased a component for one of their upstream sellers with an understanding that that component was sourced responsibly, but the buyer

916 J.M. SMITS, Contract Law: A Comparative Introduction, (Cheltenham: Edward Elgar, 2014), at p. 157 (elaborating that "in cases where performance has already taken place, it will have to be reversed" and that "the price and the delivered goods or services need to be given back in so far as this is still possible.").

917 P. Augur, P. Burke, T.M. Devinney \& J.J. Louviere, "What Will Consumers Pay for Social Product Features?," Journal of Business Ethics 42(3) (2003): 281-304, 281 (stating that "[o]ne possible avenue of redress may be found in the law of fraud or misrepresentation. If the seller of the goods has represented certain facts about the product, such as that the coffee was produced in accordance with Fair Trade standards or that the trainers were made without the employment of children, and if those representations turn out to be false, a court might rescind the contract under the common law of misrepresentation."); as cited in, H. CoLlins, "Conformity of Goods, the Network Society, and the Ethical Consumer," European Review of Private Law 5 (2014): 619-640, 629.

918 J.M. SMITS, Contract Law: A Comparative Introduction, (Cheltenham: Edward Elgar, 2014), at p. 167 (referencing how fraud is treated in France, Germany, and the PECL).

919 J.M. SMITS, Contract Law: A Comparative Introduction, (Cheltenham: Edward Elgar, 2014), at p. 167 (adding that in accordance with 3:44 (3) BW, "fraud occurs when someone induces another person to execute a certain juridical act by deliberately making an incorrect statement, by deliberately concealing a fact that had to be disclosed, or by another artifice. Endorsements in general terms, even if they are untrue, do not as such constitute fraud”).

920 Eurycleia Partners v. Sewward \& Kissel, 12 N.Y.3d 553, 559 (N.Y. Ct. App. 2009) (stating the four elements necessary to establish fraud in civil cases as: (1) material misrepresentation of fact, (2) knowledge of falsity and intent to induce reliance, (3) justifiable reliance, and (4) damages); Orchis Constr. Corp. v. Gottbetter, 89 A.D.3d 708 (2 ${ }^{\text {nd }}$ Dept. 2011) (noting for cases of fraud in the inducement, plaintiff must meet the aforementioned four criteria); Albion Alliance Mezzanine Fund v. State Street Bank and Trust Co., 8 Misc. 3d 264, 269 (Sup. Ct., NY Co. 2003), affd 2 A.D.3d 162 (1 st $^{\text {st }}$ Dept. 2003) (noting that with regards to fraudulent concealment, in addition to the four aforementioned requirements, an additional requirement of a special relationship of trust between the parties must be demonstrated); see also, NeW York GeNeral Business LAw \$349 DeCEPTIVE ACTS AND PRACTICES UNLAWFUL (stating “(a) Deceptive acts or practices in the conduct of any business, trade or commerce or in the furnishing of any service in this state are hereby declared unlawful. (b) Whenever the attorney general shall believe from evidence satisfactory to him that any person, firm, corporation or association or agent or employee thereof has engaged in or is about to engage in any of the acts or practices stated to be unlawful he may bring an action in the name and on behalf of the people of the state of New York to enjoin such unlawful acts or practices and to obtain restitution of any moneys or property obtained directly or indirectly by any such unlawful acts or practices. In such action, preliminary relief may be granted under article sixty-three of the civil practice law and rules."). With regards to the Deceptive Practices Acts, this is another possible claim for the plaintiffs, albeit an easier one for plaintiffs to succeed on given that there is no reliance requirement or intent to defraud.

921 J.M. SMITS, Contract Law: A Comparative Introduction, (Cheltenham: Edward Elgar, 2014), at p. 160 (noting that claim for damages is possible "if the deceived party has incurred costs in reliance on the validity of the contract."). 
subsequently discovers that the seller had lied about this point, the buyer can not only invalidate the contract, but the fraudulent seller could be on the hook for collateral damages that the buyer suffered as a result of the fraud. ${ }^{922}$

From a practical perspective, a party alleging to be a victim of fraud usually makes a claim of mistake as well, ${ }^{923}$ which brings us to the second possible claim that a consumer or the downstream buyer can bring against a company that claimed to be socially responsible, when in fact they were not. The primary difference between fraud and mistake is the seller's lack of intent to deceive: In a fraud claim, a plaintiff could find it difficult to prove that the seller knew the truth and lied about it, especially in the context of the global supply chain, but a mistake claim on the other hand does not require the plaintiff to prove the element of intent. While there are various ways in which the law goes about classifying the doctrine of mistake into various types of mistakes (e.g. unilateral, common, mutual, etc.), for the purposes of this analysis, the most relevant mistake is the common mistake of fact, ${ }^{924}$ where both the buyer and the seller mistakenly believed that the product in question was socially responsible, when in fact it was not. ${ }^{925}$ In this case, consumers or the downstream buyers who reasonably relied on this mistaken claim and purchased the particular product or component in question can invalidate the contract. ${ }^{926}$ It is worth noting here that while this is the case within the EU and many civil law jurisdictions, common law jurisdictions generally place more emphasis on protecting the reasonable reliance of the other party; however, jurisdictions like New York and California do recognize the doctrine of mistake as well. ${ }^{927}$

While the plaintiff's claim based on these arguments could indeed be successful, and thus entitle the consumer or the downstream buyer to invalidate the contract and possibly even seek damages, there are three foreseeable problems with this particular approach: First

922 J.M. SMITS, Contract Law: A Comparative Introduction, (Cheltenham: Edward Elgar, 2014), at p. 216 (defining collateral damage or consequential loss as the damage caused in the course of performing the contract and citing to Article 6:74 BW as the legal basis for collateral damage in the Netherlands).

923 J.M. SMITS, Contract Law: A Comparative Introduction, (Cheltenham: Edward Elgar, 2014), at p. 160.

924 J.M. SMITS, Contract Law: A Comparative Introduction, (Cheltenham: Edward Elgar, 2014), at p. 166 (defining common or shared mistake as when "both parties have the same misapprehension of reality.")

925 A case like this can take place in a complicated supply chain, where the buyer does not require the seller to conduct due diligence to ensure that their supply chain is in compliance with the code of conduct, especially if the upstream supply chain is located in other countries, where the company's influence and control are limited.

926 J.M. SMITS, Contract Law: A Comparative Introduction, (Cheltenham: Edward Elgar, 2014), at p. 161 (translating the relevant Dutch article, 6:228 BW, on mistake as follows: "(1) a contract which has been entered into under the influence of a mistake and which would not have been concluded has there been a correct assessment of the facts, is avoidable: (a) if the mistake is caused by information given by the other party, unless this party could assume that the contact would have been concluded even without this information; (b) if the other party, in view of what it knew or ought to have known about the mistake, should have informed the mistaken party; (c) if the other party, at the moment of concluding the contract, has based itself on the same incorrect assumption as the mistaken party, unless the other party, even if there had been a correct assessment of the facts, would not have had reason to understand that the mistaken party would therefore be prevented from entering into the contract. (2) The avoidance cannot be based on a mistake as to an exclusively future fact, or on a mistake for which, given the nature of the contract, common opinion or the circumstances of the case, the mistaken party should remain accountable.").

927 G.B. SMITH \& T.J. HALL, "Pleading and Proving Contract Reformation Claims," New York Law Journal 248(119) (2012), at p. 1 (citing to George Backer Mgmt.v. Acme Quilting, 46 N.Y.2d 211, 219 (1978). It must be noted, however that "actions at law provide no relief against contracts secured through fraud or mistake," but New York courts tend to rely on the equitable relief of reformation," in order to "bring inaccurately drafted contracts into conformity with the actual agreements between the parties." 
is the issue related to proving willful intent in the case of fraud as mentioned earlier; the second issue has to do with differentiating mere "puffs" from actual statements; and finally the third problem has to do with the limitation of available remedies even when the plaintiffs do succeed in their defects of consent claims. The first foreseeable problem has to do with the complexity of the global supply chain: When it comes to manufactured goods, there are various entities in the supply chain, including but not limited to multiple suppliers and various manufactures (as illustrated in Figure 1 of the Introduction). This is to suggest that not all of these entities are directly complicit in the exploitation of laborers, but if the initial supplier has exploited a laborer, like a fruit from a poisonous tree, the entire supply chain could potentially be implicated. This could have implications for the plaintiff seeking to invalidate a contract with a retailer or that retailer attempting to invalidate the contract with one of its upstream manufacturers, if that upstream manufacturer in question was not complicit in the exploitation of laborers, but it was the initial supplier further down the supply chain that had ties with labor exploitation. In such cases, the difficulty of a consumer attempting to prove the element of intent by the retailer can prove to be incredibly difficult: As Hugh Collins noted, "[i]f the retailer has not repeated the representation, the consumer cannot rely on misrepresentation to avoid the contract but must bring a claim against the manufacturers for pure economic loss caused by a negligent misstatement (or deceit), a claim that would almost certainly fail." 928 While this may be a rather pessimistic prediction for parties making these claims, it cannot be refuted that going after businesses for exaggerating their CSR aspirations or violating their codes of conduct would be a very challenging argument to make, legally speaking. ${ }^{929}$

The second foreseeable difficulty that could arise with claims related to fraud or mistake has to do with differentiating puffs from statements that were made with the intention to actually give rights to the other party. Puffs are seller's recommendations about their own products that a buyer should not expect to be sincere or genuine (e.g. when a pizzeria advertises their pizzas as the "best in the world"). In short, these puffs do not give the buyer any rights to base their claims. ${ }^{930}$ While advertising products alleging its social responsibility will likely be recognized as a more concrete, definitive promise, statements like "best product for the earth" or "best product to help reduce labor exploitation" blurs the line between a mere puff and a sincere, genuine promise. Using this gap in coverage, companies could attempt to disguise their claims of social responsibility as puffs or include puffy language in their codes of conduct (e.g. "this company will strive to be the most socially responsible company in the universe"). This concern of how companies could draft their codes of conduct in a manner that could maximize visibility, while minimize their liability will be addressed in more detail later in this subsection.

The third foreseeable limitation, and likely the most concerning issue with regards to actually reducing labor exploitation in the supply chain, has to do with the fact that claims

928 H. Collins, "Conformity of Goods, the Network Society, and the Ethical Consumer," European Review of Private Law 5 (2014): 619-640, 630.

929 The Law COMmission AND THE SCOTTISH LAw COMmission, Consumer Redress for Misleading and Aggressive Practices: A Joint Consultation Paper, (2012), at p. xiv. Available at: http://www.scotlawcom.gov.uk/files/ 4313/0252/1699/dp149.pdf (last accessed 16 January 2016) (characterizing the process of making this type of a claim as a "fragmented, complex, and unclear" process).

930 J.M. SMITS, Contract Law: A Comparative Introduction, (Cheltenham: Edward Elgar, 2014), at p. 164. 
based on defects of consent (and other claims which will be covered in this subsection) does not meet our normative criteria. While these remedies can help the plaintiff or the defrauded buyer, in terms of what it can actually do to improve the working conditions of the exploited laborers, these individual claims leave much to be desired. This is due to the fact that even if the consumers or the downstream buyers succeed in their claims, the damage they will be able to recover "would likely amount to no more than the amount paid to purchase the product." 931 Bearing in mind that our normative framework - the adapted capabilities approach - focuses on actually empowering laborers to be more autonomous and for them to be able to learn so that they can make meaningful choices as it relates to their employment, this particular approach does not necessarily reduce instances labor exploitation, at least not directly in a manner that is consistent with our normative framework.

In the end, these three possible limitations show, at the very least, that defects of consent claims may not actually contribute to improving the working conditions of the laborers at the bottom echelons of the global supply chain. Bearing these limitations in mind, the next part of the subsection will move on to address the other vitiating factor of prohibited contracts, which could potentially come across similar limitations.

\section{B. Immoral Contracts Contrary to Public Policy}

The relevant question still being addressed here is how private actors can rely on contract/consumer law-based arguments to make corporations more accountable and, in turn, contribute to the reduction of labor exploitation in the global supply chain. Accordingly, this part of the subsection will detail how the private sector, relying on legal arguments based on contracts being illegal, immoral, or contrary to public policy and good morals, can hold companies more accountable for their actions. ${ }^{932}$ In general, immoral contracts or contracts that are contrary to public policy can be (a)voided: For example, in the Netherlands BW Article 3:40 (1) holds that a "juridical act contrary to good morals or public order is void" and similarly in the US, "[c]ontracts that are in whole, or in part, against public policy are void." 933 The basic argument for this type of a claim is as follows: If the law declares contracts that are immoral or contrary to public policy as void, and the general public views labor exploitation, sweatshop labor, and child labor to be immoral and contra-

931 A.L. VyTOPIL, Contractual Control in the Supply Chain: On Corporate Social Responsibility, Codes of Conduct, Contracts and (Avoiding) Liability, (The Hague: Eleven, 2015), at pp. 163, 170 (arguing that the damages that the consumer will be able to claim on the basis of misleading statements are "fairly limited" and that the "deterrent effect of such a claim would therefore primarily lie with the reputational damage that a company could suffer if media became aware of such legal proceedings.").

932 J.M. SMITS, Contract Law: A Comparative Introduction, (Cheltenham: Edward Elgar, 2014), at p. 157 (elaborating that "in cases where performance has already taken place, it will have to be reverse: the price and the delivered goods or services need to be given back in so far as this is still possible.").

933 Kirshenbaum v. Gen. Outdoor Adver. Co., 258 N.Y. 486, 494 (1932) as summarized in New York Commercial Litigation Guide; see also, K.C. Bisceglie, H.C. Ross \& T.J. Fleming, New York Commercial Litigation Guide, (New York: Matthew Bender \& Company, 2012), at \$11.14; Matter of V alidation Review Assocs., Inc., 223 A.D.2d 134, 136 (1996) (stating that "Contracting parties are free to incorporate into their contracts any provisions that are not illegal, unconscionable, restricted by legislation, or violate public policy”); McMullen v. Hoffman, 174 U.S. 639, 66970 (1899) (refusing to grant "either party to an illegal contract judicial aid for the enforcement of his alleged rights.”); and, RESTATEMENT (SECOND) OF CONTRACTS \$178(1) (1981) (stating that “[i]f legislation provides that it is unenforceable or the interest in its enforcement is clearly outweighed in the circumstances by a public policy against the enforcement of such terms," then contracts can be (a)voided). 
ry to stated public policies, through the law of transitive properties, many of the contracts that the private sector rely on ought to be void. ${ }^{934}$ Hugh Collins agrees that consumers and downstream buyers can indeed 'invoke a general principle of 'good morals' or public policy for the purpose of invalidating the sale," 935 but the fact that these claims are not very often made by plaintiffs, or the fact that even when they are made, they are not likely to succeed is indicative of either the lack of willingness for the court's to hear these types of cases, the lack of willingness by the consumers or businesses to make such claims, or possibly both.

This general hesitance by the private sector to make such claims, or the courts' reluctance to adjudicate on these matters, is understandable given the implications and the possible slippery slope that can emerge once such a precedent has been made (where consumers or businesses are enabled to (a)void a contract because during the manufacturing of a particular product in question, somewhere along the supply chain, exploited laborers). If such an argument of such a nature were to succeed, similar to if FNV and Alam's case against FIFA were to succeed, it could establish a precedent that could potentially breakdown the entire global supply chain or capitalism as we know it. ${ }^{936}$ Take for example, the DRC case study from the Introduction, which revealed how more than half of the world's cobalt supply - a necessary component to make lithium-ion batteries that power most, if not all of our portable electronic devices - are mined. If the arguments suggested in the aforementioned paragraph are validated and a plaintiff could successfully argue that contracts that involve electronic devices that contain lithium-ion batteries with cobalt sourced from the DRC ought to be void on the grounds that production of such items involve practices that are either illegal, immoral, or contrary to public policy, global commerce will surely be put into a state of disarray not to mention how our judiciaries will be inundated with claims of immoral contracts. Bearing in mind these considerations, especially with regards to morality and public policy related arguments, the courts must consider the broader implications and must, as noted in previous chapters, appropriately balance the interest of multiple factors, which may not benefit the laborers exploited in the bottom echelons of the supply chain in the end. ${ }^{937}$

\section{Consumer Protection Laws in the EU (The Netherlands)}

Considering the limitations of the defects in consent based arguments and the explosive implications that a successful argument based immoral/public policy arguments could

Study Group on Social Justice in European Private Law, "Social Justice in European Contract Law: A Manifesto," European Law Journal 10(6) (2004): 653-674, 668 (proclaiming that "products made using child labour should not be placed on the market or at least [the] consumers should have the right to rescind purchases of such products"); see also, H. ColuINS, "Conformity of Goods, the Network Society, and the Ethical Consumer," European Review of Private Law 5 (2014): 619-640, 622.

935 H. ColuINS, "Conformity of Goods, the Network Society, and the Ethical Consumer," European Revien of Private Law 5 (2014): 619-640, 630; citing to, L.K.L. TJON SOEI LEN, The Effects of Contracts beyond Frontiers: A Capabilities Perspective on Externalities and Contract Law in Europe (PhD Thesis, University of Amsterdam, 2013).

936 J.M. SMITS, "The Expanding Circle of Contract Law," Maastricht European Private Law Institute Working Paper 3 (2016), at p. 15 (noting that simply invalidating these types of contracts is not an optimal solution).

937 Harvard Law Review Association, "A Law and Economics Look at Contracts against Public Policy," Harvard Law Review 119(5) (2006): 1445-1466, 1466 (stating that "[t]he problem's complexity in turn demands that courts applying the doctrine take a systematic, explicit approach, as only then can there be any hope that they will appropriately balance the interest inherent in the decision."). 
have, a more ordinary approach - perhaps a middle ground between the two extremes could be an argument based on consumer protection laws and how non-conformity (in the sense that a consumer wants a socially responsible good, but did not get one) could lead to a valid breach of contract claim will be addressed in this part of the subsection. In the event that a company advertises its products to be socially responsible, but turns out that they are not, consumers can rely - above and beyond a claim of fraud or mistake - on consumer protection laws at least in the EU. ${ }^{938}$ After all, if a company benefits from presenting their operations as being socially responsible, the company should similarly be held accountable and liable if it turns out that they misrepresented their operations. ${ }^{939}$ With this in mind, this part of the subsection will now provide a descriptive overview of existing Dutch consumer laws (as influenced by the various EU Directives), followed by the next part of the subsection, which will focus on similar arguments in the US.

In the Netherlands, "both consumers... and those acting in the course of business... may claim damages from a company that misleads consumers." 940 These Dutch rules are transpositions of EU Directives (i.e. Directive on Unfair Commercial Practices ("UCP Directive") ${ }^{941}$ and the Directive on Misleading and Comparative Advertising). ${ }^{942}$ In the B2C context, only the UCP Directive is applicable, as it prohibits unfair commercial practices against consumers. First and foremost, Article 4 of the Directive (or BW Article 6:193(b)) requires companies to compensate consumers that have been misled by them. This is of course assuming that certain elements are met (i.e. the consumers can establish that they were indeed misled by "commercial practices" as defined in Article 3 of the UCP

938 A. Rühmkorf, Corporate Social Responsibility, Private Law and Global Supply Chains, (Cheltenham: Edward Elgar, 2015), at p. 84 (stating that "[f]alse information by companies about their CSR practices could constitute such misleading actions. Consumer law could therefore protect consumers in case companies are in breach of their publicly announced CSR commitments..."); M.J.C. VAN DER HEIJDEN, Liability of Transnational Corporations for Gross Human Rights Violations: Linking Standards of International Public Law to Dutch Civil Litigation Procedures, (Antwerp: Intersentia, 2011), at p. 211 (praising the existence of Member State legislations that regulate misleading statements about a company's socially responsible practices and fair trade products); see also, A.L. VYTOPIL, Contractual Control in the Supply Chain: On Corporate Social Responsibility, Codes of Conduct, Contracts and (Avoiding) Liability, (The Hague: Eleven, 2015), at p. 163 (adding that while these legislations exist in countries such as France and Belgium, lamenting that such a regulation "does not (yet) exist in the Netherlands.").

939 S.D. MURPHY, "Taking Multinational Corporate Codes of Conduct to the Next Level," Columbia Journal of Transnational Law 43(2) (2005), at p. 52 (advocating that "[t]o the extent that MNCs are using their adherence to voluntary codes as a means to assuaging public concerns about their activities abroad, then MNCs should be prepared to have those claims scrutinized as a matter of consumer protection laws"); see also, H. CoLLINS, "Conformity of Goods, the Network Society, and the Ethical Consumer," European Review of Private Law 5 (2014): 619640, 619 (adding that if consumers do indeed have "such expectations and EU contract law can protect them, the law may provide a vehicle for addressing some of the worst instances of labour exploitation worldwide.").

940 A.L. VYTOPIL, Contractual Control in the Supply Chain: On Corporate Social Responsibility, Codes of Conduct, Contracts and (Avoiding) Liability, (The Hague: Eleven, 2015), at p. 163 (citing to BW Article 6:193 and Article 6:194 elaborating that these articles are "considered as lex specialis in respect of general liability regarding torts or unlawful acts (onrechtmatige daad) as encompassed in Article 6:162 BW.").

941 European Directive 2005/29. The UCP Directive prohibits unfair commercial practices in B2C situations.

942 European Directive 2006/114. The MCA Directive, which regulates advertising practices of companies, apply only in B2B situations. If, for example, Company A were to advertise that their clothing line was " $100 \%$ sweatshop free," thus possibly distinguishing their products from that of some of their competitors to their disadvantage, and Competitor B determines that Company A's statement is misleading or Company A cannot substantiate the claim, the Competitor B can bring a claim based on the MCA Directive (or Article 6:194-6 BW); see, MCA Directive, Article 2(b) (defining misleading advertising as "any advertising which in any way, including its presentation, deceives or is likely to deceive the persons to whom it is addressed or whom it reaches and which, by reason of its deceptive nature, is likely to affect their economic behavior or which, for those reasons, injures or is like to injure a competitor.”). 
Directive (or BW Article 6:193(a)(1)(d)) and that there is a "direct connection" between the actions of the consumer and the misleading commercial practice). So if a company advertised that their products were made in a socially responsible manner and a consumer reasonably relied on that advertisement and purchased the item in question (only to find out that that the product was not made in a socially responsible manner) that consumer has a valid claim against the business on the ground of UCP Directive Article 4 (or BW Article 6:193(b)). ${ }^{943}$

In terms of procedural steps, a consumer basing his or her claim on the UCP Directive (or BW Article 6:193) against a company improperly claiming to be socially responsible, must meet a few prerequisites: 1) the seller must clearly indicate their intent to be legally bound to the code of conduct; 2) the code of conduct and the commitments made within it must be verifiable, meaning that the provisions are not merely aspirational; and possibly most difficult to establish, 3) the commitment made in the code of conduct must have caused the buyer to engage in the transaction. ${ }^{944}$ Here again, the aforementioned problem of distinguishing mere puffs or aspirational commitments from definitive statements emerges, not to mention that the remedy that a consumer will be entitled to would be a rescission of the contract and associated damages. In short, there is no causal link between a consumer wining a claim based on a company violating the UCP Directive or BW Article 6:193 and the improvement of how workers associated with that company or its supply chain are treated. The Consumer Sales Directive (99/44/EC), ${ }^{945}$ the next Directive that this part of the subsection will explore, will likely encounter the similar restrictions.

The Consumer Sales Directive ("CS Directive") Article 2 generally deals with the seller's requirement to deliver goods that are in conformity to the buyer, for example, Article 2(d) clearly elaborates that consumers can take into consideration public statements made about the product to determine its conformity. ${ }^{946}$ This means that a buyer/plaintiff can, at least in theory, claim remedies if a product, which was advertised by the seller to be socially responsible, turns out not to have been. ${ }^{947}$ This is an important acknowledgement by the

943 A.L. VyTOPIL, Contractual Control in the Supply Chain: On Corporate Social Responsibility, Codes of Conduct, Contracts and (Avoiding) Liability, (The Hague: Eleven, 2015), at p. 165 (summarizing that point that corporate communications are excluded from "commercial practices," which limits the use of the Directive and Article 6:193 DCC in practice). What limits the usefulness of this Directive in our context is Preamble 7 of the UCP Directive, which excludes the applicability of the Directive to "commercial communications aimed at investors, such as annual reports and corporate promotional literature." What this means is that "[c]orporate CSR websites and reports therefore in principle do not fall within the scope" of the UCP Directive and similarly to BW Article 6:193.

944 A. RÜHmKOrF, Corporate Social Responsibility, Private Law and Global Supply Chains, (Cheltenham: Edward Elgar, 2015), at p. 131 (adding that the seller's claim must have caused or likely to have caused the average consumer to make a decision that they would not have taken otherwise, "taking account of its factual context and of all its features and circumstances.").

945 Directive 1999/44/EC of the European Parliament and of the Council of 25 May 1999 on certain aspects of the sale of consumer goods and associated guarantees. Article $2(\mathrm{~d})$

946 CS Directive Article 2 in relevant parts note the following: (1) "the seller must deliver goods to the consumer which are in conformity with the contact of sale"; (2) consumer goods are presumed to be in conformity if they either: (a) "comply with the description," (b) "are fit for a particular purpose," (c) "are fit for the purposes for which goods of the same type are normally used," or (d) "show the quality and performance which are normal in goods of the same type and which the consumer can reasonably expect, given the nature of the goods and taking into account any public statements on the specific characteristics of the goods made about them by the seller, the producer or his representative, particularly in advertising or on labelling."

947 H. Collins, "Conformity of Goods, the Network Society, and the Ethical Consumer," European Review of Private Law 5 (2014): 619-640, 638 (arguing that "a consumer may be able to argue that her expectation of conformity in this respect has been dashed" and accordingly, "normal remedies for breach of the requirement of conformity 
Directive that what matters to consumers is not just what the product is or how it functions, but how it was manufactured. ${ }^{948}$ Accordingly, if a product was not manufactured in accordance to how it was advertised, then that product is not in conformity. ${ }^{949}$

The relevant Dutch transposition of the CS Directive Article 2 can be found in BW Article 7:21(1), which states that if the delivered object does not comply with the contract, the consumer can demand delivery of that which is lacking, repair of the delivered object (if the seller can reasonably do so), or seek replacement of the delivered object. So if a consumer thought that he or she was buying a socially responsible item, but later turns out that the product was made by exploited laborers, the consumer is entitled to remedies, which could be a replacement of the non-conforming, socially irresponsible product, with one that is socially responsible.

While the non-conformity argument is relatively straightforward, there are various practical obstacles that could complicate the proceedings for the conscious consumer/plaintiff, the biggest of which has to do with the issue of reasonable expectations. In obvious cases of non-conformity (e.g. consumer ordered a red toy car, but ended up with a blue bike), it would be easy for the consumer to establish non-conformity and to show that their expectation (of getting the red toy car) was reasonable. In arguing non-conformity of how the product was made, however, the difficulty for the consumer to win their case significantly decreases. For example, if the consumer wanted a red toy car that did not involve any exploitation of laborers, but ended up with a red toy car made in a sweatshop, the consumer has to overcome two obstacles not raised in the first hypothetical: First, the nonconformity is no longer about the intrinsic characteristics of the good (i.e. consumer wanted a red toy car and got a red toy car), but about the extrinsic characteristics of the good (i.e. consumer wanted a product produced in a socially responsible manner, but was given a product made through labor exploitation). Second, and perhaps the more debilitating issue to the consumer's claim has to do with the question of whether or not - in the global supply chain faced with increasing firm disaggregation and race-to-the-bottom style outsourcing - a consumer can reasonably expect anything to be made without any form of exploitation. Having to deal with these two issues is the reason why the plaintiffs' chances of win-

should be available, including rejection of the goods or compensation for the reduction in value"); see also, CS Directive Article 3(2) explicitly lays out the rights of the consumer in the event that seller delivers a good lacking in conformity as follows: "the consumer shall be entitled to have the goods brought into conformity free of charge by repair of replacement, in accordance with paragraph 3, or to have an appropriate reduction made in the price or the contract rescinded with regards to those goods, in accordance with paragraph 5 and 6."

948 H. Collins, "Conformity of Goods, the Network Society, and the Ethical Consumer," European Review of Private Law 5 (2014): 619-640, 639 (supporting this argument that "the value of the product to a consumer is not simply the intrinsic qualities of the product such as how well it functions or satisfies a need but also its extrinsic qualities such as its original source, its environmental impact, and the labour standards under which it is produced.").

949 F. CAFAGgi, "The Regulatory Functions of Transnational Commercial Contracts: New Architectures," Tekes Project, (2012). Available at: http://papers.ssrn.com/sol3/papers.cfm?abstract_id=2136632 (last accessed 4 April 2017), at p. 3 (concurring that "[w] hen suppliers commit to comply with social standards related to children, gender or general labor conditions and the obligations have become part of the commercial contract a breach may refer to the 'commercial' contract with the buyer, the employment contract, and to the code of conduct imposing obligations and the certification regime that attests compliance with fair labor conditions."); see also, H. CoLLINS, "Conformity of Goods, the Network Society, and the Ethical Consumer," European Review of Private Law 5 (2014): 619-640, 619 (elaborating that "whether the reasonable expectations of consumers include reference to the means of production up the supply chain and an expectation that the goods will not be produced through the use of labour that is employed under conditions that violate EU labour laws, international labour standards, and human rights laws"). 
ning a non-conformity claim based on extrinsic characteristics of the product could be a difficult claim. ${ }^{950}$

To conclude, at least within the EU, there are legitimate legal grounds for consumers to seek remedies when a company publicizes its code of conduct and upholds itself as a socially responsible company that offers socially responsible goods, when it turns out that neither the company nor the products that they offer are socially irresponsible. While there are practical limitations to such claims based on the question of whether the consumer's expectations can be deemed reasonable, at least the doctrinal framework exists so as to protect the consumers, thus empowering them to reject goods that are made in manner that does not conform to their moral sensibilities. However, similar to the limitations presented in voiding contracts based on vitiating factors, just because a consumer can seek various remedies does not necessarily mean that the working lives of workers at the other end of the supply chain will improve in a manner in alignment with our normative framework. Bearing this point in mind, the next part of the subsection will illustrate how similar arguments could be made in the US by relying on the Kasky case as a representative example.

\section{Consumer Protection Laws in the US (California)}

The EU/Dutch analysis above, illustrated how UCP and CS Directives (and their relevant Dutch transpositions) protect EU/Dutch consumers or remedy those who have fallen victim to companies that promised to deliver a particular product or that product in a particular manner, but failed to do so. This part of the subsection will now offer a similar analysis in the US, with a particular focus on California, which is where one of the most seminal cases about this issue, Kasky v. Nike, ${ }^{951}$ took place.

Marc Kasky initially brought suit against Nike, on behalf of the general public of the state of California, under California Business and Professions Codes $\$ 17204$ (unfair and deceptive practices) ${ }^{952}$ and $\$ 17535$ (false advertising), ${ }^{953}$ seeking monetary and injunctive relief. Kasky's claim that Nike was falsely advertising was based on the following set of facts: Nike, since 1993, had been claiming that it has "assumed responsibility for its subcontractors' compliance with applicable local laws and regulations concerning minimum wage, overtime, occupational health and safety, and environmental protection." 954 Between 1996 and 1997, however, news came to light that in many of the factories subcontracted by Nike in countries such as China, Vietnam, and Indonesia, their local labor force was routinely being exploited. ${ }^{955}$ In response to these allegations and adverse publicity, Nike denied

950 Ironically, in order for a consumer/plaintiff to increase his or her chances of successfully claiming lack of conformity on the basis of CS Directive Article 2 or BW Article 7:21(a), it might benefit the consumer if he or she remained blissfully ignorant about the production and manufacturing process that takes place across the global supply chain: This would give them plausible deniability, which could potentially increase the legitimacy of the claim that the consumer's expectation for a completely exploitation-free product was a "reasonable" one.

951 Kasky v. Nike, Inc., 27 Cal.4th 939, 947 (2002).

952 Kasky v. Nike, Inc., 27 Cal.4 $4^{\text {th }}$ 939, 947 (2002); see also, California Business and Professions Code Article 17204 stating, in relevant part, that consumers may file a suit relying on 17204 BPC if they "suffered injury in fact and has lost money or property as a result of the unfair competition."

953 Kasky v. Nike, Inc., 27 Cal.4 th 939 , 947 (2002).

954 Kasky v. Nike, Inc., 27 Cal.4 ${ }^{\text {th }}$ 939, 947 (2002).

955 Kasky $v$. Nike, Inc., 27 Cal.4 ${ }^{\text {th }} 939,947$ (2002) (stating the facts of the exploitation as follows: "[W]orkers were paid less than the applicable local minimum wage, required to work overtime allowed and encouraged to work more 
these claims vociferously. ${ }^{956}$ In short, Nike denied any and all wrongdoing in a very public manner, including but not limited to sending out press releases ensuring the public that Nike was a socially responsible company.

It was this very public response that the plaintiff claimed as the basis of his false or misleading statement argument, stating that Nike's statements in the aftermath of the scandal were made "for the purpose of maintaining and increasing its sales and profits" 957 and that Nike's statements were made "with knowledge or reckless disregard of the laws of California prohibiting false and misleading statements." 958 In response to Kasky's claims, Nike filed a demurer arguing that Kasky's suit was barred on the grounds of Nike's freedom of speech. Before the actual issue of false advertising could be debated at the California Superior Court level, the case went to the California Court of Appeal and subsequently to the California Supreme court, where the pivotal issue was whether Nike's response - its speech - was protected under the First Amendment. The California Supreme Court, ultimately held that "false and misleading speech [had] no constitutional value in itself and [was] protected only in circumstances and to the extent necessary to give breathing room for the free debate of public issues..."959 The California Supreme Court added that "when a corporation, to maintain and increase its sales and profits, makes public statements defending labor practices and working conditions at factories where its products are made, those public statements are commercial speech that may be regulated to prevent consumer deception." 960 This decision by the California Supreme Court allowed Kasky's claim to be continued. ${ }^{961}$

Once the case was sent back down to the lower court, the two parties ended up settling the case, which makes it difficult to analyze the true impact of Kasky from a purely legal perspective and leaving the answer to the original question (what consumers can do to hold companies accountable to their CSR initiatives) somewhat murky. It is worth noting, however, that the willingness of Nike to settle could be an indication of their assessment of Kasky's claim and possibly a recognition of its credibility. Above and beyond this observation, it is difficult to read into the nature of the settlement, but nevertheless, from a purely academic perspective, it would be an interesting exercise to hypothesize how the court

overtime hours than applicable local law allowed; subjected to physical, verbal, and sexual abuse; and exposed to toxic chemicals, noise, heat and dust without adequate safety equipment, in violation of applicable local occupational health and safety regulations.").

956 Kasky v. Nike, Inc., 27 Cal.4 $4^{\text {th }} 939$, 947 (2002) (holding that "Nike and the individual defendants said that workers who make Nike products are protected from physical and sexual abuse, that they are paid in accordance with applicable local laws and regulations governing wages and hours, that they are paid on average double the applicable local minimum wage, that they receive a 'living wage', that they receive free meals and health care, and that their working conditions are in compliance with applicable local laws and regulations governing occupational health and safety.").

957 Kasky v. Nike, Inc., 27 Cal.4th 939, 947 (2002).

958 Kasky v. Nike, Inc., 27 Cal.4th 939,948 (2002).

959 Kasky v. Nike, Inc., 27 Cal.4 ${ }^{\text {th }} 939,969$ (2002).

960 Kasky v. Nike, Inc., 27 Cal.4 $4^{\text {th }} 939,969$ (2002).

961 It must be noted here that on appeal, the US Supreme Court initially granted certiorari, but the Court dismissed the writ as "improvidently granted," ultimately pushing the case back to the California courts. In other words, the Supreme Court did not adjudicate on any of the substantive claims because: "(1) the judgment entered by the California Supreme Court was not final within the meaning of 28 U.S.C. $\$ 1257$; (2) neither party has standing to invoke the jurisdiction of a federal court; and (3) the reasons for avoiding the premature adjudication of novel constitutional questions apply with special force to this case." Nike, Inc. et al v Marc Kaskey, 539 U.S. 654, 658 (2003). 
would have resolved this issue had the parties not settled, which this part of the subsection will now attempt to do by relying on other precedents established by the California courts.

There are a few California lower court decisions that will aid us in this attempt: For example in Kwikset Corp. v. Superior Court, ${ }^{962}$ the Supreme Court of California held that consumers who have been misled by false labels - the case involved a merchandise that had a "Made in the USA" label, when in fact it was not made in the USA - can rely on California's Unfair Competition Law and False Advertising Law to seek remedies from the companies. ${ }^{963}$ In addition, the Ninth Circuit followed this precedent in Hinojos v. Kobl's Corp. holding that Kwikset was applicable in their case, thus expanding the sway of Kwikset to a wider jurisdiction. ${ }^{964}$ These cases suggest that, at least in California, companies making false or misleading claims regarding their social responsibility can be targets by consumers who want to hold these companies accountable to their CSR initiatives, similar to those in the EU and the Netherlands. ${ }^{965}$ If Kasky were to bring his claim today, in the aftermath of Kwikset and Hinojos, the court would have likely ruled in favor of Kasky, although it is worth bearing in mind that there are various differentiating factors that could still complicate Kasky's claims if they were made today: One such argument is the fact that Kasky relied on a public statement made by Nike, which could be characterized as a mere puff, as explained above, or similarly, Nike could have argued that Kasky's reliance on corporate statements like the ones Nike made to be unreasonable. More specifically, Nike could have argued that in this globalizing world, it is impossibly cost-prohibitive for companies to conduct due diligence throughout their entire supply chain on a continuous and routine basis. Therefore, it would be unreasonable for the consumers to expect MNCs to be able to guarantee a product that is $100 \%$ free of labor exploitation. In other words, it would be unreasonable for consumers to expect "absolutely labor exploitation free" products, especially after witnessing the fiasco of companies like Nike and Apple in the recent decades. ${ }^{966}$ Especially for the price-sensitive consumers opting to purchase cheaper products, their reliance could be further challenged as unreasonable, to expect relatively cheap, "Made in China" products to be $100 \%$ labor free.

What could potentially complicate this issue of puff versus commercial speech and an interesting area of comparative analysis even further has to do with the question of whether

962 Kwikeset Corp. v. Superior Court, 51 Cal. $4^{\text {th }} 310$ (2011).

963 These laws have been codified in the aforementioned California Business and Professional Code Sections 17200 et seq. The California Supreme Court in Kwikeset reversed the previous Court of Appeals decision and held that consumers can in fact, seek for compensation if they relied on a misleading advertisement.

964 Hinojos v. Kobl's Corp., 718 F. 3d 1098 (2013) (holding that the panel "applied the California Supreme Court's holding in [Kwikeset], and held that when a consumer purchases merchandise on the basis of false price information, and when the consumer alleges that he would not have made the purchase but for the misrepresentation, he has standing to sue under the Unfair Competition Law and Fair Advertising Law because he has suffered an economic injury."). The plaintiff alleged in this case that the defendant, a store that advertised a Samsonite suitcase as being on " $50 \%$ sale" was not in fact $50 \%$ of the original price.

965 A.L. VyTOPIL, Contractual Control in the Supply Chain: On Corporate Social Responsibility, Codes of Conduct, Contracts and (Avoiding) Liability, (The Hague: Eleven, 2015), at p. 231 (suggesting that "it would be possible for private individual to file a suit against MNC that has made claims in respect of the company's CSR performance in the supply chain that are false, if those claims led him to buy a product he would otherwise not have bought or only at a lower price.").

966 Cf. H. Collins, "Conformity of Goods, the Network Society, and the Ethical Consumer," European Review of Private Law 5 (2014): 619-640, at p. 638 (arguing that "I suspect that a court would be unwilling to permit Apple (or its retail outlets) to rely on its well-publicized failing to live up to its Code of Conduct as a defense that no consumer should have that expectation.”). 
corporations, as legal persons, are entitled to freedom of speech. This notion of corporations as people, which was also addressed in Kiobel and cases like Citizens United, and the question of whether MNCs are entitled to free speech rights much like a natural person is an ongoing debate in the US - more so than in the EU - with potential impact that goes above and beyond the questions posed in this thesis. 967

Yet another point of concern, which is related to the first point, is not purely a legal one, but a practice that can significantly impact future litigations down the line: the issue in question is the previously hinted concern of company drafting their codes of conduct in a manner that minimizes their liability. Kasky, one could argue, is the event that triggered - or at the very least contributed to - a spillover effect that brought about various unintended consequence. First of all, a spillover effect occurs when one action creates seemingly unrelated or unintended consequences. The claim being made here is that legally going after companies for unethical or socially irresponsible practices in court could have the spillover effect of makings companies "smarter" and less likely to be held accountable for their actions in the future. In Kasky, for example, the plaintiff "won" a settlement from Nike based on the argument that Nike made misleading public statements about its supply chain being socially responsible, when in fact, it was not. While Kasky and consumer protection organizations might chalk this up as a win, the spillover of this victory was the fact that companies like Nike learned from this mistake and since then, have generally been more careful about making definitive public statements. ${ }^{968}$ This impact can be seen in the way codes of conduct are now drafted as well: For example, rather than stating that "we are socially responsible," many codes of conduct and public statements uttered since state that they are "doing their best to be socially responsible," which has an entirely different legal effect. While some argue that these aspirational statements can still be relied on by con-

See e.g. A more recent development regarding businesses' right to free speech takes an interesting turn as the agricultural giant, Monsanto is going after smaller farms - like Oakhurst Dairy of Maine - that claim no growth hormones were used in their products to take such labels off their products. Monsanto's argument is that farmers that claim their products are misleading the consumers into believing their products that use artificial growth hormones is somehow unsafe or of a lower quality (with associated chilling effects) even though the US Food and Drug Administration stated that there is no such proof. As recent as 2007, Monsanto even filed a complaint with the FDA to ban these "No GMO" labels. See e.g. D. BArbOZA, "Monsanto Sues airy in Maine Over Label's Remarks on Hormones," The New York Times, (12 July 2003). Available at: http://www.nytimes.com/ 2003/07/12/business/monsanto-sues-dairy-in-maine-over-label-s-remarks-on-hormones.html (last accessed 4 April 2017). With regards to the specific case between Monsanto and Oakhurst Dairy, the party settled out of court, once again proving that large corporations with money can push around those that do not have the money to fight large legal battles. There are similar movements in EU, where laws are favoring non-disclosure of where foods are produced; see e.g. Regulation (EU) 1169/2011 of the European Parliament and of the Council of 25 October 2011 on the provision of food information to consumers, amending Regulations (EC) No 1924/2006 and (EC) No 1925/2006 of the European Parliament and of the Council, and repealing Commission Directive 87/250/EEC, Council Directive 90/496/EEC, Commission Directive 1999/10/EC, Directive 2000/13/EC of the European Parliament and of the Council, Commission Directives 2002/67/EC and 2008/5/EC and Commission Regulation (EC) No 608/2004 Text with EEA relevance; see also, F. CAPRA \& U. MATTEI, The Ecology of Law: Toward a Legal System in Tune with Nature and Community, (Oakland: Berrett-Koehler, 2015), at p. 114 (elaborating that this regulation which "allow non-disclosure of the place of production of food... [strip] away even the ecologically literate consumers of the ability to buy local.").

968 See e.g. A. RüHmkorf, Corporate Social Responsibility, Private Law and Global Supply Chains, (Cheltenham: Edward Elgar, 2015), at p. 163 (noting that "CSR commitments made by companies about the conduct of their subsuppliers are usually worded in a rather aspirational way which will make it difficult for consumers to follow this conduct up through consumer law.”). 
sumers to allege companies of failing to live up to their CSR initiatives, ${ }^{969}$ succeeding on this argument have become more difficult because what the general public can consider as mere puffs and a definitive statement is not further blurred in light of this development. ${ }^{970}$ This is to suggest that no definitive stance can be taken with regards to the codes' applicability, without considering the actual text of the code and its surrounding circumstances. ${ }^{971}$

The manifestation of this very concern can be seen in Doe v. Wal-Mart, where workers manufacturing goods for Wal-Mart in countries such as China, Bangladesh, and Nicaragua filed a claim that Wal-Mart was not living up to its CSR initiatives. ${ }^{972}$ The basis of their claim relied primarily on the fact that Wal-Mart was unjustly enriched by violating its own voluntary code of conduct by failing to properly inspect and ensure that the working condition of their subcontractors and suppliers met a certain standard. The court, however, rejected the plaintiffs' claim holding that the code was written in a manner that allowed WalMart to monitor its suppliers, but the code was not written in a manner that actually required them to monitor its suppliers. So while Wal-Mart was able to pass off to the unsuspecting public about its code of conduct, by drafting the conduct in a manner that minimized its liability, Wal-Mart was able to "get away with" not inspecting their suppliers, which is to say that the code, even with the binding nature of contracts, did not actually protect the workers at all. ${ }^{773}$

In concluding this subsection, it must be noted that arguments based on vitiating factors that (a)void the contracts or consumer protection measures that allow consumers to withdraw from a contract or seek replacement or repair, while certainly beneficial for the consumers, do not necessarily empower the laborers, nor does it reduce instances of labor exploitation, at least not directly. This appears to be a common issue with the other measures enumerated in this section (i.e. codes of conduct, certification and labeling schemes, etc.). In short, contract/consumer law-based measures focus primarily on remedying parties to the contract, but not necessarily third parties to the contract, a group that includes the exploited laborers. This lingering concern will be elaborated further in the next section, which will address the problems with the contract/consumer law-based approach to reducing instances of labor exploitation in the global supply chain.

A.L. VYTOPIL, Contractual Control in the Supply Chain: On Corporate Social Responsibility, Codes of Conduct, Contracts and (Avoiding) Liability, (The Hague: Eleven, 2015), at p. 249 (concluding that "aspirational wording ('MNC X will contribute to...') will be unlikely to lead to liability on... legal ground[s].”).

970 This particular concern of spillover effects and the law of unintended consequences will be revisited and addressed in more detail in Chapter 4.3.1C.

971 A. BECKERS, Enforcing Corporate Social Responsibility Codes. On Global Self-Regulation and National Private Law, (Oxford: Hart Publishing, 2015), at p. 93 (stating that "[t]here is one core result of this inquiry and that is that there is no generally valid answer whether or not corporate code as legally enforceable.").

972 Jane Doe et al. v. Wal-Mart Stores, 572 F.3d 677 (9 ${ }^{\text {th }}$ Cir. 2009).

973 Bear in mind that the suit targeted Wal-Mart and not the suppliers directly so the plaintiff's claims could only rely on Wal-Mart's code of conduct. 


\subsection{PROBLEMS WITH THE CONTRACT/CONSUMER LAW APPROACH}

Some of the problems observed in this chapter overlap with the problems already noted back in Chapter 4, which were the enforcement problem, the incentive problem, and the causation problem. In order for measures like codes of conduct or certification and labeling schemes to be successful, companies must be properly incentivized to adopt and implement them. In order for these measures to actually make an impact in a way that would empower laborers and reduce labor exploitation in a manner that conforms to our normative framework, these measures must be properly enforced, which companies or consumers many not have the adequate or resources or proper incentives to carry out. There are also various causation problems in the context of this chapter as well, as exemplified by the fact that just because consumers or downstream buyers can (a)void a contract based on vitiating factors or on some consumer protection measures that option, in and of itself, does not necessarily mean that the working lives of laborers at the other end of the supply chain will directly improve as a result of said measures.

In addition to these problems, this section will now present a more in-depth, interdisciplinary analysis of why the labor exploitation problems persist in light of these measures by proposing the proliferation problem (Subsection 5.3.1), the complexity problem (Subsection 5.3.2), and the communal problem (Subsection 5.3.3). These three problems are closely related as the proliferation problem leads to or exacerbates the complexity problem and the communal problem. It is the contention of this section that the existing contract/consumer law-based measures, in conjunction with all of the other measures mentioned throughout this thesis, often fail to bring about the reduction of labor exploitation in the global supply chain in a manner conforming to our normative framework, in large part due to these lingering problems.

\subsubsection{The Proliferation Problem}

The beginning of this chapter noted that we are living in an age of proliferation and how there is more of everything today: More people, more goods, more laws, more labels, and so on, which creates the proliferation problem, which could potentially trigger the choice overload problem already noted back in the context of the proliferation of certification and labeling schemes. In addition, Chapter 2 also discussed a related problem of the Goldilocks problem, in the context of over-regulation and how too many rules or laws could be detrimental to society using the Inverted-U curve to provide a visual representation of how proliferation of anything could be counterproductive, if not potentially harmful. ${ }^{974}$ The proliferation of laws (previously referred to as the legal pollution problem), various soft law measures and private initiatives, including but not limited to CSR measures like codes of conduct and certification and labeling schemes are - potentially - creating more confusion

974 T. DiDonato \& N. Gill, “Changing an Organization's Culture, Without Resistance or Blame,” Harvard Business Review, (15 July 2015) (noting that it is difficult enough for subcontractors and manufacturers to "translate words on a page into specific behaviors," but when there are multiple layers and pages from various sources, compliance becomes even more difficult, which could prove to be counterproductive."). 
for private actors at all levels of the global supply chain. This proliferation is not just limited to laws and private initiatives, but applies equally to the growing number of organizations (both governmental and non-governmental), associations, communities, consortiums, that claim to share similar goals, but go about the matter in their own manner. While one cannot underscore the importance and the various contributions that these entities are making, the number of organizations, much like the number of measures - both hard and soft - is rendering some level of confusion among the private actors.

Chapter 4 already provided a specific manifestation of this problem by noting the impact that integrated reports and transparency regulations - measures that contribute to information proliferation - can have: Recall here the argument made back in Chapter 4, which was that if investors are inundated with more and more data that could potentially be detrimental to various stakeholders. In the words of Omri Ben-Shahar, while "disclosure seems to be a fantastic solution," in reality, "disclosure can sometimes make things worse." 975 Partially because even if stakeholders know about the problem, there are no assurances that they will actually change their behavior. In many cases, blissful ignorance could be considered as the rational choice for many private actors given that "the cost of collecting and analyzing information outweighs the benefit[s]" in many cases in the age of proliferation. ${ }^{976}$

Bearing this concern in mind, the aim of this subsection is to make an argument that the proliferation problem is not just about there being overabundance over everything, but how the proliferation affects private actors at a very psychological and sociological level, and that these effects caused by the proliferation problem is making our challenge to reduce instances of labor exploitation more difficult. To illustrate specific impacts that the proliferation problem is causing, this subsection will: a) elaborate on the phenomenon of cathexis and how our instinct of acquisition is changing our psychology; b) discuss our growing cognitive dissonance and how we are lying to ourselves; and c) argue that due in part to the proliferation problem, private actors are becoming desensitized about the labor exploitations taking place within our global supply chain, which can alter their incentives to act or modify their behaviors.

\section{A. We are What We Own: Cathexis and Our Instinct of Acquisition}

The first manifestation of the proliferation problem and the impact it is having focuses on private actors at a very individual level. For the sake of this assessment, let us focus on consumers and how our consumption habits are directly linked to who we are as individuals. For this subsection, let us further focus our attention on the proliferation of consumable goods (i.e. the clothes we buy). Recall here the data presented back in the Introduction, where on average, consumers purchase about 80 billion pieces of clothing annually world-

D. ArIELY, The (Honest) Truth About Dishonesty: How We Lie to Everyone - Especially Ourselves, (New York: Harper Collins, 2012), at pp. 52, 89; see also, D.M. CAIN, G. LOEWEnSTEIN \& D.A. MOORE, "The Dirt on Coming Clean: The Perverse Effects of Disclosing Conflicts of Interest," Journal of Legal Studies 34 (2005): 1-25.

976 O. BEn-Shahar \& C.E. SCHNeIDER, More Than You Wanted to Know: The Failure of Mandated Disclosure, (Princeton: Princeton University Press, 2014), at p. 56. 
wide, which is about $400 \%$ more than we used to purchase not only a decade ago. ${ }^{977}$ What this entails is the following:

'We buy more clothes now, move through trends faster. In the olden days - the early 90's - brands produced two to four fashion cycles per year, big orders coordinated by season, planned months in advance. These days, there's no such thing as cycles, only products... [and in] this fast-fashion era, Western brands can't afford the luxury of working with the same suppliers and ensuring that they meet the company's standards." 978

This trend - sometimes referred to as "affluenza" 979 - not only affects consumers, but it increases the pressure exerted on the businesses as well. Moreover, the increasing demand by the consumers and the businesses' efforts to supply them is creating a vicious cycle where the consumers want more and more things, and in turn, businesses must keep producing more and more. In the middle of this overproduction demand and supply are the laborers that work behind the scenes to meet the demands. It is a vicious cycle given that the businesses do not have the incentive to produce less if it means less profits, preferring instead that their consumers keep buying more and more, similar to how governments prefer that their consumers keep spending more and more to inflate their GDPs.

This is the underlying status quo that is limiting the impact of various CSR initiatives for companies to be more socially responsible or attempts at ethical consumerism to curb this excessive consumerism culture. Ecological economist, Tim Jackson elaborates on this point from a more sociological perspective: "[M]aterial artifacts constitute a powerful 'language of goods' that we use to communicate with each other, not just about status, but also about identity, social affiliation, and even - through giving and receiving gifts for example - about feelings for each other, our hopes for our family, and our dreams of the good life." 980 In other words, our identities - the question of who we are - are sometimes shaped and framed by the goods that we consume and by the way we consume: Cathexis, a word coined by consumer researcher Russ Belk, is a phenomenon where we see our material possessions as an "extension of ourselves" 981 and our "instinct of acquisition" 982 is

B. Moore, “The 'True Cost' Documentary Tallies Global Effect of Cheap Clothes," Los Angeles Times, (28 May 2015). Available at: http://www.latimes.com/entertainment/movies/la-et-mn-true-cost-cheap-clothesdocumentary-20150528-story.html (last accessed 25 March 2016) (noting some of the figures noted in Andrew Morgan's documentary "True Cost" (2015)).

978 M. HobBeS, "The Myth of the Ethical Shopper," The Huffington Post, (2015). Available at: http://highline.huffingtonpost.com/articles/en/the-myth-of-the-ethical-shopper/ (last accessed 16 July 2015).

979 See, J. DE GRAAF, D. WANN \& T.H. NAYLOR, Affluenza: How Overconsumption is Killing Us - And How We Can Fight Back, (San Francisco: Berrett-Koehler Publishers, 2014), at p. 1.

980 T. JACKSON, Prosperity without Growth: Economics for a Finite Planet, (New York: Earthscan, 2009), at p. 98; see also, M. Csikszentminalyi \& E. Rochberg-HaLton, The Meaning of Tbings - Domestic Symbols and the Self, (Cambridge: Cambridge University Press, 1981).

981 See generally, R. BELK, "Possessions and the Extended Self," Journal of Consumer Research 15 (1988): 139-168; see also, F. GINO, M.I. NORTON \& D. ARIELY, “The Counterfeit Self: The Deceptive Costs of Faking it," Psychology Science 21(5) (2010): 712-20 (concluding that people who wear fake or counterfeit products - as opposed to authentic brands - behave differently in that their "moral constraints loosen to some degree"); T. JACKSON, Prosperity without Growth: Economics for a Finite Planet, (New York: Earthscan, 2009), at p. 98 (describing cathexis as "a process of attachment that leads us to think of (and even feel) material possessions as part of the extended self."); and, R.J. FABER, "Money Changes Everything: Compulsive Buying from a Biopsychosocial Perspective," American Behavioral Scientist 35 (1992): 809-819 (linking consumerism with our psychological need for recognition and acceptance); as cited in, J. DE GRAAF, D. WANN \& T.H. NAYLOR, Affluenra: How Overconsumption is Killing Us - And How We Can 
fueled by our desire for acceptance, acknowledgment, and status. Two closely related concepts to cathexis are 1) external signaling and 2) self-signaling. External signaling is how "we broadcast to others who we are by what we wear," 983 which is related to the idea of self-signaling, which suggests that "despite what we tend to think, we [do not] have a very clear notion of who we are [but]...instead, we observe ourselves in the same way we observe and judge the actions of other people - inferring who we are and what we like from our actions." 984 In other words, what we consume and how we consume affects, at least psychologically speaking, who we are and how we view ourselves. Cathexis and the psychological impact of consumerism has significant implications in explaining why existing measures are particularly ill equipped to incentivizing behavioral changes in consumers: In short, they are blunt instruments that generally fail to take into consideration, the subtle psychological or sociological impact of what consumption means to private actors. ${ }^{985}$ The remainder of this part of the subsection will elaborate on this very assertion.

From a normative standpoint, many researchers in the fields of psychology and sociology argue that prosperity should not be "synonymous with material wealth," but more "with our ability to flourish: physically, psychologically and socially." 986 The latter perspective is the view more in alignment with our normative framework, whereas the former is one that is more closely aligned to reality, at least as depicted in this thesis. This is to suggest that there is an abundance of empirical evidence to suggest that when one's aspirations are tied to financial or materialistic accumulations, there are "deleterious consequences," 987 including but not limited to the aforementioned phenomenon of affluenza, the "painful, contagious, socially transmitted condition of overload, debt, anxiety, and waste resulting from the dogged pursuit of more." 988 Even in light of contradictory evidence, however, governments continue to rely on GDP as an accurate indicator of growth and companies and consumers alike, generally consider financial or material accumulations as definitions of success or prosperity. In sum, this frame of reference needs to be reassessed if private actors are to seriously commit themselves to the problem of labor exploitation in our global supply chain. However, to the extent that many private actors today still rely on a normative framework that values economic factors or material accumulations above and beyond that of laborers' capabilities, any measure or initiative that comes out of such a system will

Fight Back [Third Edition], (San Francisco: Berrett-Koehler Publishers, 2014), at p. 26 (adding that consumerism is sometimes connected without "shaky self-image.").

982 W. MCDougall, "The Instinct of Pugnacity" in An Introduction to social Psychology, (Boston: John W. Luce \& Co., 1926): 285-302.

983 D. ARIELY, The (Honest) Truth About Dishonesty: How We Lie to Everyone - Especially Ourselves, (New York: Harper Collins, 2012), at p. 120 (making comparisons to Roman sumptuary laws that dictated who can wear what).

984 D. ArIELY, The (Honest) Truth About Dishonesty: How We Lie to Everyone - Especially Ourselves, (New York: Harper Collins, 2012), at p. 122.

985 B. SCHWARTZ \& K. SHARPe, Practical Wisdom: The Right Way to Do the Right Thing, (New York: Riverhead Books, 2010), at p. 180 (adding that there are two problems with incentives: "First, they are often too blunt an instrument to get us what we need. In situations that call for scalpels, incentives are sledgehammers. Second, when incentives are introduced into a situation, they can undermine other, better motives to do the right thing.").

986 T. JACKSON, Prosperity without Growth: Economics for a Finite Planet, (New York: Earthscan, 2009), at p. 143 (adding that " $[\mathrm{b}]$ eyond mere subsistence, prosperity hangs crucially on our ability to participate meaningfully in the life of a society.").

987 T. KASSER \& R.M. RYAN, “A Dark Side of the American Dream: Correlates of Financial Success as a Central Life Aspiration," Journal of Personality and Social Psychology 65 (1993): 410-412.

988 J. DE GraAf, D. WANN \& T.H. NAYLOR, Affluenza: How Overconsumption is Killing Us - And How We Can Fight Back [Third Edition], (San Francisco: Berrett-Koehler Publishers, 2014), at p. 2. 
likely not have the interests of the laborers at its core. This can be said for assortment of CSR measures noted in Chapter 4 and in this chapter, including but not limited to integrated reports, codes of conduct, or certification and labeling schemes. Unless there is a more fundamental change, the success of these measures remain will continue to remain uncertain and the further proliferation of these initiatives could potentially exacerbate the situation, as it masks the inadequacy of these measures and cause further confusion for the private actors.

In order to address this inadequacy, private actors must reassess not only the value of churning out more and more laws or products, but reflect upon their normative frameworks and start considering psychological and sociological impacts of these measures on private actors from a more holistic perspective. As noted earlier, both governments and private actors must realize that while consumers gain a sense of joy from purchasing new items - because it enhances their self-image - incentivizing more and more consumption can be quite detrimental: For example, the average consumer only gains momentary sense of joy or pleasure, which gradually depletes, thus compelling the consumer to make more and more purchases. ${ }^{989}$ According to psychologist Barry Schwartz, "[t]his ubiquitous feature of human psychology is a process known as adaptation. Simply put, we get used to things, and then we start to take them for granted." 990 Other psychologists confirm this phenomenon, where consumers faced with this inevitable disappointment (i.e. the gradual depreciation of the pleasure that a newly purchased item gives them), often "seek out new commodities and experiences" in what Philip Brickman and Donald Campbell refer to as the "hedonic treadmill." 991 While the hedonic treadmill has effectively contributed to our age of proliferation, our rising GDPs, and increased profits for multitude of companies, there is a dark side to this story. The hedonic treadmill not only forces average consumers to go further into debt - yet another symptom of the proliferation problem and affluenza that exacerbates the aforementioned hourglass effect - but moreover, the treadmill effect, powered by the proliferation problem, creates deep psychological and sociological problems. Last but not least, and more relevant to this thesis, the supposed gains of proliferation are only made possible through the exploitation of laborers in the lower echelons of our global supply chain.

In light of these psychological and sociological concerns aggravated by the proliferation problem, it becomes relatively clear that the surest way to increase the effectiveness of the various CSR measures and ethical consumerism initiatives would be for private actors to start thinking differently and for them to start being more mindful about the benefits of a more holistic approach, rather than to simply continue proliferating legal or semi-legal measures that fail to address private actors at their core. As Schwartz notes, similar to how "The Opponent Process Theory of Motivation," American Psychologist 35 (1980): 671-712.

990 concept of "perceptual adaptation," which is the phenomenon people experience of "decreased responsiveness to sights, sounds, odors, and the like as people to continue to experience them.").

991 P. BRICKMAN \& D. CAMPBELL, "Hedonic Relativism and Planning the Good Society," in Adaptation Level Theory: A Symposium, M.H. APpley (ED.), (New York: Academic Press, 1971): 287-302; B. SCHWARTZ, The Paradox of Choice: Why More is Less, (New York: Harper, 2004), at p. 172; and, D. KAHNEMAN, "Objective Happiness" in WellBeing: The Foundations of Hedonic Psychology, D. KAHNEMAN, E. DIENER, \& N. SCHWARTZ (EDS.) (New York: Russel Sage, 1999): 85-105 (coining the term "satisfaction treadmill"). 
consumers can adapt to take things for granted, if private actors make a conscious effort to make changes in their behavior, they can also adapt and get used to consuming in a manner that is less reliant on labor exploitation. The difficulty with actually implementing this idea, however, is that people are psychologically hardwired to justify or underplay the negative impact of their actions, which is our next topic. ${ }^{992}$

\section{B. Cognitive Dissonance and How We Lie to Ourselves}

Another facet of dealing with the proliferation problem and our growing instinct for acquisition and rampant consumerism, which ends up restricting the impact of various CSR and ethical consumerism measures, has to do with the fact that consumers - or other private actors for that matter - are very good at justifying even their most problematic behaviors. Recall for a moment, the Rana Plaza building collapse in Savar, Bangladesh that took the lives of 1134 sweatshop laborers making clothes for fast-fashion retailers like H\&M and Primark. ${ }^{993}$ Juxtapose this tragedy with the fact that the year following the building collapse (2014) was "fast-fashion industry's most profitable [year] yet, and the world's top four fastfashion brands - Zara, H\&M, Fast Retailing (which owns Uniqlo) and Gap — had sales... of more than $\$ 72$ billion, compared with $\$ 48$ billion in 2013." 994 The main concern here is how consumers and businesses alike are capable of recognizing the building collapse as a tragedy that hopefully will never occur again on one hand, but at the same time, continue behaving in a manner that almost ensures that such a tragedy will likely occur again, by increasing their consumption from fast-fashion retailers.

This Rana Plaza example is a textbook illustration of what psychologists refer to as cognitive dissonance, ${ }^{995}$ which comes from the fact that people find it uncomfortable when they have conflicting views simultaneously so they find a way to somehow justify their views or actions. ${ }^{996}$ The way we resolve this discomfort is essentially by "fool[ing] ourselves from time to time in order to keep our thoughts and beliefs consistent with what we have already done or decided." 997 For example, "[m] ore than 75 percent of American consumers report that they would avoid purchasing products made under poor working conditions and a comparable number report they are willing to pay more for garments not produced in sweatshops," but according to the very same research, only about "10 to 12 percent of

B. SCHWARTZ, The Paradox of Choice: Why More is Less, (New York: Harper, 2004), at p. 149 (noting that people have the tendency to "downplay omissions (failures to act) when we evaluate the consequences of our decisions.").

993 A. WeStervelt, "Two Years After Rana Plaza, Have Conditions Improved in Bangladesh's Factories?, The Guardian, (24 April 2015). Available at: http://www.theguardian.com/sustainable-business/2015/apr/24/bangladeshfactories-building-collapse-garment-dhaka-rana-plaza-brands-hm-gap-workers-construction (last accessed 15 May 2015).

994 B. MOORE, “The 'True Cost' Documentary Tallies Global Effect of Cheap Clothes," Los Angeles Times, (28 May 2015). Available at: http://www.latimes.com/entertainment/movies/la-et-mn-true-cost-cheap-clothesdocumentary-20150528-story.html (last accessed 25 March 2016).

995 L. Festinger \& J.M. CARLSMiTH, "Cognitive Consequences of Forced Compliance," Journal of Abnormal and Social Psychology 58 (1959): 203-10.

996 G.W.L. Low, European Contract Law between the Single Market and the Law Market: A Behavioural Perspective, (Nijmegen: Wolf Legal Publishers, 2011), at p. 221 (noting that "people find discomfort holding simultaneously two related conflicting ideas, attitudes or belief," and as a result, they "tend towards reducing or eliminating this conflict by justifying or rationalizing one over the other, or by altering one or both ideas, attitudes or beliefs so they are no longer in conflict.").

997 R.B. CiAldini, Influence: The Psychology of Persuasion, (New York: Collins Business, 2007), at p. 59. 
consumers actually make any effort" to purchase more socially responsible products, with similar findings being reported across European Member States. ${ }^{998}$

Taking these survey results at face value, both consumers and businesses experience some level of cognitive dissonance, where they believe labor exploitation to be wrong, yet they desire the byproducts of such practices: In short, we lie to ourselves. ${ }^{999}$ Understanding the presence of this cognitive dissonance is different, however from whether or not we are willing to do anything about it. That is to suggest that, while we might say that we care about workers in sweatshops, caring and doing something about it are two fundamentally different things. Moreover, given that being a socially responsible actor takes effort and willpower, which we have a limited amount of as noted back in Chapter 4, modifying the behaviors of consumers and companies require not just blunt instruments, but measures that take into consideration the difficulty and the sensitivity of our psychological tendencies, because part of the underlying reason why various CSR and ethical consumerism measures fail is due to this cognitive dissonance, where private actors say that they care about the reduction of labor exploitations, but their actions do not back their claims. What makes this uphill battle even more difficult is a related phenomenon of cognitively flexibility, which has to do with our ability to rationalize our actions, even if they are of a dubious nature.

Before elaborating on the subject of cognitive flexibility, take a moment to think about how we view ourselves as individuals. Dan Ariely notes that people are generally driven by two opposing motivations: "On one hand, we want to view ourselves as honest, honorable people. We want to be able to look at ourselves in the mirror and feel good about ourselves (psychologists call this ego motivation)," but on the other hand, there is also a part of us that "wants to benefit from cutting corners, cheating to get something that we want (this is

D. VogeL, The Market for Virtue: The Potential and Limits of Corporate Social Responsibility, (Washington D.C.: Brookings Institution Press, 2006), at p. 47-8 (citing to findings by O'Rourke and observing that " $[\mathrm{t}]$ here is a major gap between what consumers say they would do and their actual behavior."); D. O'RouRKE, "Opportunities and Obstacles for Corporate Responsibility in Reporting in Developing Countries," World Bank/International Finance Corporations (2004), at p. 22. Bear in mind that even for the small minority of the self-proclaimed socially responsible consumers, it might be difficult for them to actually distinguish companies that are truly socially responsible from those that are not; see e.g., D. VOGEL, The Market for Virtue: The Potential and Limits of Corporate Social Responsibility, (Washington D.C.: Brookings Institution Press, 2006), at p. 102 (noting that "[m]ost consumers are unaware of most corporate labor practices, except for those that have attracted negative publicity," not to mention the fact that "they have little basis on which to judge firms who claim that their labor practices have improved."); see also, H. Collins, "Conformity of Goods, the Network Society, and the Ethical Consumer," European Review of Private Law 5 (2014): 619-640, 629 (noting that "[d]espite the fact that most consumers are ignorant about the ethical features of products they purchase, studies have shown that, with some promoting from the media about an identifiable problem such as child labour or animal testing with a particular brand, consumers are likely to rate such issues near the top of the attributes of the product that they select."); and, G. SpAargaren, "The Cultural Dimension of Sustainable Consumption Practices: An Exploration in Theory and Policy," in Innovations in Sustainable Consumption: New Economics, Socio-technical Transitions and Social Practices. M.J. COHEN, H. Szejnwald BRown \& P.J. Vergragt (EDS.) (Cheltenham: Edward Elgar, 2013), at p. 231 (noting that " $[\mathrm{m}]$ ost people do not live up to the promises that they make in the surveys. Because of inadequate outcomes, policy makers in countries such as the Netherlands have quite modest expectations of improvements that can accrue from national information campaigns and other strategies premised on the individualist paradigm.”).

999 D. ArIELY, The (Honest) Truth About Dishonesty: How We Lie to Everyone - Especially Ourselves, (New York: Harper Collins, 2012), at p. 3-4, 26-27 (stating that "dishonesty is not an outcome of simply considering the costs and benefits of dishonesty," but moreover, "the level of dishonesty is unaltered by changes in the probability of being caught makes it even less likely that dishonesty is rooted in a cost-benefit analysis"); see also, T. HARFORD, The Logic of Life: The Rational Economics of an Irrational World, (New York: Random House, 2008), at p. 11. 
the standard financial motivation)." 1000 The way we deal with these two conflicting motivations, is by being cognitively flexible and rationalizing our behaviors (i.e. manifestation of cognitive dissonance) even when they are less than flattering: For example, "we are all very good at rationalizing our actions so that they are in line with our selfish motives... [and] the obscurity of our real motivations doesn't stop us from creating a perfectly logicalsounding reason for our actions, decisions, and feelings." 1001 So even if we buy something that we know was made with questionable labor practices, we find excuses or find ways to rationalize our less-than-ideal behavior so that we can "weave self-glorifying tales" about how we are not bad people. ${ }^{1002}$

So while we seek to maintain a positive self-image by signaling to others that we are socially responsible (i.e. through implementing CSR initiatives or claiming to be an ethical consumer), we are confronted with the benefits that come with cheap labor that likely increases the instances of labor exploitation. To ease any discomfort that arise from this internal contradiction, we lie to ourselves that someone or something else is already dealing with the problem, that the product was already made so it would be even more wasteful if we do not buy it, or to say that everyone else is doing it. The latter justification in particular, is actually a psychological phenomenon called pluralistic ignorance, which is what happens "[e]specially in an ambiguous situation," where we tend to first look to see what "everyone else is doing," and seeing that they are not doing anything, we either assume that someone else is doing something about it or justify our inaction. ${ }^{1003}$ This psychological phenomenon of pluralistic ignorance is exacerbated by the proliferation problem because there is already an abundance of measures that exist that are supposedly dealing with the problem of labor exploitation, which could lull private actors into a false sense of comfort that someone else is already doing something about it. When "everyone else" is indifferent or not helping those in need, we have the tendency to replicate that belief as well.

A related phenomenon to cognitive flexibility and pluralistic ignorance that compounds the problem even further is what Dan Ariely colloquially refers to as the "What-the-Hell" effect or the negative snowballing effect, where once we have misbehaved (i.e. purchased clothing from companies accused of labor exploitation), we tend to continue with that misbehavior: "Once we start violating our own standards, we are much more likely to abandon further attempts to control our behavior... and from that point on there is a good chance that we will succumb to the temptation to further misbehave" in the future. ${ }^{1004}$ What this means is that once we realize everyone else is buying clothes from fast-fashion

1000 D. ArIELY, The (Honest) Truth About Dishonesty: How We Lie to Everyone - Especially Ourselves, (New York: Harper Collins, 2012), at p. 27.

1001 D. ARIELY, The (Honest) Truth About Dishonesty: How We Lie to Everyone - Especially Ourselves, (New York: Harper Collins, 2012), at pp. 135, 164.

1002 D. ArIELY, The (Honest) Truth About Dishonesty: How We Lie to Everyone - Especially Ourselves, (New York: Harper Collins, 2012), at p. 166.

1003 R.B. Cialdini, Influence: The Psychology of Persuasion, (New York: Collins Business, 2007), at p. 129; B. LATANÉ \& J.M. DARLEY, "Group Inhibition of Bystander Intervention in Emergencies," Journal of Personality and Social Psychology 10 (1968): 215-21; and, B. LATANÉ \& J.M. DARLEY, The Unresponsive Bystander: Why Doesn't He Help?, (New York: Appleton Century Crofts, 1968) (explaining the psychology behind the Catherine Genovese case from 1964, where 38 of her neighbors saw the crime taking place, which lasted over a period of 35 minutes, but all of the bystanders failed to help Catherine Genovese).

1004 D. ARIELY, The (Honest) Truth About Dishonesty: How We Lie to Everyone - Especially Ourselves, (New York: Harper Collins, 2012), at pp. 127, 130-1. 
retailers and we partake in the process, we are more likely to say "oh what the hell," we can't do anything about it, and dismiss the idea that we can, indeed do something about it. This is to suggest that every time we consume a good without checking the label or buy the suspiciously cheap piece of clothing that is too good to pass up, we are likely reinforcing our problematic behavior.

Yet another tricky aspect of cognitive flexibility and attempting to reduce its impacts has to do with the fact that more creative we are or "higher our brain connectivity," the easier it is for us to lie to ourselves and "think of ourselves as honorable creatures" by creating more and more "avenues to explore when it comes to interpreting and explaining dubious events." 1005 As it was mentioned during the Akpan discussion about how money can afford creative defensive strategies, we fight a similar battle internally: "Just as creativity enables us to envision novel solutions to tough problems, it can also enable us to develop original paths around rules, all the while allowing us to reinterpret information in a selfserving way." 1006 What sociologist and behavioral psychologists have observed - our cognitive dissonance/flexibility, pluralistic ignorance, negative snowballing effect, ego motivation, and so on - cause serious challenges to our efforts to increase the effectiveness of various CSR and ethical consumerism measures. Without actually confronting these psychological and sociological challenges, private actors cannot begin to fully grasp the complete picture of why certain measures work, while others do not. Ultimately, if we want to reduce instances of socially undesirable actions, "we need to find a way to change the way in which we are able to rationalize our actions," 1007 and find ways to recognize and confront our cognitive dissonance at a more fundamental and internal level, rather than to simply rely on external incentives like laws or various CSR initiatives.

\section{Numb and Desensitized about Labor Exploitation}

Yet another complication that the proliferation problem creates is related to the aforementioned phenomenon of pluralistic ignorance. In a number of cases, what leads private actors to change their habits is when they experience or encounter some shocking event. In the age of proliferation, where there is a plethora of news outlets, social network platforms, and a mushrooming collection of websites where anyone and everyone can access any kind of information, more and more consumers are becoming increasingly numb and desensitized about the issues like labor exploitation. For example, in the early 1990s, the public was shocked, if not appalled, to discover the exploitation of laborers taking place in factories that manufactured goods for their favorite brands like Nike. Today, news of such atrocities have become rather commonplace and as the previous section noted on consumer's reasonable expectations, we have potentially reached a point where it is almost unreasonable for consumers to expect that a supply chain can be completely labor exploitation free.

1005 D. ArIELy, The (Honest) Truth About Dishonesty: How We Lie to Everyone - Especially Ourselves, (New York: Harper Collins, 2012), at pp. 170, 172 (suggesting that there is a link between creativity and the ability to be dishonest to ourselves because creativity allows us to "tell ourselves stories about how we are doing the right thing, even when we are not.").

1006 D. ARIELY, The (Honest) Truth About Dishonesty: How We Lie to Everyone - Especially Ourselves, (New York: Harper Collins, 2012), at p. 187.

1007 D. ARIELY, The (Honest) Truth About Dishonesty: How We Lie to Everyone - Especially Ourselves, (New York: Harper Collins, 2012), at p. 53. 
A similar claim can be said for news reports of tragedies that take place in the factories primarily around South East Asia: From news of Foxconn employees jumping off buildings in protest of their working conditions, the fire in Tazreen that killed at least 112 workers, the Rana Plaza building collapse that killed 1124, or the latest reports on yet another building collapse in Wenling, China, these events keep popping up in our news feeds and the shock and horror of it all have started to wane for some with each news. For example, why did the media coverage of the Rana Plaza collapse in April 2013 galvanize more call to action than the Wenling building collapse that took place in July 2015? Or why did the Rana Plaza collapse get more news coverage than the Wenling building collapse? ${ }^{1008}$

One possible reason could be that the building collapse in Wenling, where "one in five pairs of shoes available worldwide originate from," caused the death of "only" 12 workers compared to the Rana Building collapse which had a casualty number almost a hundred times larger. Another possible explanation, as previously hypothesized, is due to what the proliferation of news - particularly bad news - has done to private actors and their pluralistic ignorance. An argument could be made that the building collapse in Wenling was worse than that of Rana Plaza given that there was already a fire that engulfed another show factory in Wenling only in the previous year, which took the lives of 14 workers. ${ }^{1009}$ Admittedly, it is nonsensical to say that one atrocity is "less bad" or "better" than the other, as all atrocities are - by definition - terrible. However, it is a fact that many of the grave human rights violations that take place throughout the supply chain not only go unreported, but even if the news outlets do report on them, there is no guarantee that the private actors will drastically change their consumption patterns, again for the aforementioned psychological and sociological reasons.

A spillover effect worth considering in this context is if the news outlets report more and more about these atrocities, there is a possibility that these reports will only further desensitize the populace, which could lead to a majority of consumers simply accepting the issue of labor exploitation as the inevitable reality or an acceptable norm. In other words, something as atrocious as businesses operating a sweetshop that ends up crushing thousands of people to death can become - at least in the psyche of private actors - appallingly mundane. So the shock and horror of labor exploitation that may have once incentivized some to modify their behaviors in the past may now be less of an incentive for some consumers to change or adapt their consumption habits.

To conclude this subsection, the proliferation problem and the information overload that ensues are - quite possibly - making private actors numb and our collective response to labor exploitations taking place in the global supply chain somewhat deflated. The proliferation problem also creates various psychological and sociological issues for private actors, which weakens the incentives for private actors to seriously adopt, implement, and enforce various CSR and ethical consumer measures. Furthermore, as noted in the beginning of this subsection, the proliferation problem is closely related to the complexity problem, which is the subject of the next subsection. In short, the proliferation problem con-

1008 In accordance with a Google Trend comparison between the search phrases "Rana Plaza building collapse" and "Wenling building collapse".

1009 BBC, "China Factory Collapse: Six Dead and 49 Rescued," BBC News, (4 July 2015). Available at: http://www.bbc.com/news/world-asia-china-33396086 (last accessed 22 July 2015). 
tributes to the complexity problem and given our bounded rationality, this poses a serious concern, not only to the problem of reducing labor exploitation in the global supply chain, but to other collective actions problems of similar scale.

\subsubsection{The Complexity Problem}

Newton's Second Law of Thermodynamics, at the most basic level, states that entropy is always increasing, which is to state that disorder is always increasing. Chapter 3 in the context of the externalization problem discussed the disaggregation of firms and the fragmentation of enterprises, but the proliferation problem noted above also highlighted how we now live in a world where there is more of everything, which is to suggest that the world we live in today is an incredible complex one; one that perhaps private actors cannot fully comprehend, grasp, or understand given our bounded rationality. This is the underlying point of the complexity problem, which is that private actors not only have limited cognition, but to repeat Thaler's quote from the Introduction, people are constrained by the "three bounds" of "bounded rationality, bounded willpower, and bounded selfinterest." 1010 Chapter 2 already noted, in the context of the Goldilocks problem, the difficulty governments have at predicting the likely success of their laws and regulations ex ante prior to implementation. The exact same point can be made about the ability of private actors to ascertain, with any certainty, the likely impact various CSR or ethical consumerism measures will have ex ante. This is all to suggest that perhaps the world is too complicated of a place for private actors to be able to predict what kind of impact their actions will have on the lives of workers at the other end of the global supply chain. As already noted back in the context of the causation problem, it is difficult to state with absolute certainty that western corporations implementing corporate codes or consumers shopping ethically is actually making a meaningful impact on the lives to exploited laborers that empower them in a manner conforming to our normative framework. ${ }^{1011}$

In order to illustrate this problem, this subsection will have two primary goals: the first is to suggest that there are problems that neither governments nor private actors can actually find solutions to ex ante, which the labor exploitation taking place in the global supply chain could be one of; and second, that our limited cognitive abilities make it so that it might be almost impossible for us to come up with anything that resembles a panacea or a one-size-fits-all type of a solution to a problem of such magnitude and complexity. Accordingly, this subsection will: a) explain the concept of fundamentally unidentified questions; b) elaborate further about our bounded rationality; c) discuss how our cognitive abilities can be divided into two different systems; d) detail how people cope with complexity in

1010 R.H. THALER, Misbehaving: The Making of Behavioral Economics, (New York: Norton, 2015), at pp. 257-8 (suggesting that "the field of law and economics, as currently practiced, should be modified to accommodate recent findings in behavioral economics.”).

1011 T. HARFord, Adapt: Why Success Always Starts with Failure, (London: Abacus, 2012), at p. 120 (noting the difficulty of attempting to determine how Western charities can best contribute to the development of poverty-stricken countries: "[ $\mathrm{t}]$ he challenge is to figure this out in a world where much of the cash is coming from foreign governments, millionaire musicians, and millions of well-meaning Westerners who have nothing to guide them except a few well-chosen words [and photographs in pamphlets] as they try to make the best use of their donations," adding that we "struggle with complex problems that [we] barely understand, and... [we] are capable of doing serious damages with the best of intentions."). 
light of our limited cognition by relying on biases and heuristics; and finally, e) suggest that groups and organizations (i.e. companies) face similar cognitive limitations and bounded rationality issues that individuals face as well.

\section{A. Fundamentally Unidentified Questions}

In the world of econometrics, there are questions that econometricians refer to as "fundamentally unidentified questions" or as some put it, "FUQs," which are questions that "cannot be answered by an experiment." 1012 For example, the question of what causes poverty, which includes a "complex mix of causes - corruption, oppression of women, lack of credit, broken social ties" and so forth is an example of a FUQ, where the "knot is simply too tangled to be picked apart" in a manner that would ensure the predictive value of the analysis. ${ }^{1013}$ Similarly, one could argue that the question of what causes labor exploitation or what would end or reduce it could all be considered as FUQs: As noted in the previous subsection, the problem of labor exploitation in the age of proliferation has so many variables and contributing factors consisting of "complex interaction among many psychological processes that permeate our culture, including rising expectations, awareness of opportunity costs, aversion to trade-offs, adaptation, regret, self-blame, the tendency to engage in social comparisons" and so on that it would be practically impossible to find the "right way" for private actors to attempt to eliminate or reduce them. ${ }^{1014}$ In short, there are some questions that private actors just cannot answer, or problems that people cannot find proper solutions to, until they test various possible solutions and learn through trial-anderror. ${ }^{1015}$

For example, this thesis noted how "there are still no standardized metrics for CSR,"1016 meaning that it is difficult to accurately measure, analyze, and predict the impact of various CSR initiatives. At the academic level, this complexity can be illustrated by " $[t]$ he quality of writing on CSR [which] is highly uneven, and much of it has a strong normative bias, making its value difficult to assess," not to mention the fact that the quantity of it seems to "keep growing," which is yet another example of the proliferation problem. ${ }^{1017}$ From a practical perspective, this difficulty can be illustrated by the dispute over which ESG metrics are actually relevant to evaluating company's social or the fact that even major companies like Ernest \& Young, KPMG, and PriceWaterhouseCoopers that conduct routine audits for major corporations often miss instances of non-compliance. ${ }^{1018}$ The difficul-

1012 T. Harford, Adapt: Why Success Always Starts with Failure, (London: Abacus, 2012), at p. 132 (quoting an econometrician John Angrist, who Harford interviewed in 2010).

1013 T. HARFORD, Adapt: Why Success Always Starts with Failure, (London: Abacus, 2012), at p. 132.

1014 B. SCHWARTZ, The Paradox of Choice: Why More is Less, (New York: Harper, 2004), at pp. 44, 217 (adding that "it is the cumulative effect of these added choices," or what Fred Hirsch refers to as "the tyranny of small decisions" that Schwartz believes "is causing substantial distress" amongst the consumers).

1015 See e.g., C.M. Christensen, The Innovator's Dilemma: The Revolutionary Book. That Will Change the Way You Do Business, (New York: Harper Business, 2011), at p. 165 (stating that "[n]ot only are the market applications for disruptive technologies unknown at the time of their development, they are unknowable.").

1016 D. VogeL, The Market for Virtue: The Potential and Limits of Corporate Social Responsibility, (Washington D.C.: Brookings Institution Press, 2006), at p. 70.

1017 D. VoGEL, The Market for Virtue: The Potential and Limits of Corporate Social Responsibility, (Washington D.C.: Brookings Institution Press, 2006), at p. xx-xvi (adding that "CSR is very much a moving target.").

1018 D. VOGEL, The Market for Virtue: The Potential and Limits of Corporate Social Responsibility, (Washington D.C.: Brookings Institution Press, 2006), at p. 90 (stating that "[q]uestions have also been raised about the quality of audits produced by large commercial firms has been questioned”); see also, D. O'Rourke, Smoke from a Hired Gun: 
ty of conducting a thorough audit along the supply chain and analyzing compliance to CSR initiatives have led to a situation where many commercial auditing firms are leaving the social auditing business because it is simply too expensive and too difficult to carry out, leaving the auditing process to nonprofit organizations instead. ${ }^{1019}$

This situation is part of the reason why many experts in the field believe that the global supply chain is simply too complex to competently assess and analyze and that the limit or the ceiling of monitoring and compliance measures, often included in various codes of conduct, have been reached: For example, economist Tim Harford notes that " $[t]$ he modern world is mind-bogglingly complicated," and it is "simply too complicated for anyone to analyse with much success." 1020 The ILO's Janelle Diller also adds that "[e]ven if transnational private initiative can present a sustainable 'high road' for business conduct amidst the complexities of global transactions over time, claims by enterprises and other actors concerning social improvements achieved through private initiatives are not easily categorized, evaluated or compared." 1021

To reiterate, part of the difficulty that private actors have when it comes to processing complexity has to do with our cognitive limitations and our bounded rationality, which - as this thesis noted already in the Introduction - is an inescapable condition of being human. Thus, it is difficult to deny that this complexity problem is indeed limiting the effectiveness of not just various CSR and ethical consumerism measures that strive to reduce labor exploitation, but to the extent that those that work in the public sector also suffer from the same affliction, even government measures are susceptible to this problem as well. Therefore, it is entirely possible that the complexity problem is a problem that is insurmountable and an obstacle that private actors will not be able to fully overcome, but must work around instead. This realization requires us to take a closer look into our limitations directly, by observing what impact bounded rationality and cognitive limitations have on us. This exercise will allow us to reassess from a more holistic perspective, what private actors can do differently to tackle the problem of labor exploitation in the global supply chain moving forward.

\section{B. Bounded Rationality Revisited}

Recall here that our rationality, as mere human beings, are bounded, which means that we "lack the cognitive ability to solve complex problems," 1022 and "in many cases, individuals

A Critique of Nike's Labor and Environmental Auditing, (San Francisco: Transnational Resource and Action Center, 1997) (reporting that upon reexamining a number of commercial audits of Nike's factories, there were significant violations that were missed due, in part, to the fact that the commercial auditors only relied on information supplied by managers and not the workers).

1019 D. VoGeL, The Market for Virtue: The Potential and Limits of Corporate Social Responsibility, (Washington D.C.: Brookings Institution Press, 2006), at p. 91.

1020 T. HARFOrD, Adapt: Why Success Always Starts with Failure, (London: Abacus, 2012), at pp. 3, 8 (adding manufacturing an object as simple as a toaster "involve global supply chains and coordinated efforts of many individuals, scattered across the world. Many do not even know the final destination of their efforts."). Harford also quotes Bill Gates in one of his chapters, which is in alignment with the point being made here, which is that "the barrier to change is not too little caring; it is too much complexity."

1021 As quoted by S.D. MurPhy, "Taking Multinational Corporate Codes of Conduct to the Next Level," Columbia Journal of Transnational Law 43(2) (2005), at p. 40.

1022 See generally, H.A. SIMON, Models of Man, Social and Rational: Mathematical Essays on Rational Human Behavior in a Social Setting, (Oxford: Wiley, 1957) (coining the term "bounded rationality"); see also, R.H. THALER, Misbehaving: The Making of Behavioral Economics, (New York: Norton, 2015), at p. 23. 
make pretty bad decisions - decisions they would not have made if they had paid full attention and possessed complete information, unlimited cognitive abilities, and complete selfcontrol." 1023 Given that perpetually complexity is increasing - as substantiated by firm disaggregation, age of proliferation, emergence of micropowers, and Newton's Second Law - even if our cognitive ability remains static, relatively speaking, this means that our ability is increasingly becoming more and more limited: As behavioral economist, Richard Thaler noted, "in our increasingly complicated world people cannot be expected to have the expertise to make anything close to optimal decisions in all the domains in which they are forced to choose. But we all enjoy having the right to choose for ourselves, even if we sometimes make mistakes." 1024 The apt manifestation of bounded rationality was mentioned back in Chapter 2 in the context of the late Justice Scalia, who admitted that even as a sitting US Supreme Court Justice presiding on a case about Obamacare that he could not be bothered to read the entire act, understandably so, given that the Act is over two thousand pages long. ${ }^{1025}$ Here again, people might simply assume that a Supreme Court Justice is capable of reading what is required, carefully assessing the matter, weighing the pros and cons, and reaching a reasonably justified outcome, but that is not always a safe assumption in light of bounded rationality.

What people can make reasonable assumptions about, however, is the fact that because of our bounded rationality, our limited cognition, and our inability at times to resolve complex problems, we tend to behave in a "predictably irrational" manner, which has been observed, documented, and confirmed through series of experimental and empirical research. ${ }^{1026}$ The aim of this part of the subsection is to provide examples of these predicable

1023 R.H. Thaler \& C.R. Sunstein, Nudge: Improving Decisions About Health, Wealth, and Happiness, (New York: Penguin, 2009), at p. 5.

1024 R.H. Thaler, Misbehaving: The Making of Behavioral Economics, (New York: Norton, 2015), at p. 324; see also, R.B. Cialdini, Influence: The Psychology of Persuasion, (New York: Collins Business, 2007), at p. 245 (elaborating that "whenever free choice is limited or threatened, the need to retain our freedoms makes us desire them significantly more than previously."); O. BEN-SHAhAR \& C.E. SCHNEIDER, More Than You Wanted to Know: The Failure of Mandated Disclosure, (Princeton: Princeton University Press, 2014), at p. 43 (noting that left to their own devices, consumers often make decisions detrimental to themselves and listing various examples of consumers ignoring information made available to them).

1025 National Federation of Independent Business v. Seblius. Oral Arguments (28 March 2012). Available at: http://www.supremecourt.gov/oral_arguments/argument_transcripts/11-393.pdf (last accessed 4 April 2017), at p. 38 (asking the Deputy Solicitor General Edwin Kneedler, "[w] hat happened to the Eight Amendment? You really want us to go through these 2,700 pages? Do you really expect the Court to do that?"); R. STEVENS, "Torts," in The Judicial House of Lords: 1876-2009, L. BLOM-COOPER, B. DiCKSON \& G. DrEwry (EDS.) (Oxford: Oxford University Press, 2009), at p. 650 (suggesting that this problem could be worse in common law systems, than in the civil law systems given that the "law which is made on a case-by-case basis tends to lack any systematic ordering," but moreover, "[t] he judge does not have the luxury of time and space, which a textbook writer or academic possess.”).

1026 See e.g., D. ArIELy, Predictably Irrational: Hidden Forces that Shape Our Decisions, (London: Harper Collins, 2009); see also, D. Kahneman, Thinking, Fast and Slow, (London: Penguin Book, 2013), at p. 411 (stating that research conducted by Kahneman and Tversky show that "[h]umans are not well described by the rational agent model."); R.H. ThALER, Misbehaving: The Making of Behavioral Economics, (New York: Norton, 2015), at p. 98 (stating that "[h]umans do not have the brains of Einstein... nor do they have the self-control of an ascetic Buddhist monk. Rather, they have passions, faulty telescopes, treat various pots of wealth quite differently, and can be influenced by short-run returns in the stock market. We need a model of these kinds of Humans.”); see also, R.J. SHILLER, Irrational Exuberance, (Princeton: Princeton University Press, 2015), at p. 80 (stating that "[e]conomists usually like to model people as calculating optimally their investment decisions based on expectations of future price changes..." when in fact, this is not always the case). 
irrationalities, which at times, are in conflict with the classical economic characterization of people as reasonable and rational actors.

One specific illustration of the classical model's limitation is the fact that most people are loss or risk averse, which means that for them "losses loom larger than gains" 1027 making them susceptible to framing effects: Framing effect "means that [people's] decisions are influenced by how a decision is framed, even though the different frames reflect merely semantic differences rather than reality." 1028 For example, there is a difference in terms of how people perceive and react to a sign that says "cash discount of $€ 2$ " versus a "credit card surcharge of $€ 2$." In a purely neoclassical model, rational actors capable of conducting a simple cost-benefit analysis will consider these two options to be identical. In reality, however, because most people are loss averse, they are more likely to not purchase the item in question if they have to pay a surcharge, which they would consider as a loss. This is to suggest that although "neoclassical economics is built on very strong assumptions that, over time, have become established facts," most notably the assumptions that actors are rational, we now know that these assumptions are flawed, which is to say that the application of the neoclassical model of economics, as we already suggested in the Introduction, is vulnerable to reality. ${ }^{1029}$

There is an emerging subset of economics, however, that is attempting to adapt this flawed classical model: Known as "behavioral economics," Thaler explains that this is still "economics," but "with strong injections of good psychology and other social sciences." 1030 While many traditional economic models have relied on unrealistic assumptions

D. Kahneman, Tbinking, Fast and Slow, (London: Penguin Book, 2013), at p. 284; R.H. Thaler, Misbehaving: The Making of Behavioral Economics, (New York: Norton, 2015), at p. 81 (stating that there is an exception to this, which is when it comes to losses or after people have lost something, they become "risk-seeking" in an attempt to at least get back to even); see also, R.B. CIALDINI, Influence: The Psychology of Persuasion, (New York: Collins Business, 2007), at p. 238 (concurring that "[t]he idea of potential loss plays a large role in human decision making... [where] people seem to be more motivated by the thought of losing something than by the thought of gaining something of equal value.").

1028 C.R. SUNSTEIN \& R. HASTIE, Wiser: Getting Beyond Groupthink to Make Groups Smarter, (Massachusetts: Harvard Business Review Press, 2015), at p. 48 (defining framing further by noting that "[b]y a "frame," we mean to refer to how a problem is presented to someone, or how people represent or define a decision from their own perspective."); see also, B. SCHWARTZ, The Paradox of Choice: Why More is Less, (New York: Harper, 2004), at p. 63 (noting that context and the language used to frame the issue often influences choices people make using the example of a "discount for paying cash" versus "surcharge for suing credit"); and, D. KAHNEMAN \& A. TVERSKY, "Rational Choice and the Framing of Decisions," in Choices, Values, and Frames, D. KAHNEMAN \& A. TVERSKY (EDS.) (New York: Cambridge University Press, 2000), at p. 209.

1029 See generally, D. ARIELY, Predictably Irrational: Hidden Forces that Shape Our Decisions, (London: Harper Collins, 2009); see also, D. Kahneman, Thinking, Fast and Slow, (London: Penguin Book, 2013), at p. 411 (stating that research conducted by Kahneman and Tversky show that "[h]umans are not well described by the rational agent model."); R.H. THALER, Misbehaving: The Making of Behavioral Economics, (New York: Norton, 2015), at p. 98 (stating that "[h]umans do not have the brains of Einstein... nor do they have the self-control of an ascetic Buddhist monk. Rather, they have passions, faulty telescopes, treat various pots of wealth quite differently, and can be influenced by short-run returns in the stock market. We need a model of these kinds of Humans."); see also, R.J. SHILLER, Irrational Exuberance, (Princeton: Princeton University Press, 2015), at p. 80 (stating that "[e]conomists usually like to model people as calculating optimally their investment decisions based on expectations of future price changes..." when in fact, this is not always the case); A.K. SEN, "Rational Fools: A Critique of the Behavioral Foundations of Economic Theory," Philosophy and Public Affairs 6(4), (1977): 317-44, 336 (stating that "[t]he purely economic man is indeed close to being a social moron," which is to suggest that classical "[e]conomic theory has been much preoccupied with this rational fool.").

1030 R.H. THALER, Misbehaving: The Making of Behavioral Economics, (New York: Norton, 2015), at p. 9 (arguing that they multidisciplinary approach improves the accuracy of the predictions that economists and academics make). 
such as the aforementioned rational choice theory, expected utility theory, ${ }^{1031}$ and the efficient market hypothesis, ${ }^{1032}$ the behavioral economics movement suggests that " $[\mathrm{i}] \mathrm{t}$ is time to stop making excuses," and to take a more "enriched approach to doing economic research, one that acknowledges the existence and relevance of Humans," not as rational actors, but as real humans. ${ }^{1033}$ Given that classical economic theory and their key assumptions are flawed, the failure for decision-makers to recognize and acknowledge the limitation of economics has significant impact in the real world: As already noted in the Introduction, to the extent that lawmakers and private actors rely heavily on classical economics that fail to take into consideration the real nature of human beings with all of their flaws and boundaries, it is entirely conceivable that the laws or initiatives that they create could similarly fail to take into consideration the real nature of human beings, and in the process validate the complexity problem. ${ }^{1034}$ One suggestion worth making in this context to answer our research question, thus, is for stakeholders to adopt a "law and behavioral economics" approach that recognizes are cognitive limitations and bounded rationality. This is also to suggest that private actors not only look at law and economics when contemplating solutions or looking for ideas, but also to incorporate psychology, sociology, or any other field of study that can enhance our understanding of human nature, not as a perfectly rational actor, but a charmingly flawed actor, stumbling through life and trying to survive. ${ }^{1035}$

1031 See generally, J. VON NEUMANN \& O. MORGENSTERN, Theories of Games and Economic Behavior, (Princeton: Princeton University Press, 1947) (establishing the expected utility theory, which is a process that - based on a set of axioms - inevitably leads to the best course of action, at least in theory); cf. D. KAHNEMAN, Thinking, Fast and Slow, (London: Penguin Book, 2013), at p. 377 (criticizing the expected utility theory as a theory that is "entirely about the rules of rationality that should govern decision utilities," but failing to take into consideration "hedonic experiences.”); D. Kahneman \& A. TVERSky, "Prospect Theory: An Analysis of Decision under Risk," Econometrica 47(2) (1979): 263-291 (criticizing the expected utility theory and presenting an alternative theory - the prospect theory where they argue that people do not calculate the expected utilities of their actions as suggested by the expected utility theory; instead people make decisions based on the possible gain/losses of their actions.). The key difference between the two theories is that the latter attempts to take into consideration human behavior, while the expected utility theory is a more normative theory.

1032 R.J. SHILLER, Irrational Exuberance, (Princeton: Princeton University Press, 2015), at p. 195 (defining the efficient market hypothesis in the following manner: "The efficient markets theory asserts that all financial prices accurately reflect all public information at all times. In other words, financial assets are always priced correctly, given what is publicly known, at all times."); see also, R.H. THALER, Misbehaving: The Making of Behavioral Economics, (New York: Norton, 2015), at p. 230 (stating that “the efficient market hypothesis has two components: you can't beat the market (there is no free lunch), and prices are 'right"'); Cf. R.J. SHILLER, "Do Stock Prices Move Too Much to Be Justified by Subsequent Changes in Dividends?," American Economic Review 71(3) (1981): 421-36 (arguing that the efficient market hypothesis, at least the price is right component is flawed). Thaler also notes that as a normative benchmark of how the world should be, the EMH has been extraordinarily useful," but "[w]hen it comes to the EMH as a descriptive model of asset markets," Thaler believes that the "report card is mixed."

1033 R.H. THALER, Misbehaving: The Making of Behavioral Economics, (New York: Norton, 2015), at pp. 4, 7 (explaining the term "misbehaving" as the human behavior that is "inconsistent with the idealized model of behavior that is at the heart of what we call economic theory" where "people depart from the fictional creatures that populate economic models.").

1034 G.W.L. Low, European Contract Law Between the Single Market and the Law Market: A Behavioural Perspective, (Nijmegen: Wolf Legal Publishers, 2011), at p. 180 (stating that "the economic analysis of the law fails to acknowledge certain fundamental aspects of human behaviour. Therefore, when that normative framework is used as a standard by which rules and institutions may be measured or made, it leads to the development of erroneous policies and fails to correctly regulate human behaviour."); see also, D. KAHNEMAN, Thinking, Fast and Slow, (London: Penguin Book, 2013), at p. 374 (advocating for decision-makers to not take what is traditionally considered as "inconsequential factors" in economics, for granted).

1035 G.W.L. Low, European Contract Law Between the Single Market and the Law Market: A Behavioural Perspective, (Nijmegen: Wolf Legal Publishers, 2011), at p. 180 (advocating for adopting the behavioral economics and law approach, but 
In the end, this is to suggest that we "have to stop assuming that [neoclassical economic] models are accurate descriptions of behavior, and stop basing policy decisions on such flawed analyses." 1036

While some believe that this transition - from law and economics to law and behavioral economics - has already taken place, ${ }^{1037}$ the evidence presented in the chapters thus far indicate that any claims of behavioral economics' triumph are slightly premature. The lesson to be drawn from this part of the subsection, however, is not for private actors to simply discard or abandon neoclassical theory of economics all together when reassessing their current attempts to reduce instance of labor exploitation in the global supply chain. Rather, the suggestion here is for stakeholders to at least be more open to considering the legitimacy of behavioral economics or more interdisciplinary perspectives that consider psychology and sociology together with the law. This approach that is more reflective of people and their flaws will likely be more meaningful when attempting to come up with different ways in which private actors can contribute to the reduction of labor exploitation in the future. ${ }^{1038}$ This endeavor will surely require some effort on behalf of the stakeholders, and as the next part of the subsection will show, the very fact that this process requires effort - given our bounded willpower - could present some difficulties.

\section{System 1 and System 2}

One way to think about our habits - to borrow Daniel Kahneman's framework from Thinking, Fast and Slow - is to divide our cognitive process into two different systems: System 1, the part of our internal system that is responsible for "thinking fast" (i.e. rapid, automatic, emotional, and intuitive thinking as demonstrated by our biases and heuristics) and System 2, the part of our cognitive process that allows us to "think slow."1039 According to Kahneman, "System 1 operates automatically and quickly, with little or no effort and no sense of voluntary control," whereas "System 2 allocates attention to the effortful mental activities that demand it, including complex situations." 1040 Habits, accordingly, are

cautioning that the purpose of this approach is not necessary to "undermine the normative value of the economic analysis of the law, but to buttress it...").

1036 R.H. THALER, Misbehaving: The Making of Behavioral Economics, (New York: Norton, 2015), at p. 9; see also, K. MOFID \& S. SZEGHI, "Economics in Crisis: What Do We Tell the Students?," Globalisation for the Common Good Initiative (22 April 2010). Available at: http://www.gcgi.info/news/91-economics-and-economists-engulfed-by-crises-what-dowe-tell-the-students (last accessed 4 April 2017) (stating the following: "Now is the time to acknowledge the failures of standard theory and the narrowness of market fundamentalism. The ties demand a revolution in economic thought... In many respects, this means a return to the soil in which economics was initially born, moral philosophy amid issues and question of broad significance involving fullness of human existence"); as cited in, F. CAPRA \& U. MATTEI, The Ecology of Law: Toward a Legal System in Tune with Nature and Community, (Oakland: BerrettKoehler, 2015), at p. 82.

1037 R. KOROBKIN, "What Comes After Victory for Behavioral Law and Economics," University of Illinois Law Review 5 (2011): 1653-74 (claiming that "[t] he battle to separate the economic analysis of legal rules and institutions from the straightjacket of strict rational choice assumptions has been won.”).

1038 R.H. Thaler, Mishehaving: The Making of Behavioral Economics, (New York: Norton, 2015), at p. 257-8 (suggesting that "the field of law and economics, as currently practiced, should be modified to accommodate recent findings in behavioral economics.").

1039 See generally, D. Kahneman, Thinking, Fast and Slow, (London: Penguin Book, 2013).

1040 D. Kahneman, Thinking, Fast and Slow, (London: Penguin Book, 2013) at pp. 20-21; see also, S.A. SLOMAN, "The Empirical Case for Two Systems of Reasoning," Psychological Bulletin 119(1) (1996): 3-22; J. HAIDT, “The Emotional Dog and Its Rational Tail," Psychological Review 108, (2001): 814-834; and, R.H. THALER, Misbehaving: The Making of Behavioral Economics, (New York: Norton, 2015), at p. 109 (distinguishing "doers" from "planners" in this con- 
generally associated with System 1, whereas System 2 likely governs efforts the lead to ego depletion like reading and attempting to understand laws or conducting thoughtful costbenefit analyses. To illustrate this distinction, consider for a moment the fact that "more than 40 percent of the actions people perform each day [a]ren't actual decisions, but habits" (i.e. think about which shoe you put on first or which leg you put through the pant leg first each morning). ${ }^{1041}$ The role that habits play can also partially explain the cognitive dissonance that private actors are often confronted with; we purchase items sold at our local stores that we are familiar with, regardless of whether they are socially responsible or not, partially because that is a habit. We sometimes continue to do the things that we do, or believe in the things that we believe in, because that is what our habits dictate. When we do something that we are not familiar with, outside of our usual habits, we experience a certain sense of discomfort that we seek to get rid of, usually by going back to our habits.

Dan Ariely characterizes this distinction - between System 1 and System 2 - slightly differently as "a struggle between the impulsive (or emotional) and the rational (or deliberative) parts of ourselves." 1042 This dichotomy suggests that moral or value-based beliefs act quickly first when we are confronted with a situation or a dilemma and the justification or the more rational analysis of the situation, comes secondary. To illustrate this point furthermore, Jonathan Haidt has established that while people are often capable of rational, reasoned analysis (to the extent that the "three bounds" 1043 allow us), this analytical thinking, or the reasoning process only comes after the initial moral evaluation/judgment. ${ }^{1044}$ In his words, only when our moral beliefs are questioned, do we then proceed to act "like a lawyer, trying to build a case, rather than a judge, searching for the truth." 1045 Regardless of how this phenomenon is phrased, "[w] hen our deliberative reasoning ability is occupied, the impulsive system gains more control over our behavior." 1046 Think about this neurological phenomenon in the context of consumers while they are shopping. What the science is telling us is that consumers are more like to make purchasing decisions instinctively and justify their purchasing decision later. In other words, the average consumer is more like to buy a particular piece of clothing that he or she likes relying more on their System 1, and in the event that the particular item of clothing was likely produced exploiting laborers, their

text in the following manner: "it is reasonable to think of the planner as the slow, reflective, contemplative System 2 while the doers are the fast, impulsive, intuitive System 1."). Thaler also elaborated that there is "physiological basis" to substantiate the existence of System 1 and System 2.

1041 B. Verplanken \& W. WOOD, "Interventions to Break and Create Consumer Habits," Journal of Public Policy and Marketing 25(1) (2006): 93-103; see also, D.T. NEAL, W. WOOD \& J. M. QuinN, "Habits - A Repeat Performance," Current Directions in Psychological Science 15(4) (2006): 198-202; and, C. DuHIGG, The Power of Habit: Why We Do What We Do in Life and Business, (New York: Random House, 2012).

1042 D. Ariely, The (Honest) Truth About Dishonesty: How We Lie to Everyone - Especially Ourselves, (New York: Harper Collins, 2012), at p. 98.

1043 R.H. THALER, Misbehaving: The Making of Behavioral Economics, (New York: Norton, 2015), at pp. 257-8 (being "bounded rationality, bounded willpower, and bounded self-interest").

1044 J. HAIDT, “The Emotional Dog and Its Rational Tail," Psychological Review 108, (2001): 814-834, 814; as cited in, B. SChWARTZ \& K. Sharpe, Practical Wisdom: The Right Way to Do the Right Thing, (New York: Riverhead Books, 2010), at p. 74 .

1045 J. HAIDT, “The Emotional Dog and Its Rational Tail," Psychological Review 108, (2001): 814-834, 814; see also, M. GLADwELL Blink: The Power of Thinking Without Thinking, (New York: Little Brown Book, 2005) (noting our innate ability to automatically recognize patters in a blink of an eye).

1046 B. Shiv \& A. Fedorikhin, "Heart and Mind in Conflict: The Interplay of Affect and Cognition in Consumer Decision Making," The Journal of Consumer Research 26(3) (1999): 278-292; see also, D. ARIELY, The (Honest) Truth About Dishonesty: How We Lie to Everyone - Especially Ourselves, (New York: Harper Collins, 2012), at p. 79. 
System 2 will subsequently find ways to justify their cognitive dissonance. This partially explains why certain CSR and ethical consumerism measures fail to make the impact that it aims to because the average consumer is neurologically hardwired to operate in this manner.

If there is even an ounce of truth to this observation about how individuals behave and make decisions, it is worth reconsidering the existing framework that focuses primarily on laws or legalization of private initiatives as the preferred method of addressing our collective action problems. For example, if the way in which we make most of our decisions (i.e. what to buy or who to conduct business with) are - at least instinctively or initially - based on System 1, attempting to modifying the behaviors of private actors through instruments that require activation of our System 2 could potentially be inadequate, at least on various occasions. ${ }^{1047}$ This would validate our previous hypothesis, noted back in Chapter 4 in the context of the incentive problem, that in order to modify people's habits, a handful of extrinsic incentives are not enough. Especially if the extrinsic enforcement is weak, people are likely to go back to their old habits seeking familiar comforts (i.e. ignoring their cognitive dissonance and continuing to shop at fast-fashion retailers with ties to labor exploitation). ${ }^{1048}$ This is to suggest that any successful strategy will require sustained commitment as people have the tendency to go back to their bad habits without periodic reminders. In the end, understanding the difference between System 1 and System 2 is crucial in the context of how solutions to problems ought to be conceived and designed. In short, laws or private initiatives that have the binding force of law through contracts (i.e. codes of conduct) are traditionally designed to change the way private actors behave through extrinsic incentives (the aforementioned carrots and sticks). However, perhaps what is more necessary today - in a world already proliferated with laws and private initiatives - are measures that attempt to target our System 1. In order to better understand our System 1, we must now discuss our biases and heuristics that facilitate our System 1.

\section{Biases and Heuristics}

Faced with limited cognitive resources and depleting willpower, people often rely on heuristics and biases to make daily decisions. Heuristics and biases are mental rules of thumb or cognitive shortcuts that help us make decisions when faced with uncertainty and they are useful cognitive tools that help us deal with an increasing complex world. ${ }^{1049}$ The pre-

1047 C.R. Sunstein \& R. HASTIE, Wiser: Getting Beyond Groupthink to Make Groups Smarter, (Massachusetts: Harvard Business Review Press, 2015), at p. 2 (noting that "[u]nfortunately, System 1 is often in charge, and it is responsible for many of the errors that individuals make"); O. BEN-SHAHAR \& C.E. SCHNEIDER, More Than You Wanted to Know: The Failure of Mandated Disclosure, (Princeton: Princeton University Press, 2014), at p. 110 (observing that the existence of System 1 and System 2 suggests that our rationality is indeed bounded and stating that, as a result, we often "interpret, reinterpret, and misinterpret information.”).

1048 M.E.P. Seligman, Flourish, (New York: Atria, 2011), at p. 31 (noting that "[m]any aspects of human behavior do not change lastingly.")

1049 C. JOLls, C.R. SunSTEIN \& R.THALER, “A Behavioural Approach to Law and Economics,” Stanford Law Review 50 (1998): 1471-1550. 1477; cf. G. GIGERENZER \& R. SELTEN, Bounded Rationality: The Adaptive Toolbox (Cambridge: MIT Press, 2001) (advocating for an alternative Adaptive Behaviour and Cognition approach, which stresses the importance of the individuals surroundings and environment with their decision making); and, R R. SAMUELS, S. STICH \& M. BISHOP, "Ending the Rationality Wars: How to Make Disputes about Human Rationality Disappear," in Common Sense, Reasoning and Rationality, R. RENEE (ED.) (421) (New York: Oxford University Press, 2002): 236268; as cited by, G.W.L. LOW, European Contract Law between the Single Market and the Law Market: A Behavioural Perspective, (Nijmegen: Wolf Legal Publishers, 2011), at pp. 194-5 (summarizing the debate that "contrary to appearances, 
vious parts of this subsection noted that people often make predictable errors, and part of the reason why we do that is because we instinctively rely on these biases and heuristics when our System 1 is activated. However, while they do indeed facilitate our decisionmaking process - especially in times of uncertainty - that is not to say that biases and heuristics always help private actors make the best decisions at all times. ${ }^{1050}$ This part of the subsection will have two main aims: first is to present the most commonly used biases and heuristics that people rely on; and second will be to argue that laws or private initiatives that fail to take these mental shortcuts that people make will not be as successful as those that do.

Generally speaking, people are more often "guided by emotion rather than by reason, easily swayed by trivial details, and inadequately sensitive to differences between low and negligibly low probabilities." 1051 One of the main reasons why this thesis advocated not only for the acknowledgement of the law and behavioral economics approach, but for a more holistic and interdisciplinary approach to conducting legal research was because of this observation that private actors are not necessarily guided by logical reasoning or careful cost-benefit analysis when making decisions in the face of uncertainty. More often than not, individuals are not thinking about what the law says or what the contract requires them to do, but on intangible or unquantifiable reasons like emotions when making their decisions. While there are studies that confirm that this is indeed how private actors generally behave, traditional measures that attempt to modify their behaviors through extrinsic measures (i.e. laws or private initiatives like codes of conduct) are still more prevalent than measures that target private actor's intrinsic incentives or their System 1. Part of the difficulty associated with shifting a paradigm or changing a traditional framework has to do with the status quo bias or the so called endowment effect: For example, "[i]n physics, an object in a state of rest stays that way, unless something happens. People act the same way: they stick with what they have unless there is some good reason to switch, or perhaps despite there being a good reason to switch." 1052 This is to suggest that people are comfortable with what they know, and even when there are better options available, there is no guarantee that people will adopt that option because of their status quo bias.

While there is something to be said for tradition and certainty - especially in the legal context - there is also an inherent risk that the way we think and the way we behave can calcify over time, even if they are not necessarily the best course of action, which makes it difficult for private actors to adjust and adapt as reality and circumstances require: For example, "[a]s a result of the organization's reliance on routines to coordinate behaviour,

there is no substantive disagreement" and "a surprising degree of consensus" between the two different approaches).

1050 R.H. Thaler, Misbehaving: The Making of Behavioral Economics, (New York: Norton, 2015), at p. 23; see also, D. Kahneman, Thinking, Fast and Slow, (London: Penguin Book, 2013), at p. 373 (noting that people often "make their choices thoughtlessly" because of these mental shortcuts).

1051 D. Kahneman, Thinking, Fast and Slow, (London: Penguin Book, 2013), at p. 140 (summarizing the work of Slovic and noting that even the so-called "[e]xperts also show many of the same biases as the rest of us"); see, P. SLOVIC, M. Finucane, E. Peters \& D. MacGregor, "The Affect Heuristic," in Heuristics and Biases, T. Gilovich, D. GRIFFIN \& D. KAHNEMAN (EDS.) (New York: Cambridge University Press, 2002): 397-420.

1052 R.H. Thaler, Misbehaving: The Making of Behavioral Economics, (New York: Norton, 2015), at p. 154; see generally, W. SAMUELSON \& R.J. ZECKHAUSER, "Status Quo Bias in Decision Making," Journal of Risk and Uncertainty 1(1) (1988): 7-59. 
such routines are more likely to condition behaviour rather than to encourage change."1053 This inability to adapt, due in part to the status quo bias is not only manifested in organizational structures and strategies, but the manner in which private actors think. For example, Daniel Kahneman has coined the term "theory-induced blindness," which suggests that "[o]nce you have accepted a theory and used it as a tool in your thinking, it is extraordinarily difficult to notice its flaws." 1054 An argument could be made that this is indeed what is happening with our over-reliance on laws and private initiatives (a point that was initially made back in Chapter 2) to resolve problems like the labor exploitation in the global supply chain.

A related cognitive bias to the status quo bias is the halo effect, as coined by Edward Thorndike, which is our tendency to evaluate even the "things [we] have not observed," by judging whether we "like or dislike" the overall character of the person, company, or even an idea. ${ }^{1055}$ For example, if we like a particular person, even though they make less than verifiable statements, our tendency is to believe them. The problem with this type of blindness is that "when people believe a conclusion is true, they are also very likely to believe arguments that appear to support it, even when [the] arguments are unsound."1056 Economists, for example, "may be missing things by focusing too much on the data and not on what is uniquely new about the latest changes in technology or institutions many people see as heralding a new era," 1057 or similarly, lawmakers focusing on one particular solution to a problem (likely a legal solution), could be missing other, perhaps even better ways, of solving the problem. In the context of this thesis, the lesson that can be extrapolated is to think about whether stakeholders are susceptible to status quo bias or theory-induced blindness by adhering to the belief that certain government measures or private initiatives are producing good outcomes, even when there is evidence to the contrary. ${ }^{1058}$

A cognitive bias that facilitates or enables theory-induced blindness is the positivity bias, which Kahneman believes "may well be the most significant of the cognitive biases." 1059

1053 G.W.L. Low, European Contract Law between the Single Market and the Law Market: A Behavioural Perspective, (Nijmegen: Wolf Legal Publishers, 2011), at pp. 247, 252 (adding that "routines are persistently applied and are only questioned or revised when some stimuli forces the firm to do so.").

1054 See generally, D. Kahneman, Thinking, Fast and Slow, (London: Penguin Book, 2013), at p. 277; see also, A. MACK \& I. ROCK, Inattentional Blindness, (Cambridge: The MIT Press, 2000) (defending the theory or inattentional blindness and arguing that people cannot see everything in their field of view when they are focusing on one thing too narrowly).

1055 D. Kahneman, Thinking, Fast and Slow, (London: Penguin Book, 2013), at p. 82; see also, R.B. Cialdini, Influence: The Psychology of Persuasion, (New York: Collins Business, 2007), at p. 189 (suggesting that "[t]here is a natural human tendency to dislike a person who brings us unpleasant information, even when that person did not cause the bad news. The simple association with it is enough to stimulate our dislike"); and, M. MANIS, S.D. CORNELL \& J.C. MOORE, "Transmission of Attitude Relevant Information Through a Communication Chain," Journal of Personality and Social Psychology 30 (1974): 81-94.

1056 D. Kahneman, Thinking, Fast and Slow, (London: Penguin Book, 2013), at p. 45; see also, S. FrederiCK, "Cognitive Reflection and Decision Making," Journal of Economic Perspectives 19(4) (2005): 25-42.

1057 R.J. SHILLER, Irrational Exuberance, (Princeton: Princeton University Press, 2015), at p. 123 (adding that the general public sometimes overreact and miss "the basic similarity between the latest stories and similar stories that appeared many times in the past.").

1058 M.C. NussBaum, Creating Capabilities: The Human Development Approach, (Cambridge: Belknap Harvard, 2013), at p. 15 (observing that '[p]eople tend to succumb to what might be called 'the fallacy of measurement'; that is, noting that a certain thing is easy to measure, they become convinced that this thing is the most pertinent or the most central thing.").

1059 D. Kahneman, Thinking, Fast and Slow, (London: Penguin Book, 2013), at p. 255 (adding that "[m]ost of us view the world as more benign than it really is, our own attributes as more favorable than they truly are, and the goals 
One particular manifestation of this bias was already showcased in the context of the aforementioned pluralistic ignorance where people have the tendency to believe that someone or something else is already addressing the problem. This particular bias is potentially the most dangerous in the context of addressing our research question, because it gives private actors a false sense of security that there are people or institutions that know what they are doing and that they are working on a solution to all of the world's problems. The problem is, if majority of the private actors justified their inaction this way, many of our collective action problems will remain unsolved. What exacerbates this situation is the reality that governments and companies also have the tendency to "accentuate the positive and ignoring the negative" when it comes to communicating their internal affairs to the public. ${ }^{1060}$ This only enhances the reliance that citizens have on them, thus externalizing their sense of responsibility to the governments. Moreover, the belief that scientists, academics, or other experts can solve many of the problems that exist in the world is not always true: In reality, "[e]ven if public officials are expert, diverse, and well-motivated, they may not know nearly enough,"1061 which, again, is a symptom of the complexity problem. Acknowledging the existence of our positivity bias is one of the first steps to realizing that many of the problems that we face will not solve itself, and private actors must search for a more meaningful, sustainable solution themselves, rather than simply leaving it up to others.

In the context of this thesis, recall how the previous chapters illustrated the optimism that governing bodies or businesses showed about their strategies and initiatives. In a way, their optimism can be characterized as manifestations of the positivity bias: For example, Posner argues that "human rights law reflects a kind of rule naivete - the view that the good in every country can be reduced to a set of rules that can then be impartially enforced." 1062 Similarly, economist Tim Harford cautions against a more dangerous type of positivity bias and theory-induced blindness of what he refers to as the "God complex," where we claim to know the righteousness of our beliefs and actions even in the absence of evidence or contradictory facts. ${ }^{1063}$ Juxtaposing this so-called God complex with the complexity problem, we quickly realize that our psychological and neurological tendencies to want to simplify matters through the use of biases and heuristics simplifies - perhaps too much - the complexities of the problems that we face so that we can attempt to under-

we adopt as more achievable than they are likely to be. We also tend to exaggerate our ability to forecast the future, which fosters optimistic overconfidence.”).

1060 B. Horowitz, The Hard Thing About Hard Things: Building a Business When There Are No Easy Answers, (New York: Harper Collins, 2014), at pp. 64-65, 67 (noting one employee commenting on this practice as managers "blow[ing] a little sunshine up my ass," or put more delicately, "too often... company culture discourages the spread of bad news, so the knowledge lay dormant until it was too late to act." There is an "overwhelming psychological pressure to be overly positive," but this is not necessarily a good thing).

1061 C.R. Sunstein \& R. HASTIE, Wiser: Getting Beyond Groupthink to Make Groups Smarter, (Massachusetts: Harvard Business Review Press, 2015), at p. 195 (elaborating on what Hayek and his followers call the "knowledge problem"); see also, C. Fried, An Anatomy of Values: Problems of Personal and Social Choice, (London: Oxford University Press, 1970), at pp. 121-2 (stating that "not everyone can be assumed to know what is just... nor can everyone be assumed to adopt voluntarily the constraints of justice.").

1062 E.A. Posner, The Twilight of Human Rights Law, (Oxford: Oxford University Press, 2014), at p. 7 (adding that this "[r] ule naiveté is in part responsible for the proliferation of human rights, which has made meaningful enforcement impossible.").

1063 T. HARFOrD, Adapt: Why Success Always Starts with Failure, (London: Abacus, 2012), at p. 124 (describing the story of Archie Cochrane and his various attempts to show the importance of conducting experiments to challenge our God complexes). 
stand them. This reductionist approach, while good for the sake of our sanity and survival, fails to accurately capture the entirety of the enigmatic problems that we face. Therefore, to bear in mind the risks of our positivity bias moving forward, stakeholders must be cautious of overly optimistic predictions (i.e. corporate codes will improve the lives of marginalized workers or that transparency will make investors and consumers more socially responsible), because people generally tend to be overly confident about their forecasts, even in light of contrary evidence. ${ }^{1064}$ While hope and optimism are essential ingredients, one must not confuse them as replacements for hard work and making sure that their efforts are actually producing good outcomes at the other end of the supply chain.

Switching from the discussion of biases to heuristics, the two most often cited ones are availability and representativeness heuristics. ${ }^{1065}$ First, the availability heuristic is "the process of judging frequency by the "ease with which instances come to mind'," 1066 meaning that we judge a situation or an event, according to events or experiences that are readily available to us, which usually tend to be salient events or personal experiences. ${ }^{1067}$ For example, a person who just watched a documentary on how a company exploits its workers might jump to the conclusion that corporations exploit workers frequently; or in the alternative, a person who just read a book about the wonderful work of a company incorporating CSR initiatives to make the planet a better place, might believe that companies are, more often than not, doing good. Either way, what the availability heuristic does is that it makes it easier for people to reach certain conclusions by relying on readily available information, without actually researching and justifying the conclusions that they reach.

1064 R.H. Thaler, Misbehaving: The Making of Behavioral Economics, (New York: Norton, 2015), at p. 279-80; see also, R.J. SHILlER, Irrational Exuberance, (Princeton: Princeton University Press, 2015), at p. 170 (stating that "there appears to be a pervasive human tendency toward overconfidence in one's beliefs" and that "[p]eople think they know more than they do."); B. FisCHOF, P. SLOVIC \& S. LiCHTENSTEIN, "Knowing with Certainty: The Appropriateness of Extreme Confidence," Journal of Experimental Psychology 3(4) (1977): 552-64 (finding that "if people are asked simple factual questions... they tend to overestimate the probability that they are right."). It must be noted that with regards to the finding by Fischof, Slovic, and Lichtenstein, there is a caveat in that the overconfidence phenomenon "has not been found to be universal... and that people can be trained out of their overconfidence." See, G. GigerenZER, "How to Make Cognitive Illusion Disappear: Beyond 'Heuristic and Biases'," European Review of Social Psychology 2 (1991): 83-115; D. Kahneman, Thinking, Fast and Slow, (London: Penguin Book, 2013), at pp. 220, 250 (describing one of the reasons for this as the planning fallacy, where we have a tendency to make "overly optimistic forecasts" only to have to adjust); see also, B. FLYVBJERG, "From Nobel Prize to Project Management: Getting Risks Right," Project Management Journal 37 (2006): 5-15 (noting that our "prevalent tendency to underweigh or ignore distributional information...").

1065 G.W.L. Low, European Contract Law between the Single Market and the Law Market: A Behavioural Perspective, (Nijmegen: Wolf Legal Publishers, 2011), at p. 256 (noting that "[p]eople tend to use attribute substitution heuristic like availability or representativeness to estimate the probability of events.”).

1066 D. Kahneman, Thinking, Fast and Slow, (London: Penguin Book, 2013), at p.129; see also, A. TVERSKY \& D. Kahneman, “Availability: A Heuristic for Judging Frequency and Probability," Cognitive Psychology 5 (1973): $207-$ 32; and, C.R. Sunstein \& R. HASTIE, Wiser: Getting Beyond Groupthink to Make Groups Smarter, (Massachusetts: Harvard Business Review Press, 2015), at p. 138 (noting that this is a "bias of excessive focus on a single salient cue or item of information" at the cost of looking at the problem at hand from a larger, more diverse set of possible solutions).

1067 D. Kahneman, Thinking, Fast and Slow, (London: Penguin Book, 2013), at p. 130; O. BEN-SHAHAR \& C.E. SCHNEIDER, More Than You Wanted to Know: The Failure of Mandated Disclosure, (Princeton: Princeton University Press, 2014), at p. 110 (noting that "vivid and disturbing are more readily remembered than things [that are] drab and routine"); see also, C. PRESTON, "New Research Sheds Light on What Works in Charitable Appeals," The Chronicle of Philanthropy, (17 July 2007). Available at: http://philanthropy.com/article/New-Research-Sheds-Lighton/62663/ (last accessed 4 April 2017) (citing to Jonathan Baron stating that "[p]eople are also less able to empathize with suffering that takes place far away than in their own backyard."). 
Similarly, the representativeness heuristic suggests that "people tend to make judgments in uncertain situations by looking for familiar patterns and assuming that future patterns will resemble past ones, often without sufficient consideration of the reasons for the pattern or the probability of the pattern repeating itself." 1068 For example, if a company implemented a certain CSR initiative that turned out to be successful in improving the working conditions of its subcontractor's factories in one location, that company may be inclined - by relying on the representativeness heuristic - to implement the same CSR initiative in other locations expecting similar results. While that could indeed be the case, most successful businesses realize that in most cases, they cannot implement the same strategy all around the globe and expect the same results. While the representativeness heuristic much like the other biases and heuristics - do simplify and facilitate the decision-making process for private actors, it cannot guarantee that the solution in ushers will be a successful one.

In the context of this thesis, the existence of these biases and heuristics prove our tendencies to be swayed by personal anecdotes, salient news stories, or the belief that because it worked in the past, it will work again in the future. While the benefits of these biases and heuristics are clear (e.g. they allow us to focus our limited willpower and bounded rationality on things that actually require it), we must also be aware of its limitations and be cautious about their associated risks. For example, to the extent that people involuntarily rely on these biases and heuristics, private actors must be more mindful of their impact, not only on our decision-making process, but when we create initiatives that aim to modify the behavior of others (i.e. CSR and ethical consumerism measures noted in Chapters 4 and 5). Also, as noted back in Chapter 2, governments generally do not take into account these heuristics and biases in their laws and regulations as they still rely primarily on the law and economics approach that assumes citizens to be rational actors that conduct careful costbenefit analyses before making decisions. Most successful businesses, however, are already using our biases and heuristic in ways that benefit them. ${ }^{1069}$ For example, priming is a technique that marketers often use to "trigger[s] some association or thought in such a way as to affect people's choices and behavior." 1070 While they are more commonly used to prime consumers into purchasing particular items, in theory, priming could be used by private actors more effectively to reduce instances of labor exploitation in the global supply chain. This discussion of what companies are doing, is worth discussing in the next part of the subsection given that while they are more aware of our biases and heuristics and use them to their advantage, companies are not immune to the problems that biases and heuristics can create.

1068 R.J. SHILLER, Irrational Exuberance, (Princeton: Princeton University Press, 2015), at p. 172 (citing to the research conducted by Tversky and Kahneman); see, A. TVERSKY \& D. KAHNEMAN, "Judgment under Uncertainty: Heuristics and Biases," Science 185 (1974): 1124-31.

1069 See generally, O. BAR-GILL, Seduction by Contract: Law, Economics, and Psychology in Consumer Markets, (Oxford: Oxford University Press, 2013).

1070 C.R. SUNSTEIN \& R. HASTIE, Wiser: Getting Beyond Groupthink to Make Groups Smarter, (Massachusetts: Harvard Business Review Press, 2015), at p. 108. 


\section{E. "Companies are People Too"}

It is worth noting here that companies, traditionally consisting of a group people, are not immune to problems of individuals. While this subsection focused primarily on people's individual flaws, let us briefly shift gears to that of organizations (i.e. governments and businesses). Some might argue that organizations consisting of groups of people, unlike individuals on their own, do not fall victim to various cognitive limitations, biases and heuristics. While this may indeed be true in some instances, there is ample evidence to suggest that this belief is not necessarily true: For example, research shows that groups are just as susceptible to these flaws and limitations, if not more. ${ }^{1071}$ In what is known as "groupthinking," even when individuals form a group or behave as a legal entity (i.e. a company), very often, they end up producing unsatisfactory results in part because "[f]ar too often, groups actually amplify... mistakes" made by individuals, which was a concern raised back in Chapter 4 in the context of the stakeholder value model of corporate governance. ${ }^{1072}$ Moreover, not only do some organizations suffer from collective flaws and cognitive limitations as a group, but just as people have habits, businesses and institutions have routines that have calcified and may be difficult to change:

"I]t may seem like most organizations make rational choices based on deliberate decision making, but that's not really how companies operate at all. Instead, firms are guided by long-held organizational habits, patterns that often emerge from thousands of employees' independent decisions. And these habits have more profound impacts than anyone previously understood." 1073

This reality suggests that even companies and governments have routines and some of these routines lead to pretty bad outcomes, which suggestions that even companies suffer cognitive limitations like the status quo bias and positivity bias. ${ }^{1074}$ In the words of the former US Presidential Candidate, Mitt Romney "corporations are people too," and that is not necessarily a good thing.

1071 G.M. HodGSON, Institutions and Individuals: Interaction and Evolution, Organizational Studies 28(1) (2007): 95-116, 111 (noting that "[i]ndividuals have habits; groups have routines... [that] are the organizational analogues of habits"); cited by, C. Duhigg, The Power of Habit: Why We Do What We Do in Life and Business, (New York: Random House, 2012), at p. 161.

1072 C. R. Sunstein \& R. HASTIE, Wiser: Getting Beyond Groupthink to Make Groups Smarter (2015), at p. 7; see also, I.L. JANIS, Groupthink: Psychological Studies of Policy Decisions and Fiascoes [Second Edition], (New York: Houghton Mifflin, 1982) (suggesting that groups are susceptible to biases and mistakes even more than individuals because of groupthinking); and, J. Berger, Invisible Influence: The Hidden Forces that Shape Behaviour, (London: Simon \& Schuster, 2010), at p. 58 (noting that groupthink manifests when "conformity and the desire for intragroup harmony lead groups to make worse decisions."). Berger adds that "People talk about the wisdom of crowds, but crowds are only wise when the group has access to everyone's individual information. Aggregating these pieces can lead to better decisions than any person could have made alone. But if everyone just follows everyone else, or keeps their information to themselves, the value of the group is lost."

1073 C. Duhigg, The Power of Habit: Why We Do What We Do in Life and Business, (New York: Random House, 2012), at p. 161 (stating that “[r]outines provide hundreds of unwritten rules that companies need to operate.").

1074 D. ARIELY, The (Honest) Truth About Dishonesty: How We Lie to Everyone - Especially Ourselves, (New York: Harper Collins, 2012), at p. 51 (observing that " $[\mathrm{t}]$ he more I interact with companies, the more I find that they are actually far less rational than individuals (and the more I am convinced that anyone who thinks that companies are rational has never attended a corporate board meeting”); see also, R.R. NELSON \& S.G. WINTER, An Evolutionary Theory of Economic Change, (Cambridge: Belknap Press, 1982), at p. viii (noting that "[m]uch of firm behavior [is best] understood as a reflection of general habits and strategies orientations coming from the firm's past, [rather than] the result of a detailed survey of the remote twigs of the decision tree"); as cited in, C. DuHIGG, The Power of Habit: Why We Do What We Do in Life and Business, (New York: Random House, 2012), at pp. 160-1. 
In presenting the complexity problem, the aim of this subsection was twofold: 1) to suggest that there are indeed problems that neither governments nor private actors can actually find solutions to ex ante; and 2) to substantiate the claim that our limited cognitive abilities make it so that it might be almost impossible for private actors to come up with anything that remotely resembles a panacea to a problem of such magnitude and complexity like reducing labor exploitation in the global supply chain. The combination of these two possibilities is the essence of the complexity problem. To validate these claims, this subsection raised the existence of fundamentally unidentified questions in our increasingly complicated world and held how our bounded rationality and our cognitive limitations/flexibility (i.e. habits or assortment of biases and heuristics that we instinctively rely on) tend to oversimplify our decision-making and problem-solving processes. In concluding this subsection, there are two main takeaways from this analysis of the complexity problem: First, laws and legalized CSR or ethical consumer initiatives are not the only possible solutions available to private actors. This is to suggest that private actors must be more open to non-legal measures as well as embracing a multidisciplinary approach when tacking a problem like the labor exploitation in the global supply chain because the world in which they operate is too complicated of an environment to be adequately explained relying purely on a legal perspective. Second, private actors must realize that attempting to conjecture anything that resembles the "right" law or the "best" CSR initiative that has general applicability in all situations would be a fool's errand. Thus the lesson to be drawn from this part of the subsection is to entirely dismiss the notion that there is a panacea to our problem. To the extent that there is something that comes close, the problem of labor exploitation has to be broken down into the smallest instances thereof and only after then, can private actors attempt to resolve that particular problem locally, by assessing the circumstances specific to that situation, and relying on localized knowledge. This approach is likely one of the few ways in which the complexity of the global supply chain can be compartmentalized so that the stakeholders will be able to reach a workable solution that fits to their specific situation.

\subsubsection{The Communal Problem}

According to various behavioral experts, not only do we have the habit of rationalizing even our dubious actions because we lack the willpower to always do the "right" thing, but if others in our surroundings or the "herd" we associate with, (whether they are family, friends, colleagues or people that live in close proximity) exhibit similarly dubious behaviors, we have the tendency to convince ourselves that that dubious action is in line with the social norms of our particular herd. This is to suggest that in realizing our limitations and how we are affected by outside forces, it is important to understand just how susceptible we are to how our community, our peers, and our surroundings behave, because "we often take comfort when our actions fall in line with the social norms of those around us" and uncomfortable when it does not. ${ }^{1075}$ In other words, peer-pressure and the desire to fit into a group is a strong motivator to compel people to behave in a particular manner: For example, we "gain

1075 D. ARIELY, The (Honest) Truth About Dishonesty: How We Lie to Everyone - Especially Ourselves, (New York: Harper Collins, 2012), at p. 195. 
[our] authority through communal expectations. If you ignore the social obligations of your neighborhood, if you shrug off the expected patterns of your community, you risk losing your social standing." 1076 The overall aim of this subsection will be to assess the role of the community and our surrounding social environments to observe how they influence the manner in which we behave. The assumption here is that individual behavior (i.e. being an ethical consumer) is strongly influenced by what others within the community are doing. Accordingly, this subsection will discuss issues of a) our herd mentality, b) the costly signaling theory, and c) how we care less about people outside of our hear.

\section{A. Our Herd Mentality and the V arious Shades of Conformity}

The previous subsections mentioned the concept of pluralistic ignorance and how we tend to look at what others are doing when confronted with uncertainty. Part of the reason why we look to the behavior of others is that we instinctively prefer to conform to the behavior of the herd: For example, even "when we do something questionable, the act of inviting our friends to join in can help us justify our own questionable behavior..." this is because "the power of the emerging social norm that [comes] from observing the misbehavior of others" is a very compelling and influential force. ${ }^{1077}$ From a morality perspective, the impact of herd behavior and the importance of our social-self can be seen: For example, in answering the question of whether people should ever be moral, Fried explained that people act morally because "a moral person, by virtue of having certain ends, stands in certain relationships to others and feels certain emotions." 1078 In other words, our incentive to behave even morally depends, in part, on being viewed favorable by others. ${ }^{1079}$ Even from an anthropologic perspective, Michael Tomasello at the Max Planck Institute for Evolutionary Anthropology has observed that humans, even from a very early age, "have a tendency to imitate others in the group simply in order to be like them, that is, to conform (perhaps as an indicator of group identity)." 1080 Moreover, Tomasello adds that "at some point in human evolution, it became important for individuals in a group to all behave alike; there arose pressure to conform. The proximate motivation here is to be like others,

1076 C. Duhigg, The Power of Habit: Why We Do What We Do in Life and Business, (New York: Random House, 2012), at p. 225; see also, S. Milgram, Obedience to Authority, (New York: Harper \& Row, 1974) (proving, in a very controversial manner, "the extreme willingness of adults to go to almost any lengths on the command of an authority," so as not to be branded as an outsider).

1077 D. ArIELY, The (Honest) Truth About Dishonesty: How We Lie to Everyone - Especially Ourselves, (New York: Harper Collins, 2012), at p. 195, 197; see also, F. GinO, S. AyAL \& D. ArIELY, "Contagion and Differentiation in Unethical Behavior: The Effect of One Bad Apple on the Barrel," Psychological Science 20(3) (2009): 393-398; see also, R.J. SHILLER, Irrational Exuberance, (Princeton: Princeton University Press, 2015), at p. 176 (noting that people, in one way or another, react to "the information that a large group of people had reached a judgment different from theirs"); citing, M. DEUTSCH \& H.B. GERARD, "A Study of Normative and Informational Social Influences upon Individual Judgment," Journal of Abnormal and Social Psychology 51 (1955): 629-36.

1078 C. FrIED, An Anatomy of V alues: Problems of Personal and Social Choice, (London: Oxford University Press, 1970), at p. 57.

1079 J. HAidT, The Righteous Mind: Why Good People are Divided by Politics and Religion, (New York: Vintage, 2012), at p. 369 (noting that "[w]e are selfish and we are groupish," and thus we are " 90 percent chimp and 10 percent bee.").

1080 M. Tomasello, Why We Cooperate, (Cambridge: MIT Press, 2009), at p. xv; see, R.H. Thaler, Misbehaving: The Making of Behavioral Economics, (New York: Norton, 2015), at p. 146 (stating that "large portion of people can be categorized as conditional cooperators, meaning that they are willing to cooperate if enough others do," but "if cooperation rates are low, these conditional cooperators turn into free riders."); see also, E. FEHR \& S. GÄCHTER, "Cooperation and Punishment in Public Goods Experiments," American Economic Review 66(2) (2000): 980-94; and, U. FISCHBACHER, S. GÄCHTER \& E. FEHR, “Are People Conditionally Cooperative? Evidence from a Public Goods Experiment,” Economic Letters 71(3) (2001): 397-404. 
to be accepted in the group, to be one of the 'we' that constitutes the group and that competes with other groups." 1081

All of this eclectic evidence suggest that " $[\mathrm{w}] \mathrm{e}$ view a behavior as more correct in a given situation to the degree that we see others performing it," 1082 even if that behavior is not necessarily socially responsible (i.e. when the popular kid at school has a cool new leather jacket from Zara, others might be compelled to emulate his/her behavior, even if doing so might indirectly be increasing the number of people getting cancer living near a Bangladeshi tannery). Thaler and Sunstein, for example, retell the story of how the state of Minnesota improved their tax compliance rate by simply informing the late filers that an overwhelming majority of their fellow Minnesotans had already complied with their obligations. ${ }^{1083}$ This is not to suggest that if we simply inform the consumers that there are people being socially responsible that everything will change: First of all, that would not be the truth, and second, as we just covered in the previous subsection with regards to the representativeness heuristics that just because a strategy worked in one scenario does not necessarily mean that it is nevertheless guaranteed to work in another. While this particular option may not be the "right" solution in all cases, it is an option worthy of consideration in some future situations as a possible alternative to the more popular mechanisms and initiatives in current circulation. ${ }^{1084}$

This phenomenon - the tendency of people to conform to some public consensus or to the prevalent social norm ${ }^{1085}$ - has been validated time and time again, though in various different shades: For example, conformity appears in the form of "collective conservatism,"1086 "pluralistic ignorance," 1087 or what Robert Shiller has labeled as "social contagion." "1088 With regards to the idea of a social contagion, it is important to bear in mind that herd mentality, as a form of contagion, can spread bad or undesirable behaviors as well: For example, studies "show how crucial other people are in defining acceptable boundaries for our own behavior... As long as we see other members of our own social groups behaving in ways that are outside the acceptable range, it's likely that we too will recalibrate our

1081 M. Tomasello, Why We Cooperate, (Cambridge: MIT Press, 2009), at p. 93

1082 R.B. Cialdini, Influence: The Psychology of Persuasion, (New York: Collins Business, 2007), at p. 116-7 (using the example of advertisers that "love to inform us when a product is the 'fastest growing' or 'largest-selling' because they don't have to convince us directly that the product is good, they need only say that many others think so, which seems proof enough.”)

1083 R.H. Thaler \& C.R. Sunstein, Nudge: Improving Decisions About Health, Wealth, and Happiness, (New York: Penguin, 2009), at p. 67.

1084 R.H. THALER, Misbehaving: The Making of Behavioral Economics, (New York: Norton, 2015), at p. 335 (noting that "if you want people to comply with some norm or rule, it is a good strategy to inform them (if true) that most other people comply); see also, R.B. CiALDINI, Influence: The Psychology of Persuasion, (New York: Harper Business, 2006).

1085 R.B. CialdinI, Influence: The Psychology of Persuasion, (New York: Collins Business, 2007), at p. 140 (noting that "when people are uncertain, they are more likely to use others' actions to decide how they themselves should act," adding that "we are more inclined to follow the lead of a similar individual than a dissimilar one.").

1086 R.H. Thaler \& C.R. Sunstein, Nudge: Improving Decisions About Health, Wealth, and Happiness, (New York: Penguin, 2009), at p. 58 (noting "the tendency of groups to stick to established patterns as new needs arise.").

1087 R.H. Thaler \& C.R. Sunstein, Nudge: Improving Decisions About Health, Wealth, and Happiness, (New York: Penguin, 2009), at p. 59 (suggesting that "[w] may follow a practice or a tradition not because we like it, or even think it defensible, but merely because we think that most other people like it.")

1088 R.J. SHILler, The Subprime Solution: How Today's Global Financial Crisis Happened, and What to Do About It, (Princeton: Princeton University Press, 2008), at p. 41 (clarifying that this is a "contagion of ideas," and to the extent that they are contagions, Shiller considers this term to signify the spread of incorrect beliefs). 
internal moral compass and adopt their behavior as a model of our own."1089 If the particular member misbehaving is an authority figure, "chances are even higher that we'll be dragged along." 1090 This is to suggest that while the community and the herd has significant influence on how we, as individuals behave, that is not to say that the herd mentality and conformity will always influence us for the better. ${ }^{1091}$ This thesis (back in Chapter 4), already discussed the possible negative impacts of social contagion in the context of the stakeholder value or the enlightened shareholder value model of corporate governance and how the presence of an authority figure in a group can be a subtle influence that ends up becoming a "socially-imposed cognitive straitjacket," 1092 even in open, collaborative settings. This is part of the reason that this thesis has thus far advocated for any stakeholder discussions or initiatives, not only to be inclusive and collaborative, but to maintain an open-minded, tolerant atmosphere that would allow even workers in lower echelons to have a say on par with that of the other more "important" stakeholders, without succumbing to social contagion.

Of course psychological or sociological findings will not be applicable to every situation and we must be wary of "pop theories" blending in amongst legitimate ones. ${ }^{1093}$ As many of these studies willingly admit themselves, these experiments took place in specific settings with particular participants, most of them in controlled environments. ${ }^{1094}$ However, to not pay any attention or to simply dismiss other fields of study is equally dangerous.

1089 D. ArIELY, The (Honest) Truth About Dishonesty: How We Lie to Everyone - Especially Ourselves, (New York: Harper Collins, 2012), at p. 207; F. GINO, S. AYAL \& D. ARIELY, "Contagion and Differentiation in Unethical Behavior: The Effect of One Bad Apple on the Barrel,” Psychological Science 20(3) (2009): 393-398.

1090 D. AriEly, The (Honest) Truth About Dishonesty: How We Lie to Everyone - Especially Ourselves, (New York: Harper Collins, 2012), at p. 207; F. GiNO, S. AYAL \& D. ARIELY, "Contagion and Differentiation in Unethical Behavior: The Effect of One Bad Apple on the Barrel," Psychological Science 20(3) (2009): 393-398; see also, R.J. SHILLER, Irrational Exuberance, (Princeton: Princeton University Press, 2015), at p. 233 (noting that "people are ultimately highly influenced by the perceived wisdom of experts - the 'they say that...' authorities - and they will not carry out risk management well unless experts encourage them to do so.").

1091 R.J. SHILLER, Irrational Exuberance, (Princeton: Princeton University Press, 2015), at p. 233 (noting that "people are ultimately highly influenced by the perceived wisdom of experts - the 'they say that...' authorities - and they will not carry out risk management well unless experts encourage them to do so.").

1092 T. Harford, Adapt: Why Success Always Starts with Failure, (London: Abacus, 2012), at p. 48 (citing to the experiments of Solomon Asch and the ease at which we are convincingly swayed by social or group pressures, especially that of an authority figure).

1093 M.T. KAWAKAMI, "Psychological Oversight: Why Bills Advocating for Transparency Could Do More Harm Than Good", Edinburgh Student Law Review 2(1) (2013): 87-89, at p. 87 (noting that "[a]n obvious caveat with such an interdisciplinary approach - mixing behavioural psychology with the law - is that we must be careful not to make inferences from mere correlations. In other words, it is of utmost importance not to carelessly take a conclusion from one study and apply it to reach a more general conclusion. It is, however, equally unjustifiable for legislators and lawyers to simply ignore this growing scholarship and to dismiss it as completely irrelevant"); see also, R.J. SHILLER, Irrational Exuberance, (Princeton: Princeton University Press, 2015), at p. 165 (cautioning that "[i]n considering lessons from psychology, it must be noted that many popular accounts of the psychology of investing are simply not credible."); cf. M.C. NussBaum, Creating Capabilities: The Human Development Approach, (Cambridge: Belknap Harvard, 2013), at p. 181 (noting that "[h]uman beings are not limitlessly malleable, and there are psychological studies of general human tendencies that have robust cross-cultural credentials.").

1094 See e.g., C.R. SunSTEIN \& R. HASTIE, Wiser: Getting Beyond Groupthink to Make Groups Smarter, (Massachusetts: Harvard Business Review Press, 2015), at p. 87 (stating that "[n]o simple answer would make sense... [e]verything depends... and there are no guarantees...”). 


\section{B. We are Attention-Seekers: The Costly Signaling Theory}

To the extent that people are aware of the influences that we have on one another and the fact that we seek acceptance and recognition from our herd leads us to the discussion of signaling. Chapter 4 in the context of cathexis and our instinct of acquisition already mentioned external and self-signaling, which has to do we how we broadcast to others and to ourselves who we are and what we are about by what we wear, what we say, and what we do. ${ }^{1095}$ Signaling and conformity go hand in hand, given that "people become more likely to conform when they know that other people will see [them]."1096 Before diving into the topic of signaling, it is worth contemplating first, why in a global market where many of products are made through an exploited labor force, some consumers go out of their way to shop "responsibly" or why some companies incorporate as benefit corporations. The previous chapters repeatedly suggested that intrinsic motivation is the key to sustaining responsible behavior and in the context of the aforementioned telos, perhaps some of these ethical consumers and benefits corporations are indeed guided by an internal sense of purpose and they do what they do because they care and because they want to be a part of the movement that makes a difference. Another explanation, though difficult to completely disentangle from the first explanation is that ethical consumerism and CSR initiatives are forms of signaling: For example, the "costly signaling theory" suggests that socially responsible behaviors, even if it is costly than the alternative "can build a prosocial reputation and increase personal status by demonstrating the willingness and ability to sacrifice for the benefit of a group." 1097

In other words, ethical consumers and socially responsible corporations do what they do to demonstrate to the group or the herd about how good they are. Signaling is not just a term used in psychology or sociology, but a term frequently used in game theory and in political science as well: For example, "a large amount of social, family, political, and business behavior can be understood in terms of signals. A signal can be any costly action that enables separation, or at least enabled separation in the past or might plausibly be expected to cause separation in the present." 1098 The essence of the signaling theory is that social benefit or "social rewards that strongly motivate behavior," are "encouragement of social rewards and reputation." 1099 In layman's terms, the answer to the question of why some stakeholders attempt to be more ethical or socially responsible - besides, or in addition to, the possible reason that they genuinely care - could come down to the possibility that because it looks good when you tell others that you are someone that cares about treating people - even those in faraway lands - with dignity. So in the end, buying ethical products could be considered as a "status-seeking behavior" by people that "have a 'taste' for sta-

1095 D. ArIELY, The (Honest) Truth About Dishonesty: How We Lie to Everyone - Especially Ourselves, (New York: Harper Collins, 2012), at p. 120-2 (making comparisons to Roman sumptuary laws that dictated who can wear what).

1096 R.H. Thaler \& C.R. SunsteIN, Nudge: Improving Decisions About Health, Wealth, and Happiness, (New York: Penguin, 2009), at p. 57.

1097 R.H. Thaler \& C.R. Sunstein, Nudge: Improving Decisions About Health, Wealth, and Happiness, (New York: Penguin, 2009), at p. 3; see also, V. ZABKAR \& M. HOSTA, "Willingness to Act and Environmentally Conscious Consumer Behaviour: Can Prosocial Status Perceptions Help Overcome the Gap," International Journal of Consumer Studies 37(3) (2013): 257-264; and, R. WILLER, "Groups Reward Individual Sacrifice: The Status Solution to the Collective Action Problem,” American Sociological Review 74(1) (2009): 23-43.

1098 E.A. Posner, Law and Social Norms, (Cambridge: Harvard University Press, 2000), at p. 22.

1099 V. Griskevicius, B. Van Den Bergh, \& J.M. Tybur, "Going Green to Be Seen: Status, Reputation, and Conspicuous Conservation,” Journal of Personality and Social Psychology 98(3) (2010): 392-404. 
tus," meaning that "they obtain utility when they have more of some status good than others do." 1100

To conclude this part of the subsection, consider the possibility that people may associate buying goods untainted by exploitative labor paying a premium in the process, as a costly signal. In return for paying this premium, people's exogenous tendency to want to enhance their status can be satisfied. While the awareness of the costly signaling phenomenon may allow stakeholders to rely on this theory when designing alternative strategies to reducing instances of labor exploitation in the global supply chain, it is worth noting the slight tension between costly signaling and the existing government measures and legislative initiatives that attempt to level the playing field, by elevating the standard of conduct, which arguably can diminish the possibility of stakeholders to signal. Take for example the Non-Financial Disclosure Directive or the California Transparency in the Supply Chain Act, which were discussed back in Chapter 4. Although many MNCs were already voluntarily disclosing ESG metrics, arguably a costly signaling, when the law shifts that voluntary initiative to something that they are simply expected to do, the dynamic of the voluntarism changes. Chapter 4 also argued that the emergence of extrinsic incentives (i.e. laws) are capable of crowding out intrinsic motivations. ${ }^{1101}$ In our current context, laws are capable of similarly diminishing the utility of a costly signaling for stakeholders, which could create various spillover effects. Again, this is not to suggest that laws should never level and elevate the playing field, quite to the contrary, in some cases this approach is exactly what is required to address a situation. However, and this being the main point of this particular part of this subsection, the stakeholders should also consider, at the very least, the impact of imposing a top-down extrinsic incentive can have, not just on our intrinsic motivations, but on the ability for stakeholders to signal. Signaling is important because it is one of the ways in which, we not only communicate who we are to the outside, but to ourselves as well.

\section{We Care Less About What We Do Not See}

The two previous parts of this subsection discussed our herd mentality and signaling as ways to earn recognition and acceptance from the herd: In short, we are even willing to pay a steep price, through costly signaling, to obtain acknowledgement and to reach a certain status within our society. The problem, in the context of the global supply chain and the increasing complexity of the world around us - in part due to firm disaggregation, the emergence of micropowers, globalization, and outsourcing - is that the boundaries of our herds are either expanding, becoming ephemeral, or possibly both. We are increasingly relying on laborers outside of our territorial borders that it is becoming easier for many consumers to ignore or turn a collective blind eye to suffering taking place somewhere else. Similar to our discussion of the availability heuristic - about how people tend to focus their attentions on more salient events or experiences that are close and personal to them -

1100 E.A. Posner, Law and Social Norms, (Cambridge: Harvard University Press, 2000), at p.56.

1101 M.T. KAWAKAMI, "Psychological Oversight: Why Bills Advocating for Transparency Could Do More Harm Than Good," Edinburgh Student Law Review 2(1) (2013): 87-89, 89 (asking if a law "forcefully levels the playing field by requiring every major corporation to file compliance reports, the question that emerges is whether the imposition of that external motivation could lower the more internal, intrinsic motivation for corporations that are already [being] socially responsible.”). 
people have the tendency to not take into consideration, at least generally speaking, the plights of people outside of the herd. If this is indeed the case, the problem of labor exploitation will become even more difficult to address as phenomenon such as firm disaggregation and outsourcing continue to increase the distance between people or herds further and further apart. Bearing this concern in mind, this part of the subsection will validate the point on how we care less about those we do not see.

The first point to substantiate this rather callous reality comes down to the unavoidable fact of ego depletion: There is only a certain amount of care or willpower we can give, and we tend to prioritize those people that are already in our lives first. While many stakeholders probably genuinely care about the marginalized workers, helping them comes only after taking care of ourselves and those within our herds first. This is to suggest that for many of the stakeholders (i.e. consumers and western MNCs), the marginalized laborers working on the other side of the world are, for the lack of better word, "outsiders." 1102 In this context, our problem is the following: "The animating idea behind human rights is the moral obligation not to harm strangers, and possibly the moral obligation to help them if they are needed... [but] these types of obligations stop at the border of the group." 1103 For example, earlier in the thesis, it was mentioned that there are over 30 million workers currently being forced to work against their will worldwide in extremely serious cases of labor exploitation. While we feel disappointment and perhaps some anger about this problem, we are more likely to help those that are in our herd and not necessarily these 30 million workers who we cannot even identify at an individual level. This is the difference between what Schelling calls "statistical lives" as opposed to "identified lives." 1104 The distinction between the two is that "we are prepared to expend far greater resources in saving the lives of known persons in present peril, than we are prepared to devote to measures that will avert future dangers to persons, perhaps unknown and not yet even in existence." 1105 So not only do we have a way to rationalize some of our dubious behaviors (through cognitive flexibility), but when our actions cause a potential harm, and that harm is far away, it becomes even easier for us to rationalize that dubious behavior. ${ }^{1106}$

1102 T. JUDT, Ill Fares the Land, (New York: Penguin, 2010), at p. 67 (noting that "[t]he kind of society where trust is widespread is likely to be fairly compact and quite homogenous.").

1103 E. POSNER, The Twilight of Human Rights Law, (Oxford: Oxford University Press, 2014), at p. 9.

1104 T.C. SChelling, "The Life You Save May Be Your Own" in Choice and Consequences: Perspectives of an Errant Economist (Cambridge: Harvard University Press, 1984): 113-146 (observing the following: "Let a six-year-old girl with brown hair need thousands of dollars for an operation that will prolong her life until Christmas, and the post office will be swamped with nickels and dimes to save her. But let it be reported that without a sales tax the hospital facilities of Massachusetts will deteriorate and cause a barely perceptible increase in preventable deathsnot many will drop a tear or reach for their checkbooks."). Cf. L.B. RuSSELL, "Do We Really Value Identified Lives More Highly Than Statistical Lives?", Medical Decision Making 34(5) (2014): 556-559 (noting that although distinguishing the two types of lives have become "accepted as self-evident", there is reasons to believe that these lives "may be equally valuable.").

1105 C. Fried, An Anatomy of V alues: Problems of Personal and Social Choice, (London: Oxford University Press, 1970), at p. 207 (citing to the works conducted by Calabresi, Raiffa and Schelling); B. SCHWARTZ, The Paradox of Choice: Why More is Less, (New York: Harper, 2004), at p. 58 (also noting that "[s]alience or vividness matters" with regards to how people perceive and process information.).

1106 D. ARIELY, The (Honest) Truth About Dishonesty: How We Lie to Everyone - Especially Ourselves, (New York: Harper Collins, 2012), at p. 184 (noting that " $[w]$ e have an incredible ability to distance ourselves in all kinds of ways from the knowledge that we are breaking the rules, especially when our actions are a few steps removed from causing direct harm to someone else."). 
There are psychological and anthropological studies to validate this theory - that we care less about those outside of our herds - as well: For example, from a psychological perspective, researchers suggest that "increasing the psychological distance between a dishonest act and its consequences" increases instances of misbehavior, which is to suggest that companies will continue outsourcing to less than reputable manufacturers if the marginalized workers are far away and out of sight. ${ }^{1107}$ With regards to findings from anthropology - or evolutionary anthropology to be more specific - children learn to stop cooperating with those outside of the herd as they get older: People are born to be indiscriminately helpful in accordance with a phenomenon called "relatively indiscriminate cooperativeness," but as we get older, this cooperativeness becomes mediated by influences such as "[our] judgments of likely reciprocity and [our] concern for how others in the group judge [us]." 1108 This is to say that we learn to discriminate who to cooperate with or who to help and we often learn to cooperate with or help those who reciprocate or those within our herd. This is all to suggest that, generally speaking, we tend not help those outside of our herd.

Furthermore, in discussing a topics related to the observation of statistical lives versus identified lives, Paul Slovic has shown that people often tend to be "more sympathetic to a single starving child than they [are] to two children facing the same plight," arguing that this was the case because "people's instincts fail them when responding to genocide, famine, and other large-scale crises," given that the "information about the scope of a crisis" can "dilute the emotional impact of an image of a single victim." 1109 This observation is also in conformity with the aforementioned discussion about the overload problem and our limited cognitive abilities to digest and process information (which as explained earlier is why we rely on sometimes flawed biases and heuristics). Even if enough people were to care about the well-being of those in faraway places, it is still possible that we just "do not understand the interest of those foreigners and the conditions under which they live," which could mean that any "well-meaning attempts to enforce human rights treaties in those countries may, because of epistemic limits, lead to bad outcomes..."1110

Even from the perspective of laborers coming together in worldwide solidarity in some Marxian sense, the communal problem would suggest that the interests of laborers from

1107 D. ARIELY, The (Honest) Truth About Dishonesty: How We Lie to Everyone - Especially Ourselves, (New York: Harper Collins, 2012), at p. 32; see also, C. PRESTON, "New Research Sheds Light on What Works in Charitable Appeals", The Chronicle of Philanthropy, 17 July 2007. Available at: http://philanthropy.com/article/New-Research-ShedsLight-on/62663/ (last accessed 4 April 2017) (quoting Jonathan Baron that "[p]eople are also less able to empathize with suffering that takes place far away than in their own backyard.").

1108 M. Tomasello, Why We Cooperate, (Cambridge: MIT Press, 2009), at p. 4, 13 (elaborating that “children's early helping is not a behavior created by culture and/or parental socialization practices," but "an outward expression of children's natural inclination to sympathize with others in strife"; also noting that "though obviously not [in] all situations").

1109 D.C. BATSON, The Altruism Question: Toward a Social-Psychological Answer, (Hillsdale: Lawrence Erlbaum Associates, 1991) (arguing that "compassion (which he calls 'empathetic concern') is not reliable on its own, because it can easily give priority to people close to the self”); as cited by, M.C. NussBaum, Creating Capabilities: The Human Development Approach, (Cambridge: Belknap Harvard, 2013), at p. 181; see also, C. PRESTON, "New Research Sheds Light on What Works in Charitable Appeals", The Chronicle of Philanthropy, 17 July 2007. Available at: http://philanthropy.com/article/New-Research-Sheds-Light-on/62663/ (last accessed 4 April 2017) (quoting Uri Simonsohn that "people were more likely to give money to someone about whom they had recently learned one simple fact than to someone about whom they knew nothing.").

1110 E. PosNer, The Twilight of Human Rights Law, (Oxford: Oxford University Press, 2014), at p. 122. 
different communities diverge greatly. Especially in the global context, it will likely be difficult even for just the laborers to join forces as there are estimated 3.5 billion laborers worldwide and it will be nearly impossible, if not impossible for all of them to come together in solidarity to fight for a common cause. ${ }^{1111}$ While Marx believed that the proletarian revolution would be a global one, even back when there was some resemblance of a common shared cause, such revolution did not materialize, nor will it likely given our fragmented state of affairs: "The simple fact that poor people in Europe and America are in the income elite according to the standards of South Asia and Africa is why the workers of all lands have not yet united." 1112 What has happened, is that "[w]ealth and poverty has been globalized to the extent that " $[\mathrm{t}]$ he average income of the richest 5 percent in India is about the same as that of the poorest 5 percent in the United States" 1113 and conditions like this make is difficult to speak about a worldwide collective action, for people to come together to deal with a shared common cause, because issues that a laborer in India faces compared to that of what a worker faces in Detroit - albeit similar in concept - is very different in scale.

In discussing the specifics of cooperation in a capabilities approach context, Nussbaum recognizes that this fragmentation and divisiveness across communal lines amongst not just the laborers, but generally of the stakeholders is indeed a problem:

"One question that must certainly be confronted is the question of how we allocate the duties of promoting the capabilities in a world that contains nations, transnational economic agreements and agencies, other international economic agreements and agencies, corporations, NGOs, political movements, and individual people. To say that 'we all' have duties is all very well, and true. But it would be good if we could go further... it is ultimately people who should be seen as having moral duties to promote human capabilities."

Moreover, while Nussbaum notes that "humanity is under a collective obligation to find ways of living and cooperating together so that all human beings have decent lives," 1115 overcoming the communal problem and our herd mentality could prove to be a tall order. In the words of the late Tony Judt, we no longer have shared goals and all politics remain local: "The promise of globalization - and more generally, of the internationalization of laws and regulations over the past half century - lay in the prospect of transcending the conventional state... [w]e were supposed to be moving towards a cooperative trans-state era in which the conflicts inherent in territorially-defined political unites would be consigned to history." 1116 In reality, however, this may all be a dream. ${ }^{1117}$ With regards to having a collective goal, Judt poignantly and precisely, pointed to the heart of our problem:

1111 C. KENNY, "Marx is Back", Foreign Policy, (21 January 2014). Available at: http://foreignpolicy.com/2014/ 01/21/marx-is-back/ (last accessed on 4 April 2017).

1112 Ibid.

1113 Ibid.

1114 M. Nussbaum, Frontiers of Justice: Disability, Nationality, Species Membership (Tanner Lectures of Human Values (Belknap Press of Harvard University Press, 2007), at p. 307.

1115 M. Nussbaum, Frontiers of Justice: Disability, Nationality, Species Membership (Tanner Lectures of Human Values (Belknap Press of Harvard University Press, 2007), at p. 280.

1116 T. JudT, Ill Fares the Land, (New York: Penguin, 2010), at p. 196.

1117 T. JuDT, Ill Fares the Land, (New York: Penguin, 2010), at p. 197 (noting that "politics remains national, even if economics does not.") 
"While thousands of us may come together for a rally or march, we are bound together on such occasions by a single shared interest. Any effort to convert such interests into collective goals is usually undermined by the fragmented individualism of our concerns. Laudable goals... are united by nothing more than the expression of emotion. In our political as in our economic lives, we have become consumers: choosing from a broad gamut of competing objectives, we find it hard to imagine ways or reasons to combine these into a coherent whole."1118

In sum, the main takeaway of this subsection is the sobering realization about how herd mentality, peer-pressure, and opinions of the majority influence us, perhaps without our awareness of it even happening. ${ }^{1119}$ It was also mentioned that the influence is especially strong when we know that we are being watched or observed by others, especially those within our herd. This is because we seek recognition from those within our herd and through signaling, we seek to attain some level of status within our circle. As a result, we as human beings are hardwired to care more about those within our communities and have reduced empathy for "outsiders" and those that we do not see. This communal problem is why tackling a problem that has metastasized all around the globe like labor exploitation is particularly difficult for private actors to resolve.

\subsubsection{Proliferating Complexity: Emerging Trends}

The previous subsections discussed the proliferation problem, the complexity problem, and the communal problem that limit the effectiveness of the various CSR and ethical consumerism measures mentioned in this chapter with the intended aim of reducing labor exploitation in the global supply chain. These problems also have far broader implications in that they can also affect the effectiveness of other measures mentioned in previous chapters, including but not limited to various measures implemented by the government as well. This subsection will now present four emerging trends that further validate the existence of these two related problems and the impact that they are having on the private actors and their attempts to find different ways to tackle the problem of labor exploitation. Accordingly, this subsection will address the emergence of: a) micropowers and the shifting power paradigm; b) consumers that are thinking less; c) consumers from the east; and d) the protean supply chain.

\section{A. Emergence of Micropowers and the Shifting Power Paradigm}

Max Weber once believed that the source of power in modern societies lied in "bureaucratic organizations" characterized by "specific jobs with detailed rights, obligations, responsibilities, and scope of authority as well as a clear system of supervision, subordination, and

1118 T. JuDT, Ill Fares the Land, (New York: Penguin, 2010), at p. 134-135; see also, B. SCHWARTZ, The Paradox of Choice: Why More is Less, (New York: Harper, 2004), at p. 211 (noting that "[a]long with the pervasive rise in expectations, American culture" along with other similarly situated Western economies have "become more individualistic than it was, perhaps as a b-product of the desire to have control over every aspect of life."); see generally, R. PUTNAM, Bowling Alone, (New York: Simon and Schuster, 2000) (commenting on "the deterioration of social connection in contemporary life.").

1119 See generally, J. BERGER, Invisible Influence: The Hidden Forces that Shape Behaviour, (London: Simon \& Schuster, 2010). 
unity of command." 1120 Weber even hailed that the power dynamic resulting from these types of bureaucratic organizations to be unbreakable. ${ }^{1121}$ However, it is this traditional model of bureaucratic organizations advocated by Weber that is currently being challenged by the age of proliferation, where there are more players in the game. With regards to this emerging trend, journalist Moisés Naím observes the following:

"Large organization were more efficient because they operated with lower costs, thanks to economies of scale; today, however, the costs of maintaining order and control are going up. Large organizations were more effective because they centralized and warehoused scarce resources; today, resources such as commodities, information, buman talent, and customers are easier to source and serve, from distances near and far. Large organizations had a sheen of authority, modernity, and sophistication; today, headlines are being made by small newcomers that are challenging the big powers. And as the advantage of the large-scale, rational, coordinated, and centralized model of organization diminish, the opportunities increase for micropowers to make their mark using a different model for success. ",1122

Academics have also observed this shifting of powers away from bureaucratic organizations, governments, and other traditional powerhouses, albeit with slightly different terminologies: For example, Cafaggi has stated that "the regulatory State emerged as the key feature of regulatory capitalism and within the regulatory State different forms of private regulation persisted. Post-regulatory States show that they are more often rule takers than rulemakers while private transnational organizations, including business and NGOs play an ever more important role in rule-making and monitoring." 1123 This sentiment is also shared by many others in various different fields including former diplomat and conservative British politician, Douglas Hurd, who claims that "nation states are ... incompetent. Not one of them, not even the United States as the single remaining super-power, can adequately provide for the needs that its citizens now articulate. The extent of that incompetence has become sharply clearer during this century." 1124 Nobel Prize winning political economist, Elinor Ostrom, approached this issue from a slightly different angle, while making a similar

1120 M. NAím, The End of Power: From Boardrooms to Battlefields and Churches to States, Why Being in Charge Isn't What It Used to Be, (New York: Basic Books, 2013), at pp. 40-2 (summarizing arguments made by Weber in Economy and Society); see generally, M. WEBER, Economy and Society: An Outline of Interpretive Sociology, (Berkley: University of California Press, 1922).

1121 M. NAím, The End of Power: From Boardrooms to Battlefields and Churches to States, Why Being in Charge Isn't What It Used to Be, (New York: Basic Books, 2013), at pp. 40-2 (quoting Weber that bureaucratic organizations are "practically unshatterable"); see generally, M. WeBER, Politics as a Vocation, (Minneapolis: Fortress Press, 1965); see also, H.H. GERTH \& C.W. MilLS (EDS.), From Max Weber: Essays in Sociology, (New York: Routledge, 2009), at p. 228.

1122 M. NAím, The End of Power: From Boardrooms to Battlefields and Churches to States, Why Being in Charge Isn't What It Used to Be, (New York: Basic Books, 2013), at p. 75.

1123 F. CAfAGgi, "Private Regulation in European Private Law," EUI Working Papers Robert Scbuman Centre for Advanced Studies Private Regulation Series (2009). Available at: http://www.estig.ipbeja.pt/ ac_direito/RSCAS_2009_31.pdf (last accessed 2 May 2015), at p. 2 (citing to Levi-Faur) (emphasis added); see also, D. LEVI-FAur, "Regulatory Capitalism: The Dynamics of Change Beyond Telecom and Electricity," Governance 19 (2006): 497; G. TEUBNER, Global Law Without a State, (Dartmouth: Ashgate, 1997); and, J. Braithwaite \& P. Drahos, Global Business Regulation, (Cambridge: Cambridge University Press, 2000).

1124 T. Bingham, The Rule of Law, (New York: Penguin, 2010), at pp. 113-4; quoting, D. HurD, The Search for Peace, (Oxford: Oxford University Press, 1997), at p. 6 (continuing on to say that "this inadequacy of national governments to provide security, prosperity or a decent environment has brought into being a huge array of international rules, conferences and institutions; the only answer to the puzzle of the immortal but incompetence nation state is effective co-operation between those states for all the purposes that lie beyond the reach of any of them.") 
underlying point that governments and the laws that they pass do not exist in a vacuum because there are other players and considerations, which require every stakeholder to consider the reality of the "institutional diversity"1125 that exists. This means that lawyers, legislatures, and legal academics must expand the purely legal analysis to an analysis that brings about "interdisciplinary enrichment, inspiration and emerging understandings" by incorporating "different perspectives." 1126 In sum, these observations suggest that there is a "crisis of the regulatory state" today, based on the observations that it is becoming more and more difficult for states to rely on laws as a mechanism for intervention and to modify people's life and regulate markets effectively. ${ }^{1127}$ This observation is consistent with the preliminary conclusion reached in Chapter 2 and the competence problem that plagues the government and their enforcement measures.

Naím explains that the crisis of the regulatory state, in a nutshell, has to do with the fragmentation of power that comes as a result of the proliferation problem. Power can be defined generally as "the capacity to get others to do, or to stop doing, something," or more specifically as "the ability to direct or prevent the current or future actions of other groups and individuals." 1128 In short, if there are more people or more issues for governments to regulate, they will have less authority over them. The subject of power is relevant in our present discussion because it is the power that the governments wield and the authority that their laws command that can direct their citizens not to exploit laborers or to prevent businesses from running sweatshops. Chapter 2 first focused specifically on what governments are doing to reduce instances of labor exploitation in the global supply chain mainly because power has traditionally been associated with them. ${ }^{1129}$ However, according to Naím and many others, this traditional power paradigm is shifting as "the powerful are experiencing increasingly greater limits on their power... [and] power is becoming more feeble, transient, and constrained." 1130

This shifting power paradigm can also be evidenced in the private sector as well with some major businesses and other institutions traditionally associated with power hemorrhaging some of their influence and authority they once held: For example, "[p]ower in the corporate sector is diminishing - and harder to hold onto when you get it," 1131 as exemplified, not only by the fact that CEOs have far less power these days, but because "nearly

1125 See generally, E. OSTrom, Understanding Institutional Diversity, (Princeton: Princeton University Press, 2005).

1126 P. ZuMBANSEN \& G-P. CALliess, "Law, Economics, and Evolutionary Theory: State of the Art and Interdisciplinary Perspectives," Osgoode Hall Law School Comparative Research in Law \& Political Economy Research Paper No. 10 (2010), at p. 25.

1127 D. Ashiagbor, "Evaluating the Reflexive Turn in Labour Law," in The Autonomy of Labour Law, A. BOGG, C. Costello, A.C.L. Davies \& J. Prassl (EDS.), (Berlin: Walter de Gruyter, 2015).

1128 M. NAím, The End of Power: From Boardrooms to Battlefields and Churches to States, Why Being in Charge Isn't What It Used to Be, (New York: Basic Books, 2013), at pp. 1, 16.

1129 M. NAím, The End of Power: From Boardrooms to Battlefields and Churches to States, Why Being in Charge Isn't What It Used to Be, (New York: Basic Books, 2013), at p. 18 (noting that "[p]owerful institutions [like governments] have been with us for so long, and the barriers to power traditionally have been so high, that we've composed the meaning of our lives - our choices about what to do, what to accept, what to challenge - within their parameters.").

1130 M. NAím, The End of Power: From Boardrooms to Battlefields and Churches to States, Why Being in Charge Isn't What It Used to Be, (New York: Basic Books, 2013), at p. xii.

1131 M. NAím, The End of Power: From Boardrooms to Battlefields and Churches to States, Why Being in Charge Isn't What It Used to Be, (New York: Basic Books, 2013), at p. 162. 
$80 \%$ of CEOs of S\&P 500 companies have been ousted before retirement." 1132 The cause of this, at least according to Naím, are the "thousands of small micropowers" that are emerging to "tie down" business executives and government leaders alike as if they were Gulliver. ${ }^{1133}$ The point here is that in addition to firm disaggregation and the fragmentation of enterprises, there is also a proliferation of stakeholders - both internal and external who are interested in how organizations make decisions that impact the society. In lieu of providing a specific definition for what Naím refers to as micropowers, consider this list of micropowers noted by social activist Naomi Klein:

"Ethical shareholders, culture jammers, street reclaimers, McUnion organizers, human rights hacketivists, school-logo fighters and Internet corporate watchdogs are at the early stages of demanding a citizen-centered alternative to the international rule of brands. That demand, still sometimes in some areas of the world whispered for fear of a jinx, is to build a resistance both high-tech and grassroots, both focused and fragmented that is as global, and as capable of coordinated action, as the multinational corporations it seeks to subvert." "1134

Klein made this prediction back in 2002, and since then, micropowers have increased not only in number but in their collective influence, which is yet another validation of the proliferation problem. There really is more of everything today and this includes not just consumable goods, but more stakeholders and more activists that can affect the outcome of various measures with the intended aim of reducing labor exploitation. ${ }^{1135}$

The emergence of these new stakeholders, perhaps unimaginable in the days of Weber, is disrupting the status quo and challenging some of our preconceived notions about how change can come about in this modern area. If governments are not careful and fail to adapt accordingly, there is an even bigger chance that they will become more and more of a rule-taker than they already are, rather than maintaining their traditional role as rule-makers: To cement this point, a recent article in The Economist noted the following:

"[g]overnments have always been lousy at picking winners, and they are likely to become more so, as legions of entrepreneurs and tinkerers swap designs online, turn them into products at home and market them globally from a garage. As the revolution rages, governments should stick to the basics: better schools for a skilled workforce, clear rules and a level playing field for enterprises of all kinds. Leave the rest to the revolutionaries."

1132 M. NAím, The End of Power: From Boardrooms to Battlefields and Churches to States, Why Being in Charge Isn't What It Used to Be, (New York: Basic Books, 2013), at pp. 160, 163 (citing to a Wall Street Journal, report); see, D. WEIDNER, "Why Your CEO Could Be in Trouble," Wall Street Journal, (15 September 2011). Available at: http://blogs.wsj.com/deals/2011/09/15/why-your-ceo-could-be-in-trouble/ (last accessed 15 May 2015); see also, C. COMIn \& T. Philippon, "The Rise of Firm-Level Volatility: Causes and Consequences," Paper Written for the NBER's Twentieth Annual Conference on Macroeconomics, (29 July 2005). Available at: http://pages.stern.nyu.edu/ $\sim$ tphilipp/papers/diego.pdf (last accessed 15 May 2015), at p. 20 (noting that "the expected length of leadership by any particular firm has declined dramatically.").

1133 M. NAím, The End of Power: From Boardrooms to Battlefields and Churches to States, Why Being in Charge Isn't What It Used to Be, (New York: Basic Books, 2013), at p. 237.

1134 N. KLEIN, No Logo, (New York: Picador, 2002), at pp. 445-6.

1135 M. NAím, The End of Power: From Boardrooms to Battlefields and Churches to States, Why Being in Charge Isn't What It Used to Be, (New York: Basic Books, 2013), at p. 54.

1136 The Economist, “The Third Industrial Revolution," (21 April 2012). Available at: http://www.economist.com/ node/21553017 (last accessed 4 April 2017); see also, T. HARFORD, Adapt: Why Success Always Starts with Failure, 
While various outlets present this shift in the power paradigm away from governments and MNCs to the people at a more grassroots level as a positive development - that somehow the emergence of these micropowers offers us a different way to addressing or dealing with our collective action problems - we must also bear in mind that this emergence of micropowers can aggravate the proliferation problem, which in turn can increase the complexity of the system in which we operate.

Observing the rise of so-called slacktivists and celanthropists can best capsulize the two-sided nature of the emerging micropowers, but before getting into these specifics, let us first start from a more general point about what ushered in this shift in the power paradigm: What has contributed to the shifting power paradigm that Naím and others have observed, in large part, is the Internet and the Millennials, who will be the first ever generation to grow up immersed in a digital world. ${ }^{1137}$ The emergence of the Millennials, with their digital proficiency, raises interesting opportunities and challenges when dealing with a collective action problem like reducing instances of labor exploitations in the global supply chain. In an environment that is "becoming more virtual, more diverse and more volatile by the day,"1138 the Millennials supposedly have a leg up in utilizing and managing the plethora of digital tools that are available to them that previous generation lacked. For example,

"In the past several years, more effective means of collective action - such as social media, open publishing platforms, and online video sharing - have given people more levers to pull. As people pursue boycotts and disinvestment, lobby for legislation, and activate social-media campaigns with growing sophistication, they are increasingly able to influence companies' operational and strategic decision-making, thereby imposing checks and balances on today's enormous accretions of private power. $" 1139$

By 2020, it is estimated that Millennials will be "approximately $50 \%$ of the US workforce, and by $2030,75 \%$ of the global workforce," leaving many to speculate that the Millennials will be the "catalyst for accelerated change," not just in their work places, but in society as a whole. ${ }^{1140}$ However, just because the Millennials have the means and the proficiency to deal with the technological aspect of realizing social change does not necessarily mean that

(London: Abacus, 2012), at p. 149 (noting that "[t]he problem seems to be that governments love to back losers" noting to their support of big banks and car companies).

1137 Generation born in the years between early 1980s and mid 1990s.

1138 IBM INSTITUTE FOR BUSINESS VALUE, "Myths, Exaggerations and Uncomfortable Truths: The Real Story Behind Millennials in the Workplace," IBM Global Business Services Executive Summary, (January 2015). Available at: www-01.ibm.com/common/ssi/cgi-

$\mathrm{bin} /$ ssialias? subtype $=$ XB\&infotype $=$ PM\&appname=GBSE_GB_TI_USEN\&htmlfid=GBE03649USEN\&attach ment=GBE03649USEN.PDF\#loaded (last accessed 5 July 2015).

1139 L.P. MARCUS, “The People's Corporation," Project Syndicate, (15 September 2014). Available at: http://www.project-syndicate.org/commentary/lucy-p--marcus-says-that-companies-have-more-power-thanever-before--but-so-do-people (last accessed 4 April 2017).

1140 J. MeISTER, "Three Reasons You Need to Adopt a Millennial Mindset Regardless of Your Age," Forbes, (5 October 2012). Available at: http://www.forbes.com/sites/jeannemeister/2012/10/05/millennialmindse/ (last accessed 5 July 2015), as cited in; IBM INSTITUTE FOR BUSINESS VALUE, "Myths, Exaggerations and Uncomfortable Truths: The Real Story Behind Millennials in the Workplace," IBM Global Business Services Executive Summary, (January 2015). Available at: http://www-01.ibm.com/common/ssi/cgi-bin/ssialias?subtype=XB\&infotype= PM\&appname=GBSE_GB_TI_USEN\&htmlfid=GBE03649USEN\&attachment=GBE03649USEN.PDF\#loade d (last accessed 5 July 2015). 
they will actually make a difference. Part of the problem is that this digital proficiency has led to a different kind of a problem, most easily depicted by the term "Slacktivism." Concerned citizens can "act" now days without actually doing much, due in part to the aforementioned technological advances. ${ }^{1141}$ The skepticism towards Slacktivists have been neatly phrased in the following sentiment: "[Slacktivism is] the ideal type of activism for a lazy generation: why bother with sit-ins and the risk of arrest, police brutality, or torture if one can be as loud campaigning in the virtual space?"1142 This is to suggest that while it has become easier for people to find others who share the same interests, what they will actually do about it (i.e. whether they will act in furtherance of a cause that claim to care about above and beyond merely clicking on the "Like" button or changing their Facebook profile picture to rainbow to support LGBTQ rights, etc.) has some wondering if the technology and the myriad of online social platforms available today have made not just the Millennials - but private actors in general - more lazy in terms of their activism compared to those that preceded them. ${ }^{1143}$

Based on these claims, slacktivists have been branded as the "lazy, entitled, selfish and shallow" Millennials. ${ }^{1144}$ This accusation partially illustrates the aforementioned caveat about how technology and the emergence of micropowers can be perceived as a doubleedged sword. ${ }^{1145}$ While technology allows us to do great things (e.g. microfinancing through sites such as Kiva, crowd-funding startup capital to start a socially responsible business through Kickstarter, etc.), with so many causes and everyone being able to do something about it, there are problems that inevitably arise such as the emergence of slacktivists or the aforementioned choice overload problem of simply having too much choice. ${ }^{1146}$ Similarly, consumers bombarded with information online become increasingly

1141 T. JuDT, Ill Fares the Land, (New York; Penguin, 2010), at p. 120 (commenting on the "atomizing" impact of the internet and how we have formed a "global community of elective affinity", where people only care about "a highly specialized subset of news items and public events," but not global matters, which are considered as "extraneous concerns.”).

1142 E. Morozov, "The Brave New World of Slacktivism," Foreign Policy (19 May 2009). Available at: http:/ foreignpolicy.com/2009/05/19/the-brave-new-world-of-slacktivism/ (last accessed 15 May 2015).

1143 M. NAím, The End of Power: From Boardrooms to Battlefields and Churches to States, Why Being in Charge Isn't What It Used to Be, (New York: Basic Books, 2013), at p. 229 (stating that "[s]ocial and political causes today have 'followers' who 'like' them in the ether of digital media. On social media platforms, hordes of Facebook friends and Twitter followers can create the illusion that a group promoting a particular cause is indeed a powerful force. In some cases that may even be true... [b]ut that is not the most common experience. For most people in the world, Webbased social or political activism represents little more than the touching of a button.").

1144 J. STEIN, "Millennials: The Me Me Me Generation," Time Magazine (20 May 2013); see also, T. JuDT, Ill Fares the Land, (New York: Penguin, 2010), at p. 39 (asking "[h]ow should we begin to make amends for raising a generation obsessed with the pursuit of material wealth and indifferent to so much else?"); N.D. KRISTOF \& S. WuDunN, Half the Sky: How to Change the World, (London: Virago Press, 2010), at p. 98 (noting "One of the greatest failings of the American education system, in our view, is that young people can graduate from university without any understanding of poverty at home or abroad"); cf, M. NAím, The End of Power: From Boardrooms to Battlefields and Churches to States, Why Being in Charge Isn't What It Used to Be, (New York: Basic Books, 2013), at p. 66 (believing that the younger generation has the propensity "to question authority and challenge power").

1145 See e.g., B. Schwartz, The Paradox of Choice: Why More is Less, (New York: Harper, 2004), at p. 55 (noting that " $[\mathrm{t}]$ he Internet can give us information that is absolutely up-to-the-minute, but as a resource, it is democratic to a fault - everyone with a computer and an Internet hookup can express their opinion, whether they know anything or not.").

1146 M. NAím, The End of Power: From Boardrooms to Battlefields and Churches to States, Why Being in Charge Isn't What It Used to Be, (New York: Basic Books, 2013), at p. 230 (observing that "[w] hile millions of online activists may raise the social visibility of myriad issues, they also create a level of 'noise' and distraction that makes it very hard for any single cause to retain popular attention and support long enough to gain substantial and permanent strength."). 
susceptible to symptoms of the proliferation problem (i.e. desensitization, choice overload, etc.) and they often opt to simplify not only their consumption decisions, but in attempting to decide what issues they will care about. This specific aspect of the choice overload problems leading to the simplification of the consumers' decision-making process will be address in more detail in the next part of the subsection, but suffice it to suggest here that the proliferation problem is seriously affecting the way private actors behave. As one commentator put it, "[w]e live in a post-emotional age, one characterized by crocodile tears and manufactured emotion"1147 and while many of us wear colored ribbons or armbands or sign online petitions to show our "support," the question remains as to whether these gestures actually contribute to the causes that they allegedly support, which goes back to the causation problem noted back in Chapter 4. While the aim of this thesis is not to evaluate the impact of these online petitions and other impacts of social media campaigns have in resolving collective action problems, there is enough evidence to question their impact. For example, social psychologists have raised a concern that slacktivism could potentially lull private actors into a mistaken sense of accomplishment that they have actually done something just by showing their support online. There is an acknowledged phenomenon in social psychology called moral licensing, which suggests that once an individual does something good - however small that deed may be - there is a chance that this increases the chances of that individual subsequently behaving in a manner that they would have otherwise avoided had they not done that good deed prior. ${ }^{1148}$ The possibility of moral licensing adds credence to the validity of the complexity problem and our bounded rationality, given that it is extremely difficult - if not nearly impossible - for private actors to predict ex ante the impact their actions will have in the long run.

Having discussed the problems associated with the emergence of micropowers in the context of slacktivists and the proliferations of platforms where they can voice their opinions as a potential problem, let us now present the more optimistic side of the emerging micropowers. While some might scoff at the slacktivists and their crocodile tears, not all Millennials are lazy and there are new micropowers that are actually making a meaningful change for the better in a very tangible way. ${ }^{1149}$ Take for example the increasing impact of microfinancing, crowdsourcing, and the rise of "celanthropists" or the celebrity philanthropists. Keeping with Naím's theme of power erosion through fragmentation and saturation, philanthropy and activist is experiencing a similar shift in this paradigm:

1147 P. WeST, Conspicuous Compassion: Why Sometimes It Really Is Cruel to be Kind, (London: Civitas, 2004), at pp. 2, 69 (adding that the "next time you profess that you 'care' about something, consider your motives and consequences of your words and actions. Sometimes, the only person you really care about is you.").

1148 A.C. Merrit, D.A. Effron \& B. Monin, "Moral Self-Licensing: When Being Good Frees Us to Be Bad," Social and Personality Psychology Compass 4(5) (2010): 344-357, 344 (noting that “[p]ast good deeds can liberate individuals to engage in behavrios that are immoral, unethical, or otherwise problematic, behaviors that they would otherwise avoid for fear of feeling or appearing immoral.”).

1149 D. Feldmann \& E. YU, "Millennials and the Social Sector: What's Next?," Stanford Social Innovation Review (18 June 2014). Available at: https://ssir.org/articles/entry/millennials_and_the_social_sector_whats_next (last accessed 18 December 2016) (noting that Millenials are "open-minded with a strong sense of community fueled by the digital networks they've formed, and committed to saving the world"); as cited in, IBM INSTITUTE FOR Business VALuE, "Myths, Exaggerations and Uncomfortable Truths: The Real Story Behind Millennials in the Workplace," IBM Global Business Services Executive Summary, (January 2015). Available at: http://www01.ibm.com/common/ssi/cgi-

bin $/$ ssialias? subtype $=$ XB\&infotype $=$ PM\&appname=GBSE_GB_TI_USEN\&htmlfid=GBE03649USEN\&attach ment=GBE03649USEN.PDF\#loaded (last accessed 5 July 2015). 
"No longer the province of a few major foundations and public and international organizations, philanthropy has exploded into a constellation of small foundations and new modes of giving that in many cases directly match contributors with beneficiaries, bypassing the classic model of charities. International giving by US individuals and institutions quadrupled in the 1990s and doubled again from 1998 to 2007, when it reached \$39.6 billion - a sum more than 50 percent larger than the World Bank's annual commitments." 1150

The truth of the matter is that " $[\mathrm{m}]$ ore donors are giving more money to more people than ever before. To take just one rough number, from 2003 to 2010, the combined amount of official and private development aid from around the world rose from $\$ 136$ billion to $\$ 509$ billion." ${ }^{1151}$ While the most recent data available from 2012 indicate a slight dip (to $\$ 474$ billion), there is evidence to suggest that not only can private actors be empathetic, but more importantly, they can be quite charitable as well, which suggests that private actors in the age of proliferation can make a more direct influence in improving the lives of those indeed. For example, microfinancing is allowing anyone in the world with an online connection and a few extra dollars to spare in their bank accounts to give small loans to entrepreneurial laborers at the other end of the world, offering them a chance to start up their own business by giving them the financial support that they need. Microfinancing and the emerging online platforms that enable this is a great example of how private actors can address the problem of labor exploitation in a radically different way. Through a platform that directly connects private actors at one end of the supply chain with marginalized laborers stuck in the other end of the global supply chain, microfinancing platforms like Kiva empower exploited laborers by giving them a meaningful alternative (i.e. the ability to start their own business) that is in a manner that is more in alignment with our normative framework of adapted capabilities approach. While this approach is not necessarily a legal one, it offers a tangible solution to the problem that laws or private initiatives have not been able to thus far. It is worth noting, however, that to the extent that the microfinancer and the recipients of the loans are bound by a contract, this type of a contract is conducted in a manner that is more in conformity with the Aristotelian or Thomistic conception of the practice, which strengthens the aforementioned argument about the redemption of contracts.

\section{B. Consumers are Thinking Less Before Buying}

One of the crucial requirements for various CSR and ethical consumerism initiatives to succeed is a certain critical mass of engaged and informed consumers. As noted earlier, however, there is reason to suspect that faced with a bombardment of information in the age of proliferation, some consumers are actually thinking less before they make their consumption decisions. In a complicated web of questions like what is good for them, what is good for the environment, and what is good for the workers, with instruments like gov-

1150 M. NAím, The End of Power: From Boardrooms to Battlefields and Churches to States, Why Being in Charge Isn't What It Used to Be, (New York: Basic Books, 2013), at p. 8.

1151 M. NAím, The End of Power: From Boardrooms to Battlefields and Churches to States, Why Being in Charge Isn't What It Used to Be, (New York: Basic Books, 2013), at p. 205; citing, OECD, "Development Aid: Total Official and Private Flows Net Disbursements and Current Prices and Exchange Rates," (4 April 2012). Available at: http://www.oecd-ilibrary.org/development/development-aid-total-official-and-private-flows_20743866-table5 (last accessed 15 May 2015). 
ernment mandated regulations, certification and labeling schemes, and/or marketing and advertising campaigns all seeking the consumers' attention, our cognitive limitations, bounded rationality, and/or biases and heuristics kick in. As suggested earlier, when we are overwhelmed with information, our cognitive instinct - due in part to the activation of our System $1-$ is to simplify the decision by relying on what we are used to (i.e. our habits). This part of the subsection will now attempt to illustrate the manifestation of this phenomenon and how some businesses are exploiting this cognitive limitation for their benefit.

Tony Judt once observed that there is a seeming expansion of "conspicuous consumption of redundant consumer good[s]." 1152 As noted earlier, in the age of proliferation, consumers are increasingly fascinated by the idea of continual accumulation of material possessions, which substantiates an earlier claim made by Thorstein Veblen, a sociologist, who coined the term "conspicuous consumption"1153 or the likes of Paul Nystrom's "philosophy of futility," 1154 where people sought gratification from frivolous things, a precursor of what we know today as "retail therapy." 1155 Earlier in this chapter, during the initial discussions of consumerism and capitalism in the age of proliferation, this thesis suggested to the possibility that this overconsumption is what is causing many of the collective action problems that we face today, including but not limited to labor exploitation, environmental pollution, increasing rates of depression, etc. ${ }^{1156}$ Add to this observation, the increasing ease of consumption, which allows consumers to think and do less prior to purchasing, not to mention the efforts that are invested into tantalizing or manipulating the consumers in to purchasing materials goods that they may not be able to afford.

Not only are some consumers addicted to overconsumption, but this situation is exacerbated by the fact that the process of consumption - the buying process - is becoming easier and easier, ${ }^{1157}$ as businesses work very hard to make it easier for consumers to shop: Even during the early days of online shopping, consumers were given the option to store their credit card information or their delivery address so that any subsequent purchases were facilitated by "one-click" ordering:

1152 T. JUDT, Ill Fares the Land, (New York: Penguin, 2010), at p. 11.

1153 See generally, T. VeBLEN, The Theory of the Leisure Class: An Economic Study in the Evolution of Institutions, (New York: Macmillan Company, 1899) (defining the term as the phenomenon that describes those who display their accumulated wealth in order to manifest their social status, which is a term very similar to the costly signaling theory mentioned in Chapter 4.2.).

1154 See generally, P. NYSTROM, Economics of Fashion, (New York: Ronald Press Company, 1928) (observing that the consumers' increasing dependency on consumption as a source of instant gratification, fostered by narcissistic tendencies, as futile)

1155 Mary T. Schmich of the Chicago Tribune is generally credited with having coined the term "retail therapy," but the roots of this term can be traced back to Nystrom and Veblen. See, M.T. SCHMICH, "A Stopwatch on Shopping," Chicago Tribune, (24 December 1986). Available at: http://articles.chicagotribune.com/1986-1224/features/8604060073_1_shopping-shaky-ground-festive-hat (last accessed 28 July 2015) (stating that "[w]e've become a nation measuring out our lives in shopping bags and nursing our psychic ills through retail therapy.").

1156 See, J. DE GraAf, D. WANn \& T.H. NAYlor, Affluenqa: How Overconsumption is Killing Us - And How We Can Fight Back, (San Francisco: Berrett-Koehler Publishers, 2014), at p. 1 (defining "affluenza" as "a painful, contagious, socially transmitted condition of overload, debt, anxiety, and waste resulting from the dogged pursuit of more."); see also, B. SCHWARTZ, The Paradox of Choice: Why More is Less, (New York: Harper, 2004) (noting that our "culture of abundance is robbing us of our satisfaction").

1157 C. Dougherty \& H. Tabuchi, "New, Simple 'Buy’ Buttons Aim to Entice Mobile Shopping," The New York Times, (5 July 2015). Available at: http://www.nytimes.com/2015/07/06/technology/new-simple-buy-buttonsaim-to-entice-mobile-shoppers.html (last accessed 14 July 2015) (reporting that "several companies, including Google, Facebook, Twitter and Pinterest, are trying to bridge the gap between mobile browsing and desktop purchasing with a simple 'buy' button."). 
"The logic for the companies working on the new buy buttons is that... a more predictable checkout process will drive sales by reducing 'friction,' which is a technology industry euphemism for any inconvenience, no matter how small, that might cause people to wonder why they are opening their wallets. $" 1158$

The evolving functionality of smartphones and the plethora of apps available to consumers have enhanced the "shopping experience" for many consumers, but as this subsection noted earlier, technological advances and innovations are often very two-sided. With the good, also comes the bad: For example, once a consumer's card information and delivery address have been stored by an online retailer, ordering something online becomes dangerously easy. In the past, the process of having to input the card number and the delivery address manually served as a deterrent, albeit one that could easily be overcome, but by reducing these so called frictions, businesses are making it easier for the consumers to buy more things without overthinking their decisions.

Concerted business efforts to reduce friction in the decision-making process of the consumers have gone from digital screens and mobile apps to an actual, physical buttons that now allow people to order things by literally pushing a button: The Amazon Dash button, for example, is a physical button that is connected to a Wi-Fi of the consumer's home, which allows them to order pre-selected items with a single push of the button to be delivered to their homes. ${ }^{1159}$ As one commentator remarked, "[t]he future where you can just be lazy and spend money with a push of a button from Amazon is here, and it's very real." 1160
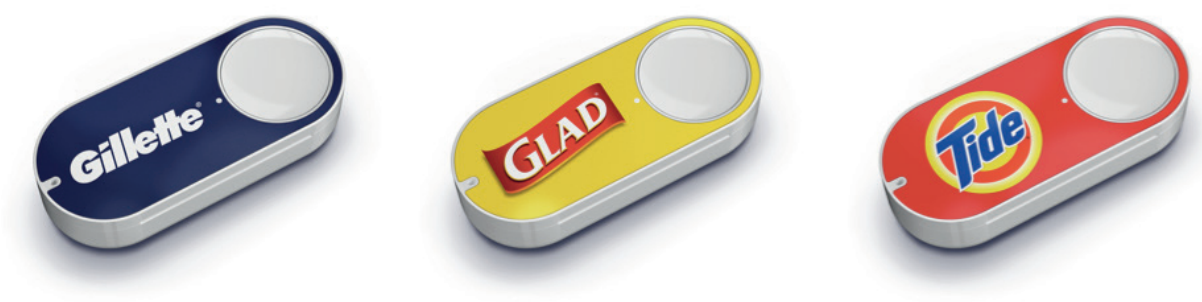

Figure 6: Amazon Dash buttons ${ }^{1161}$

1158 C. Dougherty \& H. Tabuchi, "New, Simple 'Buy’ Buttons Aim to Entice Mobile Shopping," The New York Times, (5 July 2015). Available at: http://www.nytimes.com/2015/07/06/technology/new-simple-buy-buttonsaim-to-entice-mobile-shoppers.html (last accessed 14 July 2015) (reporting that "several companies, including Google, Facebook, Twitter and Pinterest, are trying to bridge the gap between mobile browsing and desktop purchasing with a simple 'buy' button.").

1159 Amazon's own website describes the Dash button in the following manner: "Dash Button is simple to set up. Use the Amazon app on your smartphone to easily connect to your home Wi-Fi network and select the product you want to reorder with Dash Button. Once connected, a single press automatically places your order. Amazon sends an order alert to your phone, so it's easy to cancel if you change your mind. Unless you elect otherwise, Dash Button responds only to your first press until your order is delivered." Available at: https://www.amazon.com/oc/dash-button/ref=tsm_1_tw_s_amzn_nm31vy (last accessed 14 July 2015).

1160 J. Lowensohn, "Amazon Has Invented Tiny Plastic Buttons that Allow for Instant Product Ordering: Your Entire House is Now a Shopping Cart," The Verge, (31 March 2015). Available at: http://www.theverge.com/2015/3/31/8316775/amazon-dash-buttons-turn-homes-into-shopping-carts (last accessed 14 July 2015).

1161 Image available at: https://cdn2.vox-cdn.com/uploads/chorus_asset/file/3557276/TripleDash.0.png. As the image showcases, each button is attached to a specific brand. 
There are businesses such as the coffeemaker company, Quirky, that continue to push the boundaries even further, by removing the need for a consumer to push a button to purchase goods: For example, Quirky has made "a pour-over coffee maker that keeps track of both its bean reservoir and your filter supply... Get too low on beans, and you can have it set to automatically reorder for you... Quirky has [also] come up with both pet food and baby formula dispensers that keep track of how much supply you have left and will reorder when it notices you're low." 1162 As demonstrated by these so-called innovations that allow consumers to "think less" or "do nothing" before purchasing, businesses are constantly attempting to do away with the consumer mantra of "think before you buy," by reducing instances of these frictions.

The one click buttons and coffeemakers that detect the level of beans and the water supply are indeed convenient tools and perhaps crowning achievements in technology. However, these developments will likely reduce, if not deprive opportunities for consumers to make decisions that reflect upon their consumption decisions at the time of the purchase. Ultimately, this development - that of consumers thinking less and less while buying more and more - suggests a future where many consumers will inadvertently be turning a blind eye to how their consumption habits impact laborers that make their products. As a way of concluding this part of the subsection, it is worth suggesting here that if consumers genuinely want to be ethical or socially responsible and are actually interested in the reduction of labor exploitation in the supply chain, they must think more and act more directly to achieve these goals (i.e. through microfinancing). It is entirely possible that this task is made more difficult not only by our cognitive instincts to want to simplify our decisionmaking process, but by CSR and ethical consumerism measures that continue churning out more and more information to the consumers. In short, this is because these measures require the depletion of our bounded cognitive abilities and willpowers to digest and process them, which in turn could reduce the consumers' incentive to actually act in an ethical or socially responsible manner. Having discussed the emerging pattern of consumer behavior and how it manifests the proliferation problem and the complexity problem, the next part of the subsection will address a slightly different problem of consumers from the East.

\section{Consumers from the East}

In many of the existing CSR literature or writings about labor exploitation, there is an underlying tone that if the consumers and businesses in the more "developed" economies adapted the manner in which they conducted their business and consumption, the quality of life for the laborers in the more developing economies would somehow improve. ${ }^{1163}$

1162 J. Lowensohn, "Amazon Has Invented Tiny Plastic Buttons that Allow for Instant Product Ordering: Your Entire House is Now a Shopping Cart," The Verge, (31 March 2015). Available at: http://www.theverge.com/ 2015/3/31/8316775/amazon-dash-buttons-turn-homes-into-shopping-carts (last accessed 14 July 2015). The article also notes that "these same ideas are being implemented in washers from Whirlpool, printers from Brother, and filtered water pitchers from Brita."

1163 See e.g. J. EIDELSON, "Photos Show Walmart Apparel at Site of Deadly Factory Fire in Bangladesh," The Nation, (16 November 2012). Available at: http://www.thenation.com/article/photos-show-walmart-apparel-site-deadlyfactory-fire-bangladesh/ (last accessed 27 July 2015) (quoting Workers Rights Consortium Executive Director Scott Nova that "Walmart is supporting, is incentivizing, and industry strategy in Bangladesh: extreme low wages, non-existent regulation, brutal suppression of any attempt by workers to act collectively to improve wages and conditions... [Walmart's] culpability is enormous."). 
This is a tantalizing notion laced with the suggestion that what private actors do matter. This thesis has been complicit in portraying the issue in this manner as well. For example, back in Chapter 4, this thesis mentioned how CSR was a buzzword that originated in the US, noting how many of the private initiatives considered to be under the CSR umbrella in the US, mostly fall under the category of government regulations in the EU. More generally, this thesis treated - in various instances - the private actors as a rather homogenous group, often depicting them to be on one side of the supply chain and the exploited laborers being on the other end of that supply chain. Implied in this presentation, similar to many of the aforementioned existing CSR literature, was the notion that somehow, private actors in places the like US or the EU could make a meaningful impact on the working lives of laborers in places like Bangladesh, India, Qatar, and various countries Southeast Asian countries (e.g. Vietnam, Cambodia, etc.). The partial justification for presenting the case in this manner was indeed because concepts like CSR or ethical consumerism were indeed ideas that were popularized in the West and consumers in the more economically developed nations- by sheer economies of scale - had more impact on the demand fueling the global supply chain, or at least that was the case in the previous decades. This status quo, however, may no longer be the case in the not so distant future.

In addition to the emergence of the Millennials, there is a more geopolitical change taking place today that affects the issue of labor exploitation in our global supply chain, which is the increasing levels of consumerism in even the less developed economies. Earlier, this subsection stated how demand is increasing with consumers purchasing more and more and businesses adapting to meet this demand. While Western or Northern opulence is often alleged as the culprit in the plight of the laborers in areas like Southeast Asia, this portrayal is incomplete today because it overvalues the influence of the West, while undermining the rise of consumerism emerging from the developing economies in the East: "Rich countries make up just one-tenth of the world's population. In the next 15 years, their share of consumption is expected to fall from $64 \%$ to $30 \%$. Most of the 1.2 billion people the global economy added to the middle class in the last 15 years earn between $\$ 2$ and $\$ 13$ per day." 1164 What this suggests is that the power of Western consumption or this idea of "voting with our wallets" as some call it - that somehow, if more American or European consumers were more responsible, they will be able to improve the working conditions of Bangladeshi workers - may cease to have as big of an impact that many CSR or labor law literatures suggest they could have. Stated bluntly, some believe that "consumer advocacy campaigns are never going to improve working conditions in the developing world [because] Western markets simply don't matter as much as they used to" and developing-country multinationals or consumers are not as sensitive to these issues as some of their "more developed" counterparts. ${ }^{1165}$

It is worth noting here that this paradigm shift is yet another manifestation of Naím's hypothesis that traditional conception of power is eroding as it becomes more fragmented and saturated. In short, attempting to reduce instances of labor exploitation in the global

1164 M. HoBBES, "The Myth of the Ethical Shopper," The Huffington Post, (2015). Available at: http://highline.huffingtonpost.com/articles/en/the-myth-of-the-ethical-shopper/ (last accessed 16 July 2015).

1165 M. HoBBES, "The Myth of the Ethical Shopper," The Huffington Post, (2015). Available at: http://highline.huffingtonpost.com/articles/en/the-myth-of-the-ethical-shopper/ (last accessed 16 July 2015). 
supply chain by focusing on changing the laws of Western nations or increasing the number of CSR and ethical consumerism measures in more economically developed countries can only accomplish so much. As a growing number of our global population makes less and less in earnings (due in part to the aforementioned hourglass effect), goods that they can acquire will have to be cheaper and less likely that they will be made in factories where various standards are met: " $[\mathrm{L}]$ ow levels of income per capita mean that the nature of demand will be for cheap, undifferentiated goods with low acquisition costs, which runs against the major trends in demand in northern economies after 1970 that increasingly favored differentiated, high-quality positional products."1166 This reality will present unprecedented difficulties, not only for governments, but activists in more developed economies to pressure those in the developing countries to incentivize socially responsible practices or ethical consumerism. This is to suggest that given the increasing level of consumerism even in developing countries, voices of Western private actors that attempt to incentivize or admonish businesses in these countries to be more socially responsible (i.e. through the incorporation of codes of conduct in their commercial contracts) will likely to be muted to a varying degree in light of the growing internal demand:

“Consumers' power, to the extent we had any, depended on brands forcing their supply chains to do better. Now they - and we - are losing that power. And that's still not the worst of it. The really atrocious violations, the ones most likely to proliferate, are in places where we have no influence at all. ${ }^{\prime 1167}$

To summarize, the current landscape of consumption is that of fast-fashion and the expanding global supply chain, where consumers want more and more for cheaper and faster from everywhere and anywhere. Businesses are not only attempting to meet this demand by asking more and more from their workers, but at the same time, they are designing creative ways for consumers to "think less" and "do nothing" when they purchase goods. By eliminating the "friction" that comes with making purchasing decisions for consumers, businesses are making it easier for them to refrain from having to think about what they are buying, why they are buying it, never mind how the products were made or who was harmed in the process. Even if a socially conscious consumer were to express concern, there is an ongoing debate about what exactly they can do to contribute to changing the status quo. With the emergence of the tech-savvy Millennials, there is an increased concern that rather than being a "true" activist for change, more and more people might opt for or settle for becoming a slacktivists. Furthermore, as the news of sweatshops collapsing and burning down become mundane and commonplace, there is an additional risk that consumers could become desensitized and begin to accept these atrocities as the new normal. The last twist to this quagmire is the fact that even if consumers in more developed economies - those who on average can afford to pay a little extra or invest a bit more time in order to try and determine the nature of the goods that they purchase - attempt to use their consumption power as leverage into forcing companies to change their exploitative

1166 R. KAPLinSKY \& M. FAROOKI, "Global Value Chains, the Crisis, and the Shift of Markets from North to South," in Global Value Chains in a Postcrisis World: A Development Perspective, O. CatTaneo, G. Gereffi \& C. STARIZ (EDS.), (Washington D.C.: The World Bank, 2010), at p. 150.

1167 M. HOBBES, "The Myth of the Ethical Shopper," The Huffington Post, (2015). Available at: http://highline.huffingtonpost.com/articles/en/the-myth-of-the-ethical-shopper/ (last accessed 16 July 2015). 
practices, there is evidence to suggest that this leverage is not as big as it once was. This is due to the increasing consumer demand from the developing economies - those who on average may not as willing to pay a premium for goods made responsibly - as they are gaining in number and influence. So there are various alarming trends with the consumption of today and absent some alterations, the future outlook is that of concern.

\section{Protean Supply Chains}

While this thesis focused primarily on the marginalized workers at the bottom of the global supply chain thus far, let us now consider the difficulties of workers slightly higher in the food chain by briefly observing the plight of a high end fashion designer. Labor exploitation - at least as we defined it at the very beginning - is not necessarily limited to exploitations taking place in remote corners of the world, but also includes exploitations taking place in developed economies and in occupations that we generally may not associate with labor exploitation. In noting the exhausting pace in which fast-fashion retail is changing the fashion industry, fashion magazine Vogue recently wrote an expose about the departure of Christian Dior's top designer, Raf Simons. Simmons was a highly lauded designer "backed by vast budgets and a skilled, efficient atelier" that resigned from this prestigious position because he could not "hack - or refuse[d] to hack - the 24-7 obligations of creative directorship" and it's punishing workload. ${ }^{1168}$ As Vogue noted, "[Simons'] resignation implied that even he, given every advantage, couldn't keep up with fashion's breathless pace and, in the meantime, keep body and mind (and creative spirit) intact." 1169 If the designers who are near the top of the hierarchical echelon in the fashion industry are succumbing to these types of pressures, imagine the pressures that are being exerted against the workers in the factories manufacturing clothes for retailers less haute than Dior.

The proliferation problem in part can be attributed to consumerism and capitalism as this chapter noted earlier, but it is a vicious cycle in that the emergence of fast-fashion and the consumers' increasing appetite for acquisition and instant gratification has also contributed back to the proliferation problem. Order it today and have it delivered tomorrow they say. While this might be extremely convenient for the end-user, satisfying this demand creates significant burdens on the workers at the other end of the supply chain and other facilitators that make meeting this demand possible. ${ }^{1170}$ In addition, not only does the demand for more come from the consumers, but there is also demand from the business side for their supply chains to be more "protean." 1171 What this essentially means is that in

1168 M. SINGER, “The Year in Fashion: In the Wake of Fall's Designer Exits, It's Time to Start Thinking Small," Vogue, (2 December 2015). Available at: http://www.vogue.com/13373926/the-answer-to-designer-burnout-thinkingsmall/ (last accessed 21 January 2016).

1169 M. SINGER, “The Year in Fashion: In the Wake of Fall's Designer Exits, It's Time to Start Thinking Small," Vogue, (2 December 2015). Available at: http://www.vogue.com/13373926/the-answer-to-designer-burnout-thinkingsmall/ (last accessed 21 January 2016) (noting that "many emerging designers drown their creative spark in a sea of business operations" and urging that "[n]ot every brand has to do everything and be everywhere.”).

1170 R.M. Locke, The Promise and Limits of Private Power: Promoting Labor Standards in a Global Economy, (Cambridge: Cambridge University Press, 2013), at p. 175(stating that the "[b]usiness environment [is] characterized by dynamic consumer demand, shorter product life cycles, and concentrated retail channels by reorganizing their supply chains to optimize efficiencies and minimize financial and reputational risk.").

1171 J. A. CoOKE, Protean Supply Chains: Ten Dynamics of Supply and Demand Alignment, (New Jersey; Wiley, 2014), at p. 10 (explaining that the term Protean is "a reference to Proteus, a sea god in Greek mythology who could change his shape at will. Proteus had mutability. The word protean means the ability to take on different forms and shapes."). 
order to cater to capricious and volatile group of consumers, the supply chain must become more versatile than ever before and capable of shifting, changing, and adapting quickly:

"Since the 1990s, supply chain gurus have described the need for supply chains to bave flexibility, agility, and resilience in written articles, in presentations at conferences, and, of late, on blogs posted on the Internet. Although a protean supply chain has all those attributes of flexibility, agility, and resilience, its most important characteristic is mutability. It can respond and adapt to changes in business conditions and marketplace demands. It can alter its supply chain capabilities - people, resources, and technology - in rapid fashion to connect supply to demand. In short, a protean supply chain represents the next stage of evolution in the field of supply chain management.",172

While a protean supply chain might be a more efficient one - with ideas like "nearshoring" or "shared supply chains" are becoming increasingly commonplace and there are three major risks and consequences that comes as a result, which could exacerbate the proliferation problem and the complexity problem that could further limit the impact of CSR and ethical consumer measures.

First, the need for businesses to have a protean supply chain might make it more difficult for businesses to figure out where their products are actually coming from or who actually manufactures their products. Recall here the supply chain illustrated in the DRC case study back in the Introduction and the discussion about firm disaggregation and fragmented enterprises in the context of validating the complexity problem in Chapter 2. The need for expedited production requires businesses to hire intermediaries that can handle the manufacturing and processing. For example, the Apples of the world need to hire the Foxconns of the world and the Nikes of the world need to hire companies like Yue Yuen as their subcontractors. These subcontractors deal with another set of subcontractors who might get their supplies from a supplier that gets components of that supplier from another supplier. The problem is that the further upstream we go in the supply chain, the more ephemeral these businesses become, which makes it difficult not only for consumers, but even for businesses to keep track of where their products come from or how they are manufactured: For example, "Li \& Fung, which produces everything from Wal-Mart basics to Disney plush toys to Spanx, has revenues of $\$ 19.2$ billion; more than Ralph Lauren, Armani and Tommy Hilfiger combined," but more importantly, "[i]t has 15,000 supplier factories in 40 countries, but doesn't own or operate any of them" and while the company periodically inspects the suppliers in order to report back to its buyers like Wal-Mart, there is "no guarantee that orders will be filled by the same factory twice."1173

In this cascade of subcontractors and multiple suppliers, even if large corporations like Wal-Mart wanted to implement codes of conduct and enforce them throughout the supply chain, there is no guarantee that the subcontractor's supplier's supplier will actually comply

1172 J. A. CoOKE, Protean Supply Chains: Ten Dynamics of Supply and Demand Alignment, (New Jersey; Wiley, 2014), at pp. 10, 210 (insisting that "sectors will have to invest in giving their supply chains the capability to morph their shape quickly in response to changing business conditions...”).

1173 M. HoBBES, "The Myth of the Ethical Shopper," The Huffington Post, (2015). Available at: http://highline.huffingtonpost.com/articles/en/the-myth-of-the-ethical-shopper/ (last accessed 16 July 2015); see also, A.L. VyTOPIL, Contractual Control in the Supply Chain: On Corporate Social Responsibility, Codes of Conduct, Contracts and (Avoiding) Liability, (The Hague: Eleven, 2015), at p. 276 (acknowledging that based on empirical evidence, that MNCs have "limited influence" over their supply chains.). 
with them. ${ }^{1174}$ They might not be even aware of the fact that they are making clothes for Wal-Mart in the first place. A real life example to illustrate this point has been captured by Michael Hobbes in his expose, where he described how Wal-Mart banned its suppliers from using a company called Tazreen, but how a number of the products on Wal-Mart's shelves still ended up being supplied by them anyway:

"Wal-Mart hired a megasupplier called Success Apparel to fill an order for shorts. Success hired another company, Simco, to carry out the work. Simco - without telling Success, much less WalMart - sub-contracted 7 percent of the order to Tazreen's parent company, the TubaGroup, which then assigned it to Tazreen. Two other sub-(or sub-sub-sub-)contractors also placed Wal-Mart orders at Tazreen, also without telling the company."

So the ephemeral and increasingly fragmented nature of the production and manufacturing process, as exacerbated the demand for a protean supply chain, and fueled by the demand for more things by the consumer all combined is creating a situation where not only consumers lack an understanding of where stuff comes from, but businesses are similarly in the dark. This means that even contractual measures like perpetual clauses or prohibiting subcontractors to sub-subcontract out orders - both options discussed in this chapter that businesses use to increase the reach of their codes of conduct - are not necessarily effective. To frame this issue in the context of the proliferation problem and the complexity problem, "[o]ne of the paradoxes of our era is that, at the same time that corporations have become larger, more ubiquitous, and more politically influential, they have also become more exposed to risks that not only can hurt their sales, profits, and reputation but in some cases, may even put them out of business." 1176 Even if businesses want to get on top and attempt to be socially responsible, so long as they are reliant on the global supply chain, ensuring compliance upstream proves to be increasingly difficult, especially if monitoring and auditing remain the preferred method of ensuring compliance.

The second risk that comes with the protean supply chain is that it is not conducive to the goal of reducing labor exploitations. If anything, there are reasons to suspect that a protean supply chain would risk further marginalizing the already exploited labor force in the bottom echelons of the global supply chain and the basis for this statement is as follows: In our fast-retail, protean supply chain world, if a supplier or a manufacturer is unable to meet the demands of businesses for cheap prices and fast deliveries, the business has no

1174 R. MASON, “Companies Not Asked to Report Slavery in Supply Chains Under New Laws," The Guardian, (10 June 2014). Available at: http://www.theguardian.com/global-development/2014/jun/10/companies-slavery-forcedlabour-supply-chains-new-laws (last accessed 30 January 2016) (quoting the UK Home Office as stating the following: "[W]e recognize the complexity of supply chain issues, particularly where they involve links with business overseas and where the influence of UK-based companies is diminished. Cross-government action is being taken to bring businesses together to discuss the challenges and opportunities in tackling the challenges and opportunities in tackling modern slavery in supply chains."'); see also, CHARTERED INSTITUTE OF PROCUREMENT \& SUPPLY, "Professional Leaders Say UK Could be Sleepwalking into Another Supply Chain Crisis," (21 July 2014). Available at: https://www.cips.org/en/news/news/professional-leaders-say-uk-could-be-sleepwalkinginto-another-supply-chain-crisis/ (last accessed 18 December 2016) (stating that "almost three quarters (72\%) of British supply chain professionals say they have zero visibility of their supply chains beyond the second tier with only $11 \%$ saying they have visibility along the entire chain.”).

1175 M. HoBBES, "The Myth of the Ethical Shopper," The Huffington Post, (2015). Available at: http://highline.huffingtonpost.com/articles/en/the-myth-of-the-ethical-shopper/ (last accessed 16 July 2015).

1176 M. NAím, The End of Power: From Boardrooms to Battlefields and Churches to States, Why Being in Charge Isn't What It Used to Be, (New York: Basic Books, 2013), at p. 191. 
incentive to be patient and continue maintaining a business relationship with those suppliers/manufacturers. Given the availability of other options, businesses will simply find another company that can actually perform the task cheaper and on time, which creates an environment conducive to the race to the bottom. This extreme pressure to meet the demands of the buyer pushes the supplier/manufacturer to whip their laborers more in an effort to produce more, faster and cheaper. So while businesses might wish for a protean supply chain and emerging trends do indeed show that the supply chain is moving in that direction, it is worth considering the incompatibility of such a supply chain with social responsibility. In this fickle, highly pressurized environment, there is no room for growth, mutual trust, and shared goals between businesses and their upstream manufacturers and suppliers. In short, this is a recipe, not for reducing labor exploitations, but exacerbating it.

The third and final, risk of the emerging protean supply chain is that many businesses, in the end, will be unable to keep up with the growing demands of a protean supply chain, which will end up becoming a barrier to entry especially for businesses with smaller operations. This leads to a less competitive business environment dominated by a handful of conglomerates and juggernauts: "Major retailers, brand marketers, and brand manufacturers have been stressing their desire to work with fewer, larger, and more capable suppliers, strategically located around the world. In addition, there has been a consolidation among the lead firms, as the largest retailers (Walmart), traders ( $\mathrm{Li}$ and Fung), brand marketers (Nike), and brand manufacturers (VF Corporation) are increasing their market shares through mergers, acquisitions, and bankruptcies within the textile and apparel chain." 1177 Historically, when businesses are consolidated, there is an increase in concern for the monopolization of the market, not to mention the risks of artificial price inflation, production of inferior products, reduced incentives for innovation, and most significantly in our context, the risk of businesses abusing their bargaining power, not just against consumers, but also against their workers and/or their unions.

While the second and the third observations - the emergence of the micropowers and the consolidation of power by the few - may seem conflicting, if not contradictory, recall the hourglass effect discussed earlier in this chapter, where not only are our markets becoming increasing polarized, but our society as well. What this means in our context is that the emerging trend of a protean supply chain is also contributing to the hourglass effect: While powers are becoming increasingly concentrated at the top, it is becoming increasingly unstable as well, because they are capable of being disrupted by any one of the micropowers.

To conclude this section on how complexity is proliferating - as exemplified by trends like the emergence of micropowers and protean supply chains - let us consider the words of Nobel Prize winning economist, R.J. Shiller: "Most historical events, from wars to revolutions, do not have simple causes. When these events move in extreme directions, it is usually because of a confluence of factors, none of which is by itself large enough to explain these events." 1178 In other words, to solve a collective action problem of such magni-

1177 G. GerefFi \& S. Frederick, "The Global Apparel Value Chain, Trade, and the Crisis: Challenges and Opportunities for Developing Countries," in Global Value Chains in a Postcrisis World: A Development Perspective, O. CATTANeO, G. GEREFFI \& C. STARIZ (EDS.), (Washington D.C.: The World Bank, 2010), at p. 188.

1178 R.J. SHILLER, Irrational Exuberance, (Princeton: Princeton University Press, 2015), at p. 39 (adding that while this "ambiguity is unsatisfying to those of us seeking scientific certitude, especially given that it is so hard to identify 
tude like the labor exploitation that is permeating throughout our global supply chain, private actors must consider myriad of factors that can possibly influence the treatment of workers in the supply chain, from geographic locations, work culture, ownership structure, availability for workers to unionize, and so many other factors and variables that could potentially impact their analysis. In other words, there is a "plurality of factors" at all junctions. Faced with the reality of our world becoming increasingly more complex with networks of networks operating to produce even a single product, it is worth considering whether the traditional command and control frameworks is still fit for purpose, ${ }^{1179}$ which will be one of the main issues that next chapter will address. Before moving on to the next chapter, let us conclude this chapter by summarizing the case for and against the existing measures based on contract/consumer law-based measures.

\subsection{CONCLUSION: CONTRACT/CONSUMER LAW APPROACHES ARE DOUBLE-EDGED SWORDS}

The main aim of this chapter was to analyze the assortment of existing contract/consumer law-based measures that private actors are currently implementing in their attempts to reduce instances of labor exploitation in the global supply chain. By assessing the impact of the existing measures, the goal was to ascertain more information that would help us answer the research question of what private actors can do differently to further reduce instances of labor exploitation. Accordingly, this chapter started with an overview of how consumerism and capitalism have contributed to the problem of labor exploitation in Section 5.1. In this section, we also discussed how contracts were once perceived as instruments that valued notions of commutative justice during the times of Aristotle and Aquinas, but how they have eroded to a point where contracts today are perceived as instruments that facilitate those with greater bargaining powers to exploit the weaker parties. In this backdrop, this section suggested that by pairing various CSR/ethical consumerism measures with contracts, contracts can not only redeem themselves to serve a loftier purpose, but also how they can contribute to our problem of reducing labor exploitations in a manner that would actually empower the exploited laborers.

The first section was followed by Section 5.2, where we concluded that contracts can indeed transform an otherwise voluntary private initiative like codes of conduct into a legally binding document so that in the event that a seller fails to abide by the code, the buyer can technically invalidate the contract and seek damages related to the breach/nonconformity. By combining CSR initiatives with contracts, downstream buyers can impose heighted standards, increased accountability, and associated liabilities to their upstream sellers, manufactures, and suppliers. Even in a B2C context, the binding power of contracts and various remedies that are afforded to a consumer in the event of a breach, can hold the businesses more accountable to its CSR initiatives and public statements touting their social

and isolate the precipitating factors to begin with... such ambiguity justifies the constant search for new and better information to expose at least the overall contours of causation.”).

1179 R.M. LOCKE, The Promise and Limitations of Private Power: Promoting Labor Standards in a Global Economy, (Cambridge: Cambridge University Press, 2013), at p. 20. 
responsibility. This section also presented various other contract/consumer law-based measures like certification and labeling schemes and legal arguments based on vitiating factors and consumer protection measures that would - at least in theory - allow consumers to invalidate their contracts with companies that claimed to be socially responsible, when in fact, they were not.

The literature assessing these measures cited in this chapter were quite mixed: The proponents of CSR and ethical consumerism based measures believe that through careful inspections and serious audits, companies and their stakeholders can effectively monitor and thus deter code violations, which in turn, could reduce instances of labor exploitations. ${ }^{1180}$ On the other hand, there are those that believe that these CSR initiatives only produce incremental changes, if that, believing instead that the labor exploitation problem is too complex, difficult, and cost-prohibitive for private actors with bounded cognitive abilities to make sustainable or meaningful changes. This sentiment was portrayed in Section 5.3, which addressed the various problems with these existing measures by introducing the proliferation problem, the complexity problem, and the communal problem. This section also illustrated how these problems not only undermine the impact of various CSR and ethical consumer measures, but how they put into question the existing approach of what both private actors and governments are doing to actually reduce instances of labor exploitation all together. To further this line of argument, this section noted how contract/consumer-law based CSR/ethical consumer initiatives like codes of conduct run into similar obstacles as government regulations and other existing measures noted in the previous chapters: For example, the competency problem and the Goldilocks problem noted back in Chapter 2; the externalization problem and the territoriality problem noted in Chapter 3; and the enforcement problem and the causation problem noted back in Chapter 4. What this suggests is that while CSR and ethical consumerism based initiatives, together with the binding force of contracts, have significant potential, there are series of limitations and restrictions the numb the impact of this approach as well.

One common weakness of the various contract/consumer law-based claims that this chapter mentioned with major implications to our research question is the fact that the remedies available to the private actors have rather limited effect on the exploited laborers. For example, while consumers or the buyers can seek remedies against the deceiving seller, their compensation is limited to invalidating the contract and possibly seeking damages associated with the contract. ${ }^{1181}$ Even if the buyers succeed on their claims, there is no guarantee that their victory will actually contribute to the reduction of labor exploitation in the global supply chain; at least not in the manner consistent with our normative frame-

1180 See generally, R.M. LOCKE, The Promise and Limits of Private Power: Promoting Labor Standards in a Global Economy, (Cambridge: Cambridge University Press, 2013), at pp. 24-25.

1181 A.L. VYTOPIL, Contractual Control in the Supply Chain: On Corporate Social Responsibility, Codes of Conduct, Contracts and (Avoiding) Liability, (The Hague: Eleven, 2015), at pp. 163, 170 (arguing that the damages that the consumer will be able to claim on the basis of misleading statements are "fairly limited" and that the "deterrent effect of such a claim would therefore primarily lie with the reputational damage that a company could suffer if media became aware of such legal proceedings.”); see also, A. RüHMKORF, Corporate Social Responsibility, Private Law and Global Supply Chains, (Cheltenham: Edward Elgar, 2015), at p. 201 (noting that "[a]lthough the strength of private law is that it enables private parties to enforce CSR commitments, the remedies that are awarded in private law claims are, first and foremost, intended to promote the interests of the claimant. Hence, the remedies in contract are repudiation and damages, in tort the remedies are primarily damages with some injunctions and in consumer law the remedies are the right to rescind the contract and the right to a discount/damages.”). 
work of the adapted capabilities approach, which considers the empowerment of the laborers as a measuring stick of whether a particular strategy or an instrument is effective or not. ${ }^{1182}$ In addition to this overarching problem, this chapter addressed how private actors can, not only be misled by the seller's code of conduct or their publics statements, but by various labels that allege certain claims that may or may not be verifiable. In an environment inundated by codes, labels, and puffs, it is quite difficult for consumers to successfully sue companies that place deceptive labels on their products or companies that use questionable puffs to boost the image of their products. The problem is not only a legal one, but there are various psychological and sociological costs to this proliferation as well. Given that the plethora of information, disinformation, or false information is contributing to the information overload problem, the continued reliance on creating more and more private initiatives could potentially reduce the incentive of private actors to exert more effort to think and analyze the consequences of their actions prior to making their consumption decisions.

Furthermore, given the complexity of the global supply chain and the various independent legal entities that operate within them, this chapter also illustrated the difficulty of consumers and buyers suing entities further up the supply chain that they do not have any contractual privity with, including but not limited to manufactures, suppliers, subcontractors, or possibly even the certification organization that improperly granted a certification to a company who did not actually meet the requirements that their label represents. Any claim brought against these third parties by the buyers lacking in privity, must be based on tort seeking relief for economic loss that the third party allegedly claims to have caused; however, as already addressed back in Chapter 3, these cases "would almost certainly fail," based on multitude of factors including but not limited to lack of proximate causation, foreseeability, determination of actual damage caused, and so on. ${ }^{1183}$

In the end, while there is potential in pairing up various CSR/ethical consumer initiatives with the binding force of contracts, there are no assurances that the pairing would actually contribute to the reduction of labor exploitation given the aforementioned limitations. Juxtapose this preliminary conclusion to the preliminary conclusion from Chapter 2 that relying on government measures alone will not root out labor exploitation from the global supply chain. Given the limitations of both approaches, private actors must utilize and rely on both approaches, but they must also start thinking of solutions that are not strictly related to the law as well. As this chapter also suggested, there is tremendous potential in adopting an inclusive, collaborative approach that not only pairs governments and private actors together, but an approach that also embraces non-legal measures as well. In doing so, however, private actors must also bear in mind that the interaction between some government measures and voluntary private initiatives are not always complementary. In some cases, their interaction weakens the effectiveness of the other, as noted in the discus-

1182 H. Collins, "Conformity of Goods, the Network Society, and the Ethical Consumer," European Review of Private Law 5 (2014): 619-640, 622 (explaining that this is because "[t]he consumer contract with a retailer does not involve any rules or practices that interfere with the human rights of the parties. The problem of violation of labour standards and rights is rather with respect to other parties who have helped to produce and distribute the product and who may be several contractual steps removed from the final purchaser of the product.").

1183 H. Collins, "Conformity of Goods, the Network Society, and the Ethical Consumer," European Review of Private Law 5 (2014): 619-640, 630. Such tort claims would encounter similar obstacles discussed in Chapter 2.2, where the law may not be favorable to the plaintiff. 
sion of the crowding out effect back in Chapter 4. Ultimately, given the complexity problem, it is quite difficult to declare with any certainty that even the collaboration of government measures and private initiatives will resolve the problem of labor exploitations. 


\title{
Chapter
}

\section{Recommendations for the Path Forward}

\author{
"As our case is new, so we must think anew, and act anew."
}

\begin{abstract}
Abraham Lincoln
The research question that this thesis posed at the beginning was what can private actors do differently to reduce labor exploitations in the global supply chain. The aim of this thesis has not been, nor will it be to come up with the right answer, the best solution, or to devise some end-all approach. Rather, it is an infinitely more humble attempt to point out various flaws in the ways that the private sector is currently dealing with the labor exploitation problem. In other words, this thesis is taking a very critical approach by providing examples of where existing measures are failing and offering explanations as to why, not only from a legal perspective, but in a more interdisciplinary manner. In doing so, this thesis adopted the adapted capabilities approach as our normative framework and held that laws or private initiatives that empowered workers or that enhanced their capabilities to be autonomous, to be able to self-preserve, to voice their opinions, and to be able to learn and grow as our desirable criteria. In sum, to reiterate, the goal of this thesis is to observe and analyze the problems with our existing approach and to reassess the role of the private actors in a manner that is in more alignment with our normative framework moving forward.

Having established various aspects in need of critical reassessment in the previous chapters, this chapter will now summarize some of the main lessons from the previous chapters (Section 6.1); present a theoretical proposal that takes into account the lessons we have learned to answer our research question of what private actors can do differently (Section 6.2); offer some practical steps in terms of how this theoretical framework can be applied in practice by various stakeholders (Section 6.3); and finally, discuss how the combination of these measures can lead to the manifestation of the layered Swiss Cheese model that could contribute to the further reduction of labor exploitation in the global supply chain (Section 6.4).
\end{abstract}




\subsection{LESSONS LEARNED FROM OUR EXISTING MEASURES}

The previous chapters presented at least six main observations that we must keep in mind moving forward: 1) private actors cannot rely on their national governments or supranational entities alone because their laws and regulations can, at times, be slow, lacking, ineffective, or unenforced; 2) governments are particularly bad at dealing with the problem of labor exploitation and excessive consumerism given their conflict of interests; 3) too much of a good thing can become a bad thing in accordance with the Inverted- $\mathrm{U}$ curve, even with laws; 4) there is a growing shift in the power paradigm, and as a result, governments, states, and laws no longer wield as much power and authority as they once used to; 5) private actors now have more power than before, but they must be more cognizant of their actions and their impacts especially to those outside of their circles; and lastly, 6) given the state of flux and the increasing complexity of our world, all stakeholders must be mindful of just how difficult and complicated of a task the reduction of labor exploitation in the global supply chain truly is.

In making these points throughout the chapters, this thesis elaborated on a number of problems with the current ways in which private actors are attempting to deal with the problem of labor exploitation. In sum, they were: the competence problem, the goldilocks problem, the territoriality problem, the externalization problem, the enforcement problem, the incentive problem, the causation problem, the proliferation problem, the communal problem, and last but not least, the complexity problem. While some of these problems admittedly overlap with one another and they are indeed closely related, what this thesis has discovered thus far is that there is no shortage of problems or flaws with the current manner in which the private sector is attempting to deal with labor exploitations. This section will now attempt to summarize and extrapolate some commonality that these problems share and start the discussion of what can be done about them moving forward: Accordingly, this section will first make a point about how private actors are flawed (Subsection 6.1.1) and how we live in a sub-utopian world (Subsection 6.1.2) in order to offer some food for thought as this thesis works towards constructing a new framework that the private actors can rely on to better address the labor exploitation problem in the future.

\subsubsection{Private Actors are Flawed}

Many of the problems noted throughout this thesis had to do with the lack of resources that plague both governments and private actors like the competence problem, the enforcement problem, and the complexity problem. These problems were not just limited to the shortage of resources like funding or time, but had to do with our cognitive limitations as well: For example, we noted how governments cannot draft legislations that predict all future outcomes ex ante, which requires them to draft laws that can be, at times, vague and overly complicated. This makes it difficult for private actors to truly understand the law and how it affects them, which makes complying with them fully a tall order. Similarly, while private actors can implement various initiatives in the hopes of further reducing labor exploitations, previous chapters illustrated that good intentions often do no guarantee good outcomes, as even the most well-intended initiatives sometimes create detrimental and 
harmful outcomes as exemplified by the goldilocks problem and the proliferation problem. All of these problems can be traced back to our bounded rationality and our cognitive limitations, because we can never fully predict what spillover effect or unintended consequences our actions can trigger in an increasingly complicated world. Accordingly, this subsection will: a) suggest that our strategies moving forward should be more mindful of our flaws; and b) advocate that our new framework ought to adopt a more holistic approach that internalizes our limitations.

\section{A. Our Framework Should Acknowledge Our Flaws Better}

If nothing else, the previous chapters showed that we are often flawed and imperfect beings, and as a result, we sometimes create instruments that fail to meet their intended aims: For example, the Introduction noted how economic models that assume humans to be rational actors to be flawed both as descriptive and predictive models for our behavior for the very reason that we are not always rational beings. ${ }^{1184}$ To prove this point, Chapter 5 elaborated on our cognitive limitations, our instinctive reliance on our habits, biases, and heuristics (also described as our System 1). Accordingly, we noted that laws and governance models that rely on these economic models to be similarly flawed, and this is perhaps the most fundamental reason why some of the laws and private initiatives that we implement do not achieve their intended goals. ${ }^{1185}$ In short, our current approaches are flawed because we fail to adequately acknowledge or take into consideration the inherent condition of being human.

In reality, our cognitive abilities are limited and our willpower is depletable. We respond to both extrinsic and intrinsic incentives, but the current approach focuses more on the former rather than the latter. Even though there is evidence to suggest that intrinsic motivations lead to more meaningful and lasting changes in the way people behave, our current approach still generally relies on extrinsic motivators because creating them (i.e. making more laws) is easier than trying to grasp the intangible nature of intrinsic incentives. ${ }^{1186}$ For example, some believe that in order for people to be intrinsically motivated, they need what the Greeks referred to as telos - or a sense of purpose - and the belief that what they are doing matters. While governments will always be necessary and the laws that they promulgate do serve various aspirational and normative purposes, the laws themselves may not be the most appropriate instrument to instill in people a sense of purpose. Bearing all of these considerations in mind, our first core lesson from the previous chapters is that "recogniz-

1184 D. ARIELY, Predictably Irrational: The Hidden Forces that Shape Our Decisions, (New York: HarperCollins, 2010), at p. 327 (stating that "[w]hen it comes to designing things in our physical world, we all understand how flawed we are and design the physical world around us accordingly," but when it comes to "the mental and cognitive realm, we somehow assume that human beings are without bounds.").

1185 T. HARFord, Messy: How to be Creative and Resilient in a Tidy-Minded World, (London: Little, Brown, 2016), at pp. 162-3 (noting that "governments continue to be motivated by the idea that the better they comprehend the world, the better they will be able to control and exploit it. They have been joined by large corporations, which also see the value in quantifying and classifying our world... The trouble is that when we start quantifying and measuring everything, we soon begin to change the world to fit the way we measure it.").

1186 J. Berger, Invisible Influence: The Hidden Forces that Shape Behaviour, (London: Simon \& Schuster, 2010), at p. 55 (stating that " $[\mathrm{w}]$ hen trying to persuade others or convince them to do something, we tend to default to rewards or punishment... But while rewards and punishments are effective in the short term, they often undermine what they set out to achieve."). 
ing our shortcomings is a crucial first step on the path to make better decisions, creating better societies, and fixing our institutions." 1187

\section{B. Our Framework Should Adopt a More Holistic Approach}

Generally speaking, the law does not require individuals to be ethical or moral, and "[i]t is a mistake to assume that the law should always enforce morality," 1188 which is to suggest that private actors should not be prohibited, whether by government measures of private initiatives, from shopping at retailers with alleged ties to sweatshops or buying mobile phones that rely on cobalt for them to run. This point is not in conflict with the preliminary conclusions made thus far. To quote Samuel Bowles "good laws are no substitute for good citizens,"1189 which leaves open the question of where "good citizens" come from. ${ }^{1190}$ While many believe that good laws do make good citizens, or at least get them to behave like one, the truth of the matter is that laws and other extrinsic motivators do not necessarily make people or corporations "good," thus leaving the question of where good citizens come from unanswered: In coming up with ideas for different possibilities, the lessons learned above would suggest that good citizens do not emerge from creating more laws or more private initiatives; but rather, we ought to reconsider our over-reliance on them as a starting point. The prudence of this suggestion is that it not only leaves personal autonomy intact (thus conforming to our normative framework), but moreover, it gives private actors the opportunity to think about the consequences of their actions, which is the key to creating and fostering intrinsic motivations (a topic that was initially discussed back in Chapter 4). ${ }^{1191}$ Therefore, part of the solution to our problem is to reassess our over-reliance on legal sanctions and other extrinsic incentives.

Furthermore, while the extrinsic incentives (i.e. incorporating codes of conduct into contracts with suppliers, mandating certification requirements, etc.) can - at times - address various symptoms of our flaws, it does not necessary address the underlying cause of our flaws or the problem of private actors exploiting laborers. ${ }^{1192}$ As Henry David Thoreau once noted in his magnum opus, $W$ alden, in order to deal with a problem, we must strike the problem at its root and not by just hacking away at its branches. Doing so requires the will of the people to act in different ways than they have been accustomed to and adapting their current norms. This instinct to adapt, however, would preferably come from motivations within, and not forced upon the private actors: For example, as we noted back in

1187 D. ArIELY, The (Honest) Truth About Dishonesty: How We Lie to Everyone - Especially Ourselves, (New York: Harper Collins, 2012), at p. 247.

1188 P. SINGER, Writings on an Ethical Life, (New York: HarperCollins, 2001), at p. xix.

1189 S. Bowles, Machiavelli's Mistake: Why Good Laws Are No Substitute for Good Citizens, (New Haven: Yale University Press, 2012).

1190 J. DE GRAAF, D. WANN \& T.H. NAYLOR, Affluenza: How Overconsumption is Killing Us - And How We Can Fight Back [Third Edition], (San Francisco: Berrett-Koehler Publishers, 2014), at p. 563 (distinguishing consumers from citizens by quoting James Kuntsler stating the following: "We've mutated from citizens to consumers in the last sixty years," and the trouble with this is that "consumers have no duties or responsibilities or obligations to their fellow consumers); see, J.H. KuntSLER, The Geography of Nowhere: The Rise and Decline of America's Man-Made Landscape, (New York: Simon \& Schuster, 1994).

1191 Chapter 4 also suggested that in order to reduce the instances of labor exploitation, more intrinsic incentives are required, which extrinsic motivators often tend to crowd out.

1192 R. LOCKE, F. QIN \& A. Brause, "Does Monitoring Improve Labor Standards?: Lessons from Nike," MIT Sloan School of Management Working Paper No. 4612-06 (2006). Available at: http://ssrn.com/abstract=916771 (last accessed 4 April 2017), at p. 36. 
Chapter 4, there are benefit corporation legislations already in existence, but not all companies should be legally required to be a benefit corporation. There are transparency and disclosure requirements that would allow consumers to determine a company's business practices, but even though most consumers do not bother reading them, they should not be expected or compelled to do so. The point here is that we want these private actors to want to do these things intrinsically, because that is likely to address the cause of the problem, rather than just striking the surface of it.

Part of the reason why collective action problems like labor exploitations remain unresolved, as Tony Judt would argue, is that although the tools necessary to resolve our problems already exist (i.e. benefit corporations, laws that invalidate immoral contracts, etc.), what is lacking is the will and the concerted efforts of an intrinsically motivated private sector to use them as a hypothetical good citizen would. Leaving aside the veracity of the claim that the necessary tools already exist, ${ }^{1193}$ this thesis is in agreement with the idea that more emphasis should be paid to the will, or the lack thereof, of the people and less on what type of a legislation will better compel private actors to modify their behavior.

According to social psychologist, Jonathan Haidt, acknowledging the importance of intrinsic motivations and being mindful of our flaws is to recognize that we are "deeply intuitive creatures whose gut feelings drive our strategic reasoning," which, at times can make us irrational, but it also gives us "the capacity to transcend self-interest and become simply a part of a whole." 1194 This suggests that flawed as we may be, private actors are possible of transcendence and becoming a catalyst for a positive change when given the right circumstances and incentives. One possible way we can do this, accordingly to Richard Thaler and Cass Sunstein, is to realize that "[o]ften we can do more to facilitate good behavior by removing some small obstacle than by trying to shove people in a certain direction." 1195 Again, this is a suggestion for private actors to curb their enthusiasm for extrinsic incentives and start thinking outside of the box by paying more attention to fostering intrinsic motivations. This thesis, however, depicted a reality where the trend is going the other way, where we are seemingly creating more and more laws and even converting what was once considered voluntary CSR initiatives into laws and regulations, which is a trend private actors must reassess, if not resist.

One way private actors can shift this trend - thus partially answering our research question - is to start by getting more involved in the decision-making process, by bringing an

1193 Cf. R. ReICH, Supercapitalism: The Transformation of Business, Democracy, and Everyday Life, (New York: Vintage Books, 2007), at p. 214 (disagreeing with Judt's assertion by noting that "[i]t is illogical to criticize companies for playing by the current rules of the game; if we want them to play differently, we have to change the rules."). For example, shifting our measuring stick from GDP to GPI or the GNHI, restructuring our tax system to incentivize socially responsible businesses, campaign financing reform to get money out of politics, increasing minimum wage to a living wage, reducing working hours, limiting the companies' ability to externalize liabilities, just to mention a few, could all arguably change the landscape quite drastically. Although it is worth adding a caveat here that even if these laws and changes are indeed implemented, companies will likely find ways to circumvent it one way or another, which brings us back to the conclusion that the default answer to our problem of reducing labor exploitation should not be simply to create more and more rules. Thus, the suggestion that the instruments necessary to bring about the changes that we seek already exist may, at the very least, be a slightly optimistic claim.

1194 J. HAIDT, The Righteous Mind: Why Good People are Divided by Politics and Religion, (New York: Vintage, 2012), at p. 370.

1195 R.H. Thaler \& C.R. SunSTEIN, Nudge: Improving Decisions About Health, Wealth, and Happiness, (New York: Penguin, 2009), at p. 72; see also, LeVENTHAL, SINGER, \& JONES (1965). 
assortment of different ideas to the table, and by adopting a more holistic approach. This no longer just applies to the normative criteria that we established, which focused on the workers themselves getting involved, but for every private actor to start participating in the process of addressing our collective action problems. While recognizing our flaws and cognitive tendencies is a start, this realization alone does not make us immune from making mistakes, nor will it automatically lead to meaningful changes on its own. ${ }^{1196}$ What realizing our flaws does is that it liberates us from thinking about any strategies in absolutes, that one particular way will always be the best way, when in fact there are no such panaceas in reality.

In sum, as we noted back in the Introduction, a holistic, interdisciplinary approach gives, not just academics, but private actors a more complete and enriched understanding of our flaws, what influences we are susceptible to, and also of our potentials. Based on this rich tapestry, we discovered that some of the existing measures aimed to reduce labor exploitations in the global supply chain are not succeeding and not necessarily for the reasons legal academics believe to be the case. In learning about our flaws, our shortcomings, and what strategies will likely fail or succeed, we have gained a better understanding of what we can do differently moving forward. To paraphrase the words of Thomas Edison, trying something new and failing at it is really not a failure at all, but a successful process of finding out what does not work. In a way, we are developing a phronesis of our own, which is about learning from our mistakes and trying out new ideas, which is an approach that this thesis can be satisficed about. Before moving on to proposing our new framework moving forward, we must first address one other reality that not only are we flawed, but that we are living in a sub-utopian world, full of complexities and fundamentally unidentified questions. This will be the topic of the next subsection.

\subsubsection{Private Actors are Operating in a Sub-Utopian World}

It is worth noting here a commentary offered by Tom Bingham, who noted that "by and large people, including of course states, do comply with... law[s]," and lawyers and academics become too "mesmerized by breaches of the law" that they tend to "overlook the overwhelming mass of transactions which proceed smoothly, routinely and lawfully..." 1197 In other words, perhaps our portrayal of the labor exploitations taking place in the global supply chain and our incompetence to adequately deal with this problem may have been greatly exaggerated. Perhaps in adopting a critical analysis, this thesis overlooked the large majority of private actors that are actually behaving in a manner that is not complicit to the labor exploitations taking place within the global supply chain. While there is a point to be made here, to deny the fact that there are millions of workers being exploited around the world, to cling on to the belief that the authority of the governments have not waned even with the emergence of the private sector and micropowers, to not recognize the impact

1196 C. Heath \& D. HeATH, Switch: How to Change Things When Change Is Hard, (New York: Crown Business, 2010), at p. 30 (noting how we have all encountered crazy psychologists, obese doctors, and divorced marriage counselors).

1197 T. Bingham, The Rule of Law, (New York: Penguin, 2010), at p. 112-3 (adding that the "departure from [the law] is the exception, not the rule"); citing, V. LOwE, International Law, (Oxford: Oxford University Press, 2007), at pp. 18, 20 (noting that " $[\mathrm{t}]$ his pessimistic view is "particularly widespread among those whose vision is unsullied by any knowledge or experience of the matter, is hopelessly wrong."). 
that aggressive consumerism is having on our society today, and continuing instead to believe that an implementation of various top-down government regulations will be able to address the problem of such magnitude is equally misguided. Accordingly, this subsection will: a) address the state of increasing complexity and uncertainty that our sub-utopian world presents; and bearing in mind the points made in the previous chapters, b) suggest that while there may not be any panaceas in this world, the idea is to keep experimenting with different ideas taking into account all of the stakeholders' knowledge, and to keep moving forward collectively.

\section{A. Our Framework Should Be Adaptive to an Increasingly Complex Future}

Similar to how many of the problems noted in this thesis has a common cause in our bounded rationality and cognitive limitations, another commonality that many of the problems raised by this thesis share is that they are caused by the fact that we live in an increasingly complex world as noted back in Chapter 5. Given this reality, outcomes of our actions are becoming more and more difficult to predict ex ante, which is contributing - at the very least - to the competence problem, the goldilocks problem, and of course, the causation and complexity problem. What this means is that the problems caused by our bounded rationality and our cognitive limitations could be further exacerbated by the fact that the world is becoming a more complicated and entangled place. Whether it is in the context of an Uberizing economy or some technological advancement that we cannot yet foresee, this thesis illustrated various case studies that demonstrated our desperate need for new solutions. Perhaps more fundamentally, what we need are new ways in which our societies go about resolving our collective action problems rather than relying on more traditional governance structures. Moreover, given that successful solutions that may have worked in the past or in one particular jurisdiction may not be replicated elsewhere in the future, this calls for the need for private actors to be more adaptive and flexible moving forward at the very least.

\section{B. Our Framework Should Refrain from Absolutes}

While the increasing complexity might make the problem-solving process more difficult and the outcome of any effort even more unpredictable as noted above, there are benefits associated with the increasing complexity and the shifting of the power paradigm (as exemplified by the emergence of micropowers noted back in Chapter 5). For example, while increasing the number of stakeholders and people involved in the decision making process could add to the complexity problem, another way to conceptualize this is to consider the corresponding increase in "institutional diversity" or what this thesis will later describe as cognitive diversity that comes with the increase in the number of stakeholders in the decision-making process as an untapped potential. Assuming that some of these micropowers have their own sets of phroneses or have unique experiences and specific, localized, or practical knowledge, their involvement in the problem-solving process could lead to new ideas and possibilities. This lesson is the realization that many instruments and strategies discussed in this thesis cannot be simply reduced to good or bad, but that they are just two different sides of the same coin. Much like the emergence of the sharing economy, advent of the Internet, rise of the micropowers, proliferation of various CSR initiatives, and so on, have both a cost and a benefit, there is no such thing as an uninhibited good. Therefore, 
our framework should refrain from conceptualizing benefits of any instruments or strategies in absolute black or white terms. So long as our problem-solving framework leaves room for stakeholder involvement and the option to continuously adapt as necessary, there is still a chance for the private actors to improve our sub-utopian world and turn it into something less so.

Considering that there are almost 7 billion people on this earth resolving the global collective action problems that we face will require mobilization of literally billions of people, which is a problem of immense magnitude. Tackling this problem will require both the private and the public sector working in concert. ${ }^{1198}$ Before moving on to the actual proposal of this framework, it is worth reiterating here what this thesis aims to accomplish and what it does not: While the previous chapters tackled the issue of why many private initiatives fail, this thesis is not necessarily a call to arms for private actors to care or do more. While it has been said that "[i]f emotion without reason is blind, then reason without emotion is impotent," 1199 the purpose of this academic thesis is merely to observe some of the existing failures, offer possible reasons as to why such failures occur, and to hypothesize or propose a different - and possibly more effective - framework, which could end up having the additional benefit of incentivizing private actors to actually change their behaviors.

Having substantiated the claim that the current way of doing things has various areas of improvement, this thesis will finally proceed to offer a different framework or a different approach to addressing the problem of labor exploitations in the global supply chain that is more in alignment with our adapted capabilities approach and that does not succumb to the same traps as its predecessors. In the end, to the extent that we - as human beings are flawed, many of the solutions that we create will continue to be flawed and workable solutions may, in due time, become unworkable. This stresses the importance of an adaptive framework that is less bureaucratic and handcuffed by red tapes, contrary to what Weber suggested. In light of these specific observations, we must acknowledge that we live in a sub-utopian world, where governments, corporations, and people are fallible and the rule of law does not always guarantee what it promises. ${ }^{1200}$ What this implies is that private actors must continue to seek out new and different ways to resolving our increasingly complex collective action problems. The next section will propose a framework that would better enable private actors to make a difference.

\subsection{CALL FOR AN ALTERNATIVE FRAMEWORK}

Having summarized the lessons learned from the previous chapters in the last section, the aim of this section is to finally propose a different framework for the private sector to utilize in addressing the problem of labor exploitation in the global supply chain moving

1198 T. HARFORD, Adapt: Why Success Always Starts with Failure, (London: Abacus, 2012), at p. 157 (noting that it "is going to require billions of human actions each hour to change," and that "[a]ny answer is going to come either because individuals voluntarily change their behaviour, or because governments change the rules.”).

1199 P. Singer, Practical Ethics, (Cambridge: Cambridge University Press, 2011), at p. 130.

1200 T. Bingham, The Rule of Law, (New York: Penguin, 2010), at p. 85; see also, F. CAPRA \& U. MATTEI, The Ecology of Law: Toward a Legal System in Tune with Nature and Community, (Oakland: Berrett-Koehler, 2015), at p. xii (stating that "[b]oth the current globally economy and the legal order embedded in it are manifestly unsustainable..."). 
forward. This alternative framework will take into account: 1) our aforementioned flaws; 2) the problems that the existing approaches are encountering (i.e. over-reliance on external incentives, governments, etc.); and 3) the lessons we have learned along the way to offer a system that - if implemented - could enable private actors to better address the problem of labor exploitation in the global supply chain. Moreover, this approach will conform to our normative criteria that we established for this thesis - the adapted capabilities approach and will serve to empower the workers by giving them opportunities to gain more autonomy, voice, and knowledge. In short, this new framework will be a combination of private global norm production, reflexive governance, and adaptive management all working in harmony. For the lack of a better term, we will refer to it as the "alternative framework" for the purposes of this thesis.

With regards to structure, this section will first elaborate on this alternative framework broadly speaking (Subsection 6.2.1), followed by an analysis of the two main prongs of this framework, which is the adoption of a more holistic, private global norm production approach (Subsection 6.2.2) and the implementation of reflexive governance and adaptive management (Subsection 6.2.3).

\subsubsection{Private Global Norm Production, Reflexive Governance, and Adaptive Management}

Our alternative framework that combines private global norm production, reflexive governance, and adaptive management is a response to two problematic trends that we encountered throughout this thesis, which is that: 1) the traditional top-down hierarchical system of governance is failing to adequately regulate private actors that are operating at a global level; and 2) both governments and private actors are increasingly relying on laws and other extrinsic incentives in their attempts to modify behaviors of private actors. While there are instances that require exactly these types of interventions, our alternative framework recognizes that this should not be the default approach to resolving our collective action problems moving forward.

The first prong of this new framework is essentially a call to private actors to rely less on governments and their regulatory measures to resolve the labor exploitation problem. Instead, the alternative framework encourages private actors to start producing their own private norms to reduce instance of labor exploitation within their supply chains above and beyond what governments are compelling them to do. While this particular proposal is nothing earthshattering in and of itself, the point of departure from our more conventional wisdom is for the private actors to consider social norms or other non-legal measures in order to achieve this goal. While legalizing codes of conducts or laying out some extrinsic incentive may be easier to implement and perhaps the right course of action at times, this thesis has illustrated series of instances where laws and the legalization of previously voluntary initiatives turn out to be ineffective or even counterproductive. This is the very reason why the alternative framework does not give a blank endorsement for the continuation of this approach. So while watchdog consumers might want to legally enforce CSR codes against corporations or businesses might want to incentivize their suppliers and manufactures through monetary incentives or threats of legal sanctions, our alternative framework will suggest that private actors attempt to curb their enthusiasm for these measures. In- 
stead, this alternative framework believes in the potential of private global norms production, which will be elaborated further in the next subsection.

The second prong of the alternative framework deals, not with the instrument that private actors can rely on (i.e. legal norms v. social norms or extrinsic incentives v. intrinsic incentives, etc.) but more about the decision-making process itself, which is about governance and management strategies. As hinted above, the alternative framework refuses to give a blank endorsement of the more traditional methods of decision-making like the topdown hierarchical system of governance or $\mathrm{C}$ corps where the directors focus only on increasing shareholder value without giving other stakeholders any say. Instead, our framework calls for a more open and collaborative system of decision-making by adopting reflexive governance and adaptive management strategies. Again, while this is not a very innovative idea in and of itself, the point of differentiation from our more conventional wisdom is that our framework calls on both governments and private actors to be more collaborative, more open, and more inclusive of all sorts of stakeholders in the problem-solving and decision-making processes.

The combined effect of the two prongs is that our alternative framework will incentivize stakeholders to move away from the current default thinking, which is the mistaken belief that creating more and more extrinsic incentives will better motivate private actors to behave in a more socially responsible manner. Instead, this alternative framework will incentivize stakeholders to be more open to non-legal solutions, which will be made possible by the influx of cognitive diversity. This influx will come from a framework that increases the collaboration between the stakeholders - consisting of both the public sector and the private sector - in a much more meaningful way through a more open and democratic process ushered in through reflexive governance and adaptive management strategy. This framework will also allow governments to be more strategic about their use of laws and regulations, which means that they will be offered a chance to refrain from creating more laws and regulations, but rather private actors to deal with a wider variety of problems on their own, assuming - of course - that that is what the situation calls for given the totality of the circumstances.

It must be noted here at the onset that this alternative framework, even if implemented, will still produce some unsatisfactory outcomes given the increasing complexity of the world and our inability to consider all relevant factors in designing, creating, and implementing solutions ex ante. However, this is precisely why this adaptive and reflexive framework that solicits views from all types of stakeholders is crucial because it enables and encourages private actors to try new ideas and to learn from their mistakes and continue to accumulate localized knowledge - or gain organizational phronesis - which will be vital to tackling collective action problems in the future. Moreover, this alternative framework, as the remainder of this section will show, meets the adapted capabilities approach, as it will create solutions that will more likely respect the autonomy of the workers, incentivize the other private actors to allow workers to voice their opinions, and enable workers to learn and grow along with the rest of the private actors. 


\subsubsection{Adopting a More Holistic Approach that Employs Social Norms}

This thesis has continued to advocate and rely on a multi- or interdisciplinary approach to analyzing what private actors are currently doing and what they can do differently to reduce instances of labor exploitation in the global supply chain. This endorsement of a more holistic approach will now be extended to encourage other private actors to also adopt a more holistic approach as well. For all intents and purposes, the holistic approach advocated for here is in alignment with the aforementioned notion of relying on the law more strategically, to observe the Inverted-U curve phenomenon, and to reverse the current trend of creating more and more laws. What this strategic reliance on the law means, at the very minimum, is for private actors and governments alike to refrain from relying on laws too much or to rely on legal incentives to resolve all of our problems. ${ }^{1201}$ In our current context, what this subsection will attempt to suggest is that the strategic reliance on the law and adopting a more holistic approach go hand in hand; by emphasizing reliance on nonlegal norms or other possible solutions, we may alleviate some of the burdens placed on governments and laws to resolve all of our issues, and in the process, remedy the competence problem.

From a more procedural perspective, asking a room full of lawyers to solve a problem risks the possibility that the solution will end up being a legal one, given that most lawyers are generally apprehensive of mixing the law with other fields of study. ${ }^{1202}$ This is similar to how relying on GDP as the frame of reference for a nation's prosperity often leads countries to value financial assets above that of social welfare. With regards to the typical lawyer's detachment from other fields of study, Posner notes that "[1]awyers mainly read and discuss judicial opinions - which hardly affect anyone at all - while ignoring the actual behavior of governments, NGOs, and individuals." 1203 While this commentary seems quite harsh, it is true that lawyers, legislatures, and even legal academics can benefit from adopting a more holistic or multidisciplinary analyses (even if it is just comparative legal analysis). ${ }^{1204}$ Moreover, paying more attention or relying more on non-legal factors is important because "social norms, as well as other economic and cultural factors, directly determine

1201 E.H. ATIQ, "Why Motives Matter: Reframing the Crowding Out Effect of Legal Incentives," Yale Law Journal 123 (2014): 1070-1116, 1071-2; see also, S.D. MuRPHY, “Taking Multinational Corporate Codes of Conduct to the Next Level," Columbia Journal of Transnational Law 43(2) (2005), at p. 55 (commenting on the need for a "synergy between government regulation and... self-regulation.").

1202 M. SiEMS, Comparative Law, (Cambridge: Cambridge University Press, 2014), at p. 312 (noting that lawyers will caution that "other disciplines, even if they use a more scientific method and terminology, hardly provide certainty," although Siems himself seems to suggest that "pragmatically... comparative lawyers should adopt a position that tries to incorporate diverse methods and views into their thinking.").

1203 E.A. Posner, The Twilight of Human Rights Law, (Oxford: Oxford University Press, 2014), at pp. 3, 143 (expressing his doubts over the governments' ability to "selectively intervene among the continuing non-legal forms or order"); see also, C. FrIED, An Anatomy of Values: Problems of Personal and Social Choice, (London: Oxford University Press, 1970), at pp. 135-6 (noting that the "law is nothing more than one - very widespread and important - form of social organization," and that there are "various and differing forms of social relations and actions [that] are not just the means to but the very expression of values and ends that to be real must find some expression."). Lawyers are not the only ones generally incapable of opening up to other fields of study; see e.g., M.J. SANDEL, What Money Can't Buy: The Moral Limits of Markets, (London: Allen Lane, 2012), at p. 47 (noting that "most economists prefer not to deal with moral questions, at least not in their roles as economist.").

1204 M. SiEMS, Comparative Law, (Cambridge: Cambridge University Press, 2014), at p. 281 (justifying the comparative law approach by noting that "it can be said that the diversity of legal systems around the world should provide an incentive to learn from other legal systems.”). 
behaviour, irrespective of whether they are also channeled through legal rules and institutions," 1205 and "legal norms are incomprehensible without some understanding of what kind of a situation one seeks to establish with their aid." ${ }^{1206}$ Accordingly, this subsection will: a) define social or non-legal norms; b) list the possible benefits from relying on them rather than just on laws or legal norms; c) elaborate on the previously mentioned issue of over-legalization and the possible crowding out or spillover effect it can have on social norms; and finally, d) discuss the framework of private global norms production with regards to its feasibility and desirability.

Before moving on to discussing this first prong of the alternative framework, however, it is worth noting two caveats here at the onset: First, this proposal does not advocate that social norms simply replace laws in all circumstances. The suggestion is that in light of our increasing reliance on laws (as evidenced throughout this thesis), one of the main goals of this subsection will be to remind the private actors and all stakeholders involved to bear in mind the importance of non-legal norms, as they may, in some circumstances, produce better outcome than laws. Second, adopting a holistic perspective inevitably leads to pluralism of ideas and normative grand standings: While it may indeed create a "messy" state of affairs, it is "the necessary condition of a deterritorialized world where multiple overlapping communities seek to apply their norms to a single act or actors," which is to suggest that "[h]ybridity is therefore a reality, and it is the task of scholars and policymakers to develop, evaluate, and improve the mechanisms, institutions, and practices for managing pluralism." 1207 This subsection will address the first issue in this subsection and the following subsection on reflective governance and the adaptive management model will address the second issue.

\section{A. What are Social Norms?}

The presence of numerous CSR and ethical consumerism initiatives noted in Chapters 4 and 5 , as well as the number of consumers who are willing to pay more for goods produced in a socially responsible manner suggest that there are private actors that are actually attempting to be more socially responsible; the question, however, is whether this trend can be considered as a manifestation of a social norm in the absence of laws that require them to act in this manner. In order for us to answer this question, let us look at some numbers first: According to a NYU research conducted in 2013, an average of $60 \%$ of the consum-

1205 M. Siems, Comparative Law, (Cambridge: Cambridge University Press, 2014), at p. 276; see also, K.E. DAVIS \& M.J. TREBILCOCK, "The Relationship between Law and Development: Optimists versus Skeptics," American Journal of Comparative Law 56 (2008): 895-946, 897; K. PISTOR, A. HALDAR \& A. AMIRAPU, "Social Norms, Rule of Law, and Gender Reality," in Global Perspectives on the Rule of Law, J.J. HECKMAN, R.L. NELSON \& L. CABATINGAN (EDS.), (Abingdon: Routledge, 2010): 241-278, 256 (stressing the need to consider prevailing social norms in legal analyses).

1206 C. Fried, An Anatomy of V alues: Problems of Personal and Social Choice, (London: Oxford University Press, 1970), at p. 151; E.A. Posner, Law and Social Norms, (Cambridge: Harvard University Press, 2000), at p. 4 (noting that " $[\mathrm{t}]$ he law is always imposed against a background stream of nonlegal regulation - enforced by gossip, disapproval, ostracism, and violence - which itself produces important collective goods).

1207 P. SCHIfF Berman, Global Legal Pluralism: A Jurisprudence of Law Beyond Borders, (New York: Cambridge University Press, 2012), at p. 25, 326. Berman defines jurisdictional hybridity as instances where "multiple normative communities may assert dominion over, or seek to have their norms imposed on, a single act or actor" as exemplified by instances where norms or the state conflict with that of international norms, non-state norms, and so on. 
ers are willing to pay a premium with a mean of around $17.3 \%{ }^{1208}$ This is the interesting area where the law does not require consumers to buy socially responsible products and force them to pay a higher price that is usually associated with goods made responsibly. So given that this is not a legal requirement, it is worth suggesting that there is another force at play that is incentivizing private actors to behave in this manner, and the working hypothesis is that this incentive is indeed a social norm or some internal set of values. Whether it is the herd mentality or for the sake of costly signaling, an increasing number of consumers are interested in buying socially responsible products and they are willing to pay a premium for it. ${ }^{1209}$ While the previous chapters of this thesis questioned the actual impact of these practices on the marginalized workers at the other end of the supply chain, to the extent that some private actors are actually willing to do something above and beyond what they are legally required to do is enough to consider this as a manifestation of some sort of a non-legal norm. From this very cursory observation, it seems reasonable to - at least suggest that some non-legal norms are at play here, but before we can be certain of anything, we must review the basics first by going over what exactly a social norm is and how it differs from legal norms in this part of the subsection, above and beyond the initial definitions already offered back in the Introduction.

Before differentiating legal norms from social norms, a norm - generally speaking - is a "recurrent, collective behavioral pattern" that establishes boundaries of acceptability within a society and incentivizes individual behaviors to conform to it. ${ }^{1210}$ Stated differently, although individuals in most societies have varying levels of freedoms and choices, this freedom is heavily influenced, if not restricted, by an assortment of norms. With regards to the law or legal norms, Charles Fried offers what he calls the common-sense notion of the law, which is that the law "is what lawyers advise clients about, legislators put into statute books, judges decide about, policemen and sheriffs enforce" and so on. ${ }^{1211}$ Accordingly, legal norms establish boundaries through laws as implemented by legislators and enforced by the courts and the justice system. Defining social norms, on the other hand, is slightly more complicated and defining what they are runs into a similar challenge when we at-

1208 S.M. Tully \& R.S. Winer, “Are People Willing to Pay More for Socially Responsible Products: A MetaAnalysis," New York University Stern School of Business, (2013). Available at: http://web-docs.stern.nyu.edu/ pa/winer_tully.pdf (last accessed 5 April 2017) (examining "two dependent variables across 83 research papers the proportion of people who are willing to pay extra for socially responsibl[e] products (e.g., jeans made from recyclable materials) and the percentage premium that people are willing to pay for those goods" in order to reach their conclusion); see also, NYU Press Release, "NYU Stern Study Shows Customers Are Willing to Pay More for Socially Responsible Products" (7 August 2013). Available at: http://www.stern.nyu.edu/experience-stern/newsevents/winer-tully-consumer-premium (last accessed 5 April 2015).

1209 S.M. Tully \& R.S. Winer, "Are People Willing to Pay More for Socially Responsible Products: A MetaAnalysis," New York University Stern School of Business, (2013). Available at: http://web-docs.stern.nyu.edu/ pa/winer_tully.pdf (last accessed 5 April 2017) (noting that consumers are "willing to pay the highest premium for goods that provide benefits to humans (e.g., good labor practices"); see also, NYU Press Release, "NYU Stern Study Shows Customers Are Willing to Pay More for Socially Responsible Products" (7 August 2013). Available at: http://www.stern.nyu.edu/experience-stern/news-events/winer-tully-consumer-premium (last accessed 5 April 2015).

1210 C. BICCHIERI, The Grammar of Society: The Nature and Dynamics of Social Norms (Cambridge: Cambridge University Press, 2005), at p. 8.

1211 C. Fried, An Anatomy of V alues: Problems of Personal and Social Choice, (London: Oxford University Press, 1970), at p. 116 (adding that "[a]ny more precise delimitation of the area of application of the term involves theoretical commitments which it would be better to avoid at the outset."). 
tempted to define CSR earlier. ${ }^{1212}$ Here are just a few different definitions of the term: According to Robert Ellickson, a law professor at the Yale Law School, a social norm is "a rule governing an individual's behavior that is diffusely enforced by third parties other than state agents by means of social sanctions." 1213 According to Michael Tomasello, one of the leading anthropologists at the Max Planck Institute, social norm is a "socially agreed-upon and mutually known expectations bearing social force, monitored and enforced by third parties," 1214 or in the alternative, they "are sets of behavioral practices governed by various kinds of mutually recognized norms and rules... [that] represent cooperatively organized and agreed-upon ways of interacting, including rules of enforcement for noncooperators." 1215 The point here is that depending on who you ask, the definition of what a social norm is varies, albeit with some overlapping commonalities.

Applying the simplifying heuristic here, social norms - at least to the extent that it will be applied in this thesis - will be a broad construct, defined as an informal social control that regulates behavior by expecting actors to behave in a certain manner even in the absence of the law (or something with a force of the law) dictating them to do so. An example of a typical social norm is the so-called golden rule, which is to treat others as you would like to be treated yourself. Although the law generally does not require one to adhere to it, this rule of reciprocity is so commonly recognized and engrained in our psyche that according to psychologist, Robert Cialdini, failing to abide by it can lead to "internal discomfort and the possibility of external shame," which produces "a heavy psychological cost." 1216 This general definition is consistent with how this thesis attempted to disentangle laws from social norms, values, and morals back in the Introduction, where we stated that values or morals are internal standards of behavior that people possess, when collectively manifested, become the foundation of societal or social norms, and when these social norms are codified or given a legally binding force, these social norms become laws. ${ }^{1217}$

1212 C. HORNE, "Sociological Perspectives on the Emergence of Social Norms," in Social Norms, M. HECTER \& K-D. Opp (EDS.) (New York: Russell Sage Foundation, 2001), at p. 3 (stating that "the word has various meanings depending on the focus of the researcher," and elaborating that "[ $\mathrm{t}]$ he study of norms is a difficult undertaking, as is the evaluation of existing work, in part because scholars disagree about what norms are. To complicate matters, they use a variety of terms - custom, convention, role, identity, institution, culture, and so forth - to refer to concepts that are similar to or overlap with notions about norms.”).

1213 R. C. Ellickson, "The Evolution of Social Norms: A Perspective from Legal Academy," in Social Norms, M. HeCter \& K-D. Opp (EDS.) (New York: Russell Sage Foundation, 2001), at p. 35 (explaining that this definition is a common one shared amongst scholars such as Lisa Bernstein, Robert Cooter, Dan Kahan, Lawrence Lessig, Richard McAdams, Randal Picker, Eric Posner and Cass Sunstein, who Ellickson describes as the "new norms scholars"). One of these "new norms scholars" points out, however, that scholars still use this term "social norms" in a "profligate and inconsistent way"; see e.g. E.A. POSNER, Law and Social Norms, (Cambridge: Harvard University Press, 2000), at p. 5.

1214 M. Tomasello, Why We Cooperate, (Cambridge: MIT Press, 2009), at pp. 87, 104 (offering a very bare definition of social norms as "mutually expected standards of behavior").

1215 M. TOMASEllo, Why We Cooperate, (Cambridge: MIT Press, 2009), at pp. xi, xiii, 30.

1216 R.B. Cialdini, Influence: The Psychology of Persuasion, (New York: Collins Business, 2007), at pp. 17, 35.

1217 The introduction also added that the "law" at least in our context, will not be limited to codifications of norms at the hands of a sovereign government in the legal positivist sense, but the definition will be expanded to include private agreements enforced by the law of obligations. It must be stressed here that the relationship between legal norms and social norms is a complicated one: They are symbiotic in that social norms can formalize into legal norms, but legal norms can stimulate or nurture the emergence of a new social norm. Akin to "the egg or the chicken" dilemma, there is some debate as to whether a law brings about a social change or whether a social change brings about a change in the law. The rebuttable presumption or the default perspective that this thesis takes is that laws are expost instruments that are reactionary to the voice and the demand of the people. 
While deviating from a social norm could result in scorn or ostracization from one's community, in the absence of an overlapping legal norm, the deviation does not constitute a crime or breach of an obligation. ${ }^{1218}$ There are other non-legal sanctions such as blacklisting, reputational damage, and so on but they generally do not lead to the revocation of individual freedoms and rights. In this sense, social norms tend to be more informal than legal norms, but that is not to say that compliance to social norms is less observed than compliance to legal rules. ${ }^{1219}$

While laws are enacted - as extrinsic incentives - to maintain social order and for people to behave in a manner that is socially acceptable, this thesis suggested that it may not be the best instrument to actually incentivize stakeholders to behave in a more socially responsible manner relative to more intrinsic incentivizers. ${ }^{1220}$ This is to suggest, to reiterate the words of Thoreau, that the law may not strike the problem at its root. While laws ensure that people behave in a way that does not harm others, it only uses "carrots and sticks" to compel people to behave in a particular way and it does not provide them with a sense of purpose or telos as we mentioned earlier. In the end, intrinsically motivated actions - those kindled by a sense of purpose - is a vital factor in how collective actions problems like the labor exploitation in the global supply chain ought to be dealt with moving forward. ${ }^{1221}$

Speaking of carrots and sticks, let us dwell on this topic of incentives for a short moment. In the words of Emad Atiq, incentives "compensate for the inadequacy of individuals' natural motivations to behave in socially desirable ways." 1222 However, when we rely on the law as the incentive for why we act, there are problems that arise (i.e. overregulation, crowding out effects, spillover effects, etc.), but before getting into this discussion, it is worth noting that there are good incentives and bad incentives for why we do the things that we do. Although doing something good is indeed good, the reason why we do it should matter as well because that is what eventually creates meaningful and sustainable changes. Michael Sandel uses the example of paying students to read books as a perfect example of this: While we agree that reading is a good thing, students should read because they want to, and not because they are getting paid to do so. Sandel suggests that this is

1218 J.S. Coleman, Foundations of Social Theory, (Cambridge: Harvard University Press, 1990), at p. 242 (stating that "norms are ordinarily enforced by sanctions, which are either rewards for carrying out those actions regarded as correct or punishments for carrying out those actions regarded as incorrect.”).

1219 See generally, E.A. Posner, Law and Social Norms, (Cambridge: Harvard University Press, 2000) (noting that various collective behaviors occur independently of legal norms and without regards to incentives or disincentives they provide).

1220 C. FrIED, An Anatomy of V alues: Problems of Personal and Social Choice, (London: Oxford University Press, 1970), at pp. 116-7 (stating that "there is little that appears to be of intrinsic value in any of these things" and as such, they are "more or less serviceable tools for attaining various ends people might have).

1221 C.R. Sunstein \& R. HASTIE, Wiser: Getting Beyond Groupthink to Make Groups Smarter, (Massachusetts: Harvard Business Review Press, 2015), at p. 109 (noting that "[g]ood social norms and a good culture can go a long way toward reducing the potentially bad effects of social pressures."); see also, D.H. PINK, Drive: The Surprising Truth about What Motivates Us, (New York: Riverhead Books, 2009), at p. 132 (quoting psychologist Mihaly Csikszentmihalyi stating that "purpose provides activation energy for living"); and, J.G. RUGGIE, "Business and Human Rights: The Evolving International Agenda," American Journal of International Law 101 (2007): 819-840, 838 (confirming that the best course of action for us would be to "motivate, activate, and benefit from all of the moral, social, and economic rationales that can affect the behavior of corporations..." and by "providing incentives as well as punishments, identifying opportunities as well as risks, and building social movements and political coalitions that involve representation form all relevant sectors of society...").

1222 E.H. ATIQ, "Why Motives Matter: Reframing the Crowding Out Effect of Legal Incentives," Yale Law Journal 123 (2014): 1070-1116, 1072. 
because "we corrupt a good, an activity, or a social practice whenever we treat it according to a lower norm than is appropriate to it." 1223 Sandel's remark establishes the fact that - at least according to his view - there are high norms and low norms in value jurisprudence and those higher norms can be corrupted. Higher motives, for example, are notion of public service, civic duty, fighting for fairness and equality or the satisfaction that comes with helping our fellow human beings in need. ${ }^{1224}$ In sociology, these higher norms are associated with inherent goodness, which can be eroded by introducing laws and extrinsic incentives into a situation. This notion of low versus high motives or good incentives versus bad incentives lead us to the benefits of social norms vis-à-vis legal norms in the next part of the subsection and an argument for why adopting a holistic approach that equally values both is so important.

\section{B. Benefits of Social Norms vis-à-vis Legal Norms}

Having distinguished social norms from legal norms, let us now consider the benefits of emphasizing social norms and limiting our excessive reliance on legal norms. This thesis observed various instances where the imposition of legal sanctions or other forms of punishment were less than ineffective: For example, even when suppliers know that failing to meet the buyer's code of conduct could lead to reductions in future orders or termination of the contract, they still breach the code. ${ }^{1225}$ Juxtapose this reality with Tom Bingham's aforementioned point about how lawyers and academics tend to over exaggerate the instances of when laws are breached, when majority of the time, laws and extrinsic incentives are obeyed. The problem with Bingham's claim is that it is difficult to know for sure whether people generally obey the laws because they serve as strong incentives, or because of some other force. For example, Eric Posner argues that " $[\mathrm{m}]$ ost people refrain most of the time from antisocial behavior," but suggests that they do so "even when the law is absent or has no force," noting that this is because "[t]hey conform to social norms." 1226 While the truth probably lies somewhere in between, it is interesting to note that there is abundance of evidence to substantiate the claim that "informal" nature of social norms can

1223 M.J. SANDEL, What Money Can't Buy: The Moral Limits of Markets (2010), at p. 46; see also, B. SCHWARTZ \& K. SHARPE, Practical Wisdom: The Right Way to Do the Right Thing, (New York: Riverhead Books, 2010), at p. 180 (observing that once children were rewarded for reading, they started "choosing books to read on the basis of two criteria: how long they were - the shorter, the better - and how big the print was - the bigger, the better.”); see also, J. BERGER, Invisible Influence: The Hidden Forces that Shape Behaviour, (London: Simon \& Schuster, 2010), at p. 56 (observing that "[i]f vegetables were good in the first place, why would [parents] need a reward [like ice ream] to [get children to] eat them," adding that if anything, "the ice cream reward sends a subtle signal that vegetables aren't worth eating on their own."). Berger later adds that "[ $t$ ]he same goes for emplyees... [that $t]$ hey start to infer that the only reason to be on time and give good service is because they'll get paid more, not because they care about their job." Similarly, an LSE backed study of 51 studies of corporate pay for performance schemes found that extrinsic motivations such as monetary incentives "can result in a negative impact on overall performance.” See, “LSE: When Performance-Related Pay Backfires,” Financial, (25 June 2009).

1224 E.H. ATIQ, "Why Motives Matter: Reframing the Crowding Out Effect of Legal Incentives," Yale Law Journal 123 (2014): 1070-1116, 1077

1225 R.M. Locke, The Promise and Limits of Private Power: Promoting Labor Standards in a Global Economy, (Cambridge: Cambridge University Press, 2013), at pp. 38-39 (noting that "using incentives to promote compliance, the threat of sanctions in the form of reduced orders for noncompliant suppliers is rarely enforced, and factories that systematically improve their working conditions are not always rewarded (again, in the form of increased orders). Even if this threat were enforced, it could create perverse outcomes by punishing workers along with management and removing any continued incentives for factories to improve working conditions.").

1226 E.A. PosNer, Law and Social Norms, (Cambridge: Harvard University Press, 2000), at p. 4. 
be more effective and beneficial than the imposition of legal norms. Just to provide a few examples, social norms are said to be more conducive to trust making, they are more efficient means to achieving social welfare, ${ }^{1227}$ they are better at preventing market failures, ${ }^{1228}$ or solving collective action problems more effectively, ${ }^{122}$ and that they are cheaper, more efficient tools to promote a culture of loyalty, and so on. In short, "social norms are not only cheaper, but often more effective as well," relative to laws and the enforcement of legal norms. ${ }^{1230}$

To elaborate specifically on the argument that the cost of enforcing social norms is cheaper than enforcing legal norms, a slight tangent may be worth noting: Social norms, at the very basic level, influences how people behave. Sometimes, they even "encourage [people] to behave prosocially instead of merely for themselves," 1231 and with regards to enforcement, "[i] ndividuals apply sanctions to their own behavior and respond to these internally generated rewards or punishments." 1232 If a particular social norm, say the aforementioned Golden Rule, is consistent with an individual's internal set of values, external enforcement may not even be necessary because that individual will act according to his internal values. ${ }^{1233}$ Applied to this thesis, if a consumer wants to be socially responsible in their consumption or if a business wants to treat their workers with respect and dignity, the tools and the means necessary for them to do so are there, thus validating Judt's earlier claim. This would be a case where the social norm to be socially responsible has been internalized by a private actor and there is not much need for any external enforcement. ${ }^{1234}$ The issue of enforcement becomes crucial only when consumers do not really care about the welfare of the laborers or businesses are only looking at the bottom line. Thus, the relevant question that we face is not necessarily about changing the behaviors of the already-benevolent actors, but about changing the behaviors of actors that have a conflict

1227 See e.g. K.J. ARrow, "A Utilitarian Approach to the Concept of Equality in Public Expenditure," The Quarterly Journal of Economics 85(3) (1971): 409-15; see also, G.A. AKERLOF, "The Economics of Caste and of the Rat Race and Other Woeful Tales," The Quarterly Journal of Economics 90(4) (1976): 599-617.

1228 J.L. Coleman, "The Rational Choice Approach to Legal Rules," Chicago-Kent Law Review 65 (1989): 177-191; see also, E.A. POSNER, Law and Social Norms, (Cambridge: Harvard University Press, 2000), at p. 8.

1229 E. Ullmann-Margalit, The Emergence of Norms, (Oxford: Oxford University Press, 1978) (stating that "in a collective action problem, rational choices produce a Pareto-inefficient outcome. Pareto-efficiency is restored by means of norms backed by sanctions.").

1230 D. ARIELY, Predictably Irrational: The Hidden Forces That Shape Our Decisions, (New York: HarperCollins, 2008 ), at 86.

1231 C. Horne, "Sociological Perspectives on the Emergence of Social Norms," in Social Norms, M. HECTER \& K-D. OpP (EDS.) (New York: Russell Sage Foundation, 2001), at p. 4.

1232 C. Horne, "Sociological Perspectives on the Emergence of Social Norms," in Social Norms, M. HECTER \& K-D. Opp (EDS.) (New York: Russell Sage Foundation, 2001), at p. 4. Similar to what Durkheim would refer to as the internalization of norms, see e.g. C. HORNE, "Sociological Perspectives on the Emergence of Social Norms," in Social Norms, M. HECTER \& K-D. Opp (EDS.) (New York: Russell Sage Foundation, 2001), at p. 4; see also, J. BERGER, Invisible Influence: The Hidden Forces that Shape Behaviour, (London: Simon \& Schuster, 2010), at p. 1 (suggesting that the people around us have a significant and often invisible influence on whether we conform to norms); and, J. JACQUet, Is Shame Necessary: New Uses for an Old Tool, (London: Penguin Books, 2016), at pp. 10-1 (suggesting that fear of shame or being shamed can be used as a "means of social control.").

1233 C. Horne, "Sociological Perspectives on the Emergence of Social Norms," in Social Norms, M. HeCTER \& K-D. OpP (EDS.) (New York: Russell Sage Foundation, 2001), at p. 19 (noting that "[t]o the extent that normative rules are consistent with individual interests, little if any enforcement is necessary," but "[w] hen individual and group interests conflict... enforcement is crucial.").

1234 C. Horne, "Sociological Perspectives on the Emergence of Social Norms," in Social Norms, M. HECTER \& K-D. OpP (EDS.) (New York: Russell Sage Foundation, 2001), at p. 4 (stating that social norms "may be internalized when individuals come to value the behavior specified by a norm for its own sake: that is, they follow social norms because they want to."). 
between their interest and that of the society in general (i.e. to reduce instances of labor exploitation). While the enforcement of social norms is thus cheaper, to the extent that there are those that will violate norms among us, legal norms and their enforcement, though costly as they may be, will remain an essential necessity in order for societies to continue functioning.

Having covered some of the benefits of social norms, let us dig a bit further into why social norms may better enable or influence people to behave in a certain manner. Durkheim and Piaget suggested that forces behind social norms emanate from two sources: authority and reciprocity. ${ }^{1235}$ Let us start with authority, which is synonymous with the concept of power defined back in Chapter 5. Power is not simply about commanding someone to do something, nor is that type of authority the most effective way of actually making someone do or not do something. ${ }^{1236}$ For instance, "most human imperatives are not commands, e.g., 'get me water,' but rather something more indirect, such as 'I'd like some water,' which is just a statement of desire." ${ }^{1237}$ Transplanting this anthropological finding into our current legal dialogue by simply asking stakeholders to be more socially responsible will likely have a lower success rate than asking someone for some water. Thus, there is room to doubt the hypothesis that indirect statements of desire are more effective than imperatives. If anything, there are laws and there are various other soft law instruments such as the Universal Declaration of Human Rights that - while not binding serves to create a normative and aspirational framework that very clearly publishes our desires that people treat one another with basic dignity and respect, which as this thesis suggested, serve as weak imperatives at best. ${ }^{1238}$ With regards to authority being one of the sources behind social norms, some have argued that authority, which often comes in the form of a more repressive, top-down enforcement, are not really norms at all, but more akin to command and domination.

Norms based on reciprocity, on the other hand, "have power by virtue of a kind of a social contract among peers founded on mutual respect. Thus, they are true norms." 1239 This dichotomy has been acknowledged not just in sociology but in anthropology as well, where they note that humans "operate with two general types of social norms: norms of cooperation (including moral norms) and norms of conformity (including constitutive rules)," where the latter acknowledges that "rules or norms are not just regulative rules that act as a kind of traffic cop of social interaction," but "rather they are constitutive rules that actually create the game." 1240 But there is something beyond authority or promise of reci-

1235 J. PiAget, The Moral Judgment of the Child, (New York: Free Press, 1935).

1236 See generally, D. KeltneR, The Power Paradox: How We Gain and Lose Influence, (New York: Penguin Press, 2016) (arguing that the Machiavellian conception of power is outdated and that it is those who have empathy and enthusiasm for helping others that are actually considered powerful today).

1237 M. TOMAsello, Why We Cooperate, (Cambridge: MIT Press, 2009), at p. 20.

1238 Although the outcome might be different if a group of exploited laborers looked squarely into the eyes of the $\mathrm{C}$ level directors of a company exploiting them and pleaded that they stop doing so, which again, validates the aforementioned issue of our herd mentality, adherence to the creed proximus egomet mibi, and how we care less about those we do not see.

1239 M. Tomasello, Wby We Cooperate, (Cambridge: MIT Press, 2009), at p. 34; see also, J. PiAgET, The Moral Judgment of the Child, (New York: Free Press, 1935).

1240 M. Tomasello, Why We Cooperate, (Cambridge: MIT Press, 2009), at pp. 34-5, 7 (noting that "children do not just follow norms as they encounter them, but in new situations they actively seek out what they are supposed to do what the social norms and rules are in the situation- so that they can behave accordingly.”). 
procity that incentivize us to adhere to the standards cast by the society that makes us behave in a certain way, which has to do with the notion of a collectivity or a sense of belonging to a community as discussed back in Chapter 5. ${ }^{1241}$ For example, according to Tomasello, as humans grow, "they become concerned with [our] public reputations, and [we] are eager to follow and even enforce social norms, including upon [our]selves in the forms of guilt and shame." 1242 This is what Thomas Nagel calls the "view from nowhere" mindset, which can be colloquially referred to as the act of "putting yourself in someone else's shoes." 1243

To conclude this part of the subsection, while laws may be easier to create, implement, and regulate, social norms are often self-enforcing, less cost-prohibitive, and often more effective at modifying the behaviors of private actors. ${ }^{1244}$ In some cases, the imposition of legal sanctions (e.g. civil or administrative fines) can be less detrimental than say suffering reputational harm within the community, which could mean that reducing legal sanctions, as counter-intuitive as it may be, can bring about positive outcomes. ${ }^{1245}$ This is all to suggest that, at times, informal sanctioning by the group members might be a better enforcement mechanism for social norms than the law. ${ }^{1246}$ This brings us to the next part of the subsection, which is about the impact of introducing legal norms into situations better addressed by social norms.

\section{Cost of Over-Legalization: When the Law Crowds Out and Spills Over}

Let us start by dealing with the spillover effect, which as we discussed in the context of Kasky case, is when one action creates seemingly unrelated or unintended consequences. Our analysis of Kasky back in Chapter 5 argued that relying on contract/consumer laws to legally go after companies for unethical or socially irresponsible practices could have the spillover effect of makings companies smarter, more elusive, and less likely to be held accountable for their actions in the future. Chapter 5 used the example of how after the Kasky settlement, companies like Nike learned from their mistakes and since then, have generally been more careful about making definitive public statements about their social responsibility. ${ }^{1247}$ Rather than stating that "we are socially responsible," many codes of conduct and

1241 M. Tomasello, Why We Cooperate, (Cambridge: MIT Press, 2009), at p. 38.

1242 M. Tomasello, Why We Cooperate, (Cambridge: MIT Press, 2009), at p. 45; see also, J. JACQUET, Is Shame Necessary: New Uses for an Old Tool, (London: Penguin Books, 2016), at pp. 10-1 (suggesting that fear of shame or being shamed is a useful tool for social control).

1243 T. NAgeL, The Possibility of Altruism, (Princeton: Princeton University Press, 1970) (also referred to as the "bird'seye view" or "agent-neutral roles.").

1244 S. SHAVELl, "Law versus Morality as Regulators of Conduct," American Law and Economics Review 4(2) (2002): 227 257, 243 (stating the following: "Laws may enjoy advantages over morality due to the ease with which legal rules can be established, the flexible character of law, and the plausibility greater magnitude of legal sanctions over moral sanctions... However, morality may possess advantages over law, because moral sanctions are often applied with higher likelihood than legal ones (notably, internal moral sanctions apply with certainty), may reflect superior and more accurate information about conduct, and may involve lower costs of enforcement and of imposition.").

1245 R.M. LOCKE, The Promise and Limitations of Private Power: Promoting Labor Standards in a Global Economy (Cambridge: Cambridge University Press, 2013), at p. 19 (reporting that "[1]enient penalties in exchange for transparency and self-disclosure of problems have encouraged private firms to enhance their compliance with environmental regulations.").

1246 C. Horne, "Sociological Perspectives on the Emergence of Social Norms," in Social Norms, M. HECTER \& K-D. OpP (EDS.) (New York: Russell Sage Foundation, 2001), at p. 19.

1247 See e.g., A. RÜHmkorf, Corporate Social Responsibility, Private Law and Global Supply Chains, (Cheltenham: Edward Elgar, 2015), at p. 163 (noting that "CSR commitments made by companies about the conduct of their sub- 
public statements uttered since state that they are "doing their best to be socially responsible," which is an entirely different thing than actually being socially responsible. ${ }^{1248}$

Chapter 3 made a similar point in discussing the Akpan case that while Mr. Akpan may have won the case, he has yet to benefit from the win. Not only that, but Shell and other companies have learned how to better strategize for these court proceedings and quickly figured out that a court decision, without effective institutions and measures to enforce their decisions, do not really amount to much. The spillover effect from these alleged "victories" is that companies are becoming smarter and better at avoiding liability: For example, their corporate codes or their public statements are carefully tailored now as a result, so as not to invite similar lawsuits brought about by the likes of Mr. Kasky. While some have criticized the opportunistic, profit-driven nature of corporations such as Nike, Wal-Mart, Shell, etc. the one undeniable fact is that they invest significant resources into their legal departments, and they are good at their jobs. They adapt to circumstances and learn from the mistakes that they make every so often. What this suggests is two things: First, as we noted earlier in this chapter, there are no absolutes or uninhibited goodness. Even though cases like Akpan or Kasky were generally hailed as victories by the common man against big businesses, there have been negative consequences (i.e. companies have become more elusive). Second, even if we make more and more laws, or sue these companies for every breach that they commit, more often than not, they will still find ways to evade or circumvent these new laws because they are more adaptive, flexible and generally more creative than the government regulations that attempt to reign in their actions. This suggests that suing corporations or creating more and more laws may not necessarily lead to a further reduction of labor exploitation in our global supply chain.

Shifting gears now to how over-legalization could lead to a crowding out effect, we must first reiterate that for the sake of this thesis, social norms have informal sanctions, which is anything that is not a legal sanction. So both violation of legal norms and social norms may give rise to "negative gossip and ostracism," ${ }^{1249}$ but only legal norms can go above and beyond to legally sanction the party in violation (i.e. imprisonment, imposition of administrative fines, etc.). Admittedly, these two sanctions are often related and intermingled, but an increasing number of academic scholarship is starting to discover that the existence of legal norm can be detrimental to the emergence of social norms: Sociologists, Christine Horne, for example has repeatedly admonished that "the existence of a strong legal system inhibits informal sanctioning and weakens the social relations that facilitate the exercise of such control." 1250 In other words, what lawyers, legislatures and governments seldom consider is that perhaps they are overregulating and that some laws are better left uncreated as it could "reduce the likelihood that group members will impose social sanc-

suppliers are usually worded in a rather aspirational way which will make it difficult for consumers to follow this conduct up through consumer law.").

1248 A.L. VyTOPIL, Contractual Control in the Supply Chain: On Corporate Social Responsibility, Codes of Conduct, Contracts and (Avoiding) Liability, (The Hague: Eleven, 2015), at p. 249 (concluding that "aspirational wording ("MNC X will contribute to...') will be unlikely to lead to liability on... legal ground[s].").

1249 R. C. Ellickson, "The Evolution of Social Norms: A Perspective from Legal Academy," in Social Norms, M. HECTER \& K-D. Opp (EDS.) (New York: Russell Sage Foundation, 2001), at p. 35.

1250 C. Horne, "Sociological Perspectives on the Emergence of Social Norms," in Social Norms, M. HECTER \& K-D. Opp (EDS.) (New York: Russell Sage Foundation, 2001), at p. 20; see also, C. HornE, "Community and the State: The Relationship Between Normative and Legal Controls” European Sociological Review 16(3) (2000): 225-243. 
tions" that could be a better option in incentivizing the type of outcome that we want. ${ }^{1251}$ This subsection will further investigate this concern over how the excess of laws - a problem covered in some depth throughout this thesis - can be detrimental to social norms, which in turn could exacerbate the labor exploitation problem in the global supply chain. In order to substantiate this point, this part of the subsection will now present a group of relevant observations from the field of behavioral psychology and sociology to validate Horne's claims.

Margaret Clark, Judson Mills, and Alan Fiske once had a theory that "we live simultaneously in two different worlds - one where social norms prevail, and the other where [legal] norms make the rules." ${ }^{1252}$ Dan Ariely added to this by describing the world of social norms as a "warm and fuzzy" one, using the example of someone opening a door for someone else, which "provides pleasure for both of you, and reciprocity is not immediately required." 1253 This is analogous in our context to a consumer buying a product from a socially responsible business and feeling good about him- or herself, while contributing to the business striving to be more socially responsible. It is a win-win situation. On the other hand, the legal norm world is all about quid pro quo or "exchanges and sharp-edges." 1254 As Ariely explains, these two distinctly different worlds are not necessarily good or bad in their own regard, but when these worlds collide, that is when conflicts can rise. In other words, there are problems that social norms are better at addressing and other scenarios where legal norms are more ideal. The problems arise when a social norm is the preferred solution, but a more rigid, legal sanction is implemented or vice-versa.

There is a surprising number of cases where the wrong norm was implemented to address a particular problem, which exacerbated the problem: Take the often-cited Israeli daycare experiment, which was a research conducted by Uri Gneezy and Aldo Rustichini to determine whether imposing a monetary fine on parents who arrived late to pick up their children served as a useful deterrent of the undesirable behavior. ${ }^{1255}$ To keep the point short and relevant, the answer that these researchers found was that the fines did not serve as a useful deterrent, but more alarmingly, the problem (i.e. parents being late) got worse after the imposition of the fine. The researchers explained the phenomenon in the following way:

1251 C. Horne, "Sociological Perspectives on the Emergence of Social Norms," in Social Norms, M. HECTER \& K-D. Opp (EDS.) (New York: Russell Sage Foundation, 2001), at p. 20; see also, E.A. POSNER, "The Regulation of Solidary Groups: The Influence of Legal and Nonlegal Sanctions on Collective Action," University of Chicago Law Review 63(1) (1996): 133-197.

1252 D. ARIELY, Predictably Irrational: The Hidden Forces That Shape Our Decisions, (New York: HarperCollins, 2008), at p. 68 (summarizing the various arguments made by Margaret Clark, Judson Mills, and Alan Fiske); see e.g., J. MiLLS \& M.S. ClARK, "Exchange and Communal Relationships," in Review of Personality and Social Psychology, L. WHEELER (ED.) (Beverly Hills: Sage,1982): 121-144; see also, A.P. FISKE, "The Cultural Relativity of Selfish Individualism: Anthropological Evidence that Humans are Inherently Sociable," in Review of Personality and Social Psychology: Altruism and Prosocial Behavior, M.S. CLARK (ED.) (Beverly Hills: Sage, 1991). In the footnoted quote, the word "market" found in the original text was replaced with "legal," for the sake of clarity. In the context of the quote, a market norm vis-à-vis social norm is akin to legal norms in the way we use the term in this thesis.

1253 D. ArIELY, Predictably Irrational: The Hidden Forces That Shape Our Decisions, (New York: HarperCollins, 2008), at p. 68.

1254 D. ArIELY, Predictably Irrational: The Hidden Forces That Shape Our Decisions, (New York: HarperCollins, 2008), at p. 68.

1255 U. GNEEZY \& A. RuSTICHINI, “A Fine Is a Price,” Journal of Legal Studies 29(1) (2000): 1-17, 1; see also, D. ARIELY, Predictably Irrational: The Hidden Forces That Shape Our Decisions, (New York: HarperCollins, 2008), at p. 76. 
"Before the fine was introduced, the teachers and parents had a social contract, with social norms about being late. Thus, if parents were late... they felt guilty about it... and their guilt compelled them to be more prompt in picking up their kids in the future... But once the fine was imposed, the day care center had inadvertently replaced the social norms with [legal] norms.",1256

Stated differently, after the imposition of the rigid sanction, the parents did not feel guilty for being late anymore because they were paying the fine anyway. As Barry Schwartz explains, "[t]he fines demoralized what had previously been a moral act. And this is what incentives can do in general. They can change the question in people's minds from 'Is this right or wrong?' to 'Is this worth the price?"' 1257 The Israeli daycare experiment is not the only example of a rigid legal sanction or a market-based incentive crowding out a social norm.

There is a significant number of experiments that substantiate the validity of this crowding out effect. Another often cited example is the case of the Swiss Parliament's attempt to find a city where it could dispose nuclear waste, where throwing monetary incentives (the Parliament offered to pay a city to volunteer to be the site where the nuclear waste would be disposed) to address the problem backfired. The researchers in this case study noted that "[e]mphasizing social norms and civic virtue [has] greater effect on encouraging" good behavior rather than "threatening individuals with legal sanctions." 1258 This has been proven to be the case in a wide range of circumstances ranging from honesty in tax reporting to people's willingness to donate blood. ${ }^{1259}$ With regards to the latter, empirical studies have repeatedly shown that offering money incentives often decreases the instance of blood donations and for individuals to be virtuous. ${ }^{1260}$ The most impressive research conducted on this subject was conducted by Edward Deci - one of the pioneers in this field - and others who found that the crowding out effect has been tested and the results replicated in the meta-analysis of 128 studies over three decades. Deci concluded that the "crowding out effect is a robust phenomenon, and many kinds of tangible rewards for socially desirable behaviour undermine intrinsic motivation." 1261

All of these findings support what this thesis has been hinting all along, which is that incentives and motivations for why people do the things that they do matter, because "we accept inner responsibility for a behavior when we think we have chosen to perform it in

1256 D. ArIELY, Predictably Irrational: The Hidden Forces That Shape Our Decisions, (New York: HarperCollins, 2008), at pp. 76-77.

1257 B. SCHWARTZ \& K. SHARPe, Practical Wisdom: The Right Way to Do the Right Thing, (New York: Riverhead Books, 2010), at p. 191 (adding that "once lost, this moral dimension is hard to recover.").

1258 E.H. ATIQ, "Why Motives Matter: Reframing the Crowding Out Effect of Legal Incentives," Yale Law Journal 123 (2014): 1070-1116, 1084; citing, R.D. SCHWARTZ \& S. ORLEANS, On Legal Sanctions, University of Chicago Law Review 34 (1967): 274-300, 299.

1259 E.H. ATIQ, "Why Motives Matter: Reframing the Crowding Out Effect of Legal Incentives," Yale Law Journal 123 (2014): 1070-1116, 1084.

1260 R. TITMuss, The Gift Relationship: From Human Blood to Social Policy, A. OAKLEY \& J. AshTON (EDS.) (New York: New Press, 1997); see also, C. Mellströ, \& M. Johannesson, "Crowding Out in Blood Donation: Was Titmuss Right?," Journal of the European Economic Association 6(4) (2008): 845-63.

1261 E.H. ATIQ, "Why Motives Matter: Reframing the Crowding Out Effect of Legal Incentives," Yale Law Journal 123 (2014): 1070-1116, 1083; citing, E.L. DeCI, R. KoESTNER \& R.M. RYAN, “A Meta-Analytic Review of Experiments Examining the Effects of Extrinsic Rewards on Intrinsic Motivation,” Psychology Bulletin 125(6) (1999): 627-668, 659; see also, D.H. PINK, Drive, (New York: Riverhead Books, 2009), at p. 37. 
the absence of strong outside pressures." 1262 There is even more empirical research that substantiates that in many contexts, individuals lose their natural or intrinsic motivations for engaging in a prosocial activity when they are successfully induced to participate in it for extrinsic reasons, like monetary reward or fear of sanctions. ${ }^{1263}$ Laws (or legalized corporate codes for that matter) are by nature extrinsic prompts and these legal incentives "compete with or crowd out the private actors intrinsic motivation to engage in an activity." "1264 In short, extrinsic motivations such as monetary rewards or laws that compel private actors to behave in a socially responsible manner may not promote the behavior it intends to promote. ${ }^{1265}$ Becker and other proponents of the stick-and-carrot approach to motivation are inherently suspicious of actions that fail to make economic sense, but there are plenty of experts who refute the utility of the stick-and-carrot approach. ${ }^{1266}$ To support

1262 R.B. Cialdini, Influence: The Psychology of Persuasion, (New York: Collins Business, 2007), at p. 93 (adding that a "large reward is one such external pressure" and that while rewards of this nature might make us perform a certain action, "it won't get us to accept inner responsibility for the act" and “[c]onsequently, we won't feel committed to it.”); see also, J.L. FreEDMAN, "Long-term Behavioral Effects of Cognitive Dissonance," Journal of Experimental Social Psychology 4 (1966): 195-203.

1263 E.H. ATIQ, "Why Motives Matter: Reframing the Crowding Out Effect of Legal Incentives," Yale Law Journal 123 (2014): 1070-1116, 1072; see also, Y. FELDMAN \& O. LOBEL, “The Incentives Matrix: The Comparative Effectiveness of Rewards, Liabilities, Duties, and Protections for Reporting Illegality,” Texas Law Review 88(6) (2010): 11511211, 1152 (noting that whistleblowers tend to blow less when there is monetary rewards); D.M. KAHAN, "Trust, Action and Law," Boston University Law Review 81(2) (2001): 333-347, 338-9, (as cited by Atiq, noting that "the advent of incentives will produce [] less, not more, of such [desirable] behavior"); D.M. KAHAN, "The Logic of Reciprocity: Trust, Collective Action and Law," Michigan Law Review 102(1) (2003): 71-103, 72; M.J. SANDEL, What Money Can't Buy: The Moral Limits of Markets, (London: Allen Lane, 2012); R. TITMuss, The Gift Relationship: From Human Blood to Social Policy, A. OAKLEY \& J. ASHTON (EDS.) (New York: New Press, 1997), at p. 314 (noting that "commercialization of blood and donor relationships represses the expression of altruism" and "erodes the sense of community”); cited by, E.H. ATIQ, "Why Motives Matter: Reframing the Crowding Out Effect of Legal Incentives," Yale Law Journal 123 (2014): 1070-1116, 1080.

1264 E.H. ATIQ, "Why Motives Matter: Reframing the Crowding Out Effect of Legal Incentives," Yale Law Journal 123 (2014): 1070-1116, 1077.

1265 M.J. SANDEL, What Money Can't Buy: The Moral Limits of Markets, (London: Allen Lane, 2012), at p. 122 (noting that " $[\mathrm{w}]$ hen people are engaged in an activity they consider intrinsically worthwhile, offering them money may weaken their motivation by depreciating or 'crowding out' their intrinsic interest or commitment."); see also, E.L. DECI, R. KOESTNER \& R.M. RYAM, "A Meta-Analytic Review of Experiments Examining the Effects of Extrinsic Rewards on Intrinsic Motivation,” Psychological Bulletin 125(6) (1999): 627-68; see also, C. FRIED, An Anatomy of Values: Problems of Personal and Social Choice, (London: Oxford University Press, 1970), at p. 117 (noting that "the rules, arrangements and procedures in which these directing and prohibiting rules are made and manipulated seem even further removed from what people ultimately desire and value.”).

1266 E.L. DECI, "Intrinsic Motivation, Extrinsic Reinforcement, and Inequality," Journal of Personality and Social Psychology 22(1) (1972): 113-120, 119-20, (observing that "[o]ne who is interested in developing and enhancing intrinsic motivation in children, employees, students, etc., should not concentrate on external-control systems such as monetary rewards..."); E.L. DECI, "Effects of Externally Mediated Rewards on Intrinsic Motivation," Journal of Personality and Social Psychology 18(1) (1971): 105-115, 114 (suggesting that "[w]hen money is used as an external reward for some activity, the subjects lose intrinsic interest of the activity..."); H.F. HARLOW, M.K. HARLOW \& D.R. MEYER, "Learning Motivation by a Manipulation Drive," Journal of Experimental Psychology 40 (1950): 231; and, G. HAMEL, "Moon Shots for Management," Harvard Business Review, (February, 2009). Available at: https://hbr.org/2009/02/moon-shots-for-management (last accessed 18 December 2016) (observing that "As an emotional catalyst, wealth maximization lacks the power to fully mobilize human energies...”); K.R. LAKHANI \& R.G. WolF, "Why Hackers Do What They Do: Understanding Motivation and Effort in Free/Open Source Software Projects," in Perspectives on Free and Open Software, J. FelLer, B. FitzGerald, S. Hissam \& K. LAKHANI (EDS.) (Cambridge: MIT Press, 2005), at pp. 3, 12 (noting that "enjoyment-based intrinsic motivation, namely how creative a person feels when working on the project, is the strongest and most pervasive driver.”); D.H. PINK, Drive: The Surprising Truth about What Motivates Us, (New York: Riverhead Books, 2009), at 133 (concluding that "[w]e're learning that profit motive, potent though it is, can be insufficient impetus for both individuals and organizations. An equally powerful source of energy, one we've often neglected or dismissed as unrealistic, is what we might call the' purpose motive'.”); D.H. PINK, Drive, (New York: Riverhead Books, 2009), at p. 29 (“observing 
the latter cohort's argument - that intrinsic incentives or actions that might not make any economic sense (e.g. voluntarily improving a company's working conditions) could be just as effective as extrinsic incentives (e.g. increasing sanctions for poor work performance), let us look at more specific benefits of internalizing social norms. Daniel H. Pink, who has summarized many of the available research on motivation, lays out the essence of our upcoming discussion here:

"The problem is that most business haven't caught up to this new understanding of what motivates us. Too many organizations - not just companies, but governments and nonprofits as well - still operate from assumptions about human potential and individual performance that are outdated, unexamined, and rooted more in folklore than in science. They continue to pursue practices such as short-term incentive plans and pay-for-performance schemes in the face of mounting evidence that such measures usually don't work and often do harm." 1267

Furthermore, according to Ike Davis, the worldwide managing director of McKinsey \& Company, "[s]ocial pressures often indicate the existence of unmet social needs or consumer preferences. Businesses can gain advantage by spotting and supplying these before their competitors." Davis continues that "billions of dollars of shareholder value have been put at stake as the result of social issues that ultimately feed into fundamental drivers of corporate performance." 1268 This means that companies that pay close attention to social pressures can potentially benefit from it, and those that do not, will be left behind. ${ }^{1269}$ Take the B Corporation discussed back in Chapter 4 for example: According to B Corps' annual report, " $[\mathrm{t}]$ he signal generates instant branding, internal cohesion, consumer enthusiasm and links to a vibrant national B Corp network that brings in more than $\$ 4.5$ billion in revenues." 1270 Moreover, B Corps can "command higher valuations because they are more trusted by their customers, employees, suppliers and other stakeholder." 1271 In short, being mindful of intrinsic motivations, investing time in people, and paying attention to social cues - rather than just on extrinsic motivators, laws or legal developments - can bring about many benefits, even for the cost-conscious businesses.

that "external rewards and punishments - both carrots and sticks - can work nicely for algorithmic tasks... [b]ut they can be devastating for heuristic ones"); T.M. AmaBile, Creativity in Context, (Colorado: Westview Press, 1996); and, C.S. DwECK, Self-Theories: Their Role in Motivation, Personality, and Development, (Philadelphia: Psychology Press, 1999), at p. 19 (stating that "giving children a performance goal was effective for relatively straightforward problems but often inhibited children's ability to apply the concepts to new situations.").

1267 D.H. PINK, Drive, (New York: Riverhead Books, 2009), at p. 9.

1268 "The Biggest Contract," The Economist, (2005). Available at: http://www.economist.com/node/4008642 (last accessed 18 December 2016).

1269 "The Biggest Contract," The Economist, (2005). Available at: http://www.economist.com/node/4008642 (last accessed 18 December 2016) (noting that "[c]ompanies that treat social issues as either irritating distractions or simply unjustified vehicles for attack on business are turning a blind eye to impeding forces that have the potential fundamentally to alter their strategic future... [1]arge companies need to build social issues into strategy in a way which reflects their actual business importance."); see also, "Foxconn Overtime Cuts Announced, But More Needs To Be Done," Huffington Post, (21 August 2012). Available at: http://www.huffingtonpost.com/2012/08/21/ foxconn-overtime-cuts_n_1820378.html (last accessed 18 December 2016) (quoting Louis Woo who spoke about this shift in the following way: "I expect more loyalty to form as a result [of cutting down overtime], and then we can save more costs on recruitment and retainment. Yield rates will also improve. Efficiency in terms of productivity, yield again, retention and lower turnover rates should be able to improve...").

1270 J. RASKIN, "The Rise of Benefit Corporations," The Nation, (8 June 2011). Available at https://www.thenation.com/article/rise-benefit-corporations/ (last accessed 18 December 2016).

1271 B Corps Annual Report (2012), at p. 54. 
This is to state that social norms have a variety of utility that legal norms cannot always replicate. For example, consider the notion of contingent rewards (e.g. "if you do A, then you get B") in the context of the rule of law, which highly values the idea of legal certainty. While legal certainty is often lauded in legal literature, contingent regards or punishments can have negative effect on behavior, which lawmakers should bear in mind when relying on the law as the solution. To elaborate, the so-called "if-then" structure emphasized by the rule of law, (e.g. if you break the law, you get fined or if you employ good social practices, you get tax exemptions) can be construed as a forfeiture of the party's autonomy "and that can spring a hole in the bottom of their motivation, bucket..." 1272 This point of autonomy is related to the notion of costly signaling, which was described back in Chapter 5 , about how private actors want to signal to others about their good behaviors. When laws quash the opportunity for private actors to behave autonomously and their opportunity to signal their good deeds to others by making the action in question a requirement for all, something is lost: In short, "extrinsic prompts deprive the individual of that chance to exhibit her intrinsic motivations to others, which, in turn, undermines the value to the individual of having intrinsic motives." 1273 This is particularly problematic given that "there has been a gradual displacement of non-legal regulation by legal regulation." ${ }^{274}$ This is line with the aforementioned observation that the typical carrot-or-stick type of extrinsic rewards can have substantially negative effects, not just on intrinsic motivation, but more alarmingly in that it can actually incentivize unethical behavior. ${ }^{1275}$ For example, "the very presence of goals [the carrot] may lead employees to focus myopically on short-term gains and to lose sight of the potential devastating long-term effects on the organization."1276 Moreover, this crowding out effect is an observation confirmed not only by behavioral psychologists, but by evolutionary anthropologist as well: "In the case of an intrinsically rewarding activity, external rewards undermine this intrinsic motivation..."1277

Obviously, consumers are generally not tardy mothers picking up their kids from daycare or blood donors, but the point about how we as human beings perceive social norms in comparison to tougher regulations is a relatable and often replicated phenomenon. Moreover, it is worth bearing in mind that not every legal action has an undesirable crowding out effect: For example, rewards do not undermine people's intrinsic motivation for

1272 D.H. PINK, Drive, (New York: Riverhead Books, 2009), at p. 36

1273 E.H. ATIQ, "Why Motives Matter: Reframing the Crowding Out Effect of Legal Incentives," Yale Law Journal 123 (2014): 1070-1116, 1081; citing, B. FrEY, "Crowding Out and Crowding in of Intrinsic Preference," in Reflexive Governance for Global Public Goods, E. Brousseau, T. DEDEurwaERdere \& B. Siebenhüner (EDS.) (Cambridge: MIT Press, 2012): 75-84, 78.

1274 E.A. Posner, Law and Social Norms, (Cambridge: Harvard University Press, 2000), at p. 8 (adding that this was "in part because legislatures and courts sought to eliminate the pathologies produced by social norms, not because the social norms reflected values or interests that they do not share.”).

1275 E.L. DECI, R. KOESTNER \& R.M. RYAN, "A Meta-Analytic Review of Experiments Examining the Effects of Extrinsic Rewards on Intrinsic Motivation,” Psychology Bulletin 125(6) (1999): 627-668, 659; see also, D.H. PINK, Drive, (New York: Riverhead Books, 2009), at p. 48 (stating that "goals imposed by others - sales targets, quarterly returns, standardized test scores, and so on - can sometimes have dangerous side effects."); and, L.D. ORDONEZ, M.E. Schweitzer, A.D. Galinsky \& M.H. Braverman, "Goals Gone Wild: The Systematic Side Effects of Over-Prescribing Goal Setting,” Harvard Business School Working Paper No. 09-083 (2009).

1276 L.D. Ordonez, M.E. SChWEITZER, A.D. GALINSKY \& M.H. Braverman, "Goals Gone Wild: The Systematic Side Effects of Over-Prescribing Goal Setting,” Harvard Business School Working Paper No. 09-083 (2009).

1277 M. TOMASEllo, Why We Cooperate, (Cambridge: MIT Press, 2009), at p. 9 (observing that children that are rewarded to do something helped out less in repeated game situations in what is known as the "overjustification effect"). 
dull tasks because there is little or no intrinsic motivation to be undermined," 1278 but as Simon Deakin acknowledges "mandatory legal rules may not be well suited to some contexts" either. ${ }^{1279}$ So the point we come to is this: as it has been repeatedly stated throughout this thesis, laws and governments are absolutely necessary, ${ }^{1280}$ but not always, given that in some cases, they can be counterproductive and harmful. As the daycare example substantiated, at times, softer, social norms can be a more useful enforcement mechanism, even more so than stringent regulations or the imposition of legal or monetary sanctions. Given that there are increasing suggestions to legally enforcing voluntary codes of conduct, ${ }^{1281}$ taking a moment to consider the potential impact - or perhaps repercussions - of such a process must be carefully weighed and not taken lightly or at face value. Having made this point, the relevant question thus becomes, when are social norms preferred over more extrinsic types of regulation, but the answer to this question - to the extent that there is indeed one - will be tabled until the next subsection. However, before getting to this specific issue, this subsection must first address the important question of feasibility and desirability of relying on private norms to address a global problem such as the labor exploitation taking place in our supply chains.

\section{Private Global Norm Production: Its Feasibility and Desirability}

Having presented the benefits of non-legal social norms, the next relevant question is how do we create them or manage them? The short answer is that one cannot simply manufacture them on a whim: "What is important to understand is that social norms are unlikely to change as a result of simple, discrete, low-cost interventions by the government... attempts to intervene are risky, because social norms are complex, poorly understood, and sensitive to factors that are difficult to control." 1282 Both sociologists and anthropologists have, however, documented patterns that often lead to emergence of new social norms, some of which we will list here: For example, "the salience of a behavior... the frequency with which it is observed - matters," and "the actions that have greater effect on others may be more likely to be subject to disapproval than those that create only minimal externalities." 1283 The first observation points to the fact that in order for a social norm like the

1278 E.L. DECI \& R.M. RYAN, "Self-Determination Theory and Facilitation of Intrinsic Motivation, Social Development, and Well-Being," American Psychologist 55 (2000): 68-78, 68.

1279 S. DeAkin, J. MALmberg \& R. SARKAR, "Do Labour Laws Increase Equality at the Expense of Higher Unemployment? The Experience of Six OECD Countries, 1970-2010," University of Cambridge Faculty of Law Legal Studies Research Paper Studies No. 11 (2014), at p. 4; see also, S. DEAKIN, “Addressing labour market segmentation: the role of labour law," ILO Governance and Tripartism Department Working Paper No. 52 (Geneva: ILO, 2013).

1280 E.A. Posner, The Twilight of Human Rights Law, (Oxford: Oxford University Press, 2014), at p. 7 (observing that "[c]ertain small-scale interventions can do good by relieving the worst forms of misery and poverty in the short term, and, as long as they are continuously subjected to rigorous empirical testing and founded to be effective, they should be supported and continued.").

1281 See generally, A. BECKERS, Enforcing Corporate Social Responsibility Codes. On Global Self-Regulation and National Private Law, (Oxford: Hart Publishing, 2015). Jan Eijsbouts also refers to this process as "the crystallization of otherwise voluntary norms" and enforcing codes of conduct legally as a vital component of addressing the issue of labor exploitation in light of the international governance gaps that exists.

1282 E.A. Posner, Law and Social Norms, (Cambridge: Harvard University Press, 2000), at p. 8 (referring to the development of social norm as a matter of "historical accidents").

1283 C. Horne, "Sociological Perspectives on the Emergence of Social Norms," in Social Norms, M. HECTER \& K-D. OpP (EDS.) (New York: Russell Sage Foundation, 2001), at p. 7; see also, J.S. ColEMAN, "The Emergence of Norms," in Social Institutions: Their Emergence, Maintenance, and Effects, M. HECHTER, K-D OPP \& R. WIPPLER (EDS.) (New York: Aldine de Gruyter, 1990), at p. 43 (noting that "the genesis of a norm lies in externalities of actions 
golden rule to not only emerge, but to be sustainable depends on its salience amongst the community. ${ }^{1284}$ In other words, there must be a collective consciousness, an amalgamated mass of our egos, morals, values, and norms create a notion of collectivity as advocated by Emile Durkheim. ${ }^{1285}$ In other words, regardless of why people do what they do at first, "when many people engage in the same behavior, that behavior comes to be associated with a sense of 'oughtness'. Thus patterns of action emerge that then become normative." 1286 Taking these patterns into consideration, factors such as collective consciousness, conformity, herd behavior, and signaling discussed in back in Chapter 5 will all play key roles in the emergence of new norms.

Other factors that may impact the emergence of new norms are as follows: According to Christine Horne, new norms tend to "emerge when the costs of compliance with existing norms become too high relative to the rewards," or they emerge "in response to externalities produced by the behavior of others." ${ }^{2287}$ To the extent that social norms are collective manifestations of our individual morals and values, it is worth pointing out here that morals are established "in part through a complex process of socialization, learning, and inculcation," 1288 and to this extent, new social norms likely emerge when a society experiences some type of a change or an "exogenous shock" - such as technological advances, environmental changes, or emergence of different trading opportunities as brought about by globalization - that create new economic conditions. ${ }^{1289}$ Others speculate that empathy plays a role in the emergence of new social norms, coining terms such as "emotional stimulus" to describe the need for private actors to collectively grow "shared emotions," 1290 and how they can become "moral or norm entrepreneurs" to promote changes to the existing norm, but here again, this is not an exact science, ${ }^{1291}$ which once again brings back the

that cannot be overcome by simple transactions which would put control of the action in the hands of those experiencing the externalities.").

1284 E. DuRKHeIM, The Division of Labor in Society, S. LukES (ED.) (New York: Free Press, 2014).

1285 E. DuRKHEIM, The Division of Labor in Society, S. LuKES (ED.) (New York: Free Press, 2014), at p xxxi (noting that emergence of social norms to be a characteristic of a more "primitive" society, where the laws had to be more repressive); see also, D. GARLAND, "Durkheim's Theory of Punishment: A Critique," in The Power to Punish: Contemporary Penalty and Social Analysis, D. GARLAND \& P. Young (EDS.) (London: Heinemann, 1983): 37-61 (summarizing Durkheim's attempt to "understanding criminal punishment in a sociological vein," conceptualizing it as "a moral institution, shaped by collective values and social relationships, rather than a technical one shaped by the demands of crime control.").

1286 C. Horne, "Sociological Perspectives on the Emergence of Social Norms," in Social Norms, M. HECTER \& K-D. OpP (EDS.) (New York: Russell Sage Foundation, 2001), at p. 6.

1287 C. Horne, "Sociological Perspectives on the Emergence of Social Norms," in Social Norms, M. HECTER \& K-D. OpP (EDS.) (New York: Russell Sage Foundation, 2001), at pp. 8, 10 (adding that " $[\mathrm{t}] \mathrm{o}$ the extent that people are damaged by others, they will favor norms that discourage antisocial behaviors and to the extent that they benefit from others' behaviors, they will want norms that institutionalize those behaviors"); see generally, J.S. COLEMAN, Foundations of Social Theory, (Cambridge: Harvard University Press, 1990).

1288 S. SHAvell, "Law versus Morality as Regulators of Conduct," American Law and Economics Review 4(2) (2002): $227-$ $257,231$.

1289 R.C. Ellickson, "The Evolution of Social Norms: A Perspective from Legal Academy," in Social Norms, M. HeCTER \& K-D. Opp (EDS.) (New York: Russell Sage Foundation, 2001), at p. 49.

1290 R. COllins \& R. HANneman, "Modeling the Interaction Ritual Theory of Solidarity" in The Problem of Solidarity: Theories and Models, P. Doreian \& T. FARAO (EDS.), (New York: Routledge, 1998): 213-238; See also, C. HORNE, "Sociological Perspectives on the Emergence of Social Norms," in Social Norms, M. HECTER \& K-D. OPP (EDS.) (New York: Russell Sage Foundation, 2001), at p. 10; see generally, J.S. ColEMAN, Foundations of Social Theory, (Cambridge: Harvard University Press, 1990).

1291 B.M. LOwE, Emerging Moral Vocabularies: The Creation and Establishment of New Forms of Moral and Etbical Meanings, (New York: Lexington Books, 2006), at p. 25; see also, H.S. BECKER, Outsider: Studies in Sociology of Deviance, (New 
issue raised by the complexity problem that this alternative framework will eventually have to address.

In sum, a private actor cannot simply manufacture new social norms, but a group or a collective of private actors can bond together and act in unison that can lead to an emergence of a new private norm. ${ }^{1292}$ At least in theory, this suggests that a group of private actors working in concert can foster new private norms, whether through consumers adopting more caring and ethical consumption habits or corporations investing more in their workers. It must be noted again that legal norms are much easier to create and has a more normative element, whereas social norms are harder to manufacture and does not necessarily entail a normative element. ${ }^{1293}$ Second, from a sociological perspective, laws serve a very necessary symbolic purpose that create a chain reaction of compliance. ${ }^{1294}$ While social norms cannot be created like laws, the idea of "private global norm production" 1295 is worth mentioning in our context as yet another tool capable of changing the way we conceptualize the problem of dealing with labor exploitations in the global supply chain. In order to deal with a problem that has metastasized across the globe, we need norms that "transcend the boundaries of a territory" 1296 as the catalyst for change, and these transcendent norms likely will not come as a result of the traditional governmentmandated regulations, but more plausibly through the private global norm production. Private global norm production is a term coined by Gunther Teubner that recognizes the role of private actors in producing norms on a global scale and is a concept that has widely been recognized, most notably by Larry Cat Cata Backer. ${ }^{1297}$ This theory is in alignment with the stated objectives of this thesis, which cautions against overproduction of laws and various regulatory measures that could prove to have a diminished marginal utility. ${ }^{1298}$

York: Simon \& Schuster, 1963), at p. 147; R.C. ElLICKSON, “The Evolution of Social Norms: A Perspective from Legal Academy," in Social Norms, M. HeCTER \& K-D. OpP (EDS.) (New York: Russell Sage Foundation, 2001), at p. 36; see also; E.A. PoSNER, Law and Social Norms, (Cambridge: Harvard University Press, 2000), at p. 29 (noting governments can also be "norm entrepreneurs").

1292 J. BERGER, Invisible Influence: The Hidden Forces that Shape Behaviour, (London: Simon \& Schuster, 2010), at pp. 229, 231 (stating that "we are constantly shaped by the people around us," and as a result, "other people have a subtle and surprising impact on almost everything we do," including but not limited to whether we conform to a particular norm or not).

1293 M. Tomasello, Why We Cooperate, (Cambridge: MIT Press, 2009), at pp. 91-2 (noting that "social practices in which 'we' act together interdependently in interchangeable roles towards a joint goal generate, over time, mutual expectations leading to generalized, agent-neutral normative judgments."); see also, E. EHRLICH, Fundamental Principles of the Sociology of Law, (Cambridge: Harvard University Press, 1936) (noting the value of paying attention to how social networks can create living laws different from compulsory norms imposed by the state).

1294 C. Horne, "Sociological Perspectives on the Emergence of Social Norms," in Social Norms, M. HECTER \& K-D. Opp (EDS.) (New York: Russell Sage Foundation, 2001), at p. 19 (observing that "when meaning encourages one action and interests another, then enforcement is necessary to encourage people to act in appropriate symbolic ways, even if such behaviors are not in their personal interest.").

1295 G. TEubner, "Breaking Frames: The Global Interplay of Legal and Social Systems," American Journal of Comparative Law 45 (1997): 149-159, 157.

1296 See generally, L.C. BACKER, "Multinational Corporations as Objects and Sources of Transnational Regulation," ILS A Journal of International and Comparative Law 14 (2008): 499-523; and, L.C. BACKER, "Economic Globalization and the Rise of Efficient Systems of Global Private Lawmaking: Wal-Mart as Global Legislator," University of Connecticut Law Review 39(4) (2007): 1739-1784.

1297 J.M. SMITS, "Democracy and (European) Private Law: A Functional Approach," in Globalization and Private Law: The Way Forward, M. FAURE \& A. VAN DER WALT (EDS.) (Cheltenham: Edward Elgar, 2010): 15-31, 19.

1298 M.C. Nussbaum, Frontiers of Justice: Disability, Nationality, Species Membership [Tanner Lectures of Human Values], (Belknap Press of Harvard University Press, 2007), at p. 306 (noting that "[t]here is perhaps nothing more urgent, in a world increasingly driven by multinational corporations and the power motive that is built into their opera- 
The root of this norm production essentially lies in self-regulation as exemplified in previous chapters by practices such as voluntary codes of conduct and other CSR/ethical consumerism measures, where private actors go above and beyond what is required by the law on a voluntary basis. ${ }^{1299}$ While these norms "would not be recognized as binding in a traditional conception of law," as they "do not meet the formal requirement of being enacted by the relevant authorities," they are nevertheless "self-contained autonomous systems of global law" as they "set the norms for specific groups of people and are therefore important in predicting their behaviour." 1300 This is to suggest that states do not have a monopoly on establishing norms:

"II] is wrong to make the State uniquely responsible for deciding which law is to apply to its citizens. Instead, the citizens themselves should play an important role in deciding which law applies to (at least part of) their activities. This fits in with the view that the present vacuum in global regulation (the traditional suppliers of law fail to regulate things at the global level) should make the demand side more important. This demand side consists of the end-users of law, so private actors such as consumers and firms." 1301

The essence of this thesis is neatly captured in this paragraph above. While hard laws and top down regulatory styles of governance are - and forever will be - very much necessary and will continue to be an integral part of addressing collective action problems, ${ }^{1302}$ this fact alone does not justify their monopoly on norm production. ${ }^{1303}$ The demand side - or the private actors - also have the ability to shape the contours of the societal norms that they decide to adhere to, which in the end might be a higher norm as Sandel would conceptualize them. Leaving aside the actual process of how private norm can become social norms or global norms aside, the idea of private global norm production, a theory that norms can be produced by private actors is well-established and generally acknowledged

tions, than to articulate a set of humanly rich goals for development, and a set of more general attitudes about the purposes of cooperation that will be needed to sustain people in the pursuit of these goals.").

1299 See e.g. J.M SMITS, "Private Law 2.0: On the Role of Private Actors in a Post-National Society," Inaugural lecture delivered on 30 November 2010 as Maastricht-HiiL Chair on Internationalisation of Law (The Hague; Eleven, 2011). Available at: http://www.hiil.org/data/sitemanagement/media/Publication_Smits_250211(1).pdf (last accessed 4 April 2017), at p. 8 .

1300 Ibid., at p. 9; see also, G. DE BurCA, "Developing Democracy Beyond the State," Columbia Journal of Transnational Law 46(2) (2009): 102-158; see also, L.C. BACKER, "Economic Globalization and the Rise of Efficient Systems of Global Private Lawmaking: Wal-Mart as Global Legislator," University of Connecticut Law Review 39(4) (2007): 17391784 (noting that large corporations can easily create their own system of rules that they can impose on others).

1301 See e.g. J.M SMITS, "Private Law 2.0: On the Role of Private Actors in a Post-National Society," Inaugural lecture delivered on 30 November 2010 as Maastricht-HiiL Chair on Internationalisation of Law (The Hague; Eleven, 2011). Available at: http://www.hiil.org/data/sitemanagement/media/Publication_Smits_250211(1).pdf (last accessed 4 April 2017), at p. 17 (noting that citizens today not only have more freedom of movement and the autonomy to choose the laws that are applicable to them, but also have the ability to shape the contours of the rules and laws that they will choose).

1302 R.H. Thaler \& C.R. Sunstein, Nudge: Improving Decisions About Health, Wealth, and Happiness, (New York: Penguin, 2009), at p. 13 (holding that the "government is often required to act, for it is only means by which the necessary resources can be mustered, organized, and deployed.").

1303 See e.g. R.M. LOCKE, The Promise and Limits of Private Power: Promoting Labor Standards in a Global Economy, (Cambridge: Cambridge University Press, 2013), at p. 177 (noting, as mentioned previously, that "government regulation is required because only the state has the authority and legitimacy to enforce labor legislation and promote/protect citizenship rights."). 
within academia. ${ }^{1304}$ The application of this term, however, has generally been attributed to non-State actors such as the European Union or large multinational corporations with enough resources to influence the behaviors of the markets. This thesis will suggest that in addition to these non-State actors, a collection of galvanized private actors (i.e. micropowers noted back in Chapter 5) is equally capable of producing private global norms if they were to act more in concert.

The main weakness of adopting a more holistic approach that, amongst other factors, puts social norms on par with legal norms depending on the circumstances, is that social norms cannot be simply manufactured, not to mention the uncertainty of it all: For example, many scholars are "pessimistic regarding the ability of social scientists to produce general theories of norm emergence," 1305 which is in alignment with the fact that for every example proving the existence of some norm, there are antithetical examples that prove otherwise, which suggests that social norms are just as susceptible to our human flaws, including but not limited the fact that we are irrational beings, with bounded rationality. This only substantiates one of the key lessons that we raised earlier in this chapter, which was that in constructing our alternative framework, we should refrain from dealing in absolutes, meaning that relying more on social norms is not always the right answer to resolve our problem. ${ }^{1306}$ Moreover, the most common ground for criticism about emphasizing social norms over legal norms is the causal relationship between a norm and a norminduced behavior. Similar to the causation problem of various existing private initiatives, the existence of a social norm in and of itself, does not guarantee the desired behavior or outcome. Although Posner's earlier observation revealed that there are instances when compliance to social norms can be similar to, if not more binding than legal norms, the solution to our problem cannot be as simple as hoping that a new social norm emerges that brings about the specifically desired norm-induced behavior.

Yet another common criticism to relying on non-legal norms to remedy complex collective action problems is that norms differ between borders (and sometimes even within borders), perhaps more so than legal norms. Therefore, speaking of social norms in the global context may be seen as a fool's errand. This criticism is especially valid in instances where norms are transplanted from a more developed country to a less developed country that lacks the prerequisite societal structure. This could raise significant problems similar to the one raised by the territoriality problem noted back in Chapter 3 given that most of the manufacturing and the human rights violations are more common in the less-developed parts of the world, while the consumers tend to be from more developed cultures. Furthermore, amongst the "new norm scholars," the consensus seems to be that a "closely

1304 See e.g. J.M. SMITS, "Democracy and (European) Private Law: A Functional Approach," in Globalization and Private Law: The Way Forward, M. FAURE \& A. VAN DER WALT (EDS.) (Cheltenham: Edward Elgar, 2010), at p. 17 (stating that "[o]ver the last decades, an increasing number of rules and policies were developed beyond the nationstate.”); see also, R. MiChaELS \& N. JANSEN, "Private Law and the State," Rabels Zeitschrift 71 (2007): 345-97.

1305 See e.g. C. HornE, "Sociological Perspectives on the Emergence of Social Norms," in Social Norms, M. HECTER \& K-D. Opp (EDS.) (New York: Russell Sage Foundation, 2001), at p. 12 (noting that "because much work of this type lacks empirically testable propositions, this question does not lend itself to an easy answer. Research is often descriptive, explaining particular norms at specified times and places.").

1306 See e.g. T.C. SCHELliNG, Micromotives and Macrobehavior, (New York: Norton, 1978). 
knit group may generate a norm that injures outsiders more than it helps insiders." 1307 This concern suggests that solutions must be localized, which is where the idea of reflexive governance and adaptive management can come into play, but before starting the discussion of this topic, let us conclude this subsection first.

In closing this subsection, let us reiterate that the proposed alternative framework is not advocating that social norms simply replace legal norms for behavior modification in all circumstances. The recommendation is merely to remind the private sector about the importance and the potential of non-legal norms and to keep these options in mind when considering how instances of labor exploitation in the global supply chain can be dealt with differently moving forward. In short, there will be times when legal sanctions are required and times where reliance on social norms can lead to a better outcome. The question that emerges with this realization is how private actors can determine what is the appropriate course of action at any given time, which brings us to the next proposal within our framework of adopting the reflexive governance and adaptive management model.

\subsubsection{Adopting Reflexive Governance and Adaptive Management}

The previous subsection presented first of the two proposals that make up our alternative framework, which called for private actors to adopt a more holistic approach that not only relies on laws and legalized CSR initiatives to address problems, but also to incorporate non-legal norms to combat instances of labor exploitation in the global supply chain. The previous subsection also called to attention some of the difficulties with using social or private norms to address collective action problems, including but not limited to the question of how private actors can determine under which circumstances laws or extrinsic incentives would be appropriate and when a softer, more intrinsic incentive based approach would be better. In an attempt to answer this question, this subsection will now propose that the private actors adopt a reflexive governance and adaptive management strategies, ${ }^{1308}$ rather than continuing to rely on the traditional top-down regulatory approach that some have argued to be archaic, if not inadequate. ${ }^{1309}$

The arguments that this subsection will make is that through reflexive governance and adaptive management, stakeholders from both the private and the public sectors will be better enabled to determining the appropriate course of action (or which type of norm) that the situation calls for through institutional dialogue and collaboration among various stakeholders. Before addressing reflexive governance and adaptive management, what they actually are, and discussing their potential, we must first bridge the gap between the traditional regulatory framework (as illustrated in the previous chapters) and reflexive governance and adaptive management strategies.

1307 R.C. Ellickson, “The Evolution of Social Norms: A Perspective from Legal Academy,” in Social Norms, M. HECTER \& K-D. Opp (EDS.) (New York: Russell Sage Foundation, 2001), at p. 55.

1308 R. Rogowski, Reflexive Labour Law in the World Society, (Cheltenham: Edward Elgar, 2013), at p. vi (addressing the need for a "reform of labour law that pays particular attention to the global context... by making it reflexive.").

1309 D. AshiAgBOR, "Evaluating the Reflexive Turn in Labour Law," in The Autonomy of Labour Law, A. BOGG, C. Costello, A.C.L. DAvies \& J. PRAssl (EDS.) (Berlin: Walter de Gruyter, 2015) (noting the rising level of "concern about the effectiveness of the traditional regulatory techniques," particularly in the context of "labour regulation and administrative regulation in the context of changes in the institutional landscape, and changes to regulatory objectives in the areas of industrial relations and social policy."). 
The preeminent scholar on reflexivity and the law, Gunther Teubner, once opined that reflexivity is a response to the realization about the "limits of the law's effectiveness in the management of complexity." 1310 On this point of complexity, Posner's rhetoric captures the relevant concern:

"[Can] the government selectively intervene among the continuing non-legal forms or order, choosing to transform those that were undesirable while maintaining those that were good? Could it tinker with the incentives along the edges, using taxes, subsidies, and sanctions to eliminate, say the feuds and the acts of discrimination, without interfering with neighborly kindliness and trust? Or would the sheer complexity of social organization overwhelm such efforts?" 1311

Posner highlights that the globalized world that we live in consists of a conflagration of not just various tiers of law - from local, national, supranational, and international - but there is a separate and autonomous set of norms, cultures, practices that complement, or at times even challenge the multitudes of law. This complex reality, as described back in Chapter 5, casts serious doubts on the competences, not just of legislatures and courts, but of businesses and consumers alike. More alarmingly, Posner claims that these important questions are "largely ignored by mainstream legal scholars writing about how law affects behavior, and even more so by scholars writing about the appropriate direction for legal reform," 1312 a point alluded to throughout this thesis. This thesis attempted to deviate from this norm by first assessing how laws actually affect behaviors. We will now take the next step to challenge the popular top-down, hierarchical governance model in this subsection and in the process, advocate for our proposed alternative framework. In the end, reflexive governance and adaptive management will hopefully create a system that "deliberately seek[s] to create or preserve spaces for productive interaction among multiple, overlapping legal [and non-legal] systems by developing procedural mechanisms, institutions, and practices that aim to manage, without eliminating, the legal pluralism we see around us."1313

To elaborate on what exactly reflexive governance and adaptive management strategies are, this subsection will: a) define and elaborate on these two concepts; b) discuss some of the benefits of adopting these models; and finally, c) assess their feasibility and desirability in terms of how they can help private actors better address the problem of labor exploitation in the global supply chain.

\section{A. What are Reflexive Governance and Adaptive Management Strategies?}

While there are some discussions as to the precise definition of reflexive governance, ${ }^{1314}$ for the purposes of this thesis, it will be defined simply as a more collaborative process

1310 G. TeubNER, "Substantive and Reflexive Elements in Modern Law," Law and Society Review 17(2) (1983): 239-285, 242.

1311 E.A. Posner, Law and Social Norms, (Cambridge: Harvard University Press, 2000), at p. 3.

1312 E.A. Posner, Law and Social Norms, (Cambridge: Harvard University Press, 2000), at p. 3 (criticizing legal scholarship for "focusing too much on the state, for simplifying the relationship between citizens and the government, and for analyzing simple problems to the exclusion of important and interesting ones.”).

1313 P. SCHIFF Berman, Global Legal Pluralism: A Jurisprudence of Law Beyond Borders, (New York: Cambridge University Press, 2012), at p. 10 .

1314 D. Ashiagbor, "Evaluating the Reflexive Turn in Labour Law," in The Autonomy of Labour Law, A. BoGG, C. Costello, A.C.L. Davies \& J. Prassl (EDS.), (Berlin: Walter de Gruyter, 2015) (stating that the "difference between reflexive regulation and deregulation or non-regulation... as in the case of corporate codes of conduct and other instances of private lawmaking, in what ways can we distinguish reflexive regulation from the mere 
between public and private actors including but not limited to governments, businesses, consumers, and everyone in between. ${ }^{1315}$ In other words, it is a more inclusive way of collectively dealing with and solving our societal problems. Furthermore, it is a system of governance where the public sector is more concerned with the procedural aspects of governance rather than the substantive: Reflexive governance is a "less substantive, less detailed, more procedural and more generally controllable regulatory form... with a view to governing complexity and diversity in an elastic and dynamic manner." 1316 This assertion is closely related to Posner's earlier suggestion about governments establishing mere traffic rules," where the governments still play a key role in setting the minimum substantive standards for how private actors ought to conduct themselves, but above and beyond that governments' role is to invite, accommodate, and facilitate other stakeholders with their specialized knowledge to partake in the decision-making process more directly. In short, this is to suggest that governments serve a more facilitative role rather than authoritarian one. ${ }^{1317}$ Thus, under a reflexive governance model, the public sector's primary focus is not about producing optimized results, but about creating optimized conditions for autonomous individuals to present and share their phronesis, which is a strategy that is more in conformity with our adapted capabilities approach that values autonomy over say, economic efficiency. ${ }^{1318}$ In addition, Teubner suggests that the potential for reflexive governance lies in its indirect governance: For example, "indirect legal regulation... is more likely to lead to flexible solutions, given that there is a continued need for regulation. Thus, one has to abandon the idea of effective external control by law, and move towards more indirect

exercise of corporate or institutional power, unless there is countervailing power granted to the other party in the bargaining arrangement, to ensure outcomes of deliberation are not merely market outcomes but reflect general political objectives and norms of social justice."); see also, P. NONET \& P. SELZNICK, Law and Society in Transition: Toward Responsive Law, (New York: Harper, 1978) (opting to use "response" rather than "reflexive" or "adaptive" to "suggest a capacity for responsible, and hence discriminate and selective, adaption.").

1315 J. BLACK, "Decentering Regulation: Understanding the Role of Regulation and Self-Regulation in a PostRegulatory' World," Current Legal Problems 54 (2001): 103-147 (advocating for the "de-apexing of the state" and a move from "hierarchical relationship of state-society to a heterarchical one," where the state plays a role of "mediator, facilitator, enabler" and being a "diplomat" rather than a "bureaucrat".).

1316 L. ZAPPALA, "Transnational Soft Regulation of Temporary Agency Work and Adaptability Policies: Future of Guidelines with No Rights," in Transnational Labour Regulation: A Case Study of Temporary Agency Work, K. AHLBERG, B. Bercusson, N. Bruun, H. Kountouros, C. Vigneau \& L. Zappala (EDS.), (Brussels: P.I.E. Peter Lang, 2008), at p. 175; citing, T. Wilthagen \& F. Tros, "Dealing with the 'Flexibility-Security-Nexus': Institutions, Strategies, Opportunities and Barriers," Amsterdam Institute for Advanced labour Studies Working Paper No. 9 (2003), at p. 17.

1317 K. KOLBEN, "Transnational Labor Regulation and the Limits of Governance," Theoretical Inquiries in Law, 12(2) (2011): 402-437; R. Rogowski, Reflexive Labour Law in the World Society, (Cheltenham: Edward Elgar, 2013), at p. 253-4; see also, L. ZAPPALA, "Transnational Soft Regulation of Temporary Agency Work and Adaptability Policies: Future of Guidelines with No Rights," in Transnational Labour Regulation: A Case Study of Temporary Agency Work, K. Ahlberg, B. Bercusson, N. Bruun, H. Kountouros, C. Vigneau \& L. Zappala (Eds.), (Brussels: P.I.E. Peter Lang, 2008), at p. 176 (stating that “[t] he 'proceduralisation' formula should be understood as an attempt to bring substantive juridical rules, which cannot be renounced, together with mechanisms of procedural crossreferencing and autoregulation by various other possible actors which would be able to adapt substantive rules to functional differentiation of complex societies"); citing, G. TEUBNER, "Juridification - Concepts, Aspects, Limits, Solutions," in Juridification of Social Spheres: A Comparative Analysis in the Areas of Labor, Corporate, Antitrust and Social Welfare Law, G. TEuBNER (ED.), (Oxford: Hart, 1987).

1318 B. BERCUSSON, "Juridification and Disorder," in Juridification of Social Spheres: A Comparative Analysis in the Areas of Labor, Corporate, Antitrust and Social Welfare Law, G. TEubNER (ED.), (Berlin: Walter de Gruyter, 1987), at p. 57 (noting that allowing a framework or a procedure where individuals will be able to manifest results will, indirectly but unquestionably, have a real impact on the substance of the outcome). 
means of regulatory intervention." 1319 This is to suggestion that there is an overlap between reflexive governance model and self-regulation. ${ }^{1320}$ What these models have in common is that it could potentially outperform more traditional or conservative methods and instrument of problem-solving and decision-making that hold law as the primary instrument to incentivize and control behaviors of people. ${ }^{1321}$

As suspicious as some may be about a governance model that resembles self-regulation in various ways, it is crucial for these skeptics to realize that the problem of labor exploitation and its expansion happened under the watch of a top-down regulatory governance model. ${ }^{1322}$ Considering that reflexive governance originated as a reaction to the various failures of statutory and regulatory interventions and other manifestations of top-down governance models, ${ }^{1323}$ the potential benefits that could come as a result of trying a different approach that is less intrusive and potentially less harmful cannot be ignored. This idea of triggering the self-regulatory process can play out in the following example from the real world: While it is possible - at least in theory - for governments to enact laws that protect all workers (and independent contractors) by equipping them with the right to collectively bargain and strictly enforce its compliance, reflexive governance model would advocate for workers not to wait until the law tells them what they are entitled to, but to proceed on their own (perhaps in a way similar to what Uber is doing with its expansion). There is evidence to suggest that this proposal is not a theoretical construct, as the application of it have already begun sprouting in reality even in unexpected places like Wal-Mart, a company with a notorious reputation for how it mistreats its workers: "Historically, workers have waited for the government or their employer to say you have a right to build an organization," but union members are now claiming that there is a strategic shift and even companies like Wal-Mart have started to acknowledge that workers, union members, and other private actors are "going to build an organization because [they] need it," and not because the law says that they can or should. ${ }^{1324}$ Some may suggest that this is simply market forces

1319 D. Ashiagbor, "Evaluating the Reflexive Turn in Labour Law," in The Autonomy of Labour Law, A. BoGG, C. Costello, A.C.L. Davies \& J. Prassl (EDS.), (Berlin: Walter de Gruyter, 2015), at p. 128 (adding that "[t]he role of regulatory law must be seen instead as merely triggering the self-regulatory process within the economy - the regulation of schemes of self-regulation and the structuring of negotiating systems...”).

1320 M.W. SCHELTEMA, "Assessing Effectiveness of International Private Regulation in the CSR Arena," Richmond Journal of Global Law \& Business 13(2) (2014): 264-375, 265; citing, A. OvERMARS, Effecten van Gedragscodes: Twee Recente Cases, in Bestuurswetenschappen (2011), at pp. 14, 16 (defining self-regulation as "set of private norms that have been established, sometimes in collaboration with others, by those who are bound by these rules: their representatives or an overarching body and these norms being enforced.").

1321 E. A. POSNER \& A. O. SYKES, "An Economic Analysis of State and Individual Responsibility under International Law," J.M. Olin Law \& Economics Working Paper No. 279 (2006), at p. 1 (noting that it is the law that provides "third parties with incentives to control the behavior of wrongdoers whom they can monitor and influence.").

1322 R. RogowsKi, Reflexive Labour Law in the World Society, (Cheltenham: Edward Elgar, 2013), at p. 252.

1323 D. Ashiagbor, "Evaluating the Reflexive Turn in Labour Law," in The Autonomy of Labour Law, A. BoGG, C. Costello, A.C.L. Davies \& J. Prassl (EDS.), (Berlin: Walter de Gruyter, 2015) (claiming that these failures have, in part, contributed to the "weakening of our institutions of social citizenship," "the decline of the welfare state," and "the demise in the social power of trade unions").

1324 S. KNAFO \& K. BHASIN, "Walmart Activism is Effecting Change at World' Largest Retailer, Organizers Say," The Huffington Post, (7 June 2013). Available at: www.huffingtonpost.com/2013/06/06/walmart-activism-changeorganizers_n_3399169.html?view=screen (last accessed 20 February 2015) (quoting Dan Schlademan, a campaign director of United Food and Commercial Workers, which is one of the biggest union backers of the OUR Walmart campaign. The goal of the OUR Walmart campaign is to inform workers of their rights, to fight for a decent living wage, and to seek better treatment of the workers.). 
at work or an example of a tried and tested method of laissez-faire at work, ${ }^{1325}$ but this would not have been possible without the government providing the minimum standards to begin with (i.e. the right for workers to collectively bargain). The idea is that over time, the continuation of this reflexive governance model - the open method of coordination between lawmakers and other stakeholders - can move our conception of what the minimum standards will be, which suggests that the influence of private actors is not just "confined to 'soft law' measures, but [can] extended to the re-design of 'hard law' mechanisms." 1326

While reflexive governance generally refers to the government's interaction with the private sector, private actors can take a similar approach to management and their decisionmaking process, by adopting the adaptive management strategies. Adaptive management is a management style that is most commonly used in resource and ecosystem management that acknowledges the complexity of the various challenges that societies face today. ${ }^{1327}$ Given that there is so much uncertainty in our sub-utopian world, adaptive management does not deal in absolutes, but relies on a learning-based, adaptive decision-making process that is constantly evolving. This is crucial considering the reality that private actors only have a partial understanding of the global supply chain. While this idea is relatively straightforward, it is infrequently implemented in reality because organizations are generally reluctant to acknowledging uncertainty or the fact that they cannot predict the impact of their actions with substantial certainty. ${ }^{1328}$ Not only is this a collective manifestation of the various biases and heuristics noted back in Chapter 5, but more importantly, these shortcomings prevent organization from becoming adaptive, learning organizations. ${ }^{1329}$

Adaptive management, like reflexive governance, is a more inclusive and open approach relative to the traditional, top-down management frameworks noted back in Chapter 4. This means that implementing this framework is "not feasible unless the management institutions are willing to embrace uncertainty," which at the very least "means accepting that different viewpoints exist and involving stakeholders with different perspectives in identifying and addressing uncertainties." 1330 So in order for both reflexive governance and adaptive management to be successful, stakeholder involvement is critical, which is in alignment with our adapted capabilities approach that seeks to involve the workers into the

1325 R.H. THALER, Misbehaving: The Making of Behavioral Economics, (New York: Norton, 2015), at p. 87 (noting that while Adam Smith's The Wealth of Nations is credited for coining the term "invisible hand," the term in the book "appears only once" and that Smith did not believe the invisible hand to be a panacea nor the best approach).

1326 S. DEAKIN \& R. Rogowski, "Reflexive Labour Law, Capabilities and the Future of Social Europe," University of Warwick School of Law Legal Studies Research Paper No. 4 (2011), at p. 2.

1327 B.K. Williams \& E.D. Brown, Adaptive Management: The U.S. Department of the Interior Applications Guide, (Washington, D.C.: U.S. Department of the Interior, 2012), at p. v.

1328 B.K. Williams \& E.D. Brown, Adaptive Management: The U.S. Department of the Interior Applications Guide, (Washington, D.C.: U.S. Department of the Interior, 2012), at p. v (adding that institutions often suffer from risk aversion, myopic management, and an assortment of other impediments noted in the previous chapters of this thesis).

1329 B.K. Williams \& E.D. Brown, Adaptive Management: The U.S. Department of the Interior Applications Guide, (Washington, D.C.: U.S. Department of the Interior, 2012), at p. v (noting that "organizations must make a transition from a more traditional 'top down' organization structure to one that is more inclusive, collaborative, risk tolerant, and flexible."); see also, L.H. GundERSON, "Stepping Back: Assessing for Understanding in Complex Regional Systems," in Bioregional Assessments: Science at the Crossroads of Management and Policy, K.N. JOHNSON, F. SwANSON, M. Herring \& S. GreENE (EDS.) (Washington, D.C.: Island Press, 1999).

1330 B.K. Williams \& E.D. Brown, Adaptive Management: The U.S. Department of the Interior Applications Guide, (Washington, D.C.: U.S. Department of the Interior, 2012), at p. 30. 
organization's decision-making process. ${ }^{1331}$ Yet another way our alternative framework is in sync with our normative criteria is because it fosters an atmosphere of learning: Entities that adopt reflexive governance or adaptive management strategies are by their very nature learning organizations that acknowledge the various uncertainties that exist in our world and see them as opportunities for experimentation and growth. In order to address or cope with this uncertainty, learning organizations believe in the importance of people working in cross-disciplinary teams and reward learning and experimenting. ${ }^{1332}$ In short, adaptive management framework is the perfect approach for private actors to use in order to address the problem of labor exploitations in the global supply chain moving forward. This is because reflexive governance and adaptive management strategies are systems designed to "flourish [ in an environment in which surprise is anticipated, learning is promoted, and participatory decision making is the norm." 1333

New age thinkers and lauded speakers often present constructs that are essentially a version of reflexive governance and adaptive management, without labeling them as such: For example, non-academics or lawyers call it a "new power dynamic," where "the deployment of mass participation and peer coordination create changes and shift outcomes."1334 The use of catchy phrases such as "peer-driven" or "open and shared powers" describe this movement, but in reality, the ideas being promoted, is essentially that of reflexive governance and adaptive management. Essentially, it is a partial-rejection of what is perceived as the "old" or "traditional" framework that is top-down, where the power is held only by a few. ${ }^{1335}$ As stated earlier, as far back as 2002, Naomi Klein predicted the rise of the micropowers and their influence, predicting that they will "build a resistance both high-tech and grassroots, both focused and fragmented that is as global, and as capable of coordinated action, as the multinational corporations it seeks to subvert." 1336 This epitomizes the reflexive governance/adaptive management approach. It is inclusive, consisting of multitudes of people with diverse specializations, all striving to make a difference.

To conclude this definitional part of the subsection, reflexive governance and adaptive management entails the idea of learning by doing with a multidisciplinary team that can adapt to continuously morphing nature of the complex global supply chain. ${ }^{1337}$ By repeat-

1331 B.K. Williams \& E.D. Brown, Adaptive Management: The U.S. Department of the Interior Applications Guide, (Washington, D.C.: U.S. Department of the Interior, 2012), at p. 31 (emphasizing that adaptive management is "an open process of decision-making in which stakeholders are directly engaged and decision-making authority is shared among them. On requirement is that objectives and other elements of the decision process are stated explicitly and that they remain open to analysis and debate.").

1332 See generally, P.M. SEngE, The Fifth Discipline: The Art and Practice of the Learning Organization, (New York: Currency Double Day, 1990).

1333 B.K. Williams \& E.D. Brown, Adaptive Management: The U.S. Department of the Interior Applications Guide, (Washington, D.C.: U.S. Department of the Interior, 2012), at p. 29.

1334 J. HeIMANS, "What New Power Looks Like," TED Talk, (31 October 2014). Available at: https://www.ted.com/speakers/jeremy_heimans (last accessed 3 March 2015).

1335 Ibid.

1336 N. KLEIN, No Logo, (New York: Picador, 2002), at pp. 445-6.

1337 See generally, J.P. VOß \& B. BORnEMAnN, "The Politics of Reflexive Governance: Challenges for Designing Adaptive Management and Transition Management," Ecology and Society 16(2) (2011). Available at: http://www.ecologyandsociety.org/vol16/iss2/art9/main.html (last accessed 18 December 2016); S. KATO \& J. AHERN, "Learning by Doing: Adaptive Planning as a Strategy to Address Uncertainty in Planning," Journal of Environmental Planning and Management 51(4) (2008): 543-559; F. BERKES, J. COLDING \& C. FOLKE, "Introduction," in Navigating Social-Ecological Systems: Building Resilience for Complexity and Change, F. BERKES, J. COLDING \& C. FOLKE (EDs.) (Cambridge: Cambridge University Press, 2003): 1-29 (stressing that adaptive management is a continuous 
ing the process of planning, implementing, and evaluating various ideas at any given level of the supply chain, private actors relying on reflexive governance or adaptive management framework will - at least in theory - be more adaptive to any given situation relative to the more bureaucratic, top-down style of traditional governance and management. It must be clarified at the onset, however, that advocating for reflexive governance and adaptive management models does not mean that there is no longer any room for traditional regulatory frameworks. To the contrary, there will be situations when a more top-down form of governance or management will indeed be more appropriate, just like there are times when extrinsic incentives and laws work better than intrinsic incentives. The simple suggestion that this proposal offers here is that the starting point, or the default style of governance and management, be more reflexive and adaptive. When the application of these models reveals that a solution to a particular situation requires a more top-down or regulatory approach, then and only then should the stakeholders implement such measures, unlike the status quo now where the default it more top-down and extrinsic. Having provided preliminary definitions for the relevant concepts, the following parts of this subsection will now highlight the various advantages and benefits of adopting these models in the next part of the subsection.

\section{B. Benefits of Reflexive Governance and Adaptive Management}

This part of the subsection will touch upon four distinct benefits of reflexive governance and adaptive management: 1) they relieve the burdens placed on the governments; 2) they preserve personal autonomy and the right of self-determination; 3) they add to cognitive diversity through enhanced private sector involvement; and 4) they strengthen the checks balances amongst the stakeholders.

The first possible benefit of adopting reflexive governance and adaptive management strategies as advocated by our alternative framework is that by relying on the law more strategically, this framework can relieve the burdens placed on governments. This thesis previously noted the steep decline in the trust that people have in their governments back in Chapter 2. ${ }^{1338}$ The concern here is that if this trend continues, it will be very difficult for private actors to restore their trust and confidence in their governments. ${ }^{1339}$ In the traditional framework, governments are the go-to institutions that address and resolve our collective action problems. What the previous chapters depicted, however, is that there are limitations to this traditional approach in light of the various problems, including but not limited to the competence problem, the enforcement problem, the territoriality problem, and the complexity problem. While there are various discussions and proposals to how

process of learning and adapting, which by integrating knowledge from assortment of fields - whether they be scientific or professional, or localized or international - makes it more feasible to address the inherent complexity of systems).

1338 M. NAím, The End of Power: From Boardrooms to Battlefields and Churches to States, Why Being in Charge Isn't What It Used to Be, (New York: Basic Books, 2013), at p. 68 (citing to survey data collected by the Pew Global Attitude Project and Pippa Norris); see, Pew Research Center, "Public Trust in Government: 1958-2014," (13 November 2014). Available at: http://www.people-press.org/2014/11/13/public-trust-in-government/ (last accessed 15 May 2015); see also, P. NORRIS (ED.), Critical Citizens: Global Support for Democratic Government, (Oxford: Oxford University Press, 1999) (observing that "dissatisfaction with the political system and the core institutions of government is a growing and global phenomenon.”).

1339 T. JuDT, Ill Fares the Land, (New York: Penguin, 2010), at p. 67 (noting that "the absence of trust is clearly inimical to a well-run society... [and] once corroded, it is virtually impossible to restore.”). 
governments can attempt to deal with all of these limitations, ${ }^{1340}$ this thesis proposes a different approach by shifting the focus away from the public sector into the hands of private actors. What this thesis has been advocating for throughout the previous chapters is for the private sector to do more on their own, rather than to wait around for governments to make grand, systematic changes. With a more engaged private sector, governments can be more efficient by being selective and strategic about where and how they allocate their limited resources.

To provide an example of this proposal at work, let us go back to the Rana Plaza building collapse that took the lives of 1134 workers, which was mentioned back in Chapter 5 . While this tragedy created a huge public outcry at the time and many called for safer working conditions and better treatment of laborers in Bangladesh, legislative action to bring about such measure has stalled due to series of political and economic constraints. ${ }^{1341}$ Although legislative progress and reform have been slow and sclerotic, one of the more promising developments in the aftermath was the establishment of the Rana Plaza Arrangement, which created a coordinating group that focused on dealing with pragmatic issues like helping the families of the victims with their finances. ${ }^{1342}$ The beauty of the Rana Plaza Arrangement was the fact that this effort was coordinated by the Rana Plaza Coordination Committee, which was a multi-stakeholder group, consisting of government representatives, trade unions, retailers, and the ILO to list a few of the stakeholders, who were tasked with developing and overseeing the implementation of the Arrangement. ${ }^{1343}$ The Rana Plaza Coordination Committee ("RACC") is a great example of a government applying a more reflexive governance model, where the Bangladeshi government sat together with other key stakeholders to come up with ways to practically resolve issues of exploited laborers. The role of the government in this case was not to serve as the leader of the group, but merely as one of the stakeholders, and by relying on this format, the RPCC has been able to raise $\$ 20$-30 million thus far for the Rana Plaza Victim's Compensation Fund to compensate the victims of the tragic building collapse. ${ }^{1344}$

1340 M. NAím, The End of Power: From Boardrooms to Battlefields and Churches to States, Why Being in Charge Isn't What It Used to $B e$, (New York: Basic Books, 2013), at p. 239 (suggesting that we must make "profound changes in the way political parties [are] organized" and implement series of measures to "screen, monitor, hold accountable, and promote - or demote - their leaders.").

1341 A. Westervelt, “Two Years After Rana Plaza, Have Conditions Improved in Bangladesh's Factories?," The Guardian, (24 April 2015). Available at: http://www.theguardian.com/sustainable-business/2015/apr/24/ bangladesh-factories-building-collapse-garment-dhaka-rana-plaza-brands-hm-gap-workers-construction (last accessed 15 May 2015) (noting that "[t] he Rana Plaza reforms have not touched 40\% of the country's factories" and issues of worker's rights are still grossly lacking).

1342 Rana Plaza CoOrdination COMmitTee, "RPCC announce that sufficient funds now available to complete payments under the Rana Plaza arrangement," (8 June 2015). Available at: http://www.ranaplazaarrangement.org/ (last accessed 5 July 2015) (describing their work as "a coordinated, systematic approach to ensure victims, their families and dependents suffering from ill-health and financial hardship resulting from the death of a family member or life changing injuries.").

1343 RANA PLAZA COORDinATION COMMiTTEE, "RPCC announce that sufficient funds now available to complete payments under the Rana Plaza arrangement," (8 June 2015). Available at: http://www.ranaplazaarrangement.org/ (last accessed 5 July 2015) (consisting of various representatives from "the Bangladeshi government, the Bangladeshi industry, global brands and retailers, Bangladeshi and international trade unions and Bangladeshi and international Non-Governmental Organizations" along with "ILO acting as a neutral chair.").

1344 A. Westervelt, "Two Years After Rana Plaza, Have Conditions Improved in Bangladesh's Factories?," The Guardian, (24 April 2015). Available at: http://www.theguardian.com/sustainable-business/2015/apr/24/ bangladesh-factories-building-collapse-garment-dhaka-rana-plaza-brands-hm-gap-workers-construction (last accessed 15 
This collaboration between the public and private sectors and their goal-oriented approach to deliver tangible compensation to the victims and their families is not only a way to right a wrong, but also a measure that will enhance, or at least partially restore the people's faith in their governments. Prominent legal scholar on legal realism, Karl Llewellyn, once noted that the law is "a means to social ends and not an end in itself." 1345 The RPCC took this to heart by focusing their efforts on the end, which was to remedy the exploited laborers that survived a terrible tragedy first and foremost. In doing so, they did not dwell on what the proper legal basis of the remedy was or what new laws they needed to implement, but their approach was outcome-oriented and thus, in alignment with our adaptive capabilities framework. What is worth extrapolating from this example is that practicing lawyers and legal academics need to be more mindful of the fact that while the law is an important aspect of our society, it is not an end in itself nor is it the only instrument capable of bringing about social justice. If anything, this thesis has shown time and time again that over-reliance on the law can sometimes create dire repercussions and impede progress, which is why adopting the reflexive governance and adaptive management model can be beneficial: By collaborating with an assortment of stakeholders and focusing on the end goal (i.e. to empower the exploited laborers), governments and other stakeholder will be less likely to insist that the law or the legal solution is the only solution to the problem at hand.

In the end, the more autonomy that governments allow for its people, the less burden the government has to carry on its own. At the same time, the more autonomy the people have, the more motivated and productive they feel as the next part of this subsection will show. ${ }^{1346}$ This is just one of the many benefits of adopting reflexive governance and adaptive management strategies that places less emphasis on the law. Power is often distuptive in the sense that those that wield it, often want to use it. When faced with a crisis such as the Rana Plaza building collapse, it is quite normal for legislatures to want to react in order to "right the wrong," or as Winston Churchill more cynically noted, "never let a good crisis go to waste." However, in doing so, the pros and cons must be carefully weighed especially at the governmental level, bearing in mind the importance of preserving autonomy and how the introduction of governmental bureaucracy could slow down or impede the path to a more outcome-oriented resolution.

The second benefit of adopting reflexive governance and adaptive management strategies has to do with the aforementioned importance of preserving the autonomy of private actors and their self-determination. In coming up with our normative framework of the adapted capabilities approach, the Introduction stressed the importance of personal autonomy and the right to self-determination not just for laborers, but for private actors in general. ${ }^{1347}$ In addition, Chapter 4 discussed the importance of intrinsic motivations over ex-

May 2015) (reporting that companies like H\&M and Primark created a trust fund worth around \$20-30 million to award compensation for the victims and their families).

1345 K. N. Llewellyn, The Bramble Bush: The Classic Lectures on the Law and Law School, (New York: Oceana Press, 1931), at p. 72.

1346 R.M. LOCKE, The Promise and Limits of Private Power: Promoting Labor Standards in a Global Economy, (Cambridge: Cambridge University Press, 2013), at p.177 (noting that "public regulation alone is unable to fully address the myriad labor issues surrounding global supply chains. This is why public and private regulatory efforts need to work with and build off of one another.")

1347 B. SCHWARTZ, The Paradox of Choice: Why More is Less, (New York: Harper, 2004), at p. 99 (stressing the importance of freedom and autonomy as being "critical to our well-being," and how "choice is critical to freedom and auton- 
trinsic motivations in bringing about meaningful changes in the long run. To reiterate, it was suggested that the reason for one to act ought to be internally driven, self-determined, and autonomous preferably over being stimulated extrinsically through laws or legalized private initiatives. ${ }^{1348}$ The importance of self-determination and autonomy in this context can be articulated in what is generally referred to as the Self-Determination Theory ("SDT"), which is defined as follows:

"SDT begins with a notion of universal human needs. It argues that we have three inane psychological needs - competence, autonomy, and relatedness. When those needs are satisfied, we're motivated, productive, and happy. When they're thwarted, our motivation, productivity, and happiness plummet." "1349

This notion of self-determination is directly linked to the capabilities approach given that in order for private actors to feel "motivated, productive, and happy," they must be given meaningful choices and be equipped with various capabilities to manifest their choice and autonomy. In other words, being autonomous is partially about having capabilities and about having different possibilities to make choices. The importance of choice and autonomy is one of the main reasons why reflexive governance, rather than a mandatory topdown regulatory form of governance is preferable. As we mentioned back in the Introduction, just because someone decides to work in a sweatshop or in "sweatshop like conditions," does not necessarily mean that they lack any autonomy. Often, workers "choose" to go to work in sweatshops in developing countries like Bangladesh or Cambodia because they offer relatively decent wages compared to other existing options available to them. ${ }^{1350}$ Although these wages and the treatment that these workers endure are no doubt cruel and possibly inhumane, this is still a profit-maximizing behavior for some of these workers who lack better alternatives. ${ }^{1351}$ While they may lack certain capabilities - say the competence or capacity to work in a better environment for more pay - that does not necessarily mean that they are not autonomous. If anything, it could be argued that they are exercising their autonomy and determining for themselves the best course of action, even though those in the more developed economies might not see it as so. Add to this the fact that there is evidence to suggest the importance of autonomy, even when the option to exercise that autonomy may only lead to less than pleasant outcomes. ${ }^{1352}$

omy."); see also, O. BEN-Shahar \& C.E. SCHneIDER, More Than You Wanted to Know: The Failure of Mandated Disclosure, (Princeton: Princeton University Press, 2014), at p. 60.

1348 While external stimulation can possibly lead to an internal shift that meta-analysis goes beyond the scope of this legal thesis.

1349 D.H. PINK, Drive: The Surprising Truth about What Motivates Us, (New York: Riverhead Books, 2009), at p. 70; citing, E.L. DECI \& R.M. RYAN, "Self-Determination Theory and Facilitation of Intrinsic Motivation, Social Development, and Well-Being," American Psychologist 55 (2000): 68-78, 68.

1350 BBC WOrld SERvice, “Are Sweatshops Good?," Business Daily, (11 July 2014). Available at: http://www.bbc.co.uk/programmes/p0224gvl (last accessed 5 July 2015) (interviewing Ben Powell of the Free Market Institute).

1351 S. Mullainathan \& S. Eldar, Scarcity: Why Having Too Little Means So Much, (London: Macmillan, 2013) (noting that those with lesser means are more rational with their decision making and optimizing than those who are better off, "simply because opportunity costs are highly salient for them"); see also, R.H. THALER, Misbehaving: The Making of Behavioral Economics, (New York: Norton, 2015), at p. 58.

1352 D.H. PINK, Drive: The Surprising Truth about What Motivates Us, (New York: Riverhead Books, 2009), at p. 88 (noting that "[e]ven in high-poverty non-Western locales like Bangladesh, social scientists have found that autonomy is 
Bearing these findings in mind, it is worth taking a moment to reconsider, whether legally banning sweatshops or boycotting them entirely, as advocated by some, is always the right course of action that truly improves the working or living conditions of laborers in these developing countries. By taking away their "opportunity" to work for cash in a job market where options are severely limited, a legal sanction that would deprive them of yet another option, however bad they may be, could have dire and unforeseeable repercussions as noted throughout this thesis. Therefore, while the fight to eliminate or boycott sweatshops may seem noble and benefit-maximizing to some, for the laborers that actually work in these conditions, the impact of such actions could be rather mixed. ${ }^{1353}$ Therefore, it is important for governments and private actors to bear in mind that broad sweeping, topdown legislation that ban any and all sweatshops or sweatshop-like conditions without providing the workers meaningful alternatives, especially in the developing economies can actually exacerbate the situation for the already marginalized laborers. Where the reflexive governance and adaptive management model comes in, as previously noted, is that by including laborers themselves in the decision-making and problem-solving process, they will be able to voice their thoughts on whether such measures are what is really necessary to address the labor exploitation problem. This issue of a more direct stakeholder engagement brings us to the topic of the next benefit.

The third benefit of adopting reflexive governance and adaptive management strategies is the increased cognitive diversity that comes from a more open and direct stakeholder engagement. In short, our alternative framework taps into the existing know-how of the various stakeholders, thus increasing the likelihood of private actors coming up with more possible solutions to the labor exploitation problem. ${ }^{1354}$ At the beginning, this thesis suggested that in order to resolve collective action problems of such a magnitude, private actors can benefit from thinking differently and this thesis offered various areas that can benefit from a serious reassessment. ${ }^{1355}$ Along these lines, perhaps a different way of conceptualizing the alternative framework would be to consider it as the crowdsourcing of problem-solving. ${ }^{1356}$ The more governments, businesses, and individual actors participate in the problem solving process, the more insights we could gain and that is an opportunity that stakeholders should not pass up. ${ }^{1357}$ Lawyers and legislatures alike must resist the

something that people seek and that improves their lives"); citing, J. DEvINE, L. CAMFIELD \& I. GOUGH, "Autonomy or Dependence - or Both?: Perspectives from Bangladesh," Journal of Happiness Studies 9(1) (2008)).

1353 R.M. LOCKE, The Promise and Limitations of Private Power: Promoting Labor Standards in a Global Economy, (Cambridge: Cambridge University Press, 2013), at p. 156 (noting that while the team observed some mixed improvements in workplace safety and hours after the implementation of codes of conduct, enabling rights such as the right to free association and to collectively bargain were still "outside the pale".).

1354 R.M. Locke, The Promise and Limits of Private Power: Promoting Labor Standards in a Global Economy, (Cambridge: Cambridge University Press, 2013), at p. 157; see also, E. OSTROM, Governing the Commons: The Evolution of Institutions for Active Action, (Cambridge: Cambridge University Press, 1990).

1355 T. JudT, Ill Fares the Land, (New York: Penguin, 2010), at pp. 170-1 (stating that "[r]ecast[ing] our public conversation is the only realistic way to begin to bring about change. If we do not talk differently, we shall not think differently.").

1356 C.R. Sunstein \& R. HASTIE, Wiser: Getting Beyond Groupthink to Make Groups Smarter, (Massachusetts: Harvard Business Review Press, 2015), at p. 221 (noting that where "[m]any tasks can be 'crowdsourced,' in the sense that individuals can work on their contributions" as part of a bigger problem solving initiative).

1357 Cf. T. Harford, Adapt: Why Success Always Starts with Failure, (London: Abacus, 2012), at pp. 30, 62; citing to, I.L. JANIS, Victims of GroupThink, (Boston: Houghton Mifflin Co., 1972) (explaining that "[t]here is a limit to how much honest feedback most leaders really want to hear; and because we know this, most of us sugar coast our 
temptation to be exclusive, believing that governance and the legislative process is something that is strictly for the highly trained or the highly educated. Inclusiveness is important and collaboration is the key to resolving our problems, not exclusion and snobbery. ${ }^{1358}$

As noted above, the reflexive governance/adaptive management model acknowledges the ambivalence and the uncertainty that exist in reality and promotes experimentation and learning by trying in order to address our problems. ${ }^{1359}$ Moreover, it is a system that "integrates a diversity of perspectives, expectations, and strategies in a complex understanding of societal change." 1360 Another way to label reflexive governance or adaptive management, as it has been noted by Teubner, is to consider this type of governance from an "autopoietic" perspective, which suggests that governance and law ought to be considered as "a system for the coordination of action within and between semi-autonomous social subsystems." 1361 In laymen's terms, this is a view "in which [the] law can be understood as an instrument intended to regulate, not so much social behavior," but to regulate "organization, procedures and distribution of competences within society, dealing with social conflicts" that ensures "discursive consensus." 1362 This points to one of the most important contributions that the reflexive governance/adaptive management model can offer to the private actors, which is this notion of open and inclusive discourse with all of the stakeholders and the assortment of their unique views, the accumulation of which creates and develops cognitive diversity. ${ }^{1363}$

opinions whenever we speak to a powerful person. In a deep hierarchy, that process is repeated many times, until the truth is utterly concealed inside a thick layer of sweet talk.").

1358 F. CAPRA \& U. MATTEI, The Ecology of Law: Toward a Legal System in Tune with Nature and Community, (Oakland: Berrett-Koehler, 2015), at p. 109 (cautioning that "[o]nce law is passed, the lawyers, and only the lawyers, adapt it to the requirements of the legal system and interpret it in the context of making a market-friendly society. This process insulates legal principles and rules from the mutable political preferences and desires that carry inefficiency in the system. In this vision, there is no space for the community to give meaning to the law...").

1359 J.P. VOß \& B. Bornemann, “The Politics of Reflexive Governance: Challenges for Designing Adaptive Management and Transition Management," Ecology and Society 16(2) (2011) (acknowledging that this approach abandons the idea that there is only one way to look at a problem or that there is one right way to address the problem).

1360 J.P. VOß \& B. BORnEmanN, "The Politics of Reflexive Governance: Challenges for Designing Adaptive Management and Transition Management," Ecology and Society 16(2) (2011) (adding that "it embraces the understanding that societal change results from a multiplicity of distributed efforts at shaping it; and it searches for ways to retain the multi-dimensionality of problems, the openness of futures, and the diversity of approaches in searching for ways to cope with challenges and sustainable development."); see also, J.P. VOß \& R. KEMP, "Sustainability and Reflexive Governance: Introduction," in Reflexive Governance for Sustainable Development, J.P. VOB \& R. KEMP (EDS.) (Cheltenham: Edward Elgar, 2006), at pp. 3-28.

1361 D. AshiAgBOR, "Evaluating the Reflexive Turn in Labour Law," in The Autonomy of Labour Law, A. BoGG, C. Costello, A.C.L. Davies \& J. Prassl (EDS.), (Berlin: Walter de Gruyter, 2015); see also, G. TeubNER, "Substantive and Reflexive Elements in Modern Law," Law and Society Review 17(2) (1983): 239-285, 242; see also, G. TEUBNER, Law as an Autopoietic System, (Oxford: Blackwell, 1993).

1362 L. ZAPPALA, "Transnational Soft Regulation of Temporary Agency Work and Adaptability Policies: Future of Guidelines with No Rights," in Transnational Labour Regulation: A Case Study of Temporary Agency Work, K. AHLBERG, B. Bercusson, N. Bruun, H. Kountouros, C. Vigneau \& L. Zappala (EDS.), (Brussels: P.I.E. Peter Lang, 2008), at p. 176 (noting that "the law does not appear to be a system of obligations, but an ensemble of opportunities which become available under determinate conditions. These conditions can vary, but not so much that they can eliminate the benefits that, from time to time, can be achieved.')); see also, G. TEUBNER, Law as an Autopoietic System, (Oxford: Blackwell, 1993); G. TEuBNER, "Juridification - Concepts, Aspects, Limits, Solutions," in Juridification of Social Spheres: A Comparative Analysis in the Areas of Labor, Corporate, Antitrust and Social Welfare Law, G. TEubneR (ED.), (Oxford: Hart, 1987).

1363 C.R. SUNSTEIN \& R. HASTIE, Wiser: Getting Beyond Grouptbink to Make Groups Smarter, (Massachusetts: Harvard Business Review Press, 2015), at p. 105. 
While diversity generally offers different ideas and perspectives, specifically in our context, cognitive diversity stimulates the growth of our collective phronesis, which - as we initially defined the term back in Chapter 4 - is practical wisdom and intelligence that helps us determine how to act virtuously. ${ }^{1364}$ Our civil society, with the emergence and proliferation of powerful private actors and micropowers is full of ideas and perspectives that can stimulate our cognitive diversity and in the process, refine our phronesis. Political scientist, Francis Fukuyama, notes the following about our civil society:

"Civil society is a complex welter of intermediate institutions, including businesses, voluntary associations, educational institutions, clubs, unions, media, charities, and churches [that] builds, in turn, on the family, the primary instrument by which people are socialized into their culture and given the skills that allow them to live in broader society and through which the values and knowledge of that society are transmitted across the generations. "1365

This is to suggest that each of the stakeholders operating within our society possess a certain set of specialized knowledge, skills, and ideas that, when shared with others, can spread exponentially. Moreover, when ideas spread and react with others, they can mutate or lead to a creation of an entirely different set of new ideas. While not every specialized knowledge will be useful and implementing some ideas may lead to bad outcomes, so long as there is a learning process and the courage to try and implement new ideas, stakeholders can continue to learn and develop their collective phronesis. ${ }^{1366}$ In short, a system of governance or management model that enables stakeholders to share their practical knowledge, specialized skill, and localized experiences with one another prior to making decisions will likely render better solutions to our problem of reducing labor exploitations in the global supply chain as already demonstrated by the effectiveness of the Rana Plaza Coordination Committee. ${ }^{1367}$ Rather than governments calling on specialists before committees to explain a particular issue, attempting to understand the complexity of the said issue, and then making a decision based on what they think they understood, the idea is to let the specialists and the stakeholders themselves design a plan together and for them to implement that plan with the government serving more as a facilitator rather than as a regulator and an enforcer.

The essential idea here is that through a more inclusive method of problem-solving, private actors can activate the under-tapped resources that currently do not have a voice or a seat at the table. As the pioneering entrepreneur Brian Horowitz noted, "[ $t$ ] here's no recipe for [solving] really complicated, dynamic situations." 1368 In order to deal with these complicated and dynamic situations, it must be "all hands on deck" for the stakeholders,

1364 C.R. Sunstein \& R. HASTIE, Wiser: Getting Beyond Groupthink to Make Groups Smarter, (Massachusetts: Harvard Business Review Press, 2015), at p. 105.

1365 F. Fukyama, Trust: The Social Virtues and the Creation of Prosperity, (New York: Free Press Paperbacks, 1995), at pp. 4-5.

1366 T. HARFord, Adapt: Why Success Always Starts with Failure, (London: Abacus, 2012), at p. 152 (citing to what he refers to as the Palchinsky principles, and adding the caveat that "when trying something new, do it on a scale where failure is survivable.").

1367 B. SCHWARTZ, The Paradox of Choice: Why More is Less, (New York: Harper, 2004), at p. 60 (acknowledging "[t]he benefits of multi-individual information"); see also, J. SurOwIESKI, "Manic Monday (and Other Popular Delusions)," New Yorker, (26 March 2001), at p. 38.

1368 B. HoRowitz, The Hard Thing About Hard Things: Building a Business When There Are No Easy Answers, (New York: Harper Collins, 2014), at p. ix. 
which means including everyone in the problem-solving process. After all, who would have a better idea about how to fix some of the problems that is taking place on a day-to-day basis at a manufacturing plant than the workers that actually work there. Bearing this thought in mind, when it comes to problem-solving, it is not just about leaders finding solutions for everyone, but about getting everyone involved in the problem-solving process. In other words, "give the problem to the people who could not only fix it, but who would also be personally excited and motivated to do so." 1369

By combining reflexive governance and adaptive management, not only can our alternative framework enhance cognitive diversity, but in doing so, it can empower laborers who will be a part of the decision-making and problem-solving process in a manner that is in alignment with our normative framework. At a more macro-level, recall that a handful of multinational corporations now wield more power than some governments and this power allows them to accumulate a tremendous wealth of knowledge that, in some cases, can eclipse that of governments. For example, companies like Target and Wal-Mart collect and handle over terabytes of information about customers and their consumption behaviors. ${ }^{1370}$ What these powerful private actors can do with the data that they have collected, given their flexibility vis-à-vis the governments, has tremendous potential in our quest to reduce labor exploitation in the global supply chain. Incorporating their thoughts and their vision of addressing the labor exploitation in the global supply chain - similar to listening to the factory worker about the problems of the factory's day to day operation - would not only be a prudent course of action, but a necessary one moving forward.

In sum, adopting the reflexive governance/adaptive management model will not only add to the cognitive diversity, but will increase the social dialogue between different private actors, which has the potential to increase the chances of unlocking new ideas that could actually reduce instances of labor exploitation in the global supply chain in the future. ${ }^{1371}$ The enhanced social dialogue also serves to enhance meaningful checks and balance between the stakeholders as well, which will be the next benefit of our alternative framework that this part of the subsection will address.

The fourth and final benefit of adopting reflexive governance and adaptive management strategies is the enhanced monitoring and the more meaningful checks and balances that come as result of increased stakeholder engagement. Given that these new models are based on the involvement of more and more interested people getting involved in the collective problem solving process, governments, companies and other organizations must be more inclusive and transparent. In other words, people now have "the means and opportunities to ensure that companies' behavior does not go unchecked."1372 In order to

1369 B. Horowitz, The Hard Thing About Hard Things: Building a Business When There Are No Easy Answers, (New York: Harper Collins, 2014), at p. 65.

1370 C. Duhigg, The Power of Habit: Why We Do What We Do in Life and Business, (New York: Random House, 2012), at p. 183 (stating that these businesses use "customer loyalty cards, redeemed coupons they had received in the mail, or other measures to link the customers purchases to an individualized demographic profile.”).

1371 International Labour Organization, World Employment Social Outlook: Transforming Jobs to End Poverty, (2016). Available at: http://www.ilo.org/wcmsp5/groups/public/---dgreports/---dcomm/---publ/documents/ publication/wcms_481534.pdf (last accessed 18 December 2016), at p. 6 (noting that "through social dialogue, policies can be put in place and enforced to ensure that responsibility is shared and accountability boundaries drawn between different actors," while at the same time "promote solid governance structures.").

1372 L.P. MARCUS, “The People's Corporation," Project Syndicate, (15 September 2014). Available at: http://www.project-syndicate.org/commentary/lucy-p--marcus-says-that-companies-have-more-power-than- 
make good choices, one cannot be surrounded by a sea of sycophants and our alternative framework would surely offer a strong sounding board of ideas and disagreements. ${ }^{1373}$ Similar to how governments have red teams or designated opposition, whose sole aim is to challenge and discredit an idea that they want to push forward to see where the weaknesses are in their arguments, it is generally prudent to have debates and discussions within any organization, which also serve as an effective means of checks and balances. ${ }^{1374}$ Simply put, if there are more participants in the decision-making process, it will be more unlikely that misbehaving corporations (and perhaps even corrupt governments) will go undetected. This suggests that through reflexive governance and adaptive management, the level of monitoring can be enhanced, while establishing a system of checks and balances of sorts that has a potential of being better than the one that exists today. Having established four benefits of the reflexive governance/adaptive management model, the next subsection will now proceed to issue of its feasibility and desirability.

\section{Reflexive Governance and Adaptive Management: Its Feasibility and Desirability}

While the potential benefits of this approach is quite clear, what is less so is how this can work practically speaking. Admittedly, both reflexive governance and adaptive management embrace a pluralistic approach, which means that there are multiple sources of inspiration and plethora of what could be considered as legitimate ideas. This creates two fundamental questions: 1) If everyone has a say, how do we go about actually making decisions; and 2) just because the problem-solving process is more inclusive and democratic, does not guarantee a better outcome. As a matter of fact, there is research to suggest that biases and cognitive limitations that individuals have (as described back in Chapter 5) can possibly be aggregated and even aggravated in groups. ${ }^{1375}$ Taking on the second point first, as much as we would like to believe in the veracity of the law of large numbers, ${ }^{1376}$ it cannot be denied that simply because the problem solving mechanism is more inclusive or democratic, does

ever-before--but-so-do-people (last accessed 4 April 2017); see also, T. JUDT, Ill Fares the Land, (New York: Penguin, 2010), at p. 231 (noting that "If the world was becoming smaller and states more marginal to the daily operations of the international economy, what could social democracy hope to offer?").

1373 R.J. SHILLER, Irrational Exuberance, (Princeton: Princeton University Press, 2015), at p. 175 (noting that "people who communicate regularly with one another think similarly" and how this could create a blind spot in their thinking).

1374 C.R. SUNSTEIN \& R. HASTIE, Wiser: Getting Beyond Groupthink to Make Groups Smarter, (Massachusetts: Harvard Business Review Press, 2015), at p. 108 (stating that the "[h]ighest-performing companies tend to have 'extremely contentious boards that regard dissent as an obligation' and that 'have a good fight now and then"'); citing to, J.A. SONNENFELD, "What Makes Great Boards Great," Harvard Business Review (2002). Available at: https://hbr.org/2002/09/what-makes-great-boards-great (last accessed 19 February 2015)).

1375 C.R. SUNSTEIN \& R. HASTIE, Wiser: Getting Beyond Groupthink to Make Groups Smarter, (Massachusetts: Harvard Business Review Press, 2015), at pp. 55, 99, 212 (observing that "behavioral biases displayed by individuals are replicated, and often even aggravated, within groups" and that "[s]ometimes individual errors are amplified, not merely propagated, as a result of deliberation.").

1376 Law of large numbers is a theory, which states that as the sample size (i.e. data or opinions collected) increases, the closer it will be to expressing the "average" opinions of the entire population. Marquis de Condorcet utilized this theory to rationalize the notion of "the voice of the people" or vox populi. The problem with the law of large numbers or the Condorcet's principles is that it is entirely possible that the "voice of the people" can be "wrong" and the prerequisite to avoiding such a catastrophe is to have "individuals that are more likely to be right than wrong and if they are relatively independent." Yet another complexity is defining what can be considered as "right" or "wrong" is, more often than not, subjective and the law of large numbers does not offer any guidance on this normative question; see, C.R. SUNSTEIN \& R. HASTIE, Wiser: Getting Beyond Groupthink to Make Groups Smarter, (Massachusetts: Harvard Business Review Press, 2015), at pp. 144-6. 
not guarantee the group to render the "best" possible solution. Furthermore, there are other risks associated with groupthink, including but not limited to: 1) " $[\mathrm{g}]$ roups fall[ing] victim to cascade effects, as the early speakers or actors ensure that people do not learn what is known by their successors,"1377 2) "because of group polarization, members of deliberating groups often end up in a more extreme position in line with their predeliberation tendencies,"1378 or 3) "[i]n deliberating groups, shared information often dominates or crowds out unshared information, ensuring that groups do not learn everything that their members know." 1379 Given these concerns, cognitive diversity and an all-inclusive deliberation process as advocated by a more reflexive or adaptive model has its own set of problems. The other major problem associated with our alternative framework as noted above, is the question of how a large group can reach any decisions.

One practical way to accomplish this task at either the government level or the corporate level is to create an open platform for public commentary and to solicit ideas and experiences from a large array of private actors. ${ }^{1380}$ Some immediate benefits of this approach are: 1) "it can increase the likelihood that the final decisions will be well informed, simply because dispersed information will be collected," and 2) "it can increase goodwill and sense of legitimacy and fair play" as this approach would be a more transparent and democratic one. ${ }^{1381}$ This particular approach is a method that governments are already incorporating as they often rely on public commentaries and open consultations before promulgating new laws or strategies: For example, the US federal government has initiated the "notice-and-comment rule-making," which is a process where "federal agencies send out proposed rules for notice and public comment and give people a reasonable period (at least sixty days) to comment" on a new rule before taking the bill further. ${ }^{1382}$ Similar initiatives can be witnessed in EU as well, where the EU uses "social dialogue provisions" (TFEU Articles 154 and 155), ${ }^{1383}$ for example, "not only oblige the Commission to consult

1377 C.R. SunStEIn \& R. HASTIE, Wiser: Getting Beyond Groupthink to Make Groups Smarter, (Massachusetts: Harvard Business Review Press, 2015), at p. 99.

1378 C.R. Sunstein \& R. HASTIE, Wiser: Getting Beyond Groupthink to Make Groups Smarter, (Massachusetts: Harvard Business Review Press, 2015), at pp. 83-85, 99; citing to a series of academic literature, including but not limited to: R. Brown, Social Psychology [Second Edition], (New York: Free Press, 1986), at pp. 209-211; and, J. CoOPER, K.A. Kelly \& K. WeAver, “Attitudes, Norms, and Social Groups,” in Social Cognition, M.B. Brewer \& M. Hewstone (EDS.) (Oxford: Blackwell, 2004): 259, 269-270.

1379 C.R. SUNSTEIN \& R. HASTIE, Wiser: Getting Beyond Groupthink to Make Groups Smarter, (Massachusetts: Harvard Business Review Press, 2015), at p. 99 (summarizing research conducted by G. STASSER \& W. TITUS, "Pooling of unshared Information in Group Decision Making: Biased Information Sampling During Discussion," Journal of Personality and Social Psychology 48 (1985): 1467-1478); see also, D. GIGONE \& R. HASTIE, "The Common Knowledge Effect: Information Sharing and Group Judgment," Journal of Personality and Social Psychology 65 (1993): 959-974, 973.

1380 C.R. SUNSTEIN \& R. HASTIE, Wiser: Getting Beyond Groupthink to Make Groups Smarter, (Massachusetts: Harvard Business Review Press, 2015), at p. 214 (noting the importance of the public comment process where private and public groups can collect opinions and information from a lot of people).

1381 C.R. SunSTEIN \& R. HASTIE, Wiser: Getting Beyond Groupthink to Make Groups Smarter, (Massachusetts: Harvard Business Review Press, 2015), at p. 197 (also noting, however, that while "public comment can improve the perceived legitimacy of ultimate decisions... the whole enterprise might backfire... including a negative reaction from those whose comments were not heeded.)

1382 C.R. SUNSTEIN \& R. HASTIE, Wiser: Getting Beyond Groupthink to Make Groups Smarter, (Massachusetts: Harvard Business Review Press, 2015), at p. 196.

1383 TFEU Article 154(1), for example, tasking the Commission with the role of "promoting the consultation of management and labour at Union level" and taking "any relevant measure to facilitate their dialogue by ensuring balanced support for the parties." 
with management and labour prior to the submission of legislative proposals; [but] they also empower the social partners, if they so wish, to negotiate 'collective agreements', which can be implemented by Union instruments or national practice." 1384 This not only demonstrates inclusivity, but it "leave[s] a space for diversity and for self-regulation," 1385 which fits in neatly with our normative framework.

There are additional signs that governments are opening up to this reflexive governance approach, albeit with some lingering hesitations. ${ }^{1386}$ For example, in proposing amendments to the Shareholders' Rights Directive discussed back in Chapter 4,1387 the EU conducted at least three public consultations and held various informal discussions with multiple stakeholders. ${ }^{1388}$ Similarly in the US, prior to the implementation of the Dodd-Frank Act, particularly with regards to $\$ 1502$ and the monitoring of conflict minerals, the general public was consulted prior to its implementation. Chapter 5 also noted how the US Fair Trade Commission ("FTC") collected a "wide range of public input" from both consumers and businesses before revising their "Green Guide" to ensure that the claims made on sustainability labels are "truthful and non-deceptive."1389 This increasing openness and inclusivity is important on so many different levels, including but not limited to cognitive diversity, but for the sake of added accountability for the public sector and the ability for governments to have some leeway when something does not go the way they intended to (by arguing that the public had a say in the matter and that the government was simply representing the interests of the people).

In the end, involving other stakeholders, including but not limited to think tanks, consumer watchdogs, union representatives, micropowers, and any other private actors to the discussion, regardless of how contested these talks may become, is an invaluable source of knowledge and expertise. While there will always be those that are critical of this approach or the sincerity of governments to seriously take into consideration the voices of the private sector, many believe that every institution "might well benefit from some kind of notice-and-comment process, whether it is formal or informal." 1390 From a corporate per-

1384 D. Ashiagbor, "Evaluating the Reflexive Turn in Labour Law," in The Autonomy of Labour Law, A. BoGG, C. Costello, A.C.L. Davies \& J. Prassl (EDS.), (Berlin: Walter de Gruyter, 2015), at fn. 77; see also, W. STREECK, "European Social Policy after Maastricht: The 'Social Dialogue' and 'Subsidiarity'," Economic and Industrial Democracy 15 (2001): 151-77.

1385 D. AshiAgBor, "Evaluating the Reflexive Turn in Labour Law," in The Autonomy of Labour Law, A. BOGG, C. Costello, A.C.L. Davies \& J. Prassl (EDS.), (Berlin: Walter de Gruyter, 2015), fn. 77.

1386 Cf. T. HARForD, Adapt: Why Success Always Starts with Failure, (London: Abacus, 2012), at p. 27 (noting that some organizations (i.e. governments) are "pathological immune[ed] to feedback."). This goes to the point that governments and their various public law measures have a somewhat inefficient, if not bad, feedback loops and poor ways of measuring whether their performance and competence.

1387 Directive 2007/36/EC of the European Parliament and of the Council of 11 July 2007 on the exercise of certain rights of shareholders in listed companies, L 184/17 (listing the various rights of the shareholders, including but not limited to their right to put items on the agenda of the general meeting (Article 6), right to vote at the general meeting (Article 7), and their right to ask questions (Article 9)).

1388 European Commission, "Shareholder's Rights." Available at:

http://ec.europa.eu/internal_market/company/shareholders/indexa_en.htm (last accessed 14 March 2016).

1389 Federal Trade Commission, "FTC Issues Revised 'Green Guides'," (1 October 2012). Available at http://www.ftc.gov/sites/default/files/attachments/press-releases/ftc-issues-revised-greenguides/greenguides.pdf (last accessed 4 April 2017).

1390 C.R. SunSTEIN \& R. HASTIE, Wiser: Getting Beyond Groupthink to Make Groups Smarter, (Massachusetts: Harvard Business Review Press, 2015), at pp. 196-7. Sunstein and Hastie address that there are those highly critical of this process, stating that there academics that call this comment process as "fraud, a charade, a form of kabuki theater," but relying on anecdotal evidence of Sunstein's time in government that "comment period greatly matters, 
spective, the aforementioned stakeholder value model to corporate governance may just be the manifestation of this process. While some may question the feasibility of a model that embraces so much polycentricity, examples noted above clearly show that it is indeed feasible as governments and private actors are already starting to experiment with these strategies. By being inclusive to different ideas and perspectives, the reflexive governance and adaptive management frameworks also enable private actors to take into consideration differences in cultures in their decision-making process, which is crucial to addressing a problem of a rather international nature. ${ }^{1391}$

In addition, coming back to the first fundamental question of reflexive governance, there is the question of how we would actually go about making decisions, when the number of people involved is quite large. ${ }^{1392}$ While it is true that "many collective endeavors require coordination from the beginning to the end," one thing to keep in mind in offering a rebuttal to these raised concerns is the "rise of electronic networks," where many of the tasks that used to require coordination and "face-to-face, real-time collaboration can be performed with much less coordination over the networks." 1393 It is worth pointing out, however, that various governments are, as exemplified by the US and the EU, starting to embrace this notion of a reflexive or inclusive governance as evidenced by the aforementioned public commentary mechanism of the US federal government and the promotion of a social dialogue with labor and management within the EU as mandated by TFEU Articles 154 and 155. So while it is easy to cast doubt on the feasibility of reflexive governance, adaptive management or its inclusive decision-making process, there is at least anecdotal evidence that illustrate these measures functioning with the possibility of generating successful outcomes.

The white elephant in the room, which has yet to be addressed regarding the possibility of a more active private sector participation under the reflexive governance/adaptive management framework is the question of what would incentivize private actors to actually participate more under this framework relative to the more traditional top-down regulatory framework. The simple answer is the knowledge that what they say is being taken seriously and actually being considered that motivates and incentivizes private actors to actively participate in this process. Chapter 4 already noted the importance of intrinsic incentives and having a sense of purpose - or what the Greeks referred to as telos - as the galvanizing force behind people's drive. Whereas in the more traditional framework, the perception was that our voices sometimes get lost in the process as evidenced by the government's competence problem and the companies' adherence to the shareholder value model rather

and federal agencies take people's suggestions and concerns seriously" because more often than not "people have information that officials lack, and to get the rules right, officials need to take that information into account.").

1391 M. SIEMS, Comparative Law, (Cambridge: Cambridge University Press, 2014), at p. 276 (citing to the works of Benjamin D. Barros); see, B.D. BARros, "Introduction," in Hernando de Soto and Property in a Market Economy, B.D. BARROS (ED.) (Farnham: Ashgate, 2010): 1-6.

1392 R. BUXBAUM, "Juridification and Legitimation Problems in American Enterprise Law," in Juridification of Social Spheres: A Comparative Analysis in the Areas of Labor, Corporate, Antitrust and Social Welfare Law, G. TEUBNER (ED.), (Berlin: Walter de Gruyter, 1987), at p. 263 (noting that "[h]ow to shape the myriad decisions of many, hierarchically arranged actors holding complex personal as well as organizational values into the desired whole... [and] how to do this when that aggregate of decisions, even taken as a coherent whole, is designed and expected to be taken in large part on the basis of conflicting social values...”).

1393 C.R. SUNSTEIN \& R. HASTIE, Wiser: Getting Beyond Groupthink to Make Groups Smarter, (Massachusetts: Harvard Business Review Press, 2015), at pp. 211-2. 
than the stakeholder model. Under the reflexive governance/adaptive management schemes, however, stakeholders will have - at least in theory - more opportunities to voice their opinions, which increases the possibility of their voices actually being heard, which could ignite their sense of purpose that they are making a contribution to address the problem of labor exploitation. ${ }^{1394}$ This inclusivity and a newfound sense of purpose that it might offer to each and every stakeholder, even to the workers and laborers of this world will surely be capabilities-enhancing for them. ${ }^{1395}$ In other words, adopting reflexive governance and adaptive management strategies are not only desirable, but they are feasible.

The aim of this subsection was to explain how reflexive governance and adaptive management can aid private actors in their attempts to further reduce instances of labor exploitation in the global supply chain. In making the argument, this subsection offered various benefits of opting for these decision-making and problem-solving models, rather than the traditional top-down regulatory style more common today. The benefits included, but were not limited to: relieving the burdens placed on governments, respecting and preserving personal autonomy and the right to self-determination, stimulating cognitive diversity through crowdsourcing and public consultation, and enhancing meaningful check and balances. Reflexive governance and adaptive management would enable private actors to be directly involved in the problem solving process, thus providing a workaround to government decision-making, which has often been accused of being a bureaucracy plagued with sclerosis. It is worth noting here that what causes the sclerosis is often the careful deliberation of pros and cons from an autonomous political perspective about what impact, what repercussions their proposals and policies can have on society as already elaborated back in Chapter $2 .{ }^{1396}$ While there is certain value in this type of a cost-benefit or careful risk analysis, the difficulty with the field of law or governance is that more often than not, it is not exactly a predictive science. While lawmakers can carefully consider historical precedents, rely on economic indicators, and listen to highly esteemed academics, in the end, there is no guarantee that a particular legislative action will have the desired effect without any spillover effects, the latter of which could hurt the lawmaker come re-election time. So allowing private actors to learn from simply doing, rather than endlessly theorizing about the "what ifs" could offer meaningful actions.

Just to be extra clear, however, reflexive governance does not mean that there is no longer any need for governments to act. As this thesis stated time and time again, governments and their laws imposed in rather top-down fashion will continue to have their uses and at times, this approach may indeed be the best course of action. What the reflexive governance model merely acknowledges is that this top-down approach should not be the default course of action, but instead, governments should be more strategic about the way they go about making laws. This strategic way consists of governments taking a step back

1394 W. Henley, "New Breed of Ethical Startups are Taking on Giants of the Internet," The Guardian, (9 July 2013) (reporting that it is "the promise to do social and environmental good" that self-motivates private actors to participate and ultimately to come to terms with the decision made by the group).

1395 See generally, M.A. HogG \& S.A. REID, "Self Identity, Self-Categorization, and the Communication of Group Norms," Communication Theory 16(1) (2006): 7-30.

1396 T. HARford, Adapt: Why Success Always Starts with Failure, (London: Abacus, 2012), at p. 31 (noting that "[t]raditional organizations are badly equipped to benefit from a decentralized process of trial and error. Static, solved problems are ideal for such organizations; as are tasks where generalized expertise counts for much more than local knowledge."). 
when necessary and focusing on only making laws that ensure some minimum level of protection. ${ }^{1397}$ While these experimental and unproven actions may cause some unease, especially amongst the academics amongst us, to quote John Burroughs, "the smallest deed is better than the greatest intention" and the reflexive governance approach can be the harbinger for applying this theory into practice. Moreover, in advocating for the "trial and error" method or the "evolutionary approach" as an "effective tool for solving problems," which are strategies that the reflexive governance framework espouses, complexity theorists wholeheartedly believe that " $[\mathrm{g}]$ iven the likely shape of [our] ever-shifting landscapes, the evolutionary mix of small steps and occasional wild gambles is the best possible way to search for solutions." 1398 In sum, the argument posed here is that there is less red tape to cut with reflexive governance and adaptive management strategies, which is clearly beneficial when tackling a problem as complex as reducing labor exploitations in the global supply chain.

To conclude this section, the proposal for incorporating a holistic approach (or only relying on the law strategically) and the recommendation for adopting the reflexive governance/adaptive management model complement one another. A more reflexive and adaptive decision-making framework will better serve to prevent social norms from being converted into legal norms unnecessarily and the existence of a strong social norm will in turn lead to increased participation and reliance on a more collaborative and participatory framework. Having elaborated on the theoretical implications of our alternative framework, the next section of this chapter will discuss some of the pragmatic applications of the alternative framework.

\subsection{PRAGMATIC APPLICATION OF THE ALTERNATIVE FRAMEWORK}

In proposing the alternative framework, the previous section focused primarily on the theoretical aspects of the framework. In doing so, the previous section already hinted to some of the practical ways in which emphasizing the role of social norms vis-à-vis legal norms, advocating for private global norm production, and expanding the application of reflexive governance/adaptive management can be implemented in order to further reduce instances of labor exploitations in the global supply chain and to remedy the victims of the exploitation. This section will now add to and elaborate on various measures, which can also capture the benefits of private global norm production and the reflexive governance/adaptive management model in a practical manner.

1397 M. HOBBES, "The Myth of the Ethical Shopper," The Huffington Post, (2015). Available at: http://highline.huffingtonpost.com/articles/en/the-myth-of-the-ethical-shopper/ (last accessed 16 July 2015) (quoting Roberto Pires of the Institute for Applied Economic Research noting that strategic use of government can be like "regulatory acupuncture," where governments can find "specific points where applying pressure can provoke systemic effects.”).

1398 T. HARFORD, Adapt: Why Success Always Starts with Failure, (London: Abacus, 2012), at p. 14, 16 (citing to the works of Stuart Kauffmann and John Holland); see generally, E. BEINHOCKER, The Origin of Wealth: The Radical Remaking of Economics and What it Means for Business and Society, (Cambridge: Harvard Business Review Press, 2007). 
Just as a caveat, it must be stressed at the beginning that these measures are not meant to be quick fixes or the proverbial magic bullet. ${ }^{1399}$ Moreover, as it is becoming increasingly evident, instruments that often facilitate our cooperation and problem-solving capabilities can often be double-edged swords capable of also exacerbating our faults and flaws: The Internet is the perfect example of this where, for all of the good that it does, it also opens the door to new problems, some of which we have yet to fully grasp. ${ }^{1400}$ In other words, attempting to resolve a problem in a different way may actually create a new set of problems, but this thesis posits that fearing these possible consequences and sticking to the tried and tested approaches to resolve our persistent problem will likely not bring us the results that we seek. As the saying - which is often misattributed to either Albert Einstein or Mark Twain - goes: it is a sign of insanity to do something over and over again and expect different results. In order for us to resolve our challenges, both old and new, different strategies become necessary that, at the very least, reassesses the utility of keeping the status quo. This section will attempt to offer just that while bearing in mind the lessons we learned from our previous failures. As the last caveat, it is worth pointing out that this thesis does not advocate for a wholesale makeover of the existing framework, but rather, advocate for the gradual incorporation of the alternative framework into the existing system in the spirit of kaizen. ${ }^{1401}$ This is mostly due to the consideration that in our increasingly complex world, the irony of it all is that "[i]f you want to encourage someone to do something," you have to "make it easy," 1402 and sometimes, the less we try to control the situation, the more control we can attain.

With the caveats in mind, the structure of this section will be as follows: The first subsection will focus on the recommendation for governments in terms of how they can, by adopting the alternative framework, better enable private actors to participate, collaborate, and be a part of the problem-solving process (Subsection 6.3.1). The second subsection will focus on recommendations targeted at businesses so that they too can better work towards building mutually respectful and trustful relationship with other private actors in their attempts to reduce labor exploitations within their supply chains (Subsection 6.3.2). The third subsection will offer recommendations for consumers and how they can implement the alternative framework in a practical manner by becoming part of the solution (Subsection 6.3.3).

1399 M. NAím, The End of Power: From Boardrooms to Battlefields and Churches to States, Why Being in Charge Isn't What It Used to Be, (New York: Basic Books, 2013), at p. 231 (noting that "most of our domestic or international problems are immune" to such fictions and problem-solving at this level will "require sustained and consistent efforts.").

1400 M. NAím, The End of Power: From Boardrooms to Battlefields and Churches to States, Why Being in Charge Isn't What It Used to Be, (New York: Basic Books, 2013), at p. 231 (observing that " $[\mathrm{t}]$ he bombardment of technology; the explosion of digital communication and online opinion, distraction, and noise; the decline of automatic acceptance of traditional authorities... feed a disequalibilirum with broad and poorly understood consequences.”).

1401 See generally, R. MAURER, The Spirit of Kaizen: Creating Lasting Excellence One Small Step at a Time, (New York: McGraw-Hill, 2012), at p. 16 (defining kaizen as a process of continuous improvements, settling for small gradual improvements, rather than a complete overhaul): Advocates of kaizen, as opposed to those that advocate for a wholesale innovation, believe that radical changes often trigger a "fight or flight" response, which is not conducive to make sustainable changes or compromises.

1402 R.H. ThALER, Misbehaving: The Making of Behavioral Economics, (New York: Norton, 2015), at p. 337. 


\subsubsection{Recommended Role of the Governments}

To reiterate, the primary focus of this thesis is on what private actors can do to help reduce the labor exploitations taking place in the global supply chain; however, to the extent that governments can better enable private actors by applying our alternative framework, this section will address the recommended role of governments moving forward and how they can start incorporating the proposal laid out in this thesis. This thesis has already suggested that governments ought to be more reflexive or open by incorporating private actors in their problem-solving process, while resisting their urge of regulating every problem through extrinsic incentives (i.e. threats of legal sanctions). Moreover, in discussing the theoretical framework for reflexive governance, the previous chapter already suggested that governments can rely more on public commentaries and attempt to crowdsource some of the legislative process. Having already made these points before, this subsection will now: a) briefly reiterate the suggestions for governments to take a holistic approach and to rely on the law more strategically; b) advocate that they focus on creating a level playing field for the private actors; c) experiment with different regulatory methods through special district and charter cities; and lastly, d) consider the concept of open government.

\section{A. Strategic Use of the Law and Nudges}

At the onset, it is worth mentioning that in some cultures around the world, the law does not have a revered place when it comes to conflict/dispute resolution and problemsolving. ${ }^{1403}$ In many Asian cultures, for example, "instead of recourse to the courts, people resort to informal procedures of dispute settlement, characteristic of Confucianism, which discourages the settlement of conflicts in public." 1404 While some might argue that if only there were more extrinsic motivators - perhaps if government regulators increased the fine for exploiting laborers or if governments set up monitoring devices in every factory - that labor exploitations would somehow stop. We know from what we have learned throughout this thesis that these are not the solutions that we seek, at least not as default solutions. Although laws generally serve, not only as aspirational models, but as deterrents of unwanted behavior, their effectiveness or enforcement is never absolute, not to mention the fact that they often fail to address the root cause of the problem, which is the fundamental fact that we, as human beings, are flawed. The idea of creating more extrinsic incentives with threats of legal sanctions or throwing monetary incentives at this problem - could prove to be ineffective, or worse, render undesirable outcomes and externalities especially in the long run.

1403 See e.g., Y. NODA, Introduction to Japanese Law, (Tokyo: University of Tokyo Press, 1976), at pp. 159-160; cited by, H. ODA, Japanese Law [Third Edition] (Oxford: Oxford University Press, 2009), at p. 4 (noting that the "Japanese generally conceive of law as an instrument of constraint that the State uses when it wishes to impose its will. Law is thus synonymous with pain or penalty. To an honourable Japanese the law is something that is undesirable, even detestable, something to keep as far away as possible.”).

1404 H. ODA, Japanese Law: Third Edition, (Oxford: Oxford University Press, 2009), at p. 4; see also, K. ZWEIGERT \& H. KÖTZ, "Einführung in die Rechtsvergleichung auf dem Gebiets des Privatrechts," in An Introduction to Comparative Law (Third Edition], T. WeIR (Trans.) (Oxford: Oxford University Press, 1998), at pp. 289, 291 (noting that in Confucianism, which did not have "great regard of the rules of law or their enforcement in court," played a role in Asian legal systems like China and to some extent Japan, "developed a wide variety of forms of conflict-resolution outside the courts."). 
While regulations like minimum wage, work place safety standards, and conducting randomized sweeps to detect and punish violators are necessary, governments must acknowledge that these laws have spillover effects. For example, these laws could increase business outsourcing their operations to other jurisdictions where the laws are more lenient. Establishing sunshine laws, transparency requirements, and mandated disclosures that publicize business performance and compliance to social responsibility are also flawed in various ways, including but not limited to the facts that businesses sometimes lie and fudge these numbers and that even if this type of information were made available to the public, people do not often read them or bother enough to change their behaviors. Ben-Shahar refers to these disclosure or sunshine policies as "presumptively unsuccessful"1405 and insists that we only rely on them when there is actual evidence to suggest that they have a positive impact.

Taking Ben-Shahar's advice to heart, the first pragmatic step for governments is for them to admit that some of the laws are not working, because unless they admit this, private actors will be lulled into a false sense of security that something is actually being done about a problem (manifestation of the aforementioned pluralistic ignorance problem), which can crowd out the private actor's willingness to act or collaborate. Therefore, if a particular law is not working or if it is doing more harm than good, "lawmakers should stop using it, commentators should stop proposing it, and interest groups should stop advocating it." 1406 This awareness is important because once laws are made, it becomes the status quo, we become dependent on it, and it becomes difficult to move away from that status quo (manifestation of the aforementioned status quo bias). Generally speaking, people are reluctant to say the words, "I don't know," and perhaps for governments this is even more so, at times preferring to give the wrong answer rather than admitting their ignorance (manifestation of the aforementioned overconfidence and positivity bias). However, we must change this preconceived notion that not knowing is always a bad thing, because figuring out what does not work is a type of phronesis as well and also a starting point for a more inclusive dialogue and an opportunity for us to try new and ideas. ${ }^{1407}$

One relatively new strategies that governments can employ, as hinted in previous chapters is the concept of nudging, which some governments are already starting to incorporate into their policies and legislations. ${ }^{1408}$ Nudges, according to Thaler and Sunstein, are "any aspect of the choice architecture that alters people's behavior in a predictable way without

1405 O. Ben-Shahar \& C.E. SCHNEIDER, More Than You Wanted to Know: The Failure of Mandated Disclosure, (Princeton: Princeton University Press, 2014), at p. 54.

1406 O. BEn-Shahar \& C.E. SCHNeIDER, More Than You Wanted to Know: The Failure of Mandated Disclosure, (Princeton: Princeton University Press, 2014), at p. 183 (adding "unless they can convincingly show that this time it really is different.").

1407 O. Ben-Shahar \& C.E. SCHNEIDER, More Than You Wanted to Know: The Failure of Mandated Disclosure, (Princeton: Princeton University Press, 2014), at p. 12 (stating that “[e]ven if lawmakers don't know what works, at least they can know what fails, and what fails should be abandoned.").

1408 M. Whitehead, R. Jones, R. Howell, R. Lilley, \& J. Pykett, "Nudging All Over the World: Assessing the Global Impact of the Behavioural Sciences on Public Policy," Economic and Social Research Council (2014). Available at: https://changingbehaviours.files.wordpress.com/2014/09/nudgedesignfinal.pdf (last accessed 10 February 2016) (reporting that " 136 countries around the world have incorporated behavioral sciences in some aspect of public policy, and 51 'have developed centrally directed policy initiatives that have been influenced by the new behavioural sciences."'). 
forbidding any options significantly changing their economic incentives. ${ }^{1409}$ For example, the "behavioural insight unit" in the UK, colloquially known as the "nudge unit," is currently designing, creating, and implementing nudges to solve various problems that the government faces. Since its inception in 2010, the nudge unit has been credited with "signing up extra 100,000 organ donors in a year, persuading $20 \%$ more people to consider switching energy providers, doubling the number of army applicants, and increasing tax compliance" amongst some of their other accomplishments, which has saved the UK government an estimated 300 million in the process. ${ }^{1410}$ The nudge unit accomplished these tasks by understanding human behavior through behavioral psychology and applying low cost, simply tricks: For example, many of their strategies do not attempt to change people's economic incentives (i.e. increasing fines for a violation) by creating new laws, but instead, they very often change the manner in which certain information communicated to the public by using techniques such as framing and priming. One successful implementation of nudging was where the UK nudge unit was able to increase their tax compliance by emulating something that the tax authorities did in the US. ${ }^{1411}$ In the US case, which took place in the state of Minnesota, the tax authorities revealed that compliance to tax laws increased, not when tax payers were "threatened with information about the risks of punishment for noncompliance," but when they were "just told that more than 90 percent of Minnesotans already complied, in full, with their obligations under the tax law." 1412 The take away here was that threats of sanctions did not compel the taxpayers as much as the softer approach of simply letting people know that the majority of the other taxpayers in Minnesota had already complied.

Based on this finding, Sunstein and Thaler observed that "either desirable or undesirable behavior can be increased, at least to some extent, by drawing public attention to what others are doing." 1413 By understanding our cognitive limitations and quirks noted back in Chapter 5 better and using them to create nudges, the UK nudge team has made a significant impact on a wide range of problems that previously burdened the government. Based on the confirmed successes of the nudge group, various governments around the world are starting to open up to the idea that "an understanding of human behavior is vital for almost all public policy" and nudges might be a useful tool in modifying people's behaviors. ${ }^{1414}$ In

1409 R.H. Thaler \& C.R. Sunstein, Nudge: Improving Decisions About Health, Wealth, and Happiness, (New York: Penguin, 2009), at p. 6.

1410 T. RutTER, “The Rise of Nudge - The Unit Helping Politicians to Fathom Human Behaviour,” The Guardian, (23 July 2015). Available at: http://www.theguardian.com/public-leaders-network/2015/jul/23/rise-nudge-unitpoliticians-human-behaviour (last accessed 25 September 2015) (it is worth noting that while the nudge unit started as a governmental unit with the UL Cabinet Office, it was privatized in 2014, and is now jointly owned by the Cabinet Office, a charity called Nesta, and its employees).

1411 R.H. Thaler, Misbehaving: The Making of Behavioral Economics, (New York: Norton, 2015), at p. 354 (stating that "pre-informing" is an effective nudge).

1412 R.H. Thaler \& C.R. Sunstein, Nudge: Improving Decisions About Health, Wealth, and Happiness, (New York: Penguin, 2009), at p. 67.

1413 R.H. Thaler \& C.R. Sunstein, Nudge: Improving Decisions About Health, Wealth, and Happiness, (New York: Penguin, 2009), at p. 67.

1414 T. RUTTER, “The Rise of Nudge - The Unit Helping Politicians to Fathom Human Behaviour," The Guardian, (23 July 2015). Available at: http://www.theguardian.com/public-leaders-network/2015/jul/23/rise-nudge-unitpoliticians-human-behaviour (last accessed 25 September 2015); R.H. THALER, Misbehaving: The Making of Behavioral Economics, (New York: Norton, 2015), at p. 344 (observing that a "[a] study conducted by the Economic and Social Research Council published in 2014 reports that 136 countries around the world have incorporated behavioral 
the US, for example, President Obama issued an Executive Order in September 2015 creating the Social and Behavioral Sciences Team as the US counterpart to the nudge unit and other countries such as Germany, Singapore, and Australia are all following suit. If we believe that the benefits from nudging could outweigh the costs, it is a worthwhile endeavor for not just governments, but all stakeholders to at least consider how they can use nudges to reduce labor exploitations in the global supply chain. This is a positive step towards finding better ways to reducing instances of labor exploitation in the global supply chain.

More specifically in the context of reducing labor exploitation, governments could - by taking a page from the tax compliance nudge - publicize facts and figures related to how other private actors are already adopting or incorporating CSR/ethical consumerism initiatives in their businesses or consumption habits. Given that we are indeed communal creatures as noted back in Chapter 5 and highly susceptible to social influences, ${ }^{1415}$ private actors could be incentivized enough through nudging to modify their behaviors without governments having to implement more and more legislations. There is no one right answer in terms of how governments can best design or frame these nudges, but this will be highly dependent on the situation in question, and must be adapted accordingly to the circumstances. By taking into consideration localized knowledge, being open, and being adaptive, governments can learn to be less reliant on extrinsic cues and be more strategic by increasing their reliance on nudges.

While nudging is indeed one possible way governments can adopt a more holistic approach and be more strategic about promulgating new laws, it is equally important to bear in mind that nudges are not without their flaws as well: First, they do not always work. ${ }^{1416}$ The Chief Executive of the nudge unit, David Halpern, admitted that one or two in every 10 nudges fail. ${ }^{1417}$ Second, nudging is a form of libertarian paternalism, where governments essentially believe that they know what is good for us and attempt to manipulate our decision-making process, albeit preserving party autonomy and the option for the public not to comply. Third, there is evidence to prove that if the people become aware of the fact that they are being nudged, they may be less inclined to follow; after all, no one likes being manipulated into doing something. ${ }^{1418}$ Be that as it may, it is rather difficult for govern-

sciences in some aspect of public policy, and 51 'have developed centrally directed policy initiatives that have been influenced by the new behavioural sciences"'); see also, M. WHitEHEAD, R. JONES, R. HOwELL, R. LiLLEY, \& J. PYKETT, "Nudging All Over the World: Assessing the Global Impact of the Behavioural Sciences on Public Policy," Economic and Social Research Council (2014). Available at: https://changingbehaviours.files.wordpress.com/ 2014/09/nudgedesignfinal.pdf (last accessed 10 February 2016).

1415 J. BERGER, Invisible Influence: The Hidden Forces that Shape Behaviour, (London: Simon \& Schuster, 2010), at pp. 229, 231 (stating that "we are constantly shaped by the people around us," and as a result, "other people have a subtle and surprising impact on almost everything we do).

1416 T. HARForD, Adapt: Why Success Always Starts with Failure, (London: Abacus, 2012), at p. 177-8 (noting that while "[t]he idea of a nudge itself is very clever. The idea of legislating one is more difficult," adding that "[a] clumsy nudge is better than a clumsy shove or a clumsy ban, but it's still clumsy.”).

1417 T. RUTTER, “The Rise of Nudge - The Unit Helping Politicians to Fathom Human Behaviour," The Guardian, (23 July 2015). Available at: http://www.theguardian.com/public-leaders-network/2015/jul/23/rise-nudge-unitpoliticians-human-behaviour (last accessed 25 September 2015).

1418 R.H. Thaler \& C.R. Sunstein, Nudge: Improving Decisions About Health, Wealth, and Happiness, (New York: Penguin, 2009), at p. 69 (suggesting that "if you want to nudge people into socially desirable behavior, do not, by any means, let them know that their current actions are better than the social norm.”). 
ments to turn down a low cost, simple option that is effective in curtailing unwanted behavior.

To conclude, this part of the subsection made three recommendations: First, governments should acknowledge their failures when their laws or policies misfire and learn to stop recycling them over and over again in the hopes of producing different outcomes the next time around; second, on a related point to the first, governments should be more forthcoming about asking help from the public; ${ }^{1419}$ and the third recommendation is that to the extent that governments will continue to design and implement new strategies, one possible strategy worth adding to their arsenal is nudging, which is a valuable tool in that it takes into consideration many of our cognitive and human flaws discussed back in Chapter 5. Nudges are already showing great potential in practice and could be an effective tool in reducing labor exploitation in the future if designed and implemented properly. To quote Thaler and Sunstein, "[s]ometimes massive social changes, in markets and politics alike start with a small social nudge." 1420

\section{B. Ensuring a Level Playing Field}

By advocating for a reflexive/adaptive system of governance that is inclusive and collaborative, the intended aim of the alternative framework is to bring together multiple stakeholders to equally participate in the decision-making process. There is reason to doubt, however, that the idea for all stakeholders to be able to participate and to have their voices heard equally will present a challenge given that some stakeholders may wield more authority and influence than others. For example, in discussing the lobbyist problem and money's corrupting influence back in Chapter 2, this thesis suggested that while governments must, at times, cater to the interests of businesses, perhaps they do so more often relative to that of the workers. This assumption was proven, at least in part by the Gilens study noted back in Chapter 2, which revealed that there is a "vast discrepancy" between the government's responsiveness to the rich compared to the poor. ${ }^{1421}$ If reflexive governance is to be successful, governments must ensure equal opportunities for the stakeholders, at the very least around the discussion tables.

What facilitates the creation of level playing fields are various legal instruments that equip laborers with enabling rights: For example, at the international level, the ILO's Freedom of Association and Protection of the Right to Organize Convention, 1948 (No. 87) ${ }^{1422}$

1419 T. HARFord, Adapt: Why Success Always Starts with Failure, (London: Abacus, 2012), at p. 180 (noting that "[g]overnments should not be picking and choosing, in our complex economies, specific ways to save the planet," but rather, "[t]hey should be tilting the playing field to encourage us to make all our decisions with the planet in mind.").

1420 R.H. Thaler \& C.R. SunSTEIN, Nudge: Improving Decisions About Health, Wealth, and Happiness, (New York: Penguin, 2009), at pp. 3, 53. In explaining the objective behind Nudge, Thaler states that "[i]t was never our intention to claim that nudging can solve every problem. Some bans and mandates are inevitable. No society can exist without any rules and regulations." See, R.H. THALER, Misbehaving: The Making of Behavioral Economics, (New York: Norton, 2015), at p. 325.

1421 M. GILENS, "Inequality and Democratic Responsiveness," Public Opinion Quarterly 69(5) (2005): 778-796, 778.

1422 International Labor ORGANiZATiOn, International Labour Standards on Freedom of Association. Available at: http://www.ilo.org/global/standards/subjects-covered-by-international-labour-standards/freedom-of-

association/lang--en/index.htm (last accessed 4 April 2017) (proclaiming that "[t]his fundamental convention sets forth the right for workers and employers to establish and join organizations of their own choosing without previous authorization. Workers' and employers' organizations shall organize freely and not be liable to be dis- 
and the Right to Organize and Collective Bargaining Convention, 1949 (No. 98) ${ }^{1423}$ exist to ensure the rights of the workers to unionize and to collectively bargain at the international level. In short, unions have been characterized as "workplace-justice activism" by some and many countries all around the world (i.e. Germany and Sweden) have relied on independent trade unions to usher in a series of social and economic empowerment for the workers above and beyond (and even prior to) these international conventions. ${ }^{1424}$

While looking at whether governments pass laws to protect workers is one thing, but whether workers are actually protected and allowed to voice their opinions is a rather different exercise all together: This is to suggest that there is a gap between what the law provides and whether they actually deliver on that promise, especially in jurisdictions where collective bargaining agreements or unionization is restricted. This situation presents some obstacles for governments to successfully implement the reflexive governance model. With this in mind, it must be noted that even in jurisdictions where collective bargaining and unionizing is permitted, it would behoove governments to continually assess and reassess these two enabling rights are being protected. Let us observe the current state of affairs in the US in order to provide an example of how and why governments must remain vigilant that their work force has a collective voice that is not muted by their employers or business interests.

The US is an interesting case study in that while it recognizes unions, it has a history of rampant union busting and employers routinely trying to weaken or undermine unions, which is to suggest that comparatively speaking, US laws protecting the right to unionize or ensuring the proper execution of collective bargaining agreements may not be as strong as that of the Netherlands. With regards to the relevant laws, National Labor Relations Act, Tart-Hartley Act, and the Landrum-Griffin Act (Labor Management Reporting and Disclosure Act of 1959) all ensure, in one way or another, the right of private employees to join unions and to bargain collectively, with some states even extending this right substantively and/or to public workers as well. However, as this thesis noted over and over again, just because laws exist permitting employees to create and join unions does not mean that companies and employers attempt to routinely circumvent the essence of these law by finding loopholes. For example, a practice called "captive audience meetings" has increasingly become problematic in the US, where employers hire outside consultants to conduct these meetings in attempts to dissuade employees from unionizing or joining collective

solved or suspended by administrative authority, and they shall have the right to establish and join federations and confederations, which may in turn affiliate with international organizations of workers and employers.").

1423 INTERNATIONAL LABOR ORGANiZATION. International Labour Standards on Freedom of Association. Available at: http://www.ilo.org/global/standards/subjects-covered-by-international-labour-standards/freedom-of-

association/lang--en/index.htm (last accessed 4 April 2017) (stating that " $[\mathrm{t}]$ his fundamental convention provides that workers shall enjoy adequate protection against acts of anti-union discrimination, including requirements that a worker not join a union or relinquish trade union membership for employment, or dismissal of a worker because of union membership or participation in union activities. Workers' and employers' organizations under the domination of employers or employer's organizations, or the support of workers' organizations by financial or other means, with the object of placing such organization under the control of employers or employers' organizations. The convention also enshrines the right to collective bargaining.").

1424 M. CHEN, "Could Stronger Unions Make China More Democratic," The Guardian, (11 August 2014). Available at: http://www.thenation.com/blog/180938/could-stronger-unions-make-china-more-democratic\# (last accessed 4 April 2017) (quoting the Chinese labor activist, Han Dongfang, who sees unions and collective bargaining as a "vehicle for restructuring power in the workplace."). 
labor agreements by conducting "information sessions" about the pros and cons of joining a union, often painting the union as the villain in the story. Their general message consists something along these lines: "Joining a union is totally your call. But it's a really bad idea, and we're disappointed it's come to this," implying that unionizing would be disloyal to the company and there is evidence to suggest that these meetings are very effective at influencing - or at times manipulating - the workers to not join any unions or collective labor agreements. ${ }^{1425}$ Note that this is a nudging for sorts, which technically leaves the decision ultimately in the hands of the workers, but by hiring these consultants, businesses are attempting to psychologically pressure workers to not unionize. The US government, recognizing the problem of employers hiring consultants to conduct "captive audience meetings" mandated that companies disclose and report instances where consultants were brought into speak to their employers directly (hoping that this sort of sunshine policy would shame the companies from attempting to bust unions). Of course the companies found a loophole to this rule, by continuing to hire consultants for tips on dissuading workers to unionize, but instead of having the consultants lead the meeting, they were hired just to teach supervisors of the company to give the captive audience meetings instead of the consultants. This way, the businesses no longer had to report or disclose this information to the government, while still distributing the message scripted by the consultants.

Recognizing the flaw of the initial rule, the US Department of Labor fought with various business lobbies and other external pressures to create the "contentious persuader rule," which adds to the company's reporting requirements any contact with consultants even if they do not directly present in front of the employees. This example not only shows the difficulty that comes with governments attempting to create a level playing field for private actors, but it calls to attention several observations: First and foremost, the original point of this narrative was to stress to governments the importance of creating and maintaining a level playing field especially with regards to managing the relationship between businesses and employers on one side and that of the laborers and unions on the other. To the extent that some businesses often attempt to undermine unions in order to reduce expenses, governments must ensure that the workers' voices are not being muted. The second observation is to reiterate the point about how some government measures can be ineffective and susceptible to companies circumventing them. To the extent that companies do find loopholes to exploit, governments must continue to remain vigilant, learn from their mistakes, and adapt accordingly, as the US government did in this case. Third, the government's approach even with the adoption of the "contentious persuader rule" was to rely on transparency enhancing legislation in the hopes that companies will be shamed into doing the "right" thing, but as Chapter 4 noted in describing the causation problem, the effectiveness or what impact this new rule will have on actually incentivizing

D. JAMIESON, "This Is What It's Like to Sit Through an Anti-Union Meeting at Work," The Huffington Post, (3 September 2014). Available at: http://www.huffingtonpost.com/2014/09/03/captive-audience-meetings-antiunion_n_5754330.html (last accessed on 23 March 2016) (interviewing a Teamsters member, Ben Speight who notes that these coercive meetings often are sources of "relentless pressure and misinformation and half-truths."); see generally, K. BRONFENBRENNER, "No Holds Barred - The Intensification of Employer Opposition to Organizing," Economic Policy Institute Briefing Paper 235 (20 May 2009). Available at: http://www.epi.org/publication/ bp235/ (last accessed on 23 March 2016). 
companies from union avoidance remains uncertain. The fourth and the last observation, which is more of a caveat, is to clarify that while this thesis considers it essential for all stakeholders to be able to participate and share their opinions equally in a meaningful manner for our alternative framework to succeed, governments' aims need not be to protect and strengthen unions at all times.

This is to recognize the fact that while unions do often help workers, unions are not always good or necessary. ${ }^{1426}$ Taking a chapter from the so called "captive audience meetings," unions may indeed have their own self-interests, divide the workplace, or charge excessive membership fees. Moreover, if a company is indeed treating their workers with respect and dignity, unions - a third party that the workers will have to pay dues to - does not make much sense. Only to the extent that companies are not treating their workers fairly, unionizing serves a valuable purpose.

These observations lead us to the expected conclusion that it is difficult to predict how the new "contentious persuader rule" will affect unions or businesses: On one hand, the US Labor Secretary, Tom Perez argues that "[i]nformed decisions are the best decisions," and "this rule will pull back the curtain on the consultants who craft the employer's message." 1427 On the other hand, businesses are quick to rebut that the law is overstretching and the costs of compliance would be excessive. ${ }^{1428}$ The two sides cannot even agree on the cost of compliance, given that the expected compliance cost for the filers, according to the Labor Department is estimated to be around $\$ 825,000$, but the Chamber of Commerce, representing the business interests, rejects this estimate, claiming that "the rule's first-year cost burden on the economy would be at least $\$ 910$ million." ${ }^{1429}$ To make the outcome of the new law even more uncertain, businesses are already gearing up to fight this legislation in court. This contention between the government and the businesses reveals the difficulty of bringing warring sides together to the same table, but at the same time, it also stresses the vital importance of the parties actually coming together to work out a manageable compromise.

To conclude, the recommendation made in this subsection was for governments to focus on implementing laws that would level the playing field, using the example of countering the practices of union busting or union avoiding. Even this task, however, presented a number of challenges for the government as "developed" as that of the US. Bearing this in

1426 Cf. N. KRISTOF, "The Cost of a Decline in Unions," The New York Times, (19 February 2015) (noting that unions sometimes get a bad rap that they "bring corruption, nepotism and rigid work rules to the labor market, impeding the economic growth that ultimately makes a country strong," and so forth, but "even flawed ones, can provide checks and balances for flawed corporations.").

1427 D. JAmieson, "It's About to Get Harder for Companies to Hide Union-Busting," The Huffington Post, (23 March 2016). Available at: http://www.huffingtonpost.com/entry/union-busting-persuader-rule_us_56f1bdcbe4b0 c3ef52172770 (last accessed on 23 March 2016) (reporting that "between 71 to 87 percent of employers hire consultants to help manage union avoidance campaigns").

1428 K. Bogardus \& B. GoAD, "Up in Arms Over Union "Persuader' Rule," The Hill, (12 February 2014). Available at: http://thehill.com/regulation/labor/198153-union-persuader-rule-has-industry-groups-up-in-arms (last accessed on 23 March 2016) (reporting that even the American Bar Association has lodged a complaint about the overreach of this new rule, as it raises a potential confidentiality issue with their corporate clients that could possible create "a chilling effect on the legal world and scare firms away").

1429 K. Bogardus \& B. GoAD, "Up in Arms Over Union "Persuader' Rule," The Hill, (12 February 2014). Available at: http://thehill.com/regulation/labor/198153-union-persuader-rule-has-industry-groups-up-in-arms (last accessed on 23 March 2016) (reporting of complaints that the new rule "could have a chilling effect on the legal world and scare firms away from representing [business groups]."). 
mind, imagine for a moment that if this is the type of corporate behavior taking place in the US today, within the walls of MNCs like Coca-Cola and Staples, what it might be like for sweatshop workers in Bangladesh attempting to unionize. As ironic or cyclical as it may be, even in their attempts to create a level playing field for all of the stakeholders, governments can benefit from incorporating reflexive and adaptive models of governance by involving key stakeholders in the actual decision-making process, which would, at least in theory, reduce the reliance on unions along the way. In the end, the role of the government that this proposal envisions and suggests is for them to create the right environment and conditions for private actors to collaborate thrive. ${ }^{1430}$

\title{
C. Special Districts, Charter Cities, and Seasteads
}

The Westphalian conception of a state suggested that a nation state has sovereignty over its jurisdiction and the ability to govern its domestic affairs without intrusions from external powers. Even prior to globalization, this concept was allegedly in decline, but with the advent of the Internet, other technological advances, and the growth of international commerce, the notion that a state can dictate its domestic affairs without succumbing to any pressures from external forces lost connection with reality. In addition, Chapter 5 already discussed at some length about the shifting power paradigm from governments to private actors and the emergence of the so-called micropowers by citing to the works of Naím, Cafaggi, and Posner. The decline of the Westphalian conception of the state is real, and according to Naím, the erosion of traditional power structures will likely not stop there:

\begin{abstract}
"Another, even more sweeping, wave of innovation is building, one that promises to change the world as much as the technological revolution of the last two decades did. It will not be top-down, orderly, or quick, the product of summits or meetings, but messy, sprawling, and in fits and starts. Yet it is inevitable."
\end{abstract}

If we were to take this admonition at face value, now would be a good time to start rethinking about the role of governance and how legislatures can prepare for this paradigm shift. This thesis has reiterated time and time again that the solution to many of the collective action problems that we face today, and that we will face in the future, including but not limited to the persistent labor exploitation in our global supply chain, cannot be resolved simply by creating more and more laws being enforced by top-down regulatory frameworks. This has been documented by the inadequacies of national governments dealing with many of the problems associated with the global supply chain: For example, "[t]he emergence of global supply chains... has rendered these national and international strategies inadequate because authority is dispersed not only across national regimes but also

1430 S.D. MurPhy, "Taking Multinational Corporate Codes of Conduct to the Next Level," Columbia Journal of Transnational Law 43(2) (2005), at p. 8 (concurring that "[t] he role of governments would not be one of state control or corporate activity but, rather, one of helping empower the individual autonomy of corporations within certain bounds of justice, fairness and equity."). The argument put forth in this thesis is that governments should not only do so for corporations, but for their workers as well.

1431 M. NAím, The End of Power: From Boardrooms to Battlefields and Churches to States, Why Being in Charge Isn't What It Used to Be, (New York: Basic Books, 2013), at p. 244 (adding that "[d]riven by the transformation in the acquisition, use, and retention of power, humanity must, and will, find new ways of governing itself.”). 
among global buyers and their myriad suppliers." 1432 While supranational organizations such as the European Union have displayed some potential and possibilities of what coordinated cooperation between states can accomplish, supranational organizations are not immune to the assortment of problems associated with governance, which was covered indepth in Chapter 2.

The law often seems to be lagging when it comes to regulating these volatile frontiers, which is to suggest that in a world where "power is scattered among an increasing number of newer, smaller players from diverse and unexpected origins... big government, big armies, big business, and big universities will be constrained and confined as never before... [and] their demotion can also generate instability, disorder, and paralysis in the face of complex problems" such as the problem of mass migration that burdens the EU today. ${ }^{1433}$ In other words, governments will not be able to address some of the collective action problems that the world faces without shifting their default mode of governance from a topdown regulatory style to a more inclusive, collaborative reflexive style of governance that will tap into the potential of private actors more.

Given that history has a tendency of repeating itself and thus serving as a possible predictive model, incorporating a historical perspective to predict the trajectory of future governance in our context may be a worthwhile detour here: Consider the state of affairs prior to the American or French Revolution, for example, which subsequently led people who felt the growing injustice of the sovereignty that ruled over them to choose a different path all together, and in the process creating their own norms and new system of governance. This is to suggest that what tends to happen when governments are perceived as incapable, incompetent, or corrupt for a sustained amount of time is that people have gone about creating their own norms. In what Hernando de Soto calls "extralegal law," in some instances, when the laws fail its constituents, citizens have been forced to work outside governmental regulations and forming their own set of rules to abide by. De Soto argued that this informal system of governance was the more democratic response, a system of governance more in tune with the people, and a more accurate reflection of reality; therefore the creation of these informal rules could be argued as a reasonable, if not justified, course of action for the people. ${ }^{1434}$ The suggestion that rather than condemning these so called "extralegal" rules, governments should seriously consider the legitimacy of these informal norms, ${ }^{1435}$ is not without merit, but it does present us with a different kind of a problem, which is the fact that these extralegal norms and disenfranchised people doing their own thing can lead to bad outcomes as well, as the remainder of this part of the subsection will attempt to illustrate.

1432 R.M. LOCKE, The Promise and Limitations of Private Power: Promoting Labor Standards in a Global Economy, (Cambridge: Cambridge University Press, 2013), at p. 9 (noting that "[i]t is in this context that private initiatives have emerged to fill this regulatory void.").

1433 M. NAím, The End of Power: From Boardrooms to Battlefields and Churches to States, Why Being in Charge Isn't What It Used to Be, (New York: Basic Books, 2013), at pp. 9, 13.

1434 H. DE SOTO, The Other Path: The Economic Answer to Terrorism, (New York: Basic Books, 1989), at pp. 51-2.

1435 H. DE SoTO, The Other Path: The Economic Answer to Terrorism, (New York: Basic Books, 1989), at p. 132 (noting that "a law is 'good' if it guarantees and promotes economic efficiency and 'bad' if it impedes or disrupts it. The unnecessary costs of formality derive fundamentally from a bad law; the costs of informality result from the absence of a good law."). 
While privatization of various government functions is nothing new, certain emerging trends seem to suggest that there is a chance that the process of governance itself can be privatized as well. For example, consider what economist Paul Romer refers to as "charter cities" or Patri Friedman and Peter Thiel's Seasteading Institute refer to as "seasteads." The basic idea behind these projects is for people to simply create "entirely new cities with their own rules on democracy, taxes and corporate governance," which would be "governed by a set of rules designed to attract ambitious people." 1436 In a way, history is indeed repeating itself, as people interested in charter cities or seasteads are unsatisfied with the current system of governance in one way or another, and seek to create new norms in new communities with others who share that view. These efforts, accordingly, could be considered as manifestations or the legitimization of extralegal rules.

While some may dismiss these ideas as purely theoretical, a similar idea of "specialpurpose districts," which are independent local entities authorized by the state to provide certain designated functions is already a reality today: For example, in the US there are more than 35,000 special-purpose districts in existence and growing concern with them, other than the fact that there are so many of them (manifestation of the proliferation problem), is the fact that they are allowed to play by different, often more lenient, set of rules. ${ }^{1437}$ Another example, perhaps something closer to the idea of a charter city or seastead is the New Songdo International Business District, located about 40 miles from Seoul, South Korea, which "exists in a legal and regulatory bubble," and is considered to be a "free economic zone with less restrictive labour laws than the rest of South Korea and more attractive regulations for foreign corporations." 1438 By allowing different entities to operate in accordance with different set of rules - even if it leads to increased trade and economic growth - that is an example of governments implementing measures that create uneven playing fields. Moreover, the idea of special-purpose districts or allowing people to play by different rules erodes the sense of community and creates different classes of citizens, which is to suggest that governments are contributing to the growing inequality and fostering environments that will exacerbate the problem of labor exploitation. ${ }^{1439}$ There is

1436 T. HARFord, Adapt: Why Success Always Starts with Failure, (London: Abacus, 2012), at p. 150-2 (using Singapore, Hong Kong, Shenzhen, Lübeck, and New Songo City as examples of a similar idea working, but admitting that "[p]olitically it is almost inconceivable"); citing, P. Romer, "For Richer, For Poorer," Prospect, 167 (27 January 2016). Available at http://www.prospectmagazine.co.uk/features/for-richer-for-poorer (last accessed 28 March 2016); see also, "Cities on the Ocean," The Economist, (3 December 2011). Available at: http://www.economist.com/node/21540395 (last accessed 16 March 2016) (explaining the seastead as essentially the same thing as charter cities, but "on the high seas.").

1437 The problem with special-purpose districts, at least in the US, is that it arguably restricts the ability for people to vote because in some districts, the number of votes the people have depend on the size of the land that they own, which seemingly violates the Equal Protection Clause of the Fourteenth Amendment, but is permitted within these districts so long as the purpose of the district is "sufficiently specialized"; see e.g. Ball v. James, 451 U.S. 355 (1981); see also, UniTED STATES Census Bureau, "Census Bureau Reports There are 89,004 Local Governments in the United States," Press Release, (30 August 2012). Available at: https://www.census.gov/newsroom/ releases/archives/governments/cb12-161.html (last accessed 28 March 2016) (reporting that there are 37,203 specialpurpose districts in existence).

1438 T. HARFord, Adapt: Why Success Always Starts with Failure, (London: Abacus, 2012), at p. 152 (using the example of allowing companies to file official documents in English); citing, G. LINDSAY, "Cisco's Big Bet on New Songdo: Creating Cities from Scratch," Fast Company, (1 February 2010).

1439 R.B. REICH, "Secession of the Successful," The New York Times, (20 January 1991). Available at: http://www.nytimes.com/1991/01/20/magazine/secession-of-the-successful.html (last accessed 26 March 2015) (stating the following: "Across the nation, the most affluent Americans have been seceding from the rest of the 
one benefit, however, of these special districts, charter cities, and seasteads, which is intriguing from our perspective, which is that creating these special zones and treating them as a petri dish where private actors can test out different rules and how they work in reality could - in theory - lead to interesting experiments with real world lessons and implications.

In sum, the emergence of charter cities or seasteads and the popularity of government approved special-purpose districts lead us to three observations: First is the confirmation of our complexity problem noted throughout this thesis and the realization that this problem will not only persist, but likely get worse. Second, while the emergence of extralegal rules can be justified in some context that is not to suggest that the end result of legitimizing and accepting them will always be a more democratic one or a beneficial one at that. Lastly, the third observation, which is a related point to the second observation, is that government measures that create uneven playing fields and allow different players to play by different rules create not only different classes of people, but they erect barriers - both psychologically and physically - thus potentially exacerbating the problem of labor exploitation. ${ }^{1440}$ While creating these special zones would allow private actors to test various rules without governments requiring to overhaul laws and regulatory measures through the entire system, there are serious risks to the proliferation of these special zones that could outweigh any benefits that can result from this experimentation. By separating the stakeholders and catering to businesses with promises of creating special districts with "less restrictive labour laws," these government measures could literally enable labor exploitations to continue and thrive. Therefore, governments must be advised to tread carefully with permitting these special zones to proliferate.

\section{Open Source Governments}

The last idea for governments to consider implementing in alignment without alternative framework is the idea of open governments. One of the ways in which some of the governments have attempted to address the problem of their declining authority and influence is by encouraging private actors to be more active in governance. For example, former US Deputy Chief Technology Officer for Open Government, Beth Noveck imagines a future of governance that is based on "transparency, participation, and collaboration," where people not only have access to their governments, but the ability to directly shape its legislations and policies. ${ }^{141}$ Believing the current form of top-down governance to be "out-of-

nation into their own separate geographical communities with tax bases (or fees) that can underwrite much higher levels of services. They have relied increasingly on private security guards instead of public police, private spas and clubs rather than public parks and pools, and private schools. Being rich now means having enough money that you don't have to encounter anyone who isn't”); see also, J. DE GRAAF, D. WANN \& T.H. NAYLOR, Affluenza: How Overconsumption is Killing Us - And How We Can Fight Back [Third Edition], (San Francisco: Berrett-Koehler Publishers, 2014), at p. 57 (citing to statistics from Census Bureau data and noting that $10 \%$ of US homes are located in "gated communities").

1440 J. Berger, Invisible Influence: The Hidden Forces that Shape Behaviour, (London: Simon \& Schuster, 2010), at pp. 226 (discussing the phenomenon of the "neighborhood effects," where people that "live in high-poverty areas tend to fare worse on a variety of dimensions."); see also, R. SAMPSON, K. MORENOFF \& T. GANNON-ROwLEY, “Assessing Neighborhood Effects': Social Processes and New Directions in Research," Annual Review of Sociology (2002): 443-78.

1441 H. WALTERS, "Demand a More Open-Source Government: Beth Noveck at TEDGlobal 2012," TED Blog (28 June 2012). Available at: http://blog.ted.com/demand-a-more-open-source-government-beth-noveck-attedglobal-2012/ (last accessed 28 September 2015). 
date and inappropriate for our current world," Noveck advocates for an open-government that would "get people to comment on laws before they are enacted." 1442 Generally speaking, "open source" is a term that refers to software programming, where codes are made available free to the public in the hopes that the public can collaborate and add to or improve the code. Applied in the context of governance, open-source governance is a process where the legislation process is opened directly to the general public usually through a wiki, where people can write in and directly shape the legislation.

This idea of crowdsourcing governance and lawmaking is an innovative idea that is in alignment with the reflexive governance model advocated by this thesis, if not very similar. ${ }^{1443}$ Both reflexive governance and the open-source governance advocate for increased public participation, believing in the benefit of private actors to make better and more democratic decisions relying on their collective knowledge, experience, and skill. The primary difference between the two theories of governance lie in the fact that reflexive governance, at least as envisioned by this thesis, still sees governments as part of the decision making team, if not at least as a fail-safe in case of exigent circumstances; whereas opensource governance leaves the legislative process entirely in the hands of the public. ${ }^{1444}$ While skeptics might question the prudence of such measures, open-source governance is already being sampled across the globe, in places like Brazil and Chicago, where "[p]articipatory budgeting" is now a real thing and even "Russia has been using wikis to get citizens to write law." 1445 If Noveck is right, "[t]he next great superpower will be one to combine the hierarchy of the institution - because we need to retain public values and coordinate flow - with diversity, chaos and the excitement of networks." 1446 Whether that will be through reflexive governance or open-source governance remains to be seen, but this gives us an indication of the appropriate strategy governments ought to take, which is for them to involve and enable private actors to be a part of the problem-solving process.

Ultimately, the recommendation that this thesis offers to governments can be summarized as follows: Governments must resist the urge to continue promulgating more and more laws, by learning to ask for help from the private sector and by relying on laws more strategically. One way specific way governments can do so would be to continue exploring different nudges that strive to incentivize private actors to behave in a more socially responsible way, without legally requiring them to do so. By opening up the legislative process more to the private sector and focusing on ensuring a level playing field between the

1442 H. WALTERS, “Demand a More Open-Source Government: Beth Noveck at TEDGlobal 2012,” TED Blog (28 June 2012). Available at: http://blog.ted.com/demand-a-more-open-source-government-beth-noveck-attedglobal-2012/ (last accessed 28 September 2015) (arguing that governments routinely fail to reinvent its business model).

1443 D.H. PINK, Drive, New York: Riverhead Books, 2009), at p. 20 (observing that the "most powerful new business model of the twenty-first century" is the open source.)

1444 In the interest of full disclosure, there is still some debate with regards to what "open-source" governments exactly means, as it is a relatively new term.

1445 H. WALTERS, "Demand a More Open-Source Government: Beth Noveck at TEDGlobal 2012," TEB Blog (28 June 2012). Available at: http://blog.ted.com/demand-a-more-open-source-government-beth-noveck-attedglobal-2012/ (last accessed 28 September 2015).

1446 H. WALTERS, "Demand a More Open-Source Government: Beth Noveck at TEDGlobal 2012," TEB Blog (28 June 2012). Available at: http://blog.ted.com/demand-a-more-open-source-government-beth-noveck-attedglobal-2012/ (last accessed 28 September 2015). 
stakeholders, governments can better enable private actors to fight labor exploitation, but as the same time, benefit themselves from the implementing our alternative framework.

\subsubsection{Recommended Role of the Businesses}

This subsection will now shift gears to discuss the recommended role for businesses and how they can implement the alternative framework in a way that could further reduce instances of labor exploitation. It must be noted that some of the practical measures and strategies have already been described in the context of what businesses are already doing today: Incorporating as a benefit corporation, for example, is one way businesses can commit themselves to taking corporate social responsibility seriously and contribute in a meaningful way to improve the treatment of marginalized workers in the supply chain. The aforementioned nudges can also be utilized by businesses as well. ${ }^{1447}$ For example, small nudges such as requiring MBA's to take an oath similar to the one doctors must take offers some potential: Consider it as the "Hippocratic oath for business grads in which they pledge their fealty to causes above and beyond the bottom line." 1448 The benefits of these commitment devices have been described in previous chapters, but above and beyond their utility, businesses have an incentive to seriously start implementing and incorporating these measures. This is because the risks associated with operating within the global supply chain has increased significantly over the recent decades: "A study conducted in 2010 found that whereas two decades ago companies faced an average 20 percent chance of encountering a 'corporate disaster' for their reputation in a five-year period, that chance is now 82 percent." 1449 This, again, illustrates the role of technology that has enhanced our communication and collaboration (not to mention the impact of micropowers), but at the same time increased the risk for businesses because now one wrong move could "go viral" and end them. Bearing this risk in mind, the businesses have an incentive to want to adopt these recommendations as this subsection will show.

Accordingly, this subsection will offer practical measures and strategies that businesses can employ in order to reduce labor exploitation in the supply chain including, but not limited to: a) paying less attention to rankings; b) preparing for the synchronization of the supply chain and the automatization of manufacturing; and c) focusing on capability building with their business partners, rather than monitoring and punishing them.

1447 R.H. Thaler \& C.R. SunSTEIN, Nudge: Improving Decisions About Health, Wealth, and Happiness, (New York: Penguin, 2009), at p. 6 (adding that "one of the most effective ways to nudge (for good or evil) is via social influence.").

1448 D.H. PINK, Drive: The Surprising Truth about What Motivates Us, (New York: Riverhead Books, 2009), at p. 136 (describing the oath, which reads as follows: "[a]s a manager, my purpose is to serve the greater good by bringing people and resources together to create value that no single individual can create alone... I will safeguard the interests of my shareholders, co-workers, customers and the society in which we operate... I will strive to create sustainable economic, social, and environmental prosperity worldwide.”).

1449 M. NAím, The End of Power: From Boardrooms to Battlefields and Churches to States, Why Being in Charge Isn't What It Used to Be, (New York: Basic Books, 2013), at p. 166 (citing to an article from The Economist); see, "Brand Rehab," The Economist, (8 April 2010). Available at: http://www.economist.com/node/15866025 (last accessed 15 May 2015). 


\section{A. Rankings v. Emulating Industry Leaders}

Similar to the point made above with regards to what governments can do differently, businesses can also attempt to reduce their use of extrinsic incentives, whether that occurs through reduction of legal threats against their supply chain or offering up monetary incentives to their suppliers hoping for better compliance to their corporate codes. While continuing to enhance enforcement measures by making corporate codes legally binding or by going as far as adding monitoring cameras in factories might seem like worthwhile ideas to explore, this thesis argued that they may not work in the long run to actually curtail labor exploitation. Instead, businesses can potentially benefit from incorporating softer measures like fostering intrinsic motivations for their business partners to be socially responsible, rather than imposing and demanding that they do so. One way to conceptualize this, to quote Daniel Pink again is that "[a] healthy society - and healthy business organizations begins with purpose and considers profit as a way to move towards that end or a happy byproduct of its attainment." 1450 Human resources gurus also support this so-called "softer" approach rather than relying on the rule of law, contracts, and other extrinsic motivators to get the job done. ${ }^{1451}$

This strategy applies, not just at the lower echelons of the supply chain, but at the higher levels as well within the offices of multinational corporations: For example, consider the fact that at the management level, bonuses are often tied to work performance; but companies more serious about making sustainable changes, or for companies that are conscious about not crowding out the intrinsic motivations of their workers, it is best to separate bonuses from their work evaluation: "Instead of a big annual evaluation tied to bonuses, companies ought to have workers meet with their supervisors more often with no connection to bonus decisions," and "[w]ith money pressures off, managers [can] talk more freely about their struggles with the key behaviors... and instead of hearing only the bonus rating, they could actually listen for their bosses' feedback and advice." 1452 Many of the more socially conscious companies are already starting to take up this softer approach, which brings us to our current topic of rankings and emulating industry leaders.

Within the context of extrinsic incentives, the issue of rankings businesses according to their corporate social responsibility is a grey area and a practice worthy of our reassessment. One way to look at it is to consider the fact that "companies are highlighting their place on global sustainability indices including the Dow Jones Sustainability Index, FTSE4Good, and Corporate Knights' Global 100, which saw 31 new honorees in 2014" as a good sign. ${ }^{1453}$ Rankings are intriguing as it could incentivize businesses to behave in a more socially responsible manner, but depending on how a business sees the ranking, it

1450 D.H. PINK, Drive: The Surprising Truth about What Motivates Us, (New York: Riverhead Books, 2009), at p. 143.

1451 T. DiDonato \& N. GiLl, "Changing an Organization's Culture, Without Resistance or Blame," Harvard Business Review, (15 July 2015) (noting that companies "focused on the soft qualities that managers often overlook in their zeal for short-term results" and creating an organization that "keep[s] the company's interests ahead of one's own division, function, or region... [that] emphasizes collaboration and long-term perspective, while push[ing] for accountability and humility" are likely to success in the long run).

1452 T. DiDonato \& N. Gill, "Changing an Organization's Culture, Without Resistance or Blame," Harvard Business Review, (15 July 2015); T. DiDonAto, "Stop Basing Pay on Performance Reviews," Harvard Business Review, (10 January 2014).

1453 C. CASAZZA, "Oversight of Corporate Sustainability Activities," Director's Handbook Series 2014, (Washington D.C.: National Association of Corporate Directors with Ernest \& Young LLP, 2014), at p. 3. 
could become a source of extrinsic incentives and negative spillovers. For example, if businesses start perceiving the rankings just as a way to signal to consumers, investors, and competitors about their "commitment to CSR," this could potentially crowd out their intrinsic incentives (i.e. being socially responsible for the sake of being good). While many have argued for the benefits of ranking businesses (essentially a naming-and-praising or shaming device depending on where one falls in the rankings) by arguing that they serve as positive reinforcements, there are some reasons for concern as well. ${ }^{1454}$

Given that a company's "good name is worth more than riches, for the simple reason that it is the necessary basis for continued enrichment," 1455 companies work extremely hard to rank high atop prestigious rankings such as the Dow Jones Sustainability World In$\operatorname{dex}^{1456}$ and Corporate Knights Capital Global 100 Index $^{1457}$ that signals to the public - as well as to their competitors - that their company is doing great when it comes to being socially responsible. Consider for a moment, how a brand's power is heavily dependent on its reputation: For example, a survey conducted by Forbes indicated that " $41 \%$ of how people feel about a company is based on their perception of the firm's corporate social responsibility practices" and how our "willingness to buy, recommend, work for, and invest in a company is driven $60 \%$ by [our] perceptions of the company - or its reputation, and only $40 \%$ by [our] perceptions of the products or services it sells." 1458 Taking these numbers at face value, the higher a company ranks, the higher the profits could be, which is to suggest that rankings could be construed as an extrinsic motivator as well, to the extent that companies let it be so.

While rankings might incentivize socially responsible behavior, it is worth bearing in mind that "[s]ome things that you want to encourage will be quantifiable, and some will not. If you report on the quantitative goals and ignore the qualitative ones, you won't get the qualitative goals, which may be the most important ones." ${ }^{1459}$ In other words, rankings might crowd out the intrinsic incentive of companies wanting to be social responsible "because it the right thing to do" and replace it with an extrinsic motivation of ranking high in the rankings. As this thesis previously noted, companies should avoid implementing CSR standards with the attitude of "do this so you can check off all these boxes" and be ranked high. ${ }^{1460}$ As business mogul Ben Horowitz observed, "[t]o get things right, you must recognize that anything you measure automatically creates a set of employee behav-

1454 J. JacQuet, Is Shame Necessary: New Uses for an Old Tool, (London: Penguin Books, 2016), at p. 8 (noting that shaming or guilting private actors to address collective action problems like climate change or labor exploitation is asking shame and guilt to "perform a function that it is not quite up to.").

1455 S. ANHOLT, Places: Identify, Image and Reputation, (New York: Palgrave Macmillan, 2010), at p. 22 (quoting a passage from Book of Knowledge of the Beautifies of Commerce and of Cognisacnce of Good and Bad Merchandise and of Falsifications, which according to Anholt was the first ever international business "best-seller" written by Abu al-Fadl Ja'far Ibn Ali of Damascus "some time between the ninth and twelfth centuries.").

1456 http://www.sustainability-indices.com/images/DJSI_Review_Presentation_2013_tcm1071-372104.pdf

1457 http://global100.org/global-100-index/

1458 J. SMITH, "The Companies with the Best CSR Reputations," Forbes, (2 October 2013). Available at: http://www.forbes.com/sites/jacquelynsmith/2013/10/02/the-companies-with-the-best-csr-reputations-2/ (last accessed 4 April 2017) (citing a study conducted by a consulting firm in New York, the Reputation Institute).

1459 B. HoRowitz, The Hard Thing About Hard Things: Building a Business When There Are No Easy Answers, (New York: Harper Collins, 2014), at p. 132-3.

1460 D.H. PINK, Drive: The Surprising Truth about What Motivates Us, (New York: Riverhead Books, 2009), at 70 (citing to M.H. BAZERmAN, "Evaluating Your Business Ethics: A Harvard Professor Explains Why Good People Do Unethical Things,” Gallup Management Journal, (12 June 2008)). 
iors. Once you determine the result you want, you need to test the description of the result against the employee behaviors that the description will likely create. Otherwise, the sideeffect behaviors may be worse than the situation you were trying to fix." 1461 This observation not only validates our support for the adaptive management strategies, but moreover, brings us to the recommendation of emulating industry leaders and learning from what other companies are doing, instead of focusing on the rankings as such.

Before addressing the proposal for businesses to adopt a reflexive style of corporate governance and adaptive management, it is worth noting that simply because rankings can have unintended negative spillover effects is no reason for companies to keep their social responsibility accomplishments hidden. If anything, competition between companies over who can be more socially responsible is a good kind of competition, so long as they are committed to actually improving the working conditions of the marginalized workers rather than fighting over where they rank. ${ }^{1462}$ As one last side note, it is interesting to note that while rankings are important for companies because they make it easier for businesses to convey to the public about just how socially responsible they are, rankings are not generally speaking - actually making businesses appear more socially responsible. For example, the prevailing perception among the public is that "businesses are [still too] focused on their own agenda rather than helping to improve society," 1463 which shows the inane suspicion that the public now has towards businesses in general and the limited influences that the ranking system has when it comes to convincing the consumers about the businesses' good intentions.

Having addressed some of the tangential issues, let us move on to the suggestion of businesses abandoning their preoccupation with rankings, but instead, focusing on learning from other businesses and emulating their more successful CSR initiatives. In short, businesses can learn from other companies, much like governments can learn from the private sector, about how to become a "good" (corporate) citizen: For example, the shoe company TOMS donates a pair of shoes to those in need for every pair of shoes that they sell. Patagonia's emphasis on making high-quality clothing has led to an entire ad campaign where they ask their customers to reconsider purchasing their products (unless they absolutely need to) in order to reduce their carbon footprints by avoiding unnecessary consumption. ${ }^{1464}$ In November 2013, H\&M announced their Fair Living Wage policy, which voluntarily increased the wages for "textile workers in countries such as Bangladesh where the

1461 B. HorowiTz, The Hard Thing About Hard Things: Building a Business When There Are No Easy Answers, (New York: Harper Collins, 2014), at p. 133; see also, A. RÜHMKORF, Corporate Social Responsibility, Private Law and Global Supply Chains, (Cheltenham: Edward Elgar, 2015), at p. 55 (suggesting that a strategy like"[n]arrative reporting [would] enable managers to explain the company's performance without numbers and to indicate the future direction of the company's business"); and, D. Millon, “Theories of the Corporation," Duke Law Journal 39(2) (1990): 201$262,225$.

1462 J. HAIDT, The Righteous Mind: Why Good People are Divided by Politics and Religion, (New York: Vintage, 2012), at p. 367 (noting "the overriding importance of reputation and other external constraints for creating moral order.").

1463 Deloitte Touche Tohmatsu, "Business needs to reset its purpose to attract Millennials, according to Deloitte's annual survey," Press Release, (14 January 2015). Available at: http://www2.deloitte.com/an/en/pages/aboutdeloitte/articles/2015-millennial-survey-press-release.html (last accessed 2 July 2015).

1464 Y. Chouinard \& V. STAnley, The Responsible Company: What We've Learned from Patagonia's First 40 Years, (California; Patagonia Books, 2012). 
minimum wage is less than $\$ 70(€ 50)$ a month," 1465 and have been actively engaged in the lobbying efforts in an attempt to convince the Bangladeshi government and others to increase their minimum wage and working standards. ${ }^{1466}$ While there is valid reason for continued skepticism and questions over its ultimate impact, according to a Swedish watchdog, Swedwatch, there is room for some optimism as this is the first time H\&M "opened up to involving all stakeholders - the unions, the workers, the suppliers and the government" in their decision making process. ${ }^{1467}$ Even Wal-Mart voluntarily raised their baseline wage to current store employees (approximately 500,000 workers) to $\$ 10$ per hour, ${ }^{1468}$ and other companies like Ben \& Jerry's, Gap, and IKEA are following this trend by emulating industry leaders. ${ }^{1469}$ At a time where the US Congress are at a political gridlock and continuously failing to increase the federal minimum wage from $\$ 7.25$ per hour, this move by the private sector is a welcoming move, not to mention the fact that it gives companies like H\&M and Wal-Mart some much-needed positive press. While some of the initiatives may be just greenwashing or mere ad campaigns, continued and sustained efforts by intrinsically motivated companies can be a more meaningful and successful ways of remedying corporate reputation than by placing high on any ranking.

While many businesses might be afraid of emulating these measures, worrying that an ad campaign like Patagonia's or voluntarily increasing the wages of their workers like WalMart and H\&M would be an absolute disaster from a business perspective, there is plenty of evidence to show that socially responsible companies succeeded financially as well. Take for example, Alcoa (Aluminum Company of America). After choosing to improve worker safety by heavily investing in it, Alcoa increased their net income by fivefold and increased market capitalization by $\$ 27$ billion in a span of 13 years while becoming "one of the safest companies in the world" even though the business deals with smoldering aluminum. ${ }^{1470}$ The CEO of Alcoa that spearheaded this incredible feat, Paul O'Neill, stated that "you can't order people to change. That's not how the brain works," 1471 because in large companies with embedded practices, it is difficult to "flip a switch" and expect everyone to be more productive or cognizant of the bigger picture. ${ }^{1472}$ What O’Neill did was “to start by

1465 T. Sullivan, "H\&M May Raise Prices in Order to Pay Workers More," Agnece France Presse, (9 December 2013). Available at: http://www.huffingtonpost.com/2013/12/09/hm-may-prices-raise-worker_n_4414450.html (last accessed 4 April 2017).

1466 Ibid. It is worth noting here that perhaps as a result of these lobbying efforts, the Bangladeshi government did in fact raise their minimum wage to $\$ 67$ per month.

1467 Ibid. The article quoting Viveka Risberg.

1468 "Walmart announces Q4 underlying EPS of \$1.61 and additional strategic investments in people \& e-commerce Walmart U.S. comp sales increased 1.5 percent," Press Release, (19 February 2015). Available at: http://media.corporate-ir.net/media_files/IROL/11/112761/4Q15/Q4FY15_earnings_release_final.pdf (last accessed 19 February 2015).

1469 R. HisCOTT, “7 Companies That Aren't Waiting for Congress to Raise the Minimum Wage,” The Huffington Post, (26 June 2014). Available at: http://www.huffingtonpost.com/2014/06/26/companies-minimumwage_n_5530835.html (last accessed 19 February 2014).

1470 C. Duhigg, The Power of Habit: Why We Do What We Do in Life and Business, (New York: Random House, 2012), at p. 100, 101 (elaborating that "Alcoa became one of the best performing stocks in the Dow Jones index, while also becoming one of the safest places on earth" to work.).

1471 Ibid., at p. 100.

1472 Ibid., at p. 105. 
focusing on one thing. If I could start disrupting the habits around one thing [workplace safety]," he believed that that "would spread throughout the entire company."1473

Starbucks - with their seventeen thousand stores in more than fifty countries - share a similar story to that of Aloca. The one thing that Starbucks focused on though was employee empowerment. ${ }^{1474}$ By treating employees better and giving them a "sense of control" in their workplace, Starbuck was able to harness that energy into something that improved not only employee morale, but ultimately their business performance: "When people are asked to do something that takes self-control, if they think they are doing it for personal reasons if they feel like it's a choice or something they enjoy because it helps someone else - it's much less taxing. If they feel like they have no autonomy, if they're just following orders, their willpower muscles get tired much faster." 1475 (Recall here, some of the points made in this thesis back in Chapter 4 about the important of telos and having a sense of purpose or the importance of autonomy and self-determination earlier in this chapter). This idea of worker empowerment is the key to businesses reducing labor exploitation in the long run and it will be elaborated further in the subsection on capability building.

To conclude this particular part of the subsection, the main take away is that competition between businesses is fine, but a more desirable situation would be businesses learning from one another about where they succeed and where they fail. By emulating what works, good business practices can be expanded and more widely applied. Although simply cutting-and-pasting what another company does will not likely result in sustainable success for the company nor the further reduction of labor exploitations within their supply chain, if a company is properly motivated to learn from their mistakes or that of others, are willing to adapt, and intrinsically motivated to be responsible corporate citizens, they are capable of incredible changes.

\section{B. Synchronization of the Supply Chain and Automatization of Manufacturing}

Chapter 5 mentioned the emergence of the protean supply chain, but the next evolution of the supply chain will be the synchronization of the supply chain: "In theory, synchronization [of the supply chain] means that companies would make only the exact number of goods necessary to meet actual consumer demand. Synchronization means that there is no excess inventory throughout a supply chain spanning continents," believing that the synchronization of supply with demand "leads to increased output without the need for additional labor." 1476 This of course would only be possible with advances in technology and other inventions that have yet to be created. The synchronization of the supply chain is the epitome of supply chain management, which is the process of incentivizing companies "to

Ibid., at p. 100.

1474 C. Duhigg, The Power of Habit: Why We Do What We Do in Life and Business, (New York: Random House, 2012), at p. 148.

1475 C. Duhigg, The Power of Habit: Why We Do What We Do in Life and Business, (New York: Random House, 2012), at p. 150-1 (citing to a series of academic literature, including but not limited to: M. MuRAVEN, M. GAGNÉ \& H. Rosman, "Helpful Self-Control: Autonomy Support, Vitality, and Depletion," Journal of Experimental and Social Psychology 44(3) (2008): 573-85; M. MURAVEN, “Autonomous Self-Control is Less Depleting," Journal of Research in Personality 42(3) (2008): 763-70; M. MurAvEN, "Lack of Autonomy and Self-Control: Performance Contingent Rewards Lead to Greater Depletion," Motivation and Emotion 31(4) (2007): 322-30.).

1476 J.A. CoOKE, Protean Supply Chains: Ten Dynamics of Supply and Demand Alignment, (New Jersey; Wiley, 2014), at p. 2. 
pay attention to the interconnectedness of their operations"1477 to ensure that the "unify and rationalize otherwise incongruent parts of a dispersed organization." ${ }^{1478}$ While perfect synchronization may not be attainable, advances in technology is getting us closer: "[C]ompanies have moved closer to matching manufacturing output to true demand, flattening the boom-and-bust cycle of production that took place throughout the twentieth century. With no spokes in manufacturing, a company does not have to hire a drove of workers for extra shift to run more equipment." 1479 In a synchronized supply chain, the managers are more concerned about accurate forecasts and "reach[ing] perfect unity between supply and demand" and to "reduce forecast errors." 1480 The world of a synchronized supply chain, if indeed a possibility, could in fact lead to the reduction of unnecessary workers, although it is worth bearing in mind that just because the number of exploited laborers are reduced, does not mean that their lives improve as well.

While technology and tools capable of enhancing our communications and improving our collaboration could offer unimaginable ways of reducing instances of labor exploitation in the future, there will always be some spillover or some other unintended consequences as advances in technology will not only bring just benefits, but disruptions and other challenges as well: For example, in the global supply chain today, countries that can offer cheap labor - at times as a result of exploiting its labor force - has a competitive advantage to the extent that they are likely to sure up the business of those corporations concerned with profits and revenues. However, the availability of a cheaper option makes this so-called advantage ephemeral for the company offering cheap labor, as many multinational corporations tend to migrate from one country to another in search for cheaper and cheaper labor. ${ }^{1481}$ While we are quick to vilify the companies that go from country to country in search for cheaper labor options, it is worth asking the question of what happens when technology will finally be able to replace cheap, unskilled laborers. While from a business perspective, this will increase efficiency and reduce their concerns with labor exploitation, a question worth bearing in mind is what will happen to the laborers who would be replaced by automatization. ${ }^{1482}$ While this reality may be in a far away, distant future, if at all, as discussed back in Chapter 4, just because a company stops dealing with sweatshops or reduces their involvement in labor exploitation, does not necessarily mean that the lives of the workers - or former workers - will improve in the process. Acknowledging this prob-

1477 J.A. CoOKE, Protean Supply Chains: Ten Dynamics of Supply and Demand Alignment, (New Jersey; Wiley, 2014), at p. 5.

1478 P. Heckmann, D. Shorten \& H. Engel, "Supply Chain Management at 21: The Hard Road to Adulthood," Booz Allen Hamilton (2003). Available at: http://www.logisticsit.com/absolutenm/articlefiles/85Supply\%20Chain\%20Final.pdf (last accessed 4 April 2017).

1479 J.A. CoOKE, Protean Supply Chains: Ten Dynamics of Supply and Demand Alignment, (New Jersey; Wiley, 2014), at p. 3.

1480 J.A. CoOKE, Protean Supply Chains: Ten Dynamics of Supply and Demand Alignment, (New Jersey; Wiley, 2014), at p. 9.

1481 T. JuDT, Ill Fares the Land, (New York: Penguin, 2010), at p. 176-7 (noting that "[u]nskilled and semi-skilled work is fast disappearing, not just thanks to mechanized or robotized production, but also because the globalization of the labor market favors the most repressive and low-wage economies (China above all) over the advanced and more egalitarian societies of the West.").

1482 See e.g., M. FORD, Rise of the Robots: Technology and the Threat of a Jobless Future, (New York: Basic Books, 2015) (noting the possibility that many jobs will be lost as a result of automatization that will make laborers and workers obsolete); see also, C. BENEDIKT FreY \& M.A. OsBorne, “The Future of Employment: How Susceptible Are Jobs to Computerisation," Oxford Martin Programme on the Impacts of Future Technology Working Paper (2013). Available at: www.futuretech.ox.ac.uk/sites/futuretech.ox.ac.uk/files/The_Future_of_Employment_OMS_Working_Paper_1. pdf (last accessed 3 October 2015) (noting that $47 \%$ of all existing jobs is susceptible to being replaced by automatization and robotization of the supply chain within the next two decades). 
lem now, may prepare the legislatures for a possible future, of mass unemployment and the inability for people to find dignified jobs in large part due to the automatization of the manufacturing process.

Even the remote possibility of this scenario manifesting, requires us to think about how we treat our marginalized laborers in the event that we "become superfluous to the economy." 1483 Consulting firm McKinsey \& Co. estimates that "in the United States, only 30 percent of job growth now comes from algorithmic work, while 70 percent comes from heuristic work" because "[r] outine work can be outsourced or automated," while "artistic, empathic, non-routine work generally cannot." 1484 What this study suggests, is that in order to prepare for the unemployment endemic (which may or may not come), we must not only reduce the instances of labor exploitation, but we must equip the already marginalized workers with the necessary skills that would allow them to survive the synchronization of the supply chain and the automatization of the manufacturing process. With this in mind, while it is important to reduce labor exploitation today, we must also think about how to improve the lives of the marginalized workers by giving them the skills and training that will empower them and there are good reasons as to why businesses should want to do so. ${ }^{1485}$ This is due to the fact that we are looking at a future where there will be an oversupply of lowly skilled workers and a significant undersupply of workers with secondary or tertiary education and the businesses will be forced to compete with one another to retain the services of these highly-skilled laborers. This is to suggest that for businesses interested in survival and growth, it is becoming increasingly important to invest in the education and training of not their workers, but their workers of tomorrow. ${ }^{1486}$ The following subsection will bear this future need in mind in proposing how businesses, in the process of reducing labor exploitations today, can prepare for a better tomorrow at the same time.

The next recommendation of implementing a capability building approach, ${ }^{1487}$ which this thesis posits is one specific way of implementing our proposed alternative framework, is not just one way companies can change the traditional way in which they accumulate information and make decisions relative to their business, but moreover, reduce the likelihood of labor exploitation within their supply chain.

1483 T. JuDT, Ill Fares the Land, (New York: Penguin, 2010), at p. 15 (suggesting that what awaits these workers are anxiety, stress, illness and early death).

1484 D.H. PINK, Drive, (New York: Riverhead Books, 2009), at p. 28; citing, B.C. JOHNSON, J.M. MANYIKA \& L.A. YEE, "The Next Revolution in Interaction," Mckinsey Quarterly 4 (2005): 25-6.

1485 T. JUDT, Ill Fares the Land, (New York: Penguin, 2010), at pp. 176-7 (noting that "[i]n such circumstances the demand for new skills vastly outpaces our capacity to teach them - and those skills are anyway overtaken within a few years, leaving even the best-trained employee in the dust."); see also, R. DOBBS, A. MADGAVKAR, D. BARTON, E. Labaye, J. Manyika, C. Roxburgh, S. Lund \& S. Madhav, “The World at Work: Jobs, Pay, and Skills for 3.5 billion People,” McKinsey Global Institute, (12 June 2012) (predicting a severe shortage of highly-skilled laborers as the global labor force will approach 3.5 billion workers in 2030).

1486 R. Dobbs, A. Madgavkar, D. Barton, E. Labaye, J. Manyika, C. Roxburgh, S. Lund \& S. Madhav, "The World at Work: Jobs, Pay, and Skills for 3.5 billion People," McKinsey Global Institute (12 June 2012) (noting that "the world is likely to have shortage of workers without the skills necessary for full-time employment.").

1487 R.M. LOCKE, The Promise and Limits of Private Power: Promoting Labor Standards in a Global Economy, (Cambridge: Cambridge University Press, 2013), at pp. 20-22. 


\section{Capability Building Rather Than Monitoring and Punishing ${ }^{1488}$}

Chapter 4 cited to an MIT research that surveyed over 800 Nike suppliers, which concluded that companies seeking to resolve the issue of labor exploitation must start treating its workers, not as ends to some means, but as investments. ${ }^{1489}$ This part of the subsection will now address how companies can go about doing so by using the capability building approach as yet another example of how businesses can adopt our alternative framework. The premise of this approach is the adage "give a man a fish and he eats for a day, but if you teach a man how to fish, he eats for life." The basic framework of the capability building approach is for businesses to act more like "consultants by engaging in joint problem solving, information sharing, and the diffusion of best practices that were in the mutual self-interest of the suppliers and aligned with the policies of global buyers" rather than them acting as "inspectors that focus primarily on uncovering Code of Conduct violations and punishing management for these infractions." 1490 Another way to conceptualize this is to think of managers not as the "manipulative, jungle-fighter" types, but as "virtuoso[s] in interpersonal skills." 1491 What this approach recommends is that rather than always sticking to the traditional way companies enforce their codes of conduct - through inspecting, monitoring, auditing, and sanctioning their supply chain - companies should take a "less antagonistic" approach, opting instead for more cooperation and collaboration with other companies within their supply chain. ${ }^{1492}$

This could be a very effective strategy considering that most suppliers especially in developing economies already "lack resources, technical expertise, and management systems necessary to address the root causes of compliance failures" in the first place. ${ }^{1493}$ As noted back in Chapter 5, the reality of our current supply chain is that buyers are not only demanding cheaper materials from their suppliers, but they want it to be produced faster in a socially responsible manner. ${ }^{1494}$ The conflict is that asking for one often make it difficult to

1488 This part of the section was modified and will be published in M.T. KAWAKAMI, "Pitfalls of Over-Legalization," Indiana Journal of Global Legal Studies, 24(1) (2017):

1489 S.J. FrenKEL \& D. SCOTT, "Compliance, Collaboration, and Codes of Labor Practice: The Adidas Connection," California Management Review 45(1) (2002): 29-49; see also, R. LOCKE, F. QIN \& A. BRAUSE, "Does Monitoring Improve Labor Standards?: Lessons from Nike," MIT Sloan School of Management Working Paper No. $4612-06$ (2006), at p. 1-2. Available at: http://ssrn.com/abstract=916771 (last accessed 4 April 17) (noting that when monitoring mechanisms are combined with other measured focused on "tackling root causes of poor working conditions," working condition appear to improve).

1490 R.M. LOCKE, The Promise and Limits of Private Power: Promoting Labor Standards in a Global Economy, (Cambridge: Cambridge University Press, 2013), at p. 181.

1491 D. Goleman, Emotional Intelligence, (New York: Bantam Books, 2005), at p. 149 (quoting Shoshona Zuboff, a psychologist at the Harvard Business School); see also, S. ZuBofF, In the Age of Smart Machine, (New York: Basic Books, 1991).

1492 R.M. LoCKE, The Promise and Limits of Private Power: Promoting Labor Standards in a Global Economy, (Cambridge: Cambridge University Press, 2013), at pp. 18, 181 (noting also that "more collaborative buyer-supplier relations were based on a fundamental understanding that both the risks and the rewards of doing business together would be distributed more or less fairly between the parties; the gains would not be captured nor the losses borne by one or the party alone. It was this recognition and the positive spillovers it generated that created the real incentives for private firms to engage in the most effective private voluntary initiatives...”).

1493 R.M. LOCKE, The Promise and Limits of Private Power: Promoting Labor Standards in a Global Economy, (Cambridge: Cambridge University Press, 2013), at p. 78.

1494 R.M. LOCKE, The Promise and Limits of Private Power: Promoting Labor Standards in a Global Economy, (Cambridge: Cambridge University Press, 2013), at p. 38 (noting that " $[w]$ hile sourcing departments continue to squeeze factories on price, compress lead times, and demand high-quality standards, compliance officers visit the factories and document the problems but do little to change the root causes underlying poor working conditions.”). 
satisfy the other: This is to suggest that our instinct for acquisition in the age of proliferation "exacerbate the situation by making short-term orders which can only be completed by working overtime, by requiring compliance with CSR clauses without providing financial support to achieve these, by turning a blind eye on flaws in the auditing process and by not committing to suppliers long term." 1495 As a result, buyers and suppliers are locked in what was referred earlier to as a "low-trust trap," where companies expect their supply chain to deliver more, faster and cheaper. ${ }^{1496}$ What the buyers are expecting from their suppliers in many cases is the impossible and adding threats of legal sanctions to comply with corporate codes does not necessarily make the impossible any more possible.

In what Thomas Nagel calls the "view from nowhere" mindset, in order to build a relationship based on mutual respect and collaboration, what is necessary is an empathetic process of "putting yourself in someone else's shoes," a step rarely taken by the buyers who only see their suppliers as cogs in the manufacturing machine. ${ }^{1497}$ To put it differently, what we need more of are buyers that are willing to invest in building their suppliers' capabilities so that they can be socially responsible in the long run:

"Capability building programs envision a mutually reinforcing gycle in which more efficient plants invest in their workers and that these more skilled and empowered employees, in turn, promote continuous improvement processes throughout the factory, rendering these facilities more and more efficient and therefore more capable of producing high-quality goods on time, at cost, in the quantitates desired by ever-more demanding customers, while at the same time respecting corporate codes of conduct.",1498

It is this sense of a collective undertaking and working together-ness that this thesis posits as the prerequisites for modifying corporate behavior in alignment with our adapted capabilities and alternative frameworks. ${ }^{149}$ Rather than punishing suppliers even further for their failures or magically expecting them to offer unrealistically low prices while being in full compliance to their codes of conduct, the buyers must do more. This starts by acknowledging the fact that workers need "intensive attention," which includes showing them what "success" actually looks like, walking them through the process, and showing them "support along the way." 1500 Similar to how we saw back in Chapter 2 that some of the sweatshop laborers are unwilling to cooperate with auditors and investigators by lying for their exploitative owners, laborers in the supply chain will not be willing to cooperate with Western brands, if their commitment is not real and what real commitment means, at least from their perspective is physical presence - a continuous or a frequent one at that of companies buying their services. As shown back in Chapter 5, we are communal crea-

1495 A. RÜHmkORF, Corporate Social Responsibility, Private Law and Global Supply Chains, (Cheltenham: Edward Elgar, 2015), at p. 229.

1496 R.M. LoCKE, The Promise and Limits of Private Power: Promoting Labor Standards in a Global Economy, (Cambridge: Cambridge University Press, 2013), at p. 124.

1497 See generally, T. NAGEL, The Possibility of Altruism, (Princeton: Princeton University Press, 1970) (referring to this approach as taking on the "bird's-eye view" or "agent-neutral role").

1498 R.M. LOCKE, The Promise and Limits of Private Power: Promoting Labor Standards in a Global Economy, (Cambridge: Cambridge University Press, 2013), at p. at 17.

1499 M. TOMASEllo, Why We Cooperate, (Cambridge: MIT Press, 2009), at pp. 41, 57 (continuing to stress that there is a uniquely human sense of "we," which is a "sense of shared intentionality.").

1500 T. DiDONATO \& N. GiLl, "Changing an Organization's Culture, Without Resistance or Blame,” Harvard Business Review, (15 July 2015). 
tures that care less about those we do not see or those that are outside of our herds. Therefore, in order for businesses to start caring more about their employees or laborers within their supply chains is to actually meet and see the laborers, quite literally. What could benefit the suppliers is if the buyers focused on building relationships with the suppliers based on collaboration, mutual respect, and the aforementioned social norms (i.e. reciprocity), which is more conducive to creating and fostering intrinsic motivations. ${ }^{1501}$

Building this type of a relationship takes time and a significant amount of trust in an otherwise cutthroat, "protean" business environment where buyers uproot and move entire operations from a supplier in one country to another all to shed a few pennies. Perhaps this is why so few companies do so, opting instead to stick to the carrot-or-stick approach. ${ }^{1502}$ What is necessary in the end is a shift in management thinking and for the buyers to see their suppliers and their workers as assets, as something to be invested in in order to build trusting, collaborative relationships with shared goals and a common sense of purpose. ${ }^{1503}$ Labor exploitations of marginalized workers in the global supply chain can indeed be reduced, but before we can do so, we need companies not just to say that they are being socially responsible or that they implementing corporate codes, but by actually being more hands on and helping their suppliers and partners upstream treat their workers better and being understanding when even they fail. ${ }^{1504}$

Asked as to why Wal-Mart voluntarily raised their wage, CEO Doug McMillon stated that this decision was a "strategic investment" that "reignites the sense of ownership" that the workers have in their business. This is quite similar to why Starbuck and Aloca empowered their workers through education programs and gave them a voice in the process of conducting the company's business. This new wave thinking of empowering a company's labor force is something that consultancies now advocate for as well: For example, firms such as Deloitte Touche Tohmatsu now recommend that businesses ought to "focus on people and purpose, not just products and profits in the $21^{\text {st }}$ century." 1505 In order to be a "good" corporate citizen - to be considered as a benefit to a society and to provide meaningful contributions to the public - a company must first treat its own workers right, but

1501 R.M. LOCKE, The Promise and Limits of Private Power: Promoting Labor Standards in a Global Economy, (Cambridge: Cambridge University Press, 2013), at p. at 18 (describing a collaborative buyer-supplier relationship to be one that is "based on a fundamental understanding that both the risks and the rewards of doing business together would be distributed more or less fairly between the parties; the gains would not be captured nor the losses borne by one or the party alone." Locke continues to argue that "this recognition and the positive spillovers it generated" is what "created the real incentives for private firms to engage in the most effective private voluntary initiatives...”).

1502 D. VogeL, The Market for Virtue: The Potential and Limits of Corporate Social Responsibility, (Washington D.C.: Brookings Institution Press, 2006), at p. 94 (noting that "[w] hile some Western firms have developed long-term relationships with suppliers, they are exceptional.").

1503 R. LOCKE, F. QIN \& A. BRAuSE, "Does Monitoring Improve Labor Standards?: Lessons from Nike," MIT Sloan School of Management Working Paper No. 4612-06 (2006), at p. 1-2. Available at: http://ssrn.com/abstract=916771 (last accessed 4 April 2017); see also, S.J. FrENKEL \& D. SCOTT, "Compliance, Collaboration, and Codes of Labor Practice: The Adidas Connection,” 45 California Management Review 29 (2002).

1504 S.J. FrenkeL \& D. SCOTT, "Compliance, Collaboration, and Codes of Labor Practice: The Adidas Connection," California Management Review 45(1) (2002): 29-49.

1505 Deloitte Touche Tohmatsu, "Business needs to reset its purpose to attract Millennials, according to Deloitte's annual survey," Press Release, (14 January 2015). Available at: http://www2.deloitte.com/an/en/pages/aboutdeloitte/articles/2015-millennial-survey-press-release.html (last accessed 2 July 2015). 
there is more than one way to accomplish this task. ${ }^{1506}$ An empowered worker is a committed worker and businesses can empower their workers further by investing in them and training them. The return on investment for this is a group of skilled, loyal employees that, as noted earlier, will be in short supply in the near future: As the aforementioned McKinley report suggested "[b]usinesses operating in this skills-scarce world must know how to find talent pools with the skills they need and to build strategies for hiring, retaining, and training the workers who will give them competitive advantage." 1507 The argument made here is that there is no better way for businesses to build brand loyalty and improve output, than by investing in their workers and training the workers operating within their supply chain. Without creating more laws, legalizing corporate codes, or employing other extrinsic incentives and demanding their upstream subcontractors or manufacturers to meet them, downstream buyers can help their suppliers implement the capability building approach.

Above and beyond simply implementing codes of conduct and monitoring their supply chain for compliance, downstream buyers can also improve the capabilities of workers further up the supply chain by increasing their capabilities, not just in a traditional sense, but by making the lives of these workers a bit easier: For example, as Amnesty International recommends, companies should do more than just "ensuring that a plan is put in place and implemented to remove children from the worst forms of child labour," but they ought to "support children's reintegration into the school system and address children's health, physical, educational, economic and psychological needs." ${ }^{1508}$ While there are no legal obligations for companies to do so, if companies are indeed serious about being socially responsible and alleviating the plight of the workers, implementing capability enhancing programs are much more meaningful and hands on than implementing codes of conduct or seeing how high they place on rankings. For example, a handful of global firms, like Nike already have community development programs that set up schools or offer microenterprise loans for workers that work in their suppliers' factories in developing countries. ${ }^{1509}$ What is more impressive than a private label on a product claiming to be sweatshop free is if companies offered scholarships, vocational trainings, and basic necessities to the workers in their supply chain. ${ }^{1510}$

1506 B. Horowitz, The Hard Thing About Hard Things: Building a Business When There Are No Easy Answers, (New York: Harper Collins, 2014), at p. 133 (stating that "[m]anagement purely by numbers is sort of like painting by numbers - it's strictly for amateurs.").

1507 R. Dobbs, A. Madgavkar, D. Barton, E. Labaye, J. Manyika, C. Roxburgh, S. Lund \& S. Madhav, "The World at Work: Jobs, Pay, and Skills for 3.5 billion People," McKinsey Global Institute, (12 June 2012).

1508 Amnesty International \& AFrewatch, This is What We Die For: Human Rights Abuses in the Democratic Republic of the Congo Power the Global Trade in Cobalt, AFR 62/3183/2016 (London: Amnesty International, 2016), at p. 70.

1509 D. VOGEL, The Market for Virtue: The Potential and Limits of Corporate Social Responsibility, (Washington D.C.: Brookings Institution Press, 2006), at p. 81 (detailing Nike's involvement in particular and how the company, through this initiative, has sent over 10,000 employees across 37 footwear contractors in Indonesia, China and Thailand to schools); see also, L.P. HARTMAN \& R.E. WOKUTCH, "Nike, Inc.: Corporate Responsibility and Workplace Standard Initiatives in Vietnam," in Rising Above Sweatshops: Innovative Approaches to Global Labor Challenges, L.P. Hartman, D.G. ARnOld \& R.E. WOKuTCH (EDS.) (Westport: Praeger Publishers, 2003): 145-190, 150-8.

1510 E.B. KAPSTEIN, "The Corporate Ethics Crusade," Foreign Affairs, (September/October 2001). Available at https://www.foreignaffairs.com/articles/2001-09-01/corporate-ethics-crusade (last accessed 2 February 2016); cited in, D. VogeL, The Market for Virtue: The Potential and Limits of Corporate Social Responsibility, (Washington D.C.: Brookings Institution Press, 2006), at p. 99 (adding that only a small number of companies such as Ikea, H\&M, and Nike offer programs like this). 
What is necessary for any of this to be possible in the first place is for businesses to start an open dialogue with the workers in their supply chain (i.e. adopting our alternative framework), to see and look at the faces of the people manufacturing their products. This not only serves to literally close the gap both psychically and psychologically between the company and the workers in the supply chain, but based on the cognitive tendencies noted back in Chapter 5, this makes it more difficult for companies to turn their collective eyes blind. There are signs of MNCs considering the capability building approach in one way or another: For example, after a large group of Foxconn's workers committed or attempted to commit suicide back in 2010 due to punishing and degrading work environment at Foxconn's factory in China, Apple took the initiative to start a dialogue with Foxconn and agreed to share their CSR responsibilities with them, with Apple agreeing that this is not just "Foxconn's burden alone," but rather a "shared responsibility between Foxconn and its outsourcers." 1511 While this was indeed a good start, what would have been an even more impressive initiative would have been if Apple extended this dialogue to the workers at Foxconn and created a more open and accessible feedback mechanism for any of the workers in their supply chain to voice their concerns without fear of suffering any repercussions. However, considering the fact that in some of the countries where labor exploitations are most rampant, the right to unionize or to publicly voice dissent is a punishable offence, not to mention their limited access to the Internet, perhaps our expectations need to be tempered a in this regard.

The caveat in the end is the admission that soft approaches alone will not always get the job done and in some cases sanctions and punishments becomes necessary. The argument, however, was never for the capability approach to replace the implementation of corporate codes and monitoring outright. The suggestion merely was for companies to bear in mind that extrinsic incentives like codes of conduct and threats of enforcing them through legal sanctions ought to be more of "a background condition or fallback mechanism aimed at fostering the joint problem solving initiatives..."1512 By choosing to focus more on a softer, social norms (i.e. reciprocity) based approach, by being more inclusive, reflexive, and adaptive thus creating a more amicable relationship with the upstream companies, the argument was that everyone can benefit, including the workers who now have a voice and the chance to be empowered. ${ }^{1513}$ By adopting reflexive governance/adaptive management strategies, stakeholders within the company will not just be better informed, but a as result,

1511 Y.S. ANG, "Ethical Outsourcing and the Act of Acting Together," in Empowering Organizations through Corporate Social Responsibility, R. Wolf, T. ISSA \& M. ThIEL (EDS.) (Pennsylvania: IGI Global, 2015), at pp. 120, 127 (adding that "[a] sharing of CSR responsibility is empowering because each participant would take ownership over the task.").

1512 R.M. LOCKE, The Promise and Limits of Private Power: Promoting Labor Standards in a Global Economy, (Cambridge: Cambridge University Press, 2013), at p. at 181.

1513 R.M. LOCKE, The Promise and Limitations of Private Power: Promoting Labor Standards in a Global Economy (Cambridge: Cambridge University Press, 2013), at p. 124; see also, S.J. FrENKEL \& D. SCOTT, "Compliance, Collaboration, and Codes of Labor Practice: The Adidas Connection," California Management Review 45(1) (2002): 29-49; and, S.V. Coslovsky \& R. LOCKE, "Parallel Paths to Enforcement: Private Compliance, Public Regulation, and Labor Standards in the Brazilian Sugar Sector," Politics \& Society 41(4) (2013): 497-526, 519 (stressing that businesses must "find ways to educate top managers and persuade them that introducing modern production, work, and personnel practices will contribute to the bottom line."); and, S.V. CosLOVSKY, "Social Problem-Solving in the Brazilian Ministerio Publico: The Organizational Basis of Regulatory Responsiveness," Regulation \& Governance 5(1) (2001): 70-89. 
the company will be able to better determine with improved probability about which course of action would work best for the particular situation at hand. In some cases, a "radical devolution of power and responsibility to frontline employees," might be necessary, whereas in other cases, a more top-down regulatory approach might be best. ${ }^{1514}$ The beauty of having the reflexive governance/adaptive management approach as a default is that the businesses can adapt better as circumstances require.

In discussing benefit corporations back in Chapter 4, this thesis noted how in the early days of corporations, they operated within their communities and how their employees, even the directors, lived in that community. This meant that the interest of that community, the interest of the company, and that of its employees were all aligned (or at least more so than today), which reduce the reliance or even the need for the law to regulate corporate behavior. While in the aftermath of globalization, going back to this model will prove extremely difficult, if not impossible, ${ }^{1515}$ it is worth noting that "[i]n face-to-face communities where everybody has knowledge of the community's laws, customs, and uses, opportunistic extractive and selfish behavior, while certainly not absent, is collectively monitored." 1516 In light of this fact, our alternative framework, which is in alignment with our adapted capabilities approach that necessitates companies to interact more, not just with their own workers, but other relevant stakeholders within their supply chain may be argued as the most prudent strategy for businesses seriously interested in reducing instances of labor exploitation in the global supply chain.

Ultimately, the recommendations for the businesses to facilitate the implementation of the alternative framework can be summarized in the following manner: Businesses should resist the urge to implement and adopt various CSR initiatives just for the sake of good publicity and placing high on the rankings as doing so could crowd out their intrinsic incentive (i.e. to be socially responsible) with extrinsic incentives (i.e. rank higher). Instead, businesses should learn from and emulate businesses that are actually intrinsically motivated and are practicing what they believe in. Last, but not least, businesses must focus more on building the capabilities, not just of their employees, but that of their business partners up and down the supply chain. Rather than using extrinsic incentives (e.g. threatening to reduce the number or orders, terminating the contract, etc.), downstream businesses that impose a code of conduct on their upstream manufacturers or suppliers should work with them and foster a relationship of trust by teaching them how to actually be more socially responsible, by investing their time and resources.

\subsubsection{Recommended Role of the Consumers}

Having established some of the practical ways in which governments and businesses can adopt our alternative framework, this subsection will now address the role of the consum-

1514 T. HARFORD, Adapt: Why Success Always Starts with Failure, (London: Abacus, 2012), at p. 225, 227 (caution that "[t]he correct balance between centralized control and decentralized experimentation depends on circumstance.").

1515 F. CAPRA \& U. MATTEI, The Ecology of Law: Toward a Legal System in Tune with Nature and Community, (Oakland: Berrett-Koehler, 2015), at p. 112 (noting that "CEOs and boards of directors are located far from where their decisions will have dramatic impact, and corporate charters make such decisions almost obligatory.”).

1516 F. CAPRA \& U. MATTEI, The Ecology of Law: Toward a Legal System in Tune with Nature and Community, (Oakland: Berrett-Koehler, 2015), at p. 139. 
ers and how they can implement the alternative framework to further reduce instances of labor exploitation in the global supply chain. ${ }^{1517}$ The recommendation here is not for consumers to simply "abstain from consumption altogether," but bearing in mind the "inherent limitation of simply exhorting people to [consume differently] by changing their behaviours," more practical approach must be considered. ${ }^{1518}$ Accordingly, this subsection will: a) suggest that consumers learn how to change their habits; b) propose that they reconsider how they go about boycotting; c) stress the importance of moral reminders and awareness education; d) advocate for the utility of a collaborative consumer feedback mechanism; and finally, e) argue in favor of creative work centers.

By this point, it should be abundantly clear that this thesis does not offer any of the practical measures or strategies as the panacea to the problem of labor exploitation. Measures and strategies below aimed towards the consumers, similarly will not be the proverbial magic bullet, but should be considered as additional tools in the consumers' toolbox full of different strategies that, if used in the right way, at the right time, in the right circumstances may reduce instances of labor exploitation in the global supply chain.

\section{A. Learn How to Change Habits}

Having noted the importance of habits and the role of our cognitive System 1 back in Chapter 5, one way to rephrase our research question of what can consumers do differently is to ask how can our alternative framework go about changing consumers' habits in a manner that would either empower exploited laborers or alleviate their plight. First, let us equivocate buying unethically produced clothing to drinking alcohol cigarettes. Just like quitting drinking, "[g]enuine change requires work and self-understanding of the cravings driving behavior," so changing starts with questions like, "why do I want to drink?"1519 A partial explanation to why we crave to consume was already explained back in Chapter 5 with the concept of cathexis and our instinct of acquisition. Second, the "golden rule of habit change," is that "we can't extinguish a bad habit, but we can only change or replace it." 1520 Similar to how Alcoholic Anonymous replaces drinking with faith, consumers must learn how to find self-worth in something other than material possessions. ${ }^{1521}$ Understanding the key to what we crave and why we crave is the first step to changing or replacing our current behavior with perhaps a more socially responsible one.

Another explanation as to why we crave to consume is because businesses understand the psychology behind this better than anyone else and uses it to their advantage by making us not only demand their products, but by creating a craving for them. In this way businesses and marketing departments are expert nudgers that get consumers to want some-

1517 M. NAím, The End of Power: From Boardrooms to Battlefields and Churches to States, Why Being in Charge Isn't What It Used to Be, (New York: Basic Books, 2013), at p. 243 (reiterating that even "average citizens can meaningfully participate in the political process.").

1518 T. HARFORD, Adapt: Why Success Always Starts with Failure, (London: Abacus, 2012), at p. 166.

1519 C. Duhigg, The Power of Habit: Why We Do What We Do in Life and Business, (New York: Random House, 2012), at pp. 59, 77 (stating that "[c]ravings are what drive habits. And figuring out how to spark a craving makes [forming] a new [or different] habit easier.").

1520 C. Duhigg, The Power of Habit: Why We Do What We Do in Life and Business, (New York: Random House, 2012), at pp. 63,92 .

1521 D. ArIELY, The (Honest) Truth About Dishonesty: How We Lie to Everyone - Especially Ourselves, (New York: Harper Collins, 2012), at p. 70. (noting that "by creating cultures where new values become ingrained... [k]eystone habits make tough choices... easier, because when [a] person violates the culture, it's clear they have [to be let] go.”). 
thing regardless of whether consumers really need it or not. In other words businesses have successfully changed our habits so we are uncomfortable when we are not consuming or when we do not have certain products in our possession; and this dependence has made some companies fortunes. ${ }^{1522}$ While this may sound sinister, there is hope in knowing that people can be influenced and their habits changed through cleverly designed marketing schemes and advertisements, because it also suggests that they can change our habits for the better, so long as stakeholders think of intelligent ways to do this through our alternative framework. Although this is perhaps, easier said than done, another factor that might prove to be helpful in changing our habits, according to sociology, is that being "embedded in social groups" that share the same goals "[makes] change easier," 1523 which confirms our previous findings about the importance of community and our herd mentality, even in changing our habits. ${ }^{1524}$

If we are able to adapt our individual habits, then societal habits can be changed as well. ${ }^{1525}$ The process of changing societal habits, as historians and sociologists note, takes place in three stages: 1) A movement is initiated though changes in "social habits of friendship and the strong ties between close acquaintances"; 2) the movement "grows because of the habits of a community, and the weak ties that hold neighborhoods and clans together"; and finally 3 ) the movement "endures because movement's leaders give participants new habits that create fresh sense of identity and a feeling of ownership." 1526 It is interesting to note that these three steps incorporate most, if not all of the variables that our alternative framework espouses, from the importance of the community, adherence to social norms, sense of purpose (telos), and so on. In the end, "[m]ovements don't emerge because everyone suddenly decides to face the same direction at once. They rely on social patterns that begin as the habits of friendship, grow through the habits of communities, and are sustained by new habits that change participants' sense of self." 1527

With this in mind, this part of the subsection on habits can be summarized in the following manner: We are creatures of habit, acting frequently without careful deliberation or thinking through the consequences of our actions thanks to our System 1. Our consumption habits are good examples of this claim. This fact once again justifies the adoption of

1522 C. Duhigg, The Power of Habit: Why We Do What We Do in Life and Business, (New York: Random House, 2012), at pp. 37, 51 (noting how companies such as Proctor \& Gamble use people's habit loops to make billions in revenue).

1523 C. Duhigg, The Power of Habit: Why We Do What We Do in Life and Business, (New York: Random House, 2012), at p. 88; cf. T.F. HeAtherTON \& P.A. Nichols, "Personal Accounts of Successful Versus Failed Attempts at Life Change," Personality and Social Psychology, 20(6) (1994): 664-75 (observing that people who radically changed their lives or remade their habits often did so after experiencing personal tragedy or saw someone go through something awful).

1524 See generally, J. BERGER, Invisible Influence: The Hidden Forces that Shape Behaviour, (London: Simon \& Schuster, 2010).

1525 C. Duhigg, The Power of Habit: Why We Do What We Do in Life and Business, (New York: Random House, 2012), at p. 217 (suggesting that "[s]ocial habits are why some initiatives become world-changing movements, while others fail to ignite.").

1526 See generally, G. DAvis, D. MCADAM \& W. SCOTT, Social Movements and Organizations, (New York: Cambridge University Press, 2005); A. WALder, "Political Sociology and Social Movements," Annual Review of Sociology 35 (2009): 393-412; R. BENFORD \& D. SNOw, "Framing Processes and Social Movements: An Overview and Assessment," Annual Review of Sociology 26 (2000): 611-39; cited in, C. DuHIGG, The Power of Habit: Why We Do What We Do in Life and Business, (New York: Random House, 2012), at p. 217 (adding that usually "only when all three parts of this process are fulfilled can a movement become self-propelling and reach a critical mass.”).

1527 C. Duhigg, The Power of Habit: Why We Do What We Do in Life and Business, (New York: Random House, 2012), at p. 224. 
our alternative framework that advocates for a more adaptive and reflexive decisionmaking process, whether from law and economics approach to the law and behavioral economics approach, from government mandates regulations to private global norm production depending on the circumstances. While behavioral scientists generally concur that re-engineering individual habits or organizational routines is indeed possible, the prerequisite for this change to succeed is the belief that they are capable of changing their habits or changing the world outside of them: In other words, "for habits to permanently change, people must believe that change is feasible," and our alternative framework facilitates this mindset. ${ }^{1528}$

\section{B. Reconsider Boycotts and Naming-and-Shaming}

Yet another impact that the implementation of our alternative framework can have is to initiate the necessary reassessment of some of the existing strategies that consumers standby. One of the very popular strategies that consumers believe to be making an impact on whether companies exploit their workers or not is boycotting companies associated with or accused of exploiting the laborers in their supply chain. Another practice related to boycotting is the oft-used non-legal mechanism to incentivize socially responsible behavior, which is naming-and-shaming. ${ }^{1529}$ Kenneth Roth, the Executive Director of Human Rights Watch, adds that " $[\mathrm{t}]$ he key to this enforcement pressure is exposure and shame... the resulting publicity, through the media and other outlets, can undermine [the target's] credibility, embarrassing it before its people and peers and generating pressure for reform." 1530 In order for activists to galvanize the public, Daniel Diermeier, ${ }^{1531}$ states the following: Among the factors that determine a boycott's success, the following are important: 1) consumers must care passionately, 2) the cost of participation must be low, 3) the issues must be easy to understand; and 4) mass media is still essential. ${ }^{1532}$ Some firmly believe that boycotts can bring about changes for the better, and that consumers choosing to pay more for socially responsible goods will "diminish child labour and probably other harsh working conditions."1533

1528 K.E. WEICK, "Small Wins: Redefining the Scale of Social Problems," American Psychologist 39 (1984): 40-49; cited in, C. Duhigg, The Power of Habit: Why We Do What We Do in Life and Business, (New York: Random House, 2012), at p. 89, 104.

1529 D. DiERMEIER, “When Do Company Boycotts Work?," Harvard Business Review, (6 August 2012). Available at: https://hbr.org/2012/08/when-do-company-boycotts-work (last accessed 20 January 2016) (noting that "[c]ompany boycotts... have increasingly become the weapon of choice for NGOs and other activists aiming to further political and social goals.”).

1530 K. ROTH, "What are Human Rights For? Three Personal Reflections," International Human Rights Law, D. Moeckli, S. Shah, S. Sivakumaran \& D. Harris (EDS.) (Oxford: Oxford University Press, 2010), at p. 9 (adding that "[s] hame can be a powerful motivator.").

1531 The IBM Professor of Regulation and Competitive Practice Director of the Ford Motor Company Center for Global Citizenship at the Kellogg School of Management at Northwestern University.

1532 D. Diermeier, "When Do Company Boycotts Work?,” Harvard Business Review, (6 August 2012). Available at: https://hbr.org/2012/08/when-do-company-boycotts-work (last accessed 20 January 2016); see also, D. DIERMEIER, Reputation Rules: Strategies for Building Your Company's Most Valuable Asset, (New York: McGraw-Hill, 2011).

1533 H. COLLINS, "Conformity of Goods, the Network Society, and the Ethical Consumer," European Review of Private Law 5 (2014): 619-640, 626. 
However, there is conflicting evidence to suggest the limited effectiveness of boycotts, some of which have already been documented in this thesis. ${ }^{1534}$ If anything, the more popular opinion among the experts is that "[t]ypically, even high-profile protests have only negligible financial impact." 1535 Moreover, even if consumers boycott and companies do end up changing their behaviors, this could mean that companies simply sever ties with the less than reputable upstream businesses that was exploiting their laborers in the first place. This is to suggest that given the causation problem noted back in Chapter 4 and the complexity problem in Chapter 5, boycotts, if not done right, could actually end up exacerbating the plight of the marginalized workers. Again, the recommendation here is not for consumers and NGOs to simply stop boycotting, but for them to seriously consider the impact of the boycott and the people that they claim to care for.

In sum, even if consumers care enough to make socially responsible purchasing decisions or boycott purchasing from irresponsible companies, there is a lingering concern whether they will actually be capable to decipher the "socially responsible" companies from those that are not. ${ }^{1536}$ Even assuming that they are capable of combing through multiple findings, and they decide to boycott a company, there is enough evidence to suggest that most boycotts often have a very limited impact. If anything, there is a serious concern that boycotting a company, which in turn might force the targeted company to change their supplier or manufacturer, can actually exacerbate the lives of workers who have been laid off due to a decreased demand from the boycotted company. So this is one possible scenario, where good intentions lead to making the situation worse, a spillover effect leading to yet another unintended consequence.

Bearing these concerns in mind, a reassessment of boycotting or naming-and-shaming campaigns is very much necessary. This is not to suggest, again, that consumers should refrain from boycotting all together, but to think through what impact it will actually have on the laborers being exploited on the other side of the globe. If consumers are indeed serious about changing their consumption habits, a more fundamental change, is not necessarily boycotting purchasing from socially irresponsible companies and simply buying whatever items in question from another company, consumers can simply buy less. Recall here our previous discussion about the age of proliferation and our instinct of acquisition. Part of the reason why there is so much pressure being put on the laborers up and down

1534 H. Collins, "Conformity of Goods, the Network Society, and the Ethical Consumer," European Review of Private Law 5 (2014): 619-640, 626 (stating that boycotts will not bring about the improved working conditions in the global supply chain); citing, E.V. EDMONDS \& N. PAVCNIK, "The Effect of Trade Liberalization on Child Labor," Journal of International Economics 65(2) (2005): 401-419, 401; see, E.V. EDMONDS \& N. PAVCNIK, "International Trade and Child Labor: Cross-Country Evidence," Journal of International Economics 69 (2006): 115-140; D. DIERMEIER, "When Do Company Boycotts Work?," Harvard Business Review, (6 August 2012). Available at: https://hbr.org/2012/08/when-do-company-boycotts-work (last accessed 20 January 2016) (noting that while some boycotts can be effective (i.e. Greenpeace's boycott of Shell in 1995 reduced their sales in Germany by up to $40 \%$ ), "most [boycotts] fail to have any noticeable impact"); and, M. HoBBES, "The Myth of the Ethical Shopper," The Huffington Post, (2015). Available at: http://highline.huffingtonpost.com/articles/en/the-myth-of-the-ethicalshopper/ (last accessed 16 July 2015) (suggesting the idea that boycotts may be dead).

1535 D. VOGEL, The Market for Virtue: The Potential and Limits of Corporate Social Responsibility, (Washington D.C.: Brookings Institution Press, 2006), at p. 51.

1536 H. Collins, "Conformity of Goods, the Network Society, and the Ethical Consumer," European Review of Private Law 5 (2014): 619-640, 626 (noting that "[t] he consumer is probably wise not to trust completely the claims of ethical trading issued by global businesses but equally needs to be circumspect in participating in product boycotts that may backfire.”). 
the supply chain is in part due to the increasing and insatiable demand created by modern day consumers. This, as we mentioned back in Chapter 4 is exacerbating, if not causing, businesses to exploit their laborers. To be clear, even if consumers were to change their habits and "adopt a minimalist approach" to consumption, ${ }^{1537}$ this could still have unintended consequences, which requires consumers to remain vigilant, and adapt their habits continuously.

So while no conclusive recommendation can be given here with regards to naming-andshaming or boycotting other than for consumers to reconsider its effectiveness, at least one fact becomes evident: Consumers must change their own habits first before seeking to change the world around them, ${ }^{1538}$ because as Diermeier noted above, lasting changes start with the consumers taking the initiative to change their daily habits and spreading interest to the greater community. This is how our collective habits change and new norms emerge. This brings us to the conclusion that boycotting for the sake of boycotting, much like companies adopting corporate codes for the sake of rankings, may not necessarily lead to better outcomes for the marginalized workers. One broader recommendation for the consumers on this point - which is related to a recommendation that was offered to businesses in the previous subsection - is for consumers to actively supported companies that have adopted a capability building approach for their workers and their supply chains. This is the more supportive way of ensuring that the consumers are purchasing from a company that treats their workers and laborers with at least a modicum of dignity and respect.

\section{Moral Reminders and Awareness Education}

Earlier, Chapter 5 touched upon the issue of people's cognitive flexibility. On this subject, Dan Ariely observed that "lots of people cheat, but just by a bit," and the reason why they cheat by only a bit is that if they cheat by a lot, they would lose their sense of integrity. ${ }^{1539}$ Cheating in our context could be portrayed as purchasing goods because they are cheap, even when we know or suspect that the goods were likely made in sweatshops. Ariely's observation, at least in part, can explain the cognitive dissonance of the consumers, where they claim that they do not advocate for labor exploitation, but still purchase clothes made in sweatshops. In accordance with Ariely's observations, consumers also do this "up to the level that allows [them] to retain [their] self-image as reasonably honest individuals." 1540

One way to reduce instances of consumers "cheating" that does not require excessive legislative involvement and yet another possible tool in our holistic arsenal is the introduction of a moral reminder in our daily lives. Experiments in sociology and anthropology have shown that for many individuals, "merely trying to recall moral standards was enough

1537 AristotLe, Politics, (VII. 1323b) (noting, for whatever it is worth, that "those who have managed to acquire more external goods than they can possibly use... are lacking in the goods of the soul.").

1538 D. DiermeIER, "When Do Company Boycotts Work?," Harvard Business Review, (6 August 2012). Available at: https://hbr.org/2012/08/when-do-company-boycotts-work (last accessed 20 January 2016) (noting that "activists usually care passionately about a particular issue, but the public rarely shares that passion to the same degree and is easily distracted.”).

1539 D. ArIELY, The (Honest) Truth About Dishonesty: How We Lie to Everyone - Especially Ourselves, (New York: Harper Collins, 2012), at p. 21

1540 D. ArIELY, The (Honest) Truth About Dishonesty: How We Lie to Everyone - Especially Ourselves, (New York: Harper Collins, 2012), at p. 23 (Ariely and his co-researchers look at variety of empirical studies to reach this point from people fudging on their taxes, cab drivers that "long haul," filing insurance claims, doctors advising to their patients' procedures that they might not need, how we keep scores in golf, etc. to reach this conclusion). 
to improve moral behavior" and in many cases, people's tendency to cheat "diminished if [they were] given reminders of ethical standards." 1541 Subtle nudges of this nature have shown promising possibilities in modifying behaviors of individuals: For example, "when people sign their names to some kind of a pledge, it puts them into a more honest disposition (at least temporarily)." 1542 Publicizing "outstanding moral acts" often served as an effective positive reinforcement for moral behaviors, as we already noted back in the tax compliance example from the previous subsection. ${ }^{1543}$ Posting the Ten Commandments in courtrooms or implementing an honor code has actually lead to the reduction of cheating, in varying degrees. ${ }^{1544}$ Although the impact of these subtle reminders ranged from useful to useless, moral reminders and nudges ought to be considered as yet another tool in our toolbox, which could lead to further reductions of labor exploitations in the global supply chain. ${ }^{1545}$

So what kind of moral reminders could prove useful specifically in the context of reducing labor exploitations? Perhaps placing an image of a suffering sweatshop worker next to a product made in sweatshops might make some consumers reluctant to buy that product given that that purchase now might conflict with their self-image, but not too many stores would likely advertise in such a manner voluntarily (perhaps with the exception of the aforementioned Patagonia). If consumers are subtly reminded that the goods that they are about to purchase is sold by a socially irresponsible company, perhaps that would nudge consumers to be more socially responsible, but how would this work in practice? The first part of the answer is by acknowledging the existence of various independent, nonprofit organizations already in existence that keep track of various companies' social responsibility: These organizations often conduct extensive research and publicize this data on their websites offering a plethora of information, which enable consumers to educate themselves about what they are buying in a manner that is easy to understand, so as to minimize the chances of the information overload problem noted back in Chapter 2.

These organizations include, but are not limited to, GoodGuide, Knowmore, Corporate Critic, Citizens Market, and Sourcemap just to name a few. However, regardless of how accessible and easy these organizations make it for consumers to understand their data, similar to reading boilerplate general terms and conditions, consumers might be extremely reluctant to read through any additional information. If reading through these websites is indeed too cumbersome for the average consumer, websites like GoodGuide have also

1541 D. ARIELY, The (Honest) Truth About Dishonesty: How We Lie to Everyone - Especially Ourselves, (New York: Harper Collins, 2012), at p. 40.

1542 D. ArIELY, The (Honest) Truth About Dishonesty: How We Lie to Everyone - Especially Ourselves, (New York: Harper Collins, 2012), at p. 47.

1543 D. ARIELY, The (Honest) Truth About Dishonesty: How We Lie to Everyone - Especially Ourselves, (New York: Harper Collins, 2012), at p. 216.

1544 D. Ariely, The (Honest) Truth About Dishonesty: How We Lie to Everyone - Especially Ourselves, (New York: Harper Collins, 2012), at p. 43 (holding that when students are Princeton, a university that implements a strict honor code and honor classes during weekends, "were asked to sign the honor code, they did not cheat at all (but neither did the MIT or Yale students). However, when they were not asked to sign the honor code, they cheated just as much as their counterparts at MIT and Yale," pointing to a theory that "crash courses [in ethics or morality], the propaganda of morality, and the existence of honor code did not have a lasting influence on the moral fiber of the Princetonians."). What the students need are constant reminders.

1545 D. ARIELY, The (Honest) Truth About Dishonesty: How We Lie to Everyone - Especially Ourselves, (New York: Harper Collins, 2012), at p. 41. 
created smartphone apps that allow any consumer with a smartphone to scan a barcode of various products, which will then give the consumer an instant, easy-to-understand product rating about the product's environmental sustainability or the company's social responsibility without requiring consumers to conduct extensive research. This approach is in conformity with our alternative framework as it takes into account our flaws and designs a solution around it: Given our myopic tendencies, our cognitive flexibility, our instinct for acquisition, and our collective allergy to reading information that is even helpful or useful to us, the key is to use the simplifying heuristic and to make it easier for consumers to be socially responsible and to become ethical consumers.

When shopping online, for example, GoodGuide ${ }^{1546}$ also offers what they refer to as the "Transparency Toolbar," which allow consumers to preselect various personal preferences that they deem to be important (i.e. "labor \& human rights" or "climate change") and the toolbar will provide a ratings of various products for those categories. There is even an option available where the toolbar will even remove certain hits from your search query, based on the consumer's particular preferences. These developments make it easier for consumers to stick by their ethical preferences, without sacrificing their autonomy, and without the need for an excessive legislative overhaul. Moreover, by making the process of screening out products that might conflict with the consumer's ethical or moral preferences, consumers no longer have to make difficult decisions: The previous subsection suggested that if a particular consumer is truly interested in the reduction of labor exploitation, he or she might have to think more and more, but to the contrary, advances in technology have also made it easier for consumers to be socially responsible, while thinking and doing less. So installing these apps, tool bars, or extensions in your web browsers could serve as one type of a moral reminder that could reduce instances of consumers cheating. Furthermore, there is additional evidence to suggest that these types of subtle nudges not only work, but changes the cognitive hardwiring of one's self-image:

'What may occur is a change in the person's feelings about getting involved or taking action. Once he has agreed to a request, his attitude may change, he may become, in his own eyes, the kind of person who does this sort of thing, who agrees to requests made by strangers, who takes action on things he believes in, who cooperates with good causes." 1547

For example, when people write down their commitments, they tend to live up to it more. ${ }^{1548}$ Another type of a moral reminder could come in a form similar to the aforementioned Minnesota tax compliance study noted above in the context of government nudges. So if independent, non-profit organizations were to inform the public about how there are socially responsible consumers amongst the populace, this could also serve as a subtle reminder and a nudge that there are consumers that are not "cheating."

1546 http://www.goodguide.com/

1547 J.L. FreEdman \& S.C. Fraser, "Compliance Without Pressure: The Foot-in-the-Door Technique," Journal of Personality and Social Psychology 4(2) (1966): 155-202; see, R.B. CiALDINI, Influence: The Psychology of Persuasion, (New York: Collins Business, 2007), at p. 73 (elaborating on the Freedman and Fraser study stating that a simple act, such as signing a petition, can change the way in which people see themselves).

1548 R.B. Cialdini, Influence: The Psychology of Persuasion, (New York: Collins Business, 2007), at p. 79-80 (noting that businesses use this technique and have successfully countered the impact of withdrawal rights by having consumers write down their orders themselves). 
As hinted earlier in this thesis, the relationship between consumers vis-a-vis businesses evolved from a "trust me" relationship to a "tell me" relationship and now to a "show me" relationship, where more and more consumers are demanding transparency from companies that may be reluctant to disclose their socially irresponsible practices. ${ }^{1549}$ Even though we now evolved to the "show me" relationship, where companies disclose their internal figures and how socially responsible they are, there is still a lingering concern as some businesses have been found to "show" misleading or greenwashed statements, thus "showing" consumers facts and figures that are not in alignment with their true practices. This general lack of trust has led to the emergence of the aforementioned independent, non-profit organizations that present facts closer to the truth to the consumers, which in turn enable or in some cases, force - consumers to consume in a manner that does not deviate from their professed beliefs and morals. In this context, the next part of the subsection will introduce the concept of the "collaborative consumer feedback mechanism," which will push the consumer-business relationship to a new level: from a "show me" relationship to a "join me" relationship, which neatly fits into our alternative framework. ${ }^{1550}$

\section{Collaborative Consumer Feedback Mechanism}

Collaborative consumer feedback mechanism is a private initiative capable of increasing consumer awareness, empower consumers to hold misbehaving businesses accountable, and ultimately to galvanize the consumers to demand better treatment of laborers from corporations they purchase goods from, through a more grassroots, collaborative approach in line with our alternative framework. The collaborative consumer feedback mechanism relies upon the concept of reputational capital. Simply put, collaborative consumer feedback mechanism is a mechanism where consumers can collectively grade corporations, their products/services, etc. by relying on advances in social media and combing through the reviews that other consumers have posted online. Rachel Botsman and Roo Rogers envision an online market based on this collaboration between the consumers, where they praise, critique and comment on a businesses' reputation, commitment to fair treatment of their laborers, and the overall trustworthiness of the corporation. ${ }^{1551}$ What this framework does is it essentially crowdsources the auditing process of corporations. ${ }^{1552}$

Crowdsourcing, a term coined by Jeff Howe, is the "act of taking a job traditionally performed by a designated agent and outsourcing it to an undefined, generally large group of people in the form of an open call." 1553 The collaborative consumer feedback mechanism

1549 A. HenriQuS, Corporate Trutbs: The Limits to Transparency, (New York: Taylor \& Francis Group, 2007), at 77.

1550 T.H. MORAN, Beyond Sweatshops: Foreign Direct Investment and Globalization in the Developing World, (Virginia: R. R. Donnelley and Sons, 2002), at p. 88.

1551 See generally, R. BOTSMAN \& R. Roger, What's Mine is Yours: The Rise of Collaborative Consumption, (New York: HarperCollins Publishers, 2011).

1552 D. Goleman, Ecological Intelligence: The Coming Age of Radical Transparency, (London: Penguin, 2010), at p. 102, (noting that "[c]ustomers are no longer lone individuals, isolated and voiceless... The multiplier effect means networks of people pooling their knowledge can diminish information asymmetry" and the "digital revolution catalyzes new forms of information sharing, and its networks are far larger and more widely distributed than any in human history"); see, C. SHIRKY, Here Comes Everybody: The Power of Organizing without Organizations, (New York: Penguin Press, 2008).

1553 R. Botsman \& R. Roger, What's Mine is Yours: The Rise of Collaborative Consumption, (New York: HarperCollins Publishers, 2011), at p. 59. Recall here the aforementioned concept of open governments, which employs a form of crowdsourcing. 
crowdsources the monitoring and the detection of misbehaving corporations by galvanizing the myriad of consumers to expose and weed out the bad apples: In other words, "if you do something wrong or embarrassing, the whole community will know. Free riders, vandals and abusers are easily weeded out, just as openness, trust and reciprocity are encouraged and rewarded." 1554

This private, yet shared initiative is essentially a collection of digitized word of mouth references, which serves as a valid mechanism for empowering consumers to challenge businesses to improve their labor practices. Consumers, at times, can do better than governments when it comes to informing one another. ${ }^{1555}$ In essence, the mechanism is returning the power to the consumers and providing a way for the market to correct itself, rather than by relying excessively on the governments to regulate it. Most consumers, whether they are aware of it or not, are already a part of this growing collaboration, and businesses interested in profits will be compelled to respect this mechanism and will be incentivized to build trust and to make a good reputation with their consumers.

In the interest of full disclosure, the idea of collaborative consumer feedback mechanism is nothing new or innovative. In a sense, it is a glorified grapevine, a remix of an old concept enhanced by advances in technology. At its core, the mechanism is essentially the modernization of the Athenian concept of ostracism (though perhaps a bit more forgiving), where citizens voted to excommunicate a citizen that they did not like - for whatever reason - from the community. In our context, "the community" or the collection of consumers in a particular market "vote" or post feedbacks and comments in order to signal to other consumers whether a particular seller or a business is trustworthy, and in the event that the seller receives enough negative comments, that seller will be weeded out or "ostracized" from the community relying on aforementioned sites like GoodGuide, Knowmore, Corporate Critic, Citizens Market, and Sourcemap. Botsman and Rogers characterized this phenomenon as follows:

"There is now an unbounded marketplace for efficient peer-to-peer exchanges between producer and consumer, seller and buyer, lender and borrower, and neighbour and neighbour. Online exchanges mimic the close ties once formed through face-to-face exchanges in villages, but on a much larger and unconfined scale. $" 1556$

Just because the mechanism is not innovative per se or is a recycled old concept, however, does not make the initiative any less significant or weaken the argument in favor of it. These changes are happening "at a time when an extraordinary confluence of technological and cultural development makes the realization of these values not just possible but long lasting." 1557 Admittedly, these concepts behind collaborative consumer initiative are far

1554 R. Botsman \& R. Roger, What's Mine is Yours: The Rise of Collaborative Consumption, (New York: HarperCollins Publishers, 2011), at pp. 92-3.

1555 O. Ben-Shahar \& C.E. SCHNEIDER, More Than You Wanted to Know: The Failure of Mandated Disclosure, (Princeton: Princeton University Press, 2014), at p. 13 (noting to websites like Yelp and Amazon that rely on consumers informing and empowering one another as possible alternatives to government measures aimed at informing the consumer).

1556 R. Botsman \& R. Roger, What's Mine is Yours: The Rise of Collaborative Consumption, (New York: HarperCollins Publishers, 2011), at pp. xii-xiv.

1557 R. Botsman \& R. ROGER, What's Mine is Yours: The Rise of Collaborative Consumption, (New York: HarperCollins Publishers, 2011), at p. 55. 
removed from traditional legal concepts. However, according to Nobel Prize winning economist Joseph Stiglitz it is "often not the legal norm but the descriptive norm (what you believe most other people do)" that matters, ${ }^{1558}$ and as it applies to our case, the descriptive norm (a type of social, non-legal norm) can facilitate the attainment of some of our goals (e.g. to incentivize private actors to design and adopt practices that will reduce instances of labor exploitation in the global supply chain).

The most common question associated with the feasibility of this decentralized, voluntary private initiative - a manifestation of our alternative framework - in the words of James Surowiecki from The Wisdom of Crowds, is this: "How can people voluntarily - that is, without anyone telling them what to do - make their actions fit together in an efficient and orderly way?" 1559 The simple answer is this:

"If the members of some group have a common interest or object, and if they would all be better off if that objective were achieved, it has been thought to follow logically that the individuals in that group would, if they were rational and self-interested, act to achieve that objective."

On the other hand, Garrett Hardin, the founding father of "the tragedy of the commons," would likely disagree with the conclusion of this statement and there are reasonable concerns about the feasibility of this mechanism ever accomplishing anything. ${ }^{1561}$ However, Elinor Ostrom, yet another Nobel Prize winning economist dismissed these concerns and proved through empirical research that self-organized commons do indeed work. ${ }^{1562}$ However, let us not just take her words for it, but pursue this evidence on our own.

One of the reasons why collaborative private initiative work is the concept of mutualism or what others refer to as "indirect reciprocity," 1563 an idea already discussed earlier in this chapter, and the idea of a "gift economy." 1564 Under these concepts, the consumers provide comments, feedbacks, or even material possessions of value without receiving anything in return, believing that when the time comes, someone will replicate the behavior for them. Another reason as to why this voluntary mechanism functions in the words of Mark Granovetter, a sociologist at Stanford, is the phenomenon known as "the strength of weak ties," which was already alluded to earlier in the context of what leads to changes in social habits. ${ }^{1565}$ Strength of weak ties is a sociological phenomenon where social relationships of people even when there is no acquaintance can still bolster the individual's pro-

1558 J.E. STIGLITZ, Freefall: Free Markets, and the Sinking of the World Economy, (New York: W. W. Norton \& Co, 2010), at p. 123; see also, C. BICCHIERI, The Grammar of Society: The Nature and Dynamics of Social Norms, (New York: Cambridge University Press, 2006), p. 68; see also, J. Berger, Invisible Influence: The Hidden Forces that Shape Behaviour, (London: Simon \& Schuster, 2010).

1559 See e.g., J. SurowieCKI, The Wisdom of Crowds, (New York: Anchor Books, 2005), at 86.

1560 See e.g., M. Olson, The Logic of Collective Action: Public Goods and the Theory of Groups, (Massachusetts; Harvard University Press, 1971).

1561 D. ARIELY, Predictably Irrational: The Hidden Forces that Shape Our Decisions, (New York: Harper Perennial, 2008) (suggesting that people are not always rational).

1562 See e.g., E. OSTRom, Governing the Commons: The Evolution of Institutions for Collective Action, (Cambridge University Press; Cambridge, 1990).

1563 R. BOTSMAn \& R. Roger, What's Mine is Yours: The Rise of Collaborative Consumption, (New York: HarperCollins Publishers, 2011), at p.133.

1564 See generally, D.J. CHEAL, The Gift Economy, (New York: Routledge, 1998).

1565 M. GRANOVETTER, “The Strength of Weak Ties,” American Journal of Sociology 78(6) (1973): 1360-1380. 
spects and well-being. ${ }^{1566}$ This phenomenon is also what gives both our alternative framework and the collaborative consumer feedback mechanism a chance at success. Even when incentives for private actors to be altruistic are low or when those that they are helping are outside of their immediate herd in this ever-globalizing environment, the strength of weak ties suggests that private actors might still act nevertheless.

Add to this fact the aforementioned role of signaling and descriptive norms: Recall here that ' $[t]$ he message that 'everybody else is doing it' sometimes works better than trying to appeal to people's sense of social responsibility or even to their hope of safeguarding resources for future generations." 1567 Social psychologist Marilynn Brewer, who specializes in social cognition and intergroup relations, calls this phenomenon as the "social self," where individuals within a group seek belonging and this need for many people is enough of an incentive for them to "abstain from an individually beneficial but socially harmful action if they perceive that most people do too." 1568 Although these factors alone do not guarantee the success of this collaborative initiative, they substantiate that it is - at the very least feasible, especially given the prevalence of such mechanisms already in existence.

The conclusion of this part of the subsection is therefore this: assuming that there is indeed a benefit for businesses to respond to the collaborative consumer feedback mechanism, then the more grassroots pressure that comes from the consumers through this mechanism is not only a more democratic one, but one that requires less regulatory intervention from the governments, at least in the process of detecting misbehaving businesses. As Botsman and Rogers earlier pointed out, we are living in a time of "extraordinary confluence of technological and cultural development"1569 and perhaps the expansion of the collaborative consumer feedback mechanism could be the "recycled innovation" with the capacity to unbind us from repeating the same mistakes and to make private initiative a valid solution to a global problem. ${ }^{1570}$ Simply put, the collaborative consumer feedback

1566 R. Botsman \& R. Roger, What's Mine is Yours: The Rise of Collaborative Consumption, (New York: HarperCollins Publishers, 2011), at p. 178.

1567 R. Botsman \& R. RogeR, What's Mine is Yours: The Rise of Collaborative Consumption, (New York: HarperCollins Publishers, 2011), at p. 82.

1568 J.E. STIGLITZ, Freefall: Free Markets, and the Sinking of the World Economy, (New York: W. W. Norton \& Co, 2010), at p. 123.

1569 R. BOtsman \& R. Roger, What's Mine is Yours: The Rise of Collaborative Consumption, (New York: HarperCollins Publishers, 2011), at p. 55.

1570 R.J. SHILLER, Irrational Exuberance, (Princeton: Princeton University Press, 2015), at p. 168 (stating that "much of the human thinking that results in action is not quantitative, but instead takes the form of storytelling and justification" by citing to the research conducted by Pennington and Hastie); see also, N. PenNington \& R. HASTIE, "Reasoning in Explanation-Based Decision Making," Cognition 49 (1993): 123-63 (showing the "importance of stories in decision making by studying how jurors reached decisions in difficult cases."); D. KAHNEMAN, Thinking, Fast and Slow, (London: Penguin Book, 2013), at pp. 199, 209 (defining this as the narrative fallacy, where "flawed stories of the past [can] shape our views of the world and our expectations of the future," which is a case of "poor evidence [making] a very good story."); see, N.N. TALEB, The Black Swan: The Impact of the Highly Improbable, (New York: Random House, 2007). Similar risks come from media outlets as well, where people perceive the world as the media frames it; of, B. SCHWARTZ, The Paradox of Choice: Why More is Less, (New York: Harper, 2004), at p. 57 (noting how the presence of the availability heuristic could still spoil some of the benefits of this framework by noting the following: "Unfortunately, most people give substantial weight to this kind of anecdotal 'evidence,' perhaps so much so that it will cancer out the positive recommendation found"); see also, R.J. SHILLER, Irrational Exuberance, (Princeton: Princeton University Press, 2015), at p. 101 (stating that "[a]lthough the news media newspapers, magazines, and broadcast media, along with their new outlets on the Internet - present themselves as detached observers of market events, they are themselves an integral part of these events.”). 
mechanism is yet another tool that consumers can use as part of our alternative framework that is also consistent with the values espoused in our adapted capabilities approach.

\section{E. Create Work Centers}

The final strategy that consumers - or in this case, any other private actor for that matter can implement as part of our alternative framework strategy relates to the aforementioned idea that governments ought to ensure a level playing field. As exemplified in that part of the subsection, in recent history, unions have weakened and the coverage of collective bargaining has noticeably declined according to the ILO. ${ }^{1571}$ What this reality suggests is that governments are having a difficult time leveling the playing field, which could jeopardize the effectiveness of the inclusive, collaborative decision-making and problem-solving process advocated by this thesis. Ultimately, unions work only "if labor has enough autonomy to exert some control over their working conditions, through negotiation with bosses or brining legal complaints." 1572 The problem here, again, is that while we know this is the desirable state of affairs, its manifestation is not always feasible in reality.

While legalizing the right to collectively bargain is a basic and fundamental way that governments can attempt to achieve this desired state of balance between laborers and their bosses, the more pertinent question for us now is, what can private actors do to help? We all realize that utility of enabling rights comes down to the issue of recognition and enforcement. In other words, even if trade or labor unions exist or enabling rights are recognized, if they exist only on paper, they serve little to no purpose. ${ }^{1573}$ What private actors can do to empower laborers trapped in weak bargaining positions is by training them and equipping them with "bargaining skills, and organized power, rather than massive wildcat power." 1574 One practical way this can be achieved - while adhering to our normative and alternative frameworks - is for consumers and any other interested private actor to create and invest in "work centers."

Before getting into what work centers are, recall for a moment the issue of firm disaggregation and fragmented enterprises discussed back in Chapter 3 in the context of the externalization problem. One of the side effects of the externalization problem is that " $[\mathrm{a}] \mathrm{s}$ more and more companies restructure themselves into decentralized networks of smaller units (often exploited by a hierarchical relationship with the parent company), which in turn are linked to networks of suppliers and subcontractors, workers are increasingly employed through individual contract. Thus labor is losing its collective identity and bargain-

1571 InTERnational Labour Organization, World of Work Report: Developing with Jobs [Executive Summary], (Geneva: ILO, 2014), at p. 6 (noting that this trend is true even in developed economies).

1572 M. CHEN, “Could Stronger Unions Make China More Democratic," The Guardian, (11 August 2014). Available at: http://www.thenation.com/blog/180938/could-stronger-unions-make-china-more-democratic\# (last accessed 4 April 2017).

1573 China Labour Bulletin, “China’s Official Trade Union Still Fails to get the Message,” (2 December 2013). Available at: http://www.clb.org.hk/content/china $\%$ E2 $\% 80 \% 99$ s-official-trade-union-still-fails-get-message (last accessed 4 April 2017) (noting the ineffectiveness of All-China Federation of Trade Unions, the world's largest trade union is not only jeopardizing its own future, but the "wellbeing of millions of workers" as well as the legitimacy of the Chinese Communist Party.).

1574 M. Chen, “Could Stronger Unions Make China More Democratic," The Guardian, (11 August 2014). Available at: http://www.thenation.com/blog/180938/could-stronger-unions-make-china-more-democratic\# (last accessed 4 April 2017). 
ing power." 1575 The Uber case study in Chapter 2 and the FIFA case study in Chapter 3 both illustrate how serious this problem is and the difficulties that governments face in attempting to create a level playing field. In order to alleviate this problem, stakeholders must fend off attempts by corporations to bust or weaken unions even in "developed" legal jurisdictions. Even in successful collaborative relationships between businesses implementing the capabilities approach, it has been noted that "enabling rights" such as right to free association to collectively bargain, have been observed to be "outside the pale" especially in jurisdictions like China where these enabling rights are restricted by law and the governments themselves. ${ }^{1576}$

As one expert notes, "[t] he paucity of independent unions is clearly critical: if workers were able to effectively organize, the implementation of workplace standards would be selfenforcing and pressures for improvements by Western firms and activists would become less necessary." 1577 But there is a framing issue here because there is a strong business current against unions and unionizations, so our suggestion here is for consumers and other interested private actors to get together and start creating work centers, which could - in theory - serve similar purpose to unions, but without the stigma attached to it. As Naím describes, “[o]ne example [of a work center] comes from Los Angeles, where Garment Worker Center - a small, compact team of activists drawn from progressive lawyers, immigrant rights groups, and representatives of ethnic communities - managed to score major victories against companies that relied on sweatshop labor."1578 Naím continues to describe the impact of the Garment Worker Centers, by praising their work that led to "spurred settlements with several of the clothing labels that used these workers' production. Small in size, and drawing on resources from multiple organizations in different specialties, work centers are complementary to unions but operate on a nearly opposite model." 1579 Work centers epitomize our alternative framework at work, where units of private actors form a loose, collaborative environment with the aim of directly assisting workers and laborers in an adaptive manner employing holistic strategies. The increase in their popularity attests to the feasibility of work centers. ${ }^{1580}$

1575 F. CAPRA \& U. MATTEI, The Ecology of Law: Toward a Legal System in Tune with Nature and Community, (Oakland: Berrett-Koehler, 2015), at p. 121 (adding that "[m]any workers today, whether unionized or not, will not fight for higher wages or better working conditions out of fear that their jobs will be moved to another municipality, or even abroad.").

1576 R.M. LOCKE, The Promise and Limits of Private Power: Promoting Labor Standards in a Global Economy, (Cambridge: Cambridge University Press, 2013), at p. at 18.

1577 D. VOGEL, The Market for Virtue: The Potential and Limits of Corporate Social Responsibility, (Washington D.C.: Brookings Institution Press, 2006), at pp. 100-1 (admitting that the problem with this is that "in some countries, such as China, independent unions are illegal" not to mention the assortment of political and social oppositions that the unionization movement faces, even in developed, Western nations such as the United States).

1578 M. NAím, The End of Power: From Boardrooms to Battlefields and Churches to States, Why Being in Charge Isn't What It Used to Be, (New York: Basic Books, 2013), at p. 205 (noting, in reference to work centers that "some emerging models in labor activism have come through organizations that are not unions at all - in fact, ones that have taken root in industries and areas where unions have found organizing to be too complicated and costly.").

1579 M. NAím, The End of Power: From Boardrooms to Battlefields and Churches to States, Why Being in Charge Isn't What It Used to Be, (New York: Basic Books, 2013), at p. 205; citing, R. Sullivan, "Organizing Workers in the Space Between Unions: Union-Centric Labor Revitalization and the Role of Community-Based Organizations,” Critical Sociology 36 (2010): 793-819.

1580 M. NAím, The End of Power: From Boardrooms to Battlefields and Churches to States, Why Being in Charge Isn't What It Used to Be, (New York: Basic Books, 2013), at p. 205 (observing that from just 5 worker centers in the US in 1992 that number has skyrocketed to 160 in 2007); citing, R. SulLIVAN, "Organizing Workers in the Space Between Unions: 
Work centers, if designed and ran properly, exemplifies how private actors can directly help exploited laborers by empowering them, by standing up for them, by educating them, and by giving them a voice in a manner that is in conformity with our adapted capabilities approach. Work centers can offer platforms for education and legal support, which can collectively increase workers' capabilities through free vocational trainings and pro bono legal advice. These steps can empower workers perhaps to the point that they will be able to stand up against their exploiters especially in developing economies, where access to education and self-improvement for the laborers in the lower echelon of the supply chain are extremely limited. Work centers can also "train workers in negotiation strategy and techniques, including how to resist pressure from management and local governments, report on sexual harassment in factories, advice on collective bargaining and provide legal advice." 1581 In addition, the efforts of the work centers can be facilitated and made even more feasible by the "rise of social media and availability of inexpensive smartphones [that] make[ it easier for workers to organize and initiate collective action."'1582

Even in countries like China, where there are swathes of sweatshops, there are opportunities for work centers to be successful. Currently, China is experiencing a tumultuous period, which could lead to a period of transition: "China has seen scores of wildcat strikes, demonstrations, periodic riots and even the occasional boss taken hostage." 1583 This sense of urgency for collective bargaining could usher in changes to bring about a stronger workforce, which could ultimately lead to the reduction of labor exploitation in places like China. What is astounding, is that even the one party Chinese government is beginning to see this: "[T] he labor market is, in a way, akin to the country's churning consumer market: the state knows it cannot control every aspect of Chinese society and is willing to allow a measure of market 'freedom' as a self-regulating social ecosystem. Fostering commercial exchange keeps workers busy and fed and keeps factories humming." 1584 The people, at

Union-Centric Labor Revitalization and the Role of Community-Based Organizations," Critical Sociology 36 (2010): 793-819.

1581 S. Lubman, "Labor Pains: A Rising Threat to Stability in China," The Wall Street Journal (10 June 2014). Available at: http://blogs.wsj.com/chinarealtime/2014/06/10/labor-pains-a-rising-threat-to-stability-in-china/ (last accessed 4 April 2017).

1582 Ibid.

1583 M. CHEN, “Could Stronger Unions Make China More Democratic," The Guardian, (11 August 2014). Available at: http://www.thenation.com/blog/180938/could-stronger-unions-make-china-more-democratic\# (last accessed 13 August 2014). Just to note, China enacted the most recent set of labor laws in 1994, contract laws in 2005, and a set of rules regulating mediation and arbitration in 2007 in the hopes that these measures would bring about positive changes towards the perception that China's labor practices as a whole is exploitative. However, when legal remedies and access to justice is perceived as weak or corrupt, a frustrated labor force will result to strikes, and at times more extreme measures to have their voices heard. See, M.E. GALLAGHER, "China's Workers Movement \& the End of the Rapid-Growth Era," Daedalus: Journal of the American Academy of Arts \& Sciences 143(2) (2014): 81-95 (noting that these reforms have created "an unstable mixture of half-hearted adoption of "legality'," leading to a "bottom-up legal mobilization by aggrieved workers disappointed in the gap between law on the books and law in action"); see also, S. LuBMAN, "Labor Pains: A Rising Threat to Stability in China," The Wall Street Journal (10 June 2014). Available at: http://blogs.wsj.com/chinarealtime/2014/06/10/labor-pains-a-rising-threatto-stability-in-china/ (last accessed 4 April 2017) (citing to a report by Gallagher that "the number of labor disputes handled yearly in China has grown steadily from 200,000 in 2005 to approximately 1,500,000 in 2012" to coincide with the adoption of the new set of labor contract laws, and the number of strikes also growing "from 10 per month in February 2011 to almost 50 in February 2013.”).

1584 M. CHEN, "Could Stronger Unions Make China More Democratic," The Guardian, (11 August 2014). Available at: http://www.thenation.com/blog/180938/could-stronger-unions-make-china-more-democratic\# (last accessed 4 April 2017); see also, S. Lubman, "Labor Pains: A Rising Threat to Stability in China," The Wall Street Journal, (10 
least in part, are also rising up: "Compared to the anemic labor movements in the West, China's workers are emboldened, though they are still hampered by a repressive political environment." ${ }^{1585}$ These work centers can - perhaps not replace unions outright - but in areas where unionization is prohibited or difficult, serve and protect the interests of the laborers. While this predicted transition may not lead to the immediate recognition of collective bargaining rights even in places like China, work centers can - in the meantime - at least serve as an alternative measure.

To sum up this part of the subsection, "[o]ur besieged labor unions and nonprofits should bolster" organizations like work centers that are more "green, local, progressive, entrepreneurial, [and] community-focused" rather than dealing and hoping for businesses to change their tune. ${ }^{1586}$ Work centers - a manifestation of our alternative framework at work - is not only in alignment with our adaptive capabilities approach, but when designed and implemented correctly, it has the potential of empowering marginalized laborers and reducing instances of labor exploitation in the global supply chain.

In concluding this subsection, the recommendation for the consumers that this thesis can offer is for them to reconsider and reassess their current approach to addressing the problem of labor exploitation, starting with boycotts and naming-and-shaming strategies. Instead, consumers will make more impact to reducing instances of labor exploitation if they change their own consumption habits, which could be facilitated through moral reminders and awareness education. The latter strategies can be enhanced through the use of collaborative consumer feedback mechanisms and the creation of more work centers that work to detect misbehaving businesses and empower laborers by educating them and offering pro bono legal services. All of these consumer-based measures can help marginalized laborers get out of exploitative situations.

\subsection{THE SWISS CHEESE THEORY}

Having presented a handful of ways in which various private actors can implement the alternative framework, let us now consider the benefit of these measures working together in concert by introducing the Swiss Cheese Theory. This theory is a relatively well-known theory in organizational risk management that recognizes that each safety measure has its flaws (or holes), but by layering one safety measure on top of another, potential risk can be detected and prevented. ${ }^{1587}$ Applying this theory to our discussion, the argument for im-

June 2014). Available at: http://blogs.wsj.com/chinarealtime/2014/06/10/labor-pains-a-rising-threat-to-stabilityin-china/ (last accessed 4 April 2017) (citing to a report by the China Labour Bulletin predicting that "continued strikes and collective protests... will force more employers to respond to collective demands"); and, China Labour Bulletin, "Searching for the Union: The Workers' Movement in China 2011-2013" (2014). Available at: http://www.clb.org.hk/content/searching-union-workers\%E2\%80\%99-movement-china-2011-13-0 (last accessed 4 April 2017).

1585 M.E. Gallagher, “China’s Workers Movement \& the End of the Rapid-Growth Era," Daedalus: Journal of the American Academy of Arts \& Sciences 143(2) (2014): 81-95 (noting that "labor disputes and strikes are endemic").

1586 J. RASKIN, "The Rise of Benefit Corporations," The Nation, (8 June 2011). Available at https://www.thenation.com/article/rise-benefit-corporations/ (last accessed 18 December 2016).

1587 J. REASON, Managing the Risks of Organizational Accidents, (Hampshire, Ashgate Publishing, 1997), at p. 9 (noting that "in an ideal world all the defensive layers would be intact, allowing no penetration," but "in the real world, each 
plementing an inclusive, reflexive form of governance relying on holistic measures open to non-legal norms or multidisciplinary approaches is akin to the belief that by stacking several layers, risks can be detected and major fallout prevented. To quote Richard Locke, the fundamental idea is that "private voluntary regulation can best succeed when 'layered' on and interacting with public (state) regulation." 1588 Our alternative framework is ultimately about private actors helping out governments and vice versa, which is to suggest that this is a framework that "blends elements of private compliance programs with technical assistance, capability-building initiatives, and innovative government regulatory efforts in a dynamic and complementary way - one that is both adaptive to local circumstances and that builds on (and reinforced) the respective strengths of both private and public systems of regulation." 1589

Another way to conceptualize our alternative framework that this thesis has advocated for is to consider each stakeholder and their actions, not necessarily as slices of cheese, but as actions that have some externalities, both positive and negative. In the context of the supply chain, externalities are often considered in the negative context: For example, in a B2B contract between a downstream buyer and an upstream supplier, the negative externality is placed not just on the workers further up the supply chain, but as the leather tannery example noted back in the Introduction, in the communities of where these workers live. A positive externality from B2B contracts, on the other hand, could arguably be experienced by consumers who can now purchase that particular good cheaper, due in part to someone, somewhere else suffering the effect of the negative externality. ${ }^{1590}$ The unequal distribution of externalities is not only contributing to the growing inequality, but it is creating a situation rife for new norms to emerge. ${ }^{1591}$ In light of this context, this thesis cau-

layer has weaknesses and gaps," comparing each layer with a slice of Swiss cheese, where the holes are not static, but "in constant flux").

1588 R.M. LOCKE, The Promise and Limits of Private Power: Promoting Labor Standards in a Global Economy, (Cambridge: Cambridge University Press, 2013), at p. 17; see also, S.V. CosLOvsKy \& R. LOCKE, "Parallel Paths to Enforcement: Private Compliance, Public Regulation, and Labor Standards in the Brazilian Sugar Sector," Politics \& Society 41(4) (2013): 497-526, 519 (noting that "joint action of private auditors and public inspectors provides one of the many pathways for improved labor standards that had been obscured by the prevailing emphasis on either public or private enforcement regimes.").

1589 R.M. LOCKE, The Promise and Limits of Private Power: Promoting Labor Standards in a Global Economy, (Cambridge: Cambridge University Press, 2013), at p. 2; see also, S.V. Coslovsky \& R. LOCKE, "Parallel Paths to Enforcement: Private Compliance, Public Regulation, and Labor Standards in the Brazilian Sugar Sector," Politics \& Society 41(4) (2013): 497-526, 518 (stating that "[i]n recent years, researchers have begun to coalesce around the idea that both public and private regulatory enforcement regimes are necessary to improve labor standards in global supply chains"); citing, M.W. TOFFEL, J.L. SHORT \& M. OuELlET, "Reinforcing Regulatory Regimes: How States, Civil Society, and Codes of Conduct Promote Adherence to Global Labor Standards," Harvard Business School Technology \& Operations Management Unit Working Paper 13-045 (2012).

1590 The basic idea here is that even in B2B contracts, there are third parties that either benefit or suffer from externalities rendered by the B2B contracts. While they may lack the privity to sue the businesses, as noted back in Chapter 2.3.1, that is not to say that their lives are not affected by these contracts. See e.g. H. Collins, "Conformity of Goods, the Network Society, and the Ethical Consumer," European Review of Private Law 5 (2014): 619-640, 622 (noting that the "[e]conomic analysis of contracts labels the interest of third parties as 'externalities', because in making their cost/benefit assessment of the attractions of market opportunities the parties will generally not take them into account"); $f$. F. CAFAGGI, at, p. 7.

1591 J.S. Coleman, "The Emergence of Norms," in Social Institutions: Their Emergence, Maintenance, and Effects, M. HeChTER, K-D Opp \& R. WIPPLER (EDS.) (New York: Aldine de Gruyter, 1990), at p. 43 (noting that new norms often arise when those experiencing the negative externalities can do little about it). 
tioned that stakeholders can either contribute to changing the status quo or brace for a more violent emergence of new norms.

In either case, the hope is that our alternative framework, which is also in alignment with our adapted capabilities approach, can lead to a more inclusive and collaborative way to dealing with and adapting to the circumstances; but moreover, the theory behind this proposed framework and its intended aim is not just to foster more positive externalities, but making them exponentially so. The basic idea here is that by stakeholders working together, strengthening our community, developing individual and collective phronesis, and finding a sense of purpose or telos, we have a chance to change not just ourselves, but the communities and societies that we are part of and each of these actions serve to enforce and reinforce one another thus creating positive exponential externalities. For example, if governments ask private actors to participate more directly in the legislative process, this not only creates a sense of purpose (telos) for the private actors, but it would reduce some of the burdens and expectations place on governments. Moreover, this interaction and collaboration between the public and private sectors render a positive externality on the marginalized workers in the bottom echelons of the global supply chain, which could improve the status of their communities. This leads to a stronger sense of community, which could lead to reducing inequality, which is good for everyone involved. ${ }^{1592}$ Moreover, businesses taking the time to adopt the capability building approach not only improve their relationships with their upstream business partners, but by creating a direct connection with their workers and treating them, not just as third party externals but as people, this approach can improve working conditions, enhance worker loyalty, not to mention the impact this will have on the external relationship that the downstream company can have with the consumers and society at large.

It is entirely possible that by advocating and believing in the potential of this proposed framework, this thesis has succumbed to the very flaws described within it (i.e. positivity bias and theory-induced blindness at the very least come to mind). However, the proposed framework is an adaptive, ever-evolving one that espouses inclusiveness, collaboration, and open-mindedness by all relevant stakeholders that also recognizes and acknowledges our flaws. As such, it is a framework that embodies the following words noted by Martha Nussbaum:

"If our world is to be a decent world in the future, we must acknowledge right now that we are citizens of one interdependent world, held together by mutual fellowship as well as the pursuit of mutual advantage, by compassion as well as by self-interest, by love of human dignity in all people, even when there is nothing we have to gain from cooperating with them." 1593

As such, this thesis stands by the proposed framework and even ventures as far as to state that there is indeed something to be gained through mutual and collaborative cooperation on behalf of all private actors. In the end, the application and incorporation of this framework, as exemplified by holistic approaches and non-traditional initiatives such as open-

1592 See generally, R. WiLKINSON \& K. PiCKETT, The Spirit Level: Why Equality Is Better for Everyone (London: Penguin Books, 2010).

1593 M.C. Nussbaum, Frontiers of Justice: Disability, Nationality, Species Membership [Tanner Lectures of Human Values], (Belknap Press of Harvard University Press, 2007), at p. 324. 
source governments, capability building, moral reminders, collaborative consumer feedback mechanism, and work centers are early states of private global norms in the making. Once widely accepted, they will inevitably contribute to the reduction of labor exploitation in the global supply chain moving forward. 


\title{
Chapter
}

\section{Conclusion - Bringing Everything Together}

\author{
"Whenever you find yourself on the side of the majority, it is time to pause and reflect."
}

\section{Mark Twain}

The research question that this thesis raised at the very beginning was what can private actors do differently to further reduce instances of labor exploitation in the global supply chain. By conducting a critical analysis of the various existing measures and initiatives, this thesis exposed a daunting number of challenges, limitations, and problems that both governments and private actors face, which made the process of answering the research question extremely difficult and complicated. The complexity of this task was heightened even further, due partially to the fact that this thesis took on an interdisciplinary approach that analyzed not only legal issues, but included economic, psychological, and sociological considerations in order to answer the research question in more depth. Speaking of which, there is a term in psychology known as learned helplessness, which is the feeling that nothing one does can change the current state of the affairs, ${ }^{1594}$ and once this feeling sets in, it significantly decreases our incentive to do anything about it. ${ }^{1595}$ This phenomenon manifested itself at times, not only in various parts of the supply chain and how private actors felt about this problem, but during the process of researching and writing this thesis as well. However, not to be outdone by the sheer magnitude and the scale of this problem,

1594 M.E.P. Seligman, Flourish, (New York: Atria, 2011), at p. 185; see generally, M.E.P. Seligman, Helplessness: On Depression, Development, and Death, (San Francisco: Freeman, 1975); S.F. MAIER \& M.E.P. SELIGMAN, "Learned Helplessness: Theory and Evidence," Journal of Experimental Psychology: General 105 (1976): 3-46; and, B. SCHWARTZ, The Paradox of Choice: Why More is Less, (New York: Harper, 2004), at pp. 102-3 (stating that "[h] undreds of studies leave no doubt that we can learn that we don't have control.").

1595 B. SChwartz, The Paradox of Choice: Why More is Less, (New York: Harper, 2004), at p. 103 (noting that "[1]earned helplessness can affect future motivation to try.”). 
the humble aim of this thesis was to find different and new ways to address the labor exploitation problem, however incremental the steps were. ${ }^{1596}$

One of the very first steps taken in this thesis to fight off learned helplessness was to establish a normative framework that acknowledged the importance of self-preservation and autonomy given that "our most fundamental sense of well-being crucially depends on our having the ability to exert control over our environment and recognizing that we do." 1597 Accordingly, the normative framework that this thesis adopted was the adapted capabilities approach, which focused on empowering the exploited laborers by attempting to give them a voice and an education. This outcome-oriented normative framework allowed us to determine whether a particular course of action was desirable or not, based on a simple analysis of whether it actually benefited the exploited laborers. By narrowing down the aim and the scope of our focus, this thesis practiced the art of satisficing. ${ }^{1598}$ Satisficing is a different approach from maximizing, optimizing, attempting to find the very best solution, or chasing some fictive notion of "the right answer," but instead to "settle for something that is good enough and not [to] worry about the possibility that there might be something better." ${ }^{1599}$ In our context, satisficing entailed coming to terms with the fact that private actors, regardless of what laws or initiatives they rely on, will never be able to completely eradicate labor exploitation from the global supply chain, but that they ought to do what they can to reduce the instances thereof.

Bearing this reality in mind, this thesis assessed a number of existing measures in the broad categories of labor/employment law (Chapter 2), tort law (Chapter 3), company law (Chapter 4), and contract/consumer law (Chapter 5). By critically analyzing the assortment of existing measures in these chapters, this thesis came up with a wide range of flaws with the existing measures that limited their impact on actually reducing the instances of labor exploitation in the global supply chain. As a reminder, they were: 1) the competence problem, 2) the Goldilocks problem, 3) the territoriality problem, 4) the externalization problem, 5) the enforcement problem, 6) the causation problem, 7) the proliferation problem,

1596 L. LEVIN, Invisible Giants: Changing the World One Step at a Time, (Bristol: Vala, 2013), at p. 65 (noting that part of innovative problem-solving is about "finding new ways to be effective, without being consumed by the depth and scale of problems to which there [are] no adequate answers.").

1597 B. Schwartz, The Paradox of Choice: Why More is Less, (New York: Harper, 2004), at p. 103; see generally, C. Peterson, S.F. Maier \& M.E.P. Seligman, Learned Helplessness: A Theory for the Age of Personal Control, (New York: Oxford University Press, 1993).

1598 B. SCHWARTZ, The Paradox of Choice: Why More is Less, (New York: Harper, 2004), at p. 225 (stating that "[1]earning to accept 'good enough' will simplify decision making and increase satisfaction" and that although "satisficers may often do less well than maximizers according to certain objective standards, nonetheless, by settling for 'good enough' even when the 'best' could be just around the corner, satisficers will usually feel better about the decisions they make."); see also, G.W.L. LOW, European Contract Law between the Single Market and the Law Market: A Behavioural Perspective, (Nijmegen: Wolf Legal Publishers, 2011), at p. 185. (explaining that “due to man's limited resources, he is unable to expand all his energies to pursue his goals to the fullest, and must come to terms with accepting something that is good enough.”).

1599 B. SCHWARTZ, The Paradox of Choice: Why More is Less, (New York: Harper, 2004), at pp. 77-9 (noting that "the goal of maximizing is a source of great dissatisfaction, that it can make people miserable - especially in a world that insists on providing an overwhelming number of choices, both trivial and not so trivial'); see also, H. SIMON, "Rational Choice and the Structure of the Environment," Psychological Review 63 (1956): 129-138 (advocating that satisficing, considering all of the resources that it would take to make a good decision, is often the "maximizing strategy.”); see also, L.A. STOUT, "The Shareholder Value Myth,” The European Financial Review, (30 April 2013). Available at: http://www.europeanfinancialreview.com/?p=883 (last accessed 7 April 2017) (noting that "optimization is rarely the best strategy for either organisms or institutions."). 
8) the complexity problem, and 9) the communal problem. While the French Enlightenment philosopher Voltaire "relentlessly pursued the idea that the only way to obtain "good laws' is to discard all those of the past and make new ones," 1600 this thesis opted for a slightly more nuanced approach by suggesting that private actors adopt an alternative framework to addressing the labor exploitation problem moving forward in a manner that aligned with our adapted capabilities approach (Chapter 6).

In short, this framework advocated for two main changes to the existing way stakeholders go about addressing the problem of labor exploitation in the future: 1) to adopt a more holistic approach that takes into consideration our cognitive limitations and bounded rationality by relying more on non-legal norms to activate our intrinsic incentives to modify our behaviors; and 2) to adopt reflexive governance and adaptive management strategies, which are more inclusive and collaborative ways to involve all stakeholders in the decisionmaking and problem-solving processes that stimulate our cognitive diversity and build on our collective phronesis. This final chapter will now offer the general findings of this thesis (Section 7.1), validate the alternative framework as the answer to the research question posed (Section 7.2), and offer one final remark (Section 7.3).

\subsection{GENERAL FINDINGS}

The conclusion that this thesis reaches is that by adopting the alternative framework noted above, private actors can tackle the labor exploitation problem quite differently from the current default approach, which can potentially contribute to the further reduction of labor exploitation. However, even if the alternative framework is adopted and implemented by the stakeholders, labor exploitation in the global supply chain will likely remain (though hopefully the instances thereof reduced). Accordingly, this section will briefly touch upon this observation that we live in a world without a panacea (Subsection 7.1.1), but note that there are still reasons for optimism (Subsection 7.1.2).

\subsubsection{A World Without a Panacea}

To reiterate, it must be noted here that this thesis did not advocate for any specific new law or legislation and championed it as "the right law." This was partly by design given that if we focused too much on what such an instrument would have looked like, it would have "block[ed] us from asking what we, as individuals or as a society, need[ed] to do to nurture the capacity for wise judgment." 1601 That is to suggest that focusing too much on some idea of what the right law is or the best CSR/ethical consumerism initiatives are could prevent - or at least impede - private actors from adopting and implementing a practical solution. Especially in light of the complexity problem that we noted back in Chapter 5,

1600 As quoted in, F. CAPRA \& U. MATTEI, The Ecology of Law: Toward a Legal System in Tune with Nature and Community, (Oakland: Berrett-Koehler, 2015), at p. 77, 188 (comparing our current legal system that is "devouring our future" to a "rotten wood" that must be set on fire).

1601 B. SCHWARTZ \& K. SHARPE, Practical Wisdom: The Right Way to Do the Right Thing, (New York: Riverhead Books, 2010), at pp. 43-44. 
coupled with our cognitive limitations and bounded rationality, we conclude and acknowledge here that we live in a world without a panacea and that no single solution will resolve a problem of such a magnitude. ${ }^{1602}$ This absence of a panacea is the very reason the alternative framework that this thesis proposed ought to be the path forward. While some may find this conclusion and the absence of a definitive answer inadequate, attempting to solve a problem of this nature all at once with a one-size-fits-all type of a solution - as this thesis illustrated time and time again - would be a doomed endeavor. Instead, a more nuanced approach of doing what we can do, however incremental the steps may be and acknowledging that we are all part of the problem and part of the solution at the same time, is the most practical mentality to adopt moving forward. ${ }^{1603}$ In the end, meaningful "[c]hange is rarely the result of a single factor," and "the inspiration for new thinking almost always comes from multiple sources," which is why it is essential for private actors not to be overly bogged down on finding the right law or the best practice as such, but be open to collaboration and trial-and-error. ${ }^{1604}$

\subsubsection{Valorization and Reasons for Optimism}

While the conclusion that there is no "right" law of general applicability may be disappointing to some, in the process of answering the research question, this thesis stumbled into a wide variety of useful realizations that could add value to future discussions. These realizations were as follows: 1) governments and their legislative measures are governed by the Inverted- $\mathrm{U}$ curve and creating more and more laws does not necessarily equate to more utility for societies; 2) governments, even at their best, still must balance a variety of interests, meaning that protecting the marginalized laborers cannot always be their top priority, as governments must also tend to business interests; 3) companies claiming to be socially responsible may simply be greenwashing, but even the actions of companies that are seriously and sincerely implementing their CSR initiatives could have little, or possibly even detrimental effects for the laborers at the other end of the supply chain; ${ }^{1605}$ and finally, 4) consumers, especially when working as a collective or as a community, have tremendous potential and capacity to change the status quo, but more often than not, they do not act

1602 O. Ben-ShahAR \& C.E. SCHNEIDER, More Than You Wanted to Know: The Failure of Mandated Disclosure, (Princeton: Princeton University Press, 2014), at p. 190.

1603 L. LEVIN, Invisible Giants: Changing the World One Step at a Time, (Bristol: Vala, 2013), at p. 150 (referring to the practice of "relaxed environmentalism").

1604 L. LEVIN, Invisible Giants: Changing the World One Step at a Time, (Bristol: Vala, 2013), at pp. 100, 109 (adding that "the careless, unintended consequences of decisions made in one place or another, in an ever-shrinking world.").

1605 On this particular point about how the various CSR initiatives that companies are implementing or considering to implement can be ineffective or counter-productive, we interviewed - in collaboration with a Dutch NGO (NVO Nederland) - about a dozen Dutch SMEs (Small and Medium sized Enterprises) such as Blanche Dael and Tony's Chocolonely to investigate how businesses actually perceive CSR certifications (e.g. Max Havelaar Fair Trade) and their utility. See, M.T. Kawakami, G. Dijkstra, E. Charlemagne, K. Pitman, P. Su, A. Ungureanu \& M. VROOMEN, "Certification: A Sustainable Solution? Insights from Dutch Companies on the Benefits and Limitations of CSR Certifications in International Supply Chains," NVO Nederland (12 January 2015). Available at: http://mvonederland.nl/publicatie/de-toekomst-van-mvo-certificering (last accessed 7 April 2017). Based on the research that we conducted and the report that we published, a claim can be made that there is value in questioning the status quo about the proliferation of CSR initiatives like labeling and certification schemes, and that there is a demand from actual businesses for us to reassess the continuation of this existing strategy. 
upon these potentials, for a variety of reasons, including but not limited to their bounded rationality and other cognitive limitations.

While these observations mostly point to our flaws and flag them as possible points of future improvement, this thesis still remained optimistic of our collective abilities to adapt and to bring about the changes that we seek: For example, although our societies are indeed complex and our needs and challenges change continuously, "[o]ur minds contain a toolbox of psychological systems... which can be used to meet challenges and construct effective moral communities." 1606 It is this realization that justifies the level of optimism displayed in this conclusion even in the absence of discovering the right law. The existence of this toolbox is what will provide the stakeholders with the ability to come up with workable solutions fit for that specific circumstances as facilitated by our alternative framework. As times and circumstances change, this framework will allow its users to continue churning out updated solutions and this process is what we need more than conjuring up some abstract concept of the right law.

\subsection{VALIDATION OF THE ALTERNATIVE FRAMEWORK}

Having made some general conclusions above, this section will now summarize the various factors that validate the proposed framework, its utility, and its potential in light of the research question(s) posed at the beginning. To reiterate, under the main research question of what can private actors do differently to further reduce labor exploitations in the global supply chain, there were four sub-questions: 1) what is the state of the art and what are private actors currently doing to reduce labor exploitation in the global supply chain, 2) what impacts are they having, 3) what problems and limitations are they encountering, and 4) what changes can they make to further contribute to the reduction of labor exploitation in the global supply chain?

John Ruggie noted that any strategy attempting to address the problem of labor exploitation ought to "motivate, activate, and benefit from all of the moral, social, and economic rationales" that can affect the behaviors of various stakeholders and by "providing incentives as well as punishments, identifying opportunities as well as risks, and building social movements and political coalitions that involve representation from all relevant sectors of society..."1607 The alternative framework proposed in this thesis not only adopts Ruggie's recommendation, but meets our own adapted capabilities framework. To substantiate these claims, this section will reiterate how this alternative framework is inclusive, collaborative and holistic (Subsection 7.2.1); how it values plurality and polycentricity (Subsection 7.2.2); and how it is flexible and adaptable (Subsection 7.2.3), all factors that when combined, make this proposed framework a valid alternative to the existing status quo.

1606 J. HAIDT, The Righteous Mind: Why Good People are Divided by Politics and Religion, (New York: Vintage, 2012), at p. 368.

1607 J.G. RugGIE, "Business and Human Rights: The Evolving International Agenda," American Journal of International Law 101 (2007): 819-840, 838. 


\subsubsection{Collaborative and Holistic}

Strategies advocating for the reduction of labor exploitation, as Ruggie notes, requires an inclusive, collaborative approach that brings together stakeholders from all levels relying on variety of different instruments and tools. This means that governments and the private sector must work together in a more synergetic manner to be a part of the solution. Moreover, the tools and the instruments that they rely on must not only rely on laws or extrinsic incentives but equally value softer approaches like nudges and non-legal measures. The following parts of this subsection will quickly highlight the importance of both a) governments and their regulations; and b) private actors and their initiatives, while bearing in mind how the presence of one can affect the other.

\section{A. Necessity of Government Measures}

Even in light of special districts, charter cities, and seasteads, for all of the talk about the emergence of micropowers and the so-called decline of the post-Westphalian conception of state sovereignty, governments and the laws that they promulgate will continue to play a crucial role in how we as a society, go about resolving our collective action problems. Not only do we need the basic safety nets that they provide - from minimum wage protections to work place safety regulations - but, more critically, societies need functioning courts, infrastructures, and other services that we cannot take for granted. ${ }^{1608}$ This is to suggest that for all of the flaws that it has, our system of governance and the various measures that they implement is something to be satisficed about. ${ }^{1609}$ So while our current system of governance may not be in alignment with Weber's vision of a well-oiled bureaucratic organization or implement measures that fail to meet out adapted capabilities approach, we cannot - for the lack of better words - Voltaire the situation.

While we should not set ablaze all existing laws and regulations, simply relying on them will also not resolve the problem of the labor exploitation in the global supply chain. Moreover, one of the main concerns that this thesis discussed was the crowding out effect of laws and extrinsic motivations on private initiatives and intrinsic motivatons. For example, "[i]n our ever more corporate and bureaucratic culture, constant demands for efficiency, accountability, and profit have led to an increasing reliance on rules and incentives to control behavior," 1610 which is to suggest that there has been a correlating decline of softer, more intrinsic, social norm-based solutions. This trend is particularly concerning in the context of the global supply chain - where those who are exploited or marginalized are usually externalized abroad - because the law "often seeks certainty and tends to assume

1608 An often quoted line from Monty Python's Life of Brian (1979) comes to mind here: “Apart from the sanitation, medicine, education, wine, public order, irrigation, roads, the fresh water system and public health, what have the Romans ever done for us?"

1609 T. JuDT, Ill Fares the Land, (New York: Penguin, 2010), at pp. 8, 206 (stating - with regards to the need for governments - that "the practical need for strong states and interventionist governments is beyond dispute," and that " $[t]$ here are too many areas of life where we cannot be relied upon to advance our collective interests merely by doing what we think is best for each of us.").

1610 B. SCHWARTZ \& K. SHARPe, Practical Wisdom: The Right Way to Do the Right Thing, (New York: Riverhead Books, 2010), at p. 110 . 
fixed boundaries between those who are within and those who are without."1611 This is a trend that private actors must be wary of when planning their initiatives, because as important as the law is, and regardless of how appealing simplicity of creating more and more extrinsic incentives may be, private actors should bear in mind that simplicity does not always correlate with success. While there is something to be said for the rule of law and legal certainty, we cannot "substitute rules for wisdom" all together. ${ }^{1612}$ The adoption of the reflexive governance framework that this thesis advocated for, as a result, is not necessarily a system or rule of laws, but a system of people collaborating and sharing their knowledge, which brings us to the next part of the subsection about the necessity of the private sector and their involvement in search for other ways to reduce instances of labor exploitation.

\section{B. Necessity of Private Initiatives}

Bearing in mind the reality that when a law is introduced as a solution, some - believing that the problem has now been addressed - tend to switch off, our threshold conclusion is worth repeating here: the law is not always the solution. Even when a law has been passed and implemented, their actual impact must be assessed and tested. In the event that the law is deemed not to be the apt solution for the situation, the actions of private actors can contribute through other, non-legal initiatives. Therefore, the involvement of the private sector in the problem-solving process (as advocated by the alternative framework), not only adds cognitive diversity, localized knowledge, and an assortment of expertise to the discussion, but it is a more democratic process to resolving problems.

It is worth pointing out here that not all collaborations end in satisfactory or harmonyenhancing solutions that actually empower the exploited laborers. As a matter of fact, this thesis started off with the example of the CNMI case study, where government officials, businesses, and lobbyists all collaborated - or perhaps even colluded - only to render detrimental outcomes for the immigrant workers in Saipan. While laws and private initiatives acting in concert is indeed capable of much damage, ${ }^{1613}$ the inclusion of more stakeholders to the decision-making and problem-solving processes via the reflexive governance/adaptive management strategies can address this issue: By involving more stakeholders to the process, the alternative framework proposed can not only enhance the social sensitivity of the collective, but the stakeholders representing the interest of the workers would serve as an enhanced check and balance of the group, which ultimately increases the likelihood of the group's decision having more reverence towards notion of distributive and commutative justice.

1611 P. SCHIFF Berman, Global Legal Pluralism: A Jurisprudence of Law Beyond Borders, (New York: Cambridge University Press, 2012), at p. 323.

1612 B. SCHWARTZ \& K. SHARPe, Practical Wisdom: The Right Way to Do the Right Thing, (New York: Riverhead Books, 2010), at pp. 28, 43 (stating that " $[\mathrm{t}]$ he world we face is too complex and varied to be handled by rules.").

1613 See e.g., F. CAPRA \& U. MATTEI, The Ecology of Law: Toward a Legal System in Tune with Nature and Community, (Oakland: Berrett-Koehler, 2015), at p. 101 (arguing that " $[\mathrm{t}]$ he reduction of the legal system to an agreement between private property and state sovereignty has been a powerful tool in quashing nature and community."). 


\subsubsection{Plurality and Polycentricity}

The need for plurality or respecting a polycentric view, is related - perhaps even implied in the recommendation for a more inclusive, collaborative approach that the reflexive governance/adaptive management model calls for. By including all types of stakeholders, not just the lawmakers, but company representatives, members of NGOs, average consumers, laborers at the bottom end of the supply chain and so on, the decision-making process of such a composition will inevitably have cognitive diversity, but also many disagreements. In an environment of "conflicting normative positions," one "cannot simply assert a normative position and expect it to triumph." ${ }^{1614}$ This is why plurality of not just laws, but of opinions and views become a prerequisite for the successful implementation of the alternative framework. While psychologists and sociologists have observed our tendency to ask the question of "what is our best solution" and focusing only on that ideal outcome, it is important - especially given the unpredictability of the future - for stakeholders to allow "several ideas to develop in parallel [because] what seemed initially like an inferior option may turn out to be exactly what we need." 1615 This reverence for polycentricity, as this subsection will show, is nothing new or innovative, as the intellectuals that joined the Romanticism movement back in the 19th Century can attest to (Part A). In short, not everything can or should be rationalized, and some solutions should be based on intuition and emotion. This suggests that private actors and stakeholders must be open-minded and be willing to occasionally accept ideas that they might not see any value in initially (Part B). Our alternative framework, which allows for this, is yet another reason to validate its utility and potential.

\section{A. Embracing the Romantics}

Romantics like Johann Wolfgang van Goethe or William Blake questioned the "tendency of reducing all phenomena to... 'a single vision',"'1616 implying the risk often associated with monism, which is that dogged adherence to believing that there is only one absolute truth often leave the monists vulnerable to reality. Those that carry on their spirit today like Ugo Mattei, believe that the law ought to "reflect the felt needs of society, the spirit of the people, rather than the needs of state or corporate actors." 1617 To the extent that laws may not always be capable of doing so, societies must find alternative ways to express and defend their spirit or their zeitgeist, which is possible through our alternative framework that combines reflexive governance, adaptive management, and private global norm production. The idea of pluralism is essential in this context because as is, "our discourse and our legal

1614 P. SChiff Berman, Global Legal Pluralism: A Jurisprudence of Law Beyond Borders, (New York: Cambridge University Press, 2012), at p. 323 (adding that "we cannot expect that a single universal normative position is likely to prevail either, except in limited spheres and for limited times"); see also, A. RüHMKORF, Corporate Social Responsibility, Private Law and Global Supply Chains, (Cheltenham: Edward Elgar, 2015), at p. 210 (advocating for a "more pluralistic approach.’).

1615 T. HARFord, Adapt: Why Success Always Starts with Failure, (London: Abacus, 2012), at p. 87 (noting that the idea of a plurality "runs counter to our instincts").

1616 F. CAPRA \& U. MATTEI, The Ecology of Law: Toward a Legal System in Tune with Nature and Community, (Oakland: Berrett-Koehler, 2015), at p. 88.

1617 F. CAPRA \& U. MATTEI, The Ecology of Law: Toward a Legal System in Tune with Nature and Community, (Oakland: Berrett-Koehler, 2015), at p. 132. 
frameworks are too often trapped in a language of sovereignty with its purportedly clear lines of demarcation, its assumed allocation of authority, and its formalistic conceptions of legitimacy."1618 Paul Schiff Berman adds that such a framework "cannot hope to guide us in a world of interdependence, inevitably permeable borders, multiple communities, and overlapping jurisdictions." 1619 In short, while we ought to appreciate enlightened thoughts, rationalism, and the realists, plurality advocates that we should also welcome and embrace intuitions, emotions, and romanticisms at the same time.

\section{B. Acceptance and Open-Mindedness}

Part of the reason why we must take the pluralistic approach and remain open-minded is the fact that many of the issues revolving around labor exploitation or sweatshops often fall in the gray area, where the answers to even the most basic questions are never black-orwhite. ${ }^{1620}$ While a person of principle may stick to his or her own views and stubbornly see no value in the arguments of others, reality is far too complex for any problem to be resolved by sticking to one single view or the abstract notion of the one true or right law. As noted in the beginning, sometimes, governments must be more hands on, while in other instances, they must let the market or private actors deal with the problem. Sometimes, the Chicago school is right and at other times, a more Keynesian approach works better. At times, implementing a new law is the best way to resolve a problem, but in other cases, laws can backfire and exacerbate matters. We generally do not know, given the complexity of the global supply chain and our cognitive limitations, which solution or strategy works ex ante, without taking into consideration the relevant facts and taking into consideration the totality of circumstances. ${ }^{1621}$ Even then, we will continue to make mistakes, which is why we need to have a system in place that allows stakeholders to continue adapting and learning from these mistakes and calibrating future courses of action accordingly.

One related tangent with this in mind is the difficulty some institutions have in accepting different views or methodologies: For example, some academics or institutions in various corners of academia have been accused of cocooning themselves from reality, opting to reside in their ivory towers. ${ }^{1622}$ While this separation or demarcation has benefits in some instances, there are risks associated with this practice of exclusivity and haughtiness. As this thesis noted, there is a growing trend of stakeholders relying more and more on laws and extrinsic motivators as their go-to solution to any given problem. In a society,

1618 P. SCHIFF Berman, Global Legal Pluralism: A Jurisprudence of Law Beyond Borders, (New York: Cambridge University Press, 2012), at p. 324.

1619 P. SCHIFf BERMAN, Global Legal Pluralism: A Jurisprudence of Law Beyond Borders, (New York: Cambridge University Press, 2012), at p. 324; cf. D. VoGEL, The Market for Virtue: The Potential and Limits of Corporate Social Responsibility, (Washington D.C.: Brookings Institution Press, 2006), at p. 170 (warning that "There is a role for both voluntary and legally binding standards; the two should not necessarily converge.").

1620 B. SCHWARTZ \& K. SHARPE, Practical Wisdom: The Right Way to Do the Right Thing, (New York: Riverhead Books, 2010), at p. 22 (noting that these types of issues demand "an ability to see the nuance - the gray - of a particular situation, and not simply the black-and-white of the legal and the illegal.”).

1621 See generally, O. SERVICE \& R. GallaGHer, Think Small: The Surprisingly Simple Ways to Reach Big Goals, (London: Michael O’Mara Books, 2017); see also, D. HALPERN, Inside the Nudge Unit: How Small Changes can Make a Big Difference, (London: Penguin WH Allen, 2015), at p. 273 (noting that " $[\mathrm{t}]$ he dirty secret of much government policy, and professional practice, is that we don't really know if it is effective at all.").

1622 B. SChwartz \& K. Sharpe, Practical Wisdom: The Right Way to Do the Right Thing, (New York: Riverhead Books, 2010), at p. 120 (noting that "[a]cademics often live "in the world of the abstract and theoretical, a world that often eschews practical wisdom.”). 
where restrictions are placed on who can study the law - due in part to the professionalization of the field - and limiting only those with an understanding of the law to be involved in the process of creating laws, there is a great risk that the status quo is currently excluding brilliant ideas that originate from the so-called lay people. This is to suggest that while a certain line of demarcation between those that "understand the law" and "those that do not" may be appropriate, we must bear in mind that the law ought to be that of the people, and ought to be shaped, analyzed, and adapted according to the views of the people, and not just of that of legal scholars and theorists. ${ }^{1623}$ Perhaps a point that was not explicitly noted in the valorization above, but worth adding here is for the law and the study of law to be more accepting of interdisciplinary approaches. Admittedly, not all of what will result will be good, but by giving legitimacy and acceptance to plurality and the interdisciplinary approach, we may arrive at answers that legal scholars could never have imagined independently. This is yet another validation for our proposed framework, which calls for this type of open-mindedness and collaboration of all stakeholders.

\subsubsection{Flexibility and Adaptability}

The last point of validation for the proposed framework is its flexibility and adaptability. Adapting means being able to learn from our mistakes. ${ }^{1624}$ As noted above, for one to be open to plurality also means that one must be flexible and open to the idea of adapting to situations as necessary. Our dabbling into the realm of behavioral psychology showcased our heuristics and biases, including but not limited to that of our cognitive flexibility and overconfidence that sometimes lead us astray from conducting careful analyses and making good decisions. The awareness of these very human flaws, at least in theory, should incentivize the process of private actors to continuously reassess their firmly held beliefs and notions of what the right course of action is at given time. The subsequent step that comes after this reassessment, to the extent that a course-correction is indeed necessary, is for the stakeholders to adapt as the circumstances require, which given our cognitive limitations and bounded rationality, could take multiple attempts at trial-and-erroring until we reach a workable solution. Accordingly, private actors always need to have a plan in the event that their initial plan fails (Part A), and bearing in mind the level of uncertainty that exists in the world today, private actors must learn to coexist with uncertainty and adapt as situations develop (Part B). The benefit of our alternative framework is that it facilitates private actors to manage these concerns, while at the same time, conforming to our normative framework.

1623 F. CAPRA \& U. MATTEI, The Ecology of Law: Toward a Legal System in Tune with Nature and Community, (Oakland: Berrett-Koehler, 2015), at p. 132 (arguing that "[w]e need, as a society, to pierce the ideological veil of a legal system that is abstract and mechanical, 'owned' by the state, and kept distant from individual people by the professionalized culture of corporate lawyers.”); see also, E. EHrLiCH, Fundamental Principles of the Sociology of Law, (Cambridge: Harvard University Press, 1936).

1624 D. Stone, B. Patton \& S. Heen, Difficult Conversations: How to Discuss What Matters Most, (New York: Portfolio Penguin, 2011), at p. 293 (stressing that "[w]hat we need is a little empathy for ourselves. Accepting our whole selves - our mistakes, failures, and short-comings, our moments of weakness, selfishness, and stupidity - and forgiving ourselves these, are essential steps towards finding balance now and growth in the future."). 


\section{A. Getting Punched in the Mouth}

Mike Tyson once stated that "everyone has a plan until they are punched in the mouth," and this may be the perfect analogy to when lawmakers realize that the law they promulgated backfired and exacerbated the situation they intended to remedy. The uncomfortable truth is that laws flop more often than we think (e.g. the Dutch flexwet example from Chapter 2, the neutering of the Alien Tort Statute in the aftermath of Kiobel from Chapter 3) and private initiatives implemented with best of intentions sometimes help no one (e.g. integrated reporting and ESG metrics that could lead to information overload noted in Chapter 4 , proliferation of certification and labeling schemes from Chapter 5). What matters in the end is what these key stakeholders or we, as a society, do when faced with these failures. The answer is rather simple, though difficult to implement, and that is to acknowledge it as a mistake, learn from it, adapt, and try a different option. Even if a workable solution is reached, there are no assurances that it will continue to work as circumstances and paradigms continually shift: What once was considered as a working solution can suddenly stop working. ${ }^{1625}$ In situations such as this, what is more valuable than temporarily having a workable solution is an adaptive, flexible, framework that brings people together to rely on their collective wisdom to come up with other ways to solve the particular problem.

\section{B. Unknown Unknowns}

In a news briefing on 12 February 2012, then US Secretary of Defense Donald Rumsfeld, was uncharacteristically honest and forthcoming, when he uttered the following: "There are known knowns. There are things we know we know. We also know there are known unknowns. That is to say that we know there are things we do not know. But there are also unknown unknowns. The ones we don't know we don't know." Aside from the fact that this statement reads like an excerpt from a Dr. Seuss book, the existence of these unknown unknowns should give us a moment of reflection: Especially in our supply chain that is becoming more and more complex, what may have worked in the past (perhaps the known knowns), may no longer work. In such instances, what becomes necessary is a framework that will allow us to deal with the unknown unknowns in a competent, collaborative manner, and our alternative framework - as this thesis contends - is just that.

In a variety of situations, the solution that ends up working in the end can be so outside of the box that some never conceived of it as a possible option, nevermind a successful one ex ante. ${ }^{1626}$ If we are not open to admitting our limitations and flaws - that in many

1625 B. SChwartz \& K. SHARPe, Practical Wisdom: The Right Way to Do the Right Thing, (New York: Riverhead Books, 2010), at p. 110 (noting that "[a]s institutional practices like these become calcified, we lose our bead on the real aims and purposes of our work and fail to develop the moral skills we need to achieve them.”).

1626 For example, a Dutch charity, Internationaal Christelijk Steunfonds, wanted to promote literacy in Kenya through various school assistant programs and initiatives. After initiatives such as sending textbooks and other educational tools like flipcharts failed to achieve their goals, they eventually found out that what ultimately increased literacy was paying for intestinal worms. An assortment of scientists found out that children were missing schools because of intestinal worms, and that by providing them with treatment for intestinal worms, their absenteeism dropped and literacy increased. See, T. HARFORD, Adapt: Why Success Always Starts with Failure, (London: Abacus, 2012), at p. 127-9 (citing to a series of research conducted by a multidisciplinary team from Harvard, University of Minnesota, and the World Bank); P. Glewwe, M. Kremer \& S. Moulin, "Many Children Left Behind? Textbooks and Test Scores in Kenya," NBER Working Paper 13300, (2007); P. GLEwwe, M. KREMER, S. MOUlin \& E. ZiTZEWITZ, "Retrospective Versus Prospective Analyses of School Inputs: The Case of Flip Charts in Kenya," NBER Working 
cases, we can never be absolutely sure about the right course of action - and keeping an open mind to adapting, we will not be able to adequately deal with a problem such as the labor exploitation taking place in the global supply chain. Bearing this point in mind, consider for a moment the assortment of literature that profess either that a particular law is the right one or how a particular course of action is the best possible one. In reality, these claims are often exaggerations that can be quite misleading, overly simplified, or at the very least, incomplete. ${ }^{1627}$ Part of the reason why there are no "best" laws of general applicability across all jurisdictions with regards to many collective action problems is precisely because there are so many unknown unknowns. In the words of M.E.P. Seligman, "when there are too few variables to explain the rich nuances of the phenomenon in question, nothing at all is explained," 1628 and in the end, what ends up actually working "is a far more unsightly, chaotic, and rebellious organization all together." 1629 This is why reflexive governance and adaptive management ought to be the framework both governments and private actors rely more on moving forward to not only tackle the labor exploitations in the global supply chain, but other collective action problems as well.

This thesis suggested earlier that hope and optimism is not a replacement for seeking phronesis and hard work. While this statement still holds true, it is becoming apparent that what energizes stakeholders to keep exerting effort to learn, to adapt, and to continue attempting to reduce labor exploitation is hope and the belief that what we are doing has meaning or a sense of purpose: For example, "[h]ope, modern researchers are finding, does more than offer a bit of solace amid affliction; it plays a surprisingly potent role in life, offering an advantage in realms as diverse as school achievement and bearing up in onerous jobs." ${ }^{1630}$ Moreover, hope and optimism, can be learned, just like helplessness, and how to do that is by becoming self-efficient, which in psychology means to "hav[e] the belief that one has mastery over the events of one's life and can meet challenges as they come up."1631 In the end, learned helplessness or learned optimism is proof that we, as human beings, are capable of adapting to our circumstances and new challenges.

Paper 8018, (2000); E. Miguel \& M. KREMER, "Worms: Education and Health Externalities in Kenya," NBER Working Paper 8481 (2002). There is an assortment of various other unexpected solutions to a problem or strange correlations or causations; see e.g. S.D. LEVITT \& S.J. DUBNER, Freakonomics: A Rogue Economist Explores the Hidden Side of Everything, (New York: Harper Perennial, 2005).

1627 M. Siems, Comparative Law, (Cambridge: Cambridge University Press, 2014), at p. 283 (concluding that "their arguments cannot be said as having shown that law is useless or even harmful for development.”).

1628 M.E.P. Seligman, Flourish, (New York: Atria, 2011), at p. 9.

1629 T. HARForD, Adapt: Why Success Always Starts with Failure, (London: Abacus, 2012), at p. 42.

1630 D. Goleman, Emotional Intelligence, (New York: Bantam Books, 2005), at p. 87 (defining hope as "believing you have both the will and the way to accomplish your goals, whatever they may be.").

1631 D. Goleman, Emotional Intelligence, (New York: Bantam Books, 2005), at p. 89; see also, M.E.P. SELIGMAN, Flourish, (New York: Atria, 2011), at p. 189 (noting that " $[\mathrm{w}]$ e found that people who believe that the causes of setbacks in their lives are temporary, changeable, and local do not become helpless readily in the laboratory..."). 


\subsection{FINAL REMARK}

Economist Tim Harford remarked that "[m]ost original ideas turn out to be not original after all, or original for the very good reason that they are useless." 1632 The wishful thinking here is that this thesis falls in the former and not the latter. Although none of the ideas and arguments presented in the preceding pages may have been original or unique in their own right, the aim of this thesis was to combine these existing theories but from eclectic fields in a unique and different way: By looking at the problem of labor exploitation in the global supply chain, not only from a legal perspective, but by incorporating behavioral psychology and sociology into the mix, the goal of this thesis was to convince the readers that addressing a problem so complex, requires openness to plurality of ideas, collaborative/inclusive mix of approaches, and the courage to not be certain about anything.

In the end, the specific pleas that this thesis made throughout the chapters is for us, as a society: 1) to realize the various flaws and the limitations of our governments; 2) to stop relying on the law as our only source for solutions; 3) to acknowledge the need and the importance of private, non-legal initiatives, while also recognizing our very own set of human flaws; 4) bearing in mind these flaws, to constantly challenge our embedded beliefs about what solutions or strategies work; 5) to be open-minded and to implement new and different strategies even when such attempts lead to series of failures at first; 6) to learn from our failed attempts; and finally, 7) to repeat the process as necessary. What is implied in these pleas is the suggestion that "the most important source of law" is not governments or the lawmakers, but "the laboratory of the real-life experience." 1633

The framework that encompasses these pleas, as this thesis suggested, is our alternative framework that combines private global norm production, reflexive governance, and adaptive management strategies. This is a framework that intrinsically incentivizes more participation from multitude of stakeholders and an approach that puts the importance of social norms on par with that of legal norms, bearing in mind our various psychological and cognitive quirks. In the end, labor exploitation in the global supply chain is a deeply complex, entangled problem with multiple causes and myriad of players involved. There is no "right" answer or best practices, other than the acknowledgement that every situation is different and we, as a society, must treat it as such. Just because governments enforcing their labor regulations broke up a chain of sweatshops or because the implementation of a corporate code of conduct improved the working condition of a supplier's factory in some instances are not clear indications that every actor in the supply chain should simply emulate these practices. Ultimately, it is the recognition of our flaws, first and foremost, that allows us to rise above them and to evolve as necessary.

In closing, there is an apt Japanese proverb that captures the essence of this thesis, which is "nanakorobi yaoki." This roughly translates to "fall seven, get up eight." We are

1632 T. HARFOrd, Adapt: Why Success Always Starts with Failure, (London: Abacus, 2012), at p. 83; see also, J. DE GRAAF, D. WAnn \& T.H. NAYLOR, Affluenza: How Overconsumption is Killing Us - And How We Can Fight Back [Third Edition], (San Francisco: Berrett-Koehler Publishers, 2014), at p. 10 (sharing similar sentiments with regards to their contribution that: "[t] his book contains little truly new information," but its an attempt at making sense of "what we already known and how to use values, not just information" as the catalyst for change).

1633 F. CAPRA \& U. MATTEI, The Ecology of Law: Toward a Legal System in Tune with Nature and Community, (Oakland: Berrett-Koehler, 2015), at p. 160. 
beautifully flawed human beings, and as such, we are bound to fail and to make mistakes especially when tackling a challenge as overwhelming as reducing the labor exploitations taking place in the global supply chain. However, resilience is also a basic human condition and we are capable of learning from our mistakes. Although progress may be incremental, or at times we even make mistakes that set us back, what matters in the end is that we keep getting up and trying again. 


\section{Acknowledgements \& Apologies}

To my supervisors (Jan Smits and Gary Low): As cliché as it may sound, words truly cannot express the depth of gratitude and the admiration that I have for the both of you. Jan, I still remember - as if it was yesterday - walking into your office in the M Building of Tilburg University back in 2008. The meeting was actually a job interview for a student assistant position for the Tilburg Institute of Comparative and Transnational Law ("TICOM"). You hired me for the job and that was the first of many opportunities that you have given me over the years. Whether it was bringing me under your wings for the $\mathrm{PhD}$ position, giving me my first shot at teaching, or trusting me to be a coordinator of a course, you have given me so much and for that I really cannot thank you enough. I vividly recall reading the text of your inaugural lecture on "Private Law 2.0: The Role of Private Actors in a Post-National Society" while I was still working in New York City, and to this day, the text from this lecture has been my guiding frame of reference for what creative academic work ought to be like.

Speaking of TICOM, this was also when I first met you Gary, back when you were still a PhD (also under Jan's supervision) in Tilburg. I immediately took a great interest in your work, especially with regards to your interdisciplinary methodology of incorporating behavioral economics into your legal analysis. Your approach left such an impression, so much so that when I started my $\mathrm{PhD}$, I wanted to emulate your approach. Gary, I have always looked up to you - and no doubt will continue to - as my wise older brother who not only helped me through the $\mathrm{PhD}$ process, but gave me invaluable advice on teaching international business/commercial law and working as an academic.

While I tried to internalize every bit of wisdom that you two shared with me over the years and tried to incorporate every bit of advice you had for the manuscript, I apologize for whatever errors and flaws that still remain within these pages. For example, I recall from many of our thesis meetings that the comment I got most often was that my manuscript often read like a manifesto. While I wholeheartedly tried to refrain from writing in such a manner, if parts of this manuscript still read that way, I blame my bounded rationality and my cognitive limitations. Dear Jan and Gary, I feel truly blessed to have had the opportunity to learn, grow, and experience the process of researching and writing a $\mathrm{PhD}$ under your supervision. I thank you from the bottom of my heart for your patience and kind guidance in helping me navigate through what was an incredibly humbling and rewarding process.

To my sponsor (The Hague Institute for the Internationalisation of Law): I want to express my deepest appreciation for HiiL's generous contribution and funding, which made 
my research and the publication of this manuscript possible. I hope that my research and output meets your expectations.

To the members of my reading committee (Mieke Olaerts, Larry Catá Backer, Jan Eijsbouts, and Frank Hendrickx): I honestly could not have asked for a better reading committee and I am overwhelmed with joy and humbly flattered that you have accepted to be a part of my defense. I was very appreciative of your comments and feedback and I hope that I have incorporated them into the manuscript to your satisfaction. I look forward to your grilling questions.

To my paranymphs (Catalina Goanta and Anna Berlee): I've always been an only child and never really knew what it was like to have siblings. Having you two not just as two of my closest friends, but as my paranymphs though really made me feel like I had two sisters. Catalina, you were the first person that I met from the University after I decided to come to Maastricht and I knew from the moment we first met back at the KNAW in Amsterdam that you had my back and I hope that I have been able to do the same for you. Anna, having you not only as my friend, but also as my officemate was one of the most fortuitous things that could have happened to me and my research process (though it may have slightly delayed the completion of our PhDs because we ended up talking for hours about topics that were slightly outside the scope of theses). We survived some difficult times together, but I really believe that because we were - more or less - going through them together, we came out quite ok. To the both of you, I am truly grateful of your friendship, your unwavering support, and your help with the planning and coordinating my $\mathrm{PhD}$ defense.

To my wonderful friends and accomplices (Willem Loof, William Bull, Daniel On, Jiangqiu Ge, Matteo Bonelli, Frank Nellen, Nicole Kornet, Bram Akkermans, Kim Berg, Kate O’Reilly, Anna Beckers, Caroline Calomme, Christopher Mondschein, and Marieke Hopman): Willem, thank you for always being a much necessary calming influence in my life and being there for me when I needed to bounce off ideas that I was not entirely sure about. William, thank you for introducing me to Leicester and being there for a game of snooker or golf when I needed a break from it all. I will never forget our first trip to in Hamburg and I will keep retelling that story to anyone who will listen. Daniel, thank you for all the stimulating conversations and challenging me mercilessly with your questions especially during our MEPLI Talks. Jiangqiu, I am really happy that our paths crossed. I will never forget the conversation we had during the Ius Commune dinner at Leuven and still cannot thank you enough for our Shanghai adventure. Matteo, thank you for being my cheesy business partner, my co-Honorary Minnesotan, and my second favorite Italian friend. Frank, thank you for being my favorite Italian friend and for all the nights you hosted poker night, when we were able to talk candidly about our work and how behind we were on submitting our PhDs. Nicole, my fellow G\&T connoisseur, thank you for always being there for me and letting me vent about everything and anything. Bram, thank you for advising me about the inner workings of the academic life and guiding me through some of the decisions that I had to make. Kim, thank you for sticking with me through IBL and making sure that everything was under control. Kate, thank you for being such an understanding and tolerant officemate, especially when I was freaking out about how behind I was on everything. Anna, thank you for being such a trailblazer and letting me ride on your coattails. Co-editing and publishing the special edition of the Indiana Journal of Global 
Legal Studies was one of the proudest things I've done with my time in academia, and I could not have done it without you. Caroline, thank you for your input on Durkheim and all the "fun" facts. Christopher, thank you for all the fresh pots and the puns. And finally, Marieke, thank you for loving me even when I was an insufferable pain to be with while I was trying to finish the manuscript. I will be forever grateful about the fact that you actually read through my entire draft manuscript and gave me such incisive and fruitful comments. I enjoyed all of our conversations tremendously, especially when you highlighted the flaws of my arguments and - believing that I could do better - continued to challenge me. I hope we can continue our conversations for years and years to come!

To the members of the Executive Board that sit high atop the Mountain (Martin Paul, Rianne Letschert, and Nick Bos): It was an honor to work with you all during the UM40 Opening of the Academic Year celebrations and to catch a glimpse of what it takes to run and manage a University. It gave me a lot of food for thought in terms of what it means to be a good teacher and a researcher from an entirely different perspective.

To the delightful people of the law faculty who I have the honor and the privilege to call my colleagues (Hildegard Schneider, René deGroot, Monica Claes, Ton Hartlief, Sjef van Erp, Gerrit van Maanen, Kid Schwarz, Jos Hamers, Sybren de Hoo, Gijs van Dijck, Hans Nelen, Michael Faure, Jaap Hage, Menno Kamminga, Jure Vidmar, Susan Rutten, Caroline Cauffman, Marcel Schaper, Maja Brkan, Niels Philipsen, Chris Backes, Remco van Rhee, Anke Moerland, Roland Moerland, Elise Muir, Sarah Schoenmaekers, Lisa Waddington, Mariolina Eliantonio, Solange Daenen, Lars van Vliet, Diana Wallis, Pauline Kruiniger, Joyce Groneschild, Saskia Klosse, Catherine de Rijdt, Ria Wolleswinkel, Vigjilenca Abazi, Diane Fromage, Pim Oosterhuis, Sascha Hardt, Ida Wendt, Tanja van der Meer, Natasja vander Meer, Gonzalo Garfias von Furstenberg, Maria Godoy Uson, Damla Bos, Marcus Meyer, Thera Dieleman, Johannes Keiler, Hannah Brodersen, Nina Buttgen, Giulia Giardi, Marie-Therese Gold, Bastiaan Leeuw, Pauline Melin, Hoai-Thu Nguyen, Adela Ognean, Dhruv Sanghavi, Serban Vacarelu, Sabrina Wirtz, Sejla Imamovic, Bastian Kempeners, Sofie Wolf, Paul Dermine, Zvezda Vankova, Tianxiang He, Thomas Biermeyer, Jennifer Sellin, Emanuele Juvemerde-Bucci, Tobias Heldt, Sara Fattorini, Stephanie Blom, Pablo Bravo Hurtado, Federica Pitrone, Lotte Meurkens, Michael Wells-Greco, Samantha Renssen, Viivi Varakas, Liuhu Luo, Constantijn van Aartsen, Natasja Reslow, Maddalena Neglia, Tobias Jonkers, Elvira Loibl, Katja Zimmermann, Mayke Knoben, Kim Geurtjens, Suzanne Jongste, Antonia Waltermann, Julieta Marotta, Agustin Parise, Sandra Nóbrega, Benedicta Deogratias, Luca Bücken, Costas Georgiades, Sjors Vonken, Stijn te Strake, Emily Allwood, Nicol Dominiuk, Valentin Calomme, Violette Wolters, Edward King, Cristiana Cozac, and Paul Roos): Thank you for constantly inspiring me and developing the way I think. I am a better person for having had the pleasure of knowing you all.

To the incredible people at the secretariat Jose Crijnen, Peggy van Wersch-Lieben, Noëlle Tillie, Lot Van de Ven, Lydie Coenegrachts, and Joyce Berghmans): You ladies are all so incredible! I really cannot thank you enough for helping me out with everything and letting me steal the office supplies. I always loved coming to your office!

To the eternally patient people at the education office (Jolien Hendrikx, Tessa Fooij, and Patty Dautzenberg): I'm sorry I only came to your office when I needed to change my teaching schedule, switch classrooms, or pick up/drop off exams. Your help was really 
invaluable as it made it possible for me to balance my teaching and researching, which was something I really could not have done without.

To the staff members that keep the law faculty up and running (Diana Schabregs, Licette Poll, Marc Weerts, Ingrid Loontjens, Yvonne van Uden-Vermeulen, Eva Rongen, Pauline Arends, Trees Bronkhorst, Femke Buiter, Veronique Schwiebert, Paul Adriaans, Henk Verkoeyen, Kathleen Mertens, Roger Snijders, Marina Jodogne, Marjo Mullers, Jolande Pletzers, and Marlies van Dongen): Without all of the wonderful things that you do, I would have been lost. Thank you for helping me find the way.

To all the people that I have had the privilege of meeting outside of the law faculty while in Maastricht (Sueli Kyomi Brodin, Lori Mees, Gonny Willems, Jean-Paul Toonen, Robert Hoogenboom, Marin Been, Zhen Wang, Mardoeka Christensen, Ellen Krijnen, Christa Dubois, Herco Fonteijn, Alexandra Rosenbach, Michel Dumontier, Stefan Kulk, Stephen Bogle, Ellen Bastiaens, and Len Cuppens-Walder): Your friendship means a lot to me and I am ever so grateful for all of the learning opportunities that you have given me. A special thanks to Ubbo Noordhof from Datawyse for the formatting of the manuscript!

To everyone in the beautiful city of Maastricht that literally gave me sustenance and helped me survive the last 5 years (Pieter Hamel, Michael Bolstridge, Sarah Burki, Edin Rizvic, Moniek Vroomen, Sylvia Weijzen, Sandra Weijzen, Kim Jacobs, and to everyone at the Tribunal who let me use their fine establishment as my second office/backup classroom): Thank you for the food, the drinks, the love, and your kind hospitality. I would have died long before I ever finished this $\mathrm{PhD}$ had it not been for your support.

To the Wednesday Night Football Crew/Legal Eagles (Bob Platte, Sander van Attekum, Fernando Vargas, Elvis Avenyo, Sam Henry, Dominik Mahr, Dario Dotti, and Paolo Rusconi): Thank you for keeping me in shape, more or less, so that I could keep up with the grinding task of teaching and writing a $\mathrm{PhD}$.

To my friends back in the US and Japan that I have completely abandoned since I moved to Maastricht (you know who you are): I'm sorry that I've been a bad friend who missed weddings, bachelor parties, child births, and so on. Thank you for still keeping me in the loop though. I really do and continue to miss you all. One special thanks goes out to Mary Rumsey, who helped me find articles and documents that I really could not find anywhere else using her special librarian magic.

To my students and mentees who tolerate(d) my shenanigans: You give me a sense of purpose and you are the reason why I truly believe that I have the best "job" in the world. I really consider it to be a privilege and an honor to be working with you all. So thank you!

Last, but not least, to my mom and Chachan who have always looked after me. I know I am always far away and doing my own thing and I am really sorry about that. Still, you push me to follow my dreams and encourage me to keep doing what I am doing. I consider myself to be extremely fortunate to have your unconditional love and support. I hope that I can continue to make you proud and that you will find happiness in knowing that I am doing what I love, surrounded by a great group of people who support me as you see above. There are bits and pieces of Japanese wisdom scattered across this manuscript (i.e. the front cover of the kintsugi) and when I wrote about it, I always had you two in my mind and heart. Thank you for supporting me make it this far. I really could not have done this without you two. 


\section{Summary}

The main question that this thesis addressed was what private actors - from the companies to the consumers and even the laborers themselves - can do differently than what they are currently doing to further reduce instances of labor exploitation taking place in the global supply chain. To answer this question, this thesis first offered a descriptive overview of popular legal instruments and strategies that private actors are currently employing by relying on labor/employment law, tort law, company law, and contract law. This descriptive overview also addressed various semi- or non-legal instruments and initiatives with the intended aim of reducing labor exploitations as well such as corporate social responsibility initiatives and ethical consumerism campaigns.

Second, this thesis offered a critical analysis of these existing measures and strategies by highlighting instances of their failures: By relying on the adapted capabilities approach (based on Nussbaum's capabilities approach) as the relevant normative framework, this part of the thesis presented the various flaws and limitations of our current approach to reducing instances of labor exploitation in the global context. Moreover, in conducting this critical analysis, this thesis not only looked at the existing measures and strategies from an intra-disciplinary legal perspective, but conducted a more multi-disciplinary analysis using findings from sociology, anthropology, psychology, and behavioral economics to strengthen the argument that the current approach is indeed flawed.

The two main flaws discovered from conducting this critical analysis was the realization that: 1) current measures and strategies rely overwhelmingly on legal incentives and extrinsic motivators, which (mistakenly) assume private actors to be rational actors; and 2) the current problem-solving process in designing, implementing, and enforcing these measures tends to be hierarchical, rigid, and not adaptive enough to address a global collective action problem like the labor exploitations taking place within our global supply chain.

To remedy these concerns, this thesis made two general proposals: 1) for both private actors and governments alike to rely less on legal norms and resist the urge to simply create more and more legal norms; and 2) for both the private and the public sectors to adopt an alternative problem-solving framework, one that forges and espouses concepts such as private global norm production, reflexive governance, and adaptive management strategies. In sum, this thesis advocated that incorporating these proposals could potentially improve the status quo. By offering examples of how various actors can implement this alternative framework pragmatically, this thesis offered not just a reassessment of what private actors are currently doing, but made recommendations in terms of how they can adapt their strategies moving forward to better alleviate the plight of the marginalized laborers. 
Page left intentionally blank 


\section{Samenvatting ${ }^{1634}$}

De hoofdvraag van deze dissertatie was wat private actoren - van bedrijven tot consumenten en zelfs de werknemers zelf - anders kunnen doen dan wat zij op dit moment doen om de uitbuiting van arbeid die gaande is in de wereldwijde aanvoerketen verder te verminderen. Om deze vraag te beantwoorden, bood de dissertatie allereerst een beschrijvend overzicht van populaire juridische instrumenten en strategieën die op dit moment worden gebruikt door private actoren binnen het arbeidsrecht, verbintenissenrecht (uit zowel onrechtmatige daad als overeenkomst) en het vennootschapsrecht. In dit beschrijvend overzicht kwamen ook de verscheidene semi- of niet-wettelijke instrumenten en initiatieven aan de orde met het beoogde doel om arbeidsuitbuiting te verminderen, alsook initiatieven van maatschappelijk verantwoord ondernemen en ethische consumentisme campagnes.

Ten tweede bood deze dissertatie een kritische analyse van deze bestaande maatregelen en strategieën door hun mislukkingen te accentueren: Hierbij werd het normatief kader ingegeven door de 'adapted capabilities'-benadering (gebaseerd op Nussenbaum's 'capabilities approach'). Dit gedeelte van de dissertatie legde de verschillende gebreken en beperkingen van onze huidige aanpak bloot om arbeidsuitbuiting in de wereldwijde aanvoerketen te verminderen. Bij de uitvoering van deze kritische benadering werd niet alleen gekeken naar de huidige maatregelen en strategieën vanuit een intra-disciplinair juridisch perspectief, maar eveneens vanuit een meer multidisciplinaire analyse waarbij gebruik werd gemaakt van bevindingen uit de sociologie, antropologie, psychologie en gedragseconomie om aan te tonen dat de huidige aanpak inderdaad in gebreke is.

De twee belangrijkste gebreken die naar boven kwamen tijdens het onderzoek waren de realisaties dat: 1) de huidige maatregelen en strategieën in overweldigende mate steunen op juridische prikkels en extrinsieke drijfveren, die (ten onrechte) uitgaan van een rationele private actor; en 2) de huidige aanpak van dit probleem is in haar ontwerp, implementatie en tenuitvoerlegging van de maatregelen: hiërarchisch, rigide en bezit onvoldoende aanpassingsvermogen om vat te krijgen op het geplaagde probleem van de wereldwijde collectieve actie zoals de arbeidsuitbuiting in de wereldwijde aanvoerketen met zich meebrengt.

Om deze bezwaren tegen te gaan draagt deze dissertatie twee algemene voorstellen aan: 1) dat zowel private als publieke actoren minder leunen op wettelijke normen en de weerstand bieden aan de verleiding om eenvoudigweg meer en meer wettelijke normen te creeren; en 2) dat zowel de private als publieke sectoren een alternatief raamwerk voor oplossingen aannemen, een raamwerk dat streeft naar en concepten omarmt zoals private mondiale norm productie ('private global norm production'), reflexief bestuur ('reflexive gover-

1634 Translated, with my utmost gratitude, by Anna Berlee. 
nance'), en adaptief management strategieën ('adaptive management strategies'). Deze dissertatie pleit kortom voor opname van deze voorstellen ter verbetering van de status quo. Door te laten zien hoe verschillende actoren dit alternatieve kader kunnen implementeren op een pragmatische manier, biedt deze dissertatie niet alleen een herbeoordeling van wat private actoren momenteel aan het doen zijn, maar makt het aanbevelingen over hoe zij hun strategieën in het vervolg kunnen aanpassen om het lot van de gemarginaliseerde arbeiders te kunnen verlichten. 


\section{Bibliography}

\section{BOOKS}

P. AllotT, The Health of Nations: Society and Law Beyond the State, (Cambridge: Cambridge University Press, 2002).

P. Alston, Labour Rights as Human Rights: Collected Courses of the Academy of European Law, (Oxford: Oxford University Press, 2005).

T.M. AmaBile, Creativity in Context, (Colorado: Westview Press, 1996).

R. ANDERson, Confessions of a Radical Industrialist, (New York: Random House Business Books, 2011).

S. AnHolt, Brand New Justice: How Branding Places and Products Can Help the Developing World, (Oxford: Elsevier, 2005).

S. ANHOLT, Places: Identify, Image and Reputation, (New York: Palgrave Macmillan, 2010).

M. ANTOKOLSKAiA, Harmonisation of Family Law in Europe: A Historical Perspective, (Antwerp: Intersentia, 2006).

D. ARIELY, Predictably Irrational: Hidden Forces that Shape Our Decisions, (London: Harper Collins, 2009).

D. ArIEly, The (Honest) Truth About Dishonesty: How We Lie to Everyone - Especially Ourselves, (New York: Harper Collins, 2012).

D. Ashiagbor, "Evaluating the Reflexive Turn in Labour Law," in The Autonomy of Labour Law, A. BogG, C. Costello, A.C.L. Davies \& J. Prassl (EDS.), (Berlin: Walter de Gruyter, 2015).

S.M. BAinbridge, Corporate Law [Third Edition], (St. Paul: West Academic, 2015).

J. BAKAN, The Corporation: The Pathological Pursuit of Profit and Power, (New York: Free Press, 2004).

O. BAR-GILL, Seduction by Contract: Law, Economics, and Psychology in Consumer Markets, (Oxford: Oxford University Press, 2012).

B.D. BArros, "Introduction," in Hernando de Soto and Property in a Market Economy, B.D. BARros (ED.) (Farnham: Ashgate, 2010): 1-6.

G.S. BECKER, The Economic Approach to Human Behavior, (Chicago: University of Chicago Press, 1978).

H.S. BECKER, Outsider: Studies in Sociology of Deviance, (New York: Simon \& Schuster, 1963).

A. BECKers, Enforcing Corporate Social Responsibility Codes. On Global Self-Regulation and National Private Law, (Oxford: Hart Publishing, 2015).

E. BeInHOCKER, The Origin of Wealth: The Radical Remaking of Economics and What it Means for Business and Society, (Cambridge: Harvard Business Review Press, 2007).

O. Ben-Shahar \& C.E. SchneIder, More Than You Wanted to Know: The Failure of Mandated Disclosure, (Princeton: Princeton University Press, 2014).

B. BERCusson, "Juridification and Disorder," in Juridification of Social Spheres: A Comparative Analysis in the Areas of Labor, Corporate, Antitrust and Social Welfare Law, G. TeuBner (ED.), (Berlin: Walter de Gruyter, 1987).

F. Berkes, J. COLDING \& C. FOLKE, "Introduction," in Navigating Social-Ecological Systems: Building Resilience for Complexity and Change, F. BERKES, J. COLDING \& C. FOLKE (EDS.) (Cambridge: Cambridge University Press, 2003): 1-29.

G. BETLEM, "Transnational Litigation Against Multinational Corporations Before Dutch Civil Courts" in Liability of Multinational Corporations Under International Law, M.T. KAMMINGA \& S. ZIA-ZARIFI (Dordrecht: Springer, EDS.) (2000): 283-305.

C. BICCHIERI, The Grammar of Society: The Nature and Dynamics of Social Norms, (New York: Cambridge University Press, 2006).

T. BINGHAM, The Rule of Law, (New York: Penguin, 2010).

J.H. Birnbaum, The Lobbyists: How Influence Peddlers Work. Their Way in Washington, (New York: Three River Press, 1993). 
K.C. Bisceglie, H.C. Ross \& T.J. Fleming, New York Commercial Litigation Guide, (New York: Matthew Bender \& Company, 2012).

S. Blumenthal, How Bush Rules: Chronicles of a Radical Regime, (New Jersey: Princeton University Press, 2006).

R. Botsman \& R. Roger, What's Mine is Yours: The Rise of Collaborative Consumption, (New York: HarperCollins Publishers, 2011).

S. Bowles, Machiavelli's Mistake: Why Good Laws Are No Substitute for Good Citizens, (New Haven: Yale University Press, 2012).

J. Braithwaite \& P. Drahos, Global Business Regulation, (Cambridge: Cambridge University Press, 2000).

P. Brickman \& D. CAMPBEll, "Hedonic Relativism and Planning the Good Society," in Adaptation Level Theory: A Symposium, M.H. Appley (ED.), (New York: Academic Press, 1971): 287-302.

R. Brown, Social Psychology [Second Edition], (New York: Free Press, 1986).

J. BERGER, Invisible Influence: The Hidden Forces that Shape Behaviour, (London: Simon \& Schuster, 2010).

R. BUXBAUM, "Juridification and Legitimation Problems in American Enterprise Law," in Juridification of Social Spheres: A Comparative Analysis in the Areas of Labor, Corporate, Antitrust and Social Welfare Law, G. TEUBNER (ED.), (Berlin: Walter de Gruyter, 1987).

A. CALAPriCE (ED.), The New Quotable Einstein, (Princeton: Princeton University Press, 2005).

P. CAMEJO, The SRI Advantage: Why Socially Responsible Investing Has Outperformed Financially, (British Columbia: New Society, 2002).

K. CAmpBell \& D. ViCK, "Disclosure Law and the Market for Corporate Social Responsibility," in The New Corporate Accountability: Corporate Social Responsibility and the Law, D. MCBARNET, A. VOICULESCU \& T. CAMPBELL (EDS.) (Cambridge: Cambridge University Press, 2007).

F. CAPra \& U. MATTEI, The Ecology of Law: Toward a Legal System in Tune with Nature and Community, (Oakland: Berrett-Koehler, 2015).

C. CaSAzZA, "Oversight of Corporate Sustainability Activities," in Director's Handbook Series 2014, (Washington D.C.: National Association of Corporate Directors with Ernest \& Young LLP, 2014).

D.J. CHEAL, The Gift Economy, (New York: Routledge, 1998).

Y. ChOUINARD \& V. STANLEY, The Responsible Company: What We've Learned from Patagonia's First 40 Years, (California; Patagonia Books, 2012).

C.M. Christensen, The Innovator's Dilemma: The Revolutionary Book. That Will Change the Way You Do Business, (New York: Harper Business, 2011).

R.B. Cialdini, Influence: The Psychology of Persuasion, (New York: Collins Business, 2007).

J.S. Coleman, Foundations of Social Theory, (Cambridge: Harvard University Press, 1990).

J.S. COLEman, "The Emergence of Norms," in Social Institutions: Their Emergence, Maintenance, and Effects, M. HeChTER, K-D OpP \& R. WippleR (EDS.) (New York: Aldine de Gruyter, 1990).

J.A. Cooke, Protean Supply Chains: Ten Dynamics of Supply and Demand Alignment, (New Jersey: Wiley, 2014).

J. CoOper, K.A. Kelly \& K. WeAver, "Attitudes, Norms, and Social Groups," in Social Cognition, M.B. Brewer \& M. Hewstone (EDS.) (Oxford: Blackwell, 2004): 259.

J.D. Cox \& T.L. HAZEN, Treatise on the Law of Corporations [Second Edition], (New York: Aspen Publishers, 2003).

A. Crane, D. MatTen \& L. Spence, "Corporate Social Responsibility: In Global Context," in Corporate Social Responsibility: Reading and Cases in Global Context, A. Crane, D. MATTEN \& L. SPEnCE (EDS.) (London: Routledge, 2013).

M. Csikszentmihalyi \& E. Rochberg-Halton, The Meaning of Things - Domestic Symbols and the Self, (Cambridge: Cambridge University Press, 1981).

R.M. Cyert \& J.G. MARCH, A Behavioral Theory of the Firm, (New Jersey: Prentice-Hall, 1963).

A.C.L. DAvieS, Perspectives on Labour Law, (Cambridge: Cambridge University Press, 2004).

G. DAVIS, D. MCADAM \& W. SCOTT, Social Movements and Organizations, (New York: Cambridge University Press, 2005).

S. DEAKIN \& F. WILKINSON, The Labour Market: Industrialization, Employment, and Legal Evolution, (Oxford: Oxford University Press, 2005).

J. DE GraAf, D. WANn \& T.H. NAYLOR, Affluenza: How Overconsumption is Killing Us - And How We Can Fight Back (Third Edition), (San Francisco: Berrett-Koehler Publishers, 2014).

H. DE SOTO, The Other Path: The Economic Answer to Terrorism, (New York: Basic Books, 1989).

D. DiERMEIER, Reputation Rules: Strategies for Building Your Company's Most Valuable Asset, (New York: McGraw-Hill, 2011).

J. DonnelLy, Universal Human Rights in Theory and Practice [Second Edition], (Ithica: Cornell University Press, 2003). 
C. Duhigg, The Power of Habit: Why We Do What We Do in Life and Business, (New York: Random House, 2012).

E. DurkHeim, The Division of Labor in Society, S. LuKeS (ED.) (New York: Free Press, 2014).

E.A. Duruigbo, Multinational Corporations and International Law: Accountability and Compliance Issues in the Petroleum Industry, (Leiden: Martinus Nijhoff, 2003).

C.S. DweCK, Self-Theories: Their Role in Motivation, Personality, and Development, (Philadelphia: Psychology Press, 1999).

R. DWORKIN, Taking Rights Seriously, (Massachusetts: Harvard University Press, 1978).

R. Dworkin, Sovereign Virtue: The Theory and Practice of Equality, (Cambridge: Harvard University Press, 2002).

E. EHRLICH, Fundamental Principles of the Sociology of Law, (Cambridge: Harvard University Press, 1936).

R.C. Ellickson, "The Evolution of Social Norms: A Perspective from Legal Academy," in Social Norms, M. HECTER \& K-D. OpP (EDS.) (New York: Russell Sage Foundation, 2001).

J. Esbenshade, Monitoring Sweatshops: Workers, Consumers, and the Global Apparel Industry, (Philadelphia: Temple University Press, 2004).

S.L. ESQUITH, "Introduction: Institutions and Urgency," in Capabilities, Power, and Institutions: Toward a More Critical Development Ethics, S.L. ESQUiTH \& F. GIFFORD (EDS.) (Pennsylvania: Pennsylvania State University, 2010).

R. FEYnman, The Pleasure of Finding Things Out: The Best Short Works of Richard P. Feynman, J. RoBBINS (ED.) (New York: Basic Book, 1999).

A.P. FISKE, “The Cultural Relativity of Selfish Individualism: Anthropological Evidence that Humans are Inherently Sociable," in Review of Personality and Social Psychology: Altruism and Prosocial Behavior, M.S. CLARK (ED.) (Beverly Hills: Sage, 1991).

R.E. FreEMAN, Strategic Management: A Stakeholder Approach, (Cambridge: Cambridge University Press, 2010).

B.S. FreY, Not Just for the Money: An Economic Theory of Personal Motivation, (Vermont: Edward Elgar, 1997).

B.S. Frey, "Crowding Out and Crowding in of Intrinsic Preference," in Reflexive Governance for Global Public Goods, E. Brousseau, T. Dedeurwaerdere \& B. Siebenhunter (Eds.) (Cambridge: MIT Press, 2012).

C. Fried, An Anatomy of V alues: Problems of Personal and Social Choice, (London: Oxford University Press, 1970).

M. FORD, Rise of the Robots: Technology and the Threat of a Jobless Future, (New York: Basic Books, 2015).

M. Foucault, Discipline \& Punish: The Birth of the Prison [Second Vintage Books Edition], A. SHeRIDAN (TRANS.) (New York: Random House, 1995).

F. FukuYama, Trust: The Social Virtues and the Creation of Prosperity, (New York: Free Press Paperbacks, 1995).

D. Garland, "Durkheim's Theory of Punishment: A Critique," in The Power to Punish: Contemporary Penalty and Social Analysis, D. GARLAND \& P. Young (EDS.) (London: Heinemann, 1983): 37-61.

G. GEREFFI \& S. FrederiCK, "The Global Apparel Value Chain, Trade, and the Crisis: Challenges and Opportunities for Developing Countries," in Global Value Chains in a Postcrisis World: A Development Perspective, O. CATTANEO, G. GEREFFI \& C. STARIZ (EDS.), (Washington D.C.: The World Bank, 2010).

H.H. GerTH \& C.W. Mills (EDS.), From Max Weber: Essays in Sociology, (New York: Routledge, 2009).

G. Gigerenzer \& R. SElten, Bounded Rationality: The Adaptive Toolbox, (Cambridge: MIT Press, 2001).

M. GLADwELl Blink: The Power of Thinking Without Thinking, (New York: Little Brown Book, 2005).

M. Gladwell, David and Goliath: Underdogs, Misfits, and the Art of Batting Giants, (London: Little Brown \& Company, 2013).

C. GLINSKI, "Corporate Codes of Conduct: Moral or Legal Obligation," in The New Corporate Accountability: Corporate Social Responsibility and the Law, D. MCBARNET, A. VOICULESCU \& T. CAMPBELl (EDS.) (Cambridge: Cambridge University Press, 2007).

D. Goleman, Ecological Intelligence: The Coming Age of Radical Transparency, (London: Penguin, 2010).

L.H. Gunderson, "Stepping Back: Assessing for Understanding in Complex Regional Systems," in Bioregional Assessments: Science at the Crossroads of Management and Policy, K.N. JOHnSOn, F. Swanson, M. HERring \& S. GreEnE (EDS.) (Washington, D.C.: Island Press, 1999).

J.D. Gwartney, R.L. Stroup, R.S. Sobel \& D.A. Macpherson, Economics: Private and Public Choice, (Ohio: Cengage Learning, 2008).

J. HAIDT, The Righteous Mind: Why Good People are Divided by Politics and Religion, (New York: Vintage, 2012).

D. HALPERN, Inside the Nudge Unit: How Small Changes can Make a Big Difference, (London: Penguin WH Allen, 2015).

B. Hannigan, Company Law, (Oxford: Oxford University Press, 2012).

M. HARDT \& A. NEGRI, Empire, (Cambridge: Harvard University Press, 2000).

T. HARFORD, The Undercover Economist, (New York: Random House, 2007).

T. HARFORD, Adapt: Why Success Always Starts with Failure, (London: Abacus, 2012).

T. HARFord, Messy: How to be Creative and Resilient in a Tidy-Minded World, (London: Little, Brown, 2016).

H.L.A HART, The Concept of Law, (Oxford: Oxford University Press, 1961). 
L.P. HARTMAN \& R.E. WOKUTCH, "Nike, Inc.: Corporate Responsibility and Workplace Standard Initiatives in Vietnam," in Rising Above Sweatshops: Innovative Approaches to Global Labor Challenges, L.P. HARTMAN, D.G. ARNOLD \& R.E. WOKUTCH (EDS.) (Westport: Praeger Publishers, 2003): 145-190.

A. HAyden, Sharing the Work, Sparing the Planet: Work, Time, Consumption, and Ecology, (London: Zed Books, 1999).

C. Heath \& D. HeATH, Switch: How to Change Things When Change Is Hard, (New York: Crown Business, 2010).

A. HenriQus, Corporate Truths: The Limits to Transparency, (New York: Taylor \& Francis Group, 2007).

N. HerTZ, The Silent Takeover: Global Capitalism and the Death of Democracy, (New York: Harper Business, 2001).

C. Horne, "Sociological Perspectives on the Emergence of Social Norms," in Social Norms, M. HECTER \& K-D. OpP (EDS.) (New York: Russell Sage Foundation, 2001).

A.O. Hirschman, Exit, Voice, and Loyalty, (Cambridge: Harvard University Press, 1970).

C. Hitchens, Thomas Paine's Rights of Man, (New York: Grove Press, 2006).

J. Hollender \& S. Fenichell, What Matters Most: How a Small Group of Pioneers Is Teaching Social Responsibility to Big Business, and Why Big Business Is Listening, (New York: Basic Books, 2004).

B. Horowitz, The Hard Thing About Hard Things: Building a Business When There Are No Easy Answers, (New York: Harper Collins, 2014).

S.P. Huntington, Political Order in Changing Societies, (Connecticut: Yale University Press, 2006).

D. HuRD, The Search for Peace, (Oxford: Oxford University Press, 1997).

T. JACKSON, Prosperity without Growth: Economics for a Finite Planet, (New York: Earthscan, 2009).

J. JACQUeT, Is Shame Necessary: New Uses for an Old Tool, (London: Penguin Books, 2016).

I.L. JANIS, Victims of GroupThink, (Boston: Houghton Mifflin Co., 1972).

I.L. JANIS, Groupthink: Psychological Studies of Policy Decisions and Fiascoes [Second Edition], (New York: Houghton Mifflin, 1982).

T. JUDT, Ill Fares the Land, (New York: Penguin, 2010).

O. Kahn-Freund, "Legal Framework," in The System of Industrial Relations in Great Britain: Its History, Law, and Institutions, A.D. FLANDERS \& H.A. ClEGG (EDS.) (Oxford: Blackwell, 1964).

D. Kahneman, "Objective Happiness" in Well-Being: The Foundations of Hedonic Psychology, D. KaHnEMAN, E. DiENER, \& N. SCHWARTZ (EDS.) (New York: Russel Sage, 1999): 85-105.

D. KAHneman, Thinking, Fast and Slow, (London: Penguin Books, 2013).

D. Kahneman \& A. TVErsky, "Rational Choice and the Framing of Decisions," in Choices, Values, and Frames, D. Kahneman \& A. Tversky (EDS.) (New York: Cambridge University Press, 2000).

M.T. KAMMINGA \& S. ZIA-ZARIFI, “An Introduction,” in Liability of Multinational Corporations Under International Law, M.T. KAMMINGA \& S. ZiA-ZARIFI (EDS.) (Dordrecht: Springer, 2000).

R. KAPLINSKY \& M. FAROOKI, "Global Value Chains, the Crisis, and the Shift of Markets from North to South," in Global Value Chains in a Postcrisis World: A Development Perspective, O. CaTtaneO, G. GerefFi \& C. STARIZ (EDS.), (Washington D.C.: The World Bank, 2010).

G. KELL \& D. Levin, “The Global Compact Network,” in Learning to Talk: Corporate Citizenship and the Development of the UN Global Compact, M. McINTOSH, S. WAdDOCK \& G. KELL (EDS.) (Sheffield: Greenleaf, 2004).

H. Kelsen, Pure Theory of Law, (California: University of California Press, 1967).

D. Keltner, The Power Paradox: How We Gain and Lose Influence, (New York: Penguin Press, 2016).

H. KENT BAKER \& J.R. NOFsInger, "Socially Responsible Financing and Investing: An Overview," in Socially Responsible Finance and Investing, H. KENT BAKER \& J.R. NOFSINGER (EDS.) (New Jersey: Wiley, 2012).

N. KLEIN, No Logo, (New York: Picador, 2000).

H. KÖTZ \& A. FlESSNER, European Contract Law, (Oxford: Clarendon Press, 1997).

N.D. KRISTOF \& S. WuDunN, Half the Sky: How to Change the World, (London: Virago Press, 2010).

T.S. KuHN, The Structure of Scientific Revolutions, (Chicago: University of Chicago Press, 1962).

J.H. Kuntsler, The Geography of Nowhere: The Rise and Decline of America's Man-Made Landscape, (New York: Simon \& Schuster, 1994).

K.R. LAKHANi \& R.G. WOLF, "Why Hackers Do What They Do: Understanding Motivation and Effort in Free/Open Source Software Projects," in Perspectives on Free and Open Software, J. FELLER, B. FitzGERALD, S. HiSSAM \& K. LAKHANI (EDS.) (Cambridge: MIT Press, 2005).

B. Latané \& J.M. Darley, The Unresponsive Bystander: Why Doesn't He Help?, (New York: Appleton Century Crofts, 1968).

L. Lessig, Republic, Lost: How Money Corrupts Congress-And a Plan to Stop It, (New York: Twelve, 2011).

L. LEvin, Invisible Giants: Changing the World One Step at a Time, (Bristol: Vala, 2013). 
S.D. LevitT \& S.J. Dubner, Freakonomics: A Rogue Economist Explores the Hidden Side of Everything, (New York: Harper Perennial, 2005).

T. LEWIS \& E. POTTER, "Introducing Ethical Consumption," in Ethical Consumption: A Critical Introduction, T. LEWIS \& E. POTTER (EDS.) (New York: Routledge, 2011).

K. N. Llewellyn, The Bramble Bush: The Classic Lectures on the Law and Law School, (New York: Oceana Press, 1931).

R.M. LOCKE, The Promise and Limitations of Private Power: Promoting Labor Standards in a Global Economy, (Cambridge: Cambridge University Press, 2013).

G.W.L. Low, European Contract Law between the Single Market and the Law Market: A Behavioural Perspective, (Nijmegen: Wolf Legal Publishers, 2011).

B.M. Lowe, Emerging Moral Vocabularies: The Creation and Establishment of New Forms of Moral and Ethical Meanings, (New York: Lexington Books, 2006).

V. Lowe, International Law, (Oxford: Oxford University Press, 2007).

N. Luhmann, Law as a Social System, (Oxford: Oxford University Press, 2004).

E. LutTwaK, Turbo-Capitalism: Winners and Losers in the Global Economy, (New York: HarperCollins, 1999).

A. MACK \& I. ROCK, Inattentional Blindness, (Cambridge: The MIT Press, 2000).

J. Mahoney \& K. Thelen (EDs.), Explaining Institutional Change: Ambiguity, Agency, and Power, (New York: Cambridge University Press, 2010).

R. MAurer, The Spirit of Kaizen: Creating Lasting Excellence One Small Step at a Time, (New York: McGraw-Hill, 2012).

M. Mazzucato, The Entrepreneurial State: Debunking Public vs. Private Sector Myths, (London: Anthem, 2013).

D. MCBARnet \& M. KuRKChiyan, "Corporate Social Responsibility Through Contractual Control? Global Supply Chains \& 'Other Regulation'," in The New Corporate Accountability: Corporate Social Responsibility and the Law, D. McBarnet, A. Voiculescu \& T. Campbell (EDS.) (Cambridge: Cambridge University Press, 2007): 59-92.

W. McDougalL, "The Instinct of Pugnacity" in An Introduction to social Psychology, (Boston: John W. Luce \& Co., 1926): 285-302.

A. Michalos, "Job Satisfaction, Marital Satisfaction, and the Quality of Life," in Research on the Quality of Life, F.M. ANDREWS (ED.) (Ann Arbor: Institute of Social Research, 1986).

S. Milgram, Obedience to Authority, (New York: Harper \& Row, 1974).

J. Mills \& M.S. Clark, "Exchange and Communal Relationships," in Review of Personality and Social Psychology, L. WHEELER (ED.) (Beverly Hills: Sage,1982): 121-144.

T.H. Moran, Beyond Sweatshops: Foreign Direct Investment and Globalization in the Developing World, (Virginia: R. R. Donnelley and Sons, 2002).

S. Mullainathan \& S. Eldar, Scarcity: Why Having Too Little Means So Much, (London: Macmillan, 2013).

M. MwinYIHIJA, Ecotoxicological Diagnosis in the Tanning Industry, (New York: Springer, 2010).

T. NAGEL, The Possibility of Altruism, (Princeton: Princeton University Press, 1970).

M. NAím, The End of Power: From Boardrooms to Battlefields and Churches to States, Why Being in Charge Isn't What It Used to Be, (New York: Basic Books, 2013).

R.R. Nelson \& S.G. WINTER, An Evolutionary Theory of Economic Change, (Cambridge: Belknap Press, 1982).

Y. NODA, Introduction to Japanese Law, (Tokyo: University of Tokyo Press, 1976).

P. NONET \& P. SELZnICK, Law and Society in Transition: Toward Responsive Law, (New York: Harper, 1978).

J. Norberg, In Defense of Global Capitalism, (Washington D.C.: Cato Institute, 2003).

J. Norman, K Ussher \& D. Alexander, From Here to Fraternity: Perspectives on Social Responsibility, (London: CentreForum, 2007).

P. Norris (ED.), Critical Citizens: Global Support for Democratic Government, (Oxford: Oxford University Press, 1999).

M.C. NussBaum, Creating Capabilities: The Human Development Approach, (Cambridge: Belknap Harvard, 2013).

M.C. Nussbaum, Frontiers of Justice: Disability, Nationality, Species Membership [Tanner Lectures of Human Values], (Belknap Press of Harvard University Press, 2007).

M.C. Nussbaum, "Beyond the Social Contract," in The Political Philosophy of Cosmopolitanism, G. BROCK \& H BRIGHOUSE (EDS.) (Cambridge: Cambridge University Press, 2005).

P. Nystrom, Economics of Fashion, (New York: Ronald Press Company, 1928).

H. ODA, Japanese Law [Third Edition] (Oxford: Oxford University Press, 2009).

A. OfFER, The Challenge of Affluence, (Oxford: Oxford University Press, 2006).

M. Olson, The Logic of Collective Action: Public Goods and the Theory of Groups, (Massachusetts; Harvard University Press, 1971). 
D. O'Rourke, Smoke from a Hired Gun: A Critique of Nike's Labor and Environmental Auditing, (San Francisco: Transnational Resource and Action Center, 1997).

L. Osberg, "Markets, Morality, and the Auto-Corrosive Tendencies of 'Standard Economics'," in The Moralization of the Markets, N. STEhr, C. Henning \& B. Weiler (EDS.) (New Jersey: Transaction Publishers, 2006).

E. Ostrom, Governing the Commons: The Evolution of Institutions for Active Action, (Cambridge: Cambridge University Press, 1990).

E. OSTROM, Understanding Institutional Diversity, (Princeton: Princeton University Press, 2005).

C. Peterson, S.F. Maier \& M.E.P. Seligman, Learned Helplessness: A Theory for the Age of Personal Control, (New York: Oxford University Press, 1993).

J. PIAGet, The Moral Judgment of the Child, (New York: Free Press, 1935).

D.H. PINK, Drive: The Surprising Truth about What Motivates Us, (New York: Riverhead Books, 2009).

K. Pistor, A. HALDAR \& A. Amirapu, "Social Norms, Rule of Law, and Gender Reality," in Global Perspectives on the Rule of Law, J.J. HeCKMAN, R.L. NELSON \& L. CABATINGAN (EDS.), (Abingdon: Routledge, 2010): 241 278.

K. Polanyi, The Great Transformation: The Political and Economic Origins of Our Time, (Boston: Beacon Press, 2001).

E.A. Posner, Law and Social Norms, (Cambridge: Harvard University Press, 2000).

E.A. Posner, The Twilight of Human Rights Law, (Oxford: Oxford University Press, 2014).

R.A. Posner, Economic Analysis of the Law [Seventh Edition], (New York: Aspen Publishers, 2007).

R.A. POSNER \& F. PARISI, Economic Foundations of Private Law, (Cheltenham: Edward Elgar, 2002).

R.A. Posner, A Failure of Capitalism: The Crisis of '08 and the Descent into Depression, (Massachusetts: Harvard University Press, 2011).

R. PutNAM, Bowling Alone, (New York: Simon and Schuster, 2000).

J. RAwls, The Law of Peoples, (Cambridge: Harvard University Press, 1999).

L.E. READ, I, Pencil, (New York: The Foundation for Economic Education, 1958).

J. REASON, Managing the Risks of Organizational Accidents, (Hampshire, Ashgate Publishing, 1997).

R. REICH, Supercapitalism: The Transformation of Business, Democracy, and Everyday Life, (New York: Vintage Books, 2007).

D. RoDriK, The Globalization Paradox: Democracy and the Future of the World Economy, (New York: Norton, 2011).

R. RoGOwSKI, Reflexive Labour Law in the World Society, (Cheltenham: Edward Elgar, 2013).

K. Roth, "What are Human Rights For? Three Personal Reflections," in International Human Rights Law, D. MOECKLI, S. Shah, \& S. Sivakumaran, (EDS.) (Oxford: Oxford University Press, 2014).

J.G. RugGIE, Just Business: Multinational Corporations and Human Rights, (New York: W.W. Norton \& Company, 2013).

A. RÜHMkORF, Corporate Social Responsibility, Private Law and Global Supply Chains, (Cheltenham: Edward Elgar, 2015).

R. SAMUELS, S. STICH \& M. BISHOP, "Ending the Rationality Wars: How to Make Disputes about Human Rationality Disappear," in Common Sense, Reasoning and Rationality, R. RENEE (ED.) (421) (New York: Oxford University Press, 2002): 236-268.

M.J. SANDEL, Justice: What's The Right Thing to Do?, (New York: Farrad, Straus and Giroux, 2009).

M.J. SANDEL, What Money Can't Buy: The Moral Limits of Markets, (London: Allen Lane, 2012).

T.C. SCHELling, Micromotives and Macrobehavior, (New York: Norton, 1978).

P. SCHIFF BERMAN, Global Legal Pluralism: A Jurisprudence of Law Beyond Borders, (New York: Cambridge University Press, 2012).

J.B. SCHOR, Born to Buy: The Commercialized Child and the New Consumer Culture, (New York: Simon \& Schuster, 2004).

J.A. SCHumpeter, Capitalism, Socialism and Democracy [Third Edition], (New York: Harper Perennial Modern Classics, 2008).

B. SCHWARTZ, The Paradox of Choice: Why More is Less, (New York: Harper, 2004).

B. Schwartz \& K. Sharpe, Practical Wisdom: The Right Way to Do the Right Thing, (New York: Riverhead Books, 2010).

M.S. SChwartZ, Corporate Social Responsibility: An Ethical Approach, (London: Broadview, 2011).

T. SciTOvSKY, The Joyless Economy, (New York: Oxford University Press, 1976).

J. SEDDON, The Case Against ISO 9000, (Cork: Oak Tree Press, 2000).

M.E.P. Seligman, Helplessness: On Depression, Development, and Death, (San Francisco: Freeman, 1975).

M.E.P. SELIGMan, Flourish, (New York: Atria, 2011). 
R. SELten, "What is Bounded Rationality," in Bounded Rationality: The Adaptive Toolbox, G. GigerenZER \& R. SELTEN (EDS.) (Cambridge: The MIT Press, 2001).

A. SEN, Development as Freedom, (New York: Knopf, 1999).

P.M. SENGE, The Fifth Discipline: The Art and Practice of the Learning Organization, (New York: Currency Double Day, 1990).

P.M. Senge, B. Smith, N. KruschwitZ, J. LAur, \& S. Schley, The Necessary Revolution: How Individuals and Organizations are Working Together to Create a Sustainable World, (New York: Doubleday, 2008).

O. Service \& R. Gallagher, Think. Small: The Surprisingly Simple Ways to Reach Big Goals, (London: Michael O’Mara Books, 2017).

R.J. SHILlER, The Subprime Solution: How Today's Global Financial Crisis Happened, and What to Do About It, (Princeton: Princeton University Press, 2008).

R.J. SHILlER, Irrational Exuberance, (Princeton: Princeton University Press, 2015).

C. SHIRKY, Here Comes Everybody: The Power of Organizing without Organizations, (New York: Penguin Press, 2008).

J. SHKLAR, "Political Theory and the Rule of Law," in The Rule of Law: Ideal or Ideology, A. HutCHINSON \& P. MONAHAN (EDS.) (Toronto: Carswell, 1987).

M. SIEMS, Comparative Law, (Cambridge: Cambridge University Press, 2014).

H.A. Simon, Models of Man, Social and Rational: Mathematical Essays on Rational Human Behavior in a Social Setting, (Oxford: Wiley, 1957).

U. SinCLAIR, I, Candidate for Governor: And How I Got Licked, (Berkley: University of California Press, 1934).

P. SINGER, Writings on an Ethical Life, (New York: HarperCollins, 2001).

P. Singer, Practical Ethics, (Cambridge: Cambridge University Press, 2011).

P. Slovic, M. Finucane, E. Peters \& D. MacGregor, "The Affect Heuristic," in Heuristics and Biases, T. Gilovich, D. GrifFin \& D. KAHnEMAN (EDS.) (New York: Cambridge University Press, 2002): 397-420.

R. SMerdon, A Practical Guide to Corporate Governance, (London: Sweet \& Maxwell, 2010).

A. SMith, The Theory of Moral Sentiments, D.D. RAPHAEL \& A.L. MACFIE (EDS.) (Indianapolis: Liberty Classics, 1759).

N.C. SMITH, "Consumers as Drivers of Corporate Social Responsibility," in The Oxford Handbook of Corporate Social Responsibility, A. Crane, A McWilliams, D. Matten et Al. (EDs.) (Oxford: Oxford University Press, 2008).

J.M. SMITS, "Democracy and (European) Private Law: A Functional Approach," in Globalization and Private Law: The W ay Forward, M. FAURE \& A. VAN DER WALT (EDS.) (Cheltenham: Edward Elgar, 2010): 15-31.

J.M. SMITS, "Plurality of Sources in European Private Law, or: How to Live with Legal Diversity?," European Legal Method - in a Multi-Level EU Legal Order, U. NEERGAARD \& R. NiELSEN (EDS.), (Copenhagen: Djøf Forlag, 2012): 71-86.

J.M. SMITS, Contract Law: A Comparative Introduction, (Cheltenham: Edward Elgar, 2014).

J.M. SMITS, "The Future of Contract Law in Europe," in Research Handbook on EU Consumer and Contract Law. C. TwigG-FLESNER (ED.) (Cheltenham: Edward Elgar, 2016): 549-565.

J.M. SMITS, Advanced Introduction to Private Law, (Cheltenham, Edward Elgar, 2016).

G. SpaArgaren, "The Cultural Dimension of Sustainable Consumption Practices: An Exploration in Theory and Policy," in Innovations in Sustainable Consumption: New Economics, Socio-technical Transitions and Social Practices, M.J. COHEN, H. SZEjnwald Brown \& P.J. Vergragt (EDs.) (Cheltenham: Edward Elgar, 2013).

R. STEVENS, "Torts," in The Judicial House of Lords: 1876-2009. L. BLOM-COOPER, B. DiCKSON \& G. DREWRY (EDS.) (Oxford: Oxford University Press, 2009).

J.E. STIGLITZ, Freefall: Free Markets, and the Sinking of the World Economy, (New York: W. W. Norton \& Co, 2010).

D. Stone, B. Patton \& S. Heen, Difficult Conversations: How to Discuss What Matters Most, (New York: Portfolio Penguin, 2011).

L.A. STOUT, The Shareholder V alue Myth: How Putting Shareholders First Harms Investors, Corporations, and the Public, (San Francisco: Berrett-Koehler Publishers, 2012).

C.R. SunSTEIN \& R. HASTIE, Wiser: Getting Beyond Groupthink to Make Groups Smarter, (Massachusetts: Harvard Business Review Press, 2015).

J. SurowieCKI, The Wisdom of Crowds, (New York: Anchor Books, 2005).

N.N. TALEB, The Black Swan: The Impact of the Highly Improbable, (New York: Random House, 2007).

B.Z. TAmanaha, On the Rule of Law, (Cambridge: Cambridge University Press, 2004).

P.E. TeTLOCK, Expert Political Judgment, (New York: Princeton University Press, 2005). 
G. TEubNER, "Juridification - Concepts, Aspects, Limits, Solutions," in Juridification of Social Spheres: A Comparative Analysis in the Areas of Labor, Corporate, Antitrust and Social Welfare Law, G. TEuBNER (ED.) (Berlin: Walter de Gruyter, 1987).

G. TEubneR, "Breaking Frames: The Global Interplay of Legal and Social Systems," American Journal of Comparative Law 45 (1997): 149-159.

G. TEubner, Law as an Autopoietic System, (Oxford: Blackwell, 1993).

G. Teubner, Global Law Without a State, (Brookfield: Dartmouth Publishing Co., 1997).

R.H. Thaler \& C.R. Sunstein, Nudge: Improving Decisions About Health, Wealth, and Happiness, (New York: Penguin, 2009).

R.H. Thaler, Misbehaving: The Making of Behavioral Economics, (New York: Norton, 2015).

R. Titmuss, The Gift Relationship: From Human Blood to Social Policy, A. OAKLEY \& J. AshTON (EDs.) (New York: New Press, 1997).

M. TOMASEllo, Why We Cooperate, (Cambridge: MIT Press, 2009).

E. Ullmann-Margalit, The Emergence of Norms, (Oxford: Oxford University Press, 1978).

M.J.C. VAN DER HEIJDEN, Liability of Transnational Corporations for Gross Human Rights Violations: Linking Standards of International Public Law to Dutch Civil Litigation Procedures, (Antwerp: Intersentia, 2011).

T. Veblen, The Theory of the Leisure Class: An Economic Study in the Evolution of Institutions, (New York: Macmillan Company, 1899).

D. VoGeL, The Market for Virtue: The Potential and Limits of Corporate Social Responsibility, (Washington D.C.: Brookings Institution Press, 2006).

J. von Neumann \& O. MORgenstern, Theories of Games and Economic Behavior, (Princeton: Princeton University Press, 1947).

J.P. VОВ \& R. KЕмP, “Sustainability and Reflexive Governance: Introduction,” in Reflexive Governance for Sustainable Development, J.P. VOß \& R. KEMP (EDS.) (Cheltenham: Edward Elgar, 2006): 3-28.

A.L. VYTOPIL, Contractual Control in the Supply Chain: On Corporate Social Responsibility, Codes of Conduct, Contracts and (Avoiding) Liability, (The Hague: Eleven, 2015).

M. WEBER, Economy and Society: An Outline of Interpretive Sociology, (Berkley: University of California Press, 1922).

M. WEBER, Law in Economy and Society, M. RHEInSTEIN (ED.) \& E. SHILS (TrANS.) (Cambridge: Harvard University Press, 1954).

M. WEBER, Economy and Society: An Outline of Interpretive Sociology [Volume 2], (Berkeley: University of California Press, 1978).

M. WeBER, Politics as a Vocation, (Minneapolis: Fortress Press, 1965).

P. West, Conspicuous Compassion: Why Sometimes It Really Is Cruel to be Kind, (London: Civitas, 2004).

R. Wilkinson \& K. PiCKETt, The Spirit Level: Why Equality Is Better for Everyone (London: Penguin Books, 2010).

L. ZAPPALA, "Transnational Soft Regulation of Temporary Agency Work and Adaptability Policies: Future of Guidelines with No Rights," in Transnational Labour Regulation: A Case Study of Temporary Agency Work, K. Ahlberg, B. Bercusson, N. Bruun, H. Kountouros, C. Vigneau \& L. Zappala (Eds.), (Brussels: P.I.E. Peter Lang, 2008).

N.D. ZATZ, "Working Beyond the Reach or Grasp of Employment Law," in The Gloves-Off Economy: Workplace Standards at the Bottom of the Labor Market, A. BERnHARDT, H. BOuSHEY, L. Dresser \& C. TILLY (EDS.) (Urbana-Champaign: Labor and Employment Relations Association, 2008).

S. ZuBOFF, In the Age of Smart Machine, (New York: Basic Books, 1991).

K. ZweIGERT \& H. KÖTZ, "Einführung in die Rechtsvergleichung auf dem Gebiets des Privatrechts," in An Introduction to Comparative Law [Third Edition], T. WEIR (TRANS.) (Oxford: Oxford University Press, 1998).

\section{ARTICLES}

G.A. AKERLOF, “The Economics of Caste and of the Rat Race and Other Woeful Tales," The Quarterly Journal of Economics 90(4) (1976): 599-617.

P. Anderson \& M. Tushman, "Technological Discontinuities and Dominant Designs," Administrative Science Quarterly (35) (1990): 604-633.

M. ANDREws, L. PritChetT \& M. WOOlCOCK, "Capability Traps? The Mechanisms of Persistent Implementation Failure," Center for Global Development Working Paper 234 (2010). 
M. Andrews, L. PritchetT \& M. WoOlcock, “Escaping Capability Traps Through Problem Driven Iterative Adaptation," World Development 51 (2013): 234-244.

M. ANDrews \& P. HARrington, "Off Pitch: Football's Integrity Weaknesses, and How to Strengthen Them," Harvard University Center for International Development Working Paper 311 (January 2016). Available at: https://www.hks.harvard.edu/centers/cid/publications/faculty-working-papers/footballs-financial-integrity (last accessed 28 October 2016).

Y.S. ANG, "Ethical Outsourcing and the Act of Acting Together," in Empowering Organizations through Corporate Social Responsibility, R. WOLF, T. IsSA \& M. ThIEL (EDS.) (Pennsylvania: IGI Global, 2015).

K.J. ARrow, "A Utilitarian Approach to the Concept of Equality in Public Expenditure," The Quarterly Journal of Economics 85(3) (1971): 409-15.

K.J. Arrow, "Gifts and Exchanges," Philosophy \& Public Affairs 1(4) (1972): 343-62.

E.H. ATIQ, "Why Motives Matter: Reframing the Crowding Out Effect of Legal Incentives," Yale Law Journal 123 (2014): 1070-1116.

P. Augur, P. Burke, T.M. Devinney \& J.J. Louviere, "What Will Consumers Pay for Social Product Features?," Journal of Business Ethics 42(3) (2003): 281-304.

L.C. BACKER, "Economic Globalization and the Rise of Efficient Systems of Global Private Lawmaking: WalMart as Global Legislator," University of Connecticut Law Review 39(4) (2007): 1739-1784.

L.C. BACKER, "Multinational Corporations as Objects and Sources of Transnational Regulation," ILSA Journal of International and Comparative Law 14 (2008): 499-523.

C. Barnett, N. Clarke, P. Cloke \& A. Malpass, “The Political Ethics of Consumerism," Consumer Policy Review 15(2) (2005): 45-51.

R.F. BAumeister, M. Muraven \& D.M. TiCE, "Self-Control as a Limited Resource: Regulatory Depletion Patterns," Psychological Bulletin 126 (1998): 247-59.

R.F. Baumeister, M. Muraven \& D.M. TiCe, "Longitudinal Improvement of Self-Regulation Through Practice: Building Self-Control Strength Through Repeated Exercise," Journal of Social Psychology 139 (1999): 446-57.

L.A. BEBCHUK, J.E. BACHELDER, W. LERACH \& ET AL., "Director Liability,” Delaware Journal of Corporate Law 21(3) (2006): 1011-1045.

C. BECKER, "Labor Law Outside the Employment Relation,” Texas Law Review 74 (1996): 1527.

G.S. BECKER, "Investment in Human Capital: A Theoretical Analysis,” Journal of Political Economy 70(5) (1962): 949.

R. BELK, "Possessions and the Extended Self," Journal of Consumer Research 15 (1988): 139-168.

C. BenedikT Frey \& M.A. Osborne, "The Future of Employment: How Susceptible Are Jobs to Computerisation," Oxford Martin Programme on the Impacts of Future Technology Working Paper (2013). Available at: www.futuretech.ox.ac.uk/sites/futuretech.ox.ac.uk/files/The_Future_of_Employment_OMS_Working_Pa per_1.pdf (last accessed 3 October 2015).

R. BENFORD \& D. SNOw, "Framing Processes and Social Movements: An Overview and Assessment," Annual Review of Sociology 26 (2000): 611-39.

A. Bernhardt, D. POlson \& J. DeFilippis, “Working Without Laws in New York City,” Challenge 54(2) (2011).

D. BILCHITZ, "The Ruggie Framework: An Adequate Rubric for Corporate Human Rights Obligations," International Journal on Human Rights 7(12) (2010).

J. BLACK, "Decentering Regulation: Understanding the Role of Regulation and Self-Regulation in a 'PostRegulatory' World," Current Legal Problems 54 (2001): 103-147.

S. Brenton, "The Political Motivations of Ethical Consumers," International Journal of Consumer Studies 37(5) (2013): 490-497.

K. Bronfenbrenner, "No Holds Barred - The Intensification of Employer Opposition to Organizing," Economic Policy Institute Briefing Paper 235 (20 May 2009). Available at: http://www.epi.org/publication/bp235/ (last accessed on 23 March 2016).

H. L. BUXBAUM, “Transnational Regulatory Litigation,” Virginia Journal of International Law 46(2) (2006): 251-317.

F. CAFAGgI, "Private Regulation in European Private Law," EUI Working Papers Robert Scbuman Centre for Advanced Studies Private Regulation Series (2009). Available at: http://www.estig.ipbeja.pt/ ac_direito/RSCAS_ 2009_31.pdf (last accessed 2 May 2015).

F. CAFAGGI, "The Regulatory Functions of Transnational Commercial Contracts: New Architectures," Tekes Project, (2012) Available at: http://papers.ssrn.com/sol3/papers.cfm?abstract_id=2136632 (last accessed 17 December 2016). 
D.M. Cain, G. Loewenstein \& D.A. Moore, "The Dirt on Coming Clean: The Perverse Effects of Disclosing Conflicts of Interest," Journal of Legal Studies 34 (2005): 1-25.

G. CALABresi, "Some Thoughts on Risk Distribution and the Law of Torts," Yale Law Journal 70(499) (1961).

N. CANTOR, "Law and Social Sciences," American Bar Association Journal 16 (1930): 385.

M. Carrington, B. Neville \& G. Whitwell, "Why Ethical Consumers Don't Walk Their Talk: Towards a Framework for Understanding the Gap between the Ethical Purchase Intentions and Actual Buying Behaviour of Ethically-minded Consumers," Journal of Business Ethics 97(1) (2010): 139-158.

W.H. ClARK \& E.K. BABSON, "How Benefit Corporations are Redefining the Purpose of Business Corporations," William Mitchell Law Review 38(2) (2012): 818-851.

R. CRASWELL, "Taking Information Seriously: Misrepresentation and Non-disclosure in Contract Law and Elsewhere," Virginia Law Review 92 (2006): 565.

J.L. Coleman, “The Rational Choice Approach to Legal Rules,” Chicago-Kent Law Review 65 (1989): 177-191.

H. Collins, "Conformity of Goods, the Network Society, and the Ethical Consumer," European Review of Private Law 5 (2014): 619-640.

L. COMPA \& T. HinCHLIFFE-FARRICARRÈRE, "Enforcing International Labor Rights Through Corporate Codes of Conduct," Columbia Journal of Transnational Law 33 (1995): 663.

S.V. Coslovsky \& R. Locke, "Parallel Paths to Enforcement: Private Compliance, Public Regulation, and Labor Standards in the Brazilian Sugar Sector," Politics \& Society 41(4) (2013): 497-526.

S.V. Coslovsky, "Social Problem-Solving in the Brazilian Ministerio Publico: The Organizational Basis of Regulatory Responsiveness," Regulation \& Governance 5(1) (2001): 70-89.

K.E. Davis \& M.J. Trebilcock, "The Relationship between Law and Development: Optimists versus Skeptics," American Journal of Comparative Law 56 (2008): 895-946.

S. DeAkin, "Contracts and Capabilities: An Evolutionary Perspective on the Autonomy-Paternalism Debate," Erasmus Law Review 3(2) (2010).

S. DEAKIN, "Addressing labour market segmentation: the role of labour law," ILO Governance and Tripartism Department Working Paper No. 52 (Geneva: ILO, 2013).

S. DEAKIN, J. MALMBERG \& R. SARKAR, "Do Labour Laws Increase Equality at the Expense of Higher Unemployment? The Experience of Six OECD Countries, 1970-2010," University of Cambridge Faculty of Law Legal Studies Research Paper Studies No. 11 (2014).

S. DEAKIN \& R. ROGOwSKI, "Reflexive Labour Law, Capabilities and the Future of Social Europe," University of Warwick School of Law Legal Studies Research Paper No. 4 (2011).

G. DE BURCA, "Developing Democracy Beyond the State," Columbia Journal of Transnational Law 46(2) (2009): 102158.

E.L. DECI, "Intrinsic Motivation, Extrinsic Reinforcement, and Inequality," Journal of Personality and Social Psychology 22(1) (1972): 113-120.

E.L. DECI, "Effects of Externally Mediated Rewards on Intrinsic Motivation," Journal of Personality and Social Psychology 18(1) (1971): 105-115.

E.L. DECI \& R.M. RYAN, "Self-Determination Theory and Facilitation of Intrinsic Motivation, Social Development, and Well-Being," American Psychologist 55 (2000): 68-78.

E.L. DECI, R. KOESTNER \& R.M. RYAN, "A Meta-Analytic Review of Experiments Examining the Effects of Extrinsic Rewards on Intrinsic Motivation,” Psychology Bulletin 125(6) (1999): 627-668.

M. DEuTSCh \& H.B. GERARD, "A Study of Normative and Informational Social Influences upon Individual Judgment," Journal of Abnormal and Social Psychology 51 (1955): 629-36.

J. Devine, L. Camfield \& I. Gough, "Autonomy or Dependence - or Both?: Perspectives from Bangladesh," Journal of Happiness Studies 9(1) (2008): 105-138.

T.M. Devinney, P. Auger, G. ECKhardt \& T. Birtchnell, "The Other CSR: Consumer Social Responsibility," Leeds University Business School Working Paper No. 15-04 (2006).

E. Diener \& M.E.P. Seligman, "Beyond Money: Toward an Economy of Well-Being," Psychological Science in the Public Interest 5 (2004): 1-31.

P. DiMAgGio \& W.W. Powell, "The Iron Cage Revisited: Institutional Isomorphism and Collective Rationality in Organizational Fields," American Sociological Review 48 (1983): 137-160.

C.S. Ditlev-Simonsen \& F. WenstøP, "How Stakeholders View Stakeholders as CSR Motivators," Social Responsibility Journal 9(1) (2013): 137-147.

J. C. Drimmer \& S.R. LAmoreE, "Think Globally, Sue Locally: Trends and Out-of-Court Tactics in Transitional Tort Actions," Berkeley Journal of International Law 29(2) (2012). 
F.H. EASTERBROOK, “Cyberspace and the Law of the Horse," University of Chicago Legal Forum 207 (1996).

R.G. ECCles \& D. SAlTZMAN, “Achieving Sustainability Through Integrated Reporting,” Stanford Social Innovation Review, (Summer 2011): 56-61.

R.G. ECCLES, I. IOANNOU \& G. SERAFEIN, "The Impact of Corporate Sustainability on Organizational Processes and Performance,” Harvard Business School Working Paper Series 12-035 (2013).

L. Edelman, S. RigG Fuller \& I. MARA-DritA, "Diversity of Rhetoric and the Managerialization of Law," American Journal of Sociology 106(6) (2001): 1589-1642.

E.V. EDMONDS \& N. PAVCNIK, "The Effect of Trade Liberalization on Child Labor," Journal of International Economics 65(2) (2005): 401-419.

E.V. EDmonds \& N. PAvCNIK, "International Trade and Child Labor: Cross-Country Evidence," Journal of International Economics 69 (2006): 115-140.

M. El ABboubi \& A. CORnET, "Towards a Dynamic Stakeholder Management Framework for CSR Certifications," International Journal of Business and Social Science 3(4) (2012): 1-12.

K.A. Elliot \& R.B. Freeman, "White Hats or Don Quixotes? Human Rights Vigilantes in the Global Economy," National Bureau of Economic Research Working Paper 8102 (2001).

J. ELSTER, "Exploring Exploitation,” The Journal of Peace Research 15(2) (1978): 3-17.

L.F.H. EnNEKInG, "Crossing the Atlantic? The Political and Legal Feasibility of European Foreign Direct Liability Cases," George Washington International Law Review 40 (2009): 903-938.

C. EstLund, "Who Mops the Floors at the Fortune 500? Corporate Self-Regulation and Low-Wage Workplace," Lewis and Clark Law Review 12 (2008): 671-689.

R.J. FABER, "Money Changes Everything: Compulsive Buying from a Biopsychosocial Perspective," American Behavioral Scientist 35 (1992): 809-819.

A. FALK \& N. SZECH, “Morals and Markets," Science 340 (2013): 707.

E.F. FAMA \& M.C. JENSEN, "Separation of Ownership and Control,” Journal of Law and Economics 26 (1983): 301.

E. FEHR \& S. GÄCHTER, “Cooperation and Punishment in Public Goods Experiments," American Economic Review 66(2) (2000): 980-94.

Y. Feldman \& O. Lobel, "The Incentives Matrix: The Comparative Effectiveness of Rewards, Liabilities, Duties, and Protections for Reporting Illegality," Texas Law Review 88(6) (2010): 1151-1211.

L. Festinger \& J.M. CARLSmith, “Cognitive Consequences of Forced Compliance," Journal of Abnormal and Social Psychology 58 (1959): 203-10.

U. Fischbacher, S. GÄChter \& E. FEhr, "Are People Conditionally Cooperative? Evidence from a Public Goods Experiment,” Economic Letters 71(3) (2001): 397-404.

B. Fischof, P. Slovic \& S. LiChtenstein, "Knowing with Certainty: The Appropriateness of Extreme Confidence," Journal of Experimental Psychology 3(4) (1977): 552-64.

B. Flyvbjerg, "From Nobel Prize to Project Management: Getting Risks Right," Project Management Journal 37 (2006): 5-15.

J.L. FreEdman, "Long-term Behavioral Effects of Cognitive Dissonance," Journal of Experimental Social Psychology 4(1) (1966): 195-203.

J.L. Freedman \& S.C. Fraser, "Compliance Without Pressure: The Foot-in-the-Door Technique," Journal of Personality and Social Psychology 4(2) (1966): 155-202.

S. FrederiCK, “Cognitive Reflection and Decision Making," Journal of Economic Perspectives 19(4) (2005): 25-42.

S.J. FrenkEl \& D. SCOTT, "Compliance, Collaboration, and Codes of Labor Practice: The Adidas Connection," California Management Review 45(1) (2002): 29-49.

M.E. Gallagher, "China's Workers Movement \& the End of the Rapid-Growth Era,” Daedalus: Journal of the American Academy of Arts \& Sciences 143(2) (2014): 81-95.

M. GILENS, "Inequality and Democratic Responsiveness,” Public Opinion Quarterly 69(5) (2005): 778-796.

G. GigerenZER, "How to Make Cognitive Illusion Disappear: Beyond 'Heuristic and Biases'," European Review of Social Psychology 2 (1991): 83-115.

D. GigOnE \& R. HASTIE, “The Common Knowledge Effect: Information Sharing and Group Judgment,” Journal of Personality and Social Psychology 65 (1993): 959-974.

F. GinO, S. AyAl \& D. ARIEly, "Contagion and Differentiation in Unethical Behavior: The Effect of One Bad Apple on the Barrel," Psychological Science 20(3) (2009): 393-398.

F. Gino, M.I. NORTON \& D. ARIELY, “The Counterfeit Self: The Deceptive Costs of Faking it," Psychology Science 21(5) (2010): 712-20. 
P. Glewwe, M. Kremer \& S. Moulin, "Many Children Left Behind? Textbooks and Test Scores in Kenya," NBER Working Paper 13300, (2007).

P. Glewwe, M. Kremer, S. Moulin \& E. Zitzewitz, "Retrospective Versus Prospective Analyses of School Inputs: The Case of Flip Charts in Kenya," NBER Working Paper 8018, (2000).

T.P. GLYNN, "Taking the Employer Out of Employment Law? Accountability for Wage and Hour Violations in an Age of Enterprise Disaggregation," Employee Rights and Employment Policy Journal 5(1) (2011): 101-135.

U. GNeEZy \& A. Rustichini, “A Fine Is a Price,” Journal of Legal Studies 29(1) (2000): 1-17.

M. GranovetTer, “The Strength of Weak Ties,” American Journal of Sociology 78(6) (1973): 1360-1380.

V. Griskevicius, B. VAn Den Bergh, \& J.M. Tybur, “Going Green to Be Seen: Status, Reputation, and Conspicuous Conservation,” Journal of Personality and Social Psychology 98(3) (2010): 392-404.

M.S. Hagger ET AL., "Ego Depletion and the Strength Model of Self-Control: A Meta-Analysis," Psychological Bulletin 136 (2010): 495-25.

J. HAIDT, “The Emotional Dog and Its Rational Tail,” Psychological Review 108, (2001): 814-834.

H. HANSMANN \& R. KRAAKMAN, "The End of History for Corporate Law," Georgetown Law Journal 89 (2001): 439-468.

H. HANSMANN \& M. PARgEndler, "The Evolution of Shareholder Voting Rights: Separation of Ownership and Consumption,” Yale Law Journal 123 (2014): 100-164.

H.F. HARLOW, M.K. HARLOW \& D.R. MEYER, “Learning Motivation by a Manipulation Drive," Journal of Experimental Psychology 40 (1950): 231.

Harvard Law Review Association, "A Law and Economics Look at Contracts against Public Policy," Harvard Law Review 119(5) (2006): 1445-1466.

T.F. Heatherton \& P.A. Nichols, "Personal Accounts of Successful Versus Failed Attempts at Life Change," Personality and Social Psychology, 20(6) (1994): 664-75.

G.M. HODGSON, Institutions and Individuals: Interaction and Evolution, Organizational Studies 28(1) (2007): 95-116.

M.A. Hog \& S.A. REID, "Self Identity, Self-Categorization, and the Communication of Group Norms," Communication Theory 16(1) (2006): 7-30.

C. Holzmeyer, "Human Rights in an Era of Neoliberal Globalization: The Alien Tort Claims Act and Grassroots Mobilization in Doe v. Unocal," Law and Society Review 271 (2009): 271.

M.J. Hopman, "Lipstick Law, or: The Three Forms of Statutory Law," The Journal of Legal Pluralism and Unofficial Law 49(1) (2017): 54-66.

C. Horne, "Community and the State: The Relationship Between Normative and Legal Controls," European Sociological Review 16(3) (2000): 225-243.

N.M.C.P. JÄGERS \& M.J.C. VAN DER HEIJDEN, “Corporate Human Rights Violations: The Feasibility of Civil Recourse in the Netherlands," Brooklyn Journal of International Law 33(3) (2008): 833-870.

N. JAnSEn \& R. Michaels, "Private Law Beyond the State? Europeanization, Globalization, Privatization," American Journal of Comparative Law 54 (2006).

K. JAWGER, "Environmental Claims under the Alien Tort Statute," Berkeley Journal of International Law 28(2) (2010).

B.C. JohnSOn, J.M. MANYIKA \& L.A. YeE, “The Next Revolution in Interaction,” Mckinsey Quarterly 4 (2005): 2526.

C. JOLls, C.R. SunSTEIN \& R.THALER, “A Behavioural Approach to Law and Economics,” Stanford Law Review 50 (1998): 1471-1550.

H.B. Jorgensen, P.M. PruZan-Jorgensen, M. JungK \& A. Cramer, "Strengthening Implementation of Corporate Social Responsibility in Global Supply Chains," Corporate Social Responsibility Practice, (Washington D.C.: World Bank Group, 2003).

D.M. KAHAN, "Trust, Action and Law," Boston University Law Review 81(2) (2001): 333-347.

D.M. KAHAN, “The Logic of Reciprocity: Trust, Collective Action and Law," Michigan Law Review 102(1) (2003): $71-103$.

D. Kahneman \& A. Tversky, "Prospect Theory: An Analysis of Decision under Risk," Econometrica 47(2) (1979): 263-291.

T. KASSER \& R.M. RYAN, “A Dark Side of the American Dream: Correlates of Financial Success as a Central Life Aspiration," Journal of Personality and Social Psychology 65 (1993): 410-412.

S. KATO \& J. Ahern, "Learning by Doing: Adaptive Planning as a Strategy to Address Uncertainty in Planning," Journal of Environmental Planning and Management 51(4) (2008): 543-559.

M.T. KAWAKAMI, "Psychological Oversight: Why Bills Advocating for Transparency Could Do More Harm Than Good,” Edinburgh Student Law Review 2(1) (2013): 87-89. 
M.T. KAWAKAMI, "Pitfalls of Over-Legalization,” Indiana Journal of Global Legal Studies 24(1) (2017).

J.M. KEYNES, "National Self-Sufficiency,” The Yale Review 22 (1933): 755-769.

K. KOLBEN, "Transnational Labor Regulation and the Limits of Governance," Theoretical Inquiries in Law, 12(2) (2011): 402-437.

R. KOROBKIN, "What Comes After Victory for Behavioral Law and Economics," University of Illinois Law Review 5 (2011): 1653-74.

S. KUZNETS, “National Income, 1929-1932,” National Bureau of Economic Research 124 (1934).

B. LATANÉ \& J.M. DARLEy, “Group Inhibition of Bystander Intervention in Emergencies," Journal of Personality and Social Psychology 10 (1968): 215-21.

L. Lessing, “The Law of the Horse: What Cyberlaw Might Teach,” Harvard Law Review 113 (1999): 501-546.

D. Levi-FAur, "Regulatory Capitalism: The Dynamics of Change Beyond Telecom and Electricity," Governance 19 (2006): 497.

R.J. LiubiciC, "Corporate Codes of Conduct and Product Labeling Schemes: The Limits and Possibilities of Promoting International Labor Rights Through Private Initiatives," Law and Policy International Business 30 (1998): 111.

R. LOCKE, F. QIN \& A. BRAusE, “Does Monitoring Improve Labor Standards?: Lessons from Nike,” MIT Sloan School of Management Working Paper No. 4612-06 (2006). Available at: http://ssrn.com/abstract=916771 (last accessed 30 May 2014).

S.F. MAiER \& M.E.P. SELIGMAn, “Learned Helplessness: Theory and Evidence,” Journal of Experimental Psychology: General 105 (1976): 3-46.

I. MAMIC, "Managing Global Supply Chain: The Sports Footwear, Apparel and Retail Sectors," Journal of Business Ethics 59 (2005): 81-100.

M. MANIS, S.D. CORNELl \& J.C. MOORE, "Transmission of Attitude Relevant Information Through a Communication Chain," Journal of Personality and Social Psychology 30 (1974): 81-94.

D. MATTEN \& J. MOON, “'Implicit' and 'Explicit' CSR: A conceptual framework for understanding CSR in Europe," ICCSR Research Paper Series 29 (2004).

N.L. Mead, R.F. Baumeister, F. Gino, M.E. Schweitzer \& D. Ariely, "Too Tired to Tell the Truth: SelfControl Resource Depletion and Dishonesty," Journal of Experimental Social Psychology 45(3) (2009): 594-597.

R.E. Meiners, J.M. MOFSKY \& R.D. TOLlison, "Piercing the Veil of Limited Liability," Delaware Journal of Corporate Law 2 (1979): 351.

C. Mellströ, \& M. Johannesson, "Crowding Out in Blood Donation: Was Titmuss Right?," Journal of the European Economic Association 6(4) (2008): 845-63.

A.C. Merrit, D.A. Effron \& B. Monin, "Moral Self-Licensing: When Being Good Frees Us to Be Bad," Social and Personality Psychology Compass 4(5) (2010): 344-357.

R. MiCHAEls \& N. JANSEN, "Private Law and the State," Rabels Zeitschrift 71 (2007): 345-97.

E. Miguel \& M. KREMER, "Worms: Education and Health Externalities in Kenya," NBER Working Paper 8481 (2002).

D. Millon, “Theories of the Corporation,” Duke Law Journal 39(2) (1990): 201-262.

M. Muraven, M. Gagné \& H. Rosman, "Helpful Self-Control: Autonomy Support, Vitality, and Depletion," Journal of Experimental and Social Psychology 44(3) (2008): 573-85.

S.D. MurPHY, "Taking Multinational Corporate Codes of Conduct to the Next Level," Columbia Journal of Transnational Law 43(2) (2005).

M. NARAYAN DATTA \& K. BALES, “Slavery in Europe: Part 1, Estimating the Dark Figure," Human Rights Quarterly 35(3) (2013).

D.T. NeAL, W. WoOd \& J. M. Quinn, "Habits - A Repeat Performance," Current Directions in Psychological Science 15(4) (2006): 198-202.

C.P. NiEMIEC, R.M. RYAN \& E.L. DECI, "The Path Taken: Consequences of Attaining Intrinsic and Extrinsic Aspirations," Journal of Research in Personality 43 (2009): 291-306.

M.C. Nussbaum, "Beyond the Social Contract: Capabilities and Global Justice," Oxford Development Studies 32(1) (2004).

A. Ogus, “The Paradoxes of Legal Paternalism and How to Resolve Them," Legal Studies 30 (2010).

L.D. Ordonez, M.E. Schweitzer, A.D. Galinsky \& M.H. Braverman, "Goals Gone Wild: The Systematic Side Effects of Over-Prescribing Goal Setting,” Harvard Business School Working Paper No. 09-083 (2009). 
S. Prakash Sethi \& O.F. Williams, "Creating and Implementing Global Codes of Conduct: An Assessment of the Sullivan Principles as a Role Model for Developing International Codes of Conduct - Lessons Learned and Unlearned," Business \& Society Review 169 (2000).

N. Pennington \& R. Hastie, "Reasoning in Explanation-Based Decision Making," Cognition 49 (1993): 123-63.

E.A. POSNER \& A. O. SYKES, "An Economic Analysis of State and Individual Responsibility under International Law," J.M. Olin Law \& Economics Working Paper No. 279 (2006).

J.G. RugGIE, "Reconstituting the Global Public Domain: Issues, Actors and Practices," John F. Kennedy School of Government Faculty Research Working Paper (2004).

J.G. RugGiE, "Business and Human Rights: The Evolving International Agenda," American Journal of International Law 101 (2007): 819-840.

J.G. RugGIE, "Kiobel and Corporate Social Responsibility: An Issues Brief," Harvard John F. Kennedy School of Government Working Paper (2012).

R. SAmpson, K. MOREnOfF \& T. GANnON-Rowley, “'Assessing Neighborhood Effects': Social Processes and New Directions in Research,” Annual Review of Sociology (2002): 443-78.

O.O. SCHACHTER, "The Decline of the Nation-State and its Implications for International Law," Columbia Journal of Transnational Law 36(7) (1997).

M.W. SCHeltema, "Assessing Effectiveness of International Private Regulation in the CSR Arena," Richmond Journal of Global Law \& Business 13(2) (2014): 264-375.

D. SCHIEK, "Private Rule-Making and European Governance - Issues of Legitimacy," European Law Review 32 (2007).

B. SChwARTZ \& A. Grant, "Too Much of a Good Thing: The Challenges and Opportunity of the Inverted U," Perspectives on Psychological Science 6(1) (2011): 61-76.

R.D. SCHWARTZ \& S. ORLEAnS, “On Legal Sanctions,” University of Chicago Law Review 34 (1967): 274-300.

A.K. SEN, "Rational Fools: A Critique of the Behavioral Foundations of Economic Theory," Philosophy and Public Affairs 6(4), (1977): 317-44.

A.K. SEN, “The Idea of Justice,” Journal of Human Development 9(3) (2008): 331-42.

A.K. SHAH \& D.M. OPPENHEIMER, "Heuristics Made Easy: An Effort-Reduction Framework," Psychological Bulletin 134(2) (2008): 207-222.

Y. SHANY, "The Effectiveness of the Human Rights Committee and the Treaty Body Reform," Hebrew University Faculty of Law International Law Forum Research Paper No. 02-13 (2013).

S. SHAvelL, "Law versus Morality as Regulators of Conduct," American Law and Economics Review 4(2) (2002): 227257.

R.J. SHILLER, "Do Stock Prices Move Too Much to Be Justified by Subsequent Changes in Dividends?," American Economic Review 71(3) (1981): 421-36.

B. SHIV \& A. FedorikHiN, "Heart and Mind in Conflict: The Interplay of Affect and Cognition in Consumer Decision Making," The Journal of Consumer Research 26(3) (1999): 278-292.

H.A. Simon, "Invariants of Human Behavior,” Annual Review of Psychology 41 (1990): 1-19.

J. W. SINGER, "Things that We Would Like to Take for Granted: Minimum Standards for the Legal Framework of a Free and Democratic Society," Harvard Law and Policy Review 2 (2008): 139.

J. W. SINGER, "Subprime: Why a Free and Democratic Society Needs Law," Harvard Civil Rights-Civil Liberties Law Review 47 (2012): 141.

S.A. SLOMAN, “The Empirical Case for Two Systems of Reasoning,” Psychological Bulletin 119(1) (1996): 3-22.

G.B. SMiTH \& T.J. HALL, "Pleading and Proving Contract Reformation Claims," New York Law Journal 248(119) (2012).

J.M. SMITS, “The Expanding Circle of Contract Law," Maastricht European Private Law Institute Working Paper 3 (2016).

R. SOLOMON, “The Opponent Process Theory of Motivation,” American Psychologist 35 (1980): 671-712.

G. STASSER \& W. TITUS, "Pooling of unshared Information in Group Decision Making: Biased Information Sampling During Discussion,” Journal of Personality and Social Psychology 48 (1985): 1467-1478.

B. STEPHENS, "Translating Filártiga: A Comparative and International Law Analysis of Domestic Remedies for International Human Rights Violations," Yale Journal of International Law 27(1) (2002).

B. Stephens, "Sosa v. Alvarez-Machain: The Door is Still Ajar from Human Rights Litigation in U.S. Courts," Brooklyn Law Review 70 (2004): 533.

L.A. STOUT, "Why We Should Stop Teaching Dodge v. Ford," Virginia Law \& Business Review 3(1) (2008): 163-176. 
W. Streeck, "European Social Policy after Maastricht: The 'Social Dialogue' and 'Subsidiarity', Economic and Industrial Democracy 15 (2001): 151-77.

Study Group on Social Justice in European Private Law, "Social Justice in European Contract Law: A Manifesto," European Law Journal 10(6) (2004): 653-674.

R. Sullivan, "Organizing Workers in the Space Between Unions: Union-Centric Labor Revitalization and the Role of Community-Based Organizations," Critical Sociology 36 (2010): 793-819.

D.A.J. Telman, "Is the Quest for Corporate Responsibility a Wild Goose Chase? The Story of Lovenheim $v$. Iroquois Brands, Ltd.," Akron Law Review 44(2) (2011): 480-527.

S.H. TEOH, I. Welch, \& C.P. WAZZAN, "The Effect of Socially Activist Investment Policies on the Financial Markets: Evidence from the South Africa Boycott," Journal of Business 72(1) (1999): 35-89.

G. TEubner, "Substantive and Reflexive Elements in Modern Law," Law and Society Review 17(2) (1983): 239-285.

G. TeubNER, "Breaking Frames: The Global Interplay of Legal and Social Systems," American Journal of Comparative Law 45 (1997): 149-159.

L.K.L. TJON SOEI LEN, "European Contract Law and the Capabilities Approach: On Distributive Responsibility for Contract Law," Centre for the Study of European Contract Law Working Paper Series (00) (2010): 156.

M.W. TOFFEL, J.L. SHORT \& M. OUELlET, "Reinforcing Regulatory Regimes: How States, Civil Society, and Codes of Conduct Promote Adherence to Global Labor Standards," Harvard Business School Technology \& Operations Management Unit Working Paper 65 (2013).

A. Tversky \& D. Kahneman, “Availability: A Heuristic for Judging Frequency and Probability," Cognitive Psychology 5 (1973): 207-32.

A. TVersky \& D. Kahneman, “Judgment under Uncertainty: Heuristics and Biases,” Science 185 (1974): 1124-31.

M.J. van DER HeIjDEN, “Class Actions/Les Actions Collectives,” Electronic Journal of Comparative Law 14(3) (2010).

B. Verplanken \& W. WoOD, "Interventions to Break and Create Consumer Habits," Journal of Public Policy and Marketing 25(1) (2006): 93-103.

S. Vitali, J.B. GlatTfelder \& S. BAtTison, “The Network of Global Corporate Control," PLoS One 6(10) (2011).

A. WALDER, "Political Sociology and Social Movements," Annual Review of Sociology 35 (2009): 393-412.

K.E. WEICK, "Small Wins: Redefining the Scale of Social Problems,” American Psychologist 39 (1984): 40-49.

R. Willer, "Groups Reward Individual Sacrifice: The Status Solution to the Collective Action Problem," American Sociological Review 74(1) (2009): 23-43.

A. WILLIS, "The Role of the Global Reporting Initiative's Sustainability Reporting Guidelines in the Social Screening of Investments," Journal of Business Ethics 43(3) (2003): 233-237.

T. Wilthagen \& F. Tros, "Dealing with the 'Flexibility-Security-Nexus': Institutions, Strategies, Opportunities and Barriers," Amsterdam Institute for Advanced labour Studies Working Paper No. 9 (2003).

C. Winston, "The Efficacy of Information Policy: A Review of Archon Fung, Mary Graham, and David Weil's Full Disclosure: The Perils and Promise of Transparency," Journal of Economic Literature 46 (2008): 704.

V. ZABKAR \& M. HOSTA, "Willingness to Act and Environmentally Conscious Consumer Behaviour: Can Prosocial Status Perceptions Help Overcome the Gap," International Journal of Consumer Studies 37(3) (2013): 257264.

P. Zumbansen \& G-P. CALliess, "Law, Economics, and Evolutionary Theory: State of the Art and Interdisciplinary Perspectives," Osgoode Hall Law School Comparative Research in Law \& Political Economy Research Paper No. $10(2010)$.

M. ZwOLINSKI, “A Libertarian Case for the Moral Limits of Markets," Georgetown Journal of Law and Public Policy 13(2) (2015): 275-290.

\section{NEWSPAPER \& MAGAZINES}

D. BARBOZA, "Monsanto Sues airy in Maine Over Label's Remarks on Hormones," The New York Times, (12 July 2003).

M.H. BAZERMAN, "Evaluating Your Business Ethics: A Harvard Professor Explains Why Good People Do

Unethical Things," Gallup Management Journal, (12 June 2008).

S. BHATT, “Cashing In,” Seattle Times, (23 June 2013).

M. BISHOP, "Beyond GDP," The Economist, (18 April 2013). 
M. BitTMAn, "My Dream Food Label," The New York Times, (13 October 2012).

J. BoumA, “Waarom Urgenda de Klimaatzaak kan Winnen,” Troun, (14 April 2015).

R. Botsman, “Why the Law Won't Stop Uber,” Financial Review, (11 July 2014).

J. CARroll, "Buffett Dumping Exxon Points Investors to Review Oil Bets," Bloomberg (18 February 2015).

M. Chen, "Could Stronger Unions Make China More Democratic," The Guardian, (11 August 2014).

A. Cowell, "A Call to Put Social Issues on Corporate Agendas," The New York Times, (6 April 2000).

T. DiDonato, "Stop Basing Pay on Performance Reviews," Harvard Business Review, (10 January 2014).

T. DiDonato \& N. Gill, “Changing an Organization's Culture, Without Resistance or Blame," Harvard Business Review, (15 July 2015).

D. DiermeIER, “When Do Company Boycotts Work?," Harvard Business Review, (6 August 2012).

J. Dorfman, "The Death of the American Middle Class has been Greatly Exaggerated," Forbes, (15 December 2015).

C. Dougherty \& H. TABuchi, "New, Simple 'Buy' Buttons Aim to Entice Mobile Shopping," The New York Times, (5 July 2015).

C. Duhigg \& D. BArboza, "In China, Human Costs are Built into an iPad," The New York Times, (25 January 2012).

T.B. EDSALL, “Another Stumble for Ralph Reed's Beleaguered Campaign,” The Washington Post, (29 May 2006).

T. EHRLICH, "Legal Pollution,” New York Times Magazine, (8 February 1976).

J. ENTINE, "Ecolabels - The Wild West of Labeling," Ethical Corporation, (7 March 2013).

A. FEUER, "New York State Calls It a Sweatshop," The New York Times, (20 May 2009).

D. FisHeR, “New York Federal Court Dismisses Alien Tort Claims Against Arab Bank,” Forbes, (26 August 2013).

C. FreEland, "Capitalism, but With a Little Heart," The New York Times, (18 July 2013).

M. Friedman, “The Social Responsibility of Business Is to Increase Its Profits," New York Times Magazine, (September 13, 1970).

O. GIBSON, "FIFA Faces Legal Challenges Over Qatar Migrant Workers," The Guardian, (10 October 2016).

M.D. GOLDHABER, “Alien Tort Backup Plan,” The American Lawyer, (1 January 2013).

F. GuerrerA, "Welch Condemns Share Price Focus,” Finanical Times, (12 March 2009).

G. HAMEL, "Moon Shots for Management," Harvard Business Review, (February 2009).

R. Hamilton, “A History of the U.S. Alien Tort Statute,” Reuters, E. Evans (ED.) (30 September 2012).

W. Henley, "New Breed of Ethical Startups are Taking on Giants of the Internet," The Guardian, (9 July 2013).

S. HiCKEY, "Uber Tribunal Judges Criticise 'Fictions' and 'Twisted Language,," The Guardian, (28 October 2016).

M. ISAAC \& N. SINGER, “California Says Uber Driver is Employee, Not a Contractor,” The New York Times, (17 June 2015).

E.B. KAPSTEIN, “The Corporate Ethics Crusade,” Foreign Affairs, (September/October 2001).

J. KOLLEWE, “Uber Awaits Tribunal Ruling Over Drivers' Status as Wrokers,” The Guardian, (28 October 2016).

N. KRISTOF, "The Cost of a Decline in Unions," The New York Times, (19 February 2015).

P. Krugman, "In Praise of Cheap Labor: Bad Jobs at Bad Wages Are Better Than No Jobs at All," Slate Magazine, (21 March 1997).

P. Krugman, "Reckonings, Hearts and Heads," The New York Times, (22 April 2001).

G. LindSAY, “Cisco's Big Bet on New Songdo: Creating Cities from Scratch,” Fast Company, (1 February 2010).

S. Lubman, "Labor Pains: A Rising Threat to Stability in China," The W all Street Journal, (10 June 2014).

V. MAllet \& G. DinMORE, "Europe: Hidden Economy,” Financial Times, (8 June 2011).

D. MASSEY, “Labor Law Violations Seen Costly for City Workers," Crain's New York Business, (28 January 2010).

R. MASON, "Companies Not Asked to Report Slavery in Supply Chains Under New Laws," The Guardian, (10 June 2014).

J. MEISTER, “Three Reasons You Need to Adopt a Millennial Mindset Regardless of Your Age,” Forbes, (5 October 2012).

E. Morozov, “The Brave New World of Slacktivism,” Foreign Policy, (19 May 2009).

J. Mouawad, "Shell to Pay \$15.5 Million to Settle Nigerian Case," The New York Times, (8 June 2009).

L.J. Nelson, A. Chang \& P. Dave, "Uber Should be Suspended in California and Fined $\$ 7.3$ million, Judge Says,” Los Angeles Times, (15 July 2015).

C. O’CONNOR, "How Angry Walmart Workers Helped Convince Foreign Investors to Dump Shares," Forbes, (7 October 2013).

J. RASKIN, "The Rise of Benefit Corporations," The Nation, (8 June 2011).

R.B. REICH, "Secession of the Successful," The New York Times, (20 January 1991). 
R. REICH, "Big Government isn't the Problem," Salon, (31 December 2014). Available at: http://www.salon.com/2014/12/31/robert_reich_big_government_isnt_the_problem_partner/?utm_sourc $\mathrm{e}=$ facebook\&utm_medium=socialflow (last accessed 2 February 2015).

G. REIJN, "Verkoop van verantwoorde koffie stijgt explosief," De Volkskrant, (8 May 2013).

D. E. Rosenbaum, “At $\$ 500$ an Hour, Lobbyist's Influence Rise with G.O.P.,” The New York Times, (3 April 2002).

T. RutTER, “The Rise of Nudge - The Unit Helping Politicians to Fathom Human Behaviour," The Guardian, (23 July 2015).

M.T. SCHMiCH, “A Stopwatch on Shopping,” Chicago Tribune, (24 December 1986).

I. SeKularac \& A. Deutsch, "Dutch Court says Shell responsible for Nigeria Spills,” Reuters, (30 January 2013).

J. SHAw, "A Radical Fix for the Republic: Lawrence Lessig thinks American Democracy Requires a Constitutional Overhaul to Counter the "Economy of Influence," Harvard Magazine, (July-August 2012). Available at: http://harvardmagazine.com/2012/07/a-radical-fix-for-the-republic (last accessed 13 December 2013).

P. SHENON, "Made in the U.S.A.? Hard Labor on a Pacific Island/A Special Report: Saipan Sweatshops Are No American Dream," The New York Times, (18 July 1993).

M. SINGER, "The Year in Fashion: In the Wake of Fall's Designer Exits, It's Time to Start Thinking Small," Vogue, (2 December 2015).

B.R. Smith, "City Hall and Uber Clash in Struggle Over New York Streets," The New York Times, (16 July 2015).

J. SMITH, "The Companies with the Best CSR Reputations," Forbes, (2 October 2013).

J. STEIN, "Millennials: The Me Me Me Generation,” Time Magazine, (20 May 2013).

K. STIER, "Investing in Climate Change," Ethical Corporation, (2006).

J. Surowieski, "Manic Monday (and Other Popular Delusions)," New Yorker, (26 March 2001).

O. TiCKELl, "Niger Delta Oil: Shell Ignores Horrendous Pollution,” Ecologist, (4 August 2014).

M. Turner, "Effort to Bury Mistrust," Financial Times, (24 June 2004).

A. Vaccaro \& J. Fontrodona, “Academic View: The Myth of Corporate Transparency," The Economist, (7 September 2010).

P. WALKER, "Dutch Union Suing FIFA over 'Modern Slavery' at Qatar 2022 World Cup Sites in Landmark Case," Independent, (11 October 2016).

D. WEIDNER, "Why Your CEO Could Be in Trouble," Wall Street Journal, (15 September 2011).

I. WELCH, "Why Divestment Fails," The New York Times, (10 May 2014).

A. Westervelt, "Two Years After Rana Plaza, Have Conditions Improved in Bangladesh's Factories?," The Guardian, (24 April 2015).

“A Milestone for Human Rights," Bloomberg Business Week, (23 January 2005).

"The Biggest Contract," The Economist, (26 May 2005).

"Good Food?," The Economist, (7 December 2006).

"Voting with Your Trolley," The Economist, (7 December 2006).

"Diamonds: Betting on De Beers," The Economist, (12 November 2011).

"Cities on the Ocean," The Economist, (3 December 2011).

"The Third Industrial Revolution," The Economist, (21 April 2012).

"LSE: When Performance-Related Pay Backfires," Financial, (25 June 2009).

\section{REPORTS}

AMNESTY INTERnATIONAL, The Ugly Side of the Beautiful Game: Exploitation of Migrant Workers on a Qatar 2022 World Cup Site, MDE 22/3548/2016 (London: Amnesty International, 2016).

AMnESTY InTERnATIONAL \& AFREWATCH, This is What We Die For: Human Rights Abuses in the Democratic Republic of the Congo Power the Global Trade in Cobalt, AFR 62/3183/2016 (London: Amnesty International, 2016).

Amnesty International, "Exposed: Child Labour Behind Smart Phone and Electric Car Batteries," Press Release, (19 January 2016).

A. BernhardT, D. POLSON \& J. DeFilipPIS, "Working Without Laws: A Survey of Employment and Labor Law Violations in New York City,” National Employment Law Project (2010). 
British InStitute of InTERnATIONAL AND COMPARATIVE LAw, “Report II on Collective Redress,” (November 2014).

Centraal Bureau voor de Statistiek, “Dutch Labour Market Dynamics,” Press Release, (17 May 2013).

R. Dobbs, A. Madgavkar, D. Barton, E. Labaye, J. Manyika, C. Roxburgh, S. Lund \& S. Madhav, "The World at Work: Jobs, Pay, and Skills for 3.5 billion People,” McKinsey Global Institute, (12 June 2012).

Dutch National Rapporteur on Trafficking in Human Beings and Sexual Violence against Children, Trafficking in Human Beings: Ninth Report of the Dutch National Rapporteur, (2013).

EARTHRights INTERNATIONAL, "Out of Bounds: Accountability for Corporate Human Rights Abuse After Kiobel," (2013).

European Commission, "Communication from the Commission to the European Parliament, the Council, the European Economic and Social Committee and the Committee of the Regions: A renewed EU strategy 2011-14 for Corporate Social Responsibility” COM (2011) 681 final.

European Commission, "Green Paper: Promoting a European Framework for Corporate Social Responsibility,” COM (2001) 366 final.

European Commission, "Proposal for a Regulation of the European Parliament and of the Council setting up a Union system for supply chain due diligence self-certification of responsible importers of tin, tantalum and tungsten, their ores, and gold originating in conflict-affected and high-risk areas," COM/2014/0111 final (2014).

European COMmission, “Shareholders' Rights Directive Q\&A Fact Sheet,” MEMO/17/592 (14 March 2017).

European Parliament, Directorate-General for External Policies of the EU Briefing Paper, "Addressing Contemporary Forms of Slavery in EU External Policy,” (2013) Available at: http://www.europarl.europa.eu/ RegData/etudes/note/join/2013/433703/EXPO-DROI_NT(2013)433703_EN.pdf (last accessed 3 March 2014).

FriendS OF THE EARTH Europe, “No Progress: An Evaluation of the Implementation of UNEP's Environmental Assessment of Ogoniland, Three Years On” (4 August 2014). Available at: http://www.foeeurope.org/ sites/default/files/publications/foee-no-progress-040814_0.pdf (last accessed 5 August 2014).

M.T. Kawakami, G. Dijkstra, E. Charlemagne, K. Pitman, P. Su, A. Ungureanu \& M. Vroomen, "Certification: A Sustainable Solution? Insights from Dutch Companies on the Benefits and Limitations of CSR Certifications in International Supply Chains," NVO Nederland (12 January 2015). Available at: http://mvonederland.nl/publicatie/de-toekomst-van-mvo-certificering (last accessed 7 April 2017).

J. Keeble \& D. Brown, “The Business Case for Corporate Citizenship,” Arthur D. Little, Inc. (2003).

INTERNATIONAL LABOUR ORGANiZATION, ILO Global Estimate of Forced Labor: Results and Methodology, (Geneva: ILO, 2012).

International Labour Organization, Profits and Poverty: The Economics of Forced Labour, (Geneva: ILO, 2014).

InTERnATIONAL LABOUR ORGANiZATION, World of Work Report: Developing with Jobs [Executive Summary], (Geneva: ILO, 2014).

International Labour Organization, World Employment Social Outlook: Transforming Jobs to End Poverty, (2016).

MCKINSEY \& CO., “Assessing the Global Compact's Impact,” UN Global Compact Office, (2004).

New York State Department of Labor, "State Raids New York City Sweatshops: Department Issues FirstEver Order of Confiscation Against Manufacturer and Tags Contractor's Products; Garments May not be Moved or Sold Until Full Restitution is Made to Workers," Press Release, (2009). Available at: http://www.labor.state.ny.us/pressreleases/2009/April29_2009.htm (last accessed 15 March 2013).

Report of the Special Representative of the Secretary General on the issue of human rights and transnational corporations and other business enterprises, "Business and Human Rights: Mapping International Standards of Responsibility and Accountability for Corporate Acts," UN Document A/HRC.4/035 (19 February 2007).

J. RugGIE, Guiding Principles on Business and Human Rights: Implementing the United Nations "Protect, Respect and Remedy" Framework, United Nations Report HR/PUB/11/04 (2011).

J. RugGIE, "For the Game: For the World: FIFA \& Human Rights," Harvard Kennedy School Corporate Responsibility Initiative (2016).

E.J. SCHRAGE, "Promoting International Worker Rights Through Private Voluntary Initiatives: Public Relations or Public Policy?" A Report to the U.S. Department of State on behalf of the University of Iowa Center for Human Rights (2014). 
SPeCiAl TASK ForCE FOR THE APPAREL Industry, Annual Report 2005. Available at: www.labor.ny.gov/ agencyinfo/PDFs/AITF\%20Annual\%20Report\%202005.pdf (last accessed 6 June 2013).

SPECIAL TASK FORCE FOR THE APPAREL IndUSTRY, Annual Report 2004. Available at: www.labor.ny.gov/ agencyinfo/PDFs/AITF_2004_web.pdf (last accessed 5 June 2013).

SZW InSPECTORATE, “Annual Report of the Social Affairs and Employment Inspectorate: Summary,” Ministry of Social Affairs and Employment (2011). Available at: http://www.inspectieszw.nl/Images/ Summary $\% 202011 \% 20$ Annual $\% 20$ Report $\% 20$ Social $\% 20$ Affairs $\% 20$ and $\% 20$ Employment $\% 20$ Inspectorate_tcm3 35-329873.pdf (last accessed 22 February 2016).

SZW InSPECTORATE, “Annual Report of the Social Affairs and Employment Inspectorate: Summary,” Ministry of Social Affairs and Employment (2012). Available at: http://www.inspectieszw.nl/Images/2012-AnnualReport-Inspectorate-SZW-Summary_tcm335-341803.pdf (last accessed 22 February 2016).

SZW InSPECTORATE, “Annual Report of the Social Affairs and Employment Inspectorate: Summary,” Ministry of Social Affairs and Employment (2013). Available at: http://www.inspectieszw.nl/Images/Summary \%20Annual\%20Report\%202013\%20Inspectorate\%20SZW_tcm335-350953.pdf (last accessed 22 February 2016).

SZW InSPECTORATE, “Annual Report of the Social Affairs and Employment Inspectorate: Summary,” Ministry of Social Affairs and Employment (2014). Available at: http://www.inspectieszw.nl/Images/Annual-Report2014_tcm335-365558.pdf (last accessed 22 February 2016).

United NATiOns, "Secretary General's Report on the Rule of Law in Conflict and Post-Conflict Societies," S/2004/16, (23 August 2004).

United Kingdom CBI's Watkinson Commission, The Responsibilities of the British Public Company, final report of the Company Affairs Committee (Watkinson Report), (London: Confederation of British Industry, 1973).

United NATions Committee on ECONOMic, Social and Cultural Rights, UN DOC E/C.12/GC/19.

United Nations Environment Programme, “Environmental Assessment of Ogoniland,” (2011). Available at: http://postconflict.unep.ch/publications/OEA/UNEP_OEA.pdf (last accessed 5 August 2014).

United NATIONS Human DEVElOPMENT REPORT (2011). Available at: http://www.undp.org/content/ dam/undp/library/corporate/HDR/2011\%20Global\%20HDR/English/HDR_2011_EN_Complete.pdf (last accessed 4 October 2014).

United Nations Office of the High Commissioner for Human Rights, Guiding Principles on Businesses and Human Rights: Implementing the United Nations "Protect, Respect and Remedy" Framework, UN DOC HR/PUB/11/04 (2011).

United States Census Bureau, "Census Bureau Reports There are 89,004 Local Governments in the United States,” Press Release, (30 August 2012). Available at: https://www.census.gov/newsroom/releases/archives/ governments/cb12-161.html (last accessed 28 March 2016).

United States General Accounting OfFice, “'Sweatshops' in New York City: A Local Example of a Nationwide Problem," Briefing Report to the Honorable Charles E. Schumer, House of Representatives. GAO/HRD-89-101 BR (B-231284).

United States Census Bureau, Statistical Abstract of the United States: 2004-2005 (Washington D.C.: U.S. Census Bureau, 2004).

United States Department of Labor Wage and Hour Division, "The Application of the Fair Labor Standards Act's 'Suffer or Permit' Standard in the Identification of Employees Who Are Misclassified as Independent Contractors," (15 July 2015). Available at: http://www.dol.gov/whd/workers/Misclassification/ AI-2015_1.pdf (last accessed 29 July 2015).

United States Government Accountability Office, "SEC Conflict Minerals Rule: Initial Disclosures Indicate Most Companies Were Unable to Determine the Source of Their Conflict Minerals," GAO-15-561, (18 August 2015).

United States Environmental Protection Agency, “Chemical Testing \& Data Collection,” (8 August 2013). Available at: http://www.epa.gov/opptintr/chemtest (last accessed 25 March 2015).

The Global SLAVERY Index, Global Findings, (2016).

WORLD BANK, Doing Business in 2008, (Washington D.C.: World Bank, 2008). 


\section{ONLINE CONTENT}

Balboa Capital, "E-Commerce Sales Top \$50 Billion in First Quarter," (30 May 2012). Available at: http://balboacapital.com/e-commerce-sales-top-50-billion-in-first-quarter (last accessed 26 March 2015).

BBC, “Are Sweatshops Good?,” BBC Business Daily, (11 July 2014). Available at: http://www.bbc.co.uk/programmes/ p0224gvl (last accessed 5 July 2015).

BBC, "China Factory Collapse: Six Dead and 49 Rescued," BBC News, (4 July 2015). Available at: http://www.bbc.com/news/world-asia-china-33396086 (last accessed 22 July 2015).

B Corp Annual Report (2012) Available at: http://www.bcorporation.net/what-are-b-corps (last accessed 4 April 2017).

Benefit Corp Information Center, "Benefit Corp vs. Certified B Corp". Available at: http://www.benefitcorp.net/what-makes-benefit-corp-different/benefit-corp-vs-certified-b-corp (last accessed 4 April 2017).

K. Bogardus \& B. GOAD, "Up in Arms Over Union "Persuader' Rule," The Hill, (12 February 2014). Available at: http://thehill.com/regulation/labor/198153-union-persuader-rule-has-industry-groups-up-in-arms (last accessed on 23 March 2016).

British Assessment BUREAU, "ISO 9001 Proven to Help Win New Business." Available at: http://www.british-assessment.co.uk/guides/iso-9001-opens-doors-for-uk-businesses/ (last accessed 18 December 2016).

T. Callen, “Gross Domestic Product: An Economy's All,” International Monetary Fund, (28 March 2012). Available at: http://www.imf.org/external/pubs/ft/fandd/basics/gdp.htm (last accessed 26 August 2016).

Chartered InSTITUTE OF Procurement \& SuPPLy, "Professional Leaders Say UK Could be Sleepwalking into Another Supply Chain Crisis," (21 July 2014). Available at: https://www.cips.org/en/news/ news/professional-leaders-say-uk-could-be-sleepwalking-into-another-supply-chain-crisis/ (last accessed 18 December 2016).

China Labour Bulletin, “China’s Official Trade Union Still Fails to get the Message,” (2 December 2013). Available at: http://www.clb.org.hk/content/searching-union-workers $\%$ E2\%80\%99-movement-china2011-13-0 (last accessed 4 April 2017).

C. Comin \& T. PhilipPon, "The Rise of Firm-Level Volatility: Causes and Consequences," Paper Written for the NBER's Twentieth Annual Conference on Macroeconomics, (29 July 2005). Available at: http://pages.stern.nyu.edu/ tphilipp/papers/diego.pdf (last accessed 15 May 2015).

DeloitTe Touche Tohmatsu, "Business needs to reset its purpose to attract Millennials, according to Deloitte's annual survey,” Press Release, (14 January 2015). Available at: http://www2.deloitte.com/ an/en/pages/about-deloitte/articles/2015-millennial-survey-press-release.html (last accessed 2 July 2015).

ECOLABEL INDEX. Available at: http://www.ecolabelindex.com/ (last accessed 4 April 2017).

R.G. Eccles \& G. SERAFEM, “Top 1,000 Companies Wield Power Reserved for Nations,” Bloomberg, (11 September 2012). Available at: http://www.bloomberg.com/news/2012-09-11/top-1-000-companies-wield-powerreserved-for-nations.html (last accessed 4 April 2017).

K. EDwards \& S. Robinson, "Labor and Employment Law: A Career Guide," Bernard Koteen Office of Public Interest Advising Harvard Law School, C. PATTANAYAK (ED.) (2012). Available at: http://hls.harvard.edu/content/uploads/2008/06/laboremployment2012.pdf (last accessed 22 February 2016).

J. EIDELSON, "Photos Show Walmart Apparel at Site of Deadly Factory Fire in Bangladesh," The Nation, (16 November 2012). Available at: http://www.thenation.com/article/photos-show-walmart-apparel-sitedeadly-factory-fire-bangladesh/ (last accessed 27 July 2015).

Federal Trade Commission, "FTC Issues Revised 'Green Guides,", (1 October 2012). Available at http://www.ftc.gov/sites/default/files/attachments/press-releases/ftc-issues-revised-greenguides/greenguides.pdf (last accessed 4 April 2017).

D. Feldmann \& E. Yu, "Millennials and the Social Sector: What's Next?," Stanford Social Innovation Review (18 June 2014). Available at: https://ssir.org/articles/entry/millennials_and_the_social_sector_whats_next (last accessed 18 December 2016).

"Foxconn Overtime Cuts Announced, But More Needs To Be Done," Huffington Post, (21 August 2012). Available at: http://www.huffingtonpost.com/2012/08/21/foxconn-overtime-cuts_n_1820378.html (last accessed 18 December 2016). 
FriendS OF THE EARTh InTERnAtional, "Dutch Court ruling against Shell a Partial Victory," (30 January 2013). Available at: http://www.foei.org/press/archive-by-year/press-2013/dutch-court-ruling-againstshell-a-partial-victory (last accessed 4 April 2017).

S. GotTlieb, “Golden Promises End in a Sweatshop in The Hague," Radio Netherlands Worldwide, (9 April 2010). Available at: http://www.rnw.nl/english/article/golden-promises-end-a-sweatshop-hague (last accessed 4 April 2017).

C. HAunHorst, “Food from Nowhere: Producers Reject Calls for Stricter Labels," Spiegel Online International, (17 October 2012). Available at: http://www.spiegel.de/international/business/consumer-watchdogs-call-formore-detail-on-processed-food-labels-a-861411.html (last accessed 4 April 2017).

M. HobBes, "The Myth of the Ethical Shopper," The Huffington Post, (2015). Available at: http://highline.huffingtonpost.com/articles/en/the-myth-of-the-ethical-shopper/ (last accessed 16 July 2015).

"Hoge boetes wegens illegale krantenbezorgers," de Volkskerant (4 May 2010). Available at: http://www.volkskrant.nl/ recensies/hoge-boetes-wegens-illegale-krantenbezorgers a981799/ (last accessed 4 April 2017).

IBM INSTITUTE FOR BusinesS VALUE, "Myths, Exaggerations and Uncomfortable Truths: The Real Story Behind Millennials in the Workplace," IBM Global Business Services Executive Summary, (January 2015). Available at: $\quad$ www-01.ibm.com $/$ common $/$ ssi/cgi-bin/ssialias?subtype $=$ XB\&infotype $=$ PM\&appname $=$ GBSE_GB_ TI_USEN\&htmlfid=GBE03649USEN\&attachment=GBE03649USEN.PDF\#loaded (last accessed 5 July 2015).

INSPECTIE SZW, De bestrijding van slavernijachtige uitbuiting. Available at: www.inspectieszw.nl/onderwerpen/arbeids verhoudingen/arbeidsuitbuiting/de_bestrijding_van_slavernijachtige_uitbuiting/ (last accessed 3 March 2014).

INSPECTIE SZW, Boetebedragen bij overtreden Wet minimumloon. Available at: https://www.inspectieszw.nl/onderwerpen/ arbeidsverhoudingen/toezicht_eerlijk_werk/sancties_bij_overtreden_wav_wml_waadi/boetes_wml/ index.aspx (last accessed 17 December 2016).

INSPECTIE SZW, "Inspections by the Inspectorate SZW on the employment of foreign workers and the payment of the minimum wage." Available at: www.inspectieszw.nl/Images/Inspections-by-the-Inspectorate-on-theemployment-of-foreign-workers-and-the-payment-of-the-minimum-wage_tcm335-326481.pdf (Last accessed 30 May 2013).

INTERNATIONAL LABOR ORganizATION, International Labour Standards on Freedom of Association. Available at: http://www.ilo.org/global/standards/subjects-covered-by-international-labour-standards/freedom-ofassociation/lang--en/index.htm (last accessed 4 April 2017).

INTERNATIONAL ORGANIZATION FOR STANDARDIZATION, The ISO Survey of Management System Standard Certifications 2012, (2012). Available at: http://www.iso.org/iso/iso_survey_executive-summary.pdf (last accessed 4 April 2017).

International Organization FOR Standardization, Publicizing Your ISO 9001:2008 or ISO 14001:2004 Certification, (2010). Available at: http://www.iso.org/iso/publicizing_iso9001_iso14001_certification_ 2010.pdf (last accessed 4 April 2017).

D. JAMIESON, “This Is What It's Like to Sit Through an Anti-Union Meeting at Work," The Huffington Post, (3 September 2014). Available at: http://www.huffingtonpost.com/2014/09/03/captive-audience-meetingsanti-union_n_5754330.html (last accessed on 23 March 2016).

S. KNAFO \& K. BHASIN, "Walmart Activism is Effecting Change at World' Largest Retailer, Organizers Say," The Huffington Post, (7 June 2013). Available at: www.huffingtonpost.com/2013/06/06/walmart-activism-changeorganizers_n_3399169.html?view=screen (last accessed 20 February 2015).

R. KIEviT, "A Slavery Drama in the Dutch Village of Someren," Radio Netherlands Worldwide, (22 May 2009). Available at: http://www.rnw.nl/english/article/slavery-drama-dutch-village-someren (last accessed 4 April 2017).

A. LEONARD, “The Hourglass Economy," Salon, (13 September 2011). Available at: http://www.salon.com/2011/09/13/the_hourglass_economy/ (last accessed 4 April 2017).

J. Lowensohn, “Amazon Has Invented Tiny Plastic Buttons that Allow for Instant Product Ordering: Your Entire House is Now a Shopping Cart," The Verge, (31 March 2015). Available at: http://www.theverge.com/2015/3/31/8316775/amazon-dash-buttons-turn-homes-into-shopping-carts (last accessed 14 July 2015). 
L.P. MARCuS, “The People's Corporation,” Project Syndicate, (15 September 2014). Available at: http://www.project-syndicate.org/commentary/lucy-p--marcus-says-that-companies-have-more-powerthan-ever-before--but-so-do-people (last accessed 4 April 2017).

J. Markell, "A New Kind of Corporation to Harness the Power of Private Enterprise for Public Benefit," The Huffington Post, (22 July 2013). Available at: http://www.huffingtonpost.com/gov-jack-markell/publicbenefit-corporation_b_3635752.html (last accessed 4 April 2017).

Meerjarenplan 2013-2014: Inspectie Social Zaken en Werkegelegenheid [Term Plan 2013-2014]. Available at: https://www.inspectieszw.nl/Images/Meerjarenplan\%202013-2014\%20Inspectie\%20SZW_tcm335334154.pdf (last accessed 4 April 2017).

M. Migliorato, "EU CSR Strategy 2020 and the Work of CSR Europe," CSR Europe: Enterprise 2020 Presentation. Available at: http://www.sodalitas.it/public/allegati/EUCSRStrategy2020_2015213121453416.pdf (last accessed 11 March 2016).

Ministerie van SOCIALE ZAKen EN WeRKGELEGEnHeID, "Gegevens gecontroleerde bedrijven stapsgewijs openbaar,” Niewsbericht, (21 February 2014). Available at: www.inspectieszw.nl/actueel/nieuwsberichten/ gegevens_gecontroleerde_bedrijven_stapsgewijs_openbaar.aspx (last accessed 4 April 2017).

K. MOFID \& S. SzEGHI, "Economics in Crisis: What Do We Tell the Students?," Globalisation for the Common Good Initiative (22 April 2010). Available at: http://www.gcgi.info/news/91-economics-and-economists-engulfedby-crises-what-do-we-tell-the-students (last accessed 4 April 2017).

B. Moore, “The 'True Cost' Documentary Tallies Global Effect of Cheap Clothes," Los Angeles Times, (28 May 2015). Available at: http://www.latimes.com/entertainment/movies/la-et-mn-true-cost-cheap-clothesdocumentary-20150528-story.html (last accessed 25 March 2016).

New York STATE DePARTMENT OF LABOR, A Guide for Manufacturers and Retailers. Available at: http://www.labor.ny.gov/workerprotection/laborstandards/workprot/sweatshp.shtm (last accessed 3 April 2017).

NOS, "Hoe Flex is de Flexwet," (25 June 2015). Available at: http://nos.nl/op3/artikel/2043352-hoe-flex-is-deflexwet.html (last accessed 22 February 2016).

NYU Press Release, "NYU Stern Study Shows Customers Are Willing to Pay More for Socially Responsible Products" (7 August 2013). Available at: http://www.stern.nyu.edu/experience-stern/news-events/winertully-consumer-premium (last accessed 5 April 2015).

D. O'Rourke, "Opportunities and Obstacles for Corporate Responsibility in Reporting in Developing Countries," World Bank/International Finance Corporations (2004). Available at: http://documents.worldbank.org/curated/en/855331468158699854/pdf/346650Opportunities.pdf (last accessed 18 December 2016).

S. OvergaArD, “As U.S. States Look to Add Food Labels, Denmark Looks to Subtract Some,” NPR, (29 October 2012). Available at: http://www.npr.org/blogs/thesalt/2012/10/29/163869580/as-u-s-states-look-toadd-food-labels-denmark-looks-to-subtract-some (last accessed 3 April 2017).

Pew Research Center, "Public Trust in Government: 1958-2014," (13 November 2014). Available at: http://www.people-press.org/2014/11/13/public-trust-in-government/ (last accessed 15 May 2015).

Pew Research Center, "The American Middle Class is Losing Ground," (9 December 2015). Available at: http://www.pewsocialtrends.org/2015/12/09/the-american-middle-class-is-losing-ground/ (last accessed 25 March 2016).

B. Powell, "In Defense of 'Sweatshops'," Library of Economics and Liberty, (2 June 2008). Available at: http://www.econlib.org/library/Columns/y2008/Powellsweatshops.html (last accessed 4 April 2017).

C. Preston, "New Research Sheds Light on What Works in Charitable Appeals," The Chronicle of Philanthropy, (17 July 2007). Available at: http://philanthropy.com/article/New-Research-Sheds-Light-on/62663/ (last accessed 4 April 2017).

RANa Plaza COORDination COMmitTEe, "RPCC announce that sufficient funds now available to complete payments under the Rana Plaza arrangement," (8 June 2015). Available at: http://www.ranaplazaarrangement.org/ (last accessed 5 July 2015).

R. REICH, "Why We're All Becoming Independent Contractors," The Huffington Post, (22 February 2015). Available at: www.huffingtonpost.com/robert-reich/why-were-all-becoming-independent-contractors_b_6731760 .html (last accessed 22 February 2015).

P. ROMER, "For Richer, For Poorer," Prospect, 167 (27 January 2016). Available at http://www.prospectmagazine.co.uk/features/for-richer-for-poorer (last accessed 28 March 2016). 
B. Ross, "DeLay's Lavish Island Getaway," $A B C$ News, (6 April 2005). Available at: http://abcnews.go.com/WNT/Investigation/story?id=647725 (last accessed 4 April 2017).

M. SHIELDS, “The Real Scandal of Tom DeLay," CNN, (9 May 2005). Available at: http://edition.cnn.com/2005/POLITICS/05/09/real.delay/ (last accessed 4 April 2017).

J.M SMITS, "Private Law 2.0: On the Role of Private Actors in a Post-National Society," Inaugural lecture delivered on 30 November 2010 as Maastricht-HiiL Chair on Internationalisation of Law (The Hague; Eleven, 2011). Available at: http://www.hiil.org/data/sitemanagement/media/Publication_Smits_250211(1).pdf (last accessed 4 April 2017).

L.A. STOUT, "The Shareholder Value Myth," The European Financial Review, (30 April 2013). Available at: http://www.europeanfinancialreview.com/?p=883 (last accessed 7 April 2017).

T. Sullivan, "H\&M May Raise Prices in Order to Pay Workers More,” Agnece France Presse, (9 December 2013). Available at: http://www.huffingtonpost.com/2013/12/09/hm-may-prices-raise-worker_n_4414450.html (last accessed 4 April 2017).

The Law Commission and the Scottish Law Commission, Consumer Redress for Misleading and Aggressive Practices: A Joint Consultation Paper, (2012). Available at: http://www.scotlawcom.gov.uk/files/ 4313/0252/1699/dp149.pdf (last accessed 16 January 2016).

The UN Global Compact-Accenture CEO Study on Sustainability 2013: Architects of a Better World. Available at: https://www.unglobalcompact.org/docs/news_events/8.1/UNGC_Accenture_CEO_Study_2013.pdf (last accessed 4 April 2017).

The World Bank, GDP Ranking Table, (16 December 2014). Available at: http://databank.worldbank.org/data/download/GDP.pdf (last accessed 20 February 2015).

S. TuletT, "Flexible Working Rights for All - Could They Backfire?," BBC, (30 June 2014) Available at: http://www.bbc.com/news/business-26436131 (last accessed 25 February 2016).

S.M. Tully \& R.S. WineR, "Are People Willing to Pay More for Socially Responsible Products: A MetaAnalysis," New York University Stern School of Business, (2013). Available at: http://webdocs.stern.nyu.edu/pa/winer_tully.pdf (last accessed 5 April 2017).

U.S. Department of Labor WAges And Hour Division, History of Federal Minimum Wage Rates Under the Fair Labor Standards Act, 1938-2009. Available at: http://www.dol.gov/whd/minwage/chart.htm (last accessed 4 April 2017).

U.S. DePartment of THE INTERIOR OFFICE OF Insular AFFairs, Report on the Commonwealth of the Northern Mariana Islands 1999. Available at: https://www.doi.gov/sites/doi.gov/files/migrated/oia/reports/upload/ islands.pdf (last accessed 4 April 2017).

J.P. VOB \& B. BORnEMAnN, "The Politics of Reflexive Governance: Challenges for Designing Adaptive Management and Transition Management," Ecology and Society 16(2) (2011). Available at: http://www.ecologyandsociety.org/vol16/iss2/art9/main.html (last accessed 18 December 2016).

"Walmart announces Q4 underlying EPS of \$1.61 and additional strategic investments in people \& e-commerce Walmart U.S. comp sales increased 1.5 percent," Press Release, (19 February 2015). Available at: http://media.corporate-ir.net/media_files/IROL/11/112761/4Q15/Q4FY15_earnings_release_final.pdf (last accessed 19 February 2015).

WALMART, Corporate \& Financial Facts, (2014). Available at: http://news.walmart.com/walmart-facts/corporatefinancial-fact-sheet (last accessed 20 February 2015).

H. WALTERS, "Demand a More Open-Source Government: Beth Noveck at TEDGlobal 2012," TED Blog (28 June 2012). Available at: http://blog.ted.com/demand-a-more-open-source-government-beth-noveck-attedglobal-2012/ (last accessed 28 September 2015).

P. Weiss, "Run, Rummy, Run," Global Policy Forum, (8 December 2006). Available at: http://www.globalpolicy.org/component/content/article/97/32136.html (last accessed 4 April 2017).

M. Whitehead, R. Jones, R. Howell, R. Lilley, \& J. Pykett, "Nudging All Over the World: Assessing the Global Impact of the Behavioural Sciences on Public Policy," Economic and Social Research Council (2014). Available at: https://changingbehaviours.files.wordpress.com/2014/09/nudgedesignfinal.pdf (last accessed 10 February 2016).

Writ of summons drafted by the Dutch firm Prakken d'Oliveira to the Handelsgericht des Kantons Zürich (the Commercial Court of Zurich). Available at: https://www.fnv.nl/site/over-de-fnv/fnv-internationaal/ 1040331/fnvnadimsharifulalamvfifaenglish.pdf (last accessed 28 October 2016). 
WORLD ECONOMIC FORUM, "Values and Value: Communicating the Strategic Importance of Corporate Citizenship to Investors," (2003). Available at: https://www.hks.harvard.edu/m-rcbg/CSRI/publications/other_ 3_nelson_values_and_value.pdf (last accessed 22 December 2016).

J. ZwETSLOOT, “Universiteit ontduikt flexwet met 'knutselcontracten',” de Volkskerant (12 November 2015) Available at: http://www.volkskrant.nl/economie/universiteit-ontduikt-flexwet-met-knutselcontracten a4184 222/ (last accessed 25 February 2016).

\section{MISCELLANEOUS}

ARISTOTLE, Nicomachean Ethic, M. Oswald (TRANS.) (New York: Library of Liberal Art, 1962).

ARISTOTLE, Politics, (VII. 1323b).

Black's Law Dictionary (8 $8^{\text {th }}$ Ed. 2004).

W. vaN BOOM, "Introduction," Workshop on Juxtaposing Autonomy and Paternalism in Private Law, Erasmus University, Rotterdam (25 February 2010).

Brief of the European Commission on Behalf of the European Union as Amicus Curiae in Support of Neither Party, regarding Kiobel $v$ Royal Dutch Petroleum Co. (13 June 2012).

Brief of the Governments of the Kingdom of the Netherlands and the United Kingdom of Great Britain and Northern Ireland as Amici Curiae in Support of Neither Party, regarding Kiobel v Royal Dutch Petroleum Co.

The RobBins Collection, "The Common Law and Civil Law Traditions," University of California at Berkley School of Law (2010).

Confederation of British Industry, Issue Statement: Corporate Social Responsibility (2001).

European Commission Recommendation 2013/396/EU and Communication (2013) 401 final.

European Commission, “Corporate Governance Package - Frequently Asked Questions," MEMO/14/274 (9 April 2014).

European Commission, “How to Engage and Empower Stakeholders in Entrepreneurship Education,” Ref. Ares 2917375 (2013).

European Commission, "A Joint AIM-BEUC Initiative on Smarter Logos for Better Informed Consumers," Press Release, (23 March 2014).

European Commission, "European Commission proposes to strengthen shareholder engagement and introduce a 'say on pay' for Europe’s largest companies,” Press Release, (9 April 2014).

European Commission, "Statement: Disclosure of non-financial information: Europe's largest companies to be more transparent on social and environmental issues," Press Release, (29 September 2014).

European Council, "Shareholders' rights in EU companies: Presidency strikes deal with Parliament," Press Release, (16 December 2016).

European Parliament, "Report on Corporate Social Responsibility: Accountable, Transparent, and Responsible Business Behavior and Sustainable Growth,” Motion for European Parliament Resolution 2012/2098(INI) (28 January 2013).

European Parliament Directorate-General for External Policies (Policy Department), "New Options for Strengthening Standards on Social and Environmental Responsibilities of Corporations and Their Implementation," EXPO/B/DEVE/FWC/2009-01/Lot5/36 PE 457.138 (2013).

A.M. GandarA, The Law and Economics of Eco-labels, European Doctorate in Law and Economics (2013).

N. HANAUER, "Beware, Fellow Plutocrats, the Pitchforks are Coming," TED Talk, (August 2014). Available at: www.ted.com/talks/nick_hanauer_beware_fellow_plutocrats_the_pitchforks_are_coming?language=en (last accessed 25 March 2016).

J. Heimans, "What New Power Looks Like," TED Talk, (31 October 2014). Available at: https://www.ted.com/speakers/jeremy_heimans (last accessed 3 March 2015).

Judicial Council of CALIFORnia (ADministrative OfFice of THE COURTS), "Class Certification in California: Second Interim Report from the Study of California Class Action Litigation” (February 2010). Available at: http://www.courts.ca.gov/documents/classaction-certification.pdf (last accessed 4 April 2017).

Naomi Klein and Joseph Stiglitz on Economic Power. Available at: https://www.youtube.com/watch?v=qkErOTwOeo (last accessed 15 May 2015).

NYSE Listed Company Manual. 
K. MARX \& F. Engels, The Communist Manifesto, (1848).

J.S. MiLL, On Liberty, (1859).

RESTATEMENT (SECOND) OF CONTRACTS $\$ 178(1)$.

RESTATEMENT (THIRD) OF AGENCY $\$ 7.07$ (3)(a).

RESTATEMENT (THIRD) OF TORTS: LIABILITY FOR PHYSICAL AND EMOTIONAL HARM.

J. RUTHERFORD, "Wellbeing, economic growth and recession," Think-piece for the SDC Workshop: "Living Well Within Limits, (London: Sustainable Development Commission, 2008).

L.K.L. TJOn Soei Len, The Effects of Contracts beyond Frontiers: A Capabilities Perspective on Externalities and Contract Law in Europe (PhD Thesis, University of Amsterdam, 2013).

H.D. THOREAU, Walden, (1854).

A. Tocqueville, Democracy in America, (1835). Volume I, Part A.

B.K. Williams \& E.D. Brown, Adaptive Management: The U.S. Department of the Interior Applications Guide, (Washington, D.C.: U.S. Department of the Interior, 2012).

\section{CASE LAW}

\section{United States}

- National Federation of Independent Business v. Seblius. Oral Arguments (28 March 2012)

- Citizens United v. Federal Election Commission, 558 U.S. 310 (2010)

- Lochnerv. New York, 198 U.S. 45 (1905)

- Barbara Ann Berwick v. Uber Technologies, Inc. et al. Case No. 11-46739 EK (3 June 2015)

- Alatraqchi v. Uber Technologies, Inc., Case No. 11-42020 CT (1 August, 2012)

- S.G. Borello \& Sons, Inc. v. Department of Industrial Relations, 48 Cal. 3d 341, (1989)

- Walling v. Portland Terminal Co., 330 U.S. 148 (1947)

- U.S. v. Rosenwasser, 323 U.S. 360, 362-63 (1945)

- Yellow Cab Cooperative v. Workers Compensation Appeals Board, 226 Cal.App.3d (1991).

- Patrick Cotter et al. v. Lyft Inc. et al., U.S. District Court for the Northern District of California, Case Number 3:13-cv-04065, Order Denying Cross-Motions for Summary Judgment, (11 March 2015)

- Tony \& Susan Alamo Foundation v. Secretary of Labor, 471 U.S. 290 (1985)

- JKH Enterprises v. Department of Industrial Relations, 48 Cal. Rptr. 3d

- Air Couriers International v. Employment Development Department, 59 Cal. Rptr. 3d (_)

- Angelotti v. Walt Disney Co., 121 Cal. Rptr. 3d 863 (Ct. App. 2011)

- $\quad$ Doe v. Unocal, 963 F. Supp. 880 (C.D. Cal. 1997)

- Doe v. Unocal, 395 F.3d. 932 (Doe II) (9 $9^{\text {th }}$ Cir. 2002)

- Doe v. Unocal, Superior Court of California County of Los Angeles (No. BC 237980 and BC 237 679) (2004)

- Doe v. Unocal, 403 F.3d 708 (9th Cir. 2005)

- Sosa v. Alvarez-Machain, 542 U.S. 692 (2004)

- Filártiga v. Peña-Irala, 630 F.2d 876 (2d Cir. 1980)

- Kadic v. Karadzic, 70 F.3d 232 (2nd Cir. 1995)

- In re Estate of Marcos Human Rights Litigation, 25 F.3d 1467, 1475 (9 $9^{\text {th }}$ Cir. 1994)

- $\quad$ United States v. Smith, 18 U.S. 71 (1820)

- Kiobel v. Royal Dutch Petroleum Co., 621 F.3d 111 (2d Cir. 2010)

- Papa v. US, 281 F.3d 1004 (2002)

- Hilao v. Marcos, 25 F.3d 1467 (1994)

- International Shoe Co. v. Washington, 326 U.S. 310 (1945)

- Helicopteros Nacionals de Colombia S.A. v. Hall, 466 U.S. 408 (1984)

- Goodyear Dunlop Tires Operations, S.A. v Brown, 564 U.S.

- Asabi Metal Industries Co. v. Superior Court, 480 U.S. 102 (1987)

- Presbyterian Church of Sudan v. Talisman Energy, Inc., 244 F. Supp. 2 d 289 (S.D.N.Y. 2003)

- Morrison v. Nat'l Australia Bank Ltd, 561 U.S. (2010)

- Khulumani v. Barclay National Bank LTD., 504 F.3D 254 (2nd Cir. 2007) 
- Underbill v. Hernandez, 168 U.S. 250 (1987)

- $\quad$ Sarei v. Rio Tinto Plc., 221 F.Supp. 2d 1116 (C.D. Cal. 2002)

- Sarei v. Rio Tinto Plc., 456 F.3d. 1069 (9th Cir. 2006)

- Sarei v. Rio Tinto Plc., 487 F.3d 1193 (9 $9^{\text {th }}$ Cir. 2007)

- $\quad$ Sarei v. Rio Tinto Plc., 550 F.3d 822 (9th Cir. 2008)

- Sarei v. Rio Tinto Plc., No. 02-56256 (9 $9^{\text {th }}$ Cir. 2013)

- Marbury v. Madison, 5 U.S. 137 (1803)

- Bakerv. Carr, 369 U.S. 186 (1962)

- Murray v. Schooner Charming Betsy, 6 U.S. 64 (1804)

- Morrison v. National Australia Bank, 561 U.S.

- Linde v. Arab Bank Plc., 706 F.3d 92 (2nd Cir. 2013)

- $\quad$ Aguinda v. Texaco Inc., 945 F. Supp. 625 (S.D.N.Y. 1996)

- Washington Mutual Bank v. Superior Court, 24 Cal. $4^{\text {th }} 906$ (2001)

- Ladd v. County of San Mateo, 911 P.2d 496 (Cal. 1996)

- Evan F. v. Hughson United Methodist Church, 8 Cal.App.4 828 (1992)

- $\quad$ Burns v. Neiman Marcus Group, 173 Cal.App.4 479 (2009)

- Bowoto v. Chevron Corp., 621 F.3d 1116 (2010)

- Lindner vs. Thrifty Oil, 23 Cal.4 429 (2000)

- Hunt v. Washington State Apple Advertising Commission, 432 U.S. 333 (1977)

- Bano v. Union Carbide Corporation, 361 F.3d 696 (2nd Cir. 2004)

- Bano v. UCC, No 99 Civ. 11329 JFK (S.D.N.Y. 2003)

- Bano v. Union Carbide Corporation, 273 F.3d 120 (2nd Cir. 2001)

- In re Union Carbide Corp. Gas Plant Disaster, 634 F.Supp. 842 (S.D.N.Y. 1986)

- Dodge v. Ford Motor Co., 170 NW 668 (Mich, 1919)

- A.P. Smith Manufacturing Co. v. Barlow, 98 A.2d 581 (N.J. 1953)

- $\quad$ Shlensky v. Wrigley, 237 NE 2d 776 (Ill. App. 1968)

- Grobow v. Perot, 539 A.2D 180 (Del. 1988)

- Lovenheim v. Iroquois Brands, Ltd., 618 F. Supp. 554 (D.C. Dist. 1985)

- Lochner v. New York, 198 U.S. 45 (1905)

- Adkins v. Children's Hospital, 261 U.S. 525 (1923)

- Nebbia v. New York, 291 U.S. 502 (1934)

- West Coast Hotel Co. v. Parrish, 300 U.S. 379 (1937)

- Eurycleia Partners v. Seward \& Kissel, 12 N.Y.3d 553 (N.Y. Ct. App. 2009)

- Orchis Constr. Corp. v. Gottbetter, 89 A.D.3d 708 (2nd Dept. 2011)

- Albion Alliance Mezzanine Fund v. State Street Bank and Trust Co., 8 Misc. 3d 264 (Sup. Ct., NY Co. 2003), affd 2 A.D.3d 162 (1 ${ }^{\text {st }}$ Dept. 2003)

- George Backer Mgmt. v. Acme Quilting, 46 N.Y.2d 211 (1978)

- Kirshenbaum v. Gen. Outdoor Adver. Co., 258 N.Y. 486 (1932)

- Matter of Validation Review Assocs., Inc., 223 A.D.2d 134 (1996)

- McMullen v. Hoffman, 174 U.S. 639 (1899)

- Kasky v. Nike, Inc., 27 Cal.4 939 (2002)

- Nike, Inc. et al v Marc Kasky, 539 U.S. 654 (2003)

- Kwikeset Corp. v. Superior Court, 51 Cal. $4^{\text {th }} 310$ (2011)

- Hinojos v. Kohl's Corp., 718 F. 3d 1098 (2013)

- Jane Doe et al. v. Wal-Mart Stores, 572 F.3d 677 (9th Cir. 2009)

- National Federation of Independent Business v. Seblius. Oral Arguments (28 March 2012)

- Ball v. James, 451 U.S. 355 (1981)

\section{The Netherlands}

- $\quad$ Rechtbank Den Haag, 1 januari 2013, LJN BY9854 (case of Friday Alfred Akpan v. Shell)

- Rechtbank Den Haag, 1 januari 2013, LJN BY9845 (case of Barizaa Manson Tete Dooh v. Shell)

- Rechtbank Den Haag, 1 januari 2013, LJN BY9850 (case of Fidelis Ayoro Oguru and Alali Efanga v. Shell)

- Raad van State, 17 maart 2010, LJN BL7835 (Volkskerant, Troum, Algemeen Dagblad and De Telegraaf) 
- Hoge Raad, 21 december 2001, NJ 2005, 96 (Sobi.Hurks II)

- Hoge Raad, 12 juni 1998, NJ 1998, 727 (Coral/Stalt)

- Rechtbank 's-Gravenhage, 24 februari 2010, LJN BM1469

- Hoge Raad November 1997, NJ 1998, 268 (Kuipers Logistics)

- Court of Appeals (The Hague) Vie d'Or, 27 May 2004, LJN: AP0151, 01/1086

- Court of Appeals (Amsterdam) 29 May 2009, LJN: BI5744 (Shell Petroleum N.V. and the Shell Transport and Trading Comp. Ltd et al v. Dexia Bank Nederland N.V. et al)

- District Court (The Hague) 24 June 2015, ECLI:NL:RBDH:2015:7145 (Sticbting Urgenda v. Staat der Nederlanden)

Other:

- Hamilton v. Mendes (1761) 2 Burr 1198

- Vallejo v. Wheeler (1774) 1 Cowp 143

- Chandler v. Cape PLC [2012] EWCA Civ 525

- $\quad$ Case 281/02, Owusu v. Jackson [2005] ECR I-1383

- Donoghue v. Stevenson [1932] AC 562

- Smith v. Littlewoods Ltd [1987] AC 241

- Caparo Industries Plc. V. Dickman [1990] UKHL 2

- Home Office v. Dorset Yacht Co. [1970] AC 1004

- Smith v. Littlewoods Ltd. [1987] AC 241

- Chandler v. Cape Plc. [2012] EWCA Civ 525

- Adams v. Cape Industries Plc. [1990] Ch 433

- Gbemre v. Shell Petroleum Development Company and Others, AHRLR 151 (NgHC 2005) 
Page left intentionally blank 
Appendix 
A: Freedom of Information Law Request Letter from the New York State Department of Labor

Mark Kawakami

Sint Annadal 20F

6214PB Maastricht

The Netherlands

October 15, 2013

Re: Freedom of Information Law Request/

Kawakami, Mark

Our File No.: FL-13-0608

Dear Mr. Kawakami:

This letter is in response to your Freedom of Information Law (FOIL) request dated June 5,2013 , in which you requested "more recent editions of the AITF Annual Reports, which indicates the number of violations on a given year and how much fines were imposed, etc. I was able to find the reports up to 2005 on the Department of Labor web site, but I was wondering if you had something more recent, perhaps between 2010-2012?"

Pursuant to your Freedom of Information Law request previously acknowledged, a thorough investigation of the Department's files and records has been conducted and no records were found responsive to your request.

You have the right to appeal this partial denial directly to the Commissioner of Labor. Such appeal must be made in writing and should be directed to the Commissioner of Labor, Department of Labor, State Office Campus, Room 500, Building 12, Albany, New York 12240 It must have annexed to it a copy of this letter, and must state the particular ground upon which the appeal is based.

Very truly yours,

Pico Ben-Amotz

Records Access Officer

By:

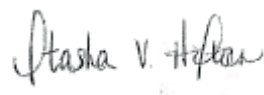

Itasha V. Hilton

Legal Assistant Trainee

PBA:IVH

Phone: (518) 485-219। Fax: (518) 485-1819 W. Averell Harriman State Office Campus, Bldg. 12, Room 509, Albany, NY 12240 
This book tackles the question of what private actors (companies, consumers, and other stakeholders) can do differently to reduce the instances of labor exploitations taking place in our global supply chain. As a starting point, this book examines a variety of existing laws, strategies, and initiatives with the intended aim of addressing this persistent problem. Then, the research relies on a multidisciplinary methodology, which incorporates findings from psychology, sociology, and other sciences to make the argument that the existing strategies are often flawed. In light of this finding, the book offers various ways for both lawmakers and private actors to adapt their current strategies to better address the problem of labor exploitation.

This research was made possible by the generous funding of the Hague Institute for the Internationalisation of Laws. 